JOCHEN KIBEL

\title{
HOFFNUNG AUF \\ EINE BESSERE \\ VERGANGENHEIT
}

KOLLEKTIVIERUNGSDISKURSE UND IHRE CODES DER VERRÄUMLICHUNG

Unter dem ungewissen Erwartungshorizont spätmoderner Gesellschaften treten verschiedene Vorstellungen kollektiver Identität in Konflikt. Jochen Kibel zeigt: Im Streit um das Neue Museum in Berlin und das Militärhistorische Museum in Dresden artikulierten sich unterschiedliche Kollektivierungsdiskurse, in denen die Vergangenheit nach den Anforderungen der Gegenwart umgeformt wurde. Der retrospektive Blick gewährt damit immer auch die prospektive Hoffnung auf eine bessere Vergangenheit. Die dynamischen Verhältnisse der Gegenwart bringen schließlich eine Form reflexiver Identitätsbildung hervor, in der auch die Fähigkeit anhaltender Selbstkritik in der Vergangenheit swieder- 
Jochen Kibel

Hoffnung auf eine bessere Vergangenheit

Re-Figuration von Räumen | Band 2 


\section{Editorial}

Der Reihe Re-Figuration von Räumen liegt die Prämisse zugrunde, dass das Soziale immer räumliche Formen annimmt. Die hier versammelten Studien befassen sich mit gegenwärtigen Transformationen sozial relevanter Räume und den damit verbundenen Konflikten, Krisen und Unsicherheiten. Sie untersuchen die These, dass es in diesen Transformationen und Konflikten ein gemeinsames Muster gibt, das als "Re-Figuration der Räume« bezeichnet wird. Die unterschiedlichen Wandlungsprozesse finden ihren Ausdruck in neu entstehenden Raumformen und -figuren, in den Kämpfen um die Aufrechterhaltung etablierter Raumstrukturen sowie den daraus resultierenden Figurationen. Oder mit anderen Worten: Der Raum ist ebenso wie die Zeit das Medium der Transformation der gegenwärtigen Gesellschaft, so dass die Analyse der Räume einen integrativen Ausgangspunkt für die Analyse der entstehenden Gesellschaftsmuster darstellt. Die Publikationen der Reihe entspringen dem Sonderforschungsbereich $1265 \mathrm{Re}-$ Figuration von Räumen und damit aus sozialwissenschaftlichen Disziplinen wie Soziologie, Geographie, Architekturwissenschaft, Kommunikationswissenschaft, Stadtplanung und Europäischer Ethnologie. Sie nehmen mitunter eine theoretische Ausrichtung ein, beruhen zumeist aber auf empirischen Studien, die qualitative, quantitative oder visuelle Methoden verwenden.

Die Reihe wird herausgegeben von Hubert Knoblauch und Martina Löw.

Jochen Kibel, geb. 1988, ist wissenschaftlicher Mitarbeiter am Fachgebiet für Planungs- und Architektursoziologie an der TU Berlin und Mitglied des DFG-Graduiertenkollegs »Identität und Erbe« sowie des DFG-Sonderforschungsbereichs »Re-Figuration von Räumen«. 
Jochen Kibel

\section{Hoffnung auf eine bessere Vergangenheit}

Kollektivierungsdiskurse und ihre Codes der Verräumlichung 
Gefördert durch die Deutsche Forschungsgemeinschaft (DFG) Projektnummer 290045248 SFB 1265 »Re-Figuration von Räumen« sowie GRK 2227 »Identität und Erbe«.

Diese Publikation wurde aus dem Open-Access-Publikationsfonds der Technischen Universität Berlin unterstützt.

\section{Bibliografische Information der Deutschen Nationalbibliothek}

Die Deutsche Nationalbibliothek verzeichnet diese Publikation in der Deutschen Nationalbibliografie; detaillierte bibliografische Daten sind im Internet über http://dnb.d-nb.de abrufbar.

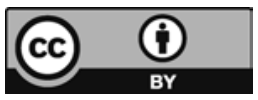

Dieses Werk ist lizenziert unter der Creative Commons Attribution 4. ० Lizenz (BY). Diese Lizenz erlaubt unter Voraussetzung der Namensnennung des Urhebers die Bearbeitung, Vervielfältigung und Verbreitung des Materials in jedem Format oder Medium für beliebige Zwecke, auch kommerziell. (Lizenztext:

https://creativecommons.org/licenses/by/4.o/deed.de)

Die Bedingungen der Creative-Commons-Lizenz gelten nur für Originalmaterial. Die Wiederverwendung von Material aus anderen Quellen (gekennzeichnet mit Quellenangabe) wie z.B. Schaubilder, Abbildungen, Fotos und Textauszüge erfordert ggf. weitere Nutzungsgenehmigungen durch den jeweiligen Rechteinhaber.

\section{Erschienen 2021 im transcript Verlag, Bielefeld (๑) Jochen Kibel}

Umschlagkonzept: Studio Gretzinger (https://www.studiogretzinger.de)

Umschlagabbildung: Militärhistorisches Museum der Bundeswehr Dresden. (c) Jochen Kibel, 2018.

Druck: Majuskel Medienproduktion $\mathrm{GmbH}$, Wetzlar

Print-ISBN 978-3-8376-5429-5

PDF-ISBN 978-3-8394-5429-9

https://doi.org/10.14361/9783839454299

Gedruckt auf alterungsbeständigem Papier mit chlorfrei gebleichtem Zellstoff. Besuchen Sie uns im Internet: https://www.transcript-verlag.de Unsere aktuelle Vorschau finden Sie unter www.transcript-verlag.de/vorschau-download 


\section{Inhalt}

Einleitung: Wiederholung ............................................. 9

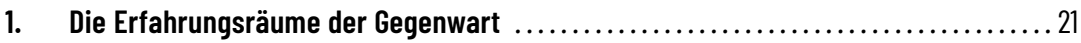

1.1. Zeitdiagnose als Phänomen der Moderne ............................... 24

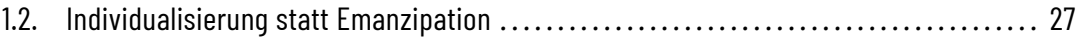

1.3. Die Abschaffung der Ewigkeit ..................................... 30

1.4. Vielheit ohne Einheit.............................................. 33

1.5. Jenseits von Anomie und Kompensation ............................. 36

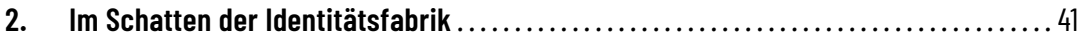

2.1. Vom Kanon zum Konflikt .......................................... 43

2.2. Vom Kollektiv zu den Kollektivierungsdiskursen ........................... 47

2.3. Sozialität des Erinnerns und Sozialisation durch Erinnern ...................... 51

2.4. Die Strukturen des Erbes: Beschwören oder Verschwören?.................. 56

3. Die diskursive Konstruktion der gebauten Welt $\ldots \ldots \ldots \ldots \ldots \ldots \ldots \ldots \ldots \ldots 6$

3.1. Wissenssoziologie und Raum: Die Deutung der gebauten Welt ................. 65

3.2. Im Diskurs oder darunter? ........................................... 68

3.3. Wissenssoziologie und Diskurs: Der Einbau der Diskursperspektive ................ 71

3.4. Wissenssoziologie und Hermeneutik: Spielräume der Kreativität ................. 77

3.5. Analysedimensionen ............................................ 81

4. Ein Bild der Ewigkeit und die Codes der Verräumlichung ................... 85

4.1. Zeitliche Sinnbildung .......................................... 85

4.1.1. Wiederholen oder Dokumentieren ............................. 89

4.1.2. Die Dialektik der gedächtnispolitischen Strategien................... 93

4.1.3. Ein episodisches Bild der Ewigkeit? .............................. 97

4.2. Räumliche Sinnbildung.......................................... 102

4.2.1. Geschichtscontainer und Raummetaphern.......................... 104

4.2.2. Empirische Rahmung ...................................... 108

4.2.3. Die Codes der Verräumlichung ............................... 112 
5. Streit um das Erbe: Der Diskurs des Neuen Museums Berlin................. 123

5.1. Die Fundamente beerben ....................................... 123

5.1.1. Baugeschichte in Fragmenten................................. 125

5.1.2. Diskursgeschichte zwischen Original und Ergänzung................... 140

5.2. Wiedererweckung und raumzeitliche Verunreinigung:

Der Kollektivierungsdiskurs der >originalgetreuen Wiederherstellung ‘............ 157

5.2.1. Heroische Vergangenheit: Die Apotheose des August Stüler ............... 158

5.2.2. "Dornröschenschloss «: Latenz und anhaltende Zerstörung .............. 162

5.2.3. »... komplottartige Struktur «: Täuschung und Verkehrung ............... 165

5.2.4. Entzeitlichung durch Wiederholung................................ 168

5.2.5. Zwischenfazit: Hoffnung auf eine bessere Vergangenheit ................ 171

5.2.6. »Historische Insel«: Die vollkommene Harmonie der Räume ............... 173

5.2.7. »Raum-Monster « und »Beton-Skelett«: Die Verwundung des Baukörpers..... 180

5.2.8. Purity endangered:

Die Wissensverhältnisse der >originalgetreuen Wiederherstellung ‘........ 190

5.3. Dokumentierte Vergangenheiten und harmonische Fragmente:

Der Kollektivierungsdiskurs der sergänzenden Wiederherstellung . ............... 193

5.3.1. Dokumentierte Zeitverläufe: Die Apotheose des Giovanni Battista Piranesi? .. 195

5.3.2. »Die tote Großmutter«: Auferstehung ausgeschlossen .................. 199

5.3.3. »... Rekonstruktion zerstört«: Die Einmaligkeit der Vergangenheit........... 200

5.3.4. Eine offene Struktur der Zeit .................................... 203

5.3.5. Zwischenfazit: Ewig bleibt die Veränderung .......................... 206

5.3.6. Doppelte Modernisierung.................................... 209

5.3.7. Das Nebeneinander der Räume: Die Konstruktion räumlicher Kohärenz .......212

5.3.8. Concordia Discors:

Die Wissensverhältnisse der sergänzenden Wiederherstellungı ............. 223

5.4. Fundierung durch zyklische und lineare Wiederholungsstrukturen.............. 226

6. Schwierige Erbschaft: Der Diskurs des Militärhistorischen Museums Dresden . ... 231

6.1. Selbstvergewisserung in schwierigem Gelände ........................ 232

6.1.1. Das doppelte Dresden ...................................... 235

6.1.2. Die institutionelle Konstellation ............................... 245

6.2. Die Kodifizierung des Selbstbildes ................................... 250

6.2.1. Das zeitkonstitutionelle Dilemma............................... 250

6.2.2. Das raumkonstitutionelle Dilemma ................................ 254

6.2.3. Individuelle Tradition und ziviles Militär .............................. 257

6.2.4. Ein dynamischer Kollektivierungsdiskurs .......................... 260

6.3. Die normative Verbindlichkeit eines negativen Geschichtsbildes ............... 261

6.3.1. Geschichte und Raum als Problem .............................. 261

6.3.2. Störung, Zerstörung und Verstörung als Wert .........................271

6.3.3. »Identitäres Trümmerfeld «: Rekonstruktion statt Dekonstruktion .......... 278 
6.3.4. Normative Vergangenheit ohne Pathos? ......................... 283

6.4. Eine doppelte Struktur von Raum und Zeit ............................ 288

6.4.1. Krieg als conditio humana? .................................. 293

6.4.2. »Multiperspektivität«: Jenseits nationalhistorischer Grenzen ............. 297

6.4.3. Der Architekt als Raum-Trickster................................ 304

6.4.4. Identität durch Kritik: »Andere Armeen haben das so nicht «.............. 307

6.5. Inkrementelle Identität:

Die Wissensverhältnisse des Kollektivierungsdiskurses der Bundeswehr........... 310

7. Unter dem Erwartungshorizont der Gegenwart:

Konstanz - Kontinuität - Kritik .................................... 317

7.1. Der Heroische Kollektivierungsdiskurs ............................. 318

7.2. Der Historizistische Kollektivierungsdiskurs ........................... 322

7.3. Der Reflexive Kollektivierungsdiskurs .............................. 330

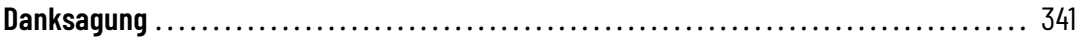

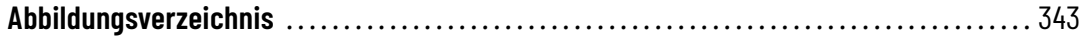

Literaturverzeichnis................................................ 347 



\section{Einleitung: Wiederholung}

Als am 16. Oktober 2009 das Neue Museum auf der Berliner Museumsinsel eröffnet wurde, wiederholte sich dieses Ereignis zum zweiten Mal in der Geschichte des Gebäudes. Das spätklassizistische Gebäude des Architekten Friedrich August Stüler galt zum Zeitpunkt seiner ersten Eröffnung im Jahr 1859 in bautechnischer und museumsdidaktischer Hinsicht als hoch modern. Von wenigen Umbauten abgesehen blieb das Museum bis zu seiner Zerstörung im Zweiten Weltkrieg weitgehend unverändert. Nach Kriegsende waren die unterschiedlich stark zerstörten Gebäudeteile 40 Jahre der Witterung ausgesetzt. Schließlich entbrannte ab dem Jahr 1994 ein Streit darüber, wie mit der Ruine des Neuen Museums umzugehen sei. Die Ernsthaftigkeit und das lang anhaltende Engagement aller Diskutanten deuteten darauf hin, dass nicht nur Fragen des architektonischen Geschmacks erörtert wurden. Zwar galt allen an der Debatte Beteiligten das baukulturelle Erbe als wertvoll und deshalb besonders schützenswert, im Streit um das Erbe formierten sich dennoch konkurrierende Diskurse, die in erbitterten Konflikt gerieten. Denn anhand der Frage, wie die einmalige Geschichte des Gebäudes zu beerben sei, schieden sich die Geister. Im Schatten des Erbes bildeten sich so zwei Erbengemeinschaften, die für ihren Umgang mit dem Erbe gleichermaßen in Anspruch nahmen, dass nur dadurch Vergangenheit und Gegenwart auf harmonische Weise in Einklang gebracht würden. Indem sie auf je spezifische Art Vergangenheitsbezüge herstellten und auch in räumlicher Hinsicht zu höchst verschiedenen Deutungen des Neuen Museums gelangten, verbanden sie sich so auch untereinander.

Als am 16. Oktober 2009 das Neue Museum zum zweiten Mal in seiner Geschichte eröffnet wurde, betraten die Gäste erneut ein modernes Museumsgebäude, in dem sowohl Räume des 19. Jahrhunderts als auch Spuren der 40-jährigen Verwitterung aufgehoben waren. Unter der Leitung des Architekten David Chipperfield und dem Restaurator Julien Harrap entstand zwischen den Jahren 1999 und 2009 ein Bauwerk, welches sowohl ein partiell restauriertes Museum des 19. Jahrhunderts, eine aufwendig konservierte Ruine als auch ein fraglos modernes Gebäude ist. Die Gegner dieser >ergänzenden Wiederherstellung`sahen darin allerdings eine Verkehrung der ursprünglichen Idee des Architekten Stüler und sprachen von einer vollständigen Zerstörung seines Werkes, die zudem das gesamte Weltkultur- 
erbe der Museumsinsel bedrohe. Nur in der originalgetreuen >Wieder-Holung বes Museums des 19. Jahrhunderts sahen sie die Bewahrung des Erbes gewährleistet. Diese erschien nicht nur prinzipiell möglich, sondern hatte geradezu verpflichtenden Charakter, da nur so die Identität des Ortes und der eigenen Geschichte gesichert sei.

Als am 14. Oktober 2011 das Militärhistorische Museum der Bundeswehr in Dresden eröffnet wurde, wiederholte sich dieses Ereignis bereits zum fünften Mal in der Geschichte des Gebäudes. Im Zentrum der bis 1876 im Norden Dresdens errichteten Albertstadt, welche einst einer der größten militärischen Komplexe Europas war, diente das Gebäude ursprünglich der sächsischen Armee als Waffendepot. Bereits kurze Zeit nach dessen Fertigstellung führten wehrtechnische Veränderungen da$\mathrm{zu}$, dass zentrale Aufbewahrungsorte für Waffen in Form von Arsenalen nicht mehr benötigt wurden. Das Arsenalhauptgebäude, welches dadurch bereits wenige Jahre nach seiner Fertigstellung aus der Zeit gefallen war, wurde fortan als Museum genutzt. Im Zeichen dieses ursprünglichen Anachronismus errichtet, blieb auch die weitere Geschichte des Hauses von historischen Zäsuren geprägt. Allerdings führten die politischen Umbrüche des 20 . Jahrhunderts zu einer bemerkenswerten Gleichzeitigkeit von Wandel und Persistenz. Seitdem die Tore des einstigen Arsenals 1889 zunächst für Angehörige des Militärs, ab 1897 auch für Zivilisten geöffnet wurden, um diese an die Triumphe ihrer Herrscher zu erinnern, dient die eindrucksvolle Architektur der Repräsentation militärischen und staatlichen Selbstverständnisses. In kontinuierlicher Diskontinuität wechselten jedoch immer wieder die Akteure dieser Inszenierungen. Sowohl die sächsische Armee im Deutschen Kaiserreich, die Reichswehr in der Weimarer Republik, die Wehrmacht während der Diktatur der Nationalsozialisten als auch die Streitkräfte der Deutschen Demokratischen Republik nutzten das Arsenalhauptgebäude als Bühne nationaler Identitätsstiftung. Obwohl die musealen Selbstbilder der verschiedenen deutschen Armeen immer wieder aus der Zeit fielen, blieb doch die Funktion des Gebäudes konstant. Als im Jahr 1994 beschlossen wurde, dem Militärhistorischen Museum auch im Museumswesen der Bundeswehr den Rang eines Leitmuseums zuzuerkennen, begann eine weitere Episode, in der sich sowohl der Gebäudezweck als auch der erneute Wandel seines musealen Ausdrucks auf nunmehr bereits bekannte Weise wiederholten. Anders als im Neuen Museum besteht das schwierige Erbe des deutschen Militärs allerdings in den Verheerungen der deutschen Militärgeschichte und dem Menschheitsverbrechen der Shoah. Nicht die kontinuierliche Verbindung, sondern die diskontinuierliche Abgrenzung von der Vergangenheit wurde somit erforderlich, um die Integrität der Bundeswehr zu wahren. Im Rahmen des Umbaus des denkmalgeschützten Arsenalhauptgebäudes sollte deshalb auch »die 
architektonische Gestaltung des Hauses neu bestimmt werden« (Konzeptgruppe 2003:28).

Als am 14. Oktober 2011 das Militärhistorische Museum in Dresden zum fünften Mal in seiner Geschichte eröffnet wurde, durchtrennte nunmehr ein weithin sichtbarer Keil aus Stahl und Beton das spätklassizistische Gebäude. Der Architekt Daniel Libeskind bestimmte mit dieser drastischen und bewusst kontrastierenden baulichen Intervention - wie dies von der Expertenkommission gefordert wurde - die architektonische Gestalt des Hauses grundlegend neu. Auch die Gegner dieser Umgestaltung sahen darin die Fundamente einer weiterhin identitätsbildenden Vergangenheit bedroht, weshalb sie von einem »zerstörerischen Eingriff» sprachen und die neue Architektur des Leitmuseums der Bundeswehr als Sinnbild eines »identitären Trümmerfeldes« deuteten.

Abbildung 1: Westliche Fassade des Neuen Museums in Berlin mit James Simon Galerie (links) und Erweiterung der Kolonnaden (rechts) durch David Chipperfield Architects; Abbildung 2: Militärhistorisches Museum der Bundeswehr in Dresden mit moderner Ergänzung durch den Architekten Daniel Libeskind.
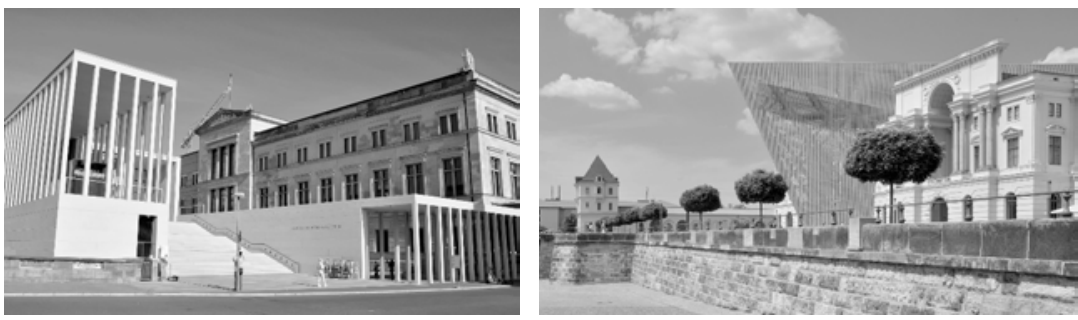

$* * *$

$\mathrm{Zu}$ Beginn seiner einflussreichen Studie zum kulturellen Gedächtnis betont Jan Assmann, dass jede Imagination von kollektiver Identität durch Akte des Erinnerns Vergangenheitsbezüge herstellt und diese in Form »kultureller Kontinuierung« in Traditionen verstetigt. Die so stabilisierten Strukturen wirken in doppeltem Sinn »konnektiv«. Denn einerseits verbinden sie - im Hinblick auf die Zeitdimension Vergangenheit, Gegenwart und Zukunft auf spezifische Art. Andererseits verbinden sie - in Bezug auf die Sozialdimension - auch Personen untereinander zu einer Gruppe (Assmann 1997:16f.). Das Prinzip, das jeder konnektiven Struktur zugrunde liegt, bestehe dabei in der Wiederholung.

Eine Wiederholung der Vergangenheit und die bruchlose Konstanz mit ihr wurden allerdings sowohl bei der Umgestaltung des Neuen Museums in Berlin als auch bei der Neugestaltung des Militärhistorischen Museums in Dresden entschieden 
zurückgewiesen. Gerade deshalb sahen die Befürworter einer originalgetreuen Rekonstruktion des Neuen Museums und die Gegner der Umgestaltung des Militärhistorischen Museums die Identität der Gebäude und damit die eigene Geschichte sowie das »eigene Herkommen« bedroht. In diesen Imaginationen von Identität bleiben die bruchlose Konstanz und die zyklische Wiederholung einer weiterhin als verbindlich angesehenen Vergangenheit konstitutiv. Diese steht jedoch nicht für einen chronologisch früheren Zeitpunkt, sondern wird zur Chiffre eines als zeitlos imaginierten Ideals. Dieser positive Referenzpunkt wird im Sinne der Rekonstruktivität des Erinnerns (Halbwachs 1985, Orig. 1925) stets nach Maßgabe der Gegenwart umgeformt, indem die ewig gültigen Orientierungspunkte in der Vergangenheit >wiedergefunden`werden. Dadurch, dass so auch Zukunft bewältigt werden kann, ist diese Form des idealisierenden Vergangenheitsbezuges nicht nur ein retrospektiver Blick zurück, sondern hält auch die prospektive Hoffnung aufeine bessere Vergangenheit bereit.

Hoffnungen dieser Art< in denen Zukunft nur über den Umweg einer sich zyklisch wiederholenden Vergangenheit erreicht werden kann, wurden sowohl in Berlin als auch in Dresden enttäuscht. Die Appelle an eine idealisierte Vergangenheit verhallten weitgehend ungehört. Die originalgetreue Rekonstruktion des Neuen Museums wurde ausgeschlossen, da auch die historischen Zwischenzeiten als legitimer Teil der Geschichte des Gebäudes anerkannt wurden. Zudem galt es, die gesamte Museumsinsel für zukünftige Aufgaben zu wappnen und somit weiterzuentwickeln, was in den engen Grenzen der Entwürfe des 19. Jahrhunderts kaum realisierbar gewesen wäre. Erschien die Wiederholung der Vergangenheit hier also vor dem Hintergrund gegenwärtiger und zukünftiger Anforderungen inopportun, so stellt eine positive Bezugnahme auf die Vergangenheit im Fall des Leitmuseums der Bundeswehr geradezu eine Gefahr für die moralische Integrität der Institution dar. In den Traditionserlässen wird deshalb an zentraler Stelle festgehalten: »Ein Unrechtsregime, wie das Dritte Reich, kann Tradition nicht begründen.« (BMVg 1982:1, P.6). In der zentralen Dienstvorschrift der Inneren Führung, mit der die Bundeswehr ihr Selbstverständnis kodifiziert, wird aus diesem unverändert übernommenen Passus die folgende Verpflichtung abgeleitet: "Eine Wiederholung gilt es für alle Zukunft auszuschließen.« (BMVg 2008:4, P.201, Herv. JK).

Auch um dieser Maxime architektonischen Ausdruck zu verleihen, musste die Gestalt des Leitmuseums der Bundeswehr grundlegend neu bestimmt werden. Obwohl das schwierige Erbe des Nationalsozialismus und der Kriegszerstörungen in beiden Fällen gerade nicht annulliert werden durfte, führte dies dennoch nicht dazu, dass keine kontinuierlichen Vergangenheitsbezüge und Imaginationen von Identität hergestellt werden konnten. Auch in den diskursiven Deutungen des Erbes, in denen die Abkehr von der Vergangenheit angestrebt und Wiederholung explizit ausgeschlossen wurde, gelang es, Wiederholungsstrukturen auszubilden und damit »konnektive Strukturen« der Selbstthematisierung zu stabilisieren. 
Als am 16. Oktober 2009 die Gäste des Neuen Museums in Berlin ein durch partielle Restaurierung, aufwendige Konservierung und moderne Ergänzungen wiederhergestelltes Gebäude betraten, fand eine eineinhalb Dekaden währende Debatte ihr vorläufiges Ende. Obwohl die sergänzende Wiederherstellung`des Neuen $\mathrm{Mu}$ seums eine Rekonstruktion des Stülerentwurfs des 19. Jahrhunderts ausschloss, argumentierten auch die involvierten Architekten und Denkmalpfleger, dass ihr Umgang mit dem Gebäude im Einklang mit seiner Vergangenheit stehe. Da das Vergangene als unwiederbringlich verloren galt, konnte es nicht wiederholt werden. Gerade weil sich die Vergangenheiten unterschieden und allen aufeinander folgenden Phasen der Gebäudegeschichte historische Bedeutung zuerkannt wurde, sollten sie dokumentiert werden. In der linearen Abfolge der disparaten historischen Spuren wurden Gemeinsamkeiten behauptet, die es erlaubten, das Gebäude entlang allgemeiner Prinzipien neu zu interpretieren. Indem betont wurde, dass auch das ursprüngliche Museum seinerzeit modern war, erschien seine gleichermaßen moderne Ergänzung in Kontinuität mit dem Werk Stülers. Nicht die materielle Wiederholung des Bauwerks des 19. Jahrhunderts, sondern die Interpretation anhand eines zeitlos gültigen Repertoires an Wesensmerkmalen gewährte nunmehr eine >geistige Kontinuität<. Die Vertreter der ergänzenden Wiederherstellung sprachen deshalb nicht von einer Wiederholung, sondern von einer Wiedererweckung im Geiste. Indem der Geist Stülers beschworen wurde, gelang es auch hier, das Erbe so zu deuten, dass eine kontinuierliche Verbindung zwischen Gestern und Heute möglich wurde. Zudem weist auch diese Form der Traditionsbildung in die Zukunft. Obwohl die Verschiedenheit der historischen Phasen anerkannt wird, kann die Geschichte des Hauses fortgeschrieben werden, da prinzipiell auch eine andere Zukunft in die geistige Kontinuität eingereiht werden kann. Indem die Vergangenheit nach Maßgabe der Gegenwart ausgelegt wird, hält auch dieser Modus des Vergangenheitsbezuges eine Hoffnung auf eine bessere Vergangenheit bereit. Der Strom der Zeit trennt zwar Vergangenheit, Gegenwart und Zukunft dauerhaft voneinander, jedoch kann er immer wieder durch die Brücke der Interpretation überwunden werden.

Als am 14. Oktober 2011 die spektakuläre Inszenierung einer historischen Zäsur, die nunmehr das Leitmuseum des deutschen Militärs in Dresden durchschneidet, der Öffentlichkeit vorgestellt wurde, deuteten die Akteure der Neugestaltung diese als musealen Ausdruck des Selbstverständnisses der Bundeswehr. Ungeachtet dessen, dass die historische Diskontinuität kontrastreich verräumlicht wurde, gelang es auch, diese so $\mathrm{zu}$ thematisieren, dass ebenfalls Wiederholungsstrukturen ausgebildet und Traditionen begründet werden konnten. In der am 20. Juli 2018 von 
der Bundesverteidigungsministerin erlassenen Konzeption der Bundeswehr heißt es zwar weiterhin, dass es »[a]ngesichts der Brüche und Zäsuren der deutschen Geschichte« keine "geradlinige deutsche Militärtradition« - und damit keinen linearen Brückenschlag - geben kann. Die Bundeswehr setze sich deshalb »kritisch mit dem Erbe der deutschen Geschichte« auseinander (BMVg 2018a:13), wobei unter der Überschrift »Selbstverständnis« ebenfalls festgestellt wird: »Tradition der Bundeswehr ist eine kritische Auseinandersetzung mit der Vergangenheit « (ebd.). Gerade aus den Brüchen und Zäsuren erwachse die Maxime der kritischen Auseinandersetzung, die zudem in den Rang einer der Bundeswehr eigentümlichen Tradition erhoben wird. An die Stelle zeitloser Konstanz und geistiger Kontinuität tritt somit anhaltende Kritik. Trotz der zentralen Thematisierung des schwierigen Erbes gelingt es so, eine Wiederholungsstruktur zu etablieren, die ein Gleichbleiben in stetigem Wandel verspricht. Denn Identität wird nunmehr durch andauernde Negation (sprich: Nicht-Identität) stabilisiert. Gerade weil nie endgültig gesagt werden kann, wie die Bundeswehr ist, muss immer wieder gesagt werden, wie sie nicht mehr ist. Auch die Werte der Kritik und der Wandlungsfähigkeit strahlen in beide Richtungen über die Gegenwart hinaus. Nicht zufällig veröffentlichte die Ministerin die neue Konzeption der Bundeswehr am 20. Juli, wurde damit doch an den Widerstand gegen den Nationalsozialismus erinnert. Die Auflehnung gegen bestehende Strukturen sowie die Fähigkeit zum eigenmächtigen Hinterfragen der Institution werden ebenfalls in der Vergangenheit swiedergefunden $\prec$ Indem die Traditionen schließlich selbst Prozesscharakter annehmen, kann sowohl auf episodische Brüche in der Vergangenheit als auch auf die dynamischen Entwicklungen in der Gegenwart mit einer gleichermaßen dynamischen Form der Traditionsbildung reagiert werden. Wie mit jeder Form kultureller Kontinuierung wird so auch Zukunft bewältigt, denn auch für die Tradition der »kritischen Auseinandersetzung mit der Vergangenheit« gilt: »Sie verbindet damit Vergangenheit mit der Gegenwart und weist in die Zukunft.«(Ebd.). Auch der negative Vergangenheitsbezug, der für das Selbstbild der Bundeswehr verpflichtenden Charakter hat, weist in die Zukunft, indem er die Vergangenheit nach Maßgabe der Gegenwart auslegt; auch er gewährt Hoffnung auf eine bessere Vergangenheit, wobei ein Gleichbleiben im Strom der Zeit nun durch anhaltende Kurskorrekturen gewährleistet wird.

In den zentralen Dokumenten der Bundeswehr, in denen diese ihr Selbstbild kodifiziert, wird die dynamische Form der Traditionsbildung vor den Hintergrund einer sich gleichermaßen dynamisch verändernden Gesellschaft gestellt. In »pluralistischen Gesellschaften « - so eine gängige Formulierung - gerieten vielfältige Überzeugungen, Lebensentwürfe, religiöse und weltanschauliche Bekenntnisse, Meinungen und Interessen in Konflikt (BMVg 2008:7, P.3.5), was dazu führe, 
dass historische Ereignisse ihren gesellschaftlich verbindlichen Charakter einbüßen (BMVg 1982:1, P.3). Thematisiert wird also explizit die Abnahme sozialer Kohäsionskraft durch eine Pluralisierung von Vergangenheitsbezügen. Damit ist eine Frage von enormer Reichweite aufgeworfen. Wie unter den Bedingungen funktional und kulturell differenzierter Gesellschaften kollektive Selbstbilder aufgebaut werden können und Sozialintegration möglich ist, kann als eine der zentralen Fragen einer Soziologie sozialer Gedächtnisse angesehen werden (Sebald/Weyand 2011). Das Anliegen der vorliegenden Arbeit besteht nun darin, sich dieser allgemeinen Frage über den speziellen Kontext von Museumsdiskursen anzunähern. Obwohl dadurch natürlich keine umfängliche Beantwortung in Aussicht gestellt werden kann, so werden dennoch zwei eng damit verbundene Erkenntnisinteressen verfolgt.

Erstens soll anhand der Analyse der Debatten um die Wiederherstellung des Neuen Museums und der Umgestaltung des Militärhistorischen Museums explorativ erschlossen werden, welche Formen der Imagination kollektiver Identitäten sich im Kontext von Museumsdiskursen empirisch rekonstruieren lassen. Kollektive Identitäten werden dabei als Formen der Selbstthematisierung verstanden (Straub 2016), durch die temporär und partiell Gleichheit (Straub 1998) hergestellt wird. Als dynamische Prozessstrukturen haben diese immer nur vorläufigen Charakter (von Scheve 2019), obwohl sie stets in unterschiedlicher Weise auf Beständigkeit rekurrieren. Mit dem Begriff Kollektivierung (anstelle von Kollektiv) soll eben diese Prozessualität unterstrichen werden. Da der analytische Zugriff auf der Ebene von Diskursen erfolgte, spreche ich im Kontext dieser Arbeit deshalb von Kollektivierungsdiskursen. Bei der idealtypischen Rekonstruktion verschiedener Kollektivierungsdiskurse möchte ich mich von der These leiten lassen, dass auch in pluralen und sich dynamisch verändernden Gesellschaften weiterhin Vorstellungen kollektiver Identität und die dafür erforderlichen Wiederholungsstrukturen ausgebildet werden können. Entgegen der zuweilen pessimistischen Einschätzung von Gegenwartsdiagnosen, die jenseits von Kompensation und Anomie (Kap. 1) der Existenz stabiler Identitäten wenig Chancen einräumen, erscheint indes fragwürdig, ob unter den Bedingungen spluralistischer Gesellschaften a auch Prozesse vergemeinschaftender Selbstthematisierung zum Erliegen kommen.

Zweitens möchte ich von der Annahme ausgehen, dass vergangenheitsbezogene Deutungen, mit denen sich Gruppen (temporär und partiell) als einheitlich beschreiben, insbesondere in Bezug auf die gebaute Welt artikuliert werden. Das zweite Erkenntnisinteresse dieser Arbeit zielt deshalb auf die Verbindung zwischen sozialen Gedächtnissen und der sozialen Konstruktion von Räumen. Gerade im Angesicht des baukulturellen Erbes werden vergemeinschaftende Vergangenheitsbezüge hergestellt, die es den Erben erlauben, sich als Gruppe zu imaginieren. Die sinnhafte Deutung des Erbes steht also in engem Bezug zu Imaginationen von Identität. Zudem modifizieren die unterschiedlichen Deutungen des Erbes auch 
dieses in seiner jeweiligen räumlichen Bedeutung immer wieder neu. Wie Zeit und Raum jeweils sinnhaft gedeutet werden und in welchem Modus das Verhältnis zwischen Identität und Erbe verhandelt wird, stellt das zweite Erkenntnisinteresse dieser Arbeit dar.

Die von Assmann beschriebenen Dimensionen konnektiver Strukturen verfügen daher nicht nur über eine Zeit- und eine Sozialdimension, sondern ebenfalls über eine Raumdimension. Der Untersuchungsgegenstand der Museen erscheint geradezu prädestiniert, um diesen dreifachen Konnex zwischen (sozialem) Raum, (sozialer) Zeit und (sozialen) Gedächtnissen zu einer Synthese zu führen, da hier in vergemeinschaftender Absicht Vergangenheitsbezüge verräumlicht werden. Mit dem Begriff der Verräumlichung wird also keineswegs nur die materielle Dimension der Architektur bezeichnet, sondern insbesondere auch die unterschiedlichen Arten, wie darauf diskursiv Bezug genommen wird. Da die räumliche Dimension der Kollektivierungsdiskurse den konflikthaften Charakter der Deutung des Erbes verdeutlicht, lassen sich verschiedene Verknüpfungsleistungen rekonstruieren, mit denen Räume sinnhaft zueinander in Beziehung gesetzt werden. Die Modi räumlicher Syntheseleistung (Löw 2012, Orig. 2001) können als Codes der Verräumlichung bezeichnet werden. Mit der Analyse der zeit- und raumkonstitutionellen Verfasstheit der Kollektivierungsdiskurse soll so auch ein Beitrag zur Verbindung zwischen Raumsoziologie und einer Soziologie sozialer Gedächtnisse geleistet werden.

Im ersten Kapitel dieser Arbeit werde ich deshalb anhand einflussreicher Gegenwartsdiagnosen darstellen, worin die raumzeitlichen Herausforderungen für die Imagination kollektiver Selbstbilder bestehen. Anhand des Kategorienpaars Erfahrungsraum und Erwartungshorizont, welches Reinhart Koselleck zur Bestimmung historischer Zeit vorgeschlagen hat, lässt sich darlegen, dass mit dem Auseinandertreten dieser Kategorien Zukunft zunehmend ungewiss wird. Übereinstimmend mit Koselleck attestieren zahlreiche soziologische Gegenwartsdiagnosen einen mit der Zeit voranschreitenden Veränderungskoeffizienten und damit eine Verschärfung dieser Entwicklung. Zwischen retrotopischer Kompensation (Bauman 2017) und individualistischer Anomie (Beck 2015, Orig. 2007) werden der Möglichkeit der Sozialintegration zumeist nur geringe Chancen eingeräumt. Die Frage, ob jenseits davon Formen der Selbstthematisierung denkbar sind, mit denen es gelingt, die ungewissen Erwartungshorizonte und die pluralen Erfahrungsräume der Gegenwart erneut anzunähern, definiert also den allgemeinen Rahmen der Arbeit.

Wenn es stimmt, dass die Geschichte zur Verzeitlichung tendiert und die Erinnerung eine Tendenz zur Verräumlichung aufweist (Borsdorf/Grütter 1999:4), dann wird dies im Kontext von Museen besonders deutlich. Wie ich im zweiten Kapitel zeigen werde, nimmt die Institution des Museums eine Schlüsselrolle bei der selbstvergewissernden Verräumlichung von Vergangenheitsbezügen ein. Die Rede von Museen als »Identitätsfabriken« (Korff/Roth 1990) erscheint unter den plura- 
len Erfahrungsräumen und den ungewissen Erwartungshorizonten der deutschen Gegenwartsgesellschaft allerdings fragwürdig. Denn nicht (nur) anhand der architektonischen Repräsentation eines Selbstbildes, sondern (auch) durch die unterschiedlichen diskursiven Rezeptionen der Museen, werden verschiedene Identitätspostulate sichtbar. Nichtsdestotrotz bleiben Museen auch unter diesen Bedingungen ein prädestinierter Untersuchungsgegenstand, wenngleich sich dadurch der Fokus von einer Analyse der Museen hin zu einer Analyse ihrer unterschiedlichen Deutungen verlagert und so anstatt des Erbes die verschiedenen Prozesse des Erbens in den Blick geraten.

Durch Akte des Erinnerns - so eine breit geteilte Annahme - wird Vergangenheit überhaupt erst rekonstruktiv hergestellt. Wird Erben als eine Modalität des Erinnerns verstanden, die einen starken Ortsbezug aufweist, dann wird deutlich, dass auch die Akte des Erbens die Orte, auf die sie sich beziehen, ebenfalls erst in ihrer räumlichen Bedeutung herstellen und anhaltend modifizieren. Die diskursiven Deutungen des baukulturellen Erbes müssen deshalb selbst als kreativ verstanden werden, da sie ihren Gegenstand auf spezifische Weise immer wieder neu hervorbringen. Dies betrifft nicht nur den diachronen Bedeutungswandel, sondern insbesondere die konkurrierenden synchronen Deutungen. Um diese in Bezug auf die gebaute Welt erfassen zu können, werden zwei zentrale Anforderungen an die Methode gestellt, die im dritten Kapitel erörtert werden. Mit der Analyse verschiedener Kollektivierungsdiskurse und ihrer räumlichen Anverwandlung baukulturellen Erbes wird eine Verbindung zum Raum erforderlich. Dies gelingt durch den Übertrag der Wissenssoziologie auf den Kontext der gebauten Welt, wie dies von Silke Steets geleistet wurde. Die Verlagerung des Untersuchungsgegenstandes von der Repräsentation zu unterschiedlichen Rezeptionen erfordert zudem die Möglichkeit, synchrone Wirklichkeitsdeutungen methodisch zu erfassen. Das Forschungsprogramm und der Diskursbegriff der wissenssoziologischen Diskursanalyse, wie sie von Reiner Keller konzeptualisiert wurden, erweisen sich dafür als besonders geeignet. Insbesondere durch die implizite Übernahme einer wissenssoziologischen Hermeneutik wird es möglich, konkurrierende Wissensverhältnisse sowohl im kreativen Handeln als auch im Hinblick auf die Strukturen, auf die dabei Bezug genommen wird - also im Sinne einer doppelten Hermeneutik (Giddens 1988:338) -, zu analysieren.

Werden Diskurse als Komplexe typischer und typisierbarer Aussageereignisse verstanden (Keller 2011), dann können sie anhand ihrer raumzeitlichen Formationsregeln differenziert werden. Dafür wiederum werden Analysekategorien benötigt, welche ich im vierten Kapitel entwickeln werde. Im Hinblick auf zeitliche Analysekategorien kann auf ein umfangreiches Repertoire empirisch gehaltvollen Theoriewissens (Kelle/Kluge 2010) zurückgegriffen werden. Für die Analyse der räumlichen Konstruktion gilt dies jedoch nur eingeschränkt. In einer Verbindung der räumlichen Kultursemiotik Juri Lotmans mit aktuellen raumsoziologi- 
schen Überlegungen (etwa Löw/Weidenhaus 2017) werden so die Voraussetzungen geschaffen, um verschiedene Modi räumlicher Syntheseleistungen differenzieren zu können. Die unterschiedlichen Logiken der Relationierung von Räumen sollen als Codes der Verräumlichung bezeichnet werden, die sich dann durch die empirische Analyse genauer bestimmen lassen.

Das fünfte Kapitel bildet die empirische Analyse der Debatte um die Wiederherstellung des Neuen Museums. Im Sinne doppelter Hermeneutik werde ich sowohl die strukturellen Aspekte der Baugeschichte als auch die Akteurskonstellation darstellen, um schließlich analysieren zu können, wie diese in unterschiedlichen Rezeptionen sinnhaft gedeutet werden. Im Sinne der empirischen Rahmungen des Gegenstandes wird dabei vor allem auf die Aspekte fokussiert, die durch die Stimmen des Diskurses selbst betont werden. Dies führt dazu, dass die räumlichen Bezüge teilweise über das Neue Museum hinausreichen. Da Relationen zu den umliegenden Gebäuden geknüpft werden - insbesondere zu der James Simon Galerie - , enden die Diskurse keinesfalls an der Museumstür. Die Analyse erlaubt es, anhand der Debatte über die Wiederherstellung des Neuen Museums zwei gleichermaßen positive, aber dennoch konkurrierende Kollektivierungsdiskurse zu rekonstruieren. Obwohl beide Diskurse die gleichen Werte in Anspruch nehmen und sich derselben Begriffe bedienen, werden dennoch geradezu gegensätzliche Wissensverhältnisse etabliert. Dass diese sich nicht an der semantischen Oberfläche, sondern in der Grammatik ihrer Konstruktion unterscheiden, wird anhand ihrer zeitlichen Strukturierung sowie ihrer jeweiligen Codes der Verräumlichung deutlich.

Können im Neuen Museum verschiedene Modi des positiven Vergangenheitsbezuges rekonstruiert werden, stellt der Kollektivierungsdiskurs der Bundeswehr im sechsten Kapitel der Arbeit den für die idealtypische Rekonstruktion raumzeitlicher Kollektivierungsdiskurse vielversprechenden Fall eines negativen Vergangenheitsbezugs dar. Anders als in der Debatte des Neuen Museums ergibt sich daraus ein zeitkonstitutionelles Dilemma. Aufgrund der Verheerungen der deutschen Militärgeschichte erscheint ein bruchloser Vergangenheitsbezug nicht möglich. Wie die Akteure der Neugestaltung aber betonen, bedürfen Institutionen wie das Militär dennoch »in besonderer Weise einer aus den Leistungen der Vergangenheit gespeisten Selbstvergewisserung und damit der Identitätsstiftung.« (Konzeptgruppe 2003:31). Besondere Bedeutung erhält deshalb neben der Darstellung der Bau- und Diskursgeschichte die institutionelle Akteurskonstellation. Denn als Dienststelle der Bundeswehr bleibt das Militärhistorische Museum unmittelbar staatlichen Entscheidungsträgern unterstellt, die auch weiterhin ein Identitätsangebot formulieren müssen. Dies führte dazu, dass eine Vielzahl von Dokumenten der Bundeswehr in die Analyse einbezogen wurde. Durch die institutionelle Verbindung ist auch diese Rahmung des Gegenstandes empirisch gedeckt. Gleiches gilt für die Entscheidung, die Ausstellung im Inneren des Gebäudes stärker in die Analyse einzubeziehen. Denn anders als im Neuen Museum nahm der Diskurs oft auf 
die grundlegend neue Inszenierung der Exponate Bezug. Obwohl, wie im Neuen Museum, ebenfalls die ablehnenden Stimmen der Gegner der Neugestaltung abgebildet werden, erscheint es sinnvoll, diesen Gegendiskurs vor allem zur besseren Konturierung des Kollektivierungsdiskurses der Bundeswehr und somit als Kontrastfolie zu nutzen.

Im siebten Kapitel werde ich schließlich versuchen, die Ergebnisse der empirischen Analysen zu einer Synthese zu führen. Es soll danach gefragt werden, ob mögliche raumzeitliche Homologien zu anderen Diskursen bestehen. Da dies einer gesonderten empirischen Prüfung bedarf, haben die abschließenden Überlegungen deshalb auch den Charakter eines Ausblicks.

Die vorliegende Arbeit beschreibt damit eine Bewegung vom Ausgangspunkt einiger zeitdiagnostischer Darstellungen, mit der lediglich der allgemeine Kreis der Bedingungen der Moderne dargestellt werden soll. Da sich daran unmittelbar die Frage nach der Konstruktionsmöglichkeit kollektiver Identitäten anschließt (Sebald/Weyand 2011), lässt sich darin ein weiterer Kreis verorten. Innerhalb dieses Kreises wiederum lassen sich die konkreten Fallanalysen der speziellen Diskurse im Kontext von Museen einzeichnen. Da sich diese Diskurskreise nicht-konzentrisch zueinander verhalten, ergeben sich Schnittpunkte, wodurch Rückbindungen der im Speziellen gewonnenen Erkenntnisse auf eine allgemeinere Ebene prinzipiell möglich erscheinen, sich aber aufgrund des engen Untersuchungsrahmens zunächst jedoch bescheiden müssen und einstweilen offen bleiben. 



\section{Die Erfahrungsräume der Gegenwart}

Postmoderne, Spätmoderne, Flüchtige Moderne, Reflexive Moderne - die Liste der Definitionsversuche der Zeit, in der wir leben, ist lang. Unabhängig von dem jeweils gewählten Attribut, lassen sich geschichtliche Epochen anhand eines Kategorienpaares benennen, welches Reinhart Koselleck zur Bestimmung historischer Zeit vorgeschlagen hat. Dabei handelt es sich um die Begriffe Erfahrungsraum und Erwartungshorizont. Geschichte werde stets im Spannungsverhältnis von Erfahrung und Erwartung konstituiert und verschränkt dabei Vergangenheit und Zukunft auf je spezifische Weise (Koselleck 1989:353). Dabei werden die beiden Kategorien keineswegs statisch aufgefasst. Denn dadurch, dass einmal gemachte Erfahrungen aus Perspektive der Gegenwart fortlaufend verändert werden, wird die temporale Struktur der Erfahrung immer auch durch rückwärts wirkende Erwartungen modifiziert (a.a.O. 358). Da Erfahrungsraum und Erwartungshorizont auf je spezifische Weise miteinander verbunden sind, lässt sich das jeweilige Verhältnis, in welches retrospektive Erinnerungen und prospektive Hoffnungen gestellt werden, zur Differenzierung geschichtlicher Zeitverhältnisse heranziehen. Das Charakteristikum der Neuzeit bestehe demnach darin, dass mit den jeweiligen Erfahrungen einer Epoche keine zuverlässigen Aussagen mehr über zukünftige Erwartungen artikuliert werden können. Erwartungen, die sich in die Zukunft erstrecken, lösen sich somit von den bisherigen Erfahrungen (a.a.O. 364).

»Erwartungen, die auf Erfahrung fußen, können, wenn sie eintreffen, nicht mehr überraschen. Überraschen kann nur, was nicht erwartet wurde: dann liegt eine neue Erfahrung vor. Die Durchbrechung des Erwartungshorizontes stiftet also neue Erfahrung. Der Erwartungsgewinn übersteigt dann die durch bisherige Erfahrungen vorgegebene Beschränkung möglicher Zukunft.« (Koselleck 1989:358).

Indem der Erwartungshorizont nunmehr einen mit der Zeit voranschreitenden Veränderungskoeffizienten besitzt (Koselleck 1989:363), wird etwa die Idee historischen oder gesellschaftlichen Fortschritts überhaupt erst denkbar. Denn dieser ist an die Bedingung geknüpft, dass etwas radikal Neues und eine potenziell andere 
Zukunft (also eine Abweichung vom Erfahrungsraum) möglich sind. ${ }^{1}$ Das Kennzeichen der Neuzeit besteht also in der zunehmenden Kluft zwischen Erfahrung und Erwartung; oder in einem Begriff, den Koselleck nicht verwendet: in der Zunahme von Kontingenz.

Dadurch, dass die Erwartungshorizonte anhaltend durchbrochen werden, müssen gemachte Erfahrungen immer wieder neu perspektiviert werden. Da Erfahrungsräume immer wieder verworfen werden, verringert sich auch die Halbwertszeit historischen Wissens, so dass auch Zukunft davon nicht unberührt bleibt. Zwar konnten "geschichtliche Strukturen« und »temporale Erfahrungen«, also die Erfahrung von Veränderungen, auch in vorneuzeitlichen Gesellschaften artikuliert werden, allerdings waren diese stets in eine kosmologische oder theologische ordo temporum eingebettet (Koselleck 1989:142). Mit der Entstehung der Geschichte als Kollektivsingular ist der Lauf der Zeit aber nicht mehr in ein kosmologisches Ordnungssystem eingebettet. "Was ehedem in Schöpfungsmythen und Kosmogonien aufgehoben war, gewinnt jetzt geschichtliche Struktur.« (Koselleck 2000:12). Die Gewissheit stiftenden Fluchtpunkte, an die historische Veränderungen rückgebunden werden konnten, gehen somit verloren. Zukunftskontingenz verdichtet sich so zur einzigen bleibenden Gewissheit, denn Zukunft bleibt nunmehr auf »bekannte Weise unbekannt« (Koselleck 1989:143).

Im Einklang mit dem voranschreitenden Veränderungskoeffizienten reproduzieren zahlreiche Zeitdiagnosen nicht nur die Grundannahme einer für die Moderne grundsätzlichen Erfahrung von Differenz und Kontingenz, sondern unterstellen zudem eine Verschärfung dieser Dynamik in der Gegenwart. Kaum eine zeitdiagnostische Beschreibung der Gegenwart kommt dabei ohne den Hinweis aus, dass eine »fortwährende Umwälzung« und eine »ununterbrochene Erschütterung aller gesellschaftlichen Zustände« im Gange seien, die »ewige Unsicherheit und Bewegung« zur Folge haben. Diese (mehr oder weniger) expliziten Bezugnahmen auf das von Marx und Engels im Kommunistischen Manifest (1973:465, Orig. 1848) beschriebene Verdampfen alles »Ständischen und Stehenden« wird so zur conditio sine qua non moderner Gesellschaften. Die anhaltende und sich verschärfende Veränderungsdynamik der bekannten Unbekanntheit der Zukunft - für die Oliver Marchart den Begriff»Ungewissheitsgewissheit« prägte (2013:26ff.) - tritt allerdings in Spannung zu einem Gedanken, den Koselleck an anderer Stelle formuliert. Dieser besteht darin, dass alle menschlichen Lebens- und Handlungsbereiche Wiederholungsstrukturen ausbilden, die sich zwar unterschiedlich schnell verändern können, in ihrer Funktion der Verstetigung allerdings von fundamentaler Bedeutung für alle Gesellschaften bleiben. Demnach »[zehrt] jede Verfassung, Institution und Organisation im politischen, sozialen oder ökonomischen Bereich [...] von einem

1 Erst indem die Kategorien auseinandertreten, also in der»Umbruchzeit «der Neuzeit, werden sie überhaupt als solche erkennbar (Koselleck 1989:374). 
Minimum an Wiederholung, ohne die sie weder anpassungs- noch erneuerungsfähig wären.« (Koselleck 2000:14). Die Notwendigkeit der Konstruktion eines Gleichbleibens über zeitliche Brüche und räumliche Differenzerfahrung hinweg, also die Stabilisierung eines Selbstbildes, welches ein Minimum an Planungssicherheit und Kohärenz ermöglicht, bleibt trotz der Dynamisierung historischen Wandels auch in der Gegenwart erhalten.

Vor diesem Hintergrund wird schließlich die Frage nach den Konstruktionsmöglichkeiten kollektiver Identitäten unter den Bedingungen moderner Gesellschaften zentral. Auch Gerd Sebald und Jan Weyand weisen dieser Frage einen zentralen Stellenwert zu und formulieren dies folgendermaßen: »Die grundlegende soziologische Frage, wie gesellschaftliche Integration unter Bedingungen der Moderne möglich ist, steht deshalb im Zentrum einer Soziologie sozialer Gedächtnisse.« (Sebald/Weyand 2011:182). In die Terminologie Kosellecks rückübersetzt, stellt sich dadurch die zentrale Frage, $o b$ Wiederholungsstrukturen unter dem ungewissen Erwartungshorizont der Gegenwart noch stabilisiert werden können.

Um die Frage nach der Möglichkeit der Konstruktion kollektiver Identität unter den »Bedingungen der Moderne« stellen zu können, sollen diese im Folgenden zunächst dargestellt werden. Dies geschieht anhand einflussreicher Gegenwartsdiagnosen. Was die hierfür herangezogenen Autoren außer ihren weitgehend einheitlichen Einschätzungen über die Charakteristika und Gefährdungslagen in der Gegenwart gemeinsam haben, ist die große Reichweite ihrer Texte. Die auflagenstarken und in mehrere Sprachen übersetzten Bücher werden auch außerhalb der disziplinären Grenzen der Geisteswissenschaften von einem großen Publikum gelesen. Dass sich etwa die »Risikogesellschaft« von Ulrich Beck (1986, aktuell 23. Aufl.) auch nach über 30 Jahren einer großen Leserschaft erfreut, deutet darauf hin, dass die darin gestellte Diagnose einer Zunahme von Risiken durch Modernisierung nach wie vor anschlussfähig ist. Neben einer grundsätzlich unterstellten Abnahme der Kohäsionskraft gesellschaftlicher Großgruppen wird dabei eine Dynamisierung von Raum und Zeit attestiert. Zygmunt Bauman etwa weist in seiner nicht weniger einflussreichen Diagnose einer »flüchtigen Moderne« (2016, Orig. 2003) der fundamentalen Veränderung der Beziehungen von Raum und Zeit explizit eine Schlüsselrolle in den Transformationen der westlichen Gegenwartsgesellschaften zu (a.a.O. 15). Der vorherrschende pessimistische Ton, der zumeist angeschlagen wird, bezieht sich im Wesentlichen auf die Dimensionen der Individualisierung (Unmöglichkeit der Sozialintegration), Dynamisierung der Zeit (Unmöglichkeit der Kontinuität) sowie auf die Dynamisierung von Räumen (Unmöglichkeit der Kohärenz). Entlang dieser Dimensionen sollen die zentralen zeitdiagnostischen Einschätzungen zunächst dargestellt werden. Denn diese, so die breit geteilte Annahme, erschweren die Konstruktion von stabilen Identitäten sowohl auf personaler als auch kollektiver Ebene. Ohne dass die grundsätzlichen »Bedingungen der Moderne« bezweifelt werden, sollen jedoch mit dieser Arbeit einige der 
daraus gezogenen Schlüsse im Hinblick auf die Artikulationsmöglichkeiten kollektiver Selbstbilder einer empirischen Prüfung unterzogen werden.

Vereinfachend lassen sich die üblicherweise auf die Frage, ob und wie Identität noch konstruiert werden kann, gegebenen Antworten in zwei Lager unterteilen. Einerseits erhebt sich ein zumeist in düsteren Farben gemaltes Bild der Anomie, in dem die Kohäsionskräfte des Sozialen nicht mehr ausreichen, die nunmehr vereinzelten Individuuen dauerhaft zu einer Gemeinschaft zusammenzubinden. Andererseits wird oft ein nicht weniger bedrückendes Bild der retrotopischen Kompensation entworfen, die als sentimentale und verklärende Hinwendung an eine Gewissheit stiftende Vergangenheit thematisiert wird. Die Frage nach den Möglichkeiten gegenwartsadäquater Formen der Selbstthematisierung und die Frage, ob zwischen Anomie und Kompensation noch weitere Wiederholungsstrukturen artikuliert werden können, bedürfen allerdings einer empirischen Klärung. Sollten weiterhin Wiederholungsstrukturen unter dem ungewissen Erwartungshorizont der Gegenwart stabilisiert werden können, dann stellt sich schließlich die weitere Frage, wie die Kluft zwischen zunehmend pluralen und disparaten Erfahrungsräumen und den durch Beschleunigung näher gerückten Erwartungshorizonten überbrückt werden kann.

\subsection{Zeitdiagnose als Phänomen der Moderne}

Bevor die Inhalte der Gegenwartsdiagnosen dargestellt werden, muss allerdings noch eine einführende Verortung dieser Textgattung vollzogen werden. Denn, dass Zeit überhaupt als diagnosebedürftig empfunden wird, ist selbst ein modernes Phänomen, welches vor allem in der Kulturkritik Nietzsches am Ende des 19. Jahrhunderts seinen Ausgang nimmt. Erst zu einem Zeitpunkt, an dem die teleologische Gewissheit auf ein >Happy End ८ der Geschichte durch deren »Zukunftsoffenheit « (Bogner 2012:34) infrage gestellt wird, kann im eigentlichen Sinn von Zeitdiagnose gesprochen werden. War der Verlauf der Geschichte zuvor noch in einen vernünftigen »Weltplan« eingebettet (a.a.O. 43), so waren zu diesem Zeitpunkt auch etwaige Interventionen oder konkrete >Therapievorschläge < überflüssig, da auf die »Selbstheilungskräfte der Geschichte« vertraut werden konnte (a.a.O. 27). Die Gattung der kulturkritischen Gegenwartsdiagnose ist also selbst ein Nebenprodukt des Auseinandertretens der Erfahrungsräume und Erwartungshorizonte. Die Verschiebung von Zeitdeutungen hin zu Zeitdiagnosen (Bogner 2012:42ff.) vollzieht sich somit erst unter dem Eindruck eines zunehmend ungewissen Erwartungshorizontes. Zielten die vorherigen Zeitdeutungen lediglich darauf, den aktuellen Entwicklungsgrad der Entfaltung (etwa des Weltgeistes) zu benennen, so wird die Aufgabe der Diagnose erst sinnvoll, sofern eine Andersartigkeit der Epochen überhaupt erwogen werden kann und die jeweils eigene Zeit bestimmungsbedürftig wird. 
Neben der starken Außenwirkung von Gesellschaftsdiagnosen über wissenschaftliche Fachgrenzen hinweg kann der oft pessimistische und zuweilen alarmistische Grundtenor auf die Herkunft dieser Textgattung aus der Kulturkritik zurückgeführt werden (Bogner 2012:23ff.). Bereits der Begriff >Diagnose`suggeriert neben einer festzustellenden Pathologie auch die Möglichkeit der Heilung und der Therapie (a.a.O. 16). Den Prototyp kulturkritischer Zeitdiagnose bildet dabei Nietzsches Kritik an der Verwissenschaftlichung seiner Zeit, wie er sie in der »Geburt der Tragödie« formulierte (2015, Orig. 1871). Darin findet sich eine wortgewaltige Modernekritik, die er an der Rationalisierung der modernen Welt festmacht. Diese rationale Kultur des "Sokratismus« bringe demnach nichts »Dionysisches« mehr hervor und verliere damit ihre vitalen Kräfte. Die von Nietzsche gestellte Diagnose lautet also auf »Sokratismus«; als »Therapieempfehlung « wird dionysische Kultur verordnet, vor allem die Musik Richard Wagners (Bogner 2012:42). Neben der Geburt der Tragödie nimmt Nietzsche in seiner zweiten »unzeitgemäßen Betrachtung« über den »Nutzen und Nachtheil der Historie für das Leben« die Kritik an der Verwissenschaftlichung der Gesellschaft erneut auf. Diese wird nun auf den Umgang mit der Vergangenheit zugespitzt. Insbesondere in einer rein analytisch-kritischen Betrachtung der Geschichte durch den Historismus als geschichtswissenschaftliche Strömung sieht Nietzsche eine Gefahr für die Kultur. Denn das »Historisieren alles Gewordenen durch den modernen Menschen« führe zum »Zersplittern und Zerfasern aller Fundamente.« (Nietzsche 2009:87, Orig. 1874). Dieses »Uebermaass an Historie« wisse nicht mehr, sich der »Vergangenheit wie einer kräftigen Nahrung zu bedienen.«(a.a.O. 107). Neben dem wortgewaltig vorgetragenen Alarmismus, der für die gesamte Gattung stilbildend bleiben wird, ist darin bereits die Sorge um die sozialen Kohäsionskräfte angelegt. Das »Zersplittern und Zerfasern aller Fundamente erlaube keine fundierenden Mythen, um die nunmehr vereinsamten Individuen zu versammeln und aneinander zu binden. Die Entzauberung der modernen Welt wird schließlich mit der Furcht verbunden, dass Identitätsbildung und Sinnstiftung zum Erliegen kommen. Zudem vermag die moderne Zeit nichts »Ueberhistorisches« mehr zu stiften. Die Wissenschaft bedrohe demnach die »aeternisirenden Mächte der Kunst und Religion«. In der Sorge der Negation all dessen, »was dem Dasein den Charakter des Ewigen und Gleichbedeutenden giebt« (a.a.O.107f., [sic!]), artikuliert sich die moderne Erfahrung des Verlustes von Letztverbindlichkeit und Ewigkeit. Auch dieser Aspekt wird in den, im Folgenden dargestellten, Diagnosen erhalten bleiben.

Im Unterschied zu Gesellschaftstheorien zeichnen sich Gegenwartsdiagnosen zudem durch ihr Konkretionsniveau aus. Anders als gesellschaftliche Großtheorien, die abstrakter und meist an ein wissenschaftliches Fachpublikum adressiert sind, zeichnen sich Gegenwartsdiagnosen durch ihre »monofaktorielle Konstruktion« aus (Bogner 2012:14). Die Grundannahme besteht darin, dass durch Beschreibungen bestimmter Aspektstrukturen moderner Gesellschaften 
ein Basisproblem identifiziert werden kann, anhand dessen sich Gesellschaft als Ganze charakterisieren lässt (a.a.O. 15). Aus dieser "pars-pro-toto«-Logik (a.a.O. 14) erklären sich auch die Bindestrich-Diagnosen einer Risikogesellschaft (Beck 1986), Erlebnisgesellschaft (Schulze 1992), Gesellschaft der Angst (Bude 2014) und dergleichen mehr. ${ }^{2}$ Neben pessimistischen Zeitdiagnosen, in denen die Gegenwart meist als Zeit des Niedergangs beschrieben wird, in der sich keine fundierenden Erzählungen mehr formulieren lassen, findet in der Soziologie oft der Begriff Gesellschaftsdiagnose Verwendung. Ungeachtet der Akzentuierung auf Gesellschaft können die Begriffe >Zeitdiagnose` und >Gesellschaftsdiagnose aber weitgehend synonym verwendet werden.

Eine weitere terminologische Variation dieser Gattungsbezeichnung findet sich bei Uwe Schimank und Ute Volkmann. Diese sprechen eher von Gegenwartsdiagnosen; wodurch >Gesellschaft< wiederum durch den zeitlichen Begriff 'Gegenwart s substituiert wird. Gegenwartsdiagnosen werden hinsichtlich ihres Abstraktionsniveaus abgegrenzt und zwischen zwei Spielarten soziologischer Gesellschaftsanalyse verortet (Schimank/Volkmann 2000). Sie sind einerseits abstrakter als Analysen einzelner nationaler Gesellschaften und zeitlich nicht auf einzelne »Schlüsselereignisse begrenzt. Im Unterschied zu soziologischen Einzelstudien liegt hierin auch der Grund für die zumeist schwache »empirische Basis« und einen »spekulativen Überhang« von Gegenwartsdiagnosen (a.a.O. 16f.). Zum anderen sind sie jedoch weniger abstrakt als Gesellschaftstheorien, wie etwa differenzierungstheoretische Perspektiven, die teilweise den Anspruch theoretischer Großentwürfe »von der Stammesgesellschaft bis heute« erheben (a.a.O. 2000:15).

Im Sinne dieser Arbeit werden die Begriffe `Zeitdiagnose $<$, >Gegenwartsdiagnose oder `Gesellschaftsdiagnose weitgehend synonym verwendet. Die im Folgenden zur Bestimmung der »Bedingungen der Moderne« herangezogenen Diagnosen verfügen - übereinstimmend mit dem Definitionskriterium der Außenwirkung - über eine große Reichweite, die weit über den soziologischen Fachdiskurs hinausreicht. Jedoch besteht der Anspruch dieser Arbeit keinesfalls darin, selbst zeitdiagnostisch oder gar therapeutisch - um in der medizinischen Terminologie $\mathrm{zu}$ bleiben - tätig zu werden. Nicht die Befunde der Gegenwartsdiagnosen sollen bestritten werden, sondern lediglich einzelne daraus gezogene Schlüsse (im Hinblick auf die Konstruktionsmöglichkeiten kollektiver Identitäten) einer empirischen Prüfung unterzogen werden. Da es um eine konkrete empirische Analyse von Kollektivierungsdiskursen im zudem äußerst begrenzten Kontext zweier $\mathrm{Mu}$ seumsdiskurse geht, liegt das Abstraktionsniveau also unterhalb dessen der Gegenwartsdiagnose. Um dies in einem sprachlichen Bild zu veranschaulichen, kann

2 Die wissenssoziologische Analyse soziologischer Gegenwartsbeschreibungen von Fran Osrecki und die metadiagnostische Diagnose einer »Diagnosegesellschaft« (2011) bilden den vorläufigen Höhepunkt dieser Entwicklung. 
der allgemeine Diskurs der Bedingungen der Moderne als ein weitgefasster Kreis beschrieben werden. Innerhalb dieses Kreises befindet sich der unmittelbar damit verbundene Kreis der Kollektivierungsdiskurse. Innerhalb dieses Kreises wiederum lässt sich ein abermals kleinerer Bereich von Museumsdiskursen markieren. Wichtig ist, dass diese Kreise nicht-konzentrisch zueinander angeordnet sind, so dass sich jeweils Schnittpunkte der Kreise (sprich: der Diskurse) ergeben. ${ }^{3}$ Da die Frage nach der Artikulationsfähigkeit kollektiver Selbstbilder in den Gegenwartsdiagnosen explizit aufgeworfen wird, ergeben sich unmittelbar zahlreiche Schnittpunkte des allgemeinen Diskurses der Bedingungen der Moderne und der verschiedenen Kollektivierungsdiskurse. In den analysierten Diskursen des Neuen Museums und des Militärhistorischen Museums kommen verschiedene Geschichtsbilder und Vorstellungen darüber, wie diese verräumlicht werden sollen, zum Ausdruck. Verschiedene Akteure wie etwa Bürgerinitiativen, Denkmalpflege oder die Bundeswehr artikulieren implizit und explizit fundierende Erzählungen, so dass sich abermals Schnittpunkte zwischen Kollektivierungsdiskursen und den speziellen Museumsdiskursen ergeben.

\subsection{Individualisierung statt Emanzipation}

In seiner einflussreichen Diagnose einer »Risikogesellschaft « attestiert der Soziologe Ulrich Beck den »Übergang in eine andere Moderne«, so der Untertitel des Buchs. Die Schwellenphase zwischen erster und zweiter Moderne bezeichnet keinen historischen Bruch, sondern das Ende der Industriegesellschaft, das paradoxerweise durch deren konsequente Umsetzung eintritt (Beck 1986:15). Dabei werden die unübersehbaren Folgen der Modernisierung »reflexiv«. Indem die so geschaffenen Gefährdungslagen und Risiken sichtbar werden, macht sich die Moderne schließlich selbst zum Thema (a.a.O. 26). Die Produktion von Gütern verhindert nun nicht mehr Risiken, sondern erzeugt durch ihre Produktionsweisen selbst neue Risiken. Neben den globalen und ökologischen Katastrophenpotenzialen der Hochrisikotechnologie werden in den Gegenwartsdiagnosen von Beck, Sennett und Bauman insbesondere Risiken der eigenen Lebensführung thematisiert, die strukturell bedingt sind und nicht mehr an gesellschaftliche Großgruppen adressiert werden können. 
Was damit gemeint ist, lässt sich vor allem anhand der Schlagworte >Individualisierung und >Enttraditionalisierung beschreiben. Jenseits von Klasse und Stand wird der oder die Einzelne zur zentralen Reproduktionseinheit des Sozialen (1986:119). Dies führt jedoch keineswegs zu einer Emanzipation der Individuen. Vielmehr ist damit gemeint, dass die »institutionsabhängige[n] Individuallagen « (ebd.) lediglich suggerieren, dass einzelne Subjekte Herren ihrer Lebensführung sind, wobei gleichzeitig strukturelle Abhängigkeiten weiterhin bestehen oder sich sogar noch verschärfen. Die Beziehungseinheit, in die der »Blitz«, etwa der Arbeitslosigkeit und Armut, einschlägt, ist nicht mehr die Gruppe oder die soziale Schicht, sondern das Markt-Individuum in seinen besonderen Umständen (a.a.O. 144). Die Erosion gesellschaftlicher Großgruppen wie Klasse und Stand, aber auch der tradierten Familienstrukturen führt gerade deshalb nicht zu einer klassenlosen Gesellschaft gleicher Individuen, da sich Individualisierung unter gesellschaftlichen Rahmenbedingungen vollziehe, die eine individuelle, verselbstständigte Lebensführung weniger denn je zulassen (Beck 1986:211). Dass der Einzelne zur »lebensweltlichen Reproduktionseinheit des Sozialen« (a.a.O. 209) wird, bedeutet, dass Schicksalsschläge nur noch im Modus des eigenen Versagens und der persönlichen Haftung verarbeitet werden können, da sie nicht mehr an strukturelle Bedingungen adressiert werden. Die Markt-Individuen der reflexiven Moderne, so ließe sich schlussfolgern, begegnen der Ohnmachtserfahrung angesichts struktureller Zwänge mit der Hybris der Selbststeuerung. Individualisierungstheorie ist für Beck deshalb gleichbedeutend mit Krisentheorie, denn das Ende sozialer Klassen ist keinesfalls gleichbedeutend mit dem Ende sozialer Ungleichheit (Beck 2008:302). Die Individuen sind also nicht emanzipiert. Indem sie für die Risiken der Lebensführung selbst haften, ist Freiheit vor allem negative Freiheit. ${ }^{4}$

Übereinstimmend mit Beck besteht auch für Zygmunt Bauman die ambivalente Freiheit der Individualisierung in der Gewährung von Autonomie de jure, egal ob sie de facto zur Verfügung steht (Bauman 2016:43, Orig. 2003). In seiner Diagnose einer "flüchtigen Moderne" geht er davon aus, dass entgegen der in der schweren Moderne befürchteten Kolonialisierung des Privaten durch die Öffentlichkeit - etwa durch einen intervenierenden und disziplinierenden Staat orwellscher Prägung (a.a.O. 36f.) - vielmehr eine Kolonisierung des Öffentlichen durch das Private erkennbar werde (a.a.O. 52). Das Verhältnis habe sich umgekehrt und führe auch hier keineswegs zu Emanzipation, sondern zu Vereinsamung. Zwar werden private Probleme öffentlichkeitstauglich, wodurch sie aber keinesfalls zu öffentlichen Anliegen werden. Vielmehr stehen sie als Privatangelegenheiten in der Öffentlichkeit 
(Bauman 2016:83). Paradoxerweise ergibt sich daraus, dass, um positive individuelle Freiheit heutzutage zu fördern, ein Mehr an »öffentlicher Sphäre« und öffentlich gefasster Macht gefordert werden müsse (a.a.O. 65). Unabhängig davon, ob die These, dass das Öffentliche durch das Private kolonisiert werde und der Kontrollraum staatlicher Überwachung und Disziplinierung verwaist sei, zutreffend ist oder nicht, hält Bauman daran fest, dass Subjekte in der flüchtigen Moderne zuvorderst Individuen und nicht mehr Bürger sind, die einen gemeinsamen öffentlichen Raum bevölkern. Die Herstellung des sozialen Gewebes muss nunmehr in Heimarbeit gelöst werden (Bauman 2016:14) und geschieht nicht mehr durch das gemeinsame Bevölkern und Herstellen eines öffentlichen Raumes (a.a.O. 50ff.). Individualisierung entspricht damit der Transformation menschlicher Identität von einer Vorgabe zu einer Aufgabe (a.a.O. 43). Diese Aufgabe der Selbstidentifikation führt auch hier nicht zu Emanzipation (a.a.O. 25ff.), sondern zu Anomie (a.a.O. 30). ${ }^{5}$

Für Bauman sind Identitäten und Gemeinschaften in der flüchtigen Moderne zuvorderst temporäre Verbindungen von Individuen, die sich nach kurzer Zeit eines Spektakels, zu dessen Zweck sie sich versammelt haben, wieder voneinander lösen. Bauman illustriert dies mithilfe einer Theatermetapher. Die »Gemeinschaft der [h] erausgeputzten « Theaterbesucher besteht aus Individuen, die zwar partiell gleich sind und sogar ein gemeinsam geteiltes Interesse verfolgen können, vielleicht sogar ein einheitliches ästhetisches Empfinden haben; diese Schnittmengen haben allerdings eine zeitlich begrenzte Gültigkeit (Bauman 2016:233ff.). Da diese Gruppen nicht mehr nach Dauerhaftigkeit streben oder sich über Konstanz legitimieren müssen, verflüchtigen sie sich so schnell, wie sie sich zusammenfinden (Bauman 2017:127). Trotz der Ähnlichkeit der individuellen Gefährdungslagen ergebe sich kein gemeinsamer öffentlicher Raum. Die Probleme der »SchicksalsIndividualisten « lassen sich nicht mehr zu einem "gemeinsamen Anliegen« verdichten. Die fehlende Kohäsion zeige sich darin, dass Individuen und ihre Anliegen zwar nebeneinanderstehen, jedoch nicht miteinander verschmelzen. So folgert Bauman, dass Gemeinschaften »in Zukunft ein Leben als artifizielles Randphänomen des endlosen Spiels der Individualität fristen« ohne, dass dabei Identitäten definiert oder geformt werden könnten (2016:32). Trotz der Ähnlichkeit der individuell gemachten Erfahrungen werden der Entstehung eines kollektiven Wir also denkbar schlechte Chancen eingeräumt.

Wie der Begriff der Individualisierung verfügt auch der Begriff der Anomie über eine lange Tradition. Bereits in der ursprünglichen Verwendung des Begriffs bei Durkheim können ein gesellschaftsdiagnostischer Impetus und der Versuch der Heilung durch »tragfähige Moral«zur Überwindung von »Desintegration und Zersplitterung« unterstellt werden (Bogner 2012:12f.). 


\subsection{Die Abschaffung der Ewigkeit}

Vor allem in der Akzentuierung temporärer Bindungen und dem Begriff des Flüchtigen wird, neben der Individualisierung, eine zweite Herausforderung für kollektive Selbstbilder in der Dynamisierung der Zeit gesehen. So wie die Gemeinschaft der Theaterbesucher sich nach der Aufführung wieder trennt, so seien auch die Gemeinschaften der flüchtigen Moderne stets temporär und kommen nicht über den Status von »Ad-Hoc-Allianzen« hinaus (2017:148).

Wie Ulrich Beck, der die »Verfassungsänderung« der Arbeitswelt (Beck 1986: 223) im Wesentlichen in einer Flexibilisierung von Raum und Zeit (a.a.O. 224ff.) erkennt, geht auch Richard Sennett in seiner einflussreichen Diagnose der Flexibilisierung der Arbeitswelt von einer Deregulierung von Raum und Zeit aus (Sennett 1998:110f.). ${ }^{6}$ In seinem Buch »The Corrosion of Character « attestiert Sennett eine Schwächung beruflicher Identitäten durch die zunehmend flexiblen Strukturen eines »neuen « Kapitalismus. Trotz einer Angleichung der Arbeitstechniken seien eine zunehmende Entfremdung vom Beruf und eine abnehmende Bindung der Arbeitenden untereinander feststellbar (a.a.O. 92). Dass neben personeller Identitätsbildung auch das Wesen moderner Institutionen zunehmend undeutlich werde, zeige sich »durch die Ablehnung jeder Routine, durch die Betonung kurzfristiger Aktivitäten, durch die Schaffung amorpher, hochkomplexer Netzwerke anstelle straff organisierter Bürokratien.«(a.a.O. 11of). Der Existenz dauerhafter sozialer Institutionen werden auch hier kaum Chancen eingeräumt.

Sinnbildlich für die charakteristische Zeitlichkeit des flexiblen Kapitalismus spricht Sennett davon, dass der »Pfeil der Zeit zerbrochen [ist]; er hat keine Flugbahn mehr in einer sich ständig umstrukturierenden, routinelosen, kurzfristigen Ökonomie.« (1998:131). Der Pfeil, der Assoziationen zu Vorstellungen einer linear verlaufenden Zeit weckt, ist zerbrochen. Der »flexible Mensch«(dt. Titel 1998) kann somit die episodische Zeitstruktur seiner Arbeit nicht mehr zu einer kontinuierlichen Erwerbsbiografie verdichten. Zukunft wird zunehmend unberechenbar und Planungssicherheit verknappt: "In der flexiblen, fragmentierten Gegenwart mag es möglich sein, zusammenhängende Erzählungen über das, was war, zu schaffen, aber nicht länger möglich, kreative vorausschauende Entwürfe dessen, was sein wird.« (Sennett 1998:184).

Was Sennett im Hinblick auf die Arbeitswelt beschreibt, stellt ein weiteres Auseinandertreten von Erfahrungsraum und Erwartungshorizont dar. Dabei scheint es 
so, dass sich einzelne Erwartungen gar nicht mehr artikulieren lassen, sondern potenziell verschiedene Zukünfte, also eine Vielzahl an Erwartungshorizonten, sichtbar werden. Die Unberechenbarkeit der Zukunft und die »Ablehnung jeder Routine« erlauben nunmehr keine kontinuierliche Lebensführung. Die Zersetzung (Corrosion) bezieht sich also nicht nur auf die Fragmentierung der individuellen Biografien (Character), sondern zeigt sich auch, wie bei Beck, in der Zersetzung gesellschaftlicher Großgruppen, da die strukturelle Verknappung von Langfristigkeit auch die Solidarität der Arbeitenden untereinander schwächt. ${ }^{7}$

Diese plausible These der Zunahme von Zukunftsungewissheit und die verringerte Halbwertszeit von Erfahrungswerten hat Hermann Lübbe als »Gegenwartsschrumpfung (Lübbe 2003, Orig. 1992) bezeichnet. Die beschleunigte Fahrt im "Zug der Zeit« führt so zu einem »verkürzten Aufenthalt in der Gegenwart«, so der Untertitel seiner Diagnose (ebd.). Neben der Flexibilisierung ist mit dem Begriff der Beschleunigung ein zweites Schlagwort der modernen Bedingungen der Zeit benannt. Hartmut Rosa hat darauf aufmerksam gemacht, dass in modernen Gegenwartsgesellschaften trotz Technisierung und des Freisetzens gewaltiger Zeitersparnisse eine massive Beschleunigung der Lebenszeit feststellbar ist (Rosa 2005). Die Frage, die sich aus der erklärungsbedürftigen Diskrepanz zwischen Zeitersparnis und Zeitverlust ergibt, beantwortet Rosa mit dem Verweis auf das »Wachstumsprinzip« und die »Beschleunigungslogik«, welche konstitutiv für jede Spielart des Kapitalismus seien (2009:98f.). Durch diese Steigerungslogik wird es, trotz fortschreitender Produktivität, zunehmend schwerer, das einmal Erreichte nochmals zu übertreffen. Auch hier halten technischer Fortschritt und die Steigerung der Produktivität keine Emanzipation bereit. Vielmehr führen sie dazu, dass die Halbwertszeit von Lebensentwürfen abnehme. Die Zyklen, in denen sich Wissensbestände umwälzen, verkürzen sich von intergenerationalem $\mathrm{zu}$ intra-generationalem Wandel. Lebenspraktiken und -entwürfe werden innerhalb einer Generation obsolet (Rosa 2009:105). Durch die Auflösung von Kontinuitäten der Lebensführung würden auch Potenziale der personellen Identitätsbildung geschwächt. Die nunmehr »situativen Identitäten« (a.a.O. 110), mit welchen vor allem Wettbewerbsfähigkeit aufrechterhalten werden kann, unterliegen ebenfalls einem strukturellen Zwang (a.a.O. 119f.). Ungeachtet dessen, dass diese Form personeller Identitätsbildung eine der Gegenwart angemessene Form der Selbstthematisierung sein mag, bleibt bei Rosa doch eine deutliche Skepsis wahrnehmbar, ob die flexibel-situativen Identitätskonstruktionen tatsächlich stabil sein können oder ob sie im Kern nicht doch labil bleiben. Temporalisierung und Beschleunigung werden bei Rosa vor dem Hintergrund einer generellen Schwächung von Identitäten thematisiert. 
Die Gefahr der Anomie bleibt, dieser Einschätzung zufolge, ein wahrscheinliches Szenario.

Auch Bauman zufolge wurde die Moderne »im Sternzeichen der Beschleunigung " geboren, welches ihre Entwicklung und ihr Schicksal präge (Bauman 2016:134f., Orig. 2003). Dieses schicksalhafte Voranschreiten erzwinge in der »flüchtigen Moderne« einen Kulturwandel im Vergleich zur »schweren Moderne«.

»Tugenden wie Geduld und das >Aufschieben von Belohnungen<, die in der Industriegesellschaft maßgeblich waren, sind nicht länger gefragt, Dauerhaftigkeit wurde als höchster Wert entthront und durch Vergänglichkeit ersetzt. Wir leben in einer Kultur der Auflösung, der Diskontinuität und des Vergessens. (Bauman 2007b:228).

Was Bauman anhand der Wirtschaftselite des leichten Kapitalismus und deren Fähigkeit, sich nicht mehr dauerhaft an Dinge zu binden, illustriert, wird zu einem funktionalen Weltbezug und avanciert zum »ultimativen Ideal« der flüchtigen Moderne (Bauman 2016:149). Da die Unendlichkeit der Möglichkeiten die Unendlichkeit der Zeit entthront habe, verliere Dauerhaftigkeit generell ihren Charme (a.a.O. 150). Vorstellungen von Ewigkeit werden damit dysfunktional. Sie wandern von der Haben- auf die Sollseite (ebd.). Das Lösen von Bindungen werde ebenso zentral wie das Knüpfen derselbigen. Besonders deutliche Worte für die Veränderung des Zeitregimes und den Abgesang auf zyklische und lineare Zeit findet Bauman, wenn er feststellt:

»In der Flüchtigen Moderne verläuft Zeit weder zyklisch noch linear, wie es in den uns bekannten Cesellschaften der Moderne und der Vormoderne der Fall war. Sie wird statt dessen in eine Vielzahl pointillistischer Momente zerlegt, von denen jeder soweit reduziert ist, dass er dem geometrischen Ideal der Nulldimensionalität so nahe kommt wie irgend möglich. (Bauman 2007a:180f.).

Daraus folge das Ende der Ewigkeit als erstrebenswertes oder erreichbares Ziel:

»In der >pointillistischen< Zeit der Flüchtigen Moderne ist die Ewigkeit kein Wert und kein Objekt der Begierde mehr; denn das, was ihren Wert ausmachte, wurde gleichsam herausgeschält und dem Augenblick implantiert. Folgerichtig trat die spätmoderne >Tyrannei des Augenblicks` mit dem Crundsatz des carpe diem an die Stelle der vormodernen Tyrannei der Ewigkeit und des memento mori.«(Bauman 2007a:185).

Mit den "pointillistischen Momenten« ist gemeint, dass Zeit nicht mehr einem Fluss, sondern nur noch einer "Ansammlung Teiche und Tümpel« entspricht (Bauman 1997:148). Aus den Pilgern von einst werden Flaneure, Vagabunden, Spieler, Touristen, deren Biografien zu unverbundenen Episoden zerfallen (Bauman 1997). Anstelle eines festen Ziels erscheinen episodisch immer wieder neue (kurzfristi- 
ge) Ziele am Horizont. Die Identitätssuche des postmodernen Menschen werde so zu einer Pilgerfahrt ohne festes Ziel. Die Einschätzung, dass lineare und zyklische Zeit angesichts "pointillistischer Momente« bedeutungslos werde, stellt eine drastische Schlussfolgerung dar. Da jede Verfassung, Institution und Organisation im politischen, sozialen oder ökonomischen Bereich von einem Minimum an Wiederholung zehren (Koselleck 2000:14), bleibt allerdings fragwürdig, ob auf Vorstellungen von Ewigkeit im Kontext politischer Institutionen und kollektiver Identitäten verzichtet werden kann. Obwohl Bauman keinen Zweifel daran lässt, dass sich in der Gegenwart eine »Entwertung der Unsterblichkeit« (Bauman 2016:150) und die »Abschaffung der Ewigkeit« (2007b:224) vollziehen, so scheint auch seine Fantasie nicht auszureichen, sich eine Gesellschaft vorzustellen, die auf jedwede Vorstellung von Ewigkeit verzichtet. Nachdenklich schließt Bauman mit den Worten: »Es ist schwer, sich eine Kultur vorzustellen, die sich gegenüber dem Unendlichen indifferent verhält und Dauerhaftigkeit meidet.«(Bauman 2016:153).

Der Erwartungshorizont zerfällt also einerseits in eine Vielzahl möglicher Zukünfte, da langfristige Perspektiven durch Ablehnung jeder Routine strukturell verknappt werden (Sennett). Durch die verringerte Halbwertszeit von Erfahrungswerten und die beschleunigte Relativierung von Wissen (Rosa) treten andererseits die Erwartungshorizonte (im Plural) nun deutlich näher. Da Dauerhaftigkeit an Bedeutung verliere und vom Strom der Zeit nur noch Teiche und Tümpel bleiben (Bauman), stellt sich die Frage, ob und (falls ja) wie unter diesen Bedingungen noch Vorstellungen von Kontinuität und ein Bild von Ewigkeit möglich sind.

\subsection{Vielheit ohne Einheit}

Im Unterschied zum »Hardwarezeitalter der schweren Moderne« transformiert der "Softwarekapitalismus der leichten Moderne« (Bauman 2016:138ff.) neben dem auf Dauer und Beständigkeit rekurrierenden Zeitregime auch den Raum. Der raumzeitliche Zusammenhang wird als zwingend angenommen. Denn die »routinisierten Zeitrhythmen hielten die Arbeit fest auf dem Boden.« Die »immobilen Fabrikanlagen« banden Arbeiterschaft und Kapital an einen Ort (ebd.). Mit dem Zeitregime der schweren Moderne transformiert sich also auch die räumliche Konstitution der flüchtigen Moderne. Die zur Illustration der Bedingungen der Moderne herangezogenen Zeitdiagnostiker widmen sich in räumlicher Hinsicht neben der arbeits- und sozialräumlichen Entgrenzung vor allem den Alteritätserfahrungen, die durch Globalisierung und Transnationalisierung verstetigt werden. ${ }^{8}$ 
Der Veränderung der räumlichen Verfassung der späten Moderne wird dabei epochale Bedeutung zugesprochen. Zygmunt Bauman zufolge war die Entstehung des Nationalismus auf die Idee territorial souveräner Staaten angewiesen, wie sie durch das cuius regio, eius religio des Westfälischen Friedens von 1648 in die Welt kam und im Zuge der Friedensverhandlungen von Versailles 1919 in cuius regio, eius natio umformuliert und abermals bekräftigt wurde (Bauman 2017:81). Übereinstimmend mit dieser epochalen Veränderung sieht auch Martina Löw in der Durchsetzung des Territorialstaatsprinzips den zentralen räumlichen Umschlagpunkt in der Geschichte der Moderne. Die »konflikthafte Re-Figuration von Räumen in der späten Moderne« allerdings (Löw 2018:47ff.) stellt einen zweiten Umschlagpunkt und eine tiefgreifende Reform der räumlichen Verfassung der (ersten) Moderne dar. Insbesondere seit den 1960er Jahren ist neben einer Dynamisierung der Zeit auch eine Dynamisierung des Raumes zu beobachten (Knoblauch/Löw 2017). Dieser tiefgreifende soziale Wandel hat unmittelbaren Einfluss auf die räumliche Verfassung der Gegenwart. Dies geschieht insbesondere durch Mediatisierung (Löw 2018:56), durch Translokalisierung, also die Verankerung an mehreren Orten, und Polykontexturalität von Raumkontexten über verschiedene Skalen und Dimensionen hinweg (a.a.O. 57). Neben dem Erodieren räumlicher Homogenitätsvorstellungen (a.a.O. 52), etwa des Nationalraums, führe dies dazu, dass Raumkonstitutionen vielfältiger und maßstabsübergreifend werden (a.a.O. 58). Vor allem hat dies zur Folge, dass Raum »nicht mehr der eine Raum«, sondern »nur noch im Plural zu haben« ist (ebd.). Mit dem Siegeszug des Containerraumes entstehen im 20. Jahrhundert dialektisch darauf bezogene Gegenbewegungen (Löw 2018:48ff.), die sich ab dem letzten Viertel des Jahrhunderts allmählich durchsetzen. Die Dynamisierung von Räumen und die damit verbundene Erosion von Homogenitätsvorstellungen haben unmittelbare Folgen für die Konstruktion kollektiver Identitäten.

Die »Unrevidierbarkeit entstandener Globalität« stellt auch für Beck ein wesentliches Unterscheidungsmerkmal zwischen Erster und Zweiter Moderne dar (Beck 2015:29). Mit Globalität ist dabei gemeint, dass die Vorstellung geschlossener nationaler, ökonomischer, kultureller und politischer Räume zunehmend haltlos wird oder bereits geworden ist (a.a.O. 27f.). Nur in diesem engen Sinne kann Beck zufolge von einer Weltgesellschaft gesprochen werden. Denn bei gleichzeitiger Schwächung des nationalstaatlichen Modells bleibt eine neue Einheit im Weltmaßstab unerkennbar.

»So wird das Modell der ersten, nationalstaatlichen Moderne, das in der Einheit von kultureller Identität ( $\left(V_{0} \mid k \iota\right)$, Raum und Staat gedacht und organisiert wurde, fragwürdig, ohne dass eine neue Einheit von Menschheit, Erde und Weltstaat in Sicht oder wünschenswert wäre. (Beck 2015:23).

Die Konstruktion von Einheit und die Koordination verschiedener kultureller, sozialer und nationaler Erfahrungsräume im Kontext unrevidierbarer Globalität 
erscheinen also äußerst limitiert. Beck zufolge können zwei unterschiedliche Umgangsweisen mit der spätmodernen räumlichen Verfassungsänderung unterschieden werden. Dabei handele es sich um verschiedene Arten des Unterscheidens (Beck 2015:95). Neben einer exklusiven Entweder-oder-Unterscheidung, in der sich Identitäten ausschließen, wird ein inklusives Ordnungsschema erkennbar, in dem Positionen zwischen den Kategorien keine Ausnahme, sondern die Regel sind (ebd.). Dieser Modus meint also »Kulturen im Plural«, wobei Kulturen als »nichtintegrierte, nicht-abgegrenzte Vielheit ohne Einheit gedacht« werden (a.a.O. 118). Beck bringt dies auf die Formel: »Welt $<$ in Weltgesellschaft heißt >Vielfalt ohne Einheit<. Demgegenüber bedeutet >nationale $<$ Gesellschaft >Einheit mit beschränkter Vielfalt «.« (a.a.O. 177).

In dem Moment, in dem die Nation den Container verlässt (2004:167), wird also die Formation eindeutiger räumlicher Grenzen sowie politischer und kultureller Einheiten erschwert. Diese bleiben bis auf Weiteres nicht erkennbar. Die entscheidende Frage sei deshalb, »ob in den Zivilgesellschaften und den politischen Öffentlichkeiten großräumig zusammenwachsender Regime ein Bewusstsein kosmopolitischer Zwangssolidarisierung entstehen kann. «(2015:184). ${ }^{9}$ Indem Beck von einer Denkhemmung oder von einem »Denkvirus « spricht, der es verhindere, Alternativen jenseits des Nationalstaates zu imaginieren, thematisiert er das Modell des Transnationalstaats als möglichen Gegenentwurf zur Container-Theorie von Staat und Gesellschaft (a.a.O. 185f.). Neben den medizinisch-pathologischen Metaphern (Hemmung, Virus) rät Beck dazu, nach Alternativen zu fragen, und empfiehlt dies mit dem bewusst ärztlich formulierten Rat »dreimal täglich!« (Beck 2015:184). Diagnostik und Therapieempfehlung liegen also auch hier dicht beieinander. Der Behandlungsvorschlag lautet: Transnationalstaat.

»Transnational meint auch transkulturell. Vorausgesetzt, Transnationalstaaten anerkennen die Nicht-Identität von Staat und Weltgesellschaft - was bedeutet dies für das kulturelle Selbstverständnis? Wenn Weltgesellschaft Vielheit ohne Einheit meint und Nationalgesellschaft Einheit mit beschränkter Vielfalt, dann meint Transnationalstaat bestimmte Vielfalt. Damit ist gesagt: Jenseits von entweder Clobalisierung oder Lokalisierung werden Varianten glokaler Kulturen im weltgesellschaftlichen Nexus erfahrbar (und) anerkannt.« (Beck 2015:189f.). 
Die Formulierung »Varianten glokaler Kulturen im weltgesellschaftlichen Nexus« klingt hinreichend abstrakt für eine gesellschaftstheoretische Reflexion über die politische Situation unserer Zeit, jedoch auffallend unkonkret, um als eine stabile Imagination von Gemeinschaft zu gelten. Was man sich darunter genau vorzustellen hat, bleibt auch in den weiteren Ausführungen Becks denkbar vage. Der Bereich jenseits von Globalisierung und Lokalisierung bleibt damit weitgehend unbesetzt. Trotz des unermüdlichen Einsatzes und des beeindruckend facettenreichen Denkens Ulrich Becks ist dennoch festzuhalten, dass trotz der die »kosmopolitischen Verhältnisse«, die sich in der Unrevidierbarkeit von universellen Interdependenzen und Interaktionen artikulieren, ein »kosmopolitisches Bewusstsein« dennoch kaum über die »Phase der Geburtswehen hinausgelangt« ist (Bauman 2017:187f.).

Wiederum in die Kategorien des Erfahrungsraums und des Erwartungshorizontes übersetzt bedeutet dies: Neben den an die Gegenwart herangerückten, sich aber nur umso schneller verändernden Erwartungshorizonten (im Plural) muss durch die pluralen Erfahrungen von kultureller und sozialer Alterität das Nebeneinander verschiedener Erfahrungsräume koordiniert werden. Die synchronen und teilweise in Konkurrenz stehenden Wirklichkeitsdeutungen erlauben keine einheitliche politische oder kulturelle Repräsentation. Die symbolische Mitte ist verloren gegangen (Löw 2013). Die Erfahrungsräume werden disparat. Die Pluralität verschiedener Erfahrungsräume bleibt zunächst eine Vielheit ohne Einheit (Beck) und deshalb notwendig unintegriert.

\subsection{Jenseits von Anomie und Kompensation}

In seinem letzten Buch argumentiert Zygmunt Bauman, dass die Erfahrungen der flüchtigen Moderne eine Sehnsucht »Zurück ans Stammesfeuer« (2017:65ff.) angeblich gewesener Gemeinschaft hervorrufen. Dabei findet eine Verlagerung der Bilder utopischer Gegenwirklichkeiten vom Raum eines besseren Anderswo in die Zeit eines schon gewesenen Vormals statt. Für dieses Phänomen prägt Bauman den Begriff der »Retrotopie«. Darunter versteht er: »Visionen, die sich anders als ihre Vorläufer nicht mehr aus einer noch ausstehenden und deshalb inexistenten $\mathrm{Zu}$ kunft speisen, sondern aus einer verlorenen/geraubten/verwaisten, jedenfalls untoten Vergangenheit.« (Bauman 2017:13).

Im Kern wird damit ein kompensationstheoretisches Argument reformuliert, welches darin besteht, dass Risiken und Schäden, die mit der Modernisierung einhergehen, ausgeglichen werden müssen (Ottmann 2010:102). Damit wird Retrotopien die Rolle des Ausgleichs von »Modernisierungsschäden« (Marquard 2013:105, Orig. 1986) zugewiesen. ${ }^{10}$ Die verklärende Zuwendung an die Vergan-

10 Kompensationstheoretiker wie Odo Marquard und Herrmann Lübbe haben diese Rolle traditionell den Ceisteswissenschaften zugewiesen (Marquard 1986). Die Idee, dass mit zuneh- 
genheit wird durch die Gefährdungslagen der flüchtigen Moderne begründet und soll diese kompensieren. Es wird davon ausgegangen, dass die mannigfaltigen Kontingenzerfahrungen der Moderne durch eine sentimentale Zuwendung und retrospektive Verklärung der Vergangenheit kompensiert werden. Implizit relativiert Bauman damit auch die zuvor gegebene Einschätzung, dass zyklische ebenso wie lineare Zeitlichkeit an Bedeutung verlieren würden. Denn indem sich das utopische Streben in Richtung Vergangenheit orientiert, muss diese wiederholt werden. So wie Vergangenheit normative Orientierung stiftet, so wird auch ihre Wiederholung zu einem normativen Gebot. Bildhaft gesprochen wird im Meer der »liquid modernity« die Vergangenheit zu einem Leuchtturm der Gewissheit, der dauerhafte Orientierung stiftet. Auch dadurch relativiert Bauman implizit die zuvor attestierte »Abschaffung der Ewigkeit«. Außerdem dient der kompensatorische Vergangenheitsbezug nicht nur als zeitliches Korrektiv und »Erleichterung«, sondern ebenso der räumlichen Distinktion von anderen.

»Welche Erleichterung ist es da, aus dieser undurchschaubaren, unergründlichen, unerfreulichen, entfremdeten und entfremdenden Welt voller Falltüren und Hinterhalte in die vertraute, gemütliche und heimatliche, manchmal schwankende, aber tröstlich unangefochtene und erträgliche Welt von gestern zurückzukehren ein Gestern, das uns - und mir als einem von >uns - gehört, das unser Gestern nämlich unsere, nicht ihre Vergangenheit - ist, das wir und nur wir allein besitzen (und also auch ge- und missbrauchen dürfen und können, wie es uns gefällt).« (Bauman 2017:79).

Mit der ausschließenden Vereinnahmung einer Vergangenheit, die »wir allein besitzen«, kann schließlich auch unter dem Horizont der flüchtigen Moderne ein Wir artikuliert werden; ebenso wie dadurch die räumliche Distinktion von anderen gewährleistet werden kann. Da die Frage einer erneuten Einbettung der freigesetzten Subjekte weitgehend unbeantwortet bleibt, gewinnt die regressive Variante einer kompensatorischen Rückkehr ans "Stammesfeuer« an Boden.

Des Argumentes der Kompensation bedient sich Bauman auch, wenn er schreibt, dass »[d]er Impuls, sich aus den risikobeladenen Komplexitäten in die geschützte Sphäre der Einheitlichkeit zurückzuziehen, allgegenwärtig [ist].«(Bauman 2016:211). Der Traum von »Klarheit und Gewissheit« lasse die »verwaisten Individuen« unter die »Fittiche der Nation« fliehen (a.a.O. 217). Die Kehrseite des

menden Modernisierungsschäden auch der Kompensationsbedarf steigt, weist den Geisteswissenschaften, aber auch der Musealisierung (Lübbe 2005) so die schmeichelhafte Rolle von Modernisierungsermöglichern zu. Das Argument der Kompensation findet sich zudem in Rekonstruktionsdebatten von Baudenkmalen. In diesem Zusammenhang betont Winfried Speitkamp die Bedeutung kompensationstheoretischer Legitimationsversuche der Denkmalpflege, wodurch dieser die Rolle der Identitätsstiftung im Moment beschleunigten Wandels zugewiesen wurde (1996:13f.). 
kosmopolitischen Projektes stellen also die Renaissance und Radikalisierung der exklusiven nationalstaatlichen Kultur dar. Diese von Beck missverständlicherweise als "gegenmodern« bezeichnete Tendenz hält das in der späten Moderne rar gewordene Gut »hergestellte[r] Fraglosigkeit« (Beck 1993:99ff.) bereit. Wie die Gegenbewegung zu einem räumlichen Containermodell, die sich im Zuge des 20. Jahrhunderts intensiviert (Löw 2018:48ff.), so wird bei Beck Re-Nationalisierung, Re-Essentialisierung, Re-Traditionalisierung als (erneute) Antithese des ebenfalls dialektisch beschriebenen Zusammenhangs zwischen Kosmopolitismus und Anti-Kosmopolitismus (Beck 2004:151ff.) thematisiert. In dem Moment, in dem die »Nation den Container verlässt« (a.a.O. 2004:167), erstarkt ebenso die kompensatorische Flucht in die wieder erstarkende Vorstellung der Nation und einer geschlossenen Gesellschaft. ${ }^{11}$ Im Hinblick auf die retrotopische Kompensation lässt sich allerdings hinzufügen, dass Individuen nicht nur unter die »Fittiche der Nation « fliehen (Bauman 2016:217), sondern ebenso in die Schutz versprechenden Arme einer besseren Vergangenheit getrieben werden. Diese vermeintliche Rückkehr ist allerdings nicht bloß eine rückwärtsgewandte Sentimentalität, sondern hält auch gewissheitsstiftende Bezugspunkte der Selbstthematisierung und somit auch eine Beantwortung der sich in der Gegenwart und Zukunft stellenden Fragen bereit. Die entzeitlichten Fluchtpunkte, egal ob sie in einer utopischen Zukunft verortet oder in einer retrotopischen Vergangenheit swiedergefunden verfügen immer auch über eine prospektive Dimension, da, was ewig gut ist, auch in Zukunft gut bleibt. So bedienen sich alle Vorstellungen von einem Gleichbleiben über die Zeit auf je spezifische Art der Vergangenheit als »kräftigende Nahrung« (Nietzsche), um sich für Gegenwart und Zukunft zu rüsten. Indem Erfahrungen durch die jeweiligen Erwartungen immer wieder neu perspektiviert und modifiziert werden, artikuliert sich in jeder Bezugnahme auf vermeintlich Gewesenes stets die Hoffnung aufeine bessere Vergangenheit.

Die modernen Bedingungen der Sozialintegration, von denen Sebald und Weyand sprachen, können nun weiter spezifiziert werden. Die Unverbindlichkeit individualisierter Erfahrungsräume schwächt die soziale Kohäsionskraft. Die Dynamisierung der Zeit führt zur beschleunigten Umwälzung von Erwartungshorizonten, zu Unberechenbarkeit und Zukunftskontingenz. Die unrevidierbare Globalisierung und anhaltende Re-Figuration von Räumen führen dazu, dass die Vielheit unterschiedlicher Erfahrungsräume die Möglichkeit integrierter Einheit erschwert. All dies stellt die Konstruktion kollektiver Identitäten vor denkbar große Herausforderungen; auch wenn dadurch gleichermaßen die Notwendigkeit ihrer Konstruktion zuzunehmen scheint. Im Spannungsfeld zwischen individualistischer

11 In ähnlichen argumentativen Fahrwassern bewegt sich ein engagierter Sammelband, in dem die Beitragenden die »große Regression « des weltweit erstarkenden populistischen Nationalismus analysieren (Geiselberger 2017). 
Anomie, die wahrscheinlich wird und oft den Grundtenor von Gegenwartsdiagnosen bildet, dem kosmopolitischen Transnationalstaat, dessen Integrationsvermögen unkonkret bleibt, und der retrotopischen Kompensation, die die Flucht in die Arme des Nationalstaates und die Geborgenheit einer idealisierten Vergangenheit attraktiv werden lässt, muss die schwierige Aufgabe der Konstruktion kollektiver Selbstbilder gelöst werden.

Der Philosoph Henning Ottmann hat darauf aufmerksam gemacht, dass gerade Kompensationstheorien - in ihrem Lamento über moderne Risiken, Verlust- und Differenzerfahrung, vor allem aber auch in ihrer Einschätzung einer beschränkten Sinnstiftung - deutliche Parallelen zu Nietzsches Kritik an der historistischen Kultur seiner Zeit aufweisen (Ottmann 2010:103). Ob allerdings die »Zersplitterung und Zerfaserung aller Fundamente«, die Nietzsche attestierte, tatsächlich bedeutet, dass keine fundierenden Erzählungen mehr formuliert werden können und ob die Extrempunkte des so abgesteckten Spannungsfeldes die einzigen Optionen darstellen, kann allerdings nur empirisch beantwortet werden. Leitend ist im Folgenden die Vermutung, dass auch zwischen der Skylla individualistischer Anomie und der Charybdis retrotopischer Kompensation kontinuierliche und kohärente Formen der Selbstthematisierung artikuliert werden können.

Der Soziologe Hubert Knoblauch hat im Kontext kommunikativer Gedächtnisse die Vermutung geäußert, dass auch in dynamischen Prozessen der Kommunikation davon auszugehen ist, dass weiterhin Traditionen, Konventionen und Institutionen ausgebildet werden können (1999:735). In diesem Zusammenhang vermutet er, dass es eventuell »eine gleichsam im Fluss befindliche sekundäre Traditionalisierung in der Kommunikationsgesellschaft gibt«, die dann die Möglichkeit einer »Art von Dauerhaftigkeit und Halt im Wandel« eröffnet (Knoblauch 2000:666). Dieser Gedanke ähnelt den Ausführungen Reinhart Kosellecks, mit denen er seine Überlegungen zum Verhältnis zwischen Erfahrungsraum und Erwartungshorizont beschließt. Denn da sich Erfahrungen nur sammeln lassen, »weil sie - als Erfahrungen - wiederholbar sind «, folge daraus, dass eine erneute Überbrückung der Differenz zwischen Erfahrung und Erwartung möglich scheint (Koselleck 1989:375). Eine dieser dauerhafteren Strukturen besteht dann etwa in der Erfahrung der anhaltenden Durchbrechung der Erwartungshorizonte oder - wie Koselleck an eingangs zitierter Stelle festgestellt hat - darin, dass »die Zukunft auf bekannte Weise unbekannt bleibt « (Koselleck 1989:143, Herv. JK). Was damit in Aussicht gestellt wird, ist letztlich die weiterhin bestehende Möglichkeit von Wiederholungsstrukturen, die es erlauben, Vergangenheit, Gegenwart und Zukunft so zueinander in Bezug zu setzen, dass trotz Dynamisierung und Fragmentierung Traditionslinien konstruiert und ein kohärentes Selbstbild stabilisiert werden können. 



\section{Im Schatten der Identitätsfabrik}

Zwei Jahre nachdem Friedrich Nietzsche die »Zersplitterung und Zerfaserung aller Fundamente« attestierte (Nietzsche 2009:87, Orig. 1874) wurde im Jahr 1876 auf der Berliner Museumsinsel die Nationalgalerie in Anwesenheit des Kaisers feierlich eröffnet (Maaz 2001:50). Unter dem Eindruck gesellschaftlicher Umbrüche und der politischen Neuordnung Deutschlands begann die Suche nach neuen fundierenden Narrativen und neuen Vergangenheiten, die eine erneute Gründung in anderen Zeitschichten versprachen. Museum, Nation, Kulturerbe - diese Triade, die sich im 19. Jahrhundert von Frankreich ausgehend in ganz Europa ausbreitete (Savoy 2018:30), veranschaulicht, dass den Institutionen der Kunstverklärung bei der Imagination neuer Vergangenheiten eine wichtige Rolle zukam (Anderson 2016:178ff., Orig. 1983). ${ }^{1}$ Der prospektive Charakter der nationalaffirmativen Vergangenheitskonstruktion der Museen zeigt sich auch darin, dass mit dem Bau der Nationalgalerie bereits sechs Jahre vor der Reichsgründung begonnen wurde. So kam es, dass sich die Einheit der Deutschen zuerst im Museum vollzog (Schuster 2001:6).

Die nationale Aneignung von Kunstobjekten (Kulturerbe) stellt ein anschauliches Beispiel einer vergangenheitsbezogenen Konstruktion kollektiver Selbstbilder und deren Verräumlichung dar. Damit sind explizit und implizit Schlüsselbegriffe dieser Arbeit benannt. Im Folgenden soll deshalb geklärt werden, was unter den Begriffen >Museum Akten des Erinnerns und des Erbens zukommt. Obwohl das Pathos und die nationale Geschlossenheit der einstigen musealen Selbst-Inszenierungen heutzutage oft problematisiert werden (Meyer/Savoy 2014), bilden Museen weiterhin geeignete Kontexte, innerhalb derer verschiedene kollektive Selbstbilder analysiert werden können. Dadurch wird allerdings eine Akzentverschiebung in Bezug auf den Untersuchungsgegenstand dieser Arbeit nötig. Zunächst muss in diesem Kapitel betont werden, dass Museen nicht als kanonischer Ausdruck einer Gesellschaft hypostasiert werden sollen. Der Gegenstand dieser Arbeit liegt vielmehr in den un- 
terschiedlichen Rezeptionen dieser kulturellen Artefakte. Museen bilden damit die Infrastruktur und den Anlass der zumeist konflikthaften Gespräche, in denen verschiedene Kollektivierungsdiskurse rekonstruierbar werden. Der Untersuchungsgegenstand verlagert sich so vom Kanon zum Konflikt.

Ausgehend von dieser Spezifizierung wird geklärt, was unter dem Begriff des Kollektivs verstanden wird und welche Rolle dabei Prozesse des Erinnerns und des Erbens spielen. Kollektive werden als diskursive Tatbestände verstanden, die aufgrund ähnlicher Formen der Selbst- und Weltbeschreibung durch empirische Binnenanalysen rekonstruiert werden können (Straub 1998). Um dem prozessualen Charakter dieser Konstrukte gerecht zu werden, wird anstelle des Begriffs >Kollektiv eher von >Kollektivierung gesprochen. Da der empirische Zugang zur Analyse dieser vergemeinschaftenden Prozesse auf diskursiver Ebene erfolgt, verwende ich schließlich den Begriff >Kollektivierungsdiskurs «. Gemeint sind damit keine festen Einheiten, sondern stets Prozessstrukturen der Vereinheitlichung. Da die Strukturen der verschiedenen Selbst- und Weltbeschreibungen, anhand derer die Kollektivierungsdiskurse rekonstruiert werden, immer gegenstandsbezogen sind, verfügen diese somit lediglich über eine »partielle Gleichheit« (Straub 2004:298).

Die Formierung der Kollektivierungsdiskurse kann über die (partielle) Gleichheit der relevant gemachten Vergangenheitsbezüge nachgezeichnet werden. Die Akte des Erinnerns sind dabei doppelt produktiv. Einerseits stellen sie überhaupt erst Vergangenheit her. Andererseits bindet sich so auch die Gemeinschaft derer, die Vergangenheit auf ähnliche Weise thematisieren, (temporär) aneinander. Erinnern ist damit nicht nur eine Funktion der Gesellschaft, sondern Gesellschaft auch immer eine Funktion des Erinnerns (Assmann 2002). Neben der Sozialität des individuellen Erinnerns kann deshalb auch von einer Sozialisation durch Erinnern gesprochen werden. Unter Erben wiederum verstehe ich eine Modalität des Erinnerns, die stärker ortsbezogen ist. Mit dieser Akzentuierung kann dann die räumliche Anverwandlung der Museumsbauten besser analysiert werden. Denn so wie durch gemeinschaftliches Kommemorieren Vergangenheit immer wieder neu und anders hervorgebracht wird, so wird durch die verschiedenen »Beschwörungen« (Derrida 2016, Orig. 1995) eines baukulturellen Erbes an einem Ort dieses überhaupt erst in seiner spezifischen räumlichen Bedeutung hergestellt und modifiziert.

Um im Folgenden den Untersuchungsgegenstand dieser Arbeit zu präzisieren (Kap. 2.1), zu klären, was unter dem Begriff Kollektivierungsdiskurs verstanden wird (Kap. 2.2), die vergemeinschaftende Dimension des Erinnerns zu betonen (Kap. 2.3) und schließlich die raumkonstitutive Dimension des Erbens darzustellen (Kap. 2.4), ist es hilfreich, zum Museumstempel der Nationalgalerie zurückzukehren. 


\subsection{Vom Kanon zum Konflikt}

Nähert man sich vom Lustgarten der Berliner Museumsinsel, so überragt die Tempelarchitektur der Alten Nationalgalerie das geschichtsträchtige Ensemble. Einem Podiumstempel gleich, verleiht das Bauwerk der Anlage den Charakter römischer Kaiserforen. Die dorischen Kolonnaden und das Reiterstandbild König Friedrich Wilhelms des IV., welches die Freitreppe vor dem Gebäude dominiert, unterstreichen diesen Eindruck noch (von Buttlar 2010:11f.). Mit den in Gold gefassten Namen, an der Fassade der Nationalgalerie, werden jedoch keine antiken Potentaten gewürdigt; vielmehr sind es die Namen deutscher Künstler, die so in den Stand von Heroen gehoben werden. Im Giebelfeld des Gebäudes verteilt die Nationalallegorie Germania Ehrenkränze an die Künstler zu ihrer Linken (Maaz 2001:97). Jedoch sind die antiken Lorbeerkränze nun durch deutsche Eichenkränze ersetzt. Die Inschrift »Der Deutschen Kunst« unterhalb des Tympanons macht zudem die nationalaffirmative Funktion des Gebäudes weithin sichtbar. Indem der Tempelbau die antike Formensprache für die pathetische Inszenierung der deutschen Kunst nutzt, kann er als idealtypischer Fall der Kunstverklärung im Dienst nationaler Identitätsstiftung angesehen werden. ${ }^{2}$

Ungeachtet dessen, dass der Museumsbau bereits 1866 begonnen und erst 1876 in Anwesenheit des Kaisers eröffnet wurde (Maaz 2001:50), ist die Widmung an der Fassade mit den römischen Ziffern MDCCCLXXI versehen. Dass das Jahr des Sieges über Frankreich, 1871, akzentuiert wird, verdeutlicht, dass es hier nicht um eine chronologische Bestimmung der Bauzeit geht, sondern vielmehr um die feierliche Erinnerung an die Gründung des Deutschen Kaiserreiches. Die Affirmation der Nation vollzog sich im Glanze ihrer militärischen Triumphe und in scharfer Abgrenzung zu ihren Feinden. Da das nationalstaatliche Projekt mit der Reichsgründung verwirklicht war, musste die Gegenwart der Nation nun mit einer Vergangenheit versehen werden, die über die Heroisierung von Gründerfiguren geschaffen und über Denkmäler und Gedenkfeiern repräsentiert wurde (Giesen 1999:213). Die Erinnerung hat damit appellativen und fundierenden Charakter. Bei der Konsolidierung der neuen politischen und gesellschaftlichen Formation fiel den Museen dieser Zeit eine entscheidende Rolle zu. Die zahlreichen heroischen Inszenierungen, die wie im Falle des Militärhistorischen Museums in Dresden oft unmittelbar aus den Reparationszahlungen Frankreichs finanziert wurden (von Loh 2012:97), sind auch Ausdruck der heroischen Kollektivierungsdiskurse des späten 19. Jahrhunderts. Der selektive Rückgriff und die Akzentuierung historischer Bezugspunkte folgen dabei der für die Konstruktion kollektiver Selbstbilder so wichtigen Mne- 
motechnik der Kanonisierung (Assmann 1997:103ff.; 1999a:27ff.). Insbesondere für die beschriebene Zeit der Reichsgründung stellt die Institution des Nationalmuseums einen bedeutenden »Rahmen der Kanonisierung« dar (Assmann 1999a:31). Die Auswahl dessen, was als Teil der eigenen Geschichte vereinnahmt und als erinnerungswürdig erachtet wird, kodifiziert und kanonisiert so »das Selbstbild einer Gesellschaft im Medium der Monumente, der Bilder, der Objekte und Inschriften« (ebd.).

Der Tempelbau der Nationalgalerie, der in rotem Sandstein nach Plänen Friedrich August Stülers von Johann Heinrich Strack ausgeführt wurde, verbindet die klassische Formensprache korinthischer Säulen und die mit Akroteren geschmückten Giebel mit einer christlich anmutenden Apsis. Die Verbindung der eigentlich »unvereinbaren Stile« (Maaz 2001:52) der griechisch-römische Antike und des christlichen Mittelalters versieht die eigene Gegenwart so mit einer würdigen Vergangenheit. Die Auswahl der Epochen, die in die Konstruktion der eigenen Geschichte einbezogen werden, steht auch hier im Dienst der Gegenwart. Die so sichtbar gemachte Geschichte ist dann nicht das Gegenbild der Gegenwart, sondern wird zu deren Fundament (Assmann 1999a:31). Die jeweils ausgewählten Aspekte der Vergangenheit werden zum kanonischen Maß aller Dinge. Sie werden »sakralisiert « und somit $\mathrm{zu}$ »letztinstanzlicher Hochverbindlichkeit " gesteigert (a.a.O. 27). In diesem Sinne handelt es sich bei der Kanonisierung »um die Norm der Norm, um Fundierung, Letztbegründung, Wertbezug, d.h. um ein sheiligendes Prinzip« (Assmann 1997:118). Vor diesem Hintergrund erscheint auch die Tempelarchitektur der Nationalgalerie nicht zufällig, sondern als »Symbol des säkularen Heiligen« der Nation (Assmann 1999a:31).

Gerade im Modus der Kunstverklärung konnte die Sehnsucht nach der Nation im 19. Jahrhundert zu einem »säkularisierten Erlösermotiv« (Giesen/Junge 1991:303) werden. Der Museumstempel der Nationalgalerie steht somit im Dienst nationaler Identitätsbildung. Um diesen Aspekt hervorzuheben, haben Gottfried Korff und Martin Roth im Kontext historischer Museen von »Identitätsfabriken« gesprochen (1990). Aber gerade weil die apologetischen Inszenierungen nationalchauvinistischer Überlegenheit heutzutage oft eher befremdlich wirken, erscheint auch der statische Begriff »Identitätsfabrik« anachronistisch. Der damit suggerierte Sinnmonismus wird vor dem Hintergrund aktueller Debatten in der Museologie zunehmend haltlos. Insbesondere die problematische Triade Museum, Nation, Kulturbesitz und die damit verbundene »materielle Aneignung« von Kunstobjekten (Savoy 2018:22) sollen zugunsten einer notwendigen Polyphonie der Stimmen überwunden werden (a.a.O. 57). Museen sind deshalb heutzutage Orte, an denen Identitätsbilder hinterfragt werden (Lorenz/Ulrich 2018:30). Die Vorstellung von historischen Museen als einem allseits verbindlichen (nationalen) Kanon erscheint unter den Bedingungen der Moderne (Kap. 1) zunehmend fragwürdig. Zwar thematisieren auch Korff und Roth eine zunehmende Bedeutungsvielfalt durch kul- 
Abbildung 3: Das Reiterstandbild König Friedrich Wilhelm des IV. steht im Kreuzungspunkt der Erschließungsachsen des Neuen Museums (mittig) und der Alten Nationalgalerie (rechts).

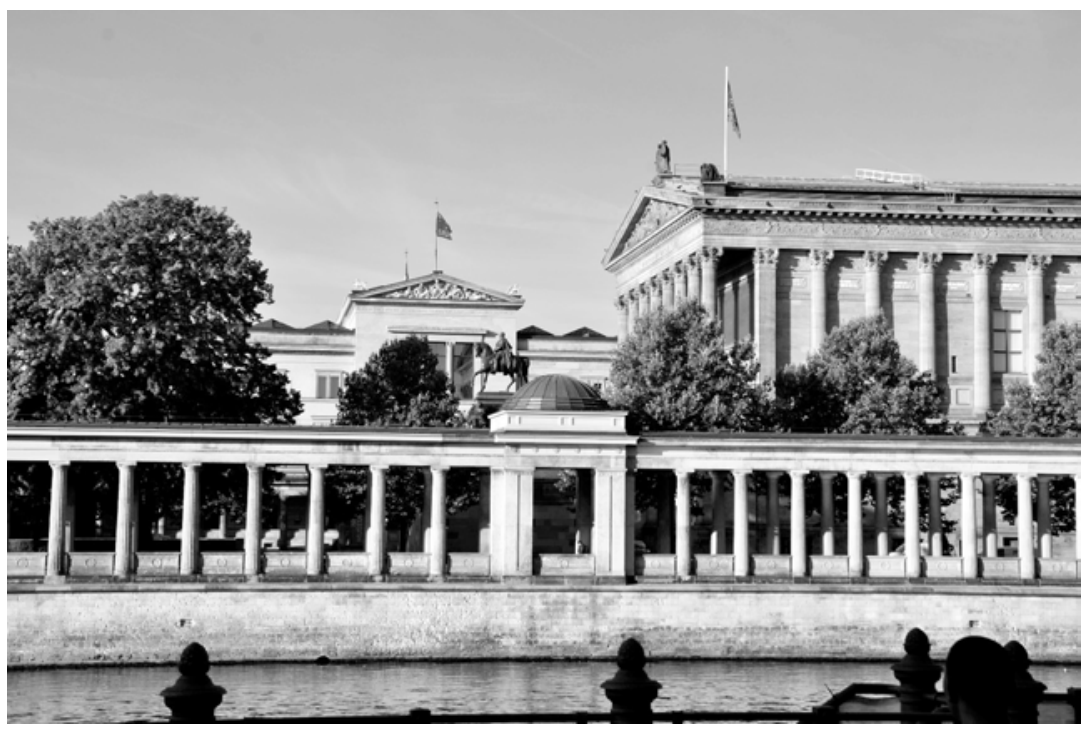

turelle Variabilität und die subjektive Erlebnisweise der Betrachtenden (Korff/Roth 1990:22f), allerdings wird dies als Teil von Massenkultur und Popularisierung eher kulturpessimistisch dramatisiert. Die Autoren stellen sich deshalb weiterhin die Frage nach dem verbindlichen »Anschauungskanon unserer Tage« (a.a.O. 30) und halten damit implizit an einer Perspektive auf Museen fest, aus der diese lediglich Repräsentationen einer dominanten (meist nationalen) Erinnerung darstellen.

Aber auch in aktuelleren Texten werden Museen oft implizit zu einem Kanon hypostasiert; etwa, wenn diese als »Repräsentations- und Identitätsort «, als »kulturelle Objektivation par excellence « und »maßgebliche Erinnerungsfigur« beschrieben werden, anhand derer (angeblich) »das kulturelle Gedächtnis einer Gesellschaft beobacht- und analysierbar ist« (Pieper 2010:195, Herv. JK). DerBegriff »Erinnerungsfigur « ist von Jan Assmann entlehnt. Durch dessen teilweise verkürzte Rezeption der Theorie Maurice Halbwachs' (Voigt 2014), wird damit die verhängnisvolle Vorstellung von einem unvermittelten Erinnerungsbestand reproduziert. ${ }^{3}$ Aus der darin besteht, dass der Begriff des »Erinnerungsbilds « Halbwachs zugeordnet wird, obwohl sich dieser in kritischer Auseinandersetzung mit seinem Lehrer Bergson davon in deutlichen Worten abgrenzt (Voigt 2014). 
problematischen Idee »unvermittelter Erfahrung« (Voigt 2014:259), wie sie das »Erinnerungsbild « suggeriert, wird bei Assmann so die nicht weniger problematische Vorstellung "gesellschaftlich verbindliche[r]« Erinnerungsfiguren (1997:38).

Die Rede von der Identitätsfabrik, in der ein verbindliches Selbstbild kanonisiert wird, erscheint nunmehr jedoch selbst aus der Zeit gefallen. So wie der Hardwarekapitalismus der schweren Moderne die Arbeiter und Fabriken fest an den Boden band und durch den Softwarekapitalismus der flüchtigen Moderne in Bewegung versetzt wurde (Kap. 1.4), so dynamisieren sich auch die Museen und das, was sie für unterschiedliche Personengruppen bedeuten. Die Produktionsstätten nationaler Identität werden schließlich zu Schauplätzen konkurrierender Wirklichkeitsund Geschichtsdeutungen. Im Schatten der »Identitätsfabriken« von einst, die zunehmend ihre Fraglosigkeit verlieren, formieren sich verschiedene Kollektive, die die Geschichte der Museen je unterschiedlich auslegen und die konkreten Orte und ihre Architektur auf verschiedene Art sinnhaft deuten. Indem die nationalaffirmativen Museen des 19. Jahrhunderts problematisiert werden, können sich so auch andere Kollektivierungsdiskurse artikulieren. Der heroische Kollektivierungsdiskurs, der eine Fundierung und Bindung des Kollektivs durch den Appell an eine kanonisch verklärte Vergangenheit vollzieht, bleibt dabei eine mögliche, jedoch keinesfalls die einzige Form der Selbstthematisierung. Annäherung und Bindung können ebenso durch die gemeinsame Forderung nach Abkehr von der Vergangenheit hergestellt werden. Mit der Vielzahl verschiedener Formen möglicher Vergangenheitsbezüge verlagert sich schließlich der Gegenstand dieser Untersuchung von einer Analyse der Museen als einem (hegemonialen) Rahmen der Kanonisierung hin zu einer Analyse von Museen als diskursiven Arenen, in denen verschiedene synchrone Deutungen der Vergangenheit und Identitätspostulate in Konflikt geraten.

Aus dieser Verlagerung des Untersuchungsgegenstandes ergeben sich methodische und sozialtheoretische Implikationen, auf die im dritten Kapitel dieser Arbeit noch genauer eingegangen wird. Mit der Akzentuierung konkurrierender Vergangenheitsbezüge und deren Verräumlichung gerät nunmehr auch die Frage nach der Imagination verschiedener kollektiver Selbstbilder in den Blick. Im Folgenden ist es deshalb erforderlich, zu einer Arbeitsdefinition des zentralen Begriffes >Kollektiv zu kommen, um dadurch zu klären, was unter Kollektivierungsdiskursen im Verständnis dieser Arbeit gemeint ist. Diese unverzichtbaren Koordinaten und Orientierungspunkte dienen dazu, sich im weiten Feld der sozial- und kulturwissenschaftlichen Identitätsforschung zurechtzufinden. Auch dafür lohnt es sich, noch einen weiteren Moment in der Alten Nationalgalerie zu verbleiben. 


\subsection{Vom Kollektiv zu den Kollektivierungsdiskursen}

Dass die Imagination einer Deutschen Nation das Produkt kultureller Arbeit ist und die Museen jener Zeit zu wichtigen Produktionsstätten wurden, zeigt sich auch darin, dass mit dem Bau der Nationalgalerie bereits 1865 die politische Entität der Nation antizipiert wurde. Die »sehnsüchtig erhoffte Einheit der Deutschen« fand also "zuerst im Museum statt (Schuster 2001:6). Die kanonische Kunstverklärung ist somit keineswegs nur ein retrospektiver Blick in die Vergangenheit, sondern verfügt auch über eine prospektive Dimension, indem sie »nicht nur feststellt, was ist, sondern vorschreibt, was sein soll.«(Assmann 1997:112). Anhand der Tatsache, dass die politische Einheit der Deutschen Nation zum Zeitpunkt des Baus der Nationalgalerie noch nicht verwirklicht war, lässt sich ein allgemeiner Zusammenhang der Konstruktion kollektiver Selbstbilder veranschaulichen.

Wie Jürgen Straub im Zusammenhang personaler Identität formuliert, sei Identität nichts Gegebenes, sondern eine Aufgabe, die sich immer wieder neu stelle (Straub 2016:163). Trotz der Gefahr vorschneller (und falscher) Übertragungen zwischen personeller und kollektiver Identität lässt sich doch zumindest in diesem Punkt eine Analogie aufzeigen. Denn auch die Imagination der Nation (Anderson 2016) wird gerade deshalb notwendig, weil sie nie fraglos gegeben ist. Ebenso sieht der Kultursoziologe Bernhard Giesen in der »Unvollkommenheit der Verwirklichung von kollektiver Identität « deren »konstitutive Funktion für soziale Prozesse.« Kollektive Identität werde damit ebenso wie Fairness oder Wahrheit, Legitimität oder Unabhängigkeit zu einer »notwendigen Illusion« (Giesen 1999:117f). Auch im Zusammenhang kollektiver Identität lässt sich argumentieren, dass sich gerade aus dem Fehlen eines natürlich Gegebenen die Aufgabe der Naturalisierung ergibt. Die Notwendigkeit dieser Illusion lässt sich in Anlehnung an die anthropologische Philosophie vereinfachend so formulieren: Gerade weil es keine natürliche Gestalt menschlichen Zusammenlebens gibt, ergibt sich ein natürlicher Zwang zur Gestaltung. Für Heidrun Friese und Aleida Assmann besteht demnach »die wichtigste Strategie, bestimmte Werte oder Grenzen als unverrückbar erscheinen zu lassen, darin [...], sie als >Natur<, als objektiv, unverfügbar und unzugänglich darzustellen, um sie damit persönlicher Entscheidbarkeit und politischer Veränderbarkeit $\mathrm{zu}$ entziehen.« Neben der Relevanz der Naturalisierung weisen die Autorinnen auch darauf hin, dass diese »essentialistische Objektivierung « und ihre »verbalen und symbolischen Strategien« im Hinblick auf ihre diskursive Konstruktion analysiert werden können (Assmann/Friese 1998:12).

All diesen Auffassungen liegt somit die geteilte Annahme zugrunde, dass Kollektive nichts fraglos Gegebenes sind, sondern sich immer im Werden befinden. Auch Christian von Scheve macht dies deutlich, indem er den Prozesscharakter sozialer Kollektive besonders betont. 
»[T] he concept developed here conceives of collectives as specific though fragile and transient episodes of dynamic stabilization in the reciprocal affections and relational self-understandings of actors involved in these formations. Because of the situational nature of affect, social collectives are therefore more expediently conceptualized and analyzed as constantly >in the making < rather than as >substantial social formations. « (von Scheve 2019:267).

Kollektive bedürfen der konstanten Arbeit dynamischer Stabilisierung. Sie sind immer gemachte und nie substanziell gegebene soziale Formationen. Von Scheve hebt insbesondere den situationsspezifischen, ephemeren Charakter dieser Kollektive hervor. "Groups, organizations, crowds, communities, and other formations may thus transiently become social collectives under certain circumstances and for a certain time. (Ebd.). Zunächst lässt sich somit feststellen, dass aufgrund fragiler und immer nur vorübergehender Episoden dynamischer Stabilisierung Kollektive nicht als feste Einheiten, sondern als anhaltendender Prozess der (partiellen) Vereinheitlichung zu verstehen sind. Dieser Einschätzung folge ich auch im Kontext dieser Arbeit, weshalb weniger von Kollektiven, sondern eher von Kollektivierung gesprochen wird. Auch Jürgen Straub betont den Aspekt der zeitlich begrenzten, dynamischen Stabilisierung. Mit dem Begriff >Kollektive Identität< bezeichnet er die jeweiligen Formationsregeln, durch die vorübergehend kollektive Einheit hergestellt wird.

»[D]ie Frage nach einer beliebigen kollektiven Identität [ist] zuallererst eine Frage nach der Konstitution des betreffenden Kollektives selbst: Welche Personen werden von wem und auf welche Weise saneinandergerückt ‘ und szusammengebunden<, unter bestimmten Cesichtspunkten als Einheit aufgefasst, indem ihnen bestimmte gemeinsame Merkmale und Bindungen zugeschrieben werden?«(Straub 1998:98).

Mit kollektiver Identität sind also keine festen Einheiten, sondern Prozessstrukturen gemeint, mittels derer die für die Konstitution eines Kollektivs entscheidende Arbeit des Aneinanderrückens und Zusammenbindens vollzogen wird.

»Der Ausdruck der kollektiven Identität stellt eine Chiffre für dasjenige dar, was bestimmte Personen in der einen oder anderen Weise miteinander verbindet, diese also erst zu einem Kollektiv macht, dessen Angehörige zumindest streckenweise einheitlich charakterisiert werden können, weil sie sich selbst (in gewisser Hinsicht) einheitlich verhalten und sich selbst einheitlich beschreiben." (Straub 2004:300, Herv. im Orig.).

Die Rede von »kollektiver Identität« ist lediglich »unter bestimmten Gesichtspunkten « und immer nur »streckenweise « gerechtfertigt. Kollektive sind somit nicht nur zeitlich, sondern auch inhaltlich begrenzt. Keineswegs wird eine vollständi- 
ge Gleichheit der Personen eines Kollektivs unterstellt, sondern immer nur "partielle Gleichheit « im Hinblick auf zu »spezifizierende Gemeinsamkeit im praktischen Selbst- und Weltverhältnis« einzelner Personen (Straub 2004:298f.). Worin diese jeweils bestehen, bedarf stets der empirischen Klärung, wobei es insbesondere die »konsensfähigen und konjunktiven Selbst-und Weltbeschreibungen « sind, mit denen die Unterstellung einer kollektiven Identität begründbar wird (Straub 2004:299f., Herv. JK). Kollektive, so möchte ich daraus folgern, sind immer das Resultat einer Wenn-dann-Konstruktion. Erst wenn einheitliche Selbst- und Weltbeschreibungen in Bezug auf thematisch und zeitlich begrenzte Zusammenhänge empirisch rekonstruiert werden können, dann kann von »kollektiven Identitäten« in wissenschaftlicher Hinsicht gesprochen werden (Straub 2004:300). Wenn Personen in ihren Beschreibungen - etwa der Architektur des Neuen Museums oder des Militärhistorischen Museums - übereinkommen (konsensfähig) und sich durch diese Deutungen auch untereinander verbinden (konjunktiv) und sich darin von anderen abgrenzen, dann ist es empirisch gerechtfertigt, von einem Kollektiv zu sprechen.

Christian von Scheve betont eher die »situational nature of affect« im Moment der Kollektivierung, womit er sich eher für die Situationsspezifik der »Episoden dynamischer Stabilisierung« (von Scheve 2019:267), etwa von Publika bei Großveranstaltungen, interessiert. Jürgen Straub hingegen hebt die diskursiven Konstruktionsleistungen der Kollektivierung hervor, wenn er darauf hinweist, dass kollektive Identitäten vor allem »kommunikative Konstrukte« und »diskursive Tatbestände« darstellen (Straub 1998:104). Dies bleibt jedoch in erster Linie eine Frage des methodischen Zugangs, der sich aus dem jeweiligen empirischen Erkenntnisinteresse ergibt. Da im Kontext dieser Arbeit der analytische Zugriff auf der Ebene von Diskursen erfolgt, soll im Folgenden anstelle von kollektiver Identität der Begriff >Kollektivierungsdiskurs « verwendet werden. Mit der Betonung der »empirisch-rekonstruktiven Binnenanalysen « (Straub 1998:104) ist auch gesagt, dass die Erforschung dieser Diskurse nicht durch normierende Zuschreibung erfolgen darf (a.a.O. 98). Zuschreibungen im Sinne einer deutschen oder französischen Identität würden so hinter die Annahme der Prozessualität von Kollektiven zurückfallen und die (falsche) Idee einer »substantial social formation« (von Scheve 2019:267) erneut einführen. Mit der begrifflichen Präzisierung wird also deutlich, dass Kollektivierungsdiskurse immer nur anhand spezifischer Selbst- und Weltbeschreibungen rekonstruiert werden können. Diese Beschreibungen sind auch deshalb immer den Stimmen des Diskurses zu entnehmen, da durch normierende Zuschreibung eventuell relevante Raumbezüge für die Analyse verloren gingen (Kap. 4). Lassen sich allerdings im Hinblick auf thematisch begrenzte Gegenstände einheitliche Formationsregeln der Kollektivierung empirisch nachweisen, so rechtfertigt dies, von verschiedenen Kollektivierungsdiskursen zu sprechen. 
Die (immer nur) »partielle Gleichheit« bedeutet somit, dass der Prozess der Kollektivierung immer gegenstandsbezogen ist. Die jeweiligen Gegenstände, auf die sich einheitliche Selbst- und Weltbeschreibungen beziehen, können als Teil dessen gefasst werden, was Christian von Scheve die Infrastruktur des Kollektivs nennt. Darunter versteht er einerseits den physischen Raum, in dem sich Kollektive verbinden: "Crowds and gatherings are usually situated in a specific material space. This space is often transformed into a socially meaningful place that can be conducive to actors' mutually affecting one another. " (von Scheve 2019:270).

Besonders kompatibel mit dem Erkenntnisinteresse dieser Arbeit ist von Scheves Verweis auf die Bedeutung von Orten und deren räumliche Anverwandlung im Prozess der Kollektivierung. Andererseits werden unter >Infrastruktur auch Symbolsysteme verstanden, die kaum soziale Interaktion beinhalten. Auch dieser Hinweis kann für die empirische Analyse und den methodischen Zugang nutzbar gemacht werden, da auf der symbolischen Ebene, auf die von Scheve hinweist, etwa auch Diskurse verortet werden können. »Infrastructures can also consist of symbol systems which hardly involve any social interaction, but in which affect [...] works through exposure to and reception of cultural artifacts, such as monuments, architecture, sites, novels, poetry, lyrics, and other artworks.« (von Scheve 2019:270).

Vor allem die unterschiedliche »reception of cultural artifacts« ist für diese Arbeit von entscheidender Bedeutung. Eng damit verbunden ist der wichtige Hinweis, dass diese Rezeptionen stets konflikthaft sind. Neben dem umkämpften physischen Raum gilt dies insbesondere für das »symbolic universe of a nation state«, welches per Definition »a matter of constant contestation« ist (von Scheve 2019:270). Mit dem »symbolic universe« als Gegenstand konstanter Anfechtungen kann die Ebene diskursiver Deutungskämpfe assoziiert werden. Wie bereits eingangs dargelegt, besteht der Gegenstand der Untersuchung nicht in der Analyse von Museen als Repräsentationen eines verbindlichen Kanons. In der Terminologie von Scheves geht es vielmehr um die konflikthaften Rezeptionen der kulturellen Artefakte, insbesondere der Architektur und der Monumente. Museen werden somit als Infrastrukturen verstanden, in denen verschiedene Deutungen der Vergangenheit und des physischen Raumes in Konflikt geraten. Vor allem in der konflikthaften Beschreibung dieser Infrastrukturen können so verschiedene Kollektivierungsdiskurse entlang ihrer Formationsregeln differenziert werden.

Die Gegenstandsverschiebung vom Museum zum Diskurs ist damit auch eine Verlagerung von der Repräsentation zu den konflikthaften Rezeptionen kultureller Artefakte. Auch die einheitlichen (konsensfähigen) und verbindenden (konjunktiven) Rezeptionen bleiben in hohem Maße vergangenheitsbezogen. Hermann Lübbe hat zudem darauf hingewiesen, dass der Begriff >Rezeption< im Kontext der Hermeneutik ohnehin immer eine Beziehung zu Vergangenem herstellt. Denn Rezeption wird stets als »Vorgang der Vergegenwärtigung eines Vergangenen« in Ab- 
hängigkeit gegenwärtiger Interessen verstanden (Lübbe 2003:14, Orig. 1992). Damit wird die Frage nach der Bedeutung und der Wirkweise des Erinnerns relevant.

\subsection{Sozialität des Erinnerns und Sozialisation durch Erinnern}

$\mathrm{Zu}$ Beginn seiner für die kulturwissenschaftliche Identitätsforschung einflussreichen Studie zum kulturellen Gedächtnis hebt Jan Assmann die Relevanz des Erinnerns für die Schaffung »konnektiver Strukturen« hervor. Durch Formen des Vergangenheitsbezugs (Erinnern) wird ein bestimmtes Selbstbild (Identität) imaginiert und schließlich durch »kulturelle Kontinuierung« (Tradition) verstetigt (Assmann 1997:16). Konnektiv sind die Strukturen, die dabei aufgebaut werden, in doppelter Hinsicht. Denn entlang ihrer "Sozialdimension« werden gemeinsame »Erfahrungs-, Erwartungs- und Handlungsräume« gebildet, die als »symbolische Sinnwelten ${ }^{4}$ die Kohäsionskraft menschlicher Beziehungen erzeugen und so »den Menschen an den Mitmenschen« binden.

»Was einzelne Individuen zu einem solchen Wir zusammenbindet, ist die konnektive Struktur eines gemeinsamen Wissens und Selbstbild, das sich zum einen auf die Bindung an gemeinsame Regeln und Werte, zum anderen auf die Erinnerung an eine gemeinsam bewohnte Vergangenheit stützt.« (Assmann 1997:16f.).

Neben den gemeinsamen Werten ist mit der "gemeinsam bewohnten Vergangenheit« die zweite Dimension der Konnektivität benannt: die »Zeitdimension«. Indem das »Gestern ans Heute« gebunden wird, formen sich die "prägenden Erfahrungen und Erinnerungen « und werden gegenwärtig (ebd.). Sowohl der normative Aspekt gemeinsamer Werte als auch der narrative Aspekt der Erzählung über die Vergangenheit »fundieren Zugehörigkeit und Identität, ermöglichen dem Einzelnen, »wir« sagen zu können.« (a.a.O. 16). Dieses Argument der Schaffung von Gruppenkohäsion durch einen gemeinsamen Vergangenheitsbezug besteht in einer Umkehrung der Wirkrichtung der Sozialität des Erinnerns.

Die soziale Bedingtheit des individuellen Erinnerns hat etwa Maurice Halbwachs in den »Cadres sociaux de la mémoire« (Halbwachs 1985, Orig. 1925) dargelegt, indem er darauf hinweist, dass die sozialen Rahmen dem individuellen Bild der Erinnerung vorausgehen und unauflösbar damit verbunden bleiben. ${ }^{5}$ Halbwachs

Assmann übernimmt diesen Begriff von Peter L. Berger und Thomas Luckmanns, womit ein enger Bezug zur modernen Wissenssoziologie hergestellt wird. Die »konnektiven Strukturen«sind so kompatibel mit dem, was Reiner Keller »Wissensverhältnisse«nennt (Kap. 3). 
grenzt sich dabei zwar teilweise von seinem Lehrer Henri Bergson ab, insbesondere von dessen Idee unvermittelter »Erinnerungsbilder (Voigt 2014); dennoch bleibt der Antidualismus Bergsons - also der Versuch, den cartesianischen Dualismus zwischen Geist und Materie zu überwinden - auch für die Perspektive Halbwachs' grundlegend. Denn »jede noch so persönliche Erinnerung« stehe unaufhörlich mit der Gesamtheit des "ganzen materiellen und geistigen Leben der Gruppen, zu denen wir gehören und gehört haben«, in Beziehung (Halbwachs 1985:71). Dieser Auffassung folgend, entstehen das innerweltliche (Selbst-)Bewusstsein sowie das individuelle Gedächtnis immer über den Umweg der sozialen Welt. Die dezentrierte Subjektauffassung dieser Perspektive bleibt einer dialektischen Tradition verhaftet, in der Selbstbewusstsein immer werdendes Selbstbewusstsein ist (Hegel). ${ }^{6}$ Auch Assmann hält an dieser Wirkrichtung der Sozialität des Erinnerns fest. Gedächtnis, Bewusstsein, Sprache und Personalität sind auch für ihn unabänderlich soziale Phänomene. »[I]ndem wir uns erinnern, steigen wir nicht nur in die Tiefen unseres ureigensten Innenlebens herab, sondern bringen eine Ordnung und eine Struktur in dieses Innenleben, die gesellschaftlich bedingt sind und uns mit der sozialen Welt verbinden (Assmann 2002:64).

Wichtig ist allerdings, dass Assmann die Sozialität des Erinnerns in einen doppelten Funktionszusammenhang stellt und damit auch die gegenläufige Wirkrichtung, die Gruppenkohäsion durch das Erinnern, unterstreicht. Er wendet die Sozialität des Erinnerns so zu einer Sozialisation durch Erinnern.

»Die Sozialisation ermöglicht uns nicht nur, uns zu erinnern, sondern unsere Erinnerungen ermöglichen uns auch umgekehrt, uns zu sozialisieren. Sozialisation ist nicht nur eine Grundlage, sondern auch eine Funktion des Cedächtnisses. Man kann geradezu von einem >Bindungsgedächtnis<sprechen.« (Assmann 2002:66).

Erinnern ist also nicht nur eine Funktion der Gesellschaft, sondern Gesellschaft auch eine Funktion des Erinnerns. Assmann spricht deshalb auch vom »Erinnern, um dazuzugehören«. (1995). Die Arbeit des Aneinanderrückens und Zusammenbindens, von der weiter oben die Rede war, wird in hohem Maße und in beiderlei Wirkrichtung durch Akte des Erinnerns vermittelt. Auch aktuelle wissenssoziologische Arbeiten weisen auf diese vergesellschaftende Funktion gemeinsamer

6 Damit wird Bergson zum doppelten Urahn der kulturwissenschaftlichen Gedächtnisforschung. Einerseits ist er neben Durkheim einer der Lehrer Halbwachs'. Andererseits entfaltete sein antidualistisches Denken großen Einfluss auf die Sozialphilosophie des amerikanischen Pragmatismus. Insbesondere in den Arbeiten G.H. Meads wird der Einfluss Bergsons explizit gemacht (Mead 1927). Auch für Mead bringen sich Subjekte überhaupt erst als »social objects, as selves« hervor, indem sie die Rollen des "generalized other internalisieren und sich in anhaltendem Austausch mit der sozialen Welt befinden (Mead 1925:268f.). Mead bringt dies auf die einprägsame Formel: »We must be others if we are to be ourselves.«(a.a.O. 276). 
Formen des Vergangenheitsbezugs hin. Dem Gedächtnis kommt dabei die Rolle einer »Instanz zur Klassifizierung von Wissensbeständen« zu (Leonhard 2014:203ff.). Insbesondere im Falle beschleunigten sozialen Wandels und der Inkompatibilität verschiedener Vergangenheitsbezüge werden auch hier Fragen gesellschaftlicher Integration virulent (Leonhard 2014). Somit sind es gerade die Irritation symbolischer Sinnwelten und die Konkurrenz verschiedener Wissensbestände, die den Zusammenhang zwischen (partiell) einheitlichen Formen des Erinnerns und Prozessen der Vergesellschaftung aufzeigen. Zudem wird damit die Dynamik sozialer Gedächtnisse angesprochen. Diese fungieren nicht lediglich als »Lagerstätten der Vergangenheit, sondern [sind] dynamische Strukturen (der Lebenswelt), deren Hauptfunktion in der pfadabhängigen Selektion von Orientierungen besteht.« (Dimbath/Heinlein 2014:9). Die oft im Kontext sozialer Gedächtnisse verwendete Metapher des Rückgriffs auf Vergangenes ist somit irreführend. Vielmehr unterliegen Erinnerungen der fortlaufenden (Re-)Aktualisierung und Modifikation, nach Maßgaben der Gegenwart. Die dynamische Veränderung und die verbindende Funktion des Erinnerns deuten schließlich auf zwei zentrale Erkenntnisse hin, die quasi axiomatischen Stellenwert in der Erforschung sozialer Gedächtnisse erhalten haben. Anhand Maurice Halbwachs' Studie »La topographie légendaire des évangiles en Terre Sainte (2003, Orig. 1914) sollen die zentralen Aspekte der Rekonstruktivität und der Verräumlichung des Erinnerns dargestellt und für die vorliegende Arbeit nutzbar gemacht werden.

In dieser klassisch gewordenen Studie zum kollektiven Gedächtnis untersucht Maurice Halbwachs den Bedeutungswandel der heiligen Stätten in Palästina. Nicht die Frage, ob oder inwiefern die heiligen Stätten wirklichkeitstreu mit früheren Begebenheiten übereinstimmen, sondern die geformten und andauernd umgeformten Erinnerungen im historisch-diachronen Vergleich über einen Zeitraum von 15 Jahrhunderten stehen im Zentrum seines Interesses. Gleich zu Beginn wird die Rekonstruktivität der Erinnerung deutlich betont. Erinnerung ist demnach fortlaufend durch die Erfordernisse der Gegenwart geprägt. ${ }^{7}$

»Wenn, wie wir glauben, das kollektive Gedächtnis wesentlich eine Rekonstruktion der Vergangenheit bedeutet, wenn es dementsprechend sein Bild früherer Tatsachen den religiösen Überzeugungen und spirituellen Bedürfnissen der Cegenwart anpaßt, wird das Wissen darum, was ursprünglich war, mindestens zweitrangig, wenn nicht ganz und gar überflüssig: die Wirklichkeit der Vergangenheit,

7 Differenzierte Halbwachs diesbezüglich noch zwischen Gedächtnis und Geschichte (2003:194), so weist Winfried Speitkamp darauf hin, dass sich Gedächtnis und Geschichte hinsichtlich der Rekonstruktivität durchaus ähnlich sind, wenn er feststellt, dass auch »vor dem Geschichtsbild das Gegenwartsverständnis, vor der Pflege der Geschichte das Interesse an der Gegenwart [steht].« (1996:25). 
eine unveränderliche Vorlage, der man zu entsprechen hätte, gibt es nicht mehr.« (Halbwachs 2003:20f.).

Um den Wandel der Erinnerung im Lauf der Jahrhunderte zu veranschaulichen, wird der Reisebereicht eines Pilgers aus Bordeaux, der im 4. Jahrhundert das Heilige Land bereist hat, zu einer wichtigen Referenz. Im vierten Jahrhundert unserer Zeitrechnung vollzieht sich allerdings auch ein epochaler Wandel: Das Christentum wird römische Staatsreligion. Gerade weil nach dieser historischen Wasserscheide der Geschichte des Christentums eine rege Bautätigkeit einsetzt, wird auch die Erinnerung an die biblischen Ereignisse einer Transformation unterworfen. Der Erfahrungsbericht des Pilgers gerät so zu einer wichtigen Kontrastfolie, durch die sich die Veränderungen der Erinnerung konturieren lassen. Noch vor der Verbreitung der evangelischen Erzählungen des Lebens Jesu bewegen sich seine Erinnerungen ganz in der jüdischen Rezeption (Halbwachs 2003:69). Da das christliche Gedächtnis zu dieser Zeit »nur im Jüdischen Gedächtnis Wurzeln geschlagen hat«, besucht der Pilger des vierten Jahrhunderts noch ganz andere Stätten und lässt solche, die erst durch die »spätere Tradition den Prägestempel« (a.a.O. 70) der römischen Staatsreligion erhielten, abseits seines Weges liegen. Findet sich in diesem Bericht lediglich eine einzige Erwähnung der Evangelien (a.a.O. 59), ändert sich dies Jahrhunderte später in den Erinnerungen, durch die die Kreuzfahrer an gänzlich andere Orte geführt werden. Denn diese »Erinnerungen« bildeten sich in der Ferne und damit »ohne dass die Wirklichkeit Einspruch erhoben hätte.«(Halbwachs 2003:170).

Anhand des Beispiels Bethlehems macht Halbwachs deutlich, dass die Rekonstruktivität der Erinnerung immer dem Geist der Gegenwart entspringt. So ging es im Falle Bethlehems um die Legitimation des Christentums durch die Anbindung an die jüdische Tradition: »Lange Zeit wurde in Bethlehem auch das Grab Davids gezeigt, und wenn man Jesus in Bethlehem zur Welt kommen ließ, dann um die Geburt des Messias dorthin zu legen, wo sein Ahne selbst geboren wurde." (Halbwachs 2003:81). Bethlehem wurde also nicht zu einer zentralen Stätte des Christentums, da Jesus hier geboren wurde. Vielmehr machte es die Kontinuität mit dem Hause David erforderlich, dass auch der christliche Messias in Bethlehem zur Welt kommen musste. In einer eleganten Umkehrung weist Halbwachs schließlich darauf hin, dass es »die Erinnerung an den Bethlehemiter David«war, die »die Krippe des Heilands« nach Bethlehem führte (a.a.O. 87).

Damit ist bereits der zweite wichtige Aspekt der Verräumlichung angesprochen. Die Schilderung der Ereignisse vollzieht sich nicht nur im Geist der Gegenwart - in diesem Fall der religiösen Legitimation -, sondern entfaltet auch unmittelbaren Einfluss auf die Orte in ihrer spezifischen räumlichen Bedeutung. Mit der Verräumlichung des Gedächtnisses erhalten die jeweiligen physischen Or- 
te überhaupt erst ihren räumlichen Sinn. Anhand der Gedenkstätten in Nazareth veranschaulicht Halbwachs dies.

»All diese Ortsbestimmungen sind also verhältnismäßig spät erfolgt. Das christliche Gedächtnis, das hier keine Überlieferung vorfand, hat sich dabei an ganz konkrete Einzelheiten, an physische Besonderheiten gehalten, um dorthin schließlich Ereignisse zu legen, deren Stätten es aufzufinden suchte.« (Halbwachs 2003:138).

Nicht eine (wie auch immer) an einem Ort kondensierte Geschichte setzt die Erzählungen in Gang, sondern die Erzählungen konstruieren die an einem Ort dann (vermeintlich) sichtbare Geschichte. Nicht die Orte repräsentieren die Ereignisse, die sich an ihnen zugetragen haben, sondern die Erzählungen, die nach Maßgabe der Gegenwart über die Orte verfasst werden, erzeugen an den Orten die Räume in ihrer spezifischen Bedeutung. Das Finden geht somit paradoxerweise der $\mathrm{Su}$ che voraus. Denn erst nachdem konkrete Orte (vor-)gefunden werden, beginnt in rekonstruktiver Absicht die Suche nach einer ihnen gemäßen Vergangenheit.

Auch wenn der Begriff des Erinnerns einen starken Bezug zur Zeit herstellt, so sind die Erinnerung und die Imagination einer Vergangenheit stets zeit- und ortskonkret. Ähnlich wie die Geschichte zur Verzeitlichung neige, braucht das Gedächtnis Orte; »es tendiert zur Verräumlichung« (Borsdorf/Grütter 1999:4). Diese Tendenz zur Lokalisierung kann als ein wichtiger Mechanismus der Kodifizierung und Bezeugung von Erinnerung angesehen werden. Auch Halbwachs hebt die Funktion der Legitimation und der Intensitätssteigerung hervor. Denn die Stätten bezeugen die "Wahrheit« der Vergangenheit sowie durch die lebhafte Begegnung mit dem Vergangen an einem konkreten Ort dieses »im Gedächtnis einer Gruppe festmachen« kann (Halbwachs 2003:163). Durch die Auffindung der Stätten der evangelischen Überlieferung vergegenständlicht sich so das kollektive (christliche) Gedächtnis, indem es sich selbst ein Bild im Raum gibt (a.a.O. 208).

Die sehr freie Übersetzung des französischen Titels, "La topographie légendaire des évangiles en Terre Sainte«, mit »Stätten der Verkündigung« lässt sich durchaus im Sinne dieser Doppeldeutigkeit interpretieren. Die Stätten erscheinen dann nicht nur als die Orte, an denen sich eine Verkündigung zugetragen hat. Im Sinne eines objektiven Genitivs sind sie einerseits die Stätten, die davon kündigen, was sich hier (angeblich) zugetragen hat. Meines Erachtens können die "Stätten der Verkündigung« aber ebenso im Sinn eines subjektiven Genitivs interpretiert werden. Dann sind es nämlich die Stätten, die durch die Verkündigung des Evangeliums, die verschiedenen Rezeptionen der Heiligen Schrift und die politischen und sozialen Bedingungen in 15 Jahrhunderten überhaupt erst in ihrer spezifischen Qualität hervorgebracht und immer wieder neu modifiziert werden. Der Wert dieser Perspektive, die durch Halbwachs' klassische Studie eingenommen werden kann, liegt darin, dass Erinnern nicht nur konnektiv in vergemeinschaften- 
der und zeitlicher Hinsicht ist, sondern dass es auch als konstruktiv in räumlicher Hinsicht aufgefasst werden kann.

\subsection{Die Strukturen des Erbes: Beschwören oder Verschwören?}

Das Heilige Land bleibt auch im 21. Jahrhundert ein lehrreiches Beispiel, anhand dessen die Konflikthaftigkeit der vergangenheitsbezogenen Deutungen von Orten nahezu täglich virulent wird. Der israelische Architekt und Publizist Sharon Rotbard veranschaulicht dies in seiner Studie »White City, Black City« (2015) anhand des (vermeintlichen) Bauhaus-Erbes Tel Avivs. Wie in Halbwachs' „Stätten der Verkündigung « erhält das Erbe auch hier durch die Art, wie geerbt und welche Vergangenheit beerbt wird, seine spezifische räumliche Bedeutung. Dabei kann veranschaulicht werden, dass erst die wechselhaften Wertzuschreibungen an eine bestimmte Architektur diese zu einem baukulturellen Erbe machen.

Rotbard kann zunächst überzeugend darlegen, dass architekturgeschichtlich wenig für eine direkte Verbindung zwischen den modern anmutenden Gebäuden Tel Avivs und den Architekten des Bauhauses spricht (Rotbard 2015:16ff.). So betont etwa Aryeh Sharon, ein tatsächlicher Bauhausschüler, dass der größte Einfluss auf die Architektur Tel Avivs von Le Corbusier und gerade nicht vom Bauhaus ausging (a.a.O. 31). Ungeachtet dessen, dass Begriffe wie >Funktionalismus«, >Rationalismus oder sinternationaler Stik angemessener wären, um die Architektur der Stadt zu beschreiben, wird diese dennoch als »Tel Aviv Bauhaus« bezeichnet (a.a.O.19). Sharon Rotbard zeichnet nach, wie das Label >Bauhaus< entgegen aller architekturgeschichtlichen Evidenz zu einer Projektionsfläche unterschiedlicher vergangenheitsbezogener Erwartungen geriet. Neben der allgemeinen Chiffre der Modernität wird so eine Verbindung zur »cultural noblesse« des aschkenasischen Judentums hergestellt. Der »Funken der Utopie« des Neuen konnte so mit der »Patina der Tradition« versöhnt und veredelt werden. Die »whiteness of the European avant-garde« verschmolz so mit dem »dazzling Mediterranean light.« (a.a.O. 11). Damit die lokale israelische Identität ihre Wurzeln rückwirkend in Richtung eines fortschrittlichen »europäischen Modernismus« (a.a.O. 26) ausschlagen konnte, musste schließlich eine raumzeitliche Assoziation zwischen den Gründungsorten des Bauhauses und der östlichen Levante hergestellt werden. Eben dies leistet das Erbe des »Tel Aviv Bauhaus«; gerade hierin liegt sein Wert.

»That it was Dessau of Germany, specifically, which became a central reference point [...] was not entirely surprising. It reflected the commonplace faith put in Ashkenazi social hierarchies and the status of Yekkes (German Jews) at the top of the ladder. This particular nationality of Jews had always been given the stamp of cultural noblesse in Israel - not solely because the Jewish region of Ashkenaz in 
Cermany had been the historical and geographical origin of all Ashkenazi Jews, but because of a desire to paint Israeli Ashkenazim as a continuation of modern, intellectual and secular tradition of Cerman Jewry, synonymous with the age of Enlightenment. This was considered a much worthier heritage to have than, for example, one which linked Israelis back to the poverty, traditionalism and religious fervour of Polish Jewry.« (Rotbard 2015:27, Herv. JK).

Dadurch, dass das aufgeklärte Judentum Mitteleuropas als wertvolleres Erbe (worthier heritage) erachtet wird, erhielt die liberale Tradition des Bauhauses den Vorzug vor dem religiösen Eifer (religious fervour) des osteuropäischen Schtetls. Indem Dessau zum Referenzpunkt (central reference point) des Vergangenheitsbezugs wurde, werden die weißen Flachdachhäuser im Wüstensand schließlich zur »Fortsetzung einer modernen, intellektuellen und säkularen jüdischen Tradition« aus der Mitte Europas. Daneben dienen die fortschrittlichen Gebäude auch der Distinktion von anderen lokalen Bautraditionen, so wie die glatten Fassaden schließlich zur Projektionsfläche des Triumphes einer von den Nazis gehassten, sozialdemokratisch-liberalen Idee werden konnten. Das Bauhaus-Erbe wird sogar zum späten Sieg über den Nazismus.

»This sentimental kitsch - philosophy students who became builders, the White City bravely standing in front of Orientalism, or the celebration of Tel Aviv's victory over Nazism - has finally became the rhetoric and apologetics of the city: Tel Aviv is not only beautiful, but just; it is not white, it is whiter than white.« (Rotbard 2015:43).

Die moderne Architektur Tel Avivs wird so zum Symbol der Pionierleistungen eines utopischen Neubeginns auf der zuvor symbolisch bereinigten tabula rasa der unbebauten Wüste (a.a.O. 43ff.). Gerade im Topos der utopischen Neugründung in der (angeblichen) Leere der Dünen sieht Rotbard einen zentralen Anspruch und eine wichtige Legitimationsfigur des Zionismus. Er stellt fest: "The White city on the dunes - illustrated the famous Zionist formula of sa land without people for a people without land , which has structured the whole nation's working rhetoric." (Rotbard 2015:50). Indem die Konstruktion des Bauhaus-Erbes Tel Avivs im Schatten seiner weißen Flachbauten zum Prototyp der nationalen Selbstthematisierung wird, kann damit auch die »konjunktive« Dimension dieser Weltbeschreibung (Straub) verdeutlicht werden, die dem Einzelnen schließlich erlaubt, »wir« sagen zu können (Assmann).

Die Errichtung einer zionistischen Utopie auf unbebautem Wüstensand verweist auf einen weiteren Aspekt, der anhand der Studie über die Konstruktion baukulturellen Erbes und dessen fortlaufender Re-Produktion vermittelt werden kann. Die Rivalität verschiedener Vergangenheitsbezüge und die politische Dimension des Erbens werden eindringlich veranschaulicht. Denn die Affirmation des Er- 
bes Tel Avivs geht mit der Negation des baukulturellen Erbes der arabischen Stadt Jaffas einher. Tel Aviv wird zur »White City«, indem es sich die »Black City« als Negativ konstruiert. Das Eigene wird so durch die negative Definition des Anderen formuliert: »Tel Aviv defines everything outside the imagined walls of the White City as its opposite.« (a.a.O. 59). Dies zeigt einerseits, dass die Zuschreibungen an die »Black City« Jaffa nur in Relation zur »White City« (a.a.O. 66) existieren. Andererseits bedarf die moderne »White City« der Ko-Konstruktion einer rückständigen »Black City«, die Jaffa als einzigen chaotischen Zustand der Unordnung imaginiert.

In historischer Analyse zeichnet Rotbard nach, wie ab dem Jahr 1921 Jaffa durch die Separation der Bevölkerung zunehmend von einer kosmopolitischen zu einer arabischen Stadt wurde (Rotbard 2015:88). Dadurch gerieten die Städte Tel Aviv und Jaffa schließlich zu Verkörperungen der jeweiligen nationalen Aspirationen der Israelis und der Palästinenser (a.a.O. 98). Das zur arabischen Enklave gewordene Jaffa wurde als Bedrohung wahrgenommen, was schließlich im Krieg von 1947 zur Vertreibung der Bevölkerung sowie zur weitgehenden Zerstörung der Stadt führte: »The almost complete disappearance of Jaffa's Palestinian community, which had constituted roughly 97 percent of the city's population as a whole even in late 1947, was just as unnerving as the city's physical destruction." (Rotbard 2015:106).

Durch die Schaffung der sogenannten >Big Zone im Jahr 1948 wurde das Zentrum des alten Jaffa weitgehend geräumt. Auf die physische Zerstörung folgte die symbolische Neubesetzung durch eine umfangreiche bauliche Umordnung des Stadtzentrums. Mit der Errichtung einer neuen Altstadt an diesem Ort entstand so auch eine neue Vergangenheit.

»All that was left from the historic city of Jaffa was this small collection of choice remnants, the Church of St Petrus, Napoleon's cannon, and the Andromeda Rock in the sea. Jaffa has become everything but an Arab city. In its place the >Fort of Jaffa ' has broken out. Jaffa has become Old Jaffa, Ancient Jaffa, Antique Jaffa. In the middle of the twentieth century, Tel Aviv has built itself a European medieval crusader outpost.«(Rotbard 2015:122).

Die neue Vergangenheit manifestierte sich als Rekonstruktion eines mittelalterlichen Außenpostens europäischer Kreuzfahrer anstelle des (vormals) arabischen Jaffa. Hierbei handelt es sich um einen besonders frappierenden Fall einer produzierten Altstadt (Enss/Vinken 2016). Sie steht, in einem sehr wörtlichen Sinne, für die Rekonstruktivität der Vergangenheit und damit im Dienst politischer Ziele der Gegenwart. Sie wird so zu einer Sonderzone in den Funktionsräumen der neuen Stadt und der neuen Machthaber (Vinken 2010:14). Mit der Wiederholung des »White City architectural narrative« verstummen also auch zunehmend das Erbe und die Erinnerung an das arabische Jaffa (a.a.O. 174). Rotbards Studie wird damit zu einer politischen Streitschrift. Wie der Untertitel des Buches »Architecture and War in Tel Aviv and Jaffa« bereits zum Ausdruck bringt, ist es gerade die machtvolle Ver- 
fügungsgewalt über die Vergangenheit, die anhand der Doppelstadt Tel Aviv-Jaffa studiert werden kann. Da sich Tel Aviv und Jaffa hierin nicht von vielen anderen israelischen Städten unterscheiden (Rotbard 2015:160), stellt Rotbard am Ende seiner Studie die Frage, ob der Nahostkonflikt vielleicht weniger als nationale Herausforderung, sondern eher als urbanes Problem thematisiert werden sollte (a.a.O. 180). Da der Konflikt auch ein Kampf um die Narrative des städtischen Erbes ist, wird Stadt- und Erbepolitik in den Städten des Nahen Ostens somit oft auch zu Weltpolitik.

Wie anhand von »White City, Black City« deutlich wird, befindet sich das Erbe in seiner materiellen Gestalt sowie in Bezug auf seinen Bedeutungsgehalt in beständiger Umformung. Dies kann mit einem Gedanken theoretisiert werden, den Jaques Derrida in Bezug auf den Umgang mit dem Erbe des Marxismus zum Ausdruck gebracht hat. So wie Jürgen Straub Identität als etwas niemals fraglos Gegebenes, sondern als Aufgabe beschrieben hat (Straub 2016:163), so formulierte Derrida bereits 1995 unter dem Eindruck der Transformation der sozialistischen Staaten mit den gleichen Begriffen: »Das Erbe ist niemals ein Gegebenes, es ist immer eine Aufgabe.« (Derrida 2016:81). Derrida verknüpft seine Gedanken zum Umgang mit dem Erbe des Marxismus mit der freudschen Theorie der Trauerarbeit (a.a.O. 78). Indem er betont, dass alle Erben »trauernde Erben« seien (a.a.O. 81), macht er deutlich, dass in der Art, wie Vergangenheit thematisiert wird (triumphierend oder affirmierend) diese einerseits präsent gehalten, andererseits umgeformt wird (Derrida 2016:78ff.). Das Erbe führt somit ein gespenstisches Dasein in einer Zwischenwelt »jenseits der Opposition zwischen dem Leben und dem Tod« (a.a.O. 81). In der Beschwörung der Vergangenheit lässt sich auch hier unschwer der Aspekt der Rekonstruktivität wiedererkennen. Doch geschieht dabei noch mehr, denn bei der Beschwörung handelt es sich um eine "performative Interpretation«; eine Interpretation also, die das, was sie interpretiert, gleichsam verändert (a.a.O. 77). Dieses an Hegel orientierte Erbeverständnis ist damit eng mit dem Aspekt der Arbeit verbunden (Vinken 2017:161). An die Stelle des Nomens Erbe tritt somit das Verb (oder auch der Imperativ) erben als eine Aufgabe der performativen Interpretation, die - egal ob ablehnend oder affirmierend - das Erbe anhaltend umformt.

Im Folgenden soll deshalb eher vom aktiven Prozess des Erbens gesprochen werden. So wie Gesellschaft eine Funktion des Erinnerns ist, so soll im Kontext dieser Arbeit das Erbe als eine Funktion des Erbens verstanden werden. Unter erben verstehe ich somit eine Modalität des Erinnerns, die ortsbezogen ist und durch Aktualisierung und Reformulierung von Vergangenheitsbezügen die gebaute Welt in ihrer räumlichen Bedeutung (immer wieder neu) hervorbringt. Anders als beim Nachlass einer Person ruft nicht das Erbe die Erben auf den Plan, sondern das Gespräch der Erben formt das Erbe in anhaltender »Beschwörung« immer wieder neu. In seiner dialektischen Natur bleibt dieser Prozess zudem reziprok. Im Angesicht des Erbes und durch gemeinsam geteilte Deutungen findet auch die 
Gemeinschaft der Erben zueinander und bindet ihre Mitglieder aneinander. Die »konsensfähigen und konjunktiven Selbst- und Weltbeschreibungen « (Straub) in Bezug auf das Erbe erlauben schließlich den einzelnen Mitgliedern, »wir« sagen $\mathrm{zu}$ können (Assmann). Indem sich die Erben im Schatten ihrer Monumente versammeln und diese (in partieller Gleichheit) einheitlich deuten, verbinden sie sich einerseits untereinander, so wie sie andererseits mit ihrem Diskurs auch die kulturellen Artefakte, Architekturen, Monumente, auf die sie sich beziehen, in ihrer räumlichen Bedeutung modifizieren.

Die »Beschwörung« des Erbes stellt dabei nur eine Möglichkeit im Umgang mit dem Erbe dar. Die Bewahrung der Vergangenheit ist nur eine mögliche Interpretation der »Struktur des Erbes« (Derrida 2016:81). Da im Umgang mit der Vergangenheit allerdings kein "glühender Eifer « notwendig ist (ebd.), kann ein Erbe aber auch ausgeschlagen werden. Allerdings wird auch dadurch das Erbe umgeformt. Auch durch die Ablehnung des Erbes des Marxismus findet eine Transformation statt. Diese sieht Derrida etwa in Francis Fukuyamas einflussreichem Buch »Das Ende der Geschichte« verwirklicht. Indem der »angebliche Tod des Marxismus« postuliert wird (Derrida 2016:93), werde dieser zur Vorbedingung der Verwirklichung des Ideals der liberalen Demokratie. In dieser »Verschwörung« des triumphierenden Diskurses gegen das Erbe bleibt dieses gerade in der Ablehnung erhalten (hegelianisch: in der Negation aufgehoben), so wie es durch "performative Interpretation « umgeformt wird. ${ }^{8}$ Nicht nur das Postulat eines glanzvollen Erbes und die Beschwörung einer heroischen Vergangenheit im Sinne eines 'So waren wir (schon immer)<, sondern auch die Ablehnung eines nicht (mehr) gewollten Erbes - also die Verschwörung gegen eine nunmehr als problematisch aufgefasste Vergangenheit im Sinne eines >So sind wir nicht (mehr)< - beschreiben mögliche Strukturen des Erbens.

Im Falle des Neuen Museums wurde die Vergangenheit des Gebäudes als hoher Wert und als schützenswertes Gut angesehen. Im Falle des Militärhistorischen Museums hingegen muss mit dem schwierigen Erbe der verheerenden deutschen Militärgeschichte im 20. Jahrhundert umgegangen werden. Wurde im ersten Fall vor allem über die Art der richtigen »Beschwörung « des Erbes gestritten, so bildet der zweite Fall die für Identitätsbildungsprozesse in der deutschen Gegenwartsgesellschaft hoch relevante Konstellation eines diskontinuierlichen Vergangenheitsbezugs. In der Terminologie Derridas liegt hier also eine »Verschwörung« gegen das Erbe vor. Indem die abschließende Historisierung und der Versuch, das Erbe endgültig den Geschichtsbüchern zu übergeben, nicht gelingen (und nicht gelingen dürfen), bleibt dieses Erbe gerade in seiner Ablehnung dennoch ein zentraler ausgedrückt. Mit »Conjurer - Le marxisme« (1995:75-110) ist somit - wie die Übersetzerin betont - sowohl »beschwören« als auch »sich verschwören« gemeint. 
Referenzpunkt. ${ }^{9}$ Die Fallauswahl der beiden zu analysierenden Diskurse ergibt sich somit vor allem aus der Tatsache, dass hier unterschiedliche Strukturen des Erbes analysiert werden können.

Gerade weil die Triade Museum, Nation, Kulturerbe (Savoy) ihre Fraglosigkeit verloren hat und die Identitätsfabriken (Korff/Roth) von einst keine kanonische Verbindlichkeit mehr stiften, werden verschiedene Kollektivierungsdiskurse hörbar, die entlang der jeweiligen Strukturen des Erbens unterschieden werden können. Das Museum als umkämpfte Infrastruktur (von Scheve) bleibt dafür auch weiterhin ein prädestinierter Untersuchungsgegenstand. Im Schatten einstigen Identitätsfabriken versammeln sich die Erben von Heute und verbinden sich (partiell und temporär) zu verschiedenen Kollektivierungsdiskursen (Straub), so wie sie durch ihre jeweils geteilten performativen Interpretationen (Derrida) auch das Erbe transformieren, auf das sie sich beziehen.

9 Die Forderung nach abschließender Historisierung der nationalsozialistischen Menschheitsverbrechen artikuliert sich immer wieder in dem Topos des Schlussstrichs. Freudianisch gesprochen und keineswegs in einem wertenden Sinn gemeint, würde diese abschließende Historisierung einer gelungenen Trauerarbeit entsprechen; mit dieser würde (so das Kalkül rechtspopulistischer Kreise) aber auch das Erbe selbst verschwinden. 



\section{Die diskursive Konstruktion der gebauten Welt}

$1776 \mathrm{ft}$., $7 \times 7=49,40,1^{\circ}-$ die kryptische Sprache dieser Zahlen bedarf der Übersetzung! 1776 Fuß bezeichnet nicht nur die Höhe des Freedom Towers, der am New Yorker Ground Zero errichtet wurde, sondern verweist auch auf das Jahr der amerikanischen Unabhängigkeitserklärung. Die Zahl sieben besitzt im Judentum besondere Bedeutung. Multipliziert mit sich selbst ergibt sie das Produkt 49. So verweisen die 49 Pfeiler im Hof des Jüdischen Museums (angeblich) auf das Gründungsjahr Israels - ungeachtet der Tatsache, dass Israel im Jahr 1948 gegründet wurde. ${ }^{1} 40,1^{\circ}$ bezeichnet ein Winkelmaß, welchem in der Diskursivierung des Militärhistorischen Museums in Dresden ein besonderer Stellenwert zukommt. Der Winkel wird dabei zur Chiffre eines komplexen Verweissystems (stadt-)räumlicher Relationen.

Anhand der symbolisch hochgradig aufgeladenen Entwürfe des Jüdischen Museums und des Ground Zeros kann der Architektursoziologe Paul Jones überzeugend darlegen, dass der >starchitect< Daniel Libeskind nicht nur ein Meister des Bauens, sondern ebenso ein Meister der Interpretation ist, mit der er seine Architektur deutet und verkauft. Indem er in Erklärungen zu Wettbewerbsentwürfen (Jones 2006:552) oder in Publikationen zur Museumsarchitektur die komplexe Zahlensymbolik versprachlicht, werden Deutungsangebote formuliert, ohne die die spektakuläre Architektur kaum je in dem behaupteten Sinne wahrgenommen werden könnte. Insbesondere die Verbindung zwischen sogenannten »landmark buildings « und »collective identities« werde laut Jones diskursiv hergestellt (2006:550ff.). Vor, während und nach der Errichtung der Gebäude vollzieht sich also neben deren materieller auch immer ihre diskursive Konstruktion.

Dabei wird der "powerful elite of transnational architects « eine entscheidende Rolle zugewiesen (ebd.). Da >starchitects` so zu Statthaltern ökonomischpolitischer Interessen und $\mathrm{zu}$ »agents of capitalist globalisation « werden (Jones 2009:2530), ergibt sich jedoch eine strukturtheoretische Akzentuierung (ebd.). So 
besteht die Gefahr, die kontingente Auslegung der Architektur auf den Aspekt der Repräsentation kultureller und politischer Hegemonie oder sogar als direkten Ausdruck kollektiver Identität zu verkürzen (Delanty/Jones 2002). Da im Zentrum dieser Arbeit aber gerade die verschiedenen Strukturen des Erbens und nicht (nur) die kanonische Repräsentation gesellschaftlich verbindlicher Erinnerungsfiguren (Assmann 1997:38) stehen (Kap. 2), eignen sich derlei strukturtheoretische Perspektiven auf die Diskursivierung von Architektur nur bedingt. Indem die Vielstimmigkeit der verschiedenen Wirklichkeitsdeutungen so konzeptionell zum Verstummen gebracht würde, ginge die Vieldeutigkeit der Architektur für die soziologische Analyse verloren. Damit ist sowohl ein raumtheoretisches Problem zwischen struktur- und handlungstheoretischen Ansätzen benannt (Löw 2018:25ff.) als auch ein methodisches Problem, das mit der Bezugnahme auf das Forschungsprogramm der wissenssoziologischen Diskursanalyse gelöst werden kann. Entgegen eher struktur- und hegemonietheoretischen Ansätzen ist es einerseits wichtig, den konkurrierenden Wirklichkeitsdeutungen »Spielräume der Kreativität« (Keller 2012:34) zu gewähren und diese nicht nur als Ausdruck von Struktureffekten zu beschreiben (a.a.O. 30). Der »Einbau einer Diskursperspektive« (Keller 2011:185) in die Wissenssoziologie erscheint dafür besonders geeignet. Im Rückgriff auf die wissenssoziologische Hermeneutik steht hierbei die Analyse von Alltagsdeutungen im Vordergrund. Als Oberflächenhermeneutik nimmt sie die kreativen Sinnkonstruktionen subjektiver Weltdeutungen ernst, ohne sie als bloße Effekte tieferliegender Strukturen abzutun.

Andererseits muss die synchrone Analyse unterschiedlicher räumlicher Sinnproduktion methodologisch gewährleistet werden. Mit der Adaption der modernen Wissenssoziologie auf die gebaute Welt, wie sie von Silke Steets geleistet wurde, ist dies möglich. Dass etwa das materielle Erbe der Museumsinsel sehr verschieden beerbt werden kann, hieße in wissenssoziologischer Übersetzung, dass ein und dieselbe Externalisierung von Sinn eine Objektivation (etwa der Umbau der Museen) darstellt, die wiederum höchst unterschiedlich internalisiert und gedeutet werden kann. Bieten die Arbeiten von Silke Steets eine Verbindung zwischen Wissenssoziologie und Raum (Kap. 3.1), so wird durch den Ansatz der wissenssoziologischen Diskursanalyse (Keller), also durch die Verbindung zwischen Wissenssoziologie und Diskurs (Kap. 3.3), der analytische Zugang auf der Ebene von Diskursen möglich. Die Verbindung der einflussreichen Theorietraditionen der Wissenssoziologie und der Diskursforschung, die lange Zeit in wechselseitiger NichtBeachtung koexistierten, bietet außerdem die Möglichkeit der komplementären Ergänzung (Knoblauch 2001). Mit dem Rückgriff auf das methodengeleitete Analysevorgehen des interpretativen Paradigmas, insbesondere der Verbindung zwischen Wissenssoziologie und Hermeneutik (Kap. 3.3), werden zudem Analysedimensionen bereitgestellt. Diese ergänzen das weitgehend intransparente Vorge- 
hen der foucaultschen Diskursanalyse (Keller 2012:29) und werden im letzten Teil dieses Kapitels (Kap. 3.4) für die Untersuchung nutzbar gemacht.

\subsection{Wissenssoziologie und Raum: Die Deutung der gebauten Welt}

In einem der einflussreichsten soziologischen Texte fundieren Peter L. Berger und Thomas Luckmann ein sozialkonstruktivistisches Programm - »Die soziale Konstruktion der Wirklichkeit« (1980, Orig. 1969). Die zentrale Frage besteht darin, wie aus einem bestimmten Vorrat von »Wissen « gesellschaftlich etablierte »Wirklichkeit« werden kann (Berger/Luckmann 1980:3). Die Schlüsselbegriffe »Wirklichkeit« und »Wissen« werden dabei bewusst niedrigschwellig definiert. So ist mit »Wirklichkeit« schlicht die Qualität von Phänomenen gemeint, die ungeachtet unseres Wollens vorhanden sind. »Wissen« hingegen ist als Gewissheit definiert, dass Phänomene wirklich sind (a.a.O. 1). Mit »Wirklichkeit« ist also primär soziale Wirklichkeit gemeint, wodurch Berger und Luckmann ihren Gegenstandsbereich von dem der Philosophie abgrenzen. Nicht das Subjektverhältnis zu einer absoluten Wirklichkeit und die Spekulation über deren ontologischen Status, sondern Wirklichkeit als die intersubjektive Welt (a.a.O. 21ff.) gemeinsam geteilter Wissensbestände ist der Gegenstand der (Wissens-)Soziologie. Auch Wissen beschreibt dabei keinesfalls nur lexikalisches Wissen, sondern explizit und in besonderem Maße das Alltagswissen oder »Jedermannswissen« (Berger/Luckmann 1980:26). Verschiedene intersubjektiv geteilte Wissensbestände können zu unterschiedlichen Wirklichkeiten führen. Was für einen tibetanischen Mönch wirklich ist, braucht für einen amerikanischen Geschäftsmann nicht wirklich zu sein. Denn »spezifische Konglomerate von Wirklichkeit und Wissen führen so zu spezifischen gesellschaftlichen Gebilden« (a.a.O. 3). Der Alltagswirklichkeit als Wirklichkeit par excellence (a.a.O. 24) wird dabei eine herausragende Rolle zuerkannt.

Mit der Frage »Wie aus einer Welt von Handeln eine Welt von Sachen wird« (Berger/Luckmann 1980:20) vermitteln die Autoren zudem zwischen Strukturalismus (Durkheim) und Handlungstheorie (Weber). Die Vermittlung zwischen Struktur und Handeln bleibt als dynamischer Prozess aufeinander bezogen, wodurch der Einfluss des Pragmatismus (Mead) und damit einer dritten Theorietradition erkennbar wird. Der Doppelcharakter der Gesellschaft als objektive Faktizität und subjektiv gemeinter Sinn (ebd.) ist bereits in der Zweiteilung des Buches in »Gesellschaft als objektive Wirklichkeit « und »Gesellschaft als subjektive Wirklichkeit« angelegt. Soziale Wirklichkeit ist somit keineswegs nur die Prägewalze, die den Subjekten gesellschaftliche Passform verleiht. Mit der Einverleibung historischer Wissensbestände werden diese nicht nur internalisiert, sondern auch modifiziert. Sie werden also anverwandelt. Durch die dialektische Beziehung von Externalisierung (Entäußerung), Objektivierung (Vergegenständlichung) und Internalisierung 
(Einverleibung) von Sinn hat Wirklichkeit also immer nur vorläufigen Charakter und bleibt demnach lebendig. Berger und Luckmann haben diese protosoziologische Überlegung folgendermaßen auf den Punkt gebracht: »Gesellschaft ist ein menschliches Produkt. Gesellschaft ist eine objektive Wirklichkeit. Der Mensch ist ein gesellschaftliches Produkt.«(a.a.O. 65).

Die Rezeption der »Sozialen Konstruktion der Wirklichkeit« sowie der empirische Fokus der Autoren auf die Sprach- und Religionssoziologie führten zu einer Blickverengung auf immaterielle Objektivationen. Dies scheint eher rezeptionsgeschichtlich und weniger durch eine konzeptionelle Fehlstelle begründet zu sein. Indem Silke Steets die Trialektik der Wissenssoziologie Bergers und Luckmanns auf den Gegenstandsbereich der Architektur überträgt, gelingt ihr somit eine Weitung des üblichen Blickfeldes und eine wissenssoziologische Perspektivierung auf materielle Objektivationen und raumbezogene Sinnproduktionen. Bisherige Bemühungen, Architektur soziologisch zu betrachten, würden einerseits das Gebaute primär als Abbild des Sozialen und als Materialisierung sozialer Tatsachen verstehen. Die Gefahr dieser strukturalistischen Perspektive bestehe demnach darin, den in den Gebäuden objektivierten Sinn absolut zu setzen (Steets 2015a:56). Entgegen einem strukturalistischen Sinnmonismus betonen Handlungstheorien andererseits die kontextspezifische Bedeutung von Artefakten, wobei ihr Sinn nur durch die Zuschreibungen menschlichen Handelns verständlich ist (Steets 2015a:32). Einen dritten theoretischen Zugang zur soziologischen Betrachtung von Architektur böten poststrukturalistische Ansätze, in denen Materialität nicht mehr nur ein Abbild des Sozialen ist, sondern ihr gleichermaßen eine »soziale Effektivität« zuerkannt wird (a.a.O. 44). ${ }^{2}$ Der Vorteil der wissenssoziologischen Perspektive liege nun darin, dass all diese Dimensionen in einem Modell konzeptualisiert werden können (Steets 2015b:106). Da der Mensch also in all seinem Tun und Denken subjektiven Sinn ausdrückt und damit fortwährend sein Verhältnis zur Umwelt und zu seinen Mitmenschen deutet (Steets 2015a:109), kann auch das Entwerfen von Architektur als Externalisierung von Sinn verstanden werden. Daraus folgt: »Externalisierung bedeutet dann nichts anderes als das Entwerfen und Bauen von Gebäuden; diese wiederum lassen sich als materielle Objektivationen begreifen, welche über verschiedene Modi der Aneignung internalisiert werden.« (a.a.O. 10).

2 Zwar impliziert die wissenssoziologische Architekturtheorie, die Steets entwickelt, durch den Übertrag der »Sozialen Konstruktion« bereits die verbindungstheoretische Synthese aus Durkheim, Weber und Mead. Dass die Dimensionen dann nicht als strukturalistisch, handlungstheoretisch und pragmatistisch (anstatt poststrukturalistisch) bezeichnet werden und die Akteur-Netzwerk-Theorie (ANT) damit dem poststrukturalistischen Lager zugerechnet wird, erscheint hingegen überraschend; zumal die ANT in ihrer Subjektschwäche und Subjektverteiltheit durchaus als eine Radikalisierung des Pragmatismus bezeichnet werden kann. 
Anhand der Arbeiten von vier Architekten beschreibt Steets je verschiedene Modi der Externalisierung von Sinn (a.a.O. 118ff.). Geht es Walter Gropius um die prototypische Lösung industrieller Aufgaben, so bedeutet Entwerfen für den Schweizer Architekten Caminada das Lösen singulärer Aufgaben durch die Übersetzung historisch-regionaler Besonderheiten. Allen unterschiedlichen Externalisierungen in den jeweiligen architektonischen Entwürfen ist jedoch gemein, dass sie die Sinnprovinz der Architektur, indem sie sie reproduzieren, gleichermaßen modifizieren. Das Entwerfen entspricht zunehmend einer »Arbeit an den Grenzen der Sinnprovinz « und damit einer anhaltenden Umformung (Steets 2015a:162f.). Auch nachdem Entwürfe umgesetzt wurden, ist der Sinn der gebauten Welt damit nicht fixiert. Zwar können die jeweiligen Entwürfe als Objektivationen, also als Sinnverfestigungen (a.a.O. 170f.), verstanden werden; einmal in der Welt, werden diese jedoch unterschiedlich entschlüsselt und kreativ anverwandelt. Somit erscheinen auch materielle Objektivationen zu einem gewissen Grad labil, da sie, ebenso wie immaterielle Objektivationen wie Sprache, letztlich in Bezug auf ihre Bedeutung wissensvermittelt bleiben (a.a.O. 205).

Im Unterschied $\mathrm{zu}$ immateriellen Objektivationen umfasst der Umgang mit materiellen Objektivationen - wie etwa Architektur - in besonderem Maße Körperwissen, welches zusätzlich internalisiert werden muss (Steets 2015a:178). »Die Internalisierung der gebauten Umwelt ist nur im dialektischen Wechselspiel von Körper/Leib und Bewusstsein zu verstehen.«(a.a.O. 217). Im Anschluss an die Tradition des Pragmatismus führt Steets weiter aus, dass Ich- und Dingkonstitution einander bedingen, da »die Dingwelt für Mead ebenso wie die Ich-Identität eines Subjektes ein Produkt interaktiver sozialer Handlungen ist.« (a.a.O. 35). Daraus folgt: "Die Art, wie wir mit Dingen umgehen, macht uns ein Stück weit zu dem, wer wir sind." (Steets 2015a:243). Die Internalisierung stellt selbst wiederum eine Externalisierung von Sinn dar. So wird sie schließlich zum Umschlagplatz zwischen subjektiver und objektiver (besser: objektivierter) Wirklichkeit: »Jede aneignende Handlung der gebauten Umwelt impliziert ihre mehr oder weniger weit gehende und mehr oder weniger kreative Veränderung durch diejenigen, die sie handhaben. Hier unterscheidet sich Architektur also nicht von Sprache.« (a.a.O. 230). Pointiert führt Steets dies anhand des konventionellen Umgangs einer Reinigungskraft mit dem ganz und gar unkonventionellen Maison à Bordeaux von Rem Kolhaas aus (a.a.O. 206ff.). Indem die »alltäglichen Reinigungsrituale« scheitern, wird aus der »Luxusvilla« ein »suspektes technisches Wunderwerk.« Die in dem Gebäude »objektivierten Weltdeutungen« bleiben kontingent, was schließlich zur »Systemkollision« führt. Die Reinigungskraft folgert: »Katastrophe!« (ebd.).

Wie bereits festgestellt wurde, wird auch baukulturelles Erbe im Sinne einer "performativen Interpretation« (Derrida 2016:77) immer wieder neu hervorgebracht (Kap. 2). Durch die Verbindung des sinnhaften Aufbaus der gebauten Welt mit der Trialektik der modernen Wissenssoziologie, wie sie von Steets geleistet 
wurde, wird schließlich verständlich, dass es gerade die unterschiedlichen Internalisierungen der (objektivierten) Architektur sind, die zu immer wieder neuen Externalisierungen von Sinn führen und so ihren Gegenstand anhaltend und kreativ umformen. Dies macht diese Perspektive für die Untersuchung synchroner raumbezogener Deutungsakte besonders wertvoll.

Die Erweiterung der raumbezogenen Sinnsetzungsprozesse um »körpersoziologische und leibphänomenologische Gesichtspunkte« (2015a:59) erlaubt zudem, den sinnhaften Aufbau der gebauten Welt sowohl als reflexiven Bewusstseinsakt (denkend, innerweltlich) als auch als performative (quasi präreflexive) Körpertechnik zu verstehen (a.a.O. 91). Auch wenn damit prinzipiell auch diskursive Formen der Externalisierung in den Blick genommen werden können, so liegt Steets' Fokus auf die gebaute Welt dennoch »unterhalb des Diskurses« (Knoblauch 2016). Denn im Zentrum ihrer Untersuchung steht gerade das leib/körperliche Erleben der Architektur. Im Anschluss soll deshalb die >Flughöhe dieser Untersuchung auf der Ebene diskursiver Konstruktion bestimmt werden. Dazu wird im Folgenden die zweite Verbindung - zwischen Wissenssoziologie und Diskurs - hergestellt.

\subsection{Im Diskurs oder darunter?}

Die intensive Forschung im Kontext von Museen generiert aktuell eine große Menge unterschiedlicher Daten. Dies erzwingt eine theoretische und methodologische Standortbestimmung der Untersuchung (Burzan 2017a:20). Für die Bestimmung der >Flughöhe< der Untersuchung erscheint die Unterscheidung zwischen kommunikativer und diskursiver Konstruktion hilfreich. Mit der Klärung des empirischen Status des Untersuchungsmaterials lässt sich auch die Reichweite der daraus gezogenen Schlüsse bestimmen.

Obwohl sich auch Nicole Burzan der Erforschung von Raum- und Zeitstrukturierungen in Museen widmet (2017b), ist damit doch gänzlich anderes gemeint als die hier zu analysierenden raumzeitlichen Wirklichkeitsdeutungen auf der Ebene von Diskursen. Ausgehend von der spannungsreichen Tendenz einer zunehmenden Betonung der »Souveränität des Publikums« einerseits sowie dessen Steuerung (durch Wegeführung, Audioguides) andererseits liegt Burzans Erkenntnisinteresse auf den »lokalen und temporalen Strukturierungen« des Museumspublikums. Die »Souveränitätsrhetorik«, mit der das Publikum adressiert wird, bewegt sich in einem »klar definierten Optionsrahmen« (Burzan 2017b:177). Indem die raumzeitlichen Strukturierungen als Ausdruck zunehmender Erlebnisorientierung beschrieben werden (a.a.O. 172), verhandelt Burzan diese in erster Linie als »eventisierungsbedingte Strukturierungseffekte« (a.a.O. 183). Das Publikum erscheint dabei seltsam passiv. Obwohl situativ anderslautende Deutungen möglich sind, wird 
die Möglichkeit der kreativen Anverwandlung der Museumsdisplays kaum thematisiert.

Solcherlei situative Deutungsakte hingegen, die auf der Ebene kommunikativer Bedeutungskonstruktion vollzogen werden, lassen sich im Datenkorpus der untersuchten Museen oft finden. Anhand eines empirischen Beispiels lässt sich dies veranschaulichen. Eine Mitarbeiterin des Militärhistorischen Museums schildert, dass im Ausstellungsteil Krieg und Gedächtnis, in welchem die vielfältigen Verbindungen zwischen Krieg und sozialem Erinnern thematisiert werden, nie die ursprünglich intendierte Konzeption umgesetzt werden konnte. Die eng gestellten Schaukästen, die Assoziationen zu Kompaktanlagen in Bibliotheken und Archiven wecken, sollten ursprünglich per Knopfdruck geöffnet und geschlossen werden. Ungeachtet dessen, dass dies nicht umgesetzt werden konnte, werden die Vitrinen von Besuchenden (darunter auch Experten) sehr positiv wahrgenommen und in der situativen (leib/körperlichen) Rezeption sinnhaft gedeutet.

»Eigentlich ein Sorgenkind, aber komischerweise funktioniert es ganz gut, technisch bisher nicht freigegeben, weil der TÜV sagt, es ist nicht gewährleistet, dass irgendein Besucher einen andern, der drin ist, erdrückt und ich habe jetzt auch schon mehrfach von Besuchern gehört, also gerade von Fachkollegen: Ah, toll, da wird man gezwungen, an die Objekte ran [zu gehen], es wird entmystifiziert.« (MHM-3, 85-106).

Was hier beschrieben wird, sind ad-hoc-Deutungen, in denen eine Intention unterstellt wird (Zwang, sich den Objekten zu nähern; Entmystifizierung). Dadurch wird der starke subjektive Deutungsdruck veranschaulicht, der von der objektivierten Wirklichkeit ausgeht. Gerade in Museen als Orte, die eine besondere Erwartungshaltung evozieren, ist anzunehmen, dass der Zwang zur sinnhaften Deutung eher noch gesteigert ist. Diese Bedeutungskonstruktion im Angesicht konzeptionsloser Vitrinen lässt sich mit einem Begriff der Architektursoziologin Albana Yaneva beschreiben. Diese spricht im Zusammenhang von nicht-intendierten architektonischen Resultaten, die nachträglich mit Bedeutung versehen werden, von »accidental results« (Yaneva 2008).

Als was objektivierte Wirklichkeit gedeutet wird, entsteht hier also - unter Einbeziehung der leib/körperlichen Erfahrung (etwa die erzwungene Nähe zu den Vitrinen) - unterhalb der Ebene von Diskursen. Dieses »unterhalb« entspricht laut Hubert Knoblauch der Ebene der Sozialtheorie, auf der geklärt wird, wie das, was schließlich Diskurs genannt wird, überhaupt entsteht (Knoblauch 2016:12f.). Der kreative Umgang mit den unvollendet gebliebenen Ausstellungsvitrinen und die ad-hoc-Deutungen der Besuchenden stellen damit grundlegende Gegenstandsbestimmungen dar. Allerdings bleiben diese in Bezug auf strukturelle Aspekte einstweilen folgenlos (obwohl dies bei ausreichend häufigen Wiederholungen durchaus denkbar wäre, etwa durch die schriftliche Fixierung einer oft wiederholten Deu- 
Abbildung 4: Vitrinen im Ausstellungsteil Krieg und Gedächtnis. Führungsschienen im Boden deuten auf die ursprüngliche Intention hin.

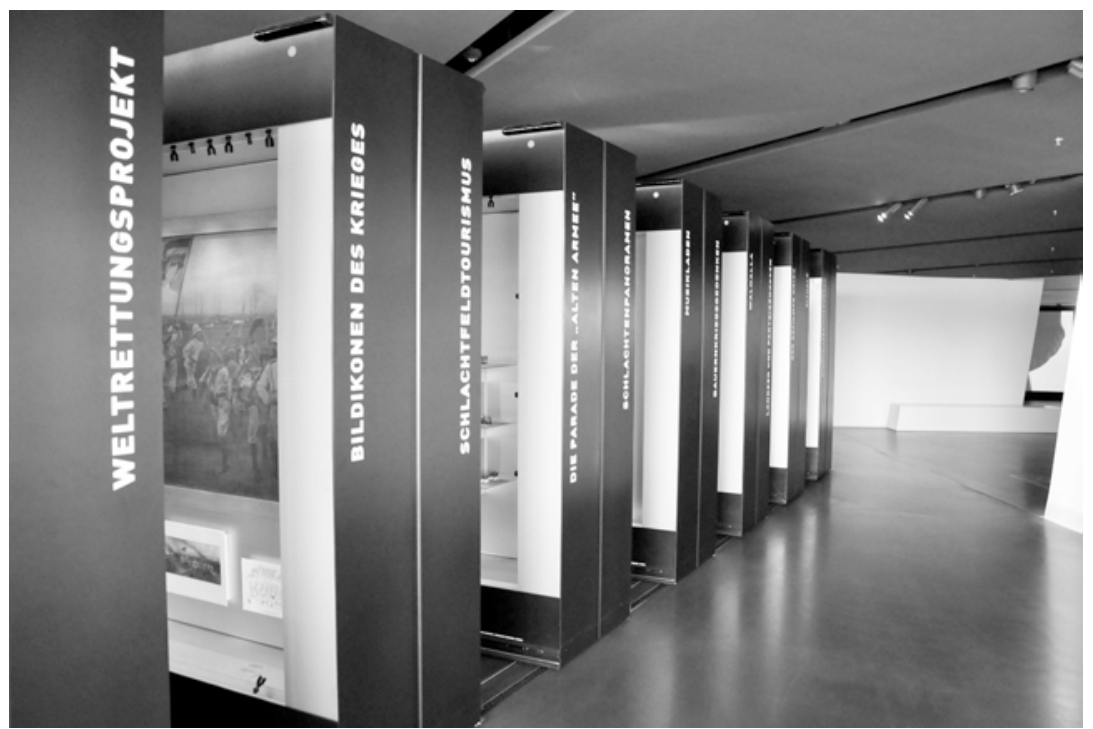

tung in einem der Ausstellungskataloge). Diskurstheorie (im Verständnis Reiner Kellers) erscheint Knoblauch somit eher als Gesellschaftstheorie, da diskursive Äußerungen »reichsunmittelbar direkt mit ihrer Struktur in Verbindung« gebracht werden (Knoblauch 2016:19) und von bereits bestehenden Diskursen ausgegangen wird (a.a.O. 24). In der Tat ergibt sich aus dem analytischen Zugriff auf diskursiver Ebene auch in der vorliegenden Untersuchung eine Betonung gesellschaftstheoretischer Zusammenhänge. Die Analyse bewegt sich also im Diskurs und nicht darunter. Zwar erlaubt die Rekonstruktion der diskursiven Deutungsakte eine prinzipielle Analyse von Grundprozessen der sozialen Wirklichkeit nur eingeschränkt; fundamentale Gegenstandsbestimmungen sind aber dennoch nicht gänzlich ausgeschlossen. Denn empirisch zeigt sich, dass Bestimmungen des Diskursgegenstandes durchaus auch auf der Ebene des Diskurses vollzogen werden können.

Da die diskursive Konstruktion einen erheblichen Teil der sozialen Konstruktion der Wirklichkeit darstellt (Keller et al. 2001, Keller 2012), ist es umso erstaunlicher, dass die Wissenssoziologie Wirklichkeitskonstruktionen auf der Ebene von Diskursen erst spät zum Gegenstand gemacht hat. Das Forschungsprogramm der wissenssoziologischen Diskursanalyse, wie es von Reiner Keller etabliert wurde, entspricht somit dem »Einbau einer Diskursperspektive« in die Wissenssoziologie (Keller 2011:185). 


\subsection{Wissenssoziologie und Diskurs: Der Einbau der Diskursperspektive}

Wenn die Zeit als eine Ordnung des Nacheinanders und der Raum als eine Ordnung des Nebeneinanders verstanden wird (Foucault 1992), dann besteht eine hohe Kompatibilität zwischen Raumsoziologie und Wissenssoziologie, da Letztere sich bereits in ihrer konstitutiven Phase der Analyse nebeneinander existierender Wissenskulturen und Denkstile (Keller 2011:54) sowie der jeweiligen Seinsverbundenheit von Wirklichkeitskonstruktionen (Mannheim) angenommen hat. Anders als in den historisch diachron angelegten Studien Foucaults zur Entstehung wissenschaftlicher Wahrheitsspiele und dem Fokus auf die Genealogie von Macht-/Wissen-Regimes (Keller 2011:120, 136) bietet die Perspektive einer wissenssoziologischen Diskursanalyse einen günstigen Ausgangspunkt für synchron ansetzende Vergleichsstudien (Keller 2012:32, 50). Zwar scheint dies auch prinzipiell in der Diskursperspektive Foucaults möglich. So spricht dieser etwa in der nur spärlich kommentierten Darstellung konkurrierender Diskurse der Pathologisierung im Fall Pierre Rivière (Foucault 1975) von einem Gefecht, in dem "gleichzeitig mehrere sich überlagernde Schlachten geschlagen" werden, und thematisiert so das (synchrone) Zusammenspiel »sich kreuzender Diskurse« (Foucault 1975:9f.). Dennoch wurde eine synchrone Diskursperspektive von Foucault kaum je systematisch ausgeführt.

Ungeachtet dessen gibt es unübersehbare Parallelen zwischen Foucaults Verständnis von Diskursen und der modernen Wissenssoziologie. So könne der foucaultsche Diskursbegriff durchaus als Prozess der Konstruktion von »Wirklichkeitsdeutungen« verstanden werden (Knoblauch 2001:211). Außerdem scheinen dessen Machtkritik sowie die Konzentration auf die leibliche Dimension gesellschaftlicher Wissensregimes in hohem Maße anschlussfähig (a.a.O. 212). Umso erstaunlicher erscheint vor diesem Hintergrund, dass die Wissenssoziologie den Begriff des Diskurses und damit die methodische Großflächigkeit lange Zeit nicht für sich genutzt hat. Der "Einbau einer Diskursperspektive« wurde schließlich ab Mitte der 1990er Jahre insbesondere durch die Arbeiten von Reiner Keller forciert. Keller definiert Diskurse als Komplexe von Aussageereignissen, die über einen rekonstruierbaren Strukturzusammenhang miteinander verbunden sind und spezifische Wissensordnungen der Realität herstellen (Keller 2011:235). Spezifische Äußerungen lassen sich dabei zu allgemeineren, weil typischen Aussagen zusammenfassen (a.a.O. 235f.). Keller entwickelt seinen Diskursbegriff im Spannungsfeld zwischen Habermas, Foucault sowie dem Pragmatismus. Denn Diskurse werden als Erzeugungsprinzip gemeinsamer Sinnhorizonte verstanden (Mead), die in öffentlichen Diskussionen (Habermas) ausgehandelt werden und mit Aspekten der machtvollen Gegenstandskonstitution (Foucault) verknüpft sind. 
Der sozialkonstruktivistische Charakter und die Anschlussfähigkeit des foucaultschen Diskursbegriff werden sofort ersichtlich, wenn Diskurse mit Foucault als Praktiken verstanden werden, »die systematisch die Gegenstände bilden, von denen sie sprechen « (Foucault 1990:74, Orig. 1969). Auch der zentrale Stellenwert, der bei der Gegenstandsbildung der Sprache zuerkannt wird, lässt Parallelen zur Wissenssoziologie und ihrem empirischen Fokus auf immaterielle Objektivationen erkennen. Auch für Foucault sind Diskurse somit produktiv. Er unterstreicht dies, indem er insistiert, dass Diskurse nicht bloß eine »reine und einfache Verschränkung der Dinge und der Wörter « und »keine dünne Kontakt- oder Reibefläche einer Wirklichkeit und einer Sprache« sind (Foucault 1990:73f.). Auf den Gegenstand dieser Untersuchung bezogen heißt dies, dass etwa die intensive Diskursivierung des Neuen Museums als Weltkulturerbe dessen Status erst hervorbringt. Wie im Kapitel zuvor gesehen, entsteht die Wirklichkeit des baulichen Erbes erst, nachdem die Erben einen umfangreichen Diskurs darüber erzeugt haben. Wie bereits gezeigt werden konnte, ruft das Erbe nicht die Erben auf den Plan, sondern das anhaltende Gespräch der Erben erzeugt das Erbe (Kap. 2.). Es ist also der Diskurs der Erben, der das Erbe erzeugt. In der Produktivität der Diskurse besteht ein breiter Konsens der ansonsten sehr disparaten diskursanalytischen Ansätze. Auch Reiner Keller hält daran fest und spricht dabei von diskursiver »Phänomenkonstitution« (2011:233).

Obwohl sich Kellers Diskursbegriff von der normativen Vorstellung einer Diskursethik löst, also einer an Verfahrensregeln orientierten Diskussionsveranstaltung (Keller 2011:111), ist doch der weitgefasste Aspekt der Öffentlichkeit dem Diskursverständnis Habermas' entlehnt. So bleibt das, was mit Diskurs gemeint ist, keineswegs auf eine Teilöffentlichkeit oder ein wissenschaftliches Expertengespräch beschränkt. Denn die wissenssoziologische Perspektivierung der Diskursforschung ermöglicht gerade die Fokussierung auf Deutungsakte mittels »Alltag- und Jedermannswissen« (Keller 2011:267; 2005:51). Im Kontext dieser Arbeit muss die Unterscheidung zwischen Spezialdiskurs und öffentlichem Diskurs jedoch methodisch reflektiert werden. Denn es zeigt sich empirisch, dass die wechselseitige Bezichtigung, außerhalb des Expertendiskus zu stehen und die diskursiven Gegner als Unwissende zu bezeichnen (Kap. 5), bereits eine Strategie der Diskreditierung darstellt. Die Bestimmung eines Diskurses des Neuen Museums oder des Militärhistorischen Museums sowie die Auswahl ihrer Dokumente sind also selbst ein Akt der Rekonstruktion des Feldes im Forschungsprozess. Was jeweils als öffentlicher Diskurs bezeichnet wird, umfasst dann sowohl Laienals auch Expertenäußerungen. Das Label `Öffentlicher Diskurs` dient somit lediglich der Bestimmung des Forschungsfeldes und beinhaltet keine wertende Hierarchisierung der Äußerungen der Diskursteilnehmer und ihrer typischen und typisierbaren Aussagen. Im Hinblick auf die Relativierung des diskursethischen Verständnisses Habermas' ist auch gesagt, dass die Entstehung stabiler 
Wirklichkeitsdeutungen keineswegs an die logische oder normative Qualität der Argumente gebunden ist. Was von wem als plausibel erachtet wird, bleibt letztlich kontingent.

Gerade dieses vernunftbetonte und auf Verfahrensregeln abzielende Diskursverständnis bildet einen weiteren Abgrenzungspunkt für Kellers Diskursbegriff. Wie Habermas bereits in seiner Habilitationsschrift formuliert, besteht dieses Verständnis im Wesentlichen darin, dass sich durch die öffentliche Konkurrenz privater Argumente ein rationaler Konsens konstituiert, durch den Wahrheit über Autorität obsiegt. Die Entstehung einer räsonierenden und diskutierenden bürgerlichen Öffentlichkeit kondensiert so im Credo »veritas non auctoritas facit legim « (1979:104f., Orig. 1962). Der damit verbundene Vernunftoptimismus sowie das Verhältnis zwischen veritas und auctoritas werden im Diskursverständnis Foucaults eher umgekehrt. Erscheinen Subjekte bei Habermas als erstaunlich frei, so kann für Foucaults Diskursbegriff das Gegenteil festgestellt werden. Zwar bereichere der Diskursbegriff die Wissenssoziologie um die Dimension der Macht, der methodischen Großflächigkeit und der historischen Sinngenese (Knoblauch 2001:213), jedoch müsse gerade die Allgemeinheit des Machtbegriffs, der keine analytische Klärung mehr erlaube (a.a.O. 212), kritisch hervorgehoben werden. Jo Reichertz formuliert dies, in Bezug auf die von Foucault zusammengestellten Diskurse der Pathologisierung im Falle des mehrfachen Mörders Pierre Rivière, in einer süffisanten Frage: »Weshalb aber gerade der Landarbeiter Pierre Rivière vom Diskurs zum Mord sgetragen wurde und Millionen Andere nicht, bleibt bei Foucault völlig unklar.« (Reichertz 2005:160). Eingebettet in "vorstrukturierte Handlungskontexte« werden dem Individuum alle "Sinnoptionen vorgegeben« (ebd.). Es ist gerade diese Unfreiheit der Subjekte, welche Veränderung bei Foucault nur als disruptive Ereignisse und epistemische Brüche erklärbar macht. Die Möglichkeit einer sukzessiven, kreativen und freien Veränderung der gesellschaftlichen Wirklichkeit bleibt konzeptionell weitgehend ausgeschlossen.

Keller vermittelt auch zwischen diesen beiden Positionen einerseits vernünftigfreier sowie andererseits kontingent-unfreier Subjekte. Neben der Weitung dessen, was als Diskurs verstanden wird (Öffentlichkeit), macht Keller die Akzentuierung von Machtaspekten für sein eigenes Diskursverständnis nutzbar. ${ }^{3}$ Um den Aspekt der machtvollen Durchsetzung von Wirklichkeitsbestimmungen zu unterstreichen, spricht Keller deshalb, in Anbindung an Marx' Produktionsverhältnisse und Becks Definitions(macht)verhältnisse (Beck 1988:24, 209ff.), von Wissensverhältnissen.

Zwar betonen auch Peter L. Berger und Thomas Luckmann, dass die Durchsetzung von Wirklichkeitsbestimmungen in der Ceschichte eher eine Frage der besseren Waffen und nicht der besseren Argumente war (1980:117). Dennoch bleiben Fragen der machtvollen Herstellung von Wissensordnungen weitgehend unbeantwortet. 
»Cesellschaftliche Wissensverhältnisse sind die sozial erzeugten und historisch situierten Konfigurationen von Wirklichkeits-, d.h. Faktizitäts- und Normativitätsbehauptungen, die den lokalen, nationalen, transnationalen, globalen Horizont dessen aufspannen, was als 'gesellschaftliche Wirklichkeit silt.« (Keller 2012:27f.).

Ergänzend dazu werden die Interventionen in den Diskurs als Wissenspolitiken bezeichnet, mit welchen es den verschiedenen sozialen Akteuren gelingt, ihre spezifischen Wissensverhältnisse zu stabilisieren. Explizit verweist Keller darauf, dass dies auch in gesellschaftlichen Handlungsfeldern außerhalb des »üblicherweise verdächtigen Raum[s] des Politischen« möglich ist (Keller 2012:28). Mit den Begriffen $>$ Wissensverhältnisse $<$ und Wissenspolitiken $`$ wird also die Frage der Deutungshoheit thematisiert. Gerade die Konkurrenz und die Durchsetzungsmacht unterschiedlicher Definitionen unterstreichen die synchrone Perspektive der wissenssoziologischen Diskusanalyse (Keller 2001:56). Mit dem konflikthaften Charakter der gesellschaftlichen Konstruktion der Wirklichkeit betont Keller zwar Machtaspekte (2012:28), jedoch gewährt der Machtbegriff genügend Freiheitsgrade zur kreativen und konkurrierenden Deutung sozialer Wirklichkeit(en).

In enger Anbindung an Keller möchte ich Diskurse auch als öffentliche Debatten verstehen, die in ihren inhaltlichen Äußerungen auf die Wiederherstellung des Neuen Museums und die Umgestaltung des Militärhistorischen Museums bezogen sind. ${ }^{4}$ In den Äußerungen in Gutachten, Museumskatalogen, Zeitungsartikeln, aber auch Pressemitteilungen, Stellungnahmen und Positionspapieren von Initiativen und Einzelpersonen sowie Kommentaren zu Publikationen können also typische und typisierbare Aussagen gefunden werden. Diskurse - im Verständnis dieser Arbeit - haben damit dezidiert öffentlichen Charakter und sind nicht an das Merkmal wissenschaftlicher oder logischer Stringenz gebunden. Sie umfassen sowohl akademisches Expertenwissen als auch laienhaftes Jedermannswissen. Dabei werden konkurrierende Wissensverhältnisse erkennbar. Diese sind machtvolle Weltdeutungen, indem sie anschlussfähige Wirklichkeitsdeutungen herstellen, die einem allgemeineren $\mathrm{Pu}$ blikum plausibel erscheinen (also geteilt werden). Als machtvoll sind diese Wissensverhältnisse vor allem dann zu bezeichnen, wenn sie Einfluss aufden Verlauf des Gesamtgesprächs nehmen. Die Schaffung von anschlussfähigen Deutungsangeboten bedient

4 Da auch innerhalb der Debatten um die Umgestaltung des Neuen Museums und des Militärhistorischen Museums typische und typisierbare »Aussageereignisse[n] [...] über einen rekonstruierbaren Strukturzusammenhang miteinander verbunden sind« (Keller 2011:235), kann ebenso von einem Diskurs des Neuen Museums und einem Diskurs des Militärhistorischen Museums gesprochen werden. Dies schließt allerdings nicht aus, dass sich in den so definierten Diskursen auch andere und allgemeinere Diskurse kreuzen und überlagern (etwa der Diskurs der Rekonstruktion, des Heroischen oder des Pazifismus). 
sich verschiedener Wissenspolitiken. Auch diese Interventionen in den Diskurs haben öffentlichen Charakter. Der Begriff der Wissenspolitik ist also keineswegs auf die Interventionen politischer Institutionen beschränkt (etwa des Landesdenkmalamts oder der Bundeswehr). Auch das Sammeln von Unterschriften, Protestaktionen oder schlicht Wortmeldungen in öffentlichen Streitgesprächen können unter dem Begriff der Wissenspolitik subsumiert werden.

Ein nicht unerheblicher Teil der Diskursdokumente verfügt zudem über Visualisierungen. Zwar wird die dramatische und ästhetisierende Inszenierung der Architektur in hohem Maße durch Visualisierungen vermittelt; dennoch sind es nicht die Visualisierungen, die zum Gegenstand der Diskurse werden. Die Diskurse bilden sich nicht um die Visualisierungen herum, sondern diese dienen lediglich dazu, die Wirklichkeitsdeutungen der jeweiligen diskursiven Formationen zu untermauern. Sowohl für den Diskurs des Militärhistorischen Museums als auch für den Diskurs des Neuen Museums gilt, dass zu keinem Zeitpunkt das Gesehene das Gesagte dominiert. Da kein objektiver Aussagegehalt von Bildern angenommen werden kann, stehen Visualisierungen immer in engem Verhältnis zu ihren unmittelbaren sprachlichen Kontexten, in denen sie platziert werden (Keller 2016:85). Auch die durchaus typischen und typisierbaren visuellen Aussagen in den zu analysierenden Diskursen bleiben damit stets in einen diskursiven Strukturierungszusammenhang eingebettet.

Entsprechend vielgestaltig stellen sich die jeweils zusammengestellten Datenkorpora dar. Die Erstellung der Datenkorpora des Neuen Museums und des Militärhistorischen Museums ging von den zahlreichen Publikationen der Museen aus (Nys/Reichert 2009; Hamm 2009; Wedel 2009; Pieken/Rogg 2011a; 2011b), in denen die Gebäude, deren Umgestaltung sowie die Ausstellungskonzeption erklärt und auf spezifische Weise gedeutet werden. In diesen Veröffentlichungen, die sich einer großen Leserschaft erfreuen und weiterhin in den Museumsshops feilgeboten werden, deuten die involvierten Akteure die architektonischen und konzeptionellen Umgestaltungen. Zudem begann bereits ab dem Jahr 2000 mit der Herausgabe von Heften eine rege Publikationstätigkeit des Militärhistorischen Museums der Bundeswehr. Allein die Existenz dieser umfangreichen Publikationen verdeutlicht, dass die Diskursivierung von den Institutionen selbst betrieben wurde.

Den immanenten Verweisen dieser Dokumente folgend, führte dies unmittelbar zu zahlreichen Positionspapieren und Expertengutachten, auf die sich die jeweils umgesetzten Veränderungen bezogen und die teilweise den strukturellen Rahmen definierten, innerhalb dessen sich die Umgestaltungen bewegen konnten (etwa das denkmalpflegerische Gutachten (Badstübner et al. 1994) oder die Konzeption für das Museumswesen in der Bundeswehr (BMVg 1994). In diesen Texten finden sich zumeist Bezugnahmen auf allgemeinere Diskurse und institutionelle Akteure (etwa Welterberichtlinien der UNESCO oder Traditionserlässe der Bundeswehr). Insbesondere die Dokumente institutioneller Akteure (etwa Landesdenk- 
malamt, Stiftung Preußischer Kulturbesitz, Bundeswehr und Militärgeschichtliches Forschungsamt) erweiterten so die Textkorpora. Im Falle des Militärhistorischen Museums waren die zentrale Dienstvorschrift der Inneren Führung (BMGg 2008) sowie die Traditionserlässe (BMVg 1965; 1982; 2018) von großer Bedeutung, da in diesen Dokumenten das Selbstverständnis der Bundeswehr kodifiziert wird.

Zusätzlich gewährten sechs Experteninterviews einen weiteren Überblick über die Diskurse sowie ein vertiefendes Wissen über weitere involvierte Akteure und den Verlauf der öffentlichen Auseinandersetzungen. ${ }^{5}$ In beiden Fällen spielte neben der Geschichte der jeweiligen Institutionen vor allem die Baugeschichte der Museumsgebäude eine wichtige Rolle, weshalb auch (kunst-)historische Publikationen (etwa von Buttlar 2010; van Wezel 2003; Lühr 2012; Lisewski 1997) in die Korpora aufgenommen wurden. Die meist an ein Fachpublikum adressierten Texte stellen ebenfalls wichtige Stimmen der Diskurse dar, da hier ebenfalls spezifische Deutungen vollzogen werden, die auch medial anschlussfähig erschienen und reproduziert wurden. Die große öffentliche Aufmerksamkeit, die den Museen vor und während ihres Umbaus zuteilwurde, fand außerdem Niederschlag in zahlreichen Zeitungs- und Fachzeitschriftenartikeln - wodurch zusätzlich für das Neue Museum ein Korpus von ca. 80, für das Militärhistorische Museum ein Korpus von ca. 50 Artikeln erstellt wurde. In beiden Fällen artikulierten sich bereits früh und langanhaltend kritische Gegenstimmen. Im Falle des Neuen Museums handelte es sich dabei um die Bürgerinitiative Gesellschaft Historisches Berlin e.V. (GHB), welche durch die Publikation eines eigenen Restaurierungskonzeptes und umfangreiche Darstellungen der (Gegen-)Positionen auf ihrer Homepage in den Diskurs intervenierte. Zudem verschaffte sich diese Bürgerinitiative über öffentlichkeitswirksame Protestaktionen Gehör, die abermals Niederschlag in der regionalen und überregionalen Presse fanden. Auch im Falle des Militärhistorischen Museums sind Stimmen gegen die Neugestaltung anhand von Zeitungsartikeln analysierbar, auch wenn sich hier keine mit der GHB vergleichbare Bürgerinitiative bildete.

Zudem wurden bei zahllosen Besuchen der Museen Ausstellungstexte auf Schautafeln vor Ort dokumentiert, in denen ebenfalls spezifische räumliche Deutungen und Vergangenheitsbezüge hergestellt werden. Die so zusammengestellten Korpora bestehen also aus Museumskatalogen und Sammelbänden, Konzeptionen zu Ausstellung und Architektur, Positionspapieren, Entwürfen der

Bis auf zwei Ausnahmen wurden alle Interviews vollständig transkribiert. Dies erschien möglich, da in Bezug auf die Experteninterviews generell zu einer Frühphase der Untersuchung ein allgemeiner Überblick über die weitausgreifenden Diskurse im Vordergrund stand und nicht eine feinanalytische Rekonstruktion spezifischer Sinnkonstruktionen. Aus diesem Grund erschien es auch legitim, lautmalerische Formulierungen und Wiederholungen, die transkribiert wurden, zugunsten einer besseren Lesbarkeit sprachlich zu glätten. 
architektonischen Wettbewerbe, denkmalpflegerischen Gutachten, museologischen Leitlinien, bau- und kunsthistorischen Publikationen, Experteninterviews, Fachzeitschriften- und Zeitungsartikeln, Flugblättern und Stellungnahmen von Bürgerinitiativen, Traditionserlässen und zentralen Dienstvorschriften sowie Festreden und Ausstellungstexten in den Museen. Das auf diese Weise zusammengestellte Datenkorpus für das Neue Museum umfasst ca. 2.000 Seiten. Für das Militärhistorische Museum konnte ein Korpus von ca. 1.000 Seiten gebildet werden. $\mathrm{Zu}$ Beginn der empirischen Kapitel werden anhand dieser Dokumente die strukturellen Bedingungen der Konstellation der involvierten Akteure sowie die Darstellung der Bau- und Diskursgeschichte nachgezeichnet. Diese wiederum fokussiert, im Sinne der empirischen Rahmung des Gegenstandes, die durch die Diskursteilnehmer selbst relevant gemachten Aspekte.

Neben den verschiedenen Vor- und Nachteilen der von Keller produktiv gemachten Diskursbegriffe wurde gegen die Vorgehensweise in der Analyse von Diskursen Foucaults oft das Fehlen empirischer Methoden vorgebracht (Knoblauch 2001:211; Keller 2007). ${ }^{6}$ Dieses Manko kann durch die Anbindung an die Tradition der wissenssoziologischen Hermeneutik ausgeglichen werden (Keller 2011:233).

\subsection{Wissenssoziologie und Hermeneutik: Spielräume der Kreativität}

Reiner Keller stellt das Forschungsprogramm der wissenssoziologischen Diskursanalyse in die Tradition des interpretativen Paradigmas der Sozialwissenschaften und schließt explizit an die wissenssoziologische Hermeneutik an (Soeffner 2004, Orig. 1989, Schröer 1997). Dieser Anschluss ermöglicht einerseits den Rückgriff auf ein methodengestütztes Analyserepertoire, worin eine weitere Ergänzung der Diskursanalyse foucaultscher Provenienz besteht. Andererseits besteht die Möglichkeit, die diskursiv vollzogenen Deutungen nicht auf strukturelle Bedingungen zu verkürzen, sondern selbst als kreativ zu verstehen. Neben der Analyse von Prozessen der sozialen Konstruktion von Deutungs- und Handlungsweisen geht es der wissenssoziologischen Diskursanalyse auch um die Untersuchung der Wirkung dieser Prozesse (Keller 2001:71). Bezeichnet Hermeneutik allgemein das »Auslegen und Verstehen des Singulären in seinen typischen und typisierbaren Beziehungen $\mathrm{zu}$ allgemeinen Strukturen « (Soeffner 2004:13), so geht wissenssoziologische Hermeneutik von einer Doppelposition der Subjekte aus (Keller 2012:33f.; Schröer 1997:109). Diese werden zwar in eine vorgedeutete Welt sozialisiert, können sich diese aber deutend anverwandeln. Sie sind so Adressat und kreativer Produzent 
von Weltdeutungen. Durch »subjektive Verarbeitung des gesellschaftlichen Typenrepertoires« wird somit auch die »soziale Ordnung lebendig« gehalten. (Hitzler et al. 1999:12, Herv. JK). Im Unterschied zu Foucault, der von einer "prinzipiellen Konstituiertheit der Subjekte« ausgeht (Keller 2012:35), gewährt die wissenssoziologische Hermeneutik den Subjekten also »Spielräume der Kreativität« (a.a.O. 34). Dies gilt unabhängig davon, ob Handlungen empirisch $\mathrm{zu}$ einem »regelkonformen Vollzug« führen, da sie sich keinesfalls darin erschöpfen (a.a.O. 35). Damit verbunden ist letztlich die Warnung vor einem »überzogenen Regel- und Strukturdeterminismus« (Keller 2011:69), der bereits in der Überbetonung von Machtaspekten deutlich wurde.

Auch dieser Zusammenhang kann anhand eines Beispiels aus dem Kontext des Diskurses des Neuen Museums veranschaulicht werden. Im Laufe der langanhaltenden Debatte um die Wiederherstellung des Neuen Museums fokussierte die Diskussion stark auf die Architektur des Gebäudes. Vom Direktor des Ägyptischen Museums im Neuen Museum, Dietrich Wildung, ist die Mahnung kolportiert, dass über die intensive Auseinandersetzung mit dem Museumsbau die herausragenden Exponate der Ausstellung nicht ins Hintertreffen geraten sollten. Das Haus sei schließlich zuvorderst aufgrund seiner ägyptischen Sammlung bedeutsam. Dieser Wunsch, der dem Direktor eines Ägyptischen Museums gemäß erscheint, ist jedoch nicht in Erfüllung gegangen. Ungeachtet der fachwissenschaftlich unzweifelhaften Qualität der Sammlungsbestände rekurrierte der Diskurs des Neuen Museums ungleich stärker auf Fragen des Umgangs mit dem kriegszerstörten und jahrzehntelang der Witterung ausgesetzten Museumsgebäude. Dieses wurde seinerseits wiederum abwechselnd als `herausragendes Erbe< des 19. Jahrhunderts oder als >stimmungsvolle Ruine < des 20. Jahrhunderts thematisiert. Aufgrund der Kontingenz in der Auslegung von Architektur und ihrer Geschichte werden die Museen somit zu >boundary objects`(Star/Griesemer 1989) - Gegenstände also, die, obwohl sie als kohärente Entitäten beschrieben werden können, gerade durch vielfältige lebensweltliche Perspektiven (1989:396ff.) zu kategorial je verschiedenen Objekten gemacht werden. Was die Museen sind und als was sie gedeutet werden, wird auch im Falle dieser Untersuchung höchst unterschiedlich beantwortet. ${ }^{7} \mathrm{Zu}$ was die $\mathrm{Mu}$ seen in ihrer Deutung gemacht werden, erschöpft sich also nicht in strukturellen Dimensionen - oder wie im Falle des Neuen Museums in seiner institutionellen Kategorisierung als Ägyptisches Museum. Der Status der Museen bleibt, wie jede soziale Ordnung, lebendig.

7 Da Star und Griesemer den Begriff des Boundary Objects im Kontext einer Untersuchung der fachkulturell verschiedenen Lesarten einer naturkundlichen Museumssammlung entwickeln, erscheint er auch für die genannten Beispiele passend (Star/Griesemer 1989). 
Für diesen Zusammenhang hat Reiner Keller den Begriff der Phänomenstruk$\operatorname{tur}^{8}$ als eine von vier Dimensionen vorgeschlagen, mittels derer Diskurse entlang ihrer inhaltlichen Strukturierung analysiert werden können (Keller 2011:240ff.). In der Konstitution des referenziellen Bezuges von Diskursen wird überhaupt erst deren spezifische Gestalt erkennbar (a.a.O. 248). „Das Konzept der Phänomenstruktur bezeichnet keineswegs Wesensmerkmale eines Diskurs-Gegenstandes, sondern die entsprechenden diskursiven Zuschreibungen« (Keller 2011:248). Eng damit verbunden ist der Anspruch, die Gegenstände der Diskurse empirisch zu bestimmen. Denn die tatsächlichen Bausteine (oder Aspekte) der Phänomenstruktur eines Diskurses (also letztlich sein Thema) können vor der Materialanalyse nicht zuverlässig benannt werden (Keller 2011:249). Trotz eines (auch) strukturtheoretischen Interesses der wissenssoziologischen Hermeneutik bleiben die Subjekte somit nicht »außen vor« (Schröer 1997:127). Im Gegenteil muss jede Analyse »bei der Rekonstruktion des subjektiv gemeinten Sinns ansetzen« (ebd.). Für diese empirische Bestimmung des Gegenstandes stellt die Oberflächenhermeneutik der Wissenssoziologie ein unerlässliches methodisches Werkzeug dar. Aufgrund der zu bestimmenden Aspekte, die von den Diskursen selbst zum Thema gemacht werden, wird somit auch das Ungleichgewicht in der Analyse von Ausstellung und Architektur in den empirischen Fällen erklärlich. Im Unterschied zum Neuen Museum ist für den Diskurs des Militärhistorischen Museums festzustellen, dass ein Hauptkonfliktpunkt in der Ausstellung gesehen wurde. Gleiches gilt für den (partiellen) Einbezug der James Simon Galerie in die Analyse, denn auch diese wurde in den diskursiven Deutungen des Neuen Museums immer wieder zum Thema gemacht und so zum (empirisch begründeten) Teil des Diskurses. ${ }^{9}$ Zudem erscheint es dadurch legitim, Museen zu vergleichen, die im Hinblick auf ihre Geschichte, ihre Gattung und ihre thematische Ausrichtung überaus verschieden sind. Denn die Museen werden nicht als das, was sie in einem (wie auch immer) ontologischen Sinn sind, verglichen, sondern als das, was sie wahrgenommen werden. Die Museen dienen somit in erster Linie als Gesprächsanlass, wobei die verschiedenen Inhalte dieser Gespräche das Phänomen, auf das sie sich beziehen, unterschiedlich und durchaus konflikthaft hervorbringen. Damit bewegt sich die Untersuchung der Diskurse weg von der Deutung der Architektur und ihrer Geschichten hin zur Deutung der Deutungen ebendieser. Wie bereits dargestellt, liegt hierin die Verlagerung von der Repräsentation $\mathrm{zu}$ den unterschiedlichen

8 Er bezieht sich dabei auf den von Karl Mannheim vorgeschlagenen Begriff der Aspektstruktur (2011:248, 2012:47f.).

9 In umgekehrter Weise begründet diese empirische Rahmung des Untersuchungsgegenstandes auch die Entscheidung, die Außenstellen des Militärhistorischen Museums in BerlinGatow sowie die Festung Königstein nicht in die Analyse einzubeziehen. Obwohl diese institutionell dem Leitmuseum unterstehen, wurde zu keinem Zeitpunkt im Diskurs darauf Bezug genommen. 
Rezeptionen (Kap.2). Mit dem impliziten Rückgriff auf die wissenssoziologische Hermeneutik kann diese Akzentverschiebung nun auch methodisch erfasst werden.

Damit hängt die Entscheidung zusammen, auf den Begriff >Dispositiv $<$ zu verzichten. Dieser Verzicht mag im Kontext einer Untersuchung über die Deutung der gebauten Welt zunächst überraschen, da Foucault darunter das Gesagte (etwa Diskurse) ebenso wie das Ungesagte (etwa Architektur) versteht (Foucault 2003:392). Diese Entscheidung ist allerdings forschungsprogrammatisch begründbar, da die Unterscheidung zwischen Dispositiv und Diskurs letztlich eine Eigensinnigkeit oder eine Effektivität des Materiellen in Aussicht stellt, wodurch tendenziell die Annahme unterlaufen wird, dass auch die materielle Wirklichkeit erst durch kreative Deutungen ihren Sinn erhält. So plausibel es erscheint, das Panoptikum als materielle Ausprägung eines Sicherheits- und Selbstdisziplinierungsdispositivs zu verstehen (Foucault 2009, Orig. 1975), so missverständlich könnte es sein, das Neue Museum etwa als Teil des Dispositivs der Ägyptologie oder der Museologie festzuschreiben. Zwar mag es dies zweifelsfrei sein, jedoch ist es - wie sich empirisch zeigt - keineswegs ausschließlicher Teil dessen. Ebenso ist das Militärhistorische Museum Teil eines militärischen Lehr- und Ausbildungsdispositiv der Bundeswehr, wodurch aber keineswegs ausgeschlossen ist, dass es gänzlich anders gedeutet werden kann. Indem der Begriff >Dispositiv < auf Macht/Wissensregime abhebt, denen Subjekte ausgeliefert sind (so der tendenziöse Sprachduktus), würde die mögliche kreative Anverwandlung der Architektur durch den Dispositivbegriff erschwert.

Wissenssoziologische Hermeneutik ist, indem sie die Deutungsakte und Auslegungen des Alltags selbst auslegt und deutet, eine Rekonstruktion von Sinnkonstruktionen und somit eine Konstruktion zweiter Ordnung (Soeffner 1999:41). Als historisch-selbstreflexiver Erkenntnisstil (ebd.) ist diese Konstruktion selbst kreativ. Jedoch baut sie in die Auslegung des Alltags eine Reflexionsschleife oder eine »methodisch eingesetzte Skepsis« ein (Hitzler et al. 1999:11). Die Auswahl der Dokumente und die daraus abgeleiteten Deutungen bleiben allerdings zugänglich und müssen transparent gemacht werden. Sie bleiben im Sinne des kritischen Rationalismus falsifizierbar (Popper 1965). Da es diesem Erkenntnisstil jedoch gelingt, Gründe für seine Annahme zu nennen (Soeffner 1999:48), kann für die Konstruktion zweiter Ordnung - als methodisch kontrolliertes wissenschaftliches Verstehen (Schröer 1997:109) - vorübergehend und unter Vorbehalt der Falsifikation dennoch ein belastbarer Konkretionszustand erreicht werden.

Wissenssoziologische Hermeneutik erhebt im Unterschied zur objektiven Hermeneutik (Oevermann 2001) also explizit den Anspruch, die »subjektiven Intentionen« rekonstruktiv und deutend verstehen zu können (Reichertz 1997:31). Da wissenssoziologische Hermeneutik die Dimensionen von Handel und Struktur transparent macht, ist sie also stets eine doppelte Hermeneutik (Giddens 1988:338). Da objektive Hermeneutik ohne die Rekonstruktion subjektiver Deutungsakte, wis- 
senssoziologische Hermeneutik aber nicht ohne das Wissen um strukturelle Aspekte auskommt, werden diese zu Beginn der empirischen Kapitel anhand der Bauund Diskursgeschichte dargestellt.

\subsection{Analysedimensionen}

Ein weiterer Grund für die Wahl der wissenssoziologischen Diskursanalyse als Methode der Untersuchung besteht darin, dass damit bereits inhaltliche Strukturierungsdimensionen ausgearbeitet sind, die auch für die vorliegende Untersuchung nutzbar gemacht werden können. So schlägt Keller vor, Diskurse entlang der Dimensionen Deutungsmuster, Klassifikation, Phänomenstruktur und narrative Struktur zu untersuchen (Keller 2011:240ff.; 2012:32, 46ff.). Die Analyse der Phänomenstruktur erweist sich, wie bereits gesehen, für die empirische Bestimmung des Gegenstandes als besonders hilfreich, da damit die tatsächlichen Thematisierungen des Diskurses entlang des Datenmaterials generiert werden können. Denn ob es sich beim Neuen Museum um ein ägyptisches Museum oder beim Militärhistorischen Museum um ein Kriegsmuseum handelt, ist aus Perspektive wissenssoziologischer Hermeneutik alles andere als gewiss.

Von den vorgeschlagenen Untersuchungsdimensionen erwies sich für die Rekonstruktion der diskursiven Wirklichkeitsdeutungen der Begriff des Deutungsmusters als besonders hilfreich. Deutungsmuster organisieren Erfahrungen und Wahrnehmungen und implizieren meist Vorstellungen angemessenen Handelns (Keller 2011:240). Der Begriff des Musters verweist auf den Aspekt des Typischen und die Notwendigkeit, einen konkreten Ereignis-Anlass (Einzelfall) in eine kohärente Erzählung zu übertragen (ebd.). Deutungsmuster lassen sich somit als Vermittlungsinstanz zwischen dem Allgemeinen und dem Speziellen bezeichnen. In diesem Punkt ist der Deutungsmusterbegriff Kellers dem der objektiven Hermeneutik Oevermanns noch ähnlich, da auch für diesen "Deutungsmuster als Paradigmen der Alltagserfahrung die Funktion [haben], Einzelerfahrungen in ihrer allgemeinen Bedeutung aufzubewahren.«(Oevermann 2001:14). Auch in der folgenden Analyse der Diskurse sollen Deutungsmuster als typische Semantiken verstanden werden, mit denen Einzelphänomene (wie etwa ein architektonischer Eingriff) vor einen allgemeineren Deutungshorizont gestellt werden. So wird die Umgestaltung des Neuen Museums durch David Chipperfield von dessen Gegnern stets als Verletzung bezeichnet und mit einer Missachtung des Alten gleichgesetzt. Begriffe aus dem semantischen Feld der Gewalt spielen dabei eine entscheidende Rolle und werden mit weiteren allgemeineren Deutungen gekoppelt. So verfestigt sich innerhalb des Gewalt-Deutungsmusters auch die Gewissheit, dass es sich bei den modernen Architekten um arrogante Selbstdarsteller handelt. Der Einzelfall (Neues Museum) wird somit in eine kohärente Erzählung eingebunden, die die Welt (die moder- 
nen Architekten) in einem allgemeineren Zusammenhang deutet. Deutungsmuster sind also vorgefertigte Interpretationsschablonen, die die soziale Welt übersichtlicher und gewisser machen. In diesem Sinne weist der Deutungsmusterbegriff Kellers Parallelen zum Begriff des Topos, wie ihn Hubert Knoblauch verwendet, auf (Knoblauch 2000). Dieser versteht unter Topoi thematische Kristallisationen (2000:659), die, indem sie schlicht für wahr gehalten werden, mit sozialen Wissensbeständen vergleichbar sind (a.a.O. 652). Als inhaltliche Fixpunkte stellen sie kommunikative Institutionen dar, durch die Kommunikation eine soziale Ordnung erhält, indem routinemäßig auf sie zurückgegriffen wird (a.a.O. 663). Für die vorliegende Untersuchung soll jedoch eher eine klassische Definition von Topoi verwendet werden. Demnach sind Topoi in erster Linie »konstante Motive« (a.a.O. 655). Im Verständnis dieser Arbeit sind Topoi also eher >Worthülsen $<$, die historisch vorgeprägt sind und von Diskursteilnehmern unterschiedlich >gefüllt $<$ werden. Denn wie sich empirisch zeigt, können dieselben Topoi höchst verschieden zueinander in Bezug gesetzt werden, wodurch sich ihr semantischer Gehalt ändert (und teilweise damit geradezu Gegensätzliches gemeint sein kann). Topoi im Sinne dieser Arbeit - sind sprachliche Klischees, die Bausteine oder Elemente also, die je spezifisch zu verschiedenen Deutungsmustern verknüpft werden und in Abhängigkeit davon ihren Inhalt ändern.

Der Begriff des Deutungsmusterns bezeichnet bei Keller »bedeutungsgenerierende Schemata (Keller 2011:243). Zwar denkt auch Oevermann Deutungsmuster als Weltinterpretationen, die prinzipiell entwicklungsoffen sind (Oevermann 2001:8), dennoch wird mit der Rede von »strukturbedingten« oder »objektiven Handlungsproblemen« (ebd.) der strukturtheoretische Akzent des oevermannschen Deutungsmusterbegriffs deutlich. So seien »soziale Deutungsmuster funktional immer auf eine Systematik von objektiven Handlungsproblemen bezogen« (a.a.O. 5). Deutungsmuster im Sinne Kellers hingegen sind »Interpretationsschemata für weltliche Phänomene, Situationen, Ereignisse und Handlungen« (Keller 2012:46), die jedoch nicht mehr nur auf objektive Handlungsprobleme, sondern auf diskursiv konstituierte Handlungsprobleme Antworten liefern (Keller 2011:243). Was jeweils problematisiert wird, ist den Äußerungen der Diskursteilnehmer selbst und damit an der Oberfläche der Äußerungen und nicht in der Tiefe der Struktur zu entnehmen. Im Unterschied zu Oevermann und mit der Verschiebung von objektiver zur wissenssoziologischen Hermeneutik lässt sich damit sagen, dass Deutungsmuster im Verständnis Kellers auf Probleme reagieren, die zuvor erst geschaffen werden müssen.

Des Weiteren verknüpfen Deutungsmuster »Faktisches mit Normativem« (Keller 2012:46). Für diese Verbindung verwendet Keller den Begriff Klassifikation. Diese kann als wertender Prozess des "Klassifizierens im Rückgriff auf angeeignete Elemente kollektiver Wissensvorräte« (a.a.O. 47) verstanden werden. Da sich Klassifikationen insbesondere auch auf die "moralische und ästhetische Bewertung von 



(Keller 2011:246) beziehen, wird der Nutzen einer solchen Analysedimension im Kontext der unterschiedlichen Wahrnehmungen von Architektur sofort ersichtlich. Klassifikationen, verstanden als normative Gewichtungen, sind in den Diskursen allgegenwärtig. Gerade die normative Dimension, die die Diskutanten den jeweiligen Konzepten im Umgang mit der Architektur der Museen zusprechen, macht den zuweilen leidenschaftlichen Sprachduktus erklärbar. Denn in der Wahrnehmung der Beteiligten werden hier nicht bloß Fragen des Geschmacks, sondern Fragen von Gut und Böse und von Richtig oder Falsch erörtert.

Wie bereits gesehen problematisieren die diskursiven Formationen verschiedene Aspekte und geben dem Diskurs damit eine je spezifische Phänomenstruktur. So wird etwa die Neugestaltung des Neuen Museums einerseits als »Skandal obersten Ranges«, als `heimliches Kriegsdenkmak und Ergebnis >komplottartiger Strukturen gedeutet (Kap. 5.2), während andererseits seine Wiederherstellung als >Vollendung eines Juwels< oder als >Vollendung eines preußischen Arkadiens< thematisiert wird (Kap. 5.3). Niedergang oder Auferstehung, Zerstörung oder Vollendung stellen konträre, aber synchrone Überschriften der Diskurse dar und verweisen auf geradezu gegensätzliche Phänomenstrukturen. Aus der unterschiedlichen Thematisierung, der Verknüpfung je spezifischer Deutungsmuster und ihren normativen Gewichtungen im Sinne von Klassifikationen ergeben sich schließlich verschiedene Erzählungen. Keller bezeichnet diese als narrative Strukturen, also den Verlauf der Erzählung. Narrative Strukturen konstituieren »(bestreitbare) Weltzustände als Erzählungen« (Keller 2012:49). Sie umfassen neben den Personen und ihren verschiedenen Positionierungen und der Dramaturgie (den Plot) der Handlung auch die spezifischen Raum- und Zeitstrukturen (Keller 2011:252). Die Wiedergabe der narrativen Struktur am Ende der Darstellung eines jeden Kollektivierungsdiskurses eignet sich zudem, die jeweiligen Problematisierungen und die wertende Verbindung der Deutungsmuster prägnant zusammenzufassen.

Gerade anhand ihrer unterschiedlichen narrativen Strukturen können die Kollektivierungsdiskurse differenziert werden. Dafür müssen jedoch Kriterien angegeben werden, mit denen sich die verschiedenen Formationsregeln dieser »abgrenzbare[n] Diskursgruppierungen« (Keller 2011:236) und die von ihnen geschaffenen Wissensverhältnisse analysiert werden können. Mit dem Hinweis auf die spezifischen Raum- und Zeitstrukturen der narrativen Struktur werden schließlich Differenzkriterien erkennbar, mit welchen die typischen und typisierbaren Formationsregeln der Kollektivierungsdiskurse bestimmt werden können. Die idealtypische Rekonstruktion von Typen entlang dieser Differenzkriterien stellt somit eine Erweiterung der Analysedimensionen Kellers auf der Ebene der narrativen Struktur dar. Da sowohl soziologische als auch kulturwissenschaftliche Untersuchungen der Konstruktion von Raum und Zeit bereits ein umfangreiches Repertoire an Typisierungen hervorgebracht haben, sollen im Rückgriff darauf Analysekategorien für 
die Untersuchung entwickelt werden. Es handelt sich um eine Kategorienbildung mittels empirisch gehaltvollen Theoriewissens (Kelle/Kluge 2010:62,68f.), welches für die Analyse der Diskurse des Neuen Museums und des Militärhistorischen $\mathrm{Mu}$ seums im Folgenden nutzbar gemacht werden kann. 


\section{Ein Bild der Ewigkeit und die Codes der Verräumlichung}

\subsection{Zeitliche Sinnbildung}

Abbildung 5: Giovanni Battista Segantini (1858-1899) »Rückkehr zur Heimat« von 1895.

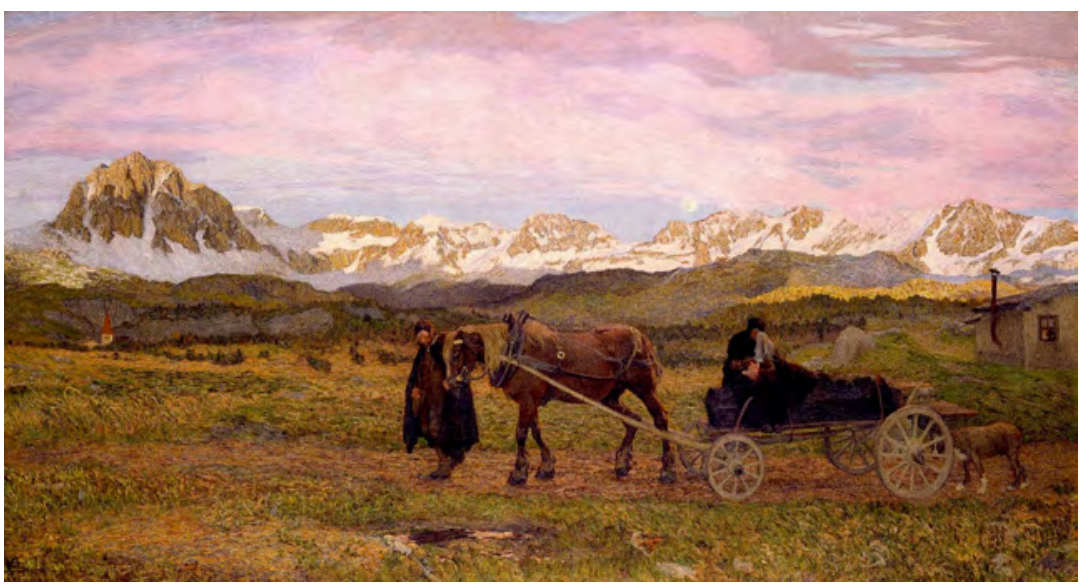

Im ersten Stock der Nationalgalerie auf der Berliner Museumsinsel überstrahlt ein Bild seine Umgebung. Giovanni Segantinis Gemälde zeigt, in zartrosa schimmernder Abendstimmung, ein alpenländisches Panorama, vor welchem ein Trauerzug vorübergeht. In der ephemeren Aura des abendlichen Lichts werden die drei Elemente Luft, Wasser und Erde durch Wolken, Schnee und Berggipfel dargestellt und scheinen durch den Wechsel von Licht und Schatten in ständigem Wandel. Den schimmernden Effekt der Farben erzielte der Maler durch das Beimischen von Gold- und Silberpartikeln, so dass das Gemälde tatsächlich in ständig wechselndem Spiel unterschiedlich reflektiert. Licht und Schatten, Tag und Nacht sowie die schneebedeckten Berge verweisen auf die zyklische Abfolge von Niedergang und 
Erneuerung, in der alles flüchtig ist und sich gerade deshalb in ewiger Wiederholung befindet. In deutlichem Kontrast zu den leuchtenden Farben der oberen Bildhälfte stehen die dunklen Farben des Bildvordergrundes. Dieser ist, durch eine in der Ferne erkennbare Kirche und einen Schuppen am rechten Bildrand, als Bereich des Menschen gekennzeichnet. Anders als das Auf und Ab der Silhouette der Berge im Bildhintergrund bewegt sich der Trauerzug im Vordergrund auf der Horizontalen. Zwei Trauernde begleiten mit gesenktem Haupt einen Pferdekarren, auf dem ein Leichnam aufgebahrt ist. Der gebückte Gang der sich zwischen der ärmlichen Behausung des Schuppens und der Kirche bewegenden Menschen scheint durch die Gerade des Weges gleichsam vorgegeben. Die Leichtigkeit der Wolken kontrastiert mit der Schwere des Trauerzuges, dessen Wagenräder sich ihren Weg durch den morastigen Grund bahnen. Da die Bewegung auf der Horizontalen durch den Farbkontrast scharf vom Hintergrund abgegrenzt ist, bleibt der Bereich des Menschen von der Ewigkeit des Hintergrunds getrennt.

Hannah Arendt hat in der Unterscheidung zwischen linearer Lebenszeit des Menschen und der zyklischen Zeit der Natur einen fundamentalen zeitkonstitutionellen Unterschied ausgemacht, den sie anhand eines weit in die Philosophiegeschichte zurückreichenden Beispiels expliziert.

»Diese individuelle Lebensgeschichte [des Menschen] unterscheidet sich von allen anderen natürlichen Prozessen dadurch, dass sie linear verläuft und so den Kreislauf des biologischen Lebens gleichsam durchschneidet. Sterblich sein - das heißt in einem Universum, in dem alles im Kreise schwingt und Anfang und Ende immerfort dasselbe sind, einen Anfang haben und ein Ende und daher in die ganz und gar >unnatürliche< Form einer geradlinigen Bewegung gebannt sein. Nur darum, meinte Alkmaion, sind die Menschen vergänglich, sweil sie den Anfang nicht an das Ende zu knüpfen vermögen.« (Arendt 2002:29, Orig. 1958, Herv. JK).

Arendts Interpretation der klassischen zeitkonstitutionellen Unterscheidung eröffnet damit eine Lesart des beschriebenen Bildes. So wie die Farbkontraste Hinterund Vordergrund trennen, grenzen sie auch den ewigen Kreislauf der Natur vom vergänglichen Lauf des menschlichen Lebens ab. Wie der Trauerzug in Segantinis Bild durchschneidet der Mensch den Kreis der Natur und ist deshalb sterblich. So wie die Bildbereiche des Gemäldes bleiben die Sphären der Natur und der Kultur getrennt, da der Mensch Anfang und Ende nicht zu verknüpfen vermag.

Für Helmuth Plessner bildet dieses Unvermögen des Menschen (also seine Sterblichkeit) den Ausgangspunkt für die soziale Konstruktion von Zeit. Der Tod des Menschen und das Wissen um seine Vergänglichkeit bilden den Horizont, unter welchem alle Lebensgeschichte konstruiert werden muss. Endlichkeit ist damit gleichbedeutend mit Zeitlichkeit (Plessner 1985:246, Orig. 1952). Ähnlich wie Koselleck (Kap. 1) betont auch Plessner, dass sich unter dem neuzeitlichen Eindruck der Entmythisierung und Rationalisierung das Moment der Wiederholung schließ- 
lich zur Geraden zu strecken beginnt (a.a.O. 228, 232). Obwohl der Unterschied zwischen linear verlaufender Geschichte und dem ewig im Kreis schwingenden Universum in der Vergänglichkeit besteht, führt dies jedoch nicht dazu, dass Vorstellungen von Beständigkeit und einem Gleichbleiben über die Zeit unmöglich werden. Plessner wendet die Unterscheidung des klassischen griechischen Denkens auf originelle Weise: Eben weil der Mensch vergänglich ist, ist er darauf angewiesen, sich eine Vorstellung von Ewigkeit zu machen (a.a.O. 248, 256). Oder mit anderen Worten: Ein Bild von Ewigkeit brauchen nur die, die vergänglich sind.

Die Frage, wie Vorstellungen von Beständigkeit über zeitliche Brüche hinweg stabilisiert werden, folgt dabei unterschiedlichen Konstruktionsmustern. Für die unterschiedlichen Techniken der Konstruktion sozialer Zeit, die oft mit der Unterscheidung zwischen Kreis und Gerade sprachlich ins Bild gesetzt wurden, hat Claude Lévi-Strauss die Unterscheidung von kalten und warmen Gesellschaften vorgeschlagen (1981:251ff., Orig. 1962). Er merkt dazu an, dass

»die unglückliche Unterscheidung zwischen den sgeschichtslosen Völkern und den anderen vorteilhaft ersetzt werden könnte durch eine Unterscheidung zwischen dem, was wir die >kalten< Gesellschaften und die swarmen< Gesellschaften genannt haben: die einen versuchen dank den Institutionen, die sie sich geben, auf gleichsam automatische Weise die Wirkung zu annullieren, die die historischen Faktoren auf ihr Gleichgewicht haben könnten, und die anderen interiorisieren entschlossen das historische Werden, um es zum Motor ihrer Entwicklung zu machen.« (Lévi-Strauss 1981:270).

Kalte und warme Optionen bezeichnen also unterschiedliche Modi im Umgang mit historischem Wandel. Sie beschreiben einerseits den Versuch, diesen zu annullieren, um dadurch die Vorstellung einer zeitlosen Konstanz zu stabilisieren. Andererseits wird das historische Werden in eine Vorstellung voranschreitender Entwicklung und damit Kontinuität überführt. Die Unterscheidung zwischen sociétés froides und sociétés chaudes birgt allerdings die Gefahr, die Klassifizierung von Gesellschaften als »primitiv« und »zivilisiert « zu reproduzieren und damit ein evolutionäres Schema beizubehalten (Assmann 1997:69). Das Annullieren historischer Faktoren, von dem Lévi-Strauss spricht, ist außerdem kein bloßes Beharren oder Festhalten. Da Kälte nicht der »Nullzustand der Kultur« ist, muss sie vielmehr beständig erzeugt werden (Assmann 1997:68). Auch die Erzeugung von Kälte, mit der das »Eindringen von Geschichte« verhindert wird (ebd.), ist eine voraussetzungsvolle kulturelle Konstruktionsleistung. Der Einbruch der Veränderung muss immer wieder aufs Neue abgewendet werden. Jan Assmann zufolge sollten die beiden Optionen als gedächtnispolitische Strategien verstanden werden, die unabhängig von einem literalen und organisatorischen gesellschaftlichen »Entwicklungsstand « gleichermaßen bedeutsam sind (ebd.). Obwohl lineare Zeitgestalten notwendig auf Speichermedien angewiesen sind, führt dennoch etwa das Medium der Schrift al- 
lein nicht dazu, dass zyklische Vorstellungen sozialer Zeit obsolet werden. Schrift ist dafür eine notwendige, aber keine hinreichende Bedingung. So ist beispielsweise die Hieroglyphenschrift der Ägypter noch im eigentlichen Sinn kein Text, der interpretiert werden kann, sondern in erster Linie ein Kodex, der die korrekte Ausführung von zyklisch zu wiederholenden Ritualen sichert (Assmann 1997:169ff.).

Sowohl »kalte« zyklische sowie »heiße ${ }^{1}$ lineare soziale Institutionen stellen also anspruchsvolle kulturelle Leistungen dar. Damit hängt der zweite Kritikpunkt, den Assmann gegen Lévi-Strauss vorbringt, zusammen, der für die Entwicklung einer zeitkonstitutionellen Untersuchungskategorie entscheidender ist. Assmann plädiert dafür, die Unterscheidung nicht auf Gesellschaften als Ganzes anzulegen, sondern sie als Kontinuum zu denken und sie auf einzelne Teilbereiche des Sozialen anzuwenden. Dazu bedient er sich medizinischer Metaphern, wenn er von Quietiven (Beruhigungsmittel) und Inzentiven (Weckmittel) spricht, die zum zeitkonstitutionellen Repertoire aller Gesellschaften gehören. Jene stehen im Dienst der kalten Option und rekurrieren aufWiederkehr und Regelmäßigkeit. Diese hingegen stehen im Dienst der heißen Option und rekurrieren auf Veränderung und Einmaligkeit (Assmann 1997:70).

Wie in der anthropologischen Philosophie Plessners betrachtet auch Jan Assmann die Notwendigkeit historischer Sinnbildung als eine Universalie, ohne die keine Gesellschaft auskomme (1999b:94). Die »Basisfunktion historischer Sinnbildung « kann durch ihre Zugehörigkeit zur Geschichte oder Anti-Geschichte differenziert werden. Besteht das Ziel der Zeitkonstruktion im Zeichen von Geschichte in der Orientierung und Kontrolle sowie der Legitimierung von Rechtsansprüchen (Assmann 1999b:92), so wird im Modus der Anti-Geschichte soziale Identität durch die ritualisierte Beschwörung einer kosmischen Ordnung erzeugt (a.a.O. 91). Die »Kontingenz geschichtlicher Ereignisse« wird dann durch die Konstruktion einer »zeitlosen Ordnung und Kohärenz« ausgeschlossen (a.a.O. 90). Anti-geschichtlich sind diese Zeitgestalten also, da nicht die Bedeutsamkeit, sondern die Abwesenheit von Geschichte konstruiert wird (a.a.O. 87). Die Hitze des geschichtlichen Fortschritts, in dem alles stetig verdampft (Marx), muss sozusagen herabgekühlt werden. Indem das »Eindringen der Geschichte« verhindert wird, kann eine ewige Gegenwart erzeugt werden. Eine Verschiedenheit des Gestern, Heute und Morgen wird ausgeschlossen beziehungsweise unsichtbar gemacht. Platon hat die Unterschiendung in Vergangenheit, Gegenwart und Zukunft als die »Teile der Zeit « bezeichnet. $^{2}$ Ungeachtet dessen, ob eine Andersartigkeit der Teile der Zeit thematisiert oder wie im Sinne der zyklisch und ewig im Kreis schwingenden Anti-

1 In der deutschen Übersetzung des Buches »Das Wilde wilde Denken« (Lévi-Strauss 1981, Orig 1962 ) ist die Rede von »warmen« Gesellschaften. Assmann hingegen übersetzt die Bezeichnung »sociétés chaudes« mit den Worten »heiße Gesellschaften.« (Assmann 1997:68).

2 Platon unterscheidet, in seinem Werk Timaios (2009:37e-38a), Ewigkeit als eine »Sphäre des Seins«, die schlichtweg ist, von der Zeit, als eine »Sphäre des Werdens«. Da Zeit im Unter- 
Geschichte ausgeblendet wird, lassen sich für die Analyse diskursiver Konstruktionen sozialer Zeit folgende Leitfragen aufstellen:

1) Welche Zeitschichten werden überhaupt benannt?

2) Wie werden diese beschrieben?

3) Wie werden sie zueinander in Bezug gesetzt?

Die Fundamentaldistinktion historischer Sinnbildung in kalte Zyklen und heiße Linearität, zwischen Geschichte und Anti-Geschichte bleibt eine zentrale Unterscheidungsoption und Konstellationsmöglichkeit sozialer Zeit. Jedoch können mit diesen Leitfragen der Analyse auch potenziell andere Mischverhältnisse der Teile der Zeit erfragt sowie ihre jeweilige Charakterisierung und gegenseitige Verknüpfung untersucht werden.

\subsubsection{Wiederholen oder Dokumentieren}

In einer Nische des Gräbersaals der ägyptischen Abteilung des Neuen Museums auf der Berliner Museumsinsel, in der die Zerstörungen des Krieges und die Beschädigungen der Nachkriegszeit weiterhin sichtbar sind, steht ein ebenfalls beschädigtes Relieffragment. Darauf tritt König Sethos I. dem Gott Osiris gegenüber. Der Totengott Osiris ist nicht nur der Herrscher der Unterwelt, sondern selbst ein toter Gott. Indem Osiris nicht etwa aufersteht, sondern tot bleibt, ist er als gestorbener Gott unvergänglich (Assmann 1983:208). Der deshalb stets als Mumie dargestellte Gott verkörpert somit die resultative Zeit des »ewigen Gestern « und damit alles, was in der Zeit zur »Endgestalt gereift « ist und dadurch unwandelbar fortdauert (ebd.). Gerade weil Osiris zur Vollendung gelangt ist und aus dem Totenreich heraus für alles, was nach Vollendung im Reich der Lebenden strebt, maßgebend bleibt, ist er unsterblich. Er wird so zu einem entzeitlichten Ideal und normativen Fluchtpunkt.

Jan Assmann, der seine für die kulturwissenschaftliche Forschung einflussreichen Ergebnisse anhand früher Kulturen gewinnt, beschreibt das "Doppelgesicht der Zeit im altägyptischen Denken« anhand von zwei Vorstellungen ewiger Zeit: Neheh und Djet (1983:201). Da diese gleichermaßen auf die »Seite des Sakralen« gehören (Assmann 2006:497), können ihnen die Götter Re (Neheh) und Osiris (Djet) zugeordnet werden (Assmann 1983:208f.). Anstelle der platonischen Dreiteilung der Chronologie (in Vergangenheit, Gegenwart, Zukunft) besteht im altägyptischen Denken eine »duale Einheit« der Zeit (ebd.). Die Konstruktion von ewiger Zeit gelingt in beiden Formen durch das Ausblenden von Wandel und Veränderung; also durch die »Negation der Zeit« (Assmann 1983:204). Die dichotome Zu-

schied zur Ewigkeit über Vergangenheit, Gegenwart und Zukunft verfügt, kann von ihr gesagt werden: »es war, ist, wird sein« (zitiert nach Assmann 1983:198). 
ordnung zu den Begriffspaaren Natur/Kultur, Diesseits/Jenseits, Raum/Zeit und zyklisch/linear greife jedoch zu kurz. Assmann sieht darin eher die Grundopposition des ägyptischen Tempussystems repräsentiert. Diese besteht in der Unterscheidung zwischen Virtualität und Resultativität (a.a.O. 199f.). Der Begriff >Neheh ist dabei der sich unendlich wiederholenden Folge der Stunden, Tage, Jahreszeiten und Jahren vorbehalten. Neheh beschreibt also einen »unerschöpfliche[n] Vorrat « an virtueller und deshalb noch unkonkreter Zeit. Djet hingegen beschreibt den resultativen Aspekt der Zeit und rekurriert damit auf das konkret Verwirklichte in der Welt. Mit der ewigen Zeit der Djet ist also die unendliche Fortdauer dessen benannt, "was sich in der Zeit vollendet hat« (a.a.O. 199f.). Da damit vor allem die Erinnerung im sozialen Gedächtnis der Lebenden antizipiert wird, die in der »starren Unwandelbarkeit des Gesteins« (a.a.O. 201) ihren Ausdruck findet, ergibt sich eine Nähe der Djet-Ewigkeit zu den Bauwerken, Denkmälern und der verräumlichten Erinnerung. ${ }^{3}$ Jedoch findet eine neuzeitliche Gegenüberstellung von Natur und Kultur im altägyptischen Denken keine Entsprechung, denn der »unerschöpfliche Vorrat « von virtueller Zeit wiederholt sich keineswegs von selbst. Vielmehr ist auch er Resultat der In-Gang-Haltung der Zeit (Assmann 2006:497) (und somit der Welt-In-Gang-Haltung überhaupt), die sich nur durch die korrekte Durchführung von Riten aufrechterhalten lässt. ${ }^{4}$ Dadurch dass im Falle des »Doppelgesicht[s] der Zeit« im altägyptischen Denken die scharfe Unterscheidung zwischen Natur und Kultur nicht besteht, da beides in den Verantwortungsbereich des Menschen fällt, lassen sich so verschiedene kulturelle Techniken des Stillstellens abbilden.

Indem Assmann den beiden Vorstellungen von Ewigkeit zwei verschiedene Modi der Verzeitlichung zuweist, erweitert er den im konkreten Fall der altägyptischen »Doppelgesichtigkeit « der Zeit gefundenen Geltungsbereich hin zu einer allgemeineren Unterscheidung kultureller Zeitgestalten. Neben der »Erneuerungszeit der Riten« (Assmann 2006:496) bestehe eine »Rechenschaftszeit der Monumente«(a.a.O. 501f.). Obwohl die Djet-Ewigkeit im konkreten ägyptischen Fall noch nicht als linear im modernen Sinn beschrieben werden kann, ${ }^{5}$ kann dies jedoch für die Verwendung der allgemeineren Kategorien Erneuerungszeit und Rechenschaftszeit geltend gemacht werden. Damit ist eine Übertragung vom konkreten

Eine verabsolutierende Zuordnung der beiden sewigen Zeiten zu den Kategorien Raum und Zeit vertritt Wolfhart Westendorf in Abgrenzung zu Assmann, wenn er schreibt: »Die NehehEwigkeit hat keinen Anteil am Raum, die Djet-Ewigkeit keinen Anteil an der Zeit« (1983:434). Reinhart Koselleck grenzt die natürliche »ewige Wiederkehr«, der Gesellschaften passiv ausgesetzt sind, von der jeweils »aktuell vollzogenen Wiederholung«, die an eine aktive kulturelle Leistung gebunden ist, ab (Koselleck 2000:13). Im altägyptischen Denken sind die natürlichen und kulturell geregelten Wiederholungsstrukturen aber gerade nicht voneinander getrennt.

5 Jan Assmann spricht in diesem Zusammenhang eher von einer räumlichen Rechenschaftszeit (2006:497) und nähert sich damit wiederum der argumentativen Linie Westendorfs. 
altägyptischen Fall hin zu einer allgemeineren Klassifizierung geleistet, die eine generelle Differenzierung sozialer Zeit ermöglicht. Zyklische oder reversible Zeit ist demnach Erneuerungszeit, ihre typischen Institutionen sind Riten und Feste (Assmann 2005:13ff.). In diesem Modus der Zeitkonstruktion wird meist nur unterschieden zwischen einer Zeit des Mythos, in der die Welt eingerichtet wurde, und der Zeit der Menschen, in der alles, was einmal in die Welt gekommen ist, unberührt von Veränderung erhalten bleibt. Der Lauf der Zeit ist in dieser Vorstellungswelt durch zyklische Bahnen eingehegt. Die Wiederkehr des immer Gleichen bedeutet aber keineswegs, dass nicht auch Veränderung integriert werden kann. So verfügt die ethnografische Forschung über einen reichen Schatz an anti-geschichtlichen Erzählungen, in denen das Eindringen der Geschichte erfolgreich abgewendet wird. Obwohl historische Veränderungen stattfinden, werden diese nicht als solche thematisiert. Meist wird der geschichtliche Wandel dadurch unsichtbar gemacht, indem die fundierenden Erzählungen modifiziert werden. Klaus E. Müller berichtet etwa von Mythen der Assiniboin, in denen Pferde, die die Bewohner der Great Plains erst gegen Ende des 17. Jahrhunderts in ihren Alltag integrieren konnten, bereits gemeinsam mit den ersten Menschen geschaffen worden seien (Müller 2005:36). Indem also die aktuellen Veränderungen in der Vergangenheit >wiedergefunden werden, kann die Gegenwart bewältigt und in Einklang mit der kosmologischen Ordnung gebracht werden. Die Anpassungsfähigkeit kalter Zeitlichkeit besteht also, obwohl auf die Veränderungen in der Zeit nicht reflexiv zurückgegriffen werden kann. Indem sich der Mythos den Veränderungen anpasst, kann ein Bewusstsein von Ewigkeit stabilisiert werden. Hierin besteht eine Verbindung zwischen zyklischer Erneuerung und Vergessen; genauer: dem anti-geschichtlichen Ausschluss (der Sichtbarkeit) von Veränderung. Es handelt sich um ein »spezifisches Vergessen im Dienst einer anderen Erinnerung (Assmann 2005:15). In der Gestalt der Erneuerungszeit befindet sich alles in ständiger Wiederholung. Da Anfang und Ende immerzu verbunden werden können, ist die Zeit noch nicht in Vergangenheit, Gegenwart und Zukunft aufgeteilt. Eine solche Unterscheidung ist innerhalb dieser Zeitgestalt strenggenommen gar nicht möglich, weil sie - im Sinne des Wortes - undenkbar ist.

Drastische Weltveränderung, Differenzerfahrung und die daraus resultierenden Identitätskrisen hingegen führen typischerweise $\mathrm{zu}$ Erinnerungsschüben im Modus der Geschichte (Assmann 2005:13f.). Linear-irreversible Zeit hängt dann eng mit Geschichtsbewusstsein zusammen. Zeit ist dann Rechenschaftszeit (ebd.). Wird durch die rituelle Wiederholung die soziale Identität gesichert, so wird in der Dokumentation von Veränderung Identität eher herausgefordert, auch wenn dies keinesfalls bedeutet, dass Geschichte nicht auch identitätspolitisch vereinnahmt werden kann. Im Gegenteil dient die Erzeugung linearer Zeit doch vor allem der »Konsolidierung von Herrschaft und sozio-politischer Identität « (Assmann 2005:11). Geschichtsschreibung sei demnach weniger Erzählung (narration), son- 
dern vielmehr Rechenschaft oder Bericht (account) (a.a.O. 13ff.). In linear voranschreitender Zeit, in der die Hitze des Fortschritts stets Neues hervorbringt und Altes der nunmehr fernen Vergangenheit zuführt, muss das Vergangene schließlich dokumentiert werden. Da die Vergangenheit fremd geworden ist, muss über ihre Bedeutung für die Gegenwart Rechenschaft abgelegt werden. Ist für erneuerungszeitliche Institutionen ein selektives Vergessen zentral, so erhält in rechenschaftszeitlichen Institutionen das Dokumentieren den Charakter eines Gebotes.

Im Einklang mit der rituellen Erneuerungszeit fundierender Erzählungen und der dokumentierenden Rechenschaftszeit geschichtlicher Berichte ordnet Jan Assmann den beiden Zeitmustern zwei Modi der Kohärenzsicherung zu. Diese bezeichnet er als rituelle und textuelle Kohärenz (1997:87ff.). Rituelle Kohärenz rekurriert dabei auf Wiederholung und erzeugt durch »selektives Vergessen« (im Dienst einer Anpassungsleistung, die nicht als solche thematisiert werden darf) eine zeitlose Ordnung. Die »Teile der Zeit« sind noch nicht konturiert. Weniger als die Vorstellung einer voranschreitenden Kontinuität erzeugt der Modus ritueller Wiederholung eher einen entzeitlichten Zustand ewiger Konstanz. ${ }^{6}$ Im Unterschied zur Repetition ritueller Kohärenz rekurriert textuelle Kohärenz auf Variation (a.a.O. 97). An die Stelle von Nachahmung und Bewahrung treten Interpretation und Vergegenwärtigung. Vergegenwärtigung bedeutet aber auch, dass Vergangenheit in die Gegenwart geholt werden muss. Durch diese selektive Akzentuierung der Vergangenheit werden eine Auslegung und Deutung des Verhältnisses zwischen Vergangenheit und Gegenwart erforderlich. Interpretation im Sinne zeitlich allumfassenderer Entwicklungsgesetze erzeugt nunmehr keine zeitlose Konstanz, sondern fortschreitende Kontinuität, wodurch eine potenziell andere Zukunft denkbar wird. Interpretation (im Unterschied zur Wiederholung) stellt also eine doppelte Erklärung dar. Einerseits werden chronologisch frühere Zeitpunkte überhaupt erst $\mathrm{zu}$ Vergangenheit erklärt; andererseits muss nun die Bedeutung des Vergangenen für die Gegenwart erklärt werden.

Die Frage, ob die »Teile der Zeit« im Bild eines ewigen Kreislaufs oder im Bild einer flüchtigen Geraden zueinander in Bezug gesetzt werden, verweist auf eine lange philosophiegeschichtliche Tradition. Da die Unterscheidung insbesondere durch Jan Assmann für die Differenzierung gedächtnispolitischer Strategien nutzbar gemacht wurde, soll sie auch zur Kategorisierung der hier zu analysierenden Diskurse immer wieder herangezogen werden. Die Frage, ob Vergangenheit, Gegenwart und Zukunft in linearer Abfolge aufeinander folgen oder ob sie durch Wiederholung nur schwach konturiert werden, bleibt also auch für diese Untersuchung eine wichtige Analysekategorie. Da die raumzeitliche Analyse der Diskurse jedoch er etwa davon spricht, dass der Sinn der Quietive in der Kontinuität liege (Assmann 1997:70). Hier wäre sicherlich der Begriff `Konstanz`adäquater. 
auf verschiedene Wirklichkeitskonstruktionen innerhalb gesellschaftlicher Teilbereiche und sogar in Bezug auf ein und denselben Gegenstand angewendet wird, verläuft sie quer zu identitätspolitischen Bezugsgrößen wie Gesellschaft, Nation oder Position im politischen Spektrum. Die Illustration einiger wesentlicher Charakteristika der Formen historischer Sinnbildung hat neben einer kategorialen Differenzierung der Diskursivierungsmuster zudem bereits erste Anknüpfungspunkte für die Interpretation der empirischen Funde eröffnet.

\subsubsection{Die Dialektik der gedächtnispolitischen Strategien}

Die Unterscheidung zwischen Anti-Geschichte und Geschichte, zwischen Erneuerungszeit und Rechenschaftszeit deckt sich ungefähr mit der Unterscheidung zwischen Gedächtnis (Memoire) und Geschichtsschreibung (Histoire). Aleida Assmann hat für die Arbeitsweise dieser "gedächtnispolitischen Strategien« die Unterscheidung in Speicher- und Funktionsgedächtnis vorgeschlagen (2010:130ff., Orig. 1999). Das ohnehin kaum vollständig zu überblickende Feld der Termini, die für die Fundamentaldistinktion sozialer Zeitkonstruktionen geprägt wurden, wird damit abermals geweitet. Wie bereits dargelegt, kann Erinnern nicht nur als eine Funktion von Gesellschaft, sondern auch umgekehrt Gesellschaft als eine Funktion des Erinnerns verstanden werden (Kap. 2.3). Jan Assmann hatte dies als Bindungsgedächtnis beschrieben, in dem das gemeinsame Erinnern überhaupt erst Gruppenkohäsion und Zugehörigkeit erzeugt (Assmann 2002:66). Genau dies ist mit der Bezeichnung Funktionsgedächtnis auch bei Aleida Assmann gemeint. Wirkt das Funktionsgedächtnis des Erinnerns also identitätsbildend und ist durch seine Akteure »bewohnt « und somit im lebhaften Gebrauch der Erinnerung im Ritus und Fest »verkörpert«, bleibt das »identitätsabstrakte« Speichergedächtnis als neutralere dokumentierende Geschichte »unbewohnt« und »entkörpert (Assmann 2010:133, Orig. 1999). Der Nutzen dieser Unterscheidung für die vorliegende Untersuchung besteht darin, dass die Begriffe nicht dualistisch kontrastiert werden, sondern sich komplementär perspektivieren (Assmann 2010:136). Denn so wie das Funktionsgedächtnis sich aus dem Hintergrund des historischen Wissensspeichers bedient, so ist auch das Speichergedächtnis kritischer Historiografie auch wenn diese antritt, »Identität zu vernichten« (Koselleck 2004) - nicht davor gefeit, selbst wiederum mythisch vereinnahmt zu werden.

Die Geschichtswissenschaft des 19. Jahrhunderts verkörpert diesen Doppelcharakter besonders deutlich. Einerseits entfachte sich an ihrem zersetzenden und identitätsabstrakten Wesen die Kulturkritik Nietzsches (Kap. 1). Durch das Übergewicht der Geschichte sah dieser die Funktionen des Gedächtnisses bedroht, welches seine zentralen Funktionen Antriebsenergie (Intensität) und die Schaffung eines formativen Selbstbildes (Identität) zunehmend verliere (Assmann 2010:131). Nietzsches Kritik richtet sich insbesondere gegen die Verwissenschaftlichung der 
Gesellschaft, welche durch ihren Werterelativismus nunmehr unfähig geworden sei, normative Orientierung zu stiften. Ziel seiner Kritik ist unter anderem die von Leopold von Ranke formelhaft geprägte geschichtswissenschaftliche Perspektivierung des Historismus, welcher davon ausgeht, dass jede Epoche unmittelbar zu Gott ist. Nietzsche sah darin eine »Uebersättigung der Zeit in Historie«, die dem Leben feindlich und gefährlich sei (Nietzsche 2009:45), da Geschichte als reine Wissenschaft nichts »Heilsames und Zukunft-Verheissendes« - sprich keine normative Orientierung - mehr bereithält (a.a.O. 19). Fiat veritas pereat vita lautete für Nietzsche der »Wahlspruch« dieser selbstgenügsamen Suche nach historischer Wahrheit, über deren Kühnheit das Leben zum Erliegen komme (a.a.O. 36).

Die Singularität jeder Epoche führt dazu, dass das Gewesene unwiederholbar bleibt und die Vergangenheit zunehmend fremd wird. ${ }^{7}$ Nietzsches Kritik daran war auch deshalb eine unzeitgemäße Betrachtung, da die Fremdheit der Vergangenheit mit der eintretenden Disparatheit zwischen Erfahrungsraum und Erwartungshorizont Einzug hält. Diese lineare Kopplung von als verschieden imaginierten Epochen ist eines der zeitkonstitutionellen Merkmale der Moderne, welche zum Ziel der Kritik Nietzsches wird. ${ }^{8}$ Mit der Trennung zwischen Vergangenheit und Gegenwart kommen sowohl der modernistische Fortschrittsglaube an eine bessere Zukunft als auch die Idee einer Unübertrefflichkeit des Alten in die Welt (Giesen 1999:214). Bernhard Giesen hat für Letzteres deshalb den Begriff des »invertierten Modernismus« vorgeschlagen (a.a.O. 231ff.), denn der auf die Zukunft fixierte Modernismus ändert lediglich seine Blickrichtung. Der gemeinsame Nenner sowohl des prospektiven als auch des retrospektiven Modernismus besteht jedoch in der Annahme einer prinzipiellen Verschiedenheit zwischen Vergangenheit, Gegenwart und Zukunft. Erst mit der Verflüssigung der Zeit in der Moderne werden sowohl der retrospektive Blick zurück in eine andere Vergangenheit als auch der prospektive Blick nach vorn in eine andere Zukunft möglich. Dadurch wird schließlich die Möglichkeit der Sinnstiftung und Konstruktion ewig gültiger Werte unterlaufen. Indem die Verbindung zur Vergangenheit getrennt wird, nimmt auch ihre normative Verbindlichkeit ab.

Ungeachtet der mythenzerstörenden Kraft (Koselleck 2004) der Geschichtswissenschaft (histoire) gegenüber dem Erinnern (mémoire) dürfen aber die identitätsstiftenden Potenziale, also die Anteile des Funktionsgedächtnisses am Speichergedächtnis, nicht außer Acht gelassen werden. Da identitätsbezogene Geschichtsschreibung nicht nur im Zeichen des Untergangs, sondern auch umgekehrt im

Diese ist auch deshalb hervorzuheben, da der Begriff ^Historismus im Kontext von Architektur und in Bezug auf die Wiederholbarkeit von Epochenstilen vom genauen Cegenteil ausgeht, was mit dem geschichtswissenschaftlichen Begriff `Historismus eigentlich beschrieben werden sollte.

8 Nietzsches Kulturkritik artikuliert sich in einem historischen Moment, in dem der Claube an einen guten Ausgang (ein Happy End) der Ceschichte erodiert (Bogner 2012). 
Zeichen der Stiftung und Erfindung entsteht, gilt: »Historismus und Nationalismus gehören zusammen." (Assmann 1999b:92f.). Insbesondere die Imagination der >Deutschen Kulturnation vollzog sich auch im Medium nationaler Geschichtsschreibung. Laut Bernhard Giesen und Kay Junge vollzieht sich in der deutschen Romantik eine Umkodierung kollektiver Identität (Giesen/Junge 1991:255ff.). An die Stelle des obrigkeitstreuen Tugenddienstes des Bildungsbürgertums tritt in dieser Zeit die ästhetische Verklärung der »Volkskunst«. Aus dem »Vaterland« der Patrioten wird so das »Volk« der Romantiker (a.a.O. 290f.). Anders als in Frankreich, wo die positivistischen Naturwissenschaften zu Leitwissenschaften aufstiegen, war die Rolle der affirmativen Konsolidierung der »Kulturnation« in Deutschland eher der wertschätzenden Entdeckung der eigenen Vergangenheit und der »Achtung der Geschichte« vorbehalten (a.a.O. 292). Die »nationale Sinnstiftung durch Geschichte« stellte erneut einen geläufigen Topos der Denkmalpflege der 1920er Jahre dar (Speitkamp 1996:111). Trotz aller wissenschaftlichen Reflexion verbleibt der Umgang mit der Vergangenheit stets im Spannungsfeld zwischen entmythisierender Kritik und fundierender Mythenbildung. Inwiefern die gegenwärtige Denkmalpflege diesem Spannungsfeld entkommt und ob sie frei von Identitätspostulaten ist, gehört zu den Gretchenfragen, die sich die Disziplin stellt.

Neben der sich professionalisierenden Denkmalpflege, die das nunmehr schwierige Gut der Vergangenheit unter Fachaufsicht stellte (Giesen 1999:229), gilt dies erst recht für die nationalaffirmativen Museen des 19. Jahrhunderts. Der Konnex zwischen dem Gebrauch der Geschichtswissenschaft zur Vergemeinschaftung wird durch die Rolle der Museen bei der Konsolidierung der deutschen Nation besonders deutlich. ${ }^{9}$ Vor allem das Neue Museum in Berlin stand trotz seines wissenschaftlichen Anspruchs ganz im Dienst nationaler Selbstvergewisserung. Dies galt umso mehr, als die Einheit des deutschen Staates zu dieser Zeit noch ausstand. Denn der universalgeschichtliche Versuch, eine »möglichst klare und ausgedehnte Uebersicht der Kunstübungen verschiedener Zeiten und Völker« darzustellen (Stüler, zitiert nach Cobbers 2009:22f.), ließ dennoch keinen Zweifel daran, dass der vorläufige Höhepunkt weltgeschichtlicher Entwicklung im preußischen Staat erreicht sei. Die Sehnsucht nach der Nation wurde zum »säkularisierten Erlösermotiv« (Giesen/Junge 1991:303). Daraus folgte, dass auch die Musealisierung

Auch für diesen Zusammenhang der Anrufung der deutschen Kulturnation ist die Alte Nationalgalerie beispielhaft. Neben ihrer tempelartigen Architektur und dem Reiterstandbild König Friedrich Wilhelms des IV., welches die Freitreppe des Bauwerks dominiert, findet sich im Innern des Cebäudes ein Relief Otto Ceyers (dazu Wullen 2002). Darin wird eine Cenealogie der deutschen Kultur von mythischer Vorzeit (Arminius) über das christliche Mittelalter (Erwin von Steinbach) und die vermeintlich >deutsche Baukunst ‘ der Gotik (Goethe 1920, Orig. 1773) bis zu den Potentaten des preußischen Staates (Friedrich Wilhelm IV.) und ihren Baumeistern (Schinkel, Stüler) konstruiert. Die Nationalgalerie zeugt somit von der Kunstverklärung im Dienst der Identitätsbildung. 
nach entwicklungsgeschichtlichen Kriterien nicht vor apologetischer und quasireligiöser Mythisierung gefeit blieb.

In allgemeinen Begriffen lässt sich hierin der Zusammenhang zwischen Mythos und Aufklärung beschreiben. So wie der Mythos, indem er die Welt sinnvoll ordnet und deutend erklärt, bereits Aufklärung ist, so schlägt jede Aufklärung wieder in Mythos um. »Wie die Mythen schon Aufklärung vollziehen, so verstrickt Aufklärung mit jedem ihrer Schritte tiefer sich in Mythologie« (Adorno/Horkheimer 2001:18, Orig. 1944). Aleida Assmann hat vermutlich dies im Blick, wenn sie vor einer dualistischen Kontrastierung von Funktions- und Speichergedächtnis warnt. Ohne diesen Zusammenhang allerdings kulturpessimistisch zu dramatisieren, akzentuiert sie eher die positiven Aspekte der Verifizierung und Orientierung. So wie das Speichergedächtnis verifiziert, kann erst das Funktionsgedächtnis normative Orientierung stiften. Das reine Speichergedächtnis wird zu »wertloser« Historiografie, das reine Funktionsgedächtnis zum mythischen »Phantasma«. Erst in der Verschränkung bestehe ein für beide Seiten »heilsames Korrektiv«(2010:142). Damit ist auch anzunehmen, dass in allen Formen der kollektiven Selbstthematisierung normative Gehalte einer sich auf Vergangenheit berufenden Gegenwartsbewältigung erhalten bleiben. Für diesen Aspekt der vergangenheitsbezogenen Konstruktion einer kulturellen Sinnstiftung hat Jan Assmann den Begriff »normative Vergangenheit« geprägt (Assmann 1999b:93). Normative Vergangenheiten kodifizieren die für die Gegenwart handlungsleitende Maxime. Die Konstruktion einer fundierenden Vergangenheit geschieht durch die Bestimmung eines Bezugspunktes in der Vergangenheit, der entzeitlicht und damit zeitlos wird. Gerade in Debatten über den richtigen Umgang mit dem baulichen Erbe stellen die Konstruktionen unterschiedlicher normativer Vergangenheiten einen essenziellen Bestandteil sämtlicher Diskursivierungsmuster dar. In ihrem wertenden Charakter bewegen sie sich damit auf der Ebene der von Reiner Keller definierten Analysedimension der Klassifikation (Kap. 3.5). Diese Vergangenheiten, die nicht vergehen, weil sie normativ verbindlich bleiben, stellen - selbst wenn sie im Modus kritischer Geschichtsschreibung operieren - einen potenziellen Umschlagplatz zwischen Entund Re-Mythisierung dar.

Die Heroismen und die nationale Apologetik verkörpern in den zu analysierenden Diskursen oft selbst ein Erbe, welches verschiedene Umgangsweisen evoziert. Der Streit um den adäquaten Umgang damit - also die Frage, wie diese Vergangenheit zu beerben sei - bildet eine der zentralen Spannungslinien. Wurde etwa der offen antisemitische und nationalistische Charakter der Innengestaltung, insbesondere der Kaulbachfresken (dazu ausführlich Kap. 5), im Neuen Museum einerseits problematisiert, so wurden diese andererseits, ungeachtet ihres Inhaltes, als historisches Zeugnis und somit als legitimes Erbe angenommen. Umso deutlicher wird die deutsche Militärgeschichte für die Bundeswehr in ihrem Leitmuseum identitätspolitisch zum Problem. Der apologetische Charakter eines nationalaffir- 
mativen Geschichtsbildes wird zum problematischen Erbe. Allerdings wird hinter der Problematisierung des nationalen Pathos vergangener Zeiten eine subtilere Rekonstruktion der Vergangenheit sichtbar, die selbst normativ gehaltvolle Aussagen und Aspekte der Sinnstiftung beinhaltet. Da aus der Geschichte auch hier für die Gegenwart handlungsleitende Maximen abgeleitet und verstetigt werden, wird erneut eine normative Vergangenheit begründet, die sich durch die Konstruktion zeitlos gültiger Werte den mythisch-fundierenden Erzählungen annähert. Gerade für das Leitmuseum der Bundeswehr, welches zudem als Schulungsort für Soldaten und Offizieren dient, gilt es, trotz aller wissenschaftlichen Auseinandersetzung mit dem Minenfeld der deutschen Militärgeschichte, ein Identitätsangebot zu artikulieren. Die Möglichkeit einer Re-Mythisierung bleibt also auch hier potenziell erhalten, da die Negation der national-heroischen Affirmation selbst wiederum durch die Funktion eines identitätsbildenden Mythos vereinnahmt werden kann. Gerade im Diskurs des Militärhistorischen Museums Dresden erhalten die kritische Distanzierung von der Vergangenheit und die anhaltende Selbst-Negation den Charakter einer für die Bundeswehr wesenhaften Eigenart. In diesem Sinne wird neben (und eventuell durch) einem geschichtskritischen Speichergedächtnis (Negation) auch ein sinnstiftendes Funktionsgedächtnis (Affirmation) stabilisiert.

\subsubsection{Ein episodisches Bild der Ewigkeit?}

Der Trauerzug in Segantinis Bild bewegt sich zwischen einer einfachen Hütte am rechten und einer in der Ferne erkennbaren Kirche am linken Bildrand. Vor den gleichmäßig ineinander übergehenden Formen und Farben des Hintergrundes sind es vor allem der Kamin der ärmlichen Behausung sowie die rote Kirchturmspitze, die diese Harmonie leise stören. Indem sie mit der Darstellung der Natur kontrastieren, kennzeichnen sie den Bereich der Menschen. Auch wenn der Bereich der Kultur von der Ewigkeit der Natur getrennt ist, so scheinen die Trauernden zwischen Haus und Kirche noch im Glauben an ein jenseitiges ewiges Leben aufgehoben. Hierbei handelt es sich also noch um eine vergleichsweise beschauliche Variante einer sich erst schrittweise beschleunigenden Lebenswelt. Für das hoch dynamische Zeitregime der Spätmoderne kann diese religiöse Zuversicht nicht mehr uneingeschränkt geltend gemacht werden. Wie bereits festgestellt wurde, gehen Autoren wie Zygmunt Bauman davon aus, dass in der flüchtigen Moderne "Zeit weder zyklisch noch linear« verlaufe und zudem in eine »Vielzahl pointillistischer Momente« zerfalle (Bauman 2007a:180f.). Vom einstigen Strom der Zeit sei in der flüchtigen Moderne demnach nur noch eine »Ansammlung von Teichen und Tümpeln« übriggeblieben (Bauman 1997:148). Dies führt dazu, dass sich das Stillstellen der Zeit nun nicht mehr darin erschöpft, Geschichte einzufrieren (also in der Konstruktion zeitloser Konstanz) oder darin, diese als Motor der Entwicklung nutzbar zu machen (also in der Konstruktion linearer 
Kontinuität). Die Ablehnung entwicklungsgeschichtlichen Fortschrittsglaubens und teleologischer Geschichtsbilder bedingt eine episodische Zeitstruktur, die nunmehr einen Umgang mit Diskontinuität erfordert.

So hilfreich und gut belegt die Unterscheidung zwischen zyklischer und linearer Zeit erscheinen mag, so ungenügend ist sie für die Betrachtung der sozialen Zeitgestalten in der deutschen Gegenwartsgesellschaft. Gerade die Tatsache, dass der Ägyptologe Jan Assmann und die Literaturwissenschaftlerin Aleida Assmann ihre Kategorien zum einen anhand früher Kulturen, zum anderen anhand literarischer Texte generieren, erschwert die Übertragung auf moderne, funktional differenzierte Gesellschaften erheblich (Sebald/Weyand 2011:177f.). ${ }^{10}$

Viel spricht also dafür, dass Zyklik und Linearität nicht mehr ausreichen, um die Zeitgestalten der Gegenwartsgesellschaften zu beschreiben. Greifen die klassischen Konstruktionen sozialer Zeit zu kurz, so scheint die von Bauman gezogene Schlussfolgerung, dass in der »pointillistischen« Zeit der flüchtigen Moderne »Ewigkeit kein Wert und kein Objekt der Begierde mehr« sei und eine »Tyrannei des Augenblicks« Einzug gehalten habe (2007a:185), wiederum vorschnell und zu weitreichend. Dass, entgegen der Behauptung Baumans, in der flüchtigen Moderne »Zeit weder zyklisch noch linear« verlaufe (a.a.O. 180f.), kann zudem empirisch bezweifelt werden. Mit den in diesem Kapitel vorgeschlagenen Analysekategorien lässt sich erfragen, ob möglicherweise ein Mischverhältnis der Teile der Zeit denkbar ist, mit dem die »Vielzahl pointillistischer Momente« dennoch so miteinander verbunden werden können, dass sich dadurch eine Vorstellung von (ewiger) Dauer stabilisieren lässt. Auch hierfür kann empirisch gehaltvolles Theoriewissen für die Analyse gewinnbringend nutzbar gemacht werden.

In einer explorativen Studie über den Zusammenhang von Lebensgeschichtlichkeit und Lebensräumlichkeit in biografischen Erzählungen geht der Raumsoziologe Gunter Weidenhaus grundsätzlich der Frage nach, ob analog zu einer physikalischen Raumzeit auch ein stabiler Zusammenhang zwischen der Konstruktion von sozialem Raum und sozialer Zeit besteht. Der Suche nach einer sozialen Raumzeit liegt die Annahme zugrunde, dass mit bestimmten Raumkonstitutionen auch spezifische Konstitutionen der Zeit zwingend einhergehen. Neben drei idealtypischen Modi der Konstitution von Lebensräumlichkeit (konzentrisch, netzwerkartig, inselhaft) rekonstruiert Weidenhaus drei Modi der Konstruktion von Lebensgeschichtlichkeit. Dabei stößt er sowohl auf einen linearen als auch einen zyklischen Konstitutionsmodus von Zeitlichkeit. In linear konstruierten Lebensgeschichten

10 Gerd Sebald und Jan Weyand sehen das zentrale Problem der Gedächtnistheorie Maurice Halbwachs', die auch den Hintergrund der Arbeiten von Jan und Aleida Assmann bildet, darin, dass weiterhin implizit die Vorstellung einer mechanischen Solidarität im Sinne Durkheims reproduziert werde. Soziale Gedächtnisse in der Moderne sind aber keineswegs lediglich Folge der Interaktion in Kollektiven (Sebald/Weyand 2011:177). 
»existiert die konkrete Imagination einer Zukunft, so dass das Leben folgerichtig von der Vergangenheit über die Gegenwart in die Zukunft geführt wird« (Weidenhaus 2015:94). Im Unterschied dazu beschreiben sich die Erzählenden im Modus zyklisch konstruierter Lebensgeschichte »über alle Zeit mit sich selbst identisch « (ebd.). Die ewige Gegenwart dieses Typus erinnert an die Abwesenheit einer klaren Unterscheidung von Vergangenheit, Gegenwart und Zukunft, wie sie anhand der altägyptischen Vorstellungen ewiger Zeit dargestellt wurde. Auch Weidenhaus beschreibt anhand von zyklisch konstruierten Erzählungen, dass den geschilderten Ereignissen kaum zu entnehmen ist, ob sie sich gestern oder vor mehreren Jahren zugetragen haben $(2015: 79,90)$. Entgegen linear konstruierter Lebensgeschichtlichkeit in Biografien, in denen Vergangenheit, Gegenwart und Zukunft klar voneinander getrennt sind und zu einer sich kontinuierlich entwickelnden Lebensgeschichte verbunden werden, erzählen Zykliker somit weniger eine stringente Geschichte als vielmehr einzelne Geschichten (a.a.O. 87). Die »ewig währende Gegenwart« dieses Typus (a.a.O. 8) entspricht somit dem stehenden Jetzt (nunc stans) in der Philosophie Platons (Timaios).

Interessant für die Frage nach der Möglichkeit einer Zeitgestalt jenseits von Zyklik und Linearität ist nun aber, dass in Weidenhaus' Studie auch ein Modus der Konstitution von Lebensgeschichtlichkeit in den Blick gerät, der sich in der klassischen Unterscheidung nicht mehr beschreiben lässt. So dokumentiert Weidenhaus ebenfalls lebensgeschichtliche Erzählungen, in denen die zeitliche Struktur als eine Aneinanderreihung von einzelnen, in sich geschlossenen Episoden erzählt wird. Diese bleiben untereinander fast ohne Verbindung (2015:93f.). In episodisch konstruierten Lebensgeschichten erhalten unterschiedliche Lebensabschnitte den Charakter lose verbundener Versatzstücke, die zwar gleichermaßen thematisiert, aber dennoch nur schwach (oder gar nicht) miteinander gekoppelt sind. Weidenhaus spricht dabei von »logischer Unabhängigkeit der einzelnen Episoden« (ebd.). Entscheidungen, die in der Gegenwart getroffen werden, entfalten in diesen Erzählungen keinerlei Bedeutung auf die lebensgeschichtliche Zukunft. An die Stelle einer klar antizipierten Zukunft tritt nunmehr eine Vielzahl möglicher Zukünfte. Wichtig ist aber festzuhalten, dass die Befragten dennoch kohärente Lebensgeschichten erzählen. Die durch Zukunftskontingenz und Ereignissukzession geprägten Biografien können nichtsdestotrotz zu einheitlichen Erzählungen zusammengefasst werden; zudem kann eine Vorstellung von Beständigkeit hergestellt werden. Denn auch Menschen, die für ihre lebensgeschichtliche Schilderung eine episodische Zeitstruktur nutzen, empfinden sich als über die Zeit hinweg kohärent. Über zeitliche Brüche, die auch als solche thematisiert werden, kann so eine Vorstellung personaler Identität stabilisiert werden. Das Mischverhältnis, in dem Vergangenheit, Gegenwart und Zukunft miteinander in Verbindung gebracht werden, unterscheidet sich nunmehr dahingehend, dass es sich auf eine andere logische Ebene verlagert. An die Stelle von klaren Berufsbezeichnungen (etwa Bäcker) 
treten nun als wesenhaft angegebene Fähigkeiten (Ich kann backen) (Weidenhaus 2015:205). Typisch für diesen Konstitutionsmodus ist etwa das Lebensmotto, wonach man sich immer wieder neu erfinden könne (a.a.O. $35 \mathrm{ff}$.). Anstatt einer berechenbaren Lebensplanung oder einer zeitlosen Konstanz des Lebens werden nun schließlich allgemeinere Haltungen entzeitlicht. Dieses »In-der-Schwebe-Halten der eigenen Identität« (Weidenhaus 2015:205) thematisiert Weidenhaus explizit als eine Bewältigungsstrategie von Zukunftskontingenz und kontextualisiert diesen Modus der Konstruktion von Lebensgeschichtlichkeit mit dem beschleunigten sozialen Wandel der Postmoderne (a.a.O. 204).

Mit dem Verweis auf episodische, aber dennoch kohärente Formen der Identitätsbehauptung auf personeller Ebene ist ein Beleg für mögliche Zeitkonstruktionen jenseits zyklischer und linearer Zeitgestalten gefunden. Die Frage, ob sich episodische Konstruktionen von Zeit im Moment eines verkürzten Aufenthaltes in der Gegenwart (Lübbe 2003), wie er für die Spätmoderne charakteristisch scheint, ebenfalls auf der Ebene kollektiver Selbstbilder stabilisieren lässt, bleibt einstweilen unbeantwortet. Die These der Raumzeit, die Weidenhaus im Zusammenhang biografischer Erzählungen formuliert, geht allerdings davon aus, dass sich auch in den individuellen Schilderungen gesellschaftliche Muster niederschlagen. Im Sinne der antidualistischen Perspektive auf personale Identitätspostulate (Kap. 2) sind die subjektiv artikulierten Weltsichten damit keineswegs vorsozial. Indem sie von Strukturen des Sozialen geprägt sind und auf diese reagieren wird die Raumzeit so zur sozialen Raumzeit. Implizit ist damit gesagt, dass raumzeitliche Muster auch in anderen Bedeutungszusammenhängen als denen von biografischen Erzählungen auffindbar sein müssen. Damit ist ein Indiz dafür gefunden, dass eine episodische Form der Verstetigung möglicherweise auch auf der Ebene von Kollektivierungsdiskursen rekonstruierbar ist. Zudem ist mit der Frage, wie die Teile der Zeit zueinander in Bezug gesetzt werden, ein hinreichend offenes Instrument gefunden, mit dem auch potenziell andere Konstellationen erfragt werden können. Genauso wie die Sterblichkeit des Menschen nicht zum Ausschluss der Vorstellung von Beständigkeit führt, scheinen auch Vorstellungen von Dauerhaftigkeit und Persistenz im Zusammenhang von beschleunigter Diskontinuität und zunehmender Entkopplung von historischen und lebensgeschichtlichen Episoden nicht ausgeschlossen.

Angesichts des reichen Fundus an empirisch gehaltvollem Theoriewissen erscheinen schließlich sowohl zyklische, lineare als auch episodische Zeitstrukturen möglich. Indem die eingangs gestellten Fragen (welche Zeitschichten benannt werden, wie diese beschrieben werden und wie sie zueinander in Bezug gesetzt werden) auf je verschiedene Weise beantwortet werden, kann die zeitliche Struktur der Wissensverhältnisse analysiert werden.

Werden lediglich zwei Zeithemisphären genannt, die unterschiedlich beschrieben und kontrastierend zueinander in Bezug gesetzt werden, so ist diese Zeitstruktur als zyklisch zu bezeichnen. Im Sinne der kalten Option (Lévi-Strauss) 
schwingt Zeit ewig im Kreis (Arendt). Die so hergestellte Wiederholungsstruktur entspricht dann der mythologischen, anti-geschichtlichen Zeit. Historischer Wandel wird nicht reflexiv, da im Modus ritueller Kohärenz durch Repetition (Jan Assmann) zeitlose Konstanz erzeugt wird. Da in dieser Zeitkonstruktion historische Veränderung zwar durch Adaption verarbeitet wird, diese Anpassungsleistung aber unsichtbar bleibt, kommt diese Wiederholungsstruktur der fundierenden Dimension des Funktionsgedächtnisses nahe (Aleida Assmann).

Werden hingegen mehrere Zeitschichten genannt, die unterschiedlich beschrieben, jedoch eng zueinander in Bezug gesetzt werden, so ist diese Zeitstruktur als linear zu bezeichnen. Im Sinne der heißen Option (Lévi-Strauss) schreitet Zeit voran. Mehrere Epochen werden benannt und im Bild der Geraden miteinander verbunden. Dies entspricht dann der geschichtlichen Zeit, in der über Vergangenheit berichtet, diese aber nicht wiederholt (oder erneuert) werden kann (Jan Assmann). Historische Veränderungen werden durch die chronologische Trennung der Ereignisse reflexiv. Da Zeit jedoch dann nicht mehr ewig im Kreis schwingt, kann sie nur noch dokumentiert werden. Dies entspricht der Dimension des Speichergedächtnisses (Aleida Assmann). Da sich die gedächtnispolitischen Strategien des Mythos und der Geschichte wechselseitig zumindest nicht vollständig ausschließen, bleibt abzuwarten, ob nicht auch im Modus linearer Zeitlichkeit eine fundierende Wiederholungsstruktur ausgebildet werden kann.

Werden schließlich mehrere Zeitschichten genannt, die unterschiedlich beschrieben werden, dabei aber nicht oder nur schwach zueinander in Bezug gesetzt werden, so ist diese Zeitstruktur als episodisch zu bezeichnen. Im Sinne einer schwachen logischen Kopplung (Weidenhaus) bilden Vergangenheit, Gegenwart und Zukunft weder Kreis noch Linie, sondern kommen den von Bauman beschriebenen pointillistischen Momenten nahe. Die Frage, ob auch die in Einzelereignisse zerfallende, diskontinuierliche Zeit durch eine Wiederholungsstruktur kontinuiert werden kann, bleibt einstweilen offen und muss ebenfalls empirisch beantwortet werden. Die abermalige Steigerung der Reflexivität gegenüber historischer Veränderung, die Einsicht, dass Zukunft auf bekannte Weise unbekannt bleibt (Kap. 1), deutet jedoch darauf hin, dass gerade in dieser »Ungewissheitsgewissheit (Marchart 2013) möglicherweise eine Klammer gefunden werden kann, mit der auch in der episodischen Zeitgestalt Anfang und Ende erneut miteinander verbunden werden können.

Segantinis Bild trägt den Titel »Rückkehr zur Heimat« und ist mit der hoffnungsvollen Botschaft verbunden, dass auch der Mensch in einen umfassenderen Kreislauf eingebunden und gleichsam aufgehoben ist. Der Horizont, unter dem der Trauerzug vorübergeht, bietet vielleicht noch eine Verbindung zur Ewigkeit, die in religiöser Zuversicht gründet; vor dem weiten Erwartungshorizont der deutschen Gegenwartsgesellschaft erscheint aber auch diese Gewissheit zu schwinden. Aber vielleicht bedeutet dies dennoch nicht das Ende der Bewältigung von Zukunfts- 
kontingenz, denn auch der emphatische Heimatbegriff ${ }^{11}$ und damit der Wunsch nach »Stillstellung« der Weltverhältnisse konnten erst entstehen, als sich Welterfahrungen bereits dynamisiert hatten (Rosa 2007:157). Hartmut Rosa folgert daraus: »Sofern Heimat die fraglose Gegebenheit unserer Weltbezüge meint, ist sie für den modernen Menschen unerreichbar, und doch kann sie auch nur für ihn einen Sinn und einen Wert haben.« (Ebd.). Vielleicht bedeuten also die zunehmend disparaten Erfahrungsräume und Erwartungshorizonte dennoch nicht das Ende der Konstruktion eines Bildes von Ewigkeit. Vielleicht lassen sich weitere Wiederholungsstrukturen finden, die es auch vermögen, über episodisch-diskontinuierliche Brüche hinweg Anfang und Ende miteinander zu verknüpfen.

\subsection{Räumliche Sinnbildung}

Begibt man sich vom ersten Stockwerk und dem Bild Segantinis ins Erdgeschoss der Alten Nationalgalerie, so durchläuft man einheitlich restaurierte Museumsräume, hinter denen die Zerstörungsgeschichte des Gebäudes verborgen bleibt. Die gleichmäßig gegliederten Kabinette der Museumsräume vermitteln den Eindruck eines unversehrten Gebäudes des 19. Jahrhunderts. Nichts deutet auf Spuren der Zerstörung hin - weder die Bodenfliesen, die roten Wände noch die indirekt beleuchteten, abgesetzten Decken, die rautenförmige Kassettierungen imitieren und durch vergoldetes Abschlussgesims gerahmt sind. Hinter einer Tapetentür im Erdgeschoss verbirgt sich jedoch ein Raum, in dem die ursprünglichen Raumhöhen und die bauzeitliche Gliederung der Räume sowie die Kriegszerstörungen, die nachkriegszeitlichen Notsicherungen und die Einbauten im Zuge der Sanierung des Gebäudes erkennbar sind. Dabei wirkt der Raum hinter der Tapetentür nicht bloß als Lagerstätte zusätzlicher historischer Informationen über das Museumsgebäude. Indem der Eindruck der ansonsten gleichmäßig geschlossenen Oberflächen und Decken gestört wird, können die erheblichen baulichen Veränderungen, die das Museum durchlaufen hat, überhaupt erst erkannt werden. Mit der Sichtbarkeit dieser Differenz ändert sich aber auch das Wissen um sämtliche andere Räume des Hauses. Anstatt lediglich eine frühere baugeschichtliche Phase darzustellen, werden durch den Raum hinter der Tapetentür alle Räume des Museums neu perspektiviert. Die ursprüngliche Deckenhöhe des alten, beschädigten Raumes macht es möglich, die abgehängten Decken der restaurierten Ausstellungsräume als solche zu erkennen. Nur indem man die kriegsbeschädigten Säulenkapitelle im Raum hinter der Tapetentür wahrnimmt, lässt sich erahnen, dass auch die Wände der gleichmäßig gestalteten Kabinette neu verkleidet wurden. Erst indem beide

11 Prägnant und sehr aufschlussreich fasst Hermann Bausinger die Begriffsgeschichte des deutschen Heimatbegriffs als Problemgeschichte zusammen (1990). 
Räume erfahrbar werden, können sie sich gegenseitig dergestalt illuminieren, dass wechselseitig neue Bedeutungsdimensionen konturiert werden.

Abbildung 6: Kriegszerstörter Raum (links), in dem die Geschichte der Alten Nationalgalerie thematisiert wird. Erst durch diesen Raum hinter der Tapetentür wird der Umfang der baulichen Veränderungen (rechts) erkennbar.


Bezeichnend in dem genannten Beispiel ist auch, dass die Abweichung von der Norm nur im Verborgenen verräumlicht wird. Die geheimnisvoll anmutende Tapetentür wird zum sprechenden Bild für diesen Umgang mit dem Abweichenden und somit zu einem als fremd charakterisierten Raum. Die Türschwelle zwischen den Räumen bildet einerseits eine Grenze, die eine Unterscheidbarkeit der Räume überhaupt erst herstellt und sie wechselseitig mit Bedeutung versieht. Ebenso wie durch die Akte der Grenzziehung die Räume überhaupt erst hergestellt werden, erhalten sie durch die Art der Relationierung ihren spezifischen Sinn. Im zuletzt beschriebenen Fall werden die verschiedenen Räume nur im Verborgenen kontrastierend gegeneinander gestellt. Hierin besteht ein Unterschied in der Verräumlichung zum Neuen Museum, wo den Kriegsschäden neue Baustoffe zur Seite gestellt wurden und die Kontrastierung der verschiedenen Zeitspuren zentral herausgestellt wurden. Es handelt sich also um verschiedene Codes der Verräumlichung, die, im Sinne der Konstruktion sozialer Zeit, unterschiedliche Teile der Zeit akzentuieren und Räume verschieden zueinander in Bezug setzen.

Analog zu den Basisfunktionen der historischen Sinnbildung und der Frage, wie die >Teile der Zeit miteinander verknüpft werden, sollen in diesem Unter- 
kapitel Analysekategorien räumlicher Sinnbildung entwickelt werden. So wie die Existenz chronologisch verschiedener Zeitpunkte noch nichts darüber aussagt, wie diese miteinander verbunden werden, so gilt dies auch für die Deutung von Räumen und ihre diskursive Konstruktion. Auch die Existenz verschiedener (Museums-)Räume sagt noch nichts über deren sinnhafte Deutung aus. In Anlehnung an die Bestimmung verschiedener sozialer Zeitgestalten lässt sich auch die Bestimmung der Raumkonstruktion in die folgenden Leitfragen übersetzen:

1) Welche Räume werden benannt?

2) Wie werden diese beschrieben?

3) Wie werden sie zueinander in Bezug gesetzt?

\subsubsection{Geschichtscontainer und Raummetaphern}

Dieter Läpple hat bereits 1992 vorgeschlagen, analog zur sozialen Konstruktion von Zeit auch den Raum in Abhängigkeit von Formen der Vergemeinschaftung zu konzeptualisieren (Läpple 1992:162). Unter Rückgriff auf die Terminologie Norbert Elias' plädiert Läpple dafür, auch Raum als »soziales Symbol« (a.a.O. 161f.) und als Resultat jeweiliger »menschlicher Syntheseleistung« (a.a.O. 164) zu verstehen. Um überhaupt sinnvoll nach einem Wie der Raumkonstitution fragen zu können, ist es somit erforderlich, auch die Herstellung von Räumen im Verantwortungsbereich sozialen Handelns zu verorten. Die raumtheoretische Heuristik Martina Löws erfüllt eben diese Bedingung. Indem Löw ihren Raumbegriff von absolutistischen Raumvorstellungen abgrenzt, entwickelt sie einen sozialwissenschaftlich brauchbaren, nicht mehr über Grenzen, sondern sich über Relationen konstituierenden Raumbegriff. Der fundamentale Weltbildunterschied zwischen einem euklidisch absoluten Containerraum (Newton) und einem relationalen Raumbegriff (Einstein) (Löw 2012:24ff.) besteht letztendlich darin, ob Menschen lediglich als Objekte im Raum verortet oder als Subjekte des Raumes verstanden werden. Dies hat zur Folge, dass Raum nunmehr nicht als universelle Gegebenheit, sondern als ein (stets nur vorläufiges) Resultat der Interaktion zwischen Struktur und Handeln verstanden wird (Löw 2008:38). Die Konstitution von Räumen wird laut Löw durch das Anordnen von sozialen und materiellen Gütern vollzogen (Löw 2012:263). Die zwei wichtigsten Mechanismen, die dem relationalen Raum zugrunde liegen, sind Spacing ${ }^{12}$ und Syntheseleistung. (a.a.O. 158).

Diese grundlegenden Herstellungsweisen des Raumes können für die Untersuchung der diskursiven Konstruktion von Räumen im Kontext der gebauten Umwelt nutzbar gemacht werden. Denn es handelt sich dabei um zwei analytisch zu

12 Löw verwendet hierbei das englische Spacing, da das deutsche Räumen, im Sinne von Leeren oder Entleeren, bereits mit einer anderen Bedeutung belegt ist (Löw 2012:158). 
trennende Aspekte der Konstitution von Raum (Löw 2018:73). Da mit Spacing die Anordnungen materieller Güter sowie die Platzierung von beweglichen Gütern und Menschen gemeint sind, können Aspekte des "Errichten[s], Bauen[s] oder Positionieren[s] « (Löw 2012:158f.) - etwa die architektonische Gestaltung sowie die Anordnung der Museumsexponate - analysiert werden. Da Syntheseleistungen die »Wahrnehmungs-, Vorstellungs- und Erinnerungsprozesse«, mit denen Güter und Menschen zu Räumen verknüpft werden, bezeichnen (a.a.O. 159), kann damit insbesondere die diskursive Deutung der platzierten Güter erklärt werden. Dadurch dass verschiedene Spacings je verschieden sinnhaft verknüpft werden, können so an einem Ort stets unterschiedliche Räume konstituiert werden (Löw 2008:43). Zudem bietet der Zusammenhang zwischen Syntheseleistung und Erinnerungsprozessen Einblicke in die Akzentuierung und den unterschiedlichen Gebrauch der Geschichte und erlaubt so die Einbindung der Zeit in die Raumkonstitution.

Analytisch ist es zudem sinnvoll, zwischen einer "Differenzlogik von Räumen« und einer »Eigenlogik von Orten« zu unterscheiden (2018:17ff.). Ein Ort ist demnach ein Platz, eine Stelle, die konkret benennbar und zumeist geografisch markiert ist (Löw 2018:17f.). >Berliner Museumsinsek ist die Bezeichnung eines konkreten Ortes, der geografisch bestimmt werden kann. Räume hingegen bezeichnen die vielfältigen, sich überlappenden und oft in Konkurrenz zueinander stehenden Anordnungen und Relationierungen verschiedener Akteure, die an einem Ort entstehen können (ebd.). Ein besonders eindringliches Beispiel für die Differenzlogik von Räumen im Kontext von sozialem Erinnern bieten Aleida Assmanns Darstellungen über verschiedene Arten, die Gedenkstätte des Todeslagers in Auschwitz räumlich anzuverwandeln. Dabei wird jedoch nicht systematisch zwischen Ort und Raum unterschieden. Assmann verwendet lediglich den Begriff `Ort . Dies führt irritierenderweise dazu, dass damit sowohl der konkrete Ort Auschwitz (übereinstimmend mit der Terminologie Löws) gemeint ist, als auch die durch jeweilige Bedeutungszuschreibung hier entstehenden Räume (konträr zu der von Löw vorgeschlagenen Unterscheidung). Dennoch können dadurch die Pluralität und Synchronität von verschiedenen und teilweise konkurrierenden räumlichen Deutungen veranschaulicht werden.

Assmann schreibt, dass die Vielschichtigkeit des Ortes (Auschwitz) vor allem in der Heterogenität der Erinnerungen und Perspektiven derer liege, die ihn aufsuchen (2010:329). Auschwitz wird so für die Polen ein Erinnerungsort ihrer nationalen Leidensgeschichte, für Opfergruppen ein Ort der Erfahrung erlittenen Leids, für Überlebende und deren Familien zu einem Friedhof, für Besuchende ohne Verbindung zu den Opfern ein Museum und Tatort, für kirchliche oder politische Gruppen ein Wallfahrtsort als Leidensstätte prominenter Märtyrer, für Staatsoberhäupter eine Kulisse öffentlicher Bekenntnisse, für Historiker ein archäologischer Schauplatz (a.a.O. 330, Herv. JK). Als all dies kann der konkrete Ort räumlich aufgefasst und damit anverwandelt werden. Assmann folgert schließlich: 
»So gegenständlich konkret [der Ort] ist, so vielfältig präsentiert er sich in den unterschiedlichen Perspektivierungen. [...] Unter dem Firnis offizieller Sinnstiftung kommt heute immer mehr die Vielstimmigkeit und meist auch Unvereinbarkeit von Erinnerungen zum Vorschein.«(Assmann 2010:330).

Damit wird deutlich, dass es kein Erinnern der Orte im Sinne eines genitivus subjectivus geben kann, indem Orte selbst zu Subjekten werden. Stattdessen bestehen Gedächtnisorte immer als Erinnerungen an die Orte im Sinne eines genitivus objectivus, da ein Gedächtnis der Orte nicht unabhängig von menschlichen Riten, Interessen und Deutungen bestehen kann (Assmann 1999:76). Es ist genau dieses Erinnern an die Orte und an den Orten, welches verschiedene Räume entstehen lässt. Durch die begriffliche Trennung von Ort und Raum kann dies deutlicher gemacht werden. Denn die konkreten Orte, etwa des Neuen Museums Berlin oder des Militärhistorischen Museums Dresden, fungieren nicht lediglich als Geschichtscontainer, an denen ein bestimmter historischer Wissensbestand hinterlegt ist, der, sofern man ihm am Ort begegnet, quasi natürlich Räume entstehen lässt. So wird durch unterschiedliche Spacings und Syntheseleistungen der Ort des Neuen Museums gleichzeitig als Raum "größtmöglicher Harmonie« und als »RaumMonster« hergestellt.

Ebenfalls von der Annahme einer synchronen Vielschichtigkeit von Räumen ausgehend, analysiert Beate Binder in einer Studie über die Debatte um das Berliner Stadtschloss unterschiedliche räumliche Bedeutungsproduktionen von Bürgerinitiativen. Dabei lassen sich unterschiedliche Vorstellungen von Raum, von daran gebundenen historischen Narrativen, Vorstellungen von Stadt, Urbanität sowie von Stadt- und Staatsbürgerschaft darstellen (Binder 2009:19). Binder geht davon aus, dass erst die sinnhafte Wahrnehmung und Deutung des Raumes »individuelle wie kollektive Sinnstiftung und Identitätskonstruktionen« ermöglichen (a.a.O. 15). Die verschiedenen Bedeutungsproduktionen ergeben sich nicht aus einer »abgespeicherte[n] oder verborgene[n] authentische[n] Geschichte, die, wird sie nur sichtbar gemacht, Identität stiftende Prozesse in Gang setzt«. (2009:57). Binder schlägt deshalb vor, »die Vorstellung einer ursprünglichen, quasi natürlichen Verbindung von Raum und Geschichte zu überwinden. «Stattdessen fragt Binder nach »den Handlungsräumen «, die durch »Bezugnahmen auf Geschichte und die Etablierung historischen Wissens geschaffen werden.«(Ebd.). Auch Binder interessiert sich für die sozialen Praktiken, die Räume im Sinne des genitivus objectivus entstehen lassen und diese nicht im Sinne des genitivus sujectivus ermächtigen.

Trotz der geteilten Ansicht, dass Raum nicht unabhängig von sozialem Handeln und von Bedeutungszuschreibungen gleichsam aus sich selbst heraus spricht, besteht im Kontext der sozialen Gedächtnisforschung zumindest die Tendenz, dem Raum eine ihm inhärente Vergangenheit zuzuschreiben und ihn damit dennoch als Subjekt und eigensinnigen Geschichtscontainer zu beschreiben. Selbst bei Beate 
Binder klingt diese Vorstellung einer im Raum abgelagerten Bedeutung an, wenn sie schreibt, dass "Stadtlandschaften wie Palimpseste [sind], auf deren Oberfläche sich Zeichen überlagern, sich kreuzen und miteinander kommunizieren «(Binder 2009:15). Spuren einer Vorstellung vom Containerraum bleiben auch erhalten, wenn Aleida Assmann von der »Stadt als Palimpsest und Geschichtsspeicher« spricht und danach fragt, wie sich Geschichte im städtischen Raum »einschreibt« und »verankert « (Assmann 2009:13). Da Begriffe wie »wiederauftauchen« und »sichern« (Binnewerg 2013:94) zumindest den Eindruck erwecken, dass Räume als Behälter für historische Fakten fungieren, konfligiert das Bild des Containerraumes nicht nur mit einem relationalen Raumbild, sondern ebenso mit der zuvor behaupteten Rekonstruktivität der Vergangenheit (Kap. 2). So wie Geschichte immer nur als Produkt der Gegenwart entsteht, so entstehen Räume immer nur durch die Bedeutungszuschreibung an konkrete Orte. Da Räume erst durch das verschiedene und oft konfliktreiche Erinnern an und das Erfahren oder Beerben von Orten hergestellt werden, erscheint der Begriff der Verräumlichung hilfreich. Damit soll die prozessuale, synchrone und anhaltende Semantisierung von Orten unterstrichen werden.

In den referierten Perspektiven artikuliert sich vielleicht weniger ein konzeptionelles Problem als vielmehr der nicht konsequent eingehaltene Verzicht auf Metaphern, die eine Eigensinnigkeit von Räumen suggerieren. Besonders deutlich wird die metaphorische Verwendung räumlicher Begriffe im Kontext von Erinnerungsdiskursen anhand Pierre Noras Erinnerungsorten. So sind darunter doch weniger geografische Orte als vielmehr kulturelle Topoi zu verstehen (Siebeck 2017:3). Da damit sowohl natürliche als auch artifizielle Gegenstände, ebenso konkrete Orte wie abstrakte Dinge gemeint sind (Nora 1989:18), erscheint der englische Terminus »realms of memory« (Nora 1996), der ins Deutsche mit Erinnerungsgefilde rückübersetzt werden kann, angemessener. Die Erinnerungsorte entsprechen eher semantischen Feldern, die zudem einer anhaltenden Transformation ihrer Bedeutung unterliegen. Der metaphorische Gebrauch des Begriffs >Ort bezeichnet hier also eher symbolische Bedeutungsgehalte kultureller Zeichenträger. So werden etwa die Marseillaise (Vovell 2005:63ff.) oder die Tour de France (Vigarello 2005:452ff.) zu französischen Erinnerungsorten, wie auch Goethe zum deutschen Erinnerungsort avanciert (Borchmeyer 2001:187ff.). Um diese Raummetaphern bei der Analyse der Raumkonstruktionen auszuschließen, ist es wichtig, dass die so rekonstruierten Phänomene tatsächlich räumlichen Charakter haben. Martina Löw und Gunter Weidenhaus haben deshalb vorgeschlagen, von räumlichen Phänomenen - in Abgrenzung zu Raummetaphern - nur dann zu sprechen, wenn diese über ein »Wo in der Welt« verfügen (Löw/Weidenhaus 2017:555). 
Das überaus erfolgreiche Projekt des französischen Historikers Pierre Nora ist zudem durch eine Ambivalenz geprägt. ${ }^{13}$ So besteht der wissenschaftliche Anspruch Noras einerseits in einer konstruktivistischen Geschichtswissenschaft, die sich in einer reflexiven Wende selbst zum Gegenstand macht (Nora 1989:11). Anstelle der Geschichte sollen nun die Akte der Geschichtsschreibungen (im Plural) selbst thematisiert werden. Indem das Projekt der Lieux de Mémoire verschiedene Geschichtsauffassungen zusammenträgt, steht nicht mehr die Vergangenheit, »wie sie eigentlich gewesen ist«, sondern ihre "ständige Wiederverwendung« im Zentrum des Interesses. Noras Ambition besteht also in einer Geschichtsschreibung »Zweiten Grades« (Nora 2005:16). Andererseits verfügt das Projekt Noras auch über eine klare gesellschaftspolitische Dimension, indem es selbst Akte der Kanonisierung vollzieht. Diese würden ebenso in der Gegenwart notwendig, da ein »end of a traditional memory« in Sicht gerät (Nora 1989:11). Wohlwissend um diesen Doppelcharakter, platziert Nora sein Projekt explizit »between Memory and History« (Nora 1989).

Im doppelten Wesen der lieux de mémoire wird abermals die bereits dargestellte Dialektik zwischen der kritisch-konstruktivistischen Geschichte (histoire) als wissenschaftlicher Disziplin und der politischen Sinnstiftung im Modus des Erinnerns (mémoire) erkennbar - womit Nora selbst zum »Gedächtnisentrepreneur « (François/Puschner 2010:16) wird. In der »monumentalen Kanonisierung nationaler Erinnerungsorte« bleibt also »trotz aller postmodernen Reflexivität« ein »national-affirmativer Gehalt« existent (Siebeck 2017:7f.). Ohne dies an dieser Stelle weiter zu problematisieren, gerät mit dem Versuch der Kanonisierung französischer, deutscher oder europäischer Erinnerungsorte noch ein weiteres Problem bei der Untersuchung von Räumlichkeit im Kontext von Identitätsbehauptungen in den Blick. So wie der Raum erst durch Produktions- und Bezeichnungsprozesse (Lefebvre 2006:334) hergestellt werden muss, gilt es auch bei der Analyse der Raumkonstruktionen, diese Prozesse empirisch zu rekonstruieren und nicht etwa durch die apriorische Setzung räumlicher Rahmen zu begrenzen und damit einzuengen.

\subsubsection{Empirische Rahmung}

Wie die Darstellung des relationalen Raumbegriffs gezeigt hat, fungieren Räume nicht als Geschichtscontainer. Sie sprechen nicht aus sich selbst heraus, obgleich

13 Ableger des Projekts der Lieux de Mémoire finden sich nicht nur in den deutschen Erinnerungsorten (François/Schulz 2001) und den europäischen Erinnerungsorten (Boer et al. 2012), sondern mittlerweile auch in Sammelwerken zu ökologischen Erinnerungsorten (Uekötter 2014), Erinnerungsorten des Christentums (Markschies et al. 2010) sowie Erinnerungsorten der DDR (Sabrow 2009). 
in Gedächtnisdiskursen eine Vielzahl von Metaphern (Palimpsest, Spuren der Geschichte) auffindbar ist, die eben dies suggerieren. Eine weitere metaphorische Verwendung stellt der räumliche Begriff des Rahmens dar. Die apriorische Rahmung der räumlichen Bezugsgrößen (etwa als deutsche oder französische Erinnerungsorte) ist für die Untersuchung räumlicher Konstruktionsformen im Kontext von Selbstthematisierung deshalb so problematisch, da sie eventuell durch die Sprechenden selbst hergestellte räumliche Rahmungen ausschließt und diese damit für die Analyse verloren gehen.

Für Halbwachs sind es die sozialen Rahmungen, die eine Erinnerung des Einzelnen überhaupt erst möglich machen, da außerhalb sozialer Bezugsrahmen kein individuelles Gedächtnis möglich ist (Halbwachs 1985:121, Orig. 1925). Diese bilden »raum-zeitliche Ordnungsraster«, die eine »Selbstobjektivierung und Selbststrukturierung « überhaupt erst ermöglichen (Assmann 1995:59). Konkrete und abstrakte Rahmungen mobilisieren unterschiedliche Erinnerungsbestände, wobei Vergangenheit nicht einfach wiedergefunden, sondern immer wieder aufs Neue konstruiert wird (ebd.). Entgegen der Vorstellung von einem statischen Bilderrahmen ist damit also ein immer wieder neu zu definierendes Bezugssystem gemeint und nichts endgültig Festgelegtes. Wie die Rahmen Eindrücke affizieren, so werden sie auch durch Eindrücke modifiziert (Halbwachs 1985:189). Den Rahmen von Familiengedächtnissen bildet also keineswegs die Blutsbande ihrer Mitglieder (a.a.O. 203ff.). Damit werden biologistische Argumentationen eindeutig zugunsten einer soziologischen Perspektivierung zurückgewiesen. Wer als Teil der Familie angesehen wird und wer sich wann außerhalb des Familienrahmens befindet, muss immer wieder neu verhandelt werden (a.a.O. 239). Was Halbwachs beschreibt, ist also nicht eine einmalig gerahmte Gemeinschaft, sondern der Prozess der Vergemeinschaftung, welcher stets neue und immer wieder andere Rahmungen vollzieht. Indem etwa durch Heirat der familiale Bezugsrahmen wechselt und so anderes soziales Wissen akzentuiert wird, werden schließlich auch andere Gedächtnisse mobilisiert. Daraus folgt, dass die relevant gemachten räumlichen Bezugssysteme als unabgeschlossene und unabschließbare Prozesse der Rahmung zu verstehen sind. ${ }^{14}$

Da Rahmen nicht gegeben sind, sondern immerzu neu hergestellt werden, müssen auch die Gegenstandsbestimmungen des Diskurses immer wieder neu bestimmt werden. Hierin wird abermals die empirische Rahmung des Diskurses re-

14 Geht es Halbwachs um die affektive Dimension der Erinnerung, die durch Rahmen akzentuiert wird, so stehen bei Coffman die handlungsspezifischen Situationsbestimmungen im Zentrum (Goffman 1964). In Anlehnung an den Begriff der neglected situation (Goffman) ließen sich die Raumbestimmungen im Diskurs als neglected spaces bezeichnen. Eine detailliertere Darstellung der Rahmenkonzeptionen von Halbwachs und Coffman sowie eine Einschätzung ihrer theoretischen Reichweiten bietet Oliver Dimbath (2013). 
levant und auf die Analyse der Raumkonstitution zugespitzt. Das Vorhaben, eine deutsche kollektive Identität zu analysieren, würde einen Bedeutungsrahmen von außen festlegen, der für die Lebenswelt der Untersuchten eventuell gar keinen sinnvollen Bezugspunkt darstellt. Mit hoher Wahrscheinlichkeit jedoch wäre dieser Rahmen nicht die einzige relevante räumliche Bezugsgröße. Der zu untersuchende Gegenstand würde mit dieser Setzung selbst erst (normierend) hergestellt werden. Diese Form der Herstellung durch Unterstellung gilt es zu vermeiden.

Die Multiplizität und Dynamik gerade von räumlichen Gegenstandsrahmungen lassen sich nicht nur in konkreten Handlungskontexten, sondern auch auf der Ebene von Diskursen nachweisen. Anhand des denkmalpflegerischen Gutachtens, welches eines der zentralen Ausgangsdokumente des Diskurses der ergänzenden Wiederherstellung des Neuen Museums darstellte, kann dies verdeutlicht werden. Die Autoren heben die Besonderheit des Ortes hervor, indem sie ihn in eine Vielzahl räumlicher Rahmungen einbinden.

»Die Berliner Museumsinsel in der Mitte der deutschen Hauptstadt bildet ein einzigartiges Ensemble von Baudenkmalen hervorragender Architekturpersönlichkeiten in einer städtebaulich unvergleichlichen Lage. Berlin darf sich glücklich schätzen, mit den fünfMuseen und ihren Sammlungen einen Komplex künstlerischer und historischer Werte zu besitzen, der weltweit als einzigartig gilt. (Badstübner et al. 1994:9, Herv. JK).

In diesem Parforceritt durch verschiedene räumliche Bezugsgrößen werden unterschiedliche Rahmen abgesteckt und die Bauwerke der Museumsinsel gleichzeitig in zahlreiche räumliche Bezüge eingebunden. So definieren die Baudenkmale einerseits einen architektonischen Raum; die Baudenkmale bilden ein »Ensemble« und gehören zusammen. Andererseits werden sie zum Teil eines Stadtraumes (Berliner Museumsinsel). Ihre unmittelbare Nähe zueinander stellt eine »städtebaulich unvergleichliche Lage« her. Die Museumsinsel bildet darüber hinaus nicht nur das Zentrum Berlins, sondern ist die »Mitte der deutschen Hauptstadt « und damit der Nation. Schließlich ist der Museumskomplex auch in globalem Maßstab von Bedeutung; er ist »weltweit einzigartig«. Die variable Einbindung in unterschiedliche räumliche Rahmungen kann somit nur empirisch bestimmt werden, da mit einer Festlegung der räumlichen Bezugsrahmen andere Aspekte für die Analyse verloren gingen.

Ebendies geschieht etwa in der vergleichenden Untersuchung verschiedener Authentizitätsbegriffe von Tino Mager (2016). Anhand eines Vergleichs zwischen dem wiederhergestellten Neuen Museum in Berlin und den Shinto-Schreinen im japanischen Ise analysiert er unterschiedliche Vorstellungen von Authentizität im Kontext von architektonischem Erbe. Dabei geht es Mager nicht darum, eine verbindliche Definition des Authentizitätsbegriffs darzulegen, sondern darum, das schillernde Wesen dieses Begriffs als Potenzial für die Denkmalpflege nutzbar zu 
machen (2016:230). Da der Begriff der Authentizität »selbst stets verhandelbar« sei, trete er »als ideales Konzept einer Disziplin zutage, die ihre gesellschaftliche Relevanz aus einem permanenten Kommunikationsprozess schöpft." Authentizität sei deshalb abhängig von »Kulturkreis und Erbengemeinschaft« (ebd.). Gerade weil der Begriff so schillernd sei, eigne er sich für die Denkmalpflege, die auf diese Form anpassungsfähiger Konzepte und deren Unschärfe angewiesen sei. So überzeugend das Argument ist, dass gerade in der Bedeutungsoffenheit des Authentizitätsbegriffs seine Funktionalität für die Denkmalpflege liegt, so bedeutungsgeschlossen und deshalb problematisch ist die Vorgehensweise Magers im Hinblick auf die räumliche Eingrenzung seines Gegenstandes.

$\mathrm{Da}$ er auf eine empirische räumliche Bestimmung seiner Untersuchung verzichtet, folgt eine weitreichende Generalisierung der Untersuchungsergebnisse. Die ergänzende Wiederherstellung des Neuen Museums wird so zum Beleg eines materialfixierten europäisch-deutschen Verständnisses von Authentizität. Die periodische Erneuerung der Ise-Schreine wird schließlich zum pars pro toto der japanischen Kultur schlechthin. Mager spricht dann von einem "japanischen Schönheitsempfinden « (2016:200) oder vom »Geschichtsbewusstsein der Japaner« (a.a.O. 201). Würde der Untersuchungsgegenstand jedoch empirisch gerahmt und die ergänzende Wiederherstellung des Neuen Museums (welche neben Konservierung und Restaurierung auch partielle Rekonstruktionen umfasste) nicht unter direkte Vormundschaft der deutschen oder europäischen Kultur gestellt werden, dann könnte ebenfalls aufgezeigt werden, dass etwa die Befürworter einer originalgetreuen Wiederherstellung des Neuen Museums einen Authentizitätsbegriff verwenden, der durchaus Parallelen zu dem von Mager in Ise beschriebenen und für Japan reservierten Authentizitätsverständnis aufweist. Die Vertreterinnen der Gesellschaft Historisches Berlin, für die nur die Rekonstruktion des Neuen Museums als einzig authentisch galt, bleiben jedoch bis auf zwei Stellen (2016:173, 211) in Magers Untersuchung unerwähnt.

Auch die Frage, ob es sich bei den Untersuchungsgegenständen um ein Berliner, ein deutsches, ein europäisches oder ein Welt-Erbe handelt, darf nicht apriorisch festgelegt werden. Durch die normierende (nicht-empirische) Zuschreibung gingen möglicherweise andere relevante räumliche Bezugsgrößen für die Analyse verloren. Selbst der Konstruktionsmodus eines kollektiven Selbstbilds im Kontext des Militärhistorischen Museums, welches dem Bundesministerium der Verteidigung untersteht, kann somit nicht per se als typisch deutsche Form der Selbstthematisierung beschrieben werden, wenngleich der nationale Bezugsrahmen offensichtlich hoch relevant bleibt. Um benennen zu können, welche räumlichen Bezugsgrößen in den jeweiligen Raumkonstitutionen Bedeutung erlangen, muss dies stets den Diskursen selbst entnommen werden und darf nicht von außen festgelegt werden. So wie eine normierende Zuschreibung von Identitäten ausgeschlossen werden muss (Kap. 2), so sind gerade die räumlichen Rahmen der Untersuchung 
ebenso wie die Phänomenstruktur der Diskurse (Kap. 3) rekonstruktiv zu bestimmen. Apriorische Unterstellungen würden den Gegenstand erst herstellen und damit das eigentlich zu Erklärende bereits vorwegnehmen. Dies ist insbesondere für die Analyse der Raumkonstruktionen entscheidend, denn die diskursive Deutung der Architektur (Syntheseleistungen) knüpft teilweise weit ausgreifende Relationen. So werden etwa in der Diskursivierung des Neuen Museums enge Bezüge $\mathrm{zu}$ den benachbarten Gebäuden der Museumsinsel geknüpft. Gerade in Bezug auf die räumliche Rahmung des Gegenstandes ist es deshalb wichtig, abermals darauf hinzuweisen, dass die Diskurse keinesfalls an den Schwellen der Museumstüren enden.

\subsubsection{Die Codes der Verräumlichung}

Als Vorbedingungen der Analyse von Raumkonstruktionen im Kontext der hier zu analysierenden Diskurse sind also folgende Voraussetzungen zu beachten: Erstens: Raum ist nicht als Invariante und insbesondere nicht als Geschichtscontainer zu verstehen. Zweitens: Konkrete Ortsbezogenheit muss gegeben sein, um Raummetaphern auszuschließen. Drittens: Räumliche Bezugsrahmen müssen empirisch bestimmt werden. Davon ausgehend kann nun das Wie der Raumkonstruktion näher untersucht werden. Auch dies geschieht in drei Schritten. Erstens ist darauf hinzuweisen, dass Akte der Grenzziehung konstitutiv für alle Raumkonstruktionen sind. Da Grenzen mindestens zwei Räume zueinander in Bezug setzen (Löw/Weidenhaus 2017), kann durch die Analyse der Grenzziehungen festgestellt werden, welche Räume überhaupt benannt werden. Zweitens kann dann danach gefragt werden, wie die so abgegrenzten Räume jeweils qualifiziert werden. Als hilfreich erweist sich dafür die Charakterisierung von Räumen in eigenräumliche Endosphären sowie fremdräumliche Exosphären. Drittens kann dann nach den Codes der Verräumlichung gefragt werden; wobei die Frage zentral ist, wie die als verschieden charakterisierten Räume zueinander in Bezug gesetzt werden und wie dabei Ein- und Ausschlüsse vollzogen werden. Unter einem Code der Verräumlichung verstehe ich deshalb die Logik der Relationierung, mit der Räume zueinander in Bezug gesetzt werden.

\section{Schöpferische Grenzziehung}

Versuche, das Wie der Konstruktion sozialer Räume zu verstehen, wurden insbesondere in der Literaturwissenschaft (Hallet/Neumann 2009:19) und der Semiotik unternommen. Einen klassischen Ansatz bietet die räumliche Kultursemiotik Jurij Lotmans, welche zudem einen Bezugspunkt für die Entwicklung des Paradigmas des kulturellen Gedächtnisses darstellte (Assmann 1997:22). Außerdem haben die Arbeiten Lotmans im Zuge des Spacial Turns in den Kulturwissenschaften eine Vielzahl empirischer Arbeiten angeregt (S. Frank/Ruhe/Schmitz 2012; Ezli 2012; M. 
Frank 2012) und $\mathrm{zu}$ konzeptionellen raumtheoretischen Überlegungen inspiriert (Koschorke 2012). Der weitgefasste Anspruch des russischen Semiotikers kommt in seinem strukturalistischen Werk bereits früh zum Ausdruck. Da ihm zufolge jeder Text und jedes Kunstwerk stets endliche Modelle einer unendlichen Welt darstellen (1972:301), erhebt die räumliche Semiotik Lotmans den Anspruch einer allgemeinen Kulturtheorie. Jede Erzählung verfügt über ein doppeltes Wesen, da jeder einzelne Text gleichzeitig sowohl ein bestimmtes spezielles als auch ein universales Objekt modelliere (a.a.O. 303). Da für Lotman jedwedes »Alles«, also jeder Ausschnitt aus der Wirklichkeit, sobald er artikuliert wird, räumlichen Charakter annimmt (a.a.O. 312), ist die räumliche Struktur literarischer Texte (sowie von Erzählungen allgemein) stets mit der räumlichen Struktur der Welt im Allgemeinen gekoppelt: »Infolgedessen wird die Struktur des Raumes eines Textes zum Modell der Struktur des Raumes der ganzen Welt, und die interne Syntagmatik der Elemente innerhalb eines Textes - zur Sprache der räumlichen Modellierung.«(Lotman 1972:312).

Die räumliche Struktur der Welt entspricht dabei aber gerade nicht der eines als absolut gedachten Welt-Raumes. Was Lotman mit der "Struktur des Raumes der ganzen Welt « meint, besteht vielmehr im Organisationsprinzip, der dem »jeweiligen Kulturtyp eigentümlich ist « (a.a.O. 313). Hierin liegt der Verbindungspunkt zwischen den räumlichen Strukturen literarischer Texte und einer jeweiligen kulturellen Gesamtheit. Damit ist auch gesagt, dass es Lotman nicht um das Verhältnis zwischen Text/Kunstwerk und Raum, sondern um das Verhältnis zwischen kulturellen Raumbildern und den sich in Bezug darauf verräumlichenden kulturellen Produkten geht. ${ }^{15}$

Die große Konstante im Werk von Lotman bildet das Konzept der Grenze (M. Frank 2012:219). Anhand des Begriffs Semiosphäre kann dies verdeutlicht werden. Darunter versteht Lotman ein semiotisches »Gesamtsystem«, welches den einzelnen Zeichenakt überhaupt erst ermöglicht (Lotman 1990:290). Semiosphären können somit als kulturelle Grammatiken bezeichnet werden, die das Organisationsprinzip der Einzelelemente darstellen und zudem durch eine doppelte Spannung gekennzeichnet sind. Neben der Ungleichmäßigkeit im Inneren sind alle Semiosphären durch die Getrenntheit von Äußerem charakterisiert (a.a.O. 290). Die Grenze wird somit zur Grundbedingung eines jeden kulturellen Zeichensystems.

»Weil die Grenze einen notwendigen Teil der Semiosphäre bildet, braucht die Semiosphäre eine snichtorganisierte äußere Umgebung und konstruiert sich diese,

15 Problematisch erscheint dabei, dass diese Raumbilder für Lotman weitgehend mit »national-sprachlichen Raummodellen « (Lotman 1972:313) zusammenfallen. Eine Kritik an dieser Reduktion des Kulturbegriffs auf verschiedene Nationalkulturen findet sich bei Susi Frank (Frank/Ruhe/Schmitz 2012). 
falls sie fehlte. Die Kultur schafft nicht nur ihre innere Organisation, sondern auch ihren eigenen Typ der äußeren Desorganisation.«(Lotman 1990:293).

Die Grenze ist also immer ein »zweisprachiger Mechanismus« (Lotman 1990:291), wodurch sie zum Bereich beschleunigter semiotischer Prozesse wird (a.a.O. 293). An der Grenze wird das Zentrum herausgefordert, so wie es dadurch überhaupt erst konstruiert werden kann. Die Peripherie und nicht das Zentrum generiert so neue Bedeutung.

»Eine der grundlegenden Mechanismen der semiotischen Individuation ist die Grenze. [...] Der Raum innerhalb dieser Grenze wird als >unser eigener<, als >vertraut<, >kultiviert<, ssicher<, sharmonisch organisiert< usw. erklärt. Ihm steht der

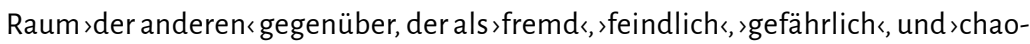
tisch< gilt.«(Lotman 2010:174).

Das Andere wird zur Bedingung für das Eigene und zu dessen Zerrbild; es besteht ein »spiegelbildliches Verhältnis von unserer und anderer Welt« (Lotman 2010:175). $\mathrm{Zu}$ betonen ist, dass auch die Dissoziation und die Behauptung von Differenz eine Assoziation und eine sinnhafte Verknüpfung darstellen. Da Raumsynthesen gerade auf diskursiver Ebene oft durch kontrastierende Vergleiche vollzogen werden, bleibt auch die kontrastierende Gegenüberstellung von Räumen eine Syntheseleistung im Sinne Martina Löws. Wichtig dabei ist nun, dass erst die Grenzüberschreitung Räume zueinander in Bezug setzt und diese so überhaupt erst in Erscheinung treten. Erst indem Grenzen überschreiten werden, werden die verschiedenen Räume diesseits und jenseits davon hergestellt. Genau hierin erkennt Lotman das »topologische Merkmal der Grenze« (1972:327).

Dabei fällt dem beschriebenen Sujet (dem Ereignis) eine konstitutive Rolle zu. Denn die Konstruktion von Räumen ist für Lotman immer an die Bewegung der als Handelnde beschriebenen Personen gebunden. Für die Analyse der räumlichen Strukturierung der Wissensverhältnisse, die in den jeweiligen Kollektivierungsdiskursen stabilisiert werden, eignet sich der Sujet-Begriff deshalb in besonderem Maße, da er dem Plot der Erzählung und damit dem entspricht, was Reiner Keller die narrative Struktur der Diskurse nennt (Kap. 3.5). Sujetlose Texte haben »klassifikatorischen Charakter « und bestätigen lediglich eine bestimmte Ordnung (Lotman 1972:336f.), da in ihnen keine Handlung stattfindet. Idealtypen sujetloser Texte bilden etwa Telefonbücher oder Kalender. Zwar ist etwa die tabellarische Auflistung historischer Daten des Neuen Museums (Henze/Sommer 2007) oder des Militärhistorischen Museums (Müller 2012) zum Verständnis ihrer Baugeschichte unerlässlich; ihr Aussagegehalt hinsichtlich relevanter räumlicher Bezüge ist jedoch gering. Dies ändert sich allerdings grundsätzlich in sujethaltigen Texten, die den überwiegenden Teil der analysierten Dokumentenkorpora bilden. Insbesondere indem die Architekten und Restauratoren, aber auch die Angehörigen der Bun- 
deswehr oder des Landesdenkmalamtes in den jeweiligen narrativen Strukturen als Figuren beschrieben werden, die das Recht haben (oder sich das Recht nehmen), Grenzen zu überschreiten, werden sie zu Handlungsträgern unterschiedlicher Sujets. Auch hier wird die Handlung der gesamten Erzählung (im wörtlichen Sinn) erst in Gang gesetzt - durch das Überschreiten von Grenzen (Lotman 1972:338). Es wird nicht nur eine bestehende Ordnung abgebildet, sondern diese wird gleichzeitig spezifisch bewertet. Was von wem als Grenzüberschreitung beschrieben wird und wie die dabei handelnden Figuren charakterisiert werden, variiert in den jeweiligen narrativen Strukturen der zu analysierenden Diskurse. Ob der Architekt David Chipperfield als >Zerstörer < der Museumsinsel oder als deren >Vollender $<$ dargestellt wird, gewährt einen unmittelbaren Blick auf zwei grundsätzlich verschiedene Sujets und damit gänzlich andere Syntheseleistungen, mit denen Räume zueinander in Bezug gesetzt werden.

Erst der Plot der Handlung macht die Grenze und damit die Räume, die dadurch getrennt werden, sichtbar; ebenso wie die jeweilige Grenzziehung dadurch herausgefordert und infrage gestellt wird. Das Überschreiten der Grenze ist also ein produktiver Akt der Bedeutungsgenese (Semiose). In diesem Sinne ist die Bewegung über die Grenze »schöpferisch« (a.a.O. 323). Bewegung ist allerdings auch subversiv, indem andererseits räumliche Ordnung infrage gestellt wird. Dies meint Lotman, wenn er folgert, »das Sujet ist revolutionär« (1972:339). Obwohl Lotman Raum als dynamisches und somit immer nur vorläufiges Ergebnis »räumlicher Modellierung« (a.a.O. 312) versteht und damit ein relationales Raumverständnis vertritt, gelingt es ihm dennoch, Grenzen - genauer die Akte der Grenzziehung und -überschreitung - zentral zu konzeptualisieren. Dies ist deshalb beachtenswert, da im Weltbild des relationalen Raumes die Schwierigkeit besteht, Grenzen zu thematisieren. Dies ist dadurch begründet, dass Raum gerade nicht von bestimmbaren oder begrenzten Rändern gedacht wird, sondern durch die Interaktion der Subjekte und somit eher als Netzwerkstruktur, nämlich als relationale (An-)Ordnung von Gütern und Lebewesen an Orten (Löw 2012, Orig. 2001). Dies hatte zur Folge, dass Grenzen nur wenig Aufmerksamkeit zuteilwurden und Grenzphänomene kaum in die raumsoziologische Forschung einbezogen wurden (Löw/Weidenhaus 2017:554). Da Grenzen allerdings Differenzen im Raum konstruieren und konstatieren (Eigmüller/Vobruba 2016:3) und Differenzierung zwischen Hier und Dort vollziehen (ebd.), ist der Begriff der Grenze für eine raumsoziologisch ausgerichtete Identitätsforschung von eminenter Bedeutung.

Einen Versuch, relationalen Raum mit Grenzen zu denken und damit eine konzeptionelle Leerstelle in der Raumsoziologie zu schließen, haben Martina Löw und Gunter Weidenhaus unternommen und kommen zu ähnlichen Ergebnissen wie Lotman. Zum einen gehen sie ebenfalls von einer performativen Grundbedingung der Grenze aus: »If it cannot be stated what is supposed to be divided by the border under what conditions, there is no border (Löw/Weidenhaus 2017:560). Werden 
Grenzen nicht relevant gemacht, existieren sie nicht; zumindest nicht in einem sozial beobachtbaren und damit soziologisch relevanten Sinn. Dies bedeutet auch für das Beispiel der eingangs dargestellten Museumsräume, dass noch nicht jede Türschwelle bereits eine Grenze darstellt. Sie muss als solche thematisiert werden. Des Weiteren betonen auch Löw und Weidenhaus die Ko-Konstruktion von mindestens zwei Räumen im Moment der Grenzziehung: »borders place at least two spaces in specific relation to one another « (a.a.O. 555). Dies führt dazu, dass die Momente der Grenzziehung entscheidend für die Raumkonstitutionen werden. Betrachtet man Grenzen als Differenzierungsleistungen, die mindestens zwei Räume zueinander relationieren, so bringt die Betonung von Differenz auch hier immer beides erst hervor: das Eigene und das Fremde, das Hier und Dort, Identität und Alterität.

Anhand einer Analyse der Berichterstattung über die Flüchtlingssituation am Ende des Jahres 2015 und der diskursiven Konstruktion von Grenzen in diesem Kontext veranschaulichen Löw und Weidenhaus schließlich ihre konzeptionellen Überlegungen (a.a.O. 562). Die Funktion nationalstaatlicher Grenzen besteht zumeist darin, rechtliche Geltungsbereiche abzustecken und die Kontrolle von Zugangsmöglichkeiten zu gewährleisten (ebd.). Grenzen stellen zunächst eine Territorialisierung von nationalem und europäischem Recht dar. Analog dazu lässt sich aber anhand der Analyse des Grenzdiskurses auch ein Phänomen nachweisen, welches sich als Territorialisierung der Moral beschreiben lässt. Der Verweis darauf, dass eine menschenwürdige Unterbringung in den Empfängerländern nicht gewährleistet sei, dient häufig dazu, den Flüchtigen die Einreise gänzlich $\mathrm{zu}$ verwehren. Implizit wird damit allerdings eine etwaige menschenunwürdige Unterbringung in den Herkunfts- oder Transitländern als legitimer Interventionsgrund zurückgewiesen. Die Territorialisierung führt zu doppelten moralischen Standards: "one moral standard for inside, one for outside.« (Löw/Weidenhaus 2017:565). Gleichzeitig wird ein etwaiger Rechtsanspruch von Geflüchteten, die auf die Dienste von Fluchthelfern zurückgreifen, nicht in Erwägung gezogen. So wird die Einschätzung des Handelns von Fluchthelfern nicht nach rechtlichen Standards bewertet, sondern geschieht - so ließe sich mit Chantal Mouffe ergänzen im »Register der Moral« (2017, Orig. 2007). Das Außen wird zur desorganisierten Gegenwelt, die durch niedrige moralische Standards gekennzeichnet ist. Zudem wird dieses Außen durch suspekte und potenziell bedrohliche Personen bevölkert. Diese werden nicht, wie im innerdeutschen Jargon und in Bezug auf die deutschdeutsche Teilung, positiv als Fluchthelfer, sondern als Schlepper oder Schleuser bezeichnet. Die Charakterisierung des Raumes jenseits der Grenze als eine Sphäre der Desorganisation (Lotman) ist auch dadurch gekennzeichnet, dass die in ihr handelnden Figuren uneindeutig bleiben. Sie bewegen sich dies- und jenseits der Grenze und stellen so die räumliche Ordnung infrage. Wie anhand von Lotmans räumlicher Kultursemiotik gezeigt, ist der Grenzübertritt auch hier schöpferisch und »revolutionär« (1972:339). 
Für die raumkonstitutionelle Analyse der Diskurse erscheint es wertvoll, den Akten der Grenzziehung besondere Aufmerksamkeit zu widmen. Zudem konnte anhand der Überlegungen zur Semiose (Bedeutungsgenese) deutlich gemacht werden, dass in der Analyse darauf geachtet werden muss, was überhaupt als Ereignis (Sujet) thematisiert und welchen Figuren dabei Handlungsmacht zuerkannt wird. Die Analysedimension der narrativen Struktur (Kap. 3) erfährt mit dem Fokus auf die Grenzüberschreitungen und den dabei als Akteure beschriebenen Personen eine räumliche Zuspitzung. Damit ist bereits die Charakterisierung der so aufgespannten Räume angesprochen. Im Folgenden sollen deshalb Begriffe definiert werden, welche die Analyse der Qualifizierung der jeweils genannten Räume ermöglichen.

\section{Die Qualität der Räume}

Nachdem mit dem Verweis auf Lotman die Akte der Grenzziehung als zentral für die Konstruktion von Räumen herausgestellt wurden, soll im Folgenden eine grundlegende Unterscheidung zur Qualifizierung der so voneinander abgegrenzten Räume dargelegt werden. Dafür erscheint ein Begriffspaar hilfreich, welches der Ethnologe und Kulturwissenschaftler Klaus E. Müller bereits 1983 geprägt hat. Laut Müller entsprechen die grundlegende Identifikation des Eigenen und die Differenzierung von Anderen einer »künstlichen Fixierung«, die räumlich funktioniert und das »Basiselement aller Orientierung« bildet (Müller 1983:94ff.). In dieser anthropologischen Herleitung steht Müller durchaus Lotman nahe, für den die Orientierung in und die Strukturierung der Welt ebenfalls als räumliche Strukturierung besteht. Für Müller liegt der »Feldstruktur der Orientierung« oder »Weltanschauung« generell ein System zweier konzentrisch angeordneter Sphären zugrunde:

»Die eigenweltliche Endosphäre umschließt rings die außerweltliche Fremd-oder Exosphäre [...]. Die Sonderung beider erfolgt aufgrund des Differenzierungsprinzips, während der Brückenschlag über die Grenzen hinweg vom Identifizierungsprinzip gewährleistet wird.«(Müller 1983:95).

Indem Müller darauf hinweist, dass erst das Zusammenwirken beider Prinzipien Verständigung möglich macht (ebd.), ist damit auch gesagt, dass das Fremde für die Imagination des Eigenen ebenso konstitutiv bleibt. Mit der Unterscheidung in eigenräumliche Endosphäre und fremdräumliche Exosphäre werden so eine Fundamentaldistinktion und eine räumliche Basisfigur sinnhafter Wirklichkeitsdeutungen benannt. Typische Operationsweisen des Differenzierungsprinzips bestehen etwa in der Konstruktion einer »verkehrten Welt«, die von monströsen Geschöpfen bevölkert ist (Müller 1983:104). Ebenso finden sich Negationsmomente im Lächerlichmachen der außerweltlichen Exosphäre als eine typische Technik des 
Befremdens (a.a.O. 111). ${ }^{16}$ Das Identifizierungsprinzip hingegen beschreibt Müller als die Schaffung von »Ruhezuständen« oder Harmonie (a.a.O. 105). Müller illustriert die Unterscheidung von Endo- und Exosphäre und die jeweils stabilisierten räumlichen Orientierungssysteme anhand von, wie er schreibt, »naturvölkische[n] Auffassungen« (a.a.O. 107ff.), womit er zeitlich auf »kalte« Institutionen rekurriert. Als besonders anschlussfähig für die angestrebte Analyse raumzeitlicher Muster der Identifikation und Befremdung erscheint die von Müller hergestellte Verbindung zwischen Raum und Zeit.

Demnach gilt: »Alle zurückliegenden Erfahrungen waren mithin endosphärischer Art und werden daher, prinzipiell jedenfalls, positiv beurteilt; alles Zukünftige dagegen ist Exosphäre und erfährt insofern eine überwiegend negative Einschätzung. «(Müller 1983:106). Die Missachtung der Gebote durch die Jugend führt in zahlreichen mythischen Erzählungen dazu, dass von dieser eine »Bedrohung der Seinsordnung« ausgehe (Müller 1983:110). Zudem wird meist eine normative Verbindlichkeit des Gewesenen deutlich: »Alles, was sich auf >Ursetzungen in der mythischen Schöpfungszeit zu gründen vermag, besitzt [...] höchste Autorität, ja einen schlechthin unanfechtbaren Gültigkeitsanspruch.«(a.a.O. 108). Die räumliche Unterscheidung zwischen Endo- und Exosphäre findet somit ihr Pendant in einer zeitlichen Annäherung beziehungsweise Distanzierung. So wie das Eigenräumliche auch zeitlich nah ist und gültig bleibt, gehört das Fremdräumliche einer anderen Zeit an, die mit Unordnung und Gefahr assoziiert wird. Räumliche und zeitliche Nähe fallen oft ineinander. Um analysieren zu können, wie die jeweils diskursiv konstruierten Räume qualifiziert werden, erscheint die fundamentale Unterscheidung in Endo- und Exosphäre besonders geeignet, da in den hier rekonstruierten Diskursen explizit die Verräumlichung der Zeit in konkreter Architektur (Spacing) sowie deren sinnhafte Deutung (Syntheseleistung) mit Identitätspostulaten verknüpft werden. Mit den Begriffen Müllers kann differenziert werden, welchen Stellenwert den jeweils beschriebenen Räumen zuerkannt wird. Die Frage, was eigen ist und was fremd bleibt, stellt dabei eine der wichtigsten Kontrastierungen dar.

Die Möglichkeit einer Affirmation des Wandels wird bei Müller allerdings bereits durch den theoretischen Zugang ausgeschlossen. Dies ist gewiss dem Gegenstand der mythischen Erzählungen geschuldet. Die Darstellung kosmologischer Weltordnungen funktional nur schwach differenzierter Gesellschaften führt hier (wie bei Assmann) zu einer starken Akzentuierung »kalter Institutionen«. So hilfreich die grundlegende Unterscheidung zwischen Eigen- und Fremdraum erscheint, so begrenzt ist sie, in der Verwendung Müllers, verschiedene Mischverhältnisse zwischen den beiden Kategorien zu denken. In »heißen« gesellschaftlichen Institutionen, die Geschichte zum Motor ihrer Entwicklung 
machen (Lévi-Strauss 1981:270), und erst recht in funktional und kulturell stark differenzierten Gegenwartsgesellschaften erscheint eine andere Thematisierung des Fremden möglich (oder vielleicht sogar strukturell notwendig). Exosphären können dann vor allem als Räume der Option, der Bereicherung oder (wie in romantischen Erzählungen) als Sphäre der Selbstfindung Bedeutung erhalten. Letztlich ist damit die Frage nach der Integrationsfähigkeit von räumlichen Weltbezügen gestellt. Wie anhand der Umgestaltung des Neuen Museums gezeigt werden kann, können eigen- und fremdräumliche Elemente durchaus als harmonische Einheit gedeutet werden. Das Fremde verliert so seinen bedrohlichen und störenden Charakter. Um schließlich die jeweils hergestellten Beziehungen zwischen Endo- und Exosphäre bestimmen zu können, ist es deshalb wichtig, die exklusive und konfrontative Gegenüberstellung zwischen Endo- und Exosphäre zwar als einen möglichen, aber keineswegs ausschließlichen Code der Verräumlichung zu verstehen.

\section{Die Qualität der Beziehungen der Räume}

Die binäre Einteilung der Welt stellt für Lotman eine Universalie dar. Dennoch sind die Typen dieser Einteilung variabel (2010:174). Grenzen stellen zwar das Eigene und das Fremde her, jedoch organisieren erst die Art der Grenze und vor allem der Grad ihrer Durchlässigkeit das Verhältnis zwischen beiden. So wie durch die diskursive Grenzkonstruktion noch nichts über die Qualität der Räume gesagt ist, so können die Kategorien Endo- und Exosphäre allein noch nichts über das Verhältnis zwischen dem Eigenen und dem Fremden aussagen. Analog zu der zeitlichen Unterscheidung, wie Vergangenheit, Gegenwart und Zukunft miteinander verbunden werden, muss deshalb auch danach gefragt werden, wie Endo- und Exosphäre zueinander in Beziehung gesetzt werden. Das jeweilige Organisationsprinzip, welches Eigen- und Fremdraum in ein Verhältnis setzt, soll deshalb als Code der Verräumlichung bezeichnet werden. In Anlehnung an die Codes kollektiver Identität (Giesen 1999) werden im Verlauf der Analyse der Raumkonstruktionen verschiedene Codes der Verräumlichung empirisch rekonstruiert. In seiner historisch angelegten Vergleichsstudie kollektiver Identitätskonstruktionen in Frankreich und Deutschland entwickelt Bernhard Giesen drei idealtypische Codes kollektiver Identitätsbildung. Grenzziehungen zwischen dem Innenraum einer Gemeinschaft und einer Außenwelt jenseits davon werden als eine »elementare Operation der Herstellung der sozialen Wirklichkeit« verstanden (Giesen 1999:24). Die idealtypischen Codes entsprechen somit einer »Logik der Grenzziehung« (a.a.O. 27).

Der erste Code kollektiver Identität stellt der primordiale Code dar (a.a.O. 32ff.). Zugehörigkeit wird durch scheinbar ursprüngliche und unveränderbare Unterscheidungen wie Geschlecht, Verwandtschaft oder Ethnizität hergestellt (ebd.). Innen und Außen werden hart und unvermittelt miteinander konfrontiert, wobei 
die Grenze zwischen beidem nicht verschoben werden kann (Giesen 1999:33). Der Biologismus des >Volkskörpers`, der durch vermeintlich natürliche Abstammung bestimmt, wer zugehörig ist und wer fremd bleibt, stellt den prototypischen Fall primordialer Codierung dar. Der Aspekt der Reinhaltung ist dabei zentral; die Außenwelt wird dämonisiert (a.a.O. 36) und muss auf Abstand gehalten werden. Die Entstehung primordialer Codes, obwohl sie sich auf Natur beruft, ist aber keinesfalls natürlich. Die Reinheitsfantasien dieses Typus (ethnische `Säuberungen`) und seine »Reduktion auf zeitlose Natur« (a.a.O. 41) lassen Primordialität als eine typisch moderne Begründung des Nationalstaates erscheinen (a.a.O. 39).

Im Unterschied dazu verweisen traditionale Codes kollektiver Identität nicht mehr auf Natur, sondern auf soziale Routinen, Traditionen und Erinnerungen. Entscheidend für diesen Code ist der Versuch, die Gegenwart in ein Kontinuitätsmuster einzureihen und so zu begründen. Dadurch wird die Dauerhaftigkeit sozialer Praktiken konstruiert (a.a.O. 42). Im Zentrum dieser Form der Vergemeinschaftung stehen Erinnerungsrituale, in denen die Vergangenheit vergegenwärtigt wird und Gründungsmythen aktualisiert werden (a.a.O. 45). Anders als bei primordialen Codes kann das Fremde durch das Erlernen der Traditionen prinzipiell integriert werden. Das Nebeneinander von lokalen Gemeinschaften und die Existenz des Fremden werden nicht als Bedrohung für das Eigene empfunden, sondern sind vielmehr durch Unverständlichkeit und Indifferenz geprägt (a.a.O. 48). Ein Beispiel für diesen Code kollektiver Identität kann in dem politischen Schlagwort >Europa der Vaterländer « gesehen werden. Die Konstruktion vielfältiger Traditionen führt jedoch nicht dazu, dass Integration angestrebt wird.

Dies ändert sich mit dem universalistischen Code. Diesen kennzeichnet, dass alle Außenseiter potenziell Mitglieder werden sollen. Die Außenwelt muss demnach erschlossen und angeeignet werden. Im Gegensatz zwischen einem bereits erlösten, mündigen oder fortschrittlichen Zentrum und der missionarischen Inklusion der Peripherie bestehen die grundlegende Spannung und die innere Dynamik dieses Typus: "So wie die traditionale Gemeinschaft der Kontinuität und Bewahrung verpflichtet ist, so drängt die universalistische Orientierung auf Veränderung des Bestehenden und revolutionäre Beschleunigung der Geschichte.« (Giesen 1999:60f.). Universalistische Codes finden sich etwa in der Expansionslogik von Imperien. Als Beispiel dafür dienen sowohl der missionarische Eifer der Erlöserreligionen als auch die Erschließung einer noch unmündigen oder rückständigen Welt durch Vernunft oder Fortschritt in den Ideen der Aufklärung und des Sozialismus (a.a.O. 55f.).

Mit dem Begriff >Code < werden also verschiedene Organisationlogiken von Einund Ausschluss beschrieben. Verstanden als Türsteher bestimmen sie darüber, was zum Eigenen werden kann und was fremd bleibt. Giesen verwendet die Idealtypen allerdings oft raummetaphorisch; etwa wenn er vom Zentrum und der Peripherie einer Gemeinschaft (Innen und Außen) spricht oder von sozialen Hierarchien 
(Oben und Unten), so ist damit keine tatsächliche räumliche Lagebestimmung gemeint. Der Begriff Code, wie er für diese Untersuchung nutzbar gemacht wird, zielt somit auf eine raumsoziologische Zuspitzung, mit der die diskursive Deutung der gebauten Welt im Hinblick auf die Formen der Identifikation und Befremdung analysiert werden kann. Diese Engführung ist deshalb nötig, da sich die Charakterisierung von konkreten Räumen als eigen oder fremd, vor allem aber ihre Relationierung zueinander, als zentral für die räumliche Sinnbildung der Kollektivierungsdiskurse erweisen.

Auch im Hinblick auf die Analyse der räumlichen Sinnbildung lassen sich die eingangs gestellten Fragen (welche Räume benannt werden, wie diese beschrieben werden und wie sie zueinander in Bezug gesetzt werden) auf je verschiedene Weise beantworten. Zwar steht anders als in Bezug auf die zeitliche Sinnbildung kein vergleichbares Kategorienrepertoire bereit; dennoch hat die Darstellung konzeptioneller Überlegungen ergeben, dass Folgendes zu beachten ist, um die räumliche Struktur der Kollektivierungsdiskurse zu analysieren: Einerseits muss den Akten der diskursiven Grenzkonstruktion besondere Aufmerksamkeit geschenkt werden. Erst durch diese Differenzierungsleistung werden die jeweils relevanten Räume überhaupt hergestellt. Mit der Charakterisierung als je eigenräumliche Endosphäre oder fremdräumliche Exosphäre werden diese mit spezifischer Bedeutung versehen. Genauere Betrachtung verdienen die Sujets, die erzählt werden, sowie die Personen, denen Handlungspotenzial zugesprochen wird. Dadurch wird schließlich das Verhältnis erkennbar, in welches die Räume zueinander gesetzt werden. Beschreiben die Begriffe `Endo- und Exosphäre lediglich die Qualität der Räume, so kann erst mit den Codes der Verräumlichung die Qualität der Relationen zwischen den zuvor als verschieden gekennzeichneten Räumen ermittelt werden. Unter einem Code der Verräumlichung verstehe ich deshalb die Art der Verknüpfungsleistung, mit der Räume sinnhaft verbunden werden.

Obwohl im Unterschied zum reichen Fundus an Kategorien zur Analyse der Zeitstrukturen kein vergleichbares Repertoire bereitsteht, so erscheinen zumindest zwei mögliche Mischverhältnisse denkbar: einerseits eine ausschließliche Art der Verknüpfung, in der verschiedene Räume kontrastreich gegenübergestellt werden. Die Grenze hat dann exkludierenden Charakter und die Räume kommen der von Lotman beschriebenen Spiegelbildlichkeit einer »verkehrten Welt « nahe. Heterogenität kann dabei nicht homogenisiert werden. Das Fremde bleibt fremd. Andererseits erscheint eine inkludierende Art der Verknüpfung denkbar, in der Räume zwar unterschieden werden, aber dennoch zu einer Einheit verknüpft werden können. Der Grenzverlauf ist dann verhandelbar und erlaubt dadurch Inklusion. Indem Heterogenität homogenisiert werden kann, verliert das Fremde seine Fremdheit. Ob diese möglichen Verknüpfungsleistungen in den zu analysierenden Kollektivierungsdiskursen auffindbar sind, wie sie jeweils beschaffen sind sowie die Frage, welche 
weiteren Codes der Verräumlichung sich rekonstruieren lassen, kann allerdings nur empirisch beantwortet werden.

Verlässt man die Alte Nationalgalerie mit den nur im Verborgenen noch zu sehenden Kriegsschäden und tritt auf die monumentale Freitreppe vor dem Gebäude, so öffnet sich der Blick auf die östliche Fassade des Neuen Museums. In dem Giebelfeld von Friedrich Drake, welches den Mittelrisaliten schmückt, unterweist die Geschichte die Kunst. Das Relief zeigt eine allegorische Darstellung der Geschichte, welche nun gleichberechtigt einen ägyptischen Pharaonenkopf zu ihrer Rechten sowie ein Marienbild zu ihrer Linken hält. Das Motiv ist so einerseits ein Sinnbild für die Singularität historischer Epochen und damit für die lineare Zeitstruktur des geschichtswissenschaftlichen Historismus. Andererseits ist das Kunstwerk Ausdruck der Aufwertung des Christentums (und des deutschen Mittelalters) sowie ein Beleg dafür, dass auch das Neue Museum trotz aller wissenschaftlichen Ansprüche im 19. Jahrhundert ein Ort der nationalen Selbstvergewisserung blieb. Die nationale Sinnstiftung profitierte, wie in der Nationalgalerie, vom Nutzen der Historie für das Leben und war keineswegs nur deren Nachteil, wie Nietzsche befürchtete (2009, Orig. 1874). Auch im Zuge der Wiederherstellung des kriegszerstörten Neuen Museums zu Beginn des 21. Jahrhunderts wurde über den Umgang mit der Geschichte des Gebäudes und dessen Relevanz für das eigene Selbstverständnis gestritten. Das ornamentlos wiederhergestellte Treppenhaus im Innern des Neuen Museums, in dem die Kriegsschäden deutlich erkennbar geblieben sind, bildete über eineinhalb Dekaden das symbolische Zentrum einer emotional geführten Debatte, in der - bedingt durch die Frage, welche Vergangenheiten beerbt werden sollen - auch unterschiedliche Codes der Verräumlichung in Konflikt gerieten. 


\section{Streit um das Erbe: Der Diskurs des Neuen Museums Berlin}

\subsection{Die Fundamente beerben}

ARTEM NON ODIT NISI IGNARUS - diese Inschrift im Mittelrisalit der Westseite des Neuen Museums stellt vielleicht die erste sprachliche Deutung des Gebäudes dar. Dass nur der Unwissende die Kunst verachtet, würde gewiss von allen am Diskurs des Neuen Museums beteiligten Akteuren bejaht werden. Sowohl die Denkmalpfleger und Architekten der >ergänzenden Wiederherstellung als auch die Fürsprecher einer >originalgetreuen Wiederherstellung« würden jeweils für sich in Anspruch nehmen, Wissende zu sein. Mit der gegenseitigen Bezichtigung der Kunstverachtung wird die Mahnung im Giebel je für die eigenen Vorstellungen, über den adäquaten Umgang mit dem kriegszerstörten Gebäude, vereinnahmt. Die Inschrift wird zur Losung, die alle diskursiven Formationen ausgeben, wenngleich daraus doch grundsätzlich Verschiedenes abgeleitet wird. Die leidenschaftlich geführte Debatte über die Wiederherstellung des Neuen Museums sowie das über viele Jahre anhaltende Engagement der Diskutanten deuten darauf hin, dass hier nicht allein Fragen des Geschmacks verhandelt wurden. Der breite Konsens darüber, dass es sich bei dem historischen Gebäude um ein unbedingt zu schützendes baukulturelles Erbe handelt, wird ebenso einhellig mit Fragen der Identität verknüpft. ${ }^{1}$ Das Neue Museum bildet somit die Infrastruktur zweier Kollektivierungsdiskurse, die sich im Schatten der Ruine artikulieren und dabei das Erbe auf sehr verschiedene Art beschwören (Kap. 2). Weitgehender Dissens besteht darin, wie mit diesem geschichtlichen Erbe umzugehen ist, welche Handlungsimperative aus dessen Geschichte abgeleitet werden und wie diese in Einklang mit der Gegenwart gebracht werden kann. Anhand der verschiedenen Deutungen des Gebäudes werden die im-

Im Sinne der empirischen Bestimmung des Cegenstandes und der jeweiligen Phänomenstrukturen (Kap. 3) gilt dies zunächst lediglich für die Teilnehmer des Diskurses. Damit ist keineswegs ausgeschlossen, dass das Neue Museum für einen nicht zu bestimmenden Teil der Bevölkerung bedeutungslos bleibt. 
pliziten Gewissheiten darüber, wer ein Wissender und wer ein Unwissender ist, sichtbar.

In beiden Diskursen werden sowohl eine Verbindung zur Vergangenheit (Zeitdimension) als auch eine Bindung der Sprechenden untereinander (Sozialdimension) aufgebaut (Kap. 2). Die konkurrierenden Wirklichkeitsdeutungen erzeugen jeweils partielle Gleichheit in Bezug auf die Selbst- und Weltbezüge (Kap. 2), wodurch die Diskurse als Kollektivierungsdiskurse rekonstruiert werden können. Dass das Erbe in beiden Fällen verbindlich bleibt, zeigt sich zudem anhand der starken normativen Semantiken, die so die Analysedimension der Klassifikation (Kap. 3) deutlich hervortreten lassen. Dennoch werden dabei sehr unterschiedliche Wissensverhältnisse stabilisiert. Jedoch zeigt sich, dass die Begriffe, mit denen die jeweiligen Diskursteilnehmer Identifikation und Befremdung herstellen, oft denselben semantischen Feldern entstammen. Einheit und Harmonie hinsichtlich der Deutungen des Raumes sowie Kontinuität und die normative Verbindlichkeit der Vergangenheit in Bezug auf die zeitlichen Deutungen nehmen beide diskursiven Formationen für ihre Konzepte in Anspruch. Einzig der Modus, in dem diese Werte konstruiert werden, unterscheidet sich grundlegend. Die Formationsregeln der beiden Kollektivierungsdiskurse variieren also weniger in Bezug auf die Semantik und damit den Inhalt der Konstruktion als vielmehr im Hinblick auf die Struktur und damit die Grammatik der Konstruktion. Diese Grammatik der Wissensverhältnisse kann mithilfe der entwickelten Analysekategorien der Zeitkonstruktionen und der Codes der Verräumlichung differenzenziert werden (Kap. 4). Dadurch treten die unterschiedlichen Kollektivierungsdiskurse deutlich ins Profil, denn obwohl sie sich auf dieselben Fundamente beziehen, beerben sie diese höchst unterschiedlich.

Mit den verschiedenen Akten des Erbens werden der Ort und das Erbe des Neuen Museums in ihren spezifischen räumlichen Bedeutungen (Kap. 2.4) erst hervorgebracht. Die Akzentverschiebung des Analysegegenstandes, von der Architektur und der Geschichte hin zu den konkurrierenden Deutungen davon, erfordert eine empirische Rahmung des Diskurses (Kap. 3 u. 4). Die räumliche Rahmung kann nicht von außen festgelegt, sondern muss den Stimmen des Diskurses selbst entnommen werden. So wird das Wesen des Neuen Museums in den Beschreibungen beider Kollektivierungsdiskurse stets eng mit den räumlichen Relationen zu seiner Umgebung gekoppelt oder sogar darüber definiert. Außerdem waren die Planung und Gestaltung eines zentralen Eingangsgebäudes (die spätere James Simon Galerie) an der Westseite des Museums und auf dem Gelände der ehemaligen Packhofanlagen bereits 1994 Teil des Wettbewerbs sowie Gegenstand des >denkmalpflegerischen Plädoyers` für die ergänzende Wiederherstellung des Neuen Museums (Badstübner et al. 1994). Dadurch wird eine Beschreibung der architektonischen und städtebaulichen Zusammenhänge erforderlich. Der Diskurs des Gebäudes endet also keinesfalls an der Museumstür. 
Gleiches gilt für die wechselvolle (Bau-)Geschichte des Neuen Museums und seiner unmittelbaren Umgebung. Eine Darstellung der wichtigsten historischen Ereignisse bleibt für die Analyse des Diskurses unerlässlich. Auch die Darstellung dieser strukturellen Bedingungen fokussiert auf die Aspekte, auf die diskursiv Bezug genommen wird; sie folgt damit den Stimmen des Diskurses. Außerdem müssen die wichtigsten Etappen der Debatte skizziert werden, um die zentralen zu analysierenden Diskursdokumente den jeweiligen Akteuren zuordnen zu können. Was im Folgenden dargestellt wird, ist deshalb eine selektive Beschreibung des Gebäudes und seiner Geschichte. Diese dient dazu, die für den Diskurs zentralen Topoi sowie dessen thematische Rahmungen zu nennen. Sie entspricht somit einer Baugeschichte in Fragmenten.

\subsubsection{Baugeschichte in Fragmenten}

Als am 11. September 1841 der erste der insgesamt 2.344 Eichenpfähle in den sumpfigen Untergrund im Norden des Berliner Lustgartens gerammt wurde, kam dabei zum ersten Mal in der Geschichte des Museumsbaus eine Dampfmaschine zum Einsatz (Henze/Sommer 2007:6; Lorenz 1994:99). ${ }^{2}$ Diese besondere Gründung der Fundamente für das Neue Museum wurde aufgrund der Geologie des Ortes nötig, die die Errichtung von schweren Baukörpern an dieser Stelle erschwerte. Da sich die eiszeitliche Auswaschung des Kolkgesteins über die Jahrtausende mit nicht tragfähiger Mudde füllte, wird ein tragfähiger Baugrund teilweise erst in Tiefen von bis zu 40 Metern erreicht. ${ }^{3}$ Ungeachtet des sumpfigen Untergrundes der Berliner Spreeinsel wünschte sich Friedrich Wilhelm der IV. - der »Romantiker auf dem Thron Preußens $\aleph^{4}$ - einen hier zu errichtenden kontemplativen Ort als städtebauliches Gegengewicht zu den »geschäftigen Linden« und deren »geräuschvolle[r] Pracht« (Waetzold 1994:9). Der König folgte damit dem Plan des Generaldirektors der Königlichen Museen, Ignaz Maria von Olfers, der in einem folgenreichen Bericht vom 20. Januar 1841 vorgeschlagen hatte, die Spreeinsel »zu einer stillen reichbegabten Freistätte für Kunst und Wissenschaft« umzugestalten (zitiert nach van Wezel 2003:135). Nachdem der König den Plänen Olfers am 08.03.1841 die Zustimmung erteilt hat, wird dieser zusammen mit dem Hofbaurat Friedrich August Stüler beauftragt, einen Entwurf für die architektonische Umsetzung auszuarbeiten (Henze/Sommer 2007:5). Der Baubeginn des Neuen Museums bildete damit den Auftakt zur Erschließung der nördlichen Spitze der Spreeinsel und ihrer Umgestaltung zur »Freistätte für Kunst und Wissenschaft«. 


\section{Die städtebauliche Situation}

Die Bauaufgabe, ein Museumsgebäude zu errichten, welches die Möglichkeit der Zurschaustellung der stark anwachsenden ägyptischen Sammlung (von Buttlar 2010:11) bot und ebenso den repräsentativen Anforderungen einer im Entstehen begriffenen »Freistätte der Kunst und Wissenschaft « gewachsen war, wurde neben dem bauphysikalisch problematischen Terrain zudem durch die städtebauliche Situation erschwert. Der ehemalige Direktor der Staatlichen Museen zu Berlin, Stephan Waetzold, beschreibt das Gebiet im Norden der Spreeinsel zu jener Zeit süffisant als »Gewerbegebiet«. Denn hier lag der Packhof mit Lagerhäusern der Zollbehörde, das Mehlhaus der Bäckerinnung, Baumaterial- und Holzlager sowie ein Landungsplatz für die Spree- und Havelschifffahrt (Waetzoldt 1994:8). Das Neue Museum entstand also im »städtebauliche[n] Abseits« (ebd.) und zudem an der Rückseite des nunmehr salt ‘ genannten Museums von Karl Friedrich Schinkel, welches es zwar ergänzen, jedoch keinesfalls übertrumpfen durfte.

Zu der beengten Lage hinter dem Alten Museum im Süden und dem Packhof im Westen schränkte zusätzlich das Levy'sche Haus im Osten das Neue Museum ein. Dadurch wurde die architektonische Bezugnahme auf das Alte Museum erschwert (Tuchen/Fuchs 2009:45). Ebenso konnten die Kolonnaden an der Nordostseite vorerst nicht fertiggestellt und das bereits fertiggestellte Vestibül nicht als Haupteingang genutzt werden (Henze/Sommer 2007:8). Somit musste das Neue Museum in den ersten Jahren von Süden und damit vom Alten Museum her erschlossen werden. Besucher betraten das Gebäude also zunächst durch den Südkuppelsaal. Aus dieser anfänglichen Erschließung des Neuen Museums und der Verbindung zum Alten Museum erklärt sich auch dessen »verzogene[r] Grundriss« (Cobbers 2009:19). Erst nach Abbruch des Levy'schen Hauses, dessen Besitzerin sich zeitlebens weigerte, ihre Wohnstätte aufzugeben, konnte schließlich der Haupteingang an der Ostfassade genutzt werden. ${ }^{5}$ Trotz des Verbindungsbaus zum Alten Museum ermöglichte die städtebauliche Situation kaum direkte architektonische Bezüge, obwohl das Neue Museum sich ursprünglich auf seinen berühmten Nachbarund Vorgängerbau beziehen sollte (Tuchen/Fuchs 2009:45). Tatsächlich nahm das ehemals an der Westseite des Gebäudes (auf dem Areal der heutigen James Simon Galerie) gelegene Direktorenhaus der Packhofanlagen Einfluss auf die Gestalt des Neuen Museums. So erklärt sich neben dem »verzogenen Grundriss« auch der rückwärtige Charakter der Westfassade aus der bauzeitlichen Situation. Denn das Neue Museum wurde, bis auf das Tympanon im westlichen Mittelrisalit, von den Packhofgebäuden verdeckt.

Für die Analyse des Diskurses ist wichtig festzuhalten, dass die städtebauliche Situation höchst unterschiedlich gedeutet wird. Mit der belustigenden Rede vom

5 Selbst die Vermittlungsversuche Alexander von Humboldts konnten die Witwe Levy nicht zur Aufgabe ihres Hauses bewegen (Tuchen/Fuchs 2009:45). 
»Gewerbegebiet « werden eine prinzipielle Fehlstellung der Gebäude und damit eine grundsätzliche Korrekturbedürftigkeit der Gesamtanlage attestiert. Zentral in diesem Zusammenhang ist die unterschiedliche Bedeutung, die den ab 1825 nach Plänen von Karl Friedrich Schinkel errichteten Packhofanlagen (Henze/Sommer 2007:2f.) und dem dazugehörigen Direktorenhaus zugeschrieben wird. Was einerseits lediglich als Teil des »Gewerbegebietes« Bedeutung erhält und zur Rechtfertigung korrigierender baulicher Eingriffe herangezogen wird, bleibt andererseits als bauzeitliche Situation maßgeblich für die Gestaltung des Areals in der Gegenwart. Zwischen der Thematisierung des Geländes als korrekturbedürftiges Ärgernis oder als weiterhin gültiges Ideal werden somit verschiedene Phänomenkonstitutionen erkennbar.

Abbildung 7: Bauliche Situation in den 1920er Jahren. Das Haus der Steuerdirektion (links) und das Alte Museum (rechts) beeinflussten die Ausrichtung des Neuen Museums; Abbildung 8: Packhofanlagen und Rückseite des Direktorenhauses (links) um 1880. Der Blick Richtung Schloss (mittig) verdeutlicht die gewerbliche Nutzung des Kupfergrabens zu dieser Zeit.


Die mangelhafte Gründung auf dem sumpfigen Untergrund bot dem Direktorenhaus des Packhofes kein sicheres Fundament mehr. Dies führte bereits 1938 dazu, dass das von Schinkel für die Steuerdirektion errichtete Haus abgerissen werden musste (Henze/Sommer 2007:16). Danach blieb die Westseite des Neuen Museums unbebaut, wenngleich die unter anderem durch die ehemaligen Packhofgebäude erzwungene Ausrichtung des Neuen Museums ein stilles Zeugnis in der Struktur des Hauses hinterlassen hat. Genau an dieser über Jahrzehnte bestehenden Leerstelle westlich des Neuen Museums begannen schließlich nach langen Debatten und zwei Wettbewerben ab 2009 die Bauarbeiten an dem nunmehr James Simon Galerie genannten zentralen Eingangsgebäude der Museumsinsel. 


\section{Kanonischer Klassizismus}

Dass das Gelände als »Gewerbegebiet« und als »städtebauliches Abseits« geschmäht wurde, erhielt seinen Sinn im Kontext des Wettbewerbs für den Entwurf eines zentralen Eingangsgebäudes auf der Museumsinsel von 1994 (Sayah). Mit dieser negativen Einschätzung der städtebaulichen Situation erschien ein moderner Eingriff an dieser Stelle gerechtfertigt. Einen Gegenpunkt zu der damit behaupteten Korrekturbedürftigkeit des architektonischen Ensembles bildet der im Diskurs ebenfalls oft auffindbare Topos des Spree-Athens. Adrian von Buttlar hat darauf hingewiesen, dass die Anlage mit ihren von Kolonnaden eingefassten Höfen, den Tempelbauten, dem Podiumstempel im Zentrum sowie dem Aufstellen eines Reiterstandbildes allerdings eher dem Typus römischer Kaiserforen und keineswegs nur dem der Athener Akropolis entspricht (von Buttlar 2010:11ff.). Ungeachtet dessen bleibt die Verknüpfung der Museumsinsel mit dem antiken Athen eine wichtige Figur der Besonderung des Ortes. Dabei wird eine Erhabenheit der Gesamtanlage konstruiert, woraus schließlich Interventionsverbote abgeleitet werden. Vor allem die Vertreterinnen der Initiative Gesellschaft Historisches Berlin e.V. (GHB) erheben die Architekten des 19. Jahrhunderts in den Stand weiterhin maßgeblicher Autoritäten, deren Plänen und Vorgaben auch in der Gegenwart unbedingt Folge zu leisten sei, da sonst die Identität des Ortes gefährdet werde.

Karl Friedrich Schinkel, der Säulenheiligen des Klassizismus, hat nicht nur mit dem Alten Museum und dem Packhofgelände die unmittelbare Nachbarschaft des Neuen Museums geprägt. Als Lehrer Friedrich August Stülers ist ihm darüber hinaus ein Einfluss auf den Entwurf des Neuen Museums gewiss. Vor allem im Hinblick auf Kubatur, Volumen und Gliederung erscheint der dreigeschossige spätklassizistische Solitärbau dem Alten Museum vergleichbar. So wie durch die Rotunde im Alten Museum wird auch das Zentrum der Vierflügelanlage mit ihren beiden Innenhöfen durch das Treppenhaus als ein »überwältigende[r] Stimmungsraum « gebildet (von Buttlar 2010:15). Neben dem Einfluss Schinkels war eine weitere herausragende Persönlichkeit des Klassizismus von entscheidender Bedeutung für den Entwurf des Neuen Museums. Der Architekt des bayerischen Königs, Leo von Klenze, präsentierte 1840 seinen Entwurf für das Königsschloss in Athen dem Preußischen König. Aller Wahrscheinlichkeit nach geschah dies in Anwesenheit August Stülers (a.a.O. 15f). Auf die unübersehbare Ähnlichkeit der Entwürfe mit der ursprünglichen Fassung des Neuen Museums hat ebenfalls Adrian von Buttlar hingewiesen (ebd.). Vor allem die Analogie der Proportionen des Mittelrisalites zu den Seitenrisaliten erscheint besonders frappierend. Die östliche Schauseite des dreigeschossigen verputzten Ziegelbaus ist durch zwei überkuppelte Seitenrisalite und ein Mittelrisalit gleichmäßig gegliedert. Dessen zentrale Erschließungsachse wird durch die dreiachsige Fensterädikula mit korinthischen Säulen auf ganzer Höhe unterstrichen (von Buttlar 2010:16). Die Gliederung der Risalite wieder- 
holt sich auch an der Westfassade, wenngleich dort die Seitenrisalite durch Fester durchbrochen und nicht überkuppelt sind. Dem trotz der dominanten Mittelachse kaum akzentuierten Eingang des Hauses sowie dem ersten Stockwerk sind an der Ostseite dorische Kolonnaden vorgelagert. Im Sockelbereich des Gebäudes sind an dieser Stelle noch Reste des ursprünglich farbigen Fassadenputzes erkennbar. Dieser Putz imitierte ursprünglich rötlich schimmernden Sandstein. Die farbige Außengestaltung des Neuen Museums war bereits vor seiner Zerstörung im Zweiten Weltkrieg weitgehend verblasst. Auf Fotografien der 1930er Jahre erweckt die Fassade eher einen monochromen Eindruck.

Für die Analyse des Diskurses ist es wichtig, auf die enorme Spannweite der Phänomenstruktur zwischen Gewerbegebiet und Spree-Athen hinzuweisen. Obgleich beides sich auf unbestrittene Aspekte der Geschichte des Gebäudes bezieht, werden durch die Diskursteilnehmer unterschiedliche Akzente gesetzt. Einerseits wird eine anhaltende Fehlstellung problematisiert, die schließlich korrigiert werden müsse und somit bauliche Eingriffe legitimiert. Andererseits wird die Zeit des Klassizismus als maßgebliche Referenz beerbt, wodurch sich bauliche Veränderungen verbieten. Vom Wettbewerb 1994 bis zur Wiedereröffnung 2009 bleiben die zentralen Spannungslinien zwischen einer Deutung als korrekturbedürftigem Missstand und als einem nicht kritisierbaren Ideal erhalten. Im Topos des SpreeAthens ist außerdem eine enge sprachliche Kopplung zwischen den Vorbildern der Antike und den Meistern des Klassizismus angelegt. Vor allem Schinkel und Stüler werden dadurch zu Vertretern einer klassischen Epoche und so in den Stand nicht $\mathrm{zu}$ hinterfragender Autoritäten erhoben. Damit wird ein Kanon der architektonischen Formensprache definiert, mit dem moderne bauliche Eingriffe strikt abgelehnt werden. Der Verweis auf den Klassizismus als identitätssichernde Epoche veranlasst die Gegner der Neubebauung an der Westseite des Neuen Museums dazu, dass einzig das schinkelsche Direktorenhaus (s. Abb.7) an dieser Stelle eine legitime bauliche Intervention darstelle.

Um dieser Forderung Nachdruck zu verleihen, wurden abermals die besonderen geologischen Bedingungen ins Feld geführt. Tatsächlich war es erneut die auf dem Kolk aufliegende Muddeschicht, die gerade unter dem künftigen Eingangsgebäude besonders mächtig ist, die den Baubeginn, wenngleich nicht verhindert, so doch verzögert hat. Die mächtige Schlammschicht konnte abermals durch den Einsatz moderner Technik bezwungen werden.

\section{Technik als zukunftsweisende Tradition}

Neben den städtebaulichen Unwägbarkeiten wurden auch dem Entwurf Stülers durch den weichen Untergrund bauphysikalische Grenzen gesetzt. Aufgrund »extrem schlechter Gründungsverhältnisse« wurde die »Reduktion der Eigenlasten des Gebäudes« (Lorenz 1994:108) erforderlich. Dies geschah durch die Verwendung 
leichter Baustoffe. Außerdem gelang es durch den Einsatz - für das 19. Jahrhundert - innovativer Bautechnik, diese Beschränkungen so weit zu umgehen, dass ein gleichermaßen geräumiges und den repräsentativen Anforderungen angemessenes Gebäude entstehen konnte. Ungeachtet der technischen Neuerungen bringt Stüler damit eine Haltung zum Ausdruck, welche auch die seines Lehrers Schinkels war, nämlich die »Industriearchitektur ästhetisch zu nobilitieren« (Zimmermann 1994:14). Dem Schinkelschüler gelang es einerseits, die klassizistische Bautradition seines einflussreichen Lehrers am Neuen Museum fortzusetzen, und andererseits, in bautechnischer Hinsicht gänzlich neue Wege zu beschreiten. Dieses neue Verständnis fand überdies im Tympanon des Mittelrisalites an der Westseite des Hauses künstlerischen Ausdruck. In dem von August Kiss ausgeführten Giebelfeld unterweist ein weiblicher Genius sowohl die alte Steinmetzkunst als auch das neue Kunstgewerbe des Eisenschmiedens (van Wezel 2003:178). Dadurch finden sowohl der Geist des Historismus, in dem die Künste »aller Zeiten« (ebd.) als gleichermaßen wertvoll erachtet werden, als auch die enge Kopplung zwischen Kunst und Technik gestalterischen Niederschlag. Die Bedeutung des Gebäudes als technikgeschichtliches Zeugnis gilt allen diskursiven Formationen als unbestritten; sie ist Bestandteil aller von den Diskutanten hergestellten Wissensverhältnisse.

Dass allerdings neben dem Klassizismus nun auch die technische Innovation des Gebäudes als Identitätsressource ins Feld geführt wird, ist Resultat der intensiven Beschäftigung mit dem Gebäude im Zuge der Wiederaufbauplanung. Diese führte zu einer erheblichen Aufwertung der kunst- und architekturgeschichtlichen Einschätzung des Gebäudes (Wolters 2010, von Buttlar 2010:18). Zentral für die diskursive Konstruktion der technikgeschichtlichen Relevanz des Gebäudes sind die Arbeiten des Technikhistorikers Werner Lorenz. Insbesondere auf seinen Aufsatz »Das Neue Museum - Inkunabel preußischer Konstruktionskunst im Zeichen der Industrialisierung (Lorenz 1994; 2009; 2014) wird in der Diskursivierung des Neuen Museums immer wieder Bezug genommen. ${ }^{6}$ Die Arbeiten Werner Lorenz' können somit als wirkmächtige wissenspolitische Intervention aufgefasst werden.

Wichtig für die Analyse des Diskurses ist, dass aus dem Topos der technischen Innovation unterschiedliche Gestaltungsansprüche abgeleitet werden. Während die Befürworter einer originalgetreuen Wiederherstellung dies lediglich als Wert anerkennen, der die exzeptionelle Bedeutung des Gebäudes zusätzlich unterstreicht, werden die modernen Eingriffe und Erweiterungen des Neuen Museums in der Gegenwart mit Verweis auf die Modernität des Stülerbaus legitimiert. chenden Konstruktionsleistung« (2010:241). Des Weiteren lässt sich die explizite Bezugnahme auf Lorenz' Texte in zahlreichen wissenschaftlichen Publikationen nachweisen (Frampton 2009, von Buttlar 2010:18; Berghorn 2016:151). 
Mit dem Hinweis auf Karl Boettichers »tektonischen Klassizismus«, der es Stüler erlaubte, »klassizistische Grundvorstellungen widerspruchsfrei mit den neuen Konstruktionsweisen und Produktionsbedingungen der >Eisenzeit zu verbinden « (Lorenz 1994:112), wird an eine »klassische« Vergangenheit appelliert, die überdies schon immer den Bedingungen der jeweiligen Gegenwart aufgeschlossen gewesen sei. Die Adaptionsfähigkeit und Weiterentwicklung der Architektur werden damit traditionalisiert. Wodurch auch die modernen Lösungen für die Wiederherstellung des Gebäudes zu Beginn des 21. Jahrhunderts im Einklang mit der Tradition des Hauses erscheinen, da dieses schon immer modern war.

$\mathrm{Zu}$ den bauphysikalischen Schwierigkeiten, die durch die genannten technischen Hilfsmittel weitgehend gelöst werden konnten, kamen ab 1848/49 politische hinzu. Die Revolution in den Ländern des Deutschen Bundes (1848/49) fand in den Straßen Berlins einen ihrer Hauptschauplätze. Materialknappheit und ein Mangel an Arbeitskräften waren die Folge, so dass die Arbeiten am Museum einstweilen niedergelegt wurden. ${ }^{7}$ Der König, der sich weigerte, eine »Krone aus der Gosse« (Lorenz 2014:16) entgegenzunehmen, und damit auf den gesamtdeutschen Thron verzichtete, überstand den Sturm der Revolution weitgehend unbeschadet, so dass auch seine Bauvorhaben hernach wieder aufgenommen werden konnten. Nach der Fertigstellung des Museumsäußeren 1856 hielten die Arbeiten im Inneren noch bis zur Fertigstellung der didaktischen Ausmalung der Ausstellungsäume und der monumentalen Fresken von Wilhelm von Kaulbach im Treppenhaus an (Henze/Sommer 2007:10). Mit der Vollendung des sechsten Wendepunktes der Weltgeschichte durch Wilhelm von Kaulbach konnte 1866 schließlich auch der Innenausbau abgeschlossen werden.

\section{Wissenschaftliche Deutung und didaktische Einheit}

Wurden die Eichenstämme am Neuen Museum erstmals mittels modernster Technik in den Grund gerammt, so mussten die ca. 2.000 Stämme, die zur Gründung des Alten Museums erforderlich waren, noch von Hand in den sumpfigen Boden getrieben werden (Lorenz 1994:99f.). ${ }^{8}$ Stand das Alte Museum noch eher in der technischen Tradition des 18. Jahrhunderts, ist der Entwurf des Neuen Museums untrennbar mit den Bauweisen des 19. Jahrhunderts verbunden (ebd.). Aber nicht nur in bautechnischer Hinsicht unterschieden sich die Gebäude erheblich voneinander. Mit der zu errichtenden »Freistätte der Kunst und Wissenschaft« hält auch eine neue Ausstellungskonzeption Einzug. Diese museumskonzeptionelle Verschie-

Die Revolution unterbrach die Bauarbeiten ab November 1848. Nach der Wiederaufnahme der Bautätigkeiten erschwerte zudem die Erhöhung der Arbeitslöhne um ca. 50 Prozent den Baufortschritt (Henze/Sommer 2007:7).

8 Mit dem Einrammen eines einzigen Gründungspfahls waren in dieser Zeit ca. 15 Arbeiter einen gesamten Arbeitstag beschäftigt (Tuchen/Fuchs 2002:49f.). 
bung besteht im Wesentlichen in der Hinwendung zum Ideal der Wissensvermittlung (Vogtherr 1997; von Welzel 2003). Lautete der Grundsatz, den die »Kommission zur Einrichtung des [Alten] Museums« noch 1828 vertrat, das Museum solle »erst erfreuen, dann erst belehren « (Henze/Sommer 2007:3), so verlor der Grundsatz des kontemplativen Kunstgenusses zugunsten des Belehrens nun an Boden.

In der Konzeption des Alten Museums sollten die Kunstwerke »im Publikum den Sinn für bildende Kunst wecken« (Schinkel, zitiert nach Cobbers 2009:29). Nach den gewandelten Maßgaben der Musealisierung sprechen die Kunstwerke nicht mehr für sich selbst, sondern werden kommentarbedürftig. Um die Forderung der Erziehung durch Bildung und der Belehrung nach wissenschaftlichen Kriterien einlösen zu können, kam der Innengestaltung des Neuen Museums eine entscheidende Rolle zu. Dabei ging es weniger um eine »historisch korrekte Rekonstruktion, sondern um ein intuitives Bildungserlebnis, das zugleich höchste Wissenschaftlichkeit beanspruchte« (a.a.O. 25). Diese ursprünglich intendierte Ausstellungskonzeption des Neuen Museums stellte in der Mitte des 19. Jahrhunderts ein museumspädagogisches Novum dar (Vogtherr 1997). Die verstummten Objekte haben nun eher Dokumentencharakter, der die vermittelnde Arbeit der wissenschaftlich-professionellen Deutung der Vergangenheit erforderlich machte. Dass das nunmehr fremde und damit »schwierige Gut « der Vergangenheit unter »berufliche Fachaufsicht « gestellt werden musste (Giesen 1999:229), schlug sich etwa in der Professionalisierung der Denkmalpflege und in der Verwaltung der Vergangenheit (Speitkamp 1996) nieder. ${ }^{9}$ Mit der Inschrift ARTEM NON ODIT NISI IGNARUS und der damit verbundenen Akzentuierung des Wissens wird somit auch das Ideal der Wissenschaftlichkeit unterstrichen.

Vor allem durch die didaktischen Malereien im Inneren sollte dieser Anspruch eingelöst werden. Insbesondere die Studien des Ägyptologen Richard Lepsius waren für die Ausgestaltung der Museumsräume instruktiv (van Wezel 2003:191ff.). Mit der Ausmalung der Räume sollte den Exponaten nicht nur ein feierlicher Rahmen gegeben werden; vielmehr dienten diese dazu, den damaligen Stand der Forschung wiederzugeben. In der Tat war es erklärtes Ziel Stülers, "größtmögliche Harmonie« (Stüler, zitiert nach Cobbers 2009:22) zwischen Räumen und Ausstellungsgegenständen herzustellen. Eng mit dem Ideal der Bildungsvermittlung verbunden ist demnach ein weiteres Charakteristikum der ursprünglichen Museumsgestaltung: die Einheit zwischen Architektur und Ausstellung.

Wie Geschichte überhaupt zum Gegenstand der staatlichen Betätigung avancieren konnte, hat Winfried Speitkamp eindrucksvoll herausgearbeitet (1996:20). Die Fremdheit der Vergangenheit hält mit dem beschleunigten Fortschritt durch Technisierung und Industrialisierung Einzug. Oder anders gesagt: mit der zunehmenden Disparatheit zwischen Erfahrungsraum und Erwartungshorizont (Kap. 1). 
Da die Sammlungsbestände wuchsen, das Museum in der stülerschen Fassung jedoch lediglich eine »Momentaufnahme« der Sammlungssituation seiner Entstehungszeit darbot, wurden bereits Anfang des 20. Jahrhunderts viele der erklärenden Wandillustrationen in dem »Wunsch, den Museumsbau anpassungsfähiger zu machen«, übermalt (a.a.O. 32f.). Die ästhetische, aber statische Einheit von Exponaten und Innenausmalung wurde schließlich durch die dynamische Weiterentwicklung des Wissensstandes und die wachsenden Ausstellungsbestände zunehmend disparat. Der Anspruch einer umfassenden Kulturschau der Menschheit ${ }^{10}$ scheiterte jedoch in der Folge an der zunehmenden Spezialisierung von Museen, die die Idee des Universalmuseums bereits am Ende des 19. Jahrhunderts haltlos machte (ebd.). Ein weiterer Aspekt, der mit der »Fremdheit der Vergangenheit« (Giesen 1999:240) nunmehr Einzug hielt und sich bis zur Jahrhundertwende noch intensivierte, bestand in der Aufwertung originaler Sammlungsstücke, wie sie etwa Wilhelm von Bode forderte (a.a.O. 239).

Auch in den Jahren der Wiederherstellung zwischen 1994 und 2009 wurden die Relevanz der didaktischen Einheit zwischen Ausstellung und Exponaten sowie die Bedeutung von Kopien höchst unterschiedlich gedeutet. Einer der Kristallisationspunkte dieser Diskussion bildete die Korenhalle des Erechtheions. Die Kopie eines Heroentempels auf der Athener Akropolis bildete in der ursprünglichen Fassung am oberen Ende des Treppenaufgangs dessen Abschluss und diente der Verklärung der griechischen Architektur als Höhepunkt der Kulturentwicklung. Sahen die Vertreter einer originalgetreuen Rekonstruktion in der Kopie des Erechtheions weiterhin ein entscheidendes Wesensmerkmal des Hauses, so wurde sie andererseits mit dem Verweis, dass sie sich bereits in ihrer Zeit überlebt habe, als anachronistisch zurückgewiesen. Nach langen Diskussionen und einer experimentellen Erprobung unterschiedlicher Lösungen wurde schließlich auf die Rekonstruktion des Erechtheions verzichtet. Als Begründung wird angegeben, dass dieses lediglich Teil der Ausstellung, insbesondere der Sammlung von Gipsabgüssen antiker Skulpturen, gewesen sei und damit nicht Teil der Architektur (NM-1, 111-138). Die didaktische Einheit zwischen Exponaten und Ausstellungsräumen erscheint nicht mehr maßgeblich und erhält lediglich als eine historische Schicht unter vielen Bedeutung.

\section{Entwicklungsgeschichte und Nationalchauvinismus}

An der östlichen Fassade des Neuen Museums befindet sich eine Büste von Aloys Hirt. Zwar geht die Idee eines königlichen Kunstmuseums auch auf seine Anregungen zurück, jedoch bewegte sich der Kunstbegriff Hirts noch ganz in den Grenzen

10 Stüler selbst formulierte den Anspruch, »eine möglichst klare und ausgedehnte Uebersicht der Kunstübungen verschiedener Zeiten und Völker« darzubieten (Stüler, zitiert nach Cobbers 2009:22f.). 
des 18. Jahrhunderts. „Der Kanon der klassischen Kunst war bei Hirt allbestimmend. Seine Theorie und Geschichte der Kunst hatten diesen nicht nur als Ausgangspunkt, sondern auch als Ziel« (van Wezel 2003:29). Die Kunst schwingt in diesem zyklisch-kanonischen Denken also ewig im Kreis (Arendt Kap. 4), weshalb Chronologie in Hirts Kunstuffassung noch keine bestimmende Rolle spielte (van Wezel 2003:25). Im Unterschied dazu standen bereits Schinkel und erst recht Stüler im Erfahrungsraum des 19. Jahrhunderts, der durch Temporalisierung und eine massive Relativierung ehemals gültiger Weltbezüge geprägt war. Diese Erfahrungen der Veränderung brachten so auch die »Entstehung des linearen historischen Bewusstseins« zu Wege (a.a.O. 40), welches sowohl für den Erbauer des Alten als auch des Neuen Museums prägend war. Unter dem ungewissen Erwartungshorizont der Zeit erhielt das Streben nach Dauerhaftigkeit seinen Wert. Schinkel glaubte diese durch die ersatzreligiöse Verklärung der Baukunst zu erreichen. Denn »[sie] sollte etwas Göttliches sein, von Menschenhänden geschaffen, etwas Menschliches, für die Ewigkeit gedacht« (ebd.). Totz des historischen Bewusstseins ging Schinkel also davon aus, dass »die Kunst nicht ausschließlich historisch, sondern zugleich >überzeitlich« ist (Schinkel, zitiert nach van Wezel 2003:52).

Mit der Rolle, die der Kunst zuerkannt wird, steht Schinkel der Philosophie Schellings und der ästhetisch-ethischen Bildung Humboldts nahe (a.a.O. 42). Der Kunst wird damit neben ihrer präreflexiven Unmittelbarkeit auch eine sittlich-normative Bedeutung zugeschrieben. Diese quasi-religiöse Kunstverklärung verlor im Lauf des 19. Jahrhunderts abermals an Boden. Im Zentrum des Neuen Museums stand nicht mehr die ästhetische Kontemplation. Denn die verschiedenen Vergangenheiten, die zunehmend fremd geworden sind, werden erklärungsbedürftig und erforderten nun vielmehr der wissenschaftlichen Reflexion. Verzeitlichung und Verwissenschaftlichung gingen somit Hand in Hand.

Auch dieses gewandelte Geschichtsverständnis findet in der Außengestaltung des Museums künstlerischen Ausdruck. Ebenso wie an der Westseite des Hauses findet sich auch an dessen Ostseite eine Figurengruppe im Giebelfeld des Tympanons. Das von Friedrich Drake stammende Relief mit dem Titel »Die Künste im Studium des Althertums « verweist auf den Anspruch eines historischen Museums. Dass im Giebelfeld sowohl ein ägyptischer Pharaonenkopf als auch eine Madonna mit Kind dargestellt sind (van Wezel 2003:178ff.), reflektiert abermals den Geist des Historismus. Hieß es in Schinkels Altem Museum noch »Kunst selbst ist Religion« (Schinkel, zitiert nach van Wezel 2003:50), so wurde in Stülers Neuem Museum der historische Fortschritt zum strukturgebenden Element der Ausstellung und der Architektur. Der in diesem Zusammenhang oft zitierte Ausspruch Wilhelm von Kaulbachs, »Geschichte ist die Religion unserer Zeit. Geschichte allein ist zeitgemäß« (Wagner 1994:87; van Wezel 2003:107), steht also in deutlichem Kontrast zu Schinkels Sakralisierung der Kunst. 
Wurde der »überwältigende Stimmungsraum« im Alten Museum noch durch eine zur Kontemplation einladende und das Pantheon zitierende Rotunde gebildet, so steht im unumstrittenen Zentrum des Neuen Museums das monumentale Treppenhaus. Dieses wurde stets mit Hegels Geschichtsphilosophie in Verbindung gebracht (Wagner 1994:88; Frampton 2009:97; Cobbers 2009:22). Der Einfluss Hegels, der zu jener Zeit das Geistesleben Berlins prägte, blieb insbesondere durch den König nicht unwidersprochen (van Wezel 2003:111ff.). Monika Wagner hat außerdem darauf hingewiesen, dass das Neue Museum Stülers mehrere geschichtsphilosophische Ansätze vereinte (Wagner 1994:88). Allerdings besteht in der zentralen Betonung der Reflexion statt des Kunstgenusses tatsächlich eine gewisse Nähe zum Geschichtsverständnis Hegels. Um die verschiedenen geschichtswissenschaftlichen Einflüsse kenntlich zu machen, schlage ich die begriffliche Unterscheidung zwischen Historismus und Historizismus vor. Die Vorstellung der Alterität geschichtlicher Epochen, wie sie für den Historismus Leopold Rankes zentral ist, führte im Neuen Museum dazu, dass auch zuvor noch als wertlos Erachtetes, wie etwa die Kunst des Mittelalters (Cobbers 2009:30), ausgestellt wurde. Anders als im Klassizismus des Alten Museums, in dem primär die griechisch-römische Antike den kanonischen Bezugspunkt darstellt, wird nun eine Vielzahl verschiedener und in sich einzigartiger Stile und Epochen vergegenwärtigt. Jedoch bleiben die verschiedenen Epochen auf ein geschichtliches Telos gerichtet. Dieser hegelsche Fortschrittsgedanke entspricht einer geschichtsmetaphysischen Vorstellung, die mit Karl Popper als Historizismus bezeichnet werden kann. Die Vorstellung, dass »historische Vorhersagen« (Popper 1965:2) möglich sind, ist dabei wesentlich. Die Verschiedenheit der geschichtlichen Epochen wird also durch die Behauptung einer zielgerichteten und antizipierbaren Entwicklung wieder zu einem welthistorischen Ganzen verknüpft. Durch diese historizistische Behauptung erscheint auch die Verbindung ehemals unvereinbarer Ausstellungsteile kommensurabel.

Von besonderer Bedeutung für die bauzeitliche Fassung des Hauses war der monumentale Bilderzyklus des Münchner Historienmalers Wilhelm von Kaulbauch. Übereinstimmend mit dem eklektischen Umgang verschiedener geschichtswissenschaftlicher Ansätze im stülerschen Museum zeigt auch der Zyklus deutliche Spuren des Historismus sowie des Historizismus. Der monumentale "Nationalepos«, durch den Weltgeschichte als preußisch-deutsche Nationalgeschichte erzählt wurde (Menke-Schwinghammer 1994), war bereits in einem Vertrag vom 15. Mai 1843 mit dem Künstler vereinbart worden (Henze/Sommer 2007:6) und damit von Anbeginn der Planungen ein wesentlicher Bestandteil des Museums. In Analogie zu den sechs Schöpfungstagen illustrierte Kaulbauch sechs »Wendepunkte« in der Weltgeschichte (ebd.). Auf 75 Metern Länge entwarf er ein Bildprogramm, das von der »Zerstörung des Babylonischen Turms« bis 
zum »Zeitalter der Reformation « reichte. ${ }^{11}$ Bereits der Titel des Bilderzyklus, »Culturentwicklung aller Völker und Zeiten in ihrer geschichtlichen Hauptphase« (Zimmermann 1994:15), bringt eine entwicklungsgeschichtliche Auffassung und einen universalistischen Anspruch zum Ausdruck. Kaulbauch galt nicht nur als einer der berühmtesten Historienmaler seiner Zeit, sondern kann als Schüler Cornelius', der noch ganz dem Geist des klassischen Altertums verpflichtet war (van Wezel 2003:113), als Ausdruck des neuen historisch-säkularen Denkens angesehen werden. Die von ihm ausgeführten Wandfresken entfalteten im späten 19. Jahrhundert eine ungeheure nationale Strahlkraft (Wagner 1994:87); die Berühmtheit dieser Fresken überragte zeitweise sogar die des Hauses, welches sie eigentlich schmücken sollten.

Der gewaltige Aufgang des Treppenhauses wurde also mit dem Fortgang der Geschichte in Verbindung gebracht und dadurch zum Ausdruck des entwicklungsgeschichtlichen Ansatzes des Museums. Die typisch historistische Vorstellung singulärer Epochen zeigt sich in der Anordnung der Ausstellungbereiche (von Ägypten nach Griechenland). Diese wurden jedoch durch die Kaulbachfresken in ein historizistisches Entwicklungsnarrativ eingebunden (von Babylon zur deutschen Nation). Die Unterscheidung in verschiedene Epochen führte also nicht zu einem Relativismus, der dem geisteswissenschaftlichen Historismus oft vorgeworfen wurde (Nietzsche, Kap. 1), sondern zu einem Kulturchauvinismus, der die deutsche Kultur als Endpunkt einer menschheitsgeschichtlichen Entwicklung verklärte.

Indem eine unverbrüchliche Kontinuität vom Turmbau zu Babel bis zur deutschen Nation gespannt wurde, wird eine nationale Heilsgeschichte konstruiert, die zielstrebig auf den preußischen Staat als historisches Telos zuläuft. In einer zeitgenössischen Rezeption des Bildzyklus lautete dies etwa folgendermaßen: »Der deutsche Reitersmann vor dem Babelturm wird also der Staatsmann der deutschen Nation sein « (zitiert nach Wagner 1994:91). Die eigene Kultur wird zur höchsten Blüte einer welthistorischen Entwicklung erhoben; der Glanz der alten Kulturen für die eigene geschichtliche Bedeutung in Anspruch genommen. Dieses Verständnis verband sich in jener Zeit geradezu selbstverständlich mit einer »nationalhistorischen Denkweise« (Osterhammel 2001:9). Museen jener Zeit dienten also nicht nur als Instrument der bürgerlichen Bildung, sondern auch der nationalen Identitätsstiftung (von Buttlar 2010:9). Dass die politische Einheit Deutschlands zu diesem Zeitpunkt noch ausstand, veranschaulicht die prospektive Dimension der Konstruktion von Geschichtsbildern und den nationalaffirmativen Charakter des Neuen Museums in dieser Zeit. 
Dass es sich bei den Kaulbachfresken, ebenso wie in dem »bildungsbürgerlichen Kulturgedanke[n] « des erbauungszeitlichen Neuen Museums, um »nicht durchweg sympathische« Traditionen handelt (Zimmermann 1994:11), führte dazu, dass der Umgang mit dem Treppenhaus auch im Zuge der Wiederherstellung des Neuen Museums zentral thematisiert wurde. An der Frage, ob die 1943 vollständig zerstörten Kaulbachfresken wieder ausgeführt werden sollten, schieden sich die Geister. Im Diskurs bleiben die Kaulbachfresken und die Frage ihrer Rekonstruktion einer der wichtigsten Kristallisationspunkte der verschiedenen Modi der Identitätskonstruktion. Einerseits wurde argumentiert, dass die Fresken weiterhin integraler Bestandteil des Gebäudes seien. Einer erneuten Ausführung des Zyklus stehe zudem nichts im Wege, da die originalen Kartons noch existieren. Vor allem die Gesellschaft Historisches Berlin (GHB) vertrat die Meinung, dass das Kunstwerk deshalb wiederholbar sei. Andererseits wurde - zumeist von Vertretern der Denkmalpflege - argumentiert, dass gerade die Behauptung der Wiederholbarkeit des Kunstwerks einer künstlerischen Geringschätzung der individuellen Leistung Kaulbachs gleichkäme (Wagner 1994:87). Als Gewährsmann für das Verbot der Wiederholung wird also paradoxerweise Kaulbach selbst ins Feld geführt. Denn aus heutiger Sicht wäre eine Wiederholung des Bilderzyklus dem historischen Prozess zuwider, würde diese doch die an dem »Monumentalgemälde abgelagerte« Geschichte negieren (a.a.O. 97). Zudem erfordern die zeitgenössischen Implikationen des Zyklus, etwa seine "völkerphysionomische Rassenbewertung« (a.a.O. 88) oder der offen antisemitische Charakter des Werkes (a.a.O. 95), eine zeitliche Übersetzung und können nicht unkommentiert bleiben.

Wichtig für die Analyse des Diskurses ist, dass einerseits nur die Wiederholung der Fresken die Sicherung der Identität des Gebäudes gewährt. Dabei werden die geschichtlichen Implikationen des 19. Jahrhunderts nicht problematisiert. Ungeachtet ihres Inhalts werden sie weiterhin als Identitätsressource relevant gemacht. ${ }^{12}$ Andererseits bilden der Fortgang der Zeit und die Historisierung des Bildzyklus einen trennenden Graben, über den kein Weg mehr zurückführt. Die Sicherung der Geschichte liege vielmehr in ihrer Perspektivierung und nicht in einer »restaurierenden Simulation « (a.a.O. 97). Anstatt Geschichte zu rekonstruieren, gehe es darum, ihre Konstruktion zu verstehen und ihre Wirkung in der Rezeption sichtbar zu machen (a.a.O. 88). Die Phänomenstrukturen der Kaulbachfresken ergeben einerseits eine zeitlose Identitätsressource, andererseits eine historische Last, die erklärend kommentiert werden muss. 


\section{Das Weiße Museum}

Mit dem abermaligen Anwachsen der Sammlungen und durch die Veränderungen des Wissensstandes wurde die ursprüngliche Ausstellungskonzeption sukzessive revidiert. Insbesondere die Funde aus dem ägyptischen Amarna, die auch die berühmte Büste der Nofretete umfassten, machten in den Jahren zwischen 1919 und 1923 bauliche Eingriffe erforderlich. ${ }^{13}$ Durch den Einzug einer Zwischendecke im Griechischen Hof wurde zudem das Bodenniveau angehoben. Nachdem der Ägyptische Hof bereits nach Plänen Stülers überdacht wurde, erhielt nun auch der Griechische Hof seine Überdachung. Im Zuge des Umbaus zum nunmehr >Amarnasaak genannten Innenraum wurde auch die Apsis an der Südseite des Hofes abgebrochen (Henze/Sommer 2007:14f.). Die Neugestaltung der Innenräume im Zuge der Armana-Ausstellung betrafen ab den 1930er Jahren auch den Mythologischen Saal und den Gräbersaal. Hier wurden die Decken abgehängt und die reich bebilderten Wände übermalt.

Anstatt didaktischer Wandmalereien sollten die Ausstellungsobjekte möglichst für sich sprechen. Nichts sollte die Konzentration auf das Exponat stören. Nicht mehr die Weltschau eines Universalmuseums und ein intuitives Bildungserlebnis, sondern der nüchterne Blick auf die Ausstellungsobjekte sollte sich hier den Besuchenden eröffnen. Das 1936 geschaffene »Weiße Museum« (Henze/Sommer 2007:16) stellt somit einen weiteren historischen Einschnitt in der Geschichte des Hauses dar. In dieser Ausstellungskonzeption emanzipieren sich die Objekte schließlich, womit Parallelen zu dem erst deutlich später geprägten Begriff des White Cube erkennbar werden. ${ }^{14}$ Obwohl diese Bezeichnung im Zusammenhang mit der Amarna-Ausstellung anachronistisch ist und das Weiße Museum höchstens als White Cube avant la lettre bezeichnet werden kann, wird dieser Begriff in der Diskursivierung des Neuen Museums verwendet. So spricht etwa der ehemalige wissenschaftliche Referent der Staatlichen Museen, Andreas Lepik (Rauch et al. 2009), vom White Cube in dieser Zeit (zitiert nach Mager 2016:167). Unabhängig von der terminologischen Unstimmigkeit liegt der Wert dieser Bezeichnung gerade darin, den innovativen Charakter der Ausstellungskonzeption der 1930er Jahre hervorzuheben. Durch den Fortgang der Geschichte hat sich jedoch auch diese Form der Ausstellung überlebt und wurde ihrerseits historisch. Auch dem Weißen Museum wird also historische Bedeutung als ein Novum der Musealisierung zugesprochen.

Die Büste der Nofretete wurde anfänglich noch nicht mit den übrigen Amarna-Funden gezeigt, was der ungeheuren Popularität und der massenwirksamen Ästhetisierung der Exponate jedoch keinen Abbruch tat. Ludwig Borchardt, der Entdecker der Büste, wusste um die Brisanz ihrer Provenienz, die im Zuge der nationalen Vereinnahmung der Ägyptologie und in der Folge des Ersten Weltkrieges zunehmend zum Politikum wurde. Diese »deutsch-französische Affäre« um die Besitzansprüche stellt eine Langzeitfolge des Krieges dar (Savoy 2011). 
Durch Luftangriffe am 24. November 1943 sowie weitere Bombentreffer vom 03. Februar 1945 wurden schließlich der Nordwestflügel, der Südkuppelsaal samt Übergang zum Alten Museum und Teile des Südwestflügels zerstört (Henze/Sommer 2007:17). Die weiteren Beschädigungen entstammen dem Straßenkampf um Berlin. Vor allem die charakteristischen Einschläge der Schrapnellgeschosse, die heute an der Fassade des Gebäudes und den wiederaufgestellten Kolonnaden auffindbar sind, entstammen dieser Zeit. Nach den Beschädigungen der letzten Kriegstage begann ein Abschnitt in der Geschichte des Hauses, in dem das Gebäude über Jahrzehnte der Witterung ausgesetzt war. Das Neue Museum wurde zur Ruine.

\section{Ruinenzeit}

Obwohl Pläne der 1960er Jahre einen »Totalabriss« (Meuser 2002:184) und einen an Volumen und Kubatur orientierten dem Neuen Museum vergleichbaren Neubau vorsahen, der die Gliederung der Fassade durch die Risalite in ornamentloser, auf geometrische Flächen reduzierter Form aufgenommen hätte, kamen diese ambitionierten Pläne nicht über das Entwurfsstadium hinaus. ${ }^{15}$ Stattdessen wurden in der folgenden Zeit weitere Abbrucharbeiten an der Ruine vorgenommen. Diese betrafen vor allem die Reste des Übergangs zum Alten Museum, den Nordwestflügel sowie die ruinösen Teile des Südkuppelsaals (Henze/Sommer 2007:17). Erst in den 1980er Jahren wurde schließlich der Entschluss zur Wiederherstellung des Hauses nach historischem Vorbild gefasst. Ungeachtet der offiziellen Sprachregelung der DDR, in der nicht von Wiederaufbau gesprochen wurde (Schulz 2009:40), diente die Entscheidung zur historischen Rekonstruktion des Neuen Museums den Befürwortern einer originalgetreuen Wiederherstellung im Folgenden immer wieder dazu, die Legitimität ihrer Forderung zu untermauern. Bis zum Beginn der »Schaffung der Voraussetzungen und der Sicherung« (ebd.) waren große Teile der Innenräume, etwa das Treppenhaus, der Ägyptische und der Griechische Hof, fast 40 Jahre unmittelbar Umwelteinflüssen ausgesetzt. Zudem setzten Bewuchs durch Sträucher und vor allem deren Wurzeln der Bausubstanz zu. Aus der Verbindung zwischen ehemaligem Glanz des Hauses, den Kriegszerstörungen sowie der Verwilderung durch Witterung und Vegetation ergab sich schließlich ein Bild, welches im Diskurs oft mit den stimmungsvollen Ruinenstichen Piranesis verglichen wurde. Wird der ruinöse Charakter einerseits als wesentlich für die Geschichte

15 Einen hervorragenden Einblick in die Geschichte der »ungebauten Museumsinsel« bietet Philipp Meuser (2002). Anhand von Zeichnungen wird der Neubauentwurf des Neuen Museums des Architekten M. Woldt aus dem Jahr 1965 dargestellt. Dieser entsprach dem »DDRZeitgeist der Sechzigerjahre« (2002:184), indem er gegen die als Ausdruck des Konservatismus gedeuteten Museen gerichtet war (Schulz 2009:43). 
des Bauwerks anerkannt, so bleibt er andererseits ohne Wert. Die Ruinenzeit wird dann meist mit Begriffen wie >Verwahrlosung oder >Niedergang thematisiert.

Mit Beginn der Rekonstruktionsarbeiten kam es zunächst zu weiteren Abbrüchen von Bauteilen, deren Originalsubstanz, obwohl noch vorhanden, für den Neubau nicht nutzbar gemacht werden konnte. Dies betraf vor allem das Mauerwerk der erhaltenen Säulen des Ägyptischen Hofes (1988), Reste der Korenhalle (1989) sowie die Reste des Südkuppelrisaliten (1990) (Henze/Sommer 2007:17f.). Neben den Abrissen der späten $80 e r$ Jahre bestand die wesentliche bauliche Veränderung jener Zeit in den Arbeiten an einer Ersatzgründung zur Stabilisierung der Fundamente. Die erneute Gründung des Gebäudes war nötig geworden, da die 2.344 Eichenstämme, auf denen das Haus seit der Mitte des 19. Jahrhunderts ruhte, im Kontaktbereich zwischen Untergrund und Fundament verfault waren und somit kein sicheres Fundament mehr boten. So kam es dazu, dass am o1. September 1989 der erste Bohrpfahl der Neugründung vom vorletzten Kultusminister der DDR durch den Schlamm in den immer noch kolkhaltigen Untergrund der Museumsinsel getrieben wurde (Schulz 2009:40).

Abbildung 9: Das Neue Museum von Südosten im Jahr 1945. Neben den Einschusslöchern in den Kolonnaden ist die Zerstörung des Südkuppelsaals und des Übergangs zum Alten Museum (links) zu erkennen. Beide wurden später vollständig abgetragen; Abbildung 10: Im Zuge der Rekonstruktionsbemühungen in der DDR wurden die Säulen des Ägyptischen Hofes im ansonsten vollständig zerstörten nordwestlichen Flügel des Gebäudes 1988 abgerissen.
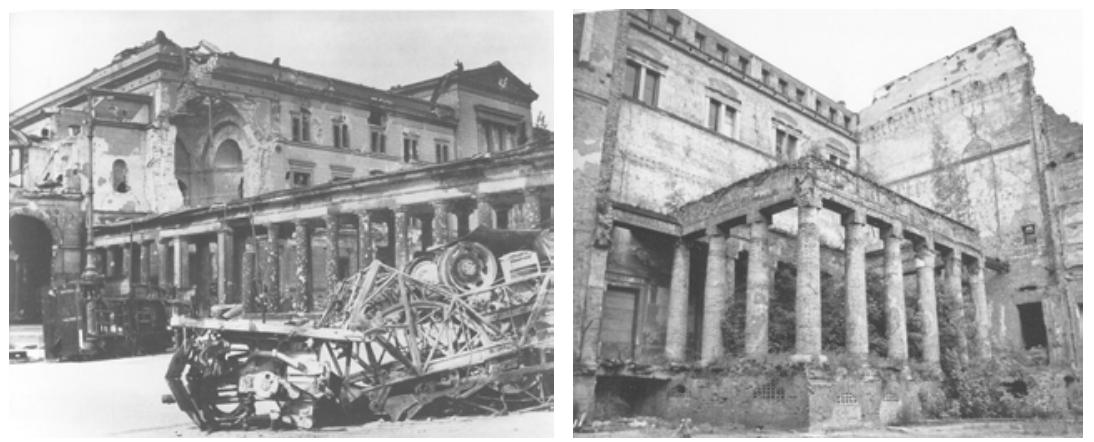

\subsubsection{Diskursgeschichte zwischen Original und Ergänzung}

Der Abschluss der Arbeiten an der neuen Bodenplatte des Gebäudes fiel bereits in die Zeit nach der deutschen Wiedervereinigung. Als das Neue Museum 1992 erneut auf festem Grund ruhte, war die DDR selbst bereits Geschichte geworden. Nach- 
dem die neue Fundierung sichergestellt war, hob nun eine langanhaltende Debatte über die Art der Wiederherstellung an. Sah die Planung der 1980er Jahre noch eine Rekonstruktion der Gebäudefassung des 19. Jahrhunderts vor, so stand nun die Frage im Raum, wie mit den vergangenen vier Dekaden der nun ihrerseits historisch gewordenen DDR umzugehen sei. Nach der erneuten Gründung des Bauwerks begann nun die diskursive Arbeit an verschiedenen Begründungen für den richtigen Umgang mit dem über Jahrzehnte Ruine gebliebenen Gebäude.

Das folgende Unterkapitel dient dazu, die wichtigsten Etappen der Debatte zu benennen und so die Zeitachse des Diskurses der Wiederherstellung des Neuen Museums nachzuzeichnen. Außerdem werden die wichtigsten Akteure des Diskurses genannt. Neben Vertretern der Denkmalpflege, die in Form des Landesdenkmalamtes (LDA) und der denkmalpflegerischen Kommission während des gesamten Wiederherstellungsprozesses einflussreich waren, sind außerdem die Bundesbaudirektion (ab 1998 Bundesamt für Bauwesen und Raumordnung (BBR)) als Auslober des Architektur-Wettbewerbes von 1994 sowie die Staatlichen Museen und die Stiftung Preußischer Kulturbesitz als Bauherren und Eigentümer zu nennen. 1997 wird schließlich das Büro David Chipperfield Architects (DCA) mit der Wiederherstellung des Neuen Museums betraut. Auch David Chipperfield, dessen Projektleiter für das Neue Museum, Martin Reichert, und vor allem der Chef-Restaurator Julian Harrap explizieren ihr Konzept der Wiederherstellung durch weitere Publikationen. Des Weiteren und als eine der vehementesten Stimmen der Kritik ist schließlich noch ein zivilgesellschaftlicher Akteur zu nennen: die Gesellschaft Historisches Berlin (GHB). Diese Bürgerinitiative bezog in einer Vielzahl von Texten Stellung gegen die sergänzende Wiederherstellung< und forderte stattdessen eine soriginalgetreue Wiederherstellung،. Der mediale Diskurs dient vor allem als Resonanzkörper der unterschiedlichen Akteurspositionen. Neben den unmittelbar auf die Debatte der Wiederherstellung bezogenen Dokumenten bestehen Verbindungen zu weiteren Dokumenten. Die Welterberichtlinien der UNESCO oder die Charta von Venedig (1964) sind ebenso Bestandteil des Diskurses. Sie gehören einem zweiten, weiter gefassten Kreis von Diskursdokumenten an, auf den in den jeweiligen Argumentationen immer wieder Bezug genommen wird. Auch aus der Bezugnahme auf diese Dokumente wurden schließlich höchst verschiedene Forderungen abgeleitet.

\section{Vom Gutachten zum Plädoyer}

Mit dem sogenannten »Denkmalpflegerischen Plädoyer« für eine »ergänzende Wiederherstellung« (Badstübner et al. 1994) wurde die Planung zu einer Rekonstruktion des erbauungszeitlichen Zustandes, wie er in den letzten Jahren der DDR beschlossen wurde, einer Revision unterzogen (a.a.O. 25). Dieses Dokument bildete außerdem den Auftakt zu einer intensiven öffentlichen Debatte 
über die Zukunft des Gebäudes und den Umgang mit seiner Geschichte, die bis 2009 anhalten sollte. Bereits zwischen 1991 und 1992 wurden Kunsthistoriker und Denkmalpfleger durch den Senator Volker Hassemer, den Generaldirektor der staatlichen Museen Wolf-Dieter Dube sowie durch die Präsidentin der Bundesbaudirektion Barbara Jakubeit aufgefordert, ein Rahmengutachten zu erstellen (Wolters 2010:242f.). Die Kommission, die erstmals am 02. Oktober 1991 zusammentrat und das ruinöse Gebäude besichtigte (Badstübner et al. 1994:20), sollte die Politik wissenschaftlich beraten. Damit werden die relative Ratlosigkeit im Umgang mit dem Gebäude sowie eine institutionell komplexe Konstellation erkennbar. 1994 schließlich wird das Rahmengutachten auf Anraten des Landeskonservators, Jörg Haspel, durch die Senatsverwaltung für Stadtentwicklung und Umweltschutz unter dem Titel »Denkmalpflegerisches Plädoyer zur ergänzenden Wiederherstellung « veröffentlicht (Wolters 2010:243). Haspel hebt außerdem die Bedeutung des Expertengutachtens für die Wiederherstellung des Neuen Museums hervor. Denn dieses bildete »die wesentliche Grundlage für vertiefende Untersuchungen und für die Konkretisierung der konservatorischen Ziele« (Haspel 2000:41). Die Akzentverlagerung vom (Rahmen-)«Gutachten« zum »Plädoyer « kann als wissenspolitischer Versuch gedeutet werden, die zu treffende Entscheidung wissenschaftlich zu legitimieren. So suggeriert die Titeländerung, dass die Politik lediglich wissenschaftlich fundierte Empfehlungen ausführe.

Zentral für das Dokument ist die bereits im Titel anklingende Spannung zwischen »Ergänzung « und »Wiederherstellung«. Eine Rekonstruktion wird demnach ebenso ausgeschlossen wie ein Neubau. Dennoch bedient sich das Plädoyer des gesamten dazwischenliegenden Spektrums und kommt den Extrempunkten dabei an manchen Stellen sehr nahe. Diese konzeptionelle Mehrgleisigkeit findet in der empfohlenen Zweiteilung der Aufgabenbereiche ihren Ausdruck. Das denkmalpflegerische Projekt der »Instandsetzung« solle sich demnach auf den Erhalt der historischen Substanz beziehen (Badstübner et al. 1994:20). Dabei werde stets nach »wissenschaftlichen Vorgaben, konservatorischen Bedingungen und denkmalpflegerischen Bewertungsmaßstäben« abgewogen. Gegenstand des architektonischen Projekts des »Ideenwettbewerbs « und damit einer freieren Gestaltungsaufgabe sei vor allem der Neubau am Kupfergraben. Jedoch gelte auch in Bezug auf den Ideenwettbewerb: "Bindungen zu beachten, die sich aus dem Charakter des Neuen Museums und aus der städtebaulichen Situation ergeben. Gesichtspunkte der Kontinuität und Verträglichkeit sind auch hier besonders zu beachten« (a.a.O. 21). Für den Außenbereich des Neuen Museums wird eine Wiederherstellung im Sinne der Charta von Venedig empfohlen. Danach sei der »Textur der Oberfläche im unterschiedlichen Nebeneinander von sichtbar gealtertem und - ebenso spürbar - von neu erstelltem Baubestand in ausreichendem Maß Rechnung « zu tragen. Dieses Vorgehen sei demnach deutlich von einer Rekonstruktion zu unterscheiden (a.a.O. 23). 
Aufgrund der Vielzahl unterschiedlicher Schadensformen wird die denkmalpflegerische Aufgabe abermals differenziert. Die Typisierung der Erhaltungszustände umfasst die Kategorien »rekonstruktionsfähig«; »teilzerstört« und »Totalverlust«. Demnach sollen »weitgehend erhaltene Oberflächen« restauriert werden. Zustände der Entstehungszeit können eingebunden werden (Badstübner et al. 1994:32). Teilzerstörte Räume sowie »ausgelagerte Bauteile« hingegen können so ergänzt werden, dass die »ursprüngliche Konzeption zumindest in wichtigen Teilen wieder verständlich« wird. Diese Räume dienen als »Bindeglied« zwischen den noch erhaltenen und gänzlich zerstörten Räumen. Schließlich sollen die "Baubereiche mit Totalverlust« in der räumlichen Grundstruktur wiederhergestellt werden. Jedoch weisen die Autoren explizit darauf hin, dass »dies keineswegs eine Wiederherstellung der stülerschen Ausstattung mit allen Dekorationen und Malereien in Form einer >originalgetreuen Rekonstruktion« beinhalte (ebd.). Trotz der Abgrenzung zu einer am erbauungszeitlichen Zustand orientierten Wiederherstellung ist wichtig herauszustellen, dass das Gutachten sowie das tatsächlich umgesetzte Konzept sich des gesamten Spektrums der Wiederherstellung bedienen. ${ }^{16}$ Diese konzeptionelle Hybridität wird vonseiten der im Wiederherstellungsprozess Beteiligten oft unterstrichen. ${ }^{17}$ Der Charakter des konsensorientierten Konzeptes, zwischen Neubau und Rekonstruktion, kommt abermals in der Handlungsempfehlung für den Wettbewerb des Neubaus zum Ausdruck.

»Die Ausgestaltungslösungen eines eigens hierfür zu veranstaltenden Wettbewerbs werden daran zu messen sein, ob sie die Biographie des Denkmals durch kontrastierende Ästhetik übertönen, durch Erneuerung verschleiern oder durch einfühlende Zurückhaltung verständlich machen«(Badstübner et al. 1994:26, Herv. JK).

Auch im Ideenwettbewerb seien also »Kontinuität und Verträglichkeit« zu wahren. Der schmale Grat zwischen einer »kontrastierenden Ästhetik« und einer verschleiernden »Erneuerung« dürfe auch hier nicht verlassen werden.

\section{Wettbewerb zur Ergänzung und Wiederherstellung}

Bereits der offizielle Titel des 1993 von der Bundesbaudirektion ausgelobten Wettbewerbs, »eingeladener Wettbewerb für die Planung der Wiederherstellung des Neuen Museums und der Errichtung von Ergänzungs- und Verbindungsbauten

Beispielhaft dafür ist der unterschiedliche Umgang mit den Schadensflächen in den jeweiligen Sälen des Museums. Das Beispiel des gotisierenden Rippengewölbes im Sternensaal, welches vollständig verloren war und dennoch rekonstruiert wurde, deutet die Spannweite und die konzeptionelle Unschärfe an. Die Rekonstruktion diente hier vor allem als »Träger der ornamentalen Reste (Wolters 2010:245ff.). 
zur Zusammenführung der Archäologischen Sammlungen der Staatlichen Museen zu Berlin - Preußischer Kulturbesitz auf der Museumsinsel«, macht deutlich, dass es dabei nicht lediglich um die Wiederherstellung des Neuen Museums, sondern letztlich um eine »zeitgemäße Weiterentwicklung der Museumsinsel« ging (Große-Rhode 2009:50). Neben der »Herstellung bzw. Wiederherstellung« von Verbindungsbauten zum Alten Museum und zum Pergamonmuseum bestand die vordergründige Aufgabe in der »Ergänzung des in Teilen zerstörten Neuen Museums einschließlich Erweiterung am Kupfergraben« (Sayah 1994:128). Damit wurde ein Entwurf für einen Neubau auf dem Gelände des ehemaligen Packhofs gefordert. Dem »denkmalpflegerischen, kunsthistorischen und wissenschaftlichen Wert der vorhandenen Bausubstanz« solle ebenso Rechnung getragen werden wie den »heutigen Anforderungen an ein funktionierendes und ein aus museologischer und architektonischer Sicht zeitgenössisch gestaltetes Museum« (a.a.O. 128f.). Neben der Bundesbaudirektion sind auch die Staatlichen Museen sowie die Denkmalpflege in den Wettbewerb eingebunden (ebd.), wodurch sich die Komplexität der Bauaufgabe auch institutionell abbildet.

Zudem unterstreicht die Präsidentin der Bundesbaudirektion den Doppelcharakter des Wettbewerbs, denn die »Entwurfsaufgabe« beschränke sich nicht nur auf die »Wiederherstellung eines teilzerstörten Bauwerks«, sondern bestand auch in der »Ergänzung eines städtebaulichen Ensembles« (Jakubeit 1994:4). Bemerkenswert ist nun jedoch, dass das »zukunftsweisende Museumskonzept « zur »Vervollständigung und Fortschreibung « beitragen solle und sich nicht in »restaurativer Wiederherstellung« erschöpfen dürfe (Saya 1994:128f.). Diese Lesart wurde auch vom medialen Diskurs aufgegriffen. So war etwa in »Die Zeit« vom 25. März $1994 \mathrm{zu}$ lesen, dass es der Stiftung um ein "Zu-Ende-Bauen und ein $\mathrm{Zu}$-Ende-Gliedern dieser monumentalen Akropolis« gehe (Stegers 1994:120). Auch die Behauptung einer von Anbeginn bestehenden Fehlstellung, die die anhaltende Korrekturbedürftigkeit der Museumsinsel begründe, erhält somit ihren Sinn durch die gegenwärtige Aufgabe. Eine bloße Rückkehr in restaurativer Absicht wird den gegenwärtigen Anforderungen nicht gerecht. Überdies werden Aspekte der Weiterentwicklung und des zukunftsorientierten Umgangs mit dem baulichen Erbe in eine Tradition des Ortes gestellt: »Der Entwurf kann insofern an die Tradition der Museumsinsel anknüpfen, die in ihrer Geschichte immer ein sich fortentwickelnder Organismus gewesen ist « (Sayah 1994:129). Die vielfältigen Anforderungen an die zu errichtenden Gebäude werden also in eine konsistente Erzählung eingebettet. In den Begriffen wissenssoziologischer Hermeneutik (Kap. 3.4) heißt dies, dass die Rede von der »ergänzenden Wiederherstellung « und die Traditionalisierung des Fortschreibens nicht nur eine kreativ sinnhafte, sondern zudem auch eine funktional sinnvolle Deutung darstellen (Reichertz 2005:164ff.). Die strikte Befolgung des klassischen Imperativs der Denkmalpflege, wie ihn Georg Dehio formulierte, »nicht restaurieren - wohl aber konservieren« (Dehio 1988:98, Orig. 1914), greift hier also zu 
kurz. ${ }^{18}$ Durch die Anforderungen an eine zeitgemäße Vermarktung und die Schaffung eines modernen Museums erscheint eine Selbstthematisierung, die die Weiterentwicklung selbst historisiert und die Veränderung als »sich fortentwickelnder Organismus « naturalisiert, sinnvoll und funktional, da damit strukturelle Zwänge der Gegenwart in die Vergangenheit des Gebäudes integriert werden können.

Im Medienecho des Wettbewerbs (Sayah 1994:112-127), dessen Resultate ab dem 31. März 1994 in den teilzerstörten Räumen des Nordostflügels des Neuen Museums zu sehen waren, überwog jedoch die Skepsis. Besonders der spektakuläre Entwurf Frank O. Gehrys zog viel Aufmerksamkeit auf sich. Dieser sah vor, die Museumsbauten mit einer »Kette von Galerien« zu verbinden. Die einzelnen Baukörper, so der Architekt, seien eine "einladende Komposition", die das "Alte Museum vorsichtig auf der Westseite berühre[n]« (Gehry 1994:56). Laut Preisgericht verhalte sich der Eingriff allerdings indifferent gegenüber der Stadttypologie und sei »gestalterisch schwer beherrschbar" (a.a.O. 58).

Gewiss bildet der Gehry-Entwurf die Extremposition der »kontrastierenden Ästhetik«, vor der noch im denkmalpflegerischen Gutachten gemahnt wurde. Dennoch präferierte der damalige Generaldirektor der Staatlichen Museen Berlin WolfDieter Dube die »poppige Arbeit« Frank O. Gehrys, der den vierten Preis erhielt, womit er zum »Kandidaten der Museumsdirektoren« wurde (Bernau 1994:114f.). Vor allem Dube forderte ein spektakuläres architektonisches Ausrufezeichen, vergleichbar der Pyramide im Louvre. Damit sollte auch der politische Anspruch der neuen Hauptstadt betont werden (Dube 1994:24). Dieses Sendungsbewusstsein und der architektonische Paukenschlag Gehrys wurden allerdings von der Denkmalpflege entschieden abgelehnt. In den Worten des denkmalpflegerischen Gutachtens pochte diese auf eine »einfühlende Zurückhaltung«. Demgemäß erschien der moderate Eingriff des Gewinners des Wettbewerbs den Vertretern der Denkmalpflege durchaus akzeptabel. Im Entwurfstext bezog sich Grassi auf die von Schinkel 1830-33 an diesem Ort geplante Packhofanlage (Marquart 1994:121f.).

»Wir haben an der Idee der Erweiterung des Neuen Museums gearbeitet, als ob diese Erweiterung der baulichen Ceschehnisse schon vorher bestanden hätte. Als ob es sich um ein Fragment jener Bauten der alten, von Schinkel hinter dem Alten Museum geplanten Packhofanlage handeln würde« (Crassi 1994:44).

18 Georg Dehio formulierte bereits zu Beginn des 20. Jahrhunderts den folgenreichen Crundsatz der Denkmalpflege, »den sie nie mehr verlassen kann: erhalten und nur erhalten! ergänzen erst dann, wenn die Erhaltung materiell unmöglich geworden ist; Untergegangenes wiederherstellen nur unter ganz bestimmten, beschränkten Bedingungen. (Dehio 1988:36, Orig. 1901). Weiterentwicklung, Veränderung, Modifikation nach Maßgaben der Cegenwart finden in diesem klassischen Verhaltenskodex der Denkmalpflege also keine Berücksichtigung. 
Laut Architekten leiteten sich schließlich aus den historischen Planungen Schinkels weitere Maßgaben für den gegenwärtigen Wettbewerbsentwurf ab:

»Dieser bestimmte architektonische Bezug hat dann die verschiedenen Momente unseres Entwurfs geleitet: von der Lage des neuen Geländes, aber auch seiner Maße im Grundriß und in der Höhe bis sogar zu den sozusagen stilistischen Entscheidungen wie die Anwendung der einfachen Materialien.«(Grassi 1994:44).

Obwohl sich Grassi mit dem Rückgriff auf die Vergangenheit noch nicht dem Verdacht der im Gutachten ebenfalls kritisierten »verschleiernden Erneuerung aussetzte, bildete der Siegerentwurf Grassis dennoch einen Gegenpunkt zu Gehrys massivem Eingriff. Das Preisgericht würdigte die "positive Zurückhaltung«, die das historische Ensemble baulich nicht überformt. Moniert wurde jedoch das »nicht ganz überzeugend ausgeformte Volumen«. Dieses erschien den Juroren als Haupteingang für die neue museale Anforderung des »Kurzrundgangs« ungeeignet (Preisgericht, zitiert in Grassi 1994:47).

Abbildung 11: Der Entwurf Frank O. Gehrys sah eine Kette kontrastierender und miteinander verbundener Baukörper vor. Die Vertreter der Staatlichen Museen präferierten diesen Entwurf. Für die Denkmalpflege war dies jedoch inakzeptabel. (Image provided by Gehry Partners, LLP).

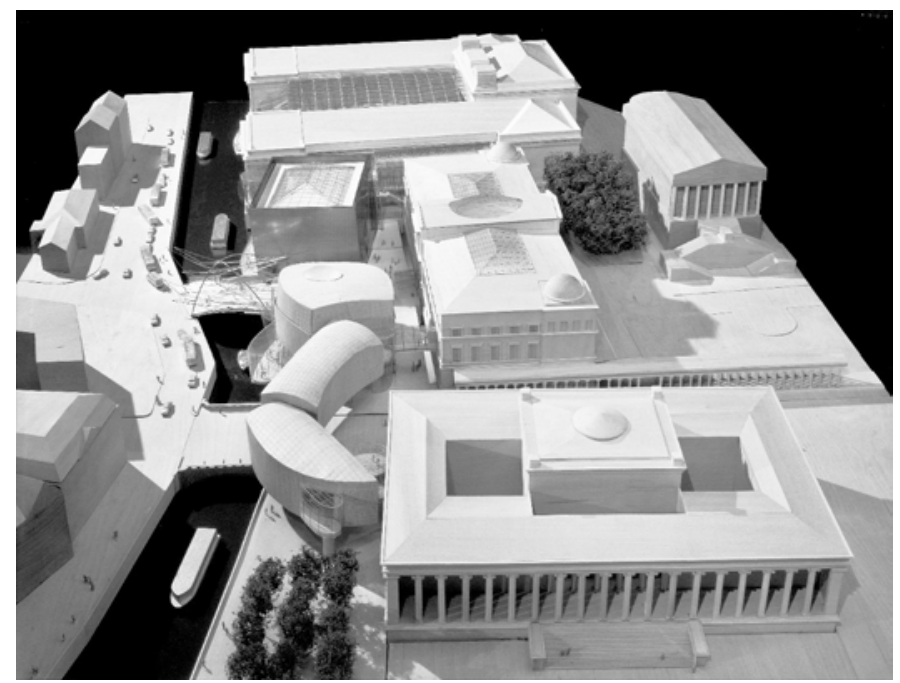

Auch die Entscheidung, hier einen Ziegelbau zu errichten, der sich hinsichtlich seiner Materialität und Farbgebung in das bestehende Ensembel einfügt, erschien ebenfalls problematisch. Denn mit dem weitgehenden Rückgriff auf die Ver- 
Abbildung 12: Der Siegerentwurf Giorgio Grassis sah ein in Volumen und Höhe den Packhofanlagen vergleichbaren Baukörper vor. Für die Denkmalpflege akzeptabel, konnte das Raumprogramm allerdings die Anforderungen, die der Museumsbetrieb stellte, nicht erfüllen.

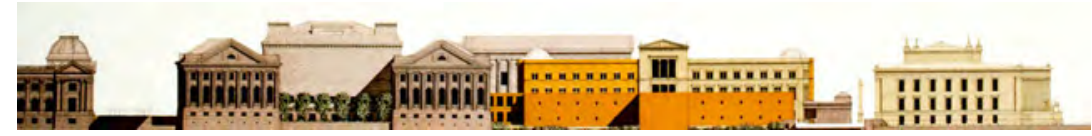

gangenheit fehlen die erforderlichen Freiheitsgrade, die zur Beantwortung aktueller musealer Fragen oder struktureller Anforderungen der zeitgemäßen Vermarktung notwendig sind. Gerade den Forderungen nach einem Kurzrundgang, der es einem zahlkräftigen Publikum ermöglichen soll, die Highlights der archäologischen Sammlung innerhalb kurzer Zeit zu besichtigen, konnte innerhalb der alten Maße und Grundrisse nicht entsprochen werden. Auch der Entwurf Grassis wird dem Doppelcharakter der Bauaufgabe zwischen Ergänzung und Wiederherstellung nicht gerecht. Trotz der einstimmigen Empfehlung der Jury für den Entwurf Grassis wurde vonseiten der Staatlichen Museen, die aus ihrer Präferenz für den Entwurf von Frank O. Gehry keinen Hehl machten, die »unzureichende Funktionalität des Entwurfes von Giorgio Grassi« hervorgehoben. Die Diskussion darüber, wie die Museumsinsel zu einem »zeitgemäßen Museumsensemble bei gleichzeitiger Wahrung ihres historischen und denkmalpflegerischen Wertes « fortgeschrieben werden könne, hielt also weiter an (Große-Rhode 2009:50, Herv. JK).

Der mediale Diskurs jener Zeit gibt die Unzufriedenheit mit den Wettbewerbsergebnissen wieder. Vor allem der Vorwurf der »Ideologie der Massenabfertigung« (Bernau 1994:115) artikulierte sich anhand des belustigend als »Touristenrollbahn« bezeichneten »Schnellrundgang[s]«(Bernau 1994:114). Ebenso wurde der Siegerentwurf Grassis als »ziegelverhüllter Bau mit winzigen, schießschartenähnlichen Löchern« (Guratzsch 1994:117) geschmäht. Die unbefriedigenden Ergebnisse des ersten Wettbewerbs sowie die Bemühungen der Denkmalpflege, den Entwurf Gehrys abzuwehren, führten schließlich dazu, dass ein Gutachterverfahren beantragt wurde. Dieses wurde unter der Ägide des Präsidenten des Bundesamtes für Bauwesen und Raumordnung, Florian Mausbach, vorangetrieben (Große-Rhode 2009:52). Nunmehr wurde der Fokus auf die Wiederherstellung des »Neuen Museums in seiner ursprünglichen Kubatur« gelegt. Mit dem Entschluss, die Entscheidung über die Bebauung am Kupfergraben zu vertagen, reduzierte sich das Raumprogramm von $16.535 \mathrm{~m}^{2}$ auf lediglich $6.890 \mathrm{~m}^{2}$ drastisch (ebd.). Schließlich wurden die ersten fünf Preisträger aufgefordert, ihre Entwürfe nochmals zu überarbeiten und ihre Ergebnisse einem Beratergremium zu präsentieren. In dem nun auf die Wie- 
derherstellung des Neuen Museums konzentrierten Wettbewerb schied Grassi, der nicht bereit war, seinen Entwurf zu überarbeiten, aus. Ende 1997 empfiehlt das Gremium schließlich David Chipperfield für den Wiederaufbau des Neuen Museums. Der Präsident der Stiftung Preußischer Kulturbesitz folgte dieser Entscheidung, woraufhin Anfang 1998 das BBR das Büro des britischen Architekten beauftragte (ebd.).

Die Tatsache, dass in dem komplexen Entscheidungsverfahren zahlreiche Akteure involviert waren, die unterschiedliche Anforderungen und Präferenzen hatten, führte dazu, dass bereits seit Anfang der Auseinandersetzung eine Vielzahl von Dokumenten entstand. Der Zwang zur Versprachlichung und Rechtfertigung des Vorgehens und damit zur verstärkten Diskursivierung ist auch nach 1998 keineswegs abgeschlossen. Vor allem durch den Restaurator des Projektes, Julian Harrap, entstehen im Prozess der Wiederherstellung weitere Dokumente zur Theoretisierung des Vorgehens. Dabei handelte es sich um die Restaurierungsstrategien (1999) und das Restaurierungskonzept (2000). Außerdem ist der »Denkmalpflegerische Leitfaden « (1999) zu nennen, welcher zwar auf dem Gutachten von 1994 aufbaute, jedoch im Verlauf der »weiteren Planung fortlaufend präzisiert und konkretisiert wurde« (BBR 2010). Vor allem der letztgenannte »Leitfaden« wird von Chipperfield als »in vielerlei Hinsicht vage« beschrieben. Dass diese Anpassungsfähigkeit jedoch $\mathrm{zu}$ Beginn des Prozesses durchaus »das richtige Instrument « war und es schwierig gewesen wäre, »konkreter zu werden«, unterstreicht der Architekt dabei deutlich (Chipperfield/Wolters 2009:232). Dieser Prozesscharakter der Entscheidungsfindung am runden Tisch wird auch durch Wolfgang Wolters (a.a.O. 232ff.), einen der Autoren des Denkmalpflegerischen Gutachtens, sowie durch Julian Harrap (2009b:123f.) hervorgehoben. Von Anfang an habe keine verbindliche oder schriftlich fixierte Festlegung für die Gestaltung der Räume bestanden. Vielmehr war die Innengestaltung das Resultat von schrittweise erarbeiteten Einzelentscheidungen (Wolters 2010:247f.). Dass das Konzept der ergänzenden Wiederherstellung somit einen gewissen Grad an Konzeptlosigkeit beinhaltete, schien der Komplexität der Bauaufgabe angemessen.

Einen ersten Höhepunkt erreichte die Debatte bereits nach dem Wettbewerb von 1994. Spätestens mit der Konkretisierung der Wiederherstellungspläne, die vorsahen, die Zeichen der Zeit am Neuen Museum sichtbar zu lassen, werden die Stimmen der Kritik ab 1997 unüberhörbar. Damit betrat ein weiterer Akteur den diskursiven Raum, der mit der Forderung nach einer originalgetreuen Wiederherstellung nicht nur den extremen Gegenpunkt zu dem von Dube favorisierten Entwurf Gehrys darstellt, sondern auch überkreuz mit den Maßgaben der Denkmalpflege lag: die Gesellschaft Historisches Berlin (GHB). 


\section{Widerspruch}

Neben der konzeptionellen Adaptionsfähigkeit wird oft der offen kommunikative Charakter der Planungsentscheidungen, die allesamt am runden Tisch abgewogen wurden, hervorgehoben. Dieser kommunikative Charakter sei von der anhaltenden Suche nach Kompromissen gekennzeichnet gewesen (Wolters 2010:247f.). Der Architekt David Chipperfield sei dabei auch den Kritikern des Projektes durchaus aufgeschlossen gewesen. Die vehementeste Stimme der Kritik bildete über die Dauer der Wiederherstellungsarbeiten die Gesellschaft Historisches Berlin (GHB). Die Artikulationsfähigkeit dieser Bürgerinitiative und der Einfluss, den sie auf die Debatte und damit den Verlauf des Gesamtgesprächs entfalten konnte, sind durchaus beachtlich. Die Forderungen der GHB entsprachen letztlich dem, was im Denkmalpflegerischen Gutachten als verschleiernde Erneuerung (Badstübner et al. 1994:26) und »restaurierende Simulation« (Wagner 1994:97) kategorisch ausgeschlossen wurde.

Die Befürworter einer originalgetreuen Rekonstruktion verwiesen neben den Wiederaufbauplänen der DDR (Wendland 2009) ebenso auf den ersten Entwurf David Chipperfields (Ahme 2007:6.) Dem Entwurfstext ist tatsächlich noch 1994 zu entnehmen, dass das Neue Museum, insbesondere das Treppenhaus, rekonstruiert werden solle (Chipperfield 1994:48). Einer der Projektleitenden der Wiederherstellung des Neuen Museums stellte in diesem Zusammenhang lapidar fest, dass aufgrund des Maßstabs 1:500 des ersten Entwurfes, auf dem man »eh nichts« erkennen konnte (NM-JSG-1, 68-69), viele davon ausgegangen seien, dass Chipperfield das Gebäude originalgetreu rekonstruieren wolle. Chipperfield selbst entkräftet die Behauptung, er hätte ursprünglich eine Rekonstruktion des Museums erwogen, indem er darauf hinweist, dass es im Wettbewerb von 1994 vor allem um die Gesamtanlage der Museumsinsel und das Eingangsgebäude ging. Außerdem habe sich die Rekonstruktion der Wandbilder erst später als technisch nicht realisierbar erwiesen (Chipperfield nach Rautenberg 2007:3f.). Mit der »Initiative Rettet die Museumsinsel!« (Ahme 2007) wird eine akute Bedrohungssituation konstruiert, die eine Rettung der erforderlichen Museumsinsel vor »zerstörerischem Umbau« und »entstellendem Neubau« erforderlich macht (Großmann 2009, Ahme 2007a).

Mit einer Eingabe an den Architekten, in Form eines Essays, artikuliert Kristian Ludwig 1998 seinen Unmut. Dieses Dokument markiert zudem den Beginn einer verstärkten Diskursivierung des Museums im Zusammenhang der Bemühungen um die Eintragung der Museumsinsel als Weltkulturerbe. Nach der Beantragung 1998 erfolgte schließlich 1999 die Aufnahme (Nr. 896) in die Liste der UNESCO. Der Status als Weltkulturerbe bildet einen wichtigen Bezugspunkt der anhaltenden Kritik. Dabei wurden vonseiten der GHB stets zwei Kritikpunkte artikuliert. Erstens würden die baulichen Eingriffe Chipperfields auf der Insel deren Welterbe- 
status bedrohen. Zweitens sei beim Verfassen des Antrages 1998 bewusst der ab Mitte des Jahres entwickelte Masterplan Museumsinsel (Lepik 2000) verschwiegen worden.

In einer Vielzahl von Dokumenten werden die Verantwortlichen der Lüge und der Täuschung bezichtigt. Insbesondere das Vorstandsmitglied der Gesellschaft, Gerhard Hoya, behauptete mit Nachdruck, dass die Pläne zur »abstrahierten Erweiterung« zwar Teil des Masterplans, jedoch nicht Teil des bei der UNESCO eingereichten Antrags für die Eintragung der Museumsinsel als Weltkulturerbe gewesen wären (Wendland/Hoya 2008). Bereits im Titel der Veröffentlichung »Bericht und Dokumentation über festgestellte und drohende Gefahren für die Welterbestätte Nr. 896 (Museumsinsel Berlin)«(GHB 2008) konstruiert die GHB eine akute Gefährdungssituation. Im Rahmen einer Pressekonferenz, die anlässlich der Publikation des Berichts abgehalten wurde, heißt es weiter:

»Aus den zuvor geschilderten Abläufen ergibt sich, dass die Öffentlichkeit von den verantwortlichen Behörden vorsätzlich falsch informiert wurde. Das gesamte Planungs- und Baugeschehen auf der Museumsinsel findet von Anfang an ohne Zustimmung der UNESCO in Paris statt. (Wendland/Hoya 2008).

Ein weiterer Kritiker der Pläne der ergänzenden Wiederherstellung ist der amerikanische Kunsthistoriker Douglas Klahr, der mit einem Brief an die UNESCO (2004) sowie durch Vorträge $(2006,2008)$ vor der Bedrohung warnt, die die Pläne Chipperfields für den Status als Welterbe darstellen würden. Obwohl Klahr kein Mitglied der GHB war, wurde der Antrag auf Eintragung in die Rote Liste für gefährdete Kulturgüter im November 2006 sowie im Oktober 2008 durch die GHB nochmals bekräftigt. Außerdem bestanden durchaus Verbindungen zwischen dem amerikanischen Petenten und der Bürgerinitiative. So veranstaltete diese 2006 die sogenannte »Schinkelkonferenz«, zu der auch Klahr als Gastredner eingeladen war. In seiner Präsentation wiederum griff dieser Flugblätter der GHB auf, um sein Plädoyer für die historisierende Rekonstruktion des Museums zu untermauern.

Neben der Einreichung bei der UNESCO artikulierte die GHB ihre Kritik durch einen Petitionsantrag, der am 16. März 2006 dem Deutschen Bundestag übergeben wurde. Im Ergebnis, welches am 17. Juni 2008 mitgeteilt wurde, wird die Petition zwar freundlich zur Kenntnis genommen, im Übrigen jedoch empfohlen, das Petitionsverfahren abzuschließen (Deutscher Bundestag 2008:11). Auf der Homepage der GHB, auf der die zahlreichen Bemühungen, die Pläne Chipperfield abzuwenden, dokumentiert sind, wird das Abweisen der Petition kommentiert. Das Abweisen der Petition an den Bundestag mit 14.145 Unterschriften wird als »am erschütterndsten für unsere Demokratie« bezeichnet (Großmann 2009). Das Gefühl, von den politischen Verantwortlichen übergangen und betrogen zu werden, kommt in zahlreichen Stellungnahmen der Initiative zum Ausdruck (Wendland 2009). Der Petitionsanstrengung von 2006 folgten weitere öffentlichkeitswirksame Aktionen. 
So wurde 2007 ein weiteres Volksbegehren zu Wege gebracht. Eine weitere Veranstaltung, die durch das mediale Echo, welches sie im November 2007 auslöste, einer diskursiven Analyse zugänglich ist, trug den plakativen Titel »Welterbe ade«. Nachdem die Baustelle des Neuen Museums der Öffentlichkeit zugänglich gemacht wurde und dies, laut der Vorsitzenden der GHB Annette Ahme, zu »Tagen des Entsetzens« (Berliner Morgenpost 2007) führte, initiierte diese eine öffentlichkeitswirksame Aktion, bei der mit 600 Grablichtern die Worte »Welterbe ade« in der Bodestraße ausgelegt wurden.

Spätestens mit dem Volksbegehren »Kein Neubau auf der Museumsinsel!«(Ahme 2007b), dem sich auch namhafte Vertreterinnen und Vertreter aus der Öffentlichkeit wie Lea Rosh, Günther Jauch, Günter de Bruyn und Wolf-Jobst Siedler anschlossen, richtet sich der Widerstand der Initiative zunehmend gegen die Pläne für ein zentrales Eingangsgebäude auf der Museumsinsel. Die enge Verbindung der Kritik an den Wiederherstellungsplänen des Neuen Museums und der Neubebauung an dessen Westseite kommt in diesem Dokument in der gleichsetzenden Formulierung vom »zerstörerische[n] Umbau (Neues Museum!)« einerseits und dem »entstellende[n] Neubau« andererseits (Ahme 2007a) deutlich zum Ausdruck. So wird argumentiert, dass die »Unversehrtheit des Weltkulturerbes« nur gewährt werde, wenn auf einen Neubau verzichtet werden würde und außerdem die laufenden Arbeiten an der Gestaltung des Neuen Museums, sofern sie sich nicht am »Original-Zustand« orientieren, abgebrochen werden müssen.

Die Kritik an der Wiederherstellung des Neuen Museums und die Darstellung der eigenen Pläne für eine originalgetreue Wiederherstellung sind neben weiteren Debattenbeiträgen, Flugblättern und den Petitionstexten auf der Homepage der GHB zugänglich. Darüber hinaus verfasste ein Vorstandsmitglied der GHB, Christa Sammler, eine 25-seitige »Konzeption der Gesellschaft Historisches Berlin zum Wiederaufbau der Treppenhalle und der Nord-Westfassade« (2005). Die Vielzahl der Dokumente und medienwirksamen Veranstaltungen der GHB stellen wissenspolitische Interventionen dar. Die darin hergestellten Wissensverhältnisse erwiesen sich durchaus als stabil, da sie für weite Teile der Öffentlichkeit anschlussfähig erschienen. Insbesondere im Hinblick auf die mehrmalige Überarbeitung der Pläne für das neue Eingangsgebäude nahmen sie zudem Einfluss auf die Debatte (Witschurke 2019:33). Von den Stimmen der Kritiker unbeirrt konnten die Arbeiten am Neuen Museum jedoch planmäßig fortgesetzt werden.

\section{Das neue Neue Museum}

Die Darstellung der Ortsgeschichte brach einstweilen mit der Fertigstellung der neuen Fundamente im Jahr 1992 ab. Nach der langanhaltenden Debatte und der Instandsetzung des Hauses im Sinne einer ergänzenden Wiederherstellung wird dieses schließlich am 16. Oktober 2009 zu zweiten Mal in seiner Geschichte feier- 
lich eröffnet. $\mathrm{Zu}$ diesem Zeitpunkt wurde eine weitere Phase der intensiven Diskursivierung des Neuen Museums erreicht. Dabei handelt es sich vor allem um die Publikation von Sammelbänden der involvierten Akteure (Nys/Reichert 2009) sowie Autoren aus Wissenschaft (von Buttlar 2010) und Medien (Wedel 2009). In den reich bebilderten Publikationen werden zumeist die Geschichte und der aufwendige Wiederherstellungsprozess ausführlich dokumentiert. Insbesondere ein gemeinsam von den Staatlichen Museen Berlin - Stiftung Preußischer Kulturbesitz (SMB), dem Bundesamt für Bawwesen und Raumordnung (BBR) und dem Landesdenkmalamt (LDA) 2009 herausgegebener Sammelband informiert auf 240 Seiten großformatig über »Das Neue Museum Berlin«. Mit dem Untertitel »Konservieren, Restaurieren, Weiterbauen im Welterbe« wird die Programmatik der Wiederherstellung zum Ausdruck gebracht. Der Untertitel, der bewusst eine Modifikation des dehioschen Imperativs, >konservieren, nicht restaurieren!^ (Dehio 1988, Orig. 1914), ist, zeigt abermals, dass sich das Konzept der ergänzenden Wiederherstellung auf dem schmalen Grat zwischen historischer Kontinuität und zeitgemäßer Veränderung bewegt. Dass dem alleinigen Konservieren nun gleichberechtigt auch die Strategien des Restaurierens und des Weiterbauens zur Seite gestellt werden, deutet auf die Funktionalität einer auf Entwicklung rekurrierenden Traditionsbildung hin.

In den aufwendig gestalteten Publikationen wird das neu entstandene Museum ästhetisierend inszeniert. Die Visualisierungen zeigen zumeist ein Gebäude, in dessen menschenleeren Räumen Originalsubstanz, Kriegszerstörung, Witterungsschäden und Neubauteile als Gesamtkunstwerk dargestellt werden. Die wieder aufgemauerten Wandflächen wurden mit Ausnahme des vollständig neu errichteten Nordwestflügels und des südlichen Seitenrisaliten geschlemmt, sodass die ehemals farbige Fassade heute ein monochromes Bild abgibt. Erbauungszeitliche Farbreste wurden jedoch mit großer Akribie gesichert und sind etwa im östlichen Sockelbereich des Hauses noch gut erkennbar. Im Inneren sind die Gliederung und Abfolge der Säle sowie die beiden Innenhöfe wiederhergestellt worden. Das Spektrum reicht dabei von nahe am bauzeitlichen Zustand verbliebenen Rekonstruktionen (Niobidensaal) über Neuinterpretationen bis zu vollkommen neuen Raumschöpfungen, etwa im ägyptischen Hof.

Der durch Bomben vollständig zerstörte nordwestliche Flügel des Gebäudes wurde im Zuge der Instandsetzung des Hauses neu ausgeführt und nimmt dabei die Fensterhöhen des, zwar kriegsbeschädigten aber erhalten gebliebenen, südwestlichen Flügels auf. Die unverputzte Fassade ist mit verschiedenfarbigen bauzeitlichen Ziegeln gebändert (von Buttlar 2010:41). Die Architekturbeton-Fertigteile nehmen im Inneren dieses Flügels sowie in allen Bereichen, in denen keine Bausubstanz mehr vorhanden war, die Struktur und das Volumen des stülerschen Entwurfes auf (Mann 2009:138). Unter den Anhängern der originalgetreuen Wiederherstellung waren es gerade diese Betonelemente, die - ungeachtet ihrer hohen 
Qualität - besonders im Fokus der Kritik standen. Als »unterkühlte glatte Ödnis« (Ludwig 1998:5) wird einerseits diffamiert, was andererseits als "größtmögliche Einheitlichkeit« gedeutet wird (Mann 2009:138).

Mit der Orientierung am ursprünglichen Volumen des Nordwestflügels entstand auch der Ägyptische Hof wieder in seinen alten Dimensionen. Dennoch ist er als Inversion des ursprünglichen Raumes neu interpretiert worden. An die Stelle der erst 1988 vollständig abgetragenen Säulen setzte Chipperfield nun Stützen, die das Bodenniveau in den ehemals offenen Luftraum anheben. So öffnet sich der Blick in das Untergeschoss. Der so entstandene Raum erinnert an eine Gruft, wobei die hier ausgestellten Sarkophage diesen Eindruck noch unterstreichen. Die Reste der Wandgemälde und die durch die Studien von Lepsius inspirierten Veduten der ägyptischen Städte wurden restauriert und teilweise auf den neu aufgemauerten Wänden als Fragmente wieder angebracht. Für die Wände wurden erbauungszeitliche Ziegel verwendet; diese entstammen Häusern aus dem 19. Jahrhundert. Unter großem Aufwand und nach umfangreichen Tests wurden ca. 1,3 Millionen Ziegel, die in Alter und Produktionsort den ursprünglich am Neuen Museum verwendeten Ziegeln vergleichbar sind, herbeigeschafft und im neuen Mauerwerk wiederverwendet (Leonhardt 2009).

Dieser Vereinheitlichung musste schließlich auch die mit Maschinenbackstein wieder aufgemauerte Wand im Treppenhaus weichen. Stammte diese noch aus der Zeit der Rekonstruktionsbemühungen der späten 1980er Jahre, so wurde mit dem Entschluss, auf die Kaulbachfresken und damit den Verputz der Wände zu verzichten, die rekonstruktive Intervention der DDR wieder rückgängig gemacht. Gleiches galt für das ursprünglich am höchsten Punkt des Treppenaufgangs befindliche Erechtheion. Nach langen Diskussionen, die sogar anhand einer modellhaften Rekonstruktion geführt wurden, wird schließlich auf die Rekonstruktion der Korenhalle verzichtet. Besonders die Wiederherstellung des Treppenhauses wird im Diskurs zentral thematisiert. Der Verzicht auf eine Rekonstruktion des im Krieg vollständig zerstörten Dekors sowie der Entschluss Chipperfields, den monumentalen Aufgang in Werkbetonstein neu zu interpretieren, sind Gegenstand sowohl des Lobes als auch der Kritik. Sprachen die Kritiker von einer vollständigen Zerstörung des Werks Stülers, so fehlt die Treppenhalle in keiner der Publikationen der Akteure des Wiederaufbaus und ziert oftmals deren Titelseiten. Damit wird sie nicht nur zum architektonischen Zentrum des Hauses, sondern auch zum symbolischen Zentrum der Debatte. Ebenso wie im Museum des 19. Jahrhunderts wird die Treppenhalle durch einen offenen Dachstuhl abgeschlossen. Die Holzkonstruktion, für die sich Chipperfield entschieden hat, unterscheidet sich jedoch in Material und Volumen deutlich von dem Bogensehnenbinder Stülers.

Auch der südliche Seitenrisalit, an den sich ehemals der Übergang zum Alten Museum anschloss, ist als unverputzter Ziegelbau wiederentstanden. Von einer rechteckigen Grundfläche erhebt sich ein Kuppelsaal. Ebenso ist der Seitenrisalit in 
Volumen und Kubatur dem erbauungszeitlichen Zustand nachempfunden. Auf die Rekonstruktion des Übergangs und die Wiederherstellung des Figurenschmucks wurde verzichtet. Kriegsbeschädigte Spolien wurden wieder angebracht, sodass die ursprüngliche Fassadengliederung nachvollziehbar bleibt. In der Wiederherstellung des Griechischen Hofes wurden die Einwirkungen durch Krieg und Witterung sichtbar gelassen. Dennoch fanden auch hier Eingriffe statt, die auf verschiedene Zeitschichten rekurrieren. Die 1919 eingezogene Zwischendecke wurde nicht wiederhergestellt, jedoch die ebenfalls im Zuge der Amarna-Sammlung erfolgte Überdachung des Hofes. Die bereits 1923 abgebrochene Apsis wurde in zeitgenössischer Interpretation ausgeführt. In dem Architekturführer zum Neuen Museum des Kunsthistorikers Adrian von Buttlar, der auch als Vorsitzender des Landesdenkmalrates als Akteur an der Wiederstellung des Neuen Museums beteiligt war, folgert dieser: Das Ergebnis der Wiederherstellung

»ist zweifellos ein neues Neues Museum, in dem jedoch das alte Museum Stülers im doppelten Sinne des Wortes saufgehoben < ist, das heißt: Seine tradierte historische Substanz und seine künstlerische Idee wurden soweit wie möglich bewahrt und dennoch in eine neue Identität überführt« (von Buttlar 2010:95).

Was mit dieser »Laudatio« (ebd.) formuliert wird, ist keineswegs nur eine neutrale Beschreibung des neuen Neuen Museums. Denn so wird mit dem bei Hegel entlehnten Begriff der Aufhebung ein absichtsvoller Bezug zur Geistesgeschichte des ursprünglichen Entwurfs des Treppenhauses hergestellt. ${ }^{19}$ Dass die neue Identität damit im Einklang mit der tradierten historischen Substanz und der künstlerischen Idee stehe, gewährt bereits einen Einblick in die Form der Identitätskonstruktion, wie sie für die Formation der ergänzenden Wiederherstellung im weiteren Verlauf der Untersuchung noch genauer analysiert wird.

154 Jahre nach seiner ersten Fertigstellung ist das neue Neue Museum also als Hybrid, dessen Einzelteile aus Original, Wiederherstellung und Neubauten gleichermaßen bestehen, wiederentstanden. Mit der feierlichen Eröffnung des Neuen Museums, vor allem aber mit dessen Erfolg, ging der Kampf für die GHB verloren. In der Folge verstummten die Stimmen der Kritik jedoch nicht, sondern wendeten sich nun umso stärker gegen den Neubau an der Westseite des Neuen Museums.

\section{Die James Simon Galerie}

Die Gründung des James Simon Galerie genannten Eingangsgebäudes begann mit der Revision der alten Fundamente des Packhofgebäudes. Im Zuge der >Baufeldfreimachung`wurde im Jahr 2009 einer der Gründungspfähle des 1938 abgebrochenen Direktorenhauses in Gänze aus dem schlammigen Grund gezogen und zur

19 Aufhebung meint im Sinne Hegels (1): aufbewahren des Vorherigen, einen Widerspruch (2) auflösen sowie auf eine neue Stufe (3) aufgehoben werden. 
Einlagerung verbracht. An die Stelle der Eichenpfähle wurden nun 1.200 Kleinbohrpfähle mit einem Durchmesser von $240 \mathrm{~mm}$ teilweise bis zu 50 Meter tief in das Erdreich getrieben (BBR 2020). ${ }^{20}$

Nachdem die Ergebnisse des Wettbewerbs von 1994 für die Bebauung des Bereichs zwischen Neuem Museum und Kupfergraben unbefriedigend geblieben waren, wurde die Entscheidung über konkrete Baupläne für das Eingangsgebäude vertagt. Obwohl sich der zweite Wettbewerb auf die Wiederherstellung des Neuen Museums konzentrierte und die Bebauung des ehemaligen Packhofgeländes vertagt wurde, wird mit der Entscheidung für Chipperfield von 1997 auch dieser mit dem Bau des Eingangsgebäudes beauftragt (Wolters 2010:242). Dass es dabei nicht $\mathrm{zu}$ einer erneuten Ausschreibung kam, wurde von der GHB stets kritisiert. Auch ohne erneuten Wettbewerb überarbeitete das Büro DCA die Pläne mehrmals. Sah der Entwurf von 1994 noch einen langgezogenen einzelnen Baukörper parallel zum Neuen Museum vor (Chipperfield 1994:48), so wurde 2001 ein Entwurf, der drei ineinander geschobene Glasvolumen vorsah, der Öffentlichkeit präsentiert (Witschurke 2019:31). Dies provozierte abermals Kritik. Jedoch wurden auch diese Pläne durch die Veränderung des Nutzungskonzepts obsolet, sah dieses nun einen Zugang zum Pergamonmuseum auf zwei Stockwerken vor. Auch mit der Vorstellung der Pläne 2007 sind die Kritiker des Bauvorhabens nicht zufrieden gestellt. Stattdessen wird nun abermals der Vorwurf einer bewussten Täuschung der Öffentlichkeit laut. Insbesondere die GHB macht in einer Reihe von Veröffentlichungen auf ihrer Homepage darauf aufmerksam, dass der Neubau den Blick auf die Westseite des Neuen Museums und damit auch den Mittelrisaliten samt Inschrift und Giebelfeld verstellen würde (Hoya 2008; Hoya 2015: GHB Bericht 2008:7, GHB Vergleich 2009, GHB Stellungnahme 2009). ${ }^{21}$

Der Betrug und die Täuschung, die die GHB witterte, scheinen nicht gänzlich aus der Luft gegriffen. Wie einer der Architekten gesteht, wurde für die Visualisierung des Entwurfes in der Tat ein sehr hoher Augpunkt gewählt, der im alltäglichen Erleben der Architektur kaum je eingenommen werden kann. Die Kritik, dass die Fassade des Neuen Museums in der Westansicht vom Kupfergraben nahezu vollständig abgedeckt werden würde, war also durchaus inhaltlich begründet (NMJSG-1, 86). Obwohl sachlich korrekt, verhallte die Kritik der GHB nun weitgehend ungehört. 2009 wird schließlich - zwei Jahre verspätet - mit dem Bau der James Simon Galerie begonnen. Tatsächlich stellten sich bereits unmittelbar nachdem die Arbeiten an der Gründung begonnen hatten, erhebliche bautechnische Probleme

20 Hier wie im Folgenden beziehe ich mich auf die umfangreiche Darstellung der Bautätigkeiten auf der Homepage des Bundesamtes für Bauwesen und Raumordnung (BBR 2020).

21 So wird auch die Grundsteinlegung von einem aus dem Umfeld der GHB stammenden Journalisten als bewusste Täuschung, als »Grundstein ohne Grund«, »reine Farce« und »WerbeGag« betitelt (Zimmermann 2013). 
ein. Einerseits wurde das Einbringen der Gründungspfähle nicht ordnungsgemäß ausgeführt, andererseits erwies sich der Umgang mit dem schlammigen Baugrund als wesentlich schwieriger als bei der ursprünglichen Planung und Kostenkalkulation zugrunde gelegt. Als 2016 schließlich das Richtfest gefeiert wurde, haben sich die Kosten auf 138 Millionen Euro nahezu verdoppelt.

Nachdem die Baugrube verfüllt wurde, das Äußere des Gebäudes fertiggestellt und die Gerüste langsam fielen, hat sich auch der Streit um das Eingangsgebäude gelegt. Mit dem allmählichen Verschwinden der bautechnischen Geräte ist ein neuer Baukörper und mit ihm ein weiterer Hof auf der Museumsinsel entstanden. Das Büro des Architekten beschreibt den Neubau als "continuation of Friedrich August Stüler's forum architecture«. Die James Simon Galerie werde als Eingang dienen, der das Ensemble zwischen Kupfergraben und der Fassade des Neuen Museums vervollständige. ${ }^{22}$ Am Tag der feierlichen Übergabe des Gebäudes spricht auch einer der geschäftsführenden Partner des Büros DCA von dem Neubau als einer »gebauten Topographie«, die unmittelbar Bezug nehme auf die frühe Zeichnung Friedrich Wilhelm IV., der hier eine Akropolis herbeigeträumt hatte und sie 1841 als »Freistätte für Kunst und Wissenschaft « zum konkreten Vorhaben machte (Schwarz, zitiert nach Schulz 13.12.2018).

Schließlich fanden sogar einige Mitglieder der GHB verhalten lobende Worte - sahen diese in dem Entwurf Chipperfields nun doch Pläne des Architekten des Pergamonmuseums, Alfred Messels, verwirklicht (Berlin Magazin 2007). Laut der Gesellschaft habe sich das jahrelange Engagement gelohnt, denn so gehe der Entwurf Chipperfields auf viele Anregungen und Forderungen der Initiative ein (ebd.) Mit einer gewissen Genugtuung kommentiert auch die ehemalige Vorsitzende der GHB, Annette Ahme, anlässlich der feierlichen Übergabe des neuen Eingangsgebäudes, in einer Pressemitteilung des 2008 neu gegründeten Vereins Berliner Historische Mitte e.V., dem sie nun vorsteht: »Es ist schön, dass David Chipperfield den ersten »von den drei Glaubenssätzen der Moderne [`form follows function<, JK] aufgibt und erklärt, er könne auf den Müllhaufen der Geschichte« (Ahme 2018).

Mit dem Emporwachsen des neuen Eingangsgebäudes klingt somit auch der Streit um die Gestaltung der Museumsinsel an dieser Stelle ab. Die verschiedenen Geschichtsdeutungen und die unterschiedlichen Gewissheiten darüber, welche normativen Maßstäbe sich daraus für die Gestaltung des Raumes ableiten, haben eine gemeinsame Schnittmenge gefunden. In diesem Bereich hat die diskursive Konfrontation schließlich zu einer Annäherung der Positionen geführt. Das Giebelfeld, in dem Kunst und Kunstgewerbe unterwiesen werden, ist ebenso wie die Inschrift ARTEM NON ODIT NISI IGNARUS nunmehr nur noch aus der Distanz $\mathrm{zu}$ erkennen.

22 »completing the ensemble between the Kupfergraben arm of the Spree Canal River and the long south-west façade of the Neues Museum.« (David Chipperfield Architects 2019). 
Abbildung 13: Wie von den Gegnerinnen und Gegnern vorausgesagt, ist das Giebelfeld mit der Inschrift ARTEM NON ODIT NISI IGNARUS aufder Westseite des Neuen Museums vom Kupfergraben nicht mehr erkennbar; Abbildung 14: Der Gründungspfahl des ehemaligen Direktorenhauses konnte in Gänze gezogen werden. Obwohl der Pfahl ca. 180 Jahre im Erdreich steckte, weist er kaum Verfallsspuren auf.
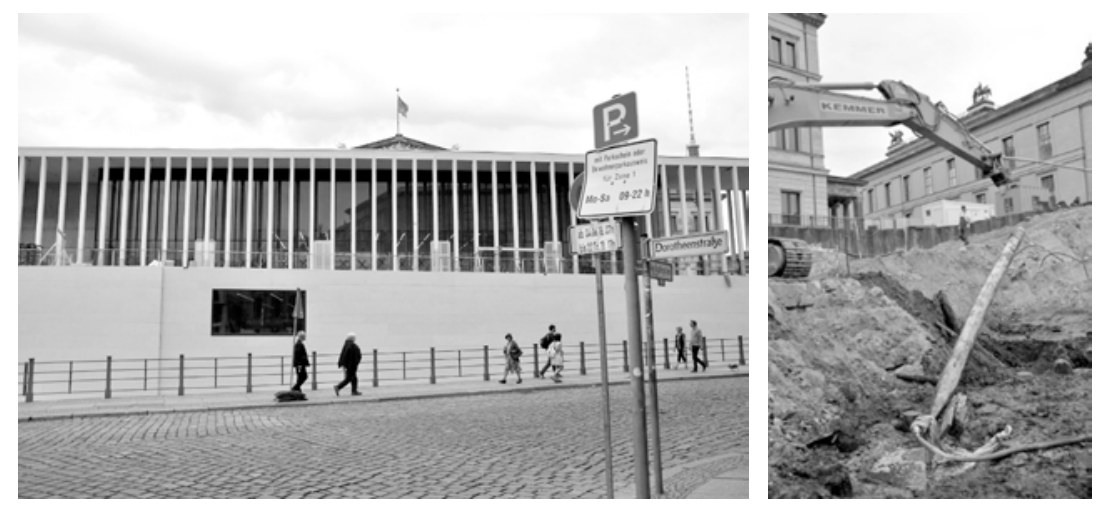

\subsection{Wiedererweckung und raumzeitliche Verunreinigung: Der Kollektivierungsdiskurs der soriginalgetreuen Wiederherstellungs}

Mit dem Aufruf »Initiative Rettet die Museumsinsel!« wendet sich die Initiatorin, Annette Ahme, im Herbst 2007 gegen den Neubau auf der Museumsinsel. Das vier Seiten umfassende Schreiben richtet sich sowohl gegen die ergänzende Wiederherstellung des Neuen Museums, die als »fetischhafte Überhöhung« der »NachkriegsVerwahrlosung « (Ahme 2007:7.) diffamiert wird, als auch gegen den Neubau an dessen Westseite. Da von beidem eine Gefahr für das Erbe ausgehe, wird eine Rettung erforderlich. Die Tatsache, dass es »um die Geschichte und das Herkommen der Stadt « gehe (ebd.), lässt die Größe der Gefahr erahnen. Der leidenschaftliche Ernst, mit dem die Diskutanten ihre Argumente vorbringen, lässt eine starke Identifikation mit den Orten, ihren Gebäuden und ihrer Geschichte erkennen. Demnach ist es "nicht eine reine Geschmacksfrage, denn die Museumsinsel steht als Weltkulturerbe unter besonderem Schutz«. Da das »kulturelle Erbe zu wertvoll ist, um es dem Tagesgeschmack zu überlassen«, fordert die Initiative, auf einen Neubau auf der Insel zu verzichten (a.a.O. 1). Auch der Verweis darauf, dass es hier nicht um Fragen des Geschmacks gehe, zeigt, dass Grundsätzlicheres zur Disposition steht. Vielmehr handele es sich um eine Frage des Erbes und damit der Identität (»Herkommen«); diese sind kurzweiligen Moden und der Zeit des Alltäglichen 
(»Tagesgeschmack«) enthoben. Demnach müsse in der »Mitte der Stadt« und damit an symbolisch zentralem Ort das »historische Erscheinungsbild« und nicht »moderne Architektur« Priorität erhalten (a.a.O. 4).

Laut den vehementesten Kritikern des Konzepts der sergänzenden Wiederherstellung liegt die Rettung der Museumsinsel einzig in einer Wiederherstellung des Stülerbaus des 19. Jahrhunderts und seiner Innenausstattung. Dies wird in einem weiteren Volksbegehren vom o1. September 2007 mit dem Titel »Kein Neubau auf der Musemsinsel« (Ahme 2007b) nochmals bekräftigt. Darin wird gefordert, anderslautende Pläne als die am »Original-Vorbild bzw. an den Original-Plänen orientierten« (ebd.) sofort einzustellen.

\subsubsection{Heroische Vergangenheit: Die Apotheose des August Stüler}

Im Sinne der entwickelten Analysekategorien soll zunächst die zeitkonstitutionelle Dimension der Argumentation rekonstruiert werden. Eine strikte Trennung zwischen raum- und zeitkonstitutionellen Aspekten lässt sich allerdings aufgrund der engen Verbindungen beider nicht in Gänze durchhalten. Dennoch sollen zunächst die Besonderheiten der Argumentation in Hinsicht auf die ihr zugrunde liegende Zeitlichkeit fokussiert werden. Das wichtigste Merkmal dieser Form der Zeitkonstitution besteht in einer Trennlinie, die einen identitätsstiftenden Teil der Geschichte (»Herkommen«) gegen eine Zeit des Niedergangs, der Verunstaltung und der Latenz (»Nachkriegs-Verwahrlosung«) abgrenzt. Diese zeitliche Zweiteilung wird in wechselseitiger Abgrenzung zueinander konstruiert.

Ein ausführlicher Text auf der Homepage der GHB mit dem Titel »Die Perle Preußischer Bildungslust, im Wiederaufbau demontiert « lässt die Ausrichtung dieser Argumentationslinie erkennen. In dem Dokument vom November 2009, also zum Zeitpunkt der Eröffnung, wird einer als mangelhaft empfundenen Gegenwart eine stolze und idealisierte Vergangenheit entgegengesetzt. Genauer dient die Gegenüberstellung der kontrafaktischen Konstruktion der beiden Zeitsphären.

»Was für ein FEST war es einst, als um 1850 Schönheit und Bildung eine Ehe eingingen! Sie hielt bis zur Hybris des Kriegsbeginns 1939. Das FEST begann zu einer Zeit, die in Preußen und dem vereinigten Deutschland Heroen zeugte, von deren Leistungen wir noch heute zehren -- vielleicht vergleichbar den Heroen der Renaissance in Italien.« (Großmann 2009).

Was hier formuliert wird, entspricht einer gründenden Erzählung und einer - im Wortsinn - heroischen Vergangenheit. Die Identität des Gebäudes wird dabei in der Mitte des 19. Jahrhunderts verortet. Die pathetische Beschreibung lässt keinen Zweifel an der herausragenden Bedeutung der Zeit, die auch für die Gegenwart maßgeblich bleibt. Der feierliche Ton des »FEST « und der »Ehe« betont die Einheit zwischen Schönheit und Bildung. Mit der Verbindung der »Heroen«Preußens und 
des »vereinigten Deutschland[s] « mit jenen der Renaissance in Italien wird an eine ebenso maßgebliche Epoche appelliert. Die heroische Vergangenheit wird jedoch keinesfalls als bloß chronologisch früherer Zeitpunkt verstanden, sondern als eine Zeit, der höchster identifikatorischer Wert beigemessen wird. Außerdem bleibt sie - einer mythischen Vorzeit gleich - potenziell über alle Zeiten hinweg verfügbar. Die Wendung »von deren Leistungen wir noch heute zehren « deutet diese doppelte Verbindung an. Als doppelt erscheint diese einerseits, da man sich den »Heroen« und ihren Ideen verbunden fühlt (sich mit ihnen identifiziert). Andererseits ist die heroische Vergangenheit auch in der Gegenwart handlungsleitend; sie bleibt also verbindlich.

In dem reich bebilderten Text der GHB finden sich häufig Darstellungen der historischen Fassung des Treppenhauses. Nur die Gestaltung des späten 19. Jahrhunderts gilt als authentisch. Die Zeit Stülers und Kaulbachs wird zur Trägerschicht der Identität des Gebäudes. In zahlreichen weiteren Publikationen der GHB wird dem historischen Treppenhaus ein Bild des Entwurfs Chipperfields zur Seite gestellt. Diese bildliche Gegenüberstellung entspricht einer wiederholt getroffenen "visuellen Äußerung«; sie kann also als typische und typisierbare »visuelle Aussage« bezeichnet werden (Keller 2016), die stets der kontrastierenden Konstruktion einer heroischen Zeit und einer Zeit des Niedergangs dient. ${ }^{23}$

Abbildung 15: Kontrastierende Bildfolgen finden sich in nahezu allen Publikationen der Gegner und Gegnerinnen der ergänzenden Wiederherstellung, die damit stets eine Geschichte des Niedergangs visualisieren.

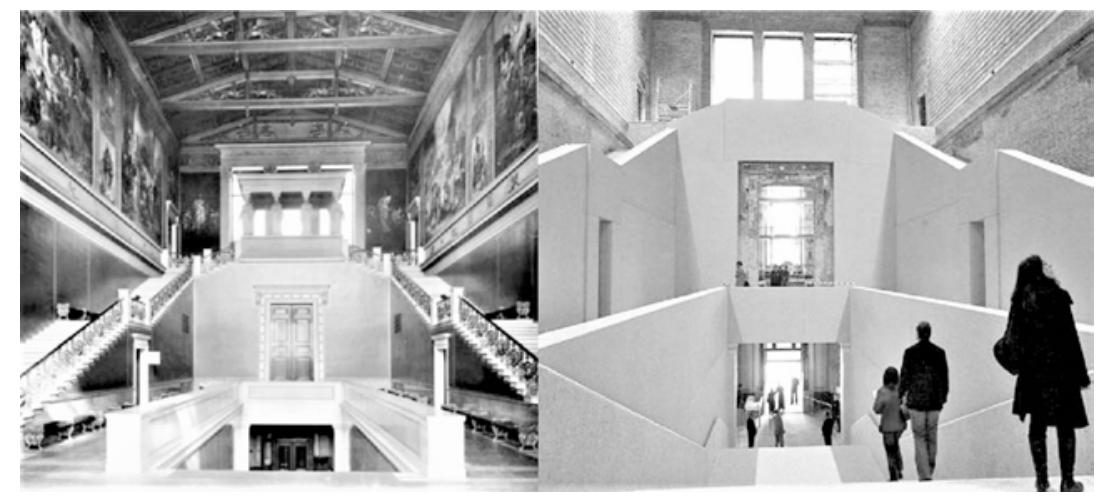

23 Diese Methode der Gegenüberstellung wird auch auf einzelne Bereiche des Treppenhauses angewandt, etwa Treppengeländer (Sammler 2005:20) oder Deckenkonstruktion (a.a.O. 24). Weitere Beispiele dieser Form der Kontrastierung lassen sich auch im Bericht der GHB (2008:14) nachweisen. 
Mit der Ko-Konstruktion der beiden Zeiten geht eine Charakterisierung der Vergangenheit einher, insbesondere der Beschreibung der Personen Schinkel und Stüler, die durch eine tendenziell apotheotische Wortwahl gekennzeichnet ist. Die Künstler werden mit (quasi-)religiösen Attributen belegt. So sei die »Genialität« der Baumeister (Jacob 2007:4) zu betonen. Auch durch die Nähe zur Antike wird diese verklärende Rhetorik deutlich. So habe Schinkel etwa ein »Spree-Athen « gebaut. ${ }^{24}$ Außerdem gelte es, den »magischen Blickpunkt « (Goßmann 2009:6) des Treppenhauses wiederherzustellen. Das Neue Museum sei ein »Tempel der Kultur und der Baukunst « gewesen und kein »Mahnmal gegen den Krieg« (Ludwig 1998:5f.). Dass dies auch in der Gegenwart maßgeblich bleiben soll, unterstreicht der Autor, indem er schließt: »Das Neue Museum war ein Tempel der Kultur und der Baukunst - und sollte es wieder werden« (ebd.). Die Zeit nach seiner Zerstörung erhält keinerlei identitätsstiftenden Wert: »Auch der Umstand, dass das Gebäude so lange als Ruine bestanden hat, rechtfertigt nicht die Unterlassung der Rekonstruktion« (ebd.). Bedeutung erhält die Zwischenzeit lediglich insofern, als in ihr das eigentlich Wesentliche nicht verfügbar ist. Auf den passiv-aggressiven Vorwurf der »Unterlassung« wird später im Kontext des Deutungsmusters der Gewalt noch einzugehen sein. Hier ist zunächst wichtig, dass die Heroen der Vergangenheit den Charakter maßgeblicher Autoritäten erhalten, denen stets dienend zu folgen sei. Da die maßgebende heroische Vergangenheit nicht geachtet wurde, bleibt nach dem Abschluss der Wiederherstellungsarbeiten lediglich ein »gedemütigtes Gebäude« (Wendland 2009) zurück.

Eine komplementäre Vervollständigung des Deutungsmusters der >Autorität des Alten besteht darin, moderne Architektur, die sich ungebührlich hervortue, $\mathrm{zu}$ infantilisieren. Einer der zentralen Vorwürfe besteht darin, dass diese selbstgefällig und egoistisch sei. Die Architekten und Denkmalpfleger der ergänzenden Wiederherstellung wollten lediglich sich selbst verwirklichen und zollten dem genius loci des Ensembles der Museumsinsel nicht den ihm gebührenden Respekt. Dies betrifft vor allem auch den Neubau an der Westseite des Museums. In einer Pressemitteilung vom 15. März 2007 stellt Annette Ahme dies folgendermaßen dar:

»Hier, wo Berlin entstanden ist - Schloß, Forum Fridericianum, Museumsinsel sollte man auf den ständigen Zwang zur >modernen Ergänzung`verzichten. Moderne Architektur als Ausrufezeichen gegen das Alte - das spricht nicht für Selbstbewußtsein, sondern offenbart eine unreife, pubertäre Haltung.«(Ahme 2007c).

24 Auch wenn sich die Vertreterinnen und Vertreter der CHB dieser Technik der Besonderung umfangreich bedienen, wird die Verklärung der Autorität des Alten, insbesondere der Baumeister, ebenso deutlich, wenn etwa die Herausgeberin des Wettbewerbs von 1994 den invasiven Entwurf Frank O. Cehrys als »wildes Architektur-Rodeo «bezeichnet, welches die »Westfassade des sakrosankten Schinkel-Baus« verstelle (Sayah 1994:125, Herv. JK). 
Die Zeit der Heroen wird kontrafaktisch gegen den Hintergrund einer infantilen Gegenwart gestellt und damit umso deutlicher konturiert. Eine Auflehnung gegen diese normative Vergangenheit, die abgeschlossen ist und deshalb auch nicht durch »moderne Ergänzungen« verändert werden darf, ist ein Zeugnis der Unreife, ist pubertär. Das damit assoziativ definierte Begriffspaar der Heroen, die Autorität genießen, und der Kinder, die sich ungebührlich auflehnen und sich wie ein »Ausrufezeichen gegen das Alte ${ }^{25}$ richten, unterstreicht dies abermals. In einem weiteren Dokument der GHB wird der Entwurf David Chipperfields zudem als »Abenteuerspielplatz« der Verantwortlichen des Umbaus bezeichnet (Wendland 2009). Auch dies steht im Zeichen der Infantilisierung der modernen Architektur, mit der deren ungebührliches Verhalten als Regelverstoß gekennzeichnet wird. Somit steht im Zentrum dieses Kollektivierungsdiskurses die normative Verbindlichkeit einer heroischen Vergangenheit, die handlungsleitend für die Gegenwart ist und dies auch in Zukunft bleibt. Aufgrund dieser fundamentalen Distinktion kann die diskursive Formation der originalgetreuen Wiederherstellung als ein heroischer Kollektivierungsdiskurs bezeichnet werden.

Ungeachtet dessen, dass Berlin keineswegs in dem beschriebenen Bereich zwischen Schloss, Forum und Museumsinsel entstanden ist, kann damit veranschaulicht werden, dass hier nicht ein chronologischer Ursprung, wohl aber ein für die Identitätsverankerung zentraler Ort beschrieben wird. Gemeint ist damit ein Ort, von dem sich die entzeitlichten Maßgaben ableiten, die gestern, heute und morgen Gültigkeit besitzen. Der Referenzpunkt, auf den dabei verwiesen wird, ist also keineswegs eindeutig chronologisch bestimmbar. Zeitkonstitutionell besteht hier keine lineare Abfolge von Vergangenheit, Gegenwart und Zukunft, sondern eher eine Zweiteilung, zwischen einer Sphäre, in der die identifikatorischen Fundamente des Ortes gelegt wurden, und einer scharf dagegen abgegrenzten Zeit, in der diese Gesetze, Gebote und ästhetischen Vorgaben in Vergessenheit geraten oder bewusst missachtet werden. Die Fundamente beziehen sich hochgradig selektiv auf eine Vielzahl von chronologisch früheren Zeitpunkten. In diesem Sinne ist der gründende Mythos einer heroischen Vergangenheit ein Komposit. Die Rekonstruktivität von Geschichte (Kap. 2) zeigt sich auch in dem freien Rückgriff auf verschiedene Personen und der Auswahl der Heroen, die teilweise fast hundert Jahre trennen. So werden die Pläne Alfred Messels ebenso wie die Schinkels gleichermaßen als Teil des Alten gewertet und gegen die modernen Architekten abgegrenzt. ${ }^{26}$ "Alt« und

25 Die Formulierung, dass sich moderne Architektur wie ein »Ausrufezeichen gegen den Altbau wendet«, findet sich unverändert auch an anderen Stellen (Ahme 2007:8.).

26 Etwa wenn Rainer Jacob anmerkt: »die UNESCO hat nicht die Werke von Herrn Gehry, Herrn Ungers oder Herrn Chipperfield zum Weltkulturerbe erklärt, sondern die Schinkels, Stülers, Ihnes, Messels« (2007:11). 
»modern« sind nicht in erster Linie chronologische, sondern normative Bezeichnungen, die in scharfer Abgrenzung zueinander konstruiert und mit den wertenden Adjektiven »richtig « und »falsch« verbunden werden (Wendland 2009). Es handelt sich hier also um die Konstruktion einer normativen Vergangenheit (Assmann, Kap. 4).

\subsection{2. „Dornröschenschloss«: Latenz und anhaltende Zerstörung}

Komplementär zur Zeit der Heroen, des "Spree-Athens« und der apotheotischen Schilderungen, mit denen Schinkel und Stüler bedacht werden, ist die Gegenwart als eine Zeit der Agonie, des Niedergangs und der anhaltenden Zerstörung charakterisiert. Demgemäß fragt die GHB: "Das Neue Museum - wie wurde es zur Perle preußischer Bildungslust und wie feiert es nach 70 Jahren Agonie und Zerstörung Auferstehung?« (Großmann 2009:1). Der Unterschied zwischen der »Perle preußischer Bildungslust « und der Zeit der »Agonie und Zerstörung« könnte kaum größer sein. Der aus religiös-christlichem Wortschatz entlehnte Begriff der »Auferstehung " gemahnt erneut an die exzeptionelle Bedeutung des Gebäudes, ungeachtet dessen, dass die Auferstehung aus Perspektive der GHB gescheitert ist.

Die Zeit der »Agonie«, mit der die Zeitspanne von 70 Jahren beschrieben wird und in der sich keinerlei bedeutende Ereignisse zugetragen haben, ist zeitkonstitutionell ebenfalls bedeutend. Denn, wie bereits gesehen wurde, rechtfertige die Tatsache, dass das Gebäude so lange als Ruine bestand, keinesfalls die »Unterlassung der Rekonstruktion. "Die Zeitspanne ist eng mit dem Topos des Vergessens verbunden. So hätte der »unauffällige Name und das Schicksal des Gebäudes da$\mathrm{zu}$ geführt, dass es im Bewusstsein der heutigen Gesellschaft fast verloren war « (Großmann 2009:1). Auch die Zeit der DDR wird als Epoche des Niedergangs und des Abstiegs des Gebäudes von den Höhen des "Spree-Athens « in die Tiefen der Bedeutungslosigkeit relevant gemacht. So »wurde das Gebäude immer weiter auf der Rangliste des Wiederaufbaus im damaligen Ost-Berlin, Hauptstadt der DDR wozu die Museumsinsel gehörte - zurückgeschoben« (a.a.O. 5.). Das aktive Zurückschieben suggeriert, wie die Unterlassung, dass dem Gebäude Unrecht widerfuhr. Jedenfalls verfällt das Neue Museum in der beschriebenen Zeit nicht nur äußerlich. Mit dem Verfall des Gebäudes gehen auch sein Abstieg auf der Rangliste und sein Fall in die Marginalität einher. Eine sprachliche Figur, die dafür immer wieder herangezogen wird, ist die des Dornröschenschlosses. In dem bereits zitierten Text heißt es dazu:

»Endlich im Fünfjahrplan 1986-1990 gab es in der DDR den Ministerratsbeschluss zum Wiederaufbau des alten richtigen, aber ruinösen Ägyptischen Museums. Bis dahin hatte sich die Ruine bei Wind und Wetter in ein >Dornröschenschloss 
verwandelt, von dessen Existenz kaum noch einer sprach. Die Zeitzeugen seiner Pracht waren immer weniger geworden« (Großmann 2009).

Das Richtige befindet sich in ruinösem Zustand. Die »Ruine« besitzt hier keinerlei Wert, sondern kündet lediglich davon, dass das, was mit dem normativen Begriff des »[R]ichtigen « beschrieben wird, aktuell nicht verfügbar ist. Das Gebäude gerät, dieser Auslegung zufolge, nach seiner Zerstörung in Vergessenheit. Die Ruinenzeit ist also als Zeit der Marginalisierung und des anhaltenden Niedergangs gekennzeichnet. Das »Dornröschenschloss«, zu dem das Gebäude geworden sei, weckt die Assoziation zum Dornröschenschlaf - eine Zeit und ein Zustand, in dem nichts passiert und das eigentlich Charakteristische nicht mehr sichtbar ist. Diese Zeit der Latenz ist von einer schwelenden Bedrohung geprägt, in der das "[R]ichtige[n], aber [R]uinöse« ständig durch Vergessen und schließlich vollständiges Verschwinden gefährdet ist. Die Charakterisierung dieser Zeit als Epoche des schleichenden Niedergangs wird zudem mit dem Sterben der Zeitzeugen unterstrichen.

Was hier beschrieben wird, ist eine Zeit des Interregnums; eine Art Zwischenzustand, dessen Uneindeutigkeit als störend empfunden wird, da das eigentlich Wesentliche verdeckt und potenziell bedroht ist. Diese Zwischenzeit vermag selbst nichts von Bedeutung hervorzubringen. Die Phase des anhaltenden Interregnums kann identifikatorisch nicht nutzbar gemacht werden. Zur Befremdung dieser Zeitspanne wird neben der Metapher des "Dornröschenschlosses« auch der Topos der Witterungsschäden herangezogen. Mit einigem Unverständnis moniert die GHB: »Die Ruine des 19. Jahrhunderts wurde wie ein archäologisches Ausgrabungsobjekt behandelt und sogar Witterungsschäden als denkmalwürdig erklärt« (a.a.O. 6.). Die Zeitverläufe, die sich an dem 40 Jahre als Ruine daliegenden Gebäude angelagert haben, erhalten keine Bedeutung. Die »Würde« eines Denkmals wird den als »Witterungsschäden« marginalisierten Spuren der Zeit nicht zugesprochen. Das eindringlich formulierte Unverständnis, wie eben diese Beschdigungen unter Schutz gestellt werden können, ist oft mit belustigenden Formulierungen verbunden. So polemisierte selbst der Direktor der Staatlichen Museen, Peter-Klaus Schuster, anfänglich noch, »man habe hier 150 Jahre Berliner Wetter unter Schutz gestellt« (zitiert nach Schulz 2005:142). Dieses Zitat wird ebenfalls an vielen anderen Stellen im Diskurs aufgegriffen.

„Die von Granaten und 150 Jahren Berliner Wetter ruinierte restliche Außenfassade soll nun bleiben, wie sie ist. >Alle noch anhaftenden Putzplacken bleiben dran< wird ein Ingenieur vom Spiegel zitiert, ssie erhalten oben eine Zementkante, damit kein Wasser dahinter laufen kann. Technisch gesehen ist das Pfusch.« (Ludwig 1998:4).

Dieses Zitat eines an der Wiederherstellung des Neuen Museums Beteiligten wird abermals von dem Kunsthistoriker Klahr in einer seiner Präsentationen auf der von 
der GHB veranstalteten »Schinkelkonferenz« (2006) aufgegriffen. Dass die Fassade bleiben soll, wie sie ist, kann nicht hingenommen werden. Die handwerkliche Leistung der Wiederherstellung wird diskreditiert. Der beschriebene Weg, den das Gebäude nahm, verläuft hier »[v] om Juwel zum Kuckucksei der Denkmalpflege« (Ludwig 1998) und schließlich vom Meisterwerk der Baukunst zum handwerklichen »Pfusch «(Schulz 2005:142). Ungeachtet der tatsächlichen handwerklichen Qualität geht es in dem obigen Zitat erneut darum, die Idee und die Ästhetik des Wiederaufbaus zu diskreditieren und sie der Lächerlichkeit preiszugeben. ${ }^{27}$ In der Trivialisierung dieses Teils der Gebäudegeschichte lässt sich also der Gegenpol zur apotheotischen Rhetorik, mit der die heroische Vergangenheit beschrieben wurde, finden. Was nach der Zerstörung war, kommt über den Stellenwert von Witterungsschäden nicht hinaus und wird mit der belustigenden Bezeichnung »Berliner Wetter« abgetan. Diese diskursive Profanierung der Geschichte des Hauses konstruiert gemeinsam mit der Verklärung der heroischen Vergangenheit ein Gegensatzpaar zwischen Heilig und Profan. Obwohl an dieser Stelle bereits raumbezogene Deutungen erwähnt werden, dienen diese doch zunächst dazu, die zeitliche Differenzierung zwischen einer heiligen Zeit magischer Ereignisse und einer profanen Zeit trivialer Nicht-Ereignisse herzustellen. Die Zeit der Latenz hält hier keinerlei Anknüpfungspunkte bereit, an denen sich eine Identifikation festmachen ließe. Was nach der Zerstörung durch den Krieg Einzug hielt, war lediglich Niedergang, Zeit der Agonie, Dornröschenschlaf, Berliner Wetter.

Anhand einer Referenz kann dies noch weiter verdeutlicht werden. Das Konzept der ergänzenden Wiederherstellung wird oft mit dem Wiederaufbau der Alten Pinakothek durch Hans Döllgast verglichen (Harrap 2009b:125; Schulz 2009:40). Auch der oben zitierte Kritiker Chipperfields stellt diesen Bezug her (Ludwig 1998:7). Jedoch sei ein Vergleich mit Döllgasts Wiederaufbau der Alten Pinakothek nicht zulässig, da diese als Symbol der unmittelbaren Nachkriegszeit und der dafür charakteristischen Materialknappheit selbst eine historisch wertvolle Rekonstruktion von »ergreifendem Pathos« sei (ebd.). Der unmittelbaren Nachkriegszeit und dem Wiederaufbau durch den berühmten und für die Münchener Architektur der 5oer Jahre so maßgeblichen Architekten Döllgast wird hier (wieder in feierlichem Ton: »ergreifendem Pathos«), anders als dem Entwurf Chipperfields für das Neue Museum, also historische Bedeutung beigemessen. Der Autor moniert außerdem, dass das Neue Museum in einem »desolaten Zustand « verbleibe, womit die Zerstörung monumentalisiert wird (Ludwig 1998:5). Der »desolate Zustand« darf aber nicht zum Monument gemacht werden. Denn Stülers Bau sei zuallererst ein

27 Über die tatsächlich hohe handwerkliche Qualität der Wiederherstellung des Neuen Museums gibt etwa ein Sonderheft der Zeitschrift »Restaurator im Handwerk« Auskunft (Leonhardt 2009), worin am Wiederaufbau beteiligte Handwerker ausführlich über ihre Arbeit informieren. 
Denkmal des 19. Jahrhunderts und seiner Bildungsbeflissenheit; dies werde durch die Monumentalisierung der Zerstörung völlig übersehen (ebd.). Das 19. Jahrhundert bleibt weiterhin die Quelle, aus der das Gebäude seine identifikatorische Kraft bezieht. Aus dieser Perspektive schlüssig, kann der Autor die Zwischenzeit nur als Zustand anhaltender Zerstörung beschreiben. Formuliert wird dies in der rhetorischen Frage: »Hat es der Architekt wirklich nötig, die Zerstörung des Gebäudes fortzuschreiben?« (Ludwig 1998:5). Mit dem Vorwurf, der Architekt der Wiederherstellung schreibe dessen Zerstörungsgeschichte fort, wird ein weiteres Motiv erkennbar, mit dem die Zwischenzeit als eine Ära der Bedrohung ausgemalt wird.

Auf nachgerade idealtypische Weise entspricht die Zeitkonstruktion des heroischen Kollektivierungsdiskurses einem »kontrapräsentischen Mythos« (Assmann 1992:52ff.). Indem die Gegenwart als eine Zeit des Niedergangs, der Latenz und der Missachtung der alten Ordnung thematisiert wird, schöpft diese Art von Mythen ihr identifikatorisches Potenzial aus dem Appell an eine glorreiche Vergangenheit. Gegenwart kann kein Selbstbild fundieren, sondern nur die kontrapräsentische Zeit einer heroischen Vergangenheit.

\subsection{3. "... komplottartige Struktur «: Täuschung und Verkehrung}

In der anhaltenden Zeit der Agonie werde demnach das Falsche zum Richtigen erhoben. Die grundlegende Idee und der ursprüngliche Geist des Gebäudes sind, dieser Deutung zufolge, negiert. Das gründende Fundament, auf dem das Selbstbild ruht, ist also in Gefahr. In einem 30-seitigen Dokument (2008) äußert sich die GHB zur Gefährdung des Welterbestatus der Museumsinsel. Dies wird anhand des sogenannten »Inversionsprinzip[s]« dargestellt.

»Die Treppe sowie die Gestaltung der Wände folgen immer wieder dem auch öffentlich mehrfach so benannten Inversionsprinzip, nämlich das jeweilige Cegenteil dessen herzustellen, was Stüler gewollt hatte: Statt stark gegliederter, reich ornamental geschmückter Wände vollkommen ungegliederte, roh wirkende Wände, notdürftig geschlämmt wie eine Kellerwand; statt der reich durchbrochenen, fast fragil und jedenfalls äußerst leicht wirkenden Treppe eine Betontreppe, wie sie massiver und schwerer nicht wirken könnte. Statt ein harmonisches Ganzes mit den gegliederten Wänden zu schaffen, hebt sich die Treppe so stark wie möglich ab: Grellweiß gegen dunkle Kellerwände im Stil des Brutalismus verflossener Modernismen.«(GHB 2008:15, Herv. JK).

»Inversion«, »Gegenteil« von Stüler, »harmonisches Ganzes « gegen massive Betontreppe sowie »Grellweiß gegen dunkle Kellerwände« - all diese Begriffe dienen in erster Linie dazu, einen Kontrast zu betonen. Ebenso sei die »braune Flachdecke« eine »neue Erfindung«, die mit dem »Original nichts zu tun« habe. All diese For- 
mulierungen, mit denen der gegenwärtige Zustand und das Ergebnis der ergänzenden Wiederherstellung befremdet werden, münden stets in den Vorwurf der »Verfälschung des Originals« (ebd., Herv. im Orig.) oder der »Verfälschung weiterer denkmalgeschützter Bausubstanz« (a.a.O. 8).

Aus Perspektive der GHB ist die Gegenwart eine Gegenzeit zur heroischen Vergangenheit; eine Art Karneval, also eine Zeit der Verkehrung, in der das Falsche zum Richtigen erhoben wird. Verbunden mit der Differenzierung zwischen »heroischer Vergangenheit « und der »Zeit der Agonie« ist Letztere nicht nur durch passives Vergessen, sondern (schlimmer noch) durch aktive Täuschungen und Betrug charakterisiert. Die Vertreter der GHB und der >originalgetreuen Wiederherstellung < fühlen sich durch die Protagonisten des Wiederaufbaus betrogen und hinters Licht geführt. Diese Betrugssemantik findet sich prototypisch für weitere Stellen im Diskurs auch im oben zitierten Dokument von 2008. Der zentrale Vorwurf, den die GHB immer wieder gegen das Landesdenkmalamt und die Stiftung Preußischer Kulturbesitz erhob, bestand darin, dass diese beim Antrag auf Aufnahme der Museumsinsel in die UNESCO-Welterbeliste, der am 25. Juli 1998 in Paris gestellt wurde, die geplanten modernen Eingriffe und den am 04. Juni 1999 verabschiedeten Masterplan bewusst verschwiegen hätten. ${ }^{28}$ Die Stiftung habe demnach

»eines der wertvollsten preußischen Erbstücke mitten im Zentrum dessen, was sie zu hüten hat, gröblich veruntreut. Die beteiligten Institutionen haben sich hier in einem erschlichenen gleichsam rechtsfreien Raum nach Belieben bewegt und sogar die UNESCO getäuscht. (Wendland 2009).

Die Stiftung habe »gröblich veruntreut«, »erschlichen«, »getäuscht«, nutzt »rechtsfreien Raum«. Dass damit eines der »wertvollsten Erbstücke« gefährdet wird, macht die Schärfe der Reaktion und der Wortwahl erklärlich. In einer Pressekonferenz der GHB vom 25. November 2008 wird außerdem gefordert, dass der von der DDR ausgesprochene Denkmalschutz weiterhin Bestand haben müsse. ${ }^{29}$ Dieser beziehe sich selbstverständlich auf das »Museum in seiner originalen, historischen Form « (Wendland/Hoya 2008). Zu dem klandestinen Vorgehen, welches die GHB wittert, gehörte es auch, dass mit dem aktuellen Denkmalstatus der falsche Teil der Gebäudegeschichte akzentuiert wird. Denn: »Heimlich still und leise wurde dieser Denkmalschutz ab 1991 aufgehoben und die Denkmalqualität nur noch der Ruine zugebilligt.« Hierin zeige sich »eine komplottartige Struktur auf hoher Ebene für ideologisch-geschmäcklerische Zielsetzungen«. Fakten würden »seit langem [...] gefälscht und Bürger und Fachwelt systematisch getäuscht«. Was vor sich gehe, sei eine »facettenreiche Skandalgeschichte unglaublichen

28 Dazu auch GHB Bericht (2008:2f.).

29 So weist die GHB oft darauf hin, dass die von der DDR 1986 beschlossene Planung für die Rekonstruktion bereits zu 90 Prozent fertiggestellt gewesen wäre (GHB 2008:14). 
Ausmaßes« (ebd.). Die falsche Akzentuierung der Gebäudegeschichte und der erschlichene Welterbestatus sind aus Perspektive der GHB das Resultat einer »komplottartige[n] Struktur«, welche die Zerstörungsgeschichte des Gebäudes fortschreibt.

Dass in dieser "Skandalgeschichte dem unbestechlichen Auge der GHB eine besondere Rolle zukommt, wird anhand der Schlusssequenz des zu Beginn dieses Kapitels zitierten Texts verdeutlicht: »Das FEST, von dem eingangs die Rede war, ist also $1939 \mathrm{zu}$ Ende gewesen [...]. Nun, nach 70 Jahren, bekommen wir das Märchen von des Kaisers neuen Kleidern vorgeführt« (Großmann 2009). Neben der klaren Trennung der Zeitspannen (»1939 zu Ende«) und den 70 Jahren des Niedergangs ist die Gegenwart nun eine Zeit der bewussten Täuschung und des Betrugs. Das Märchen von »des Kaisers neuen Kleidern«, also eine offensichtliche Scharade, lässt es nicht $\mathrm{zu}$, die ungebührliche und entblößende (»nackte Wände«) Zurschaustellung der Würde des Gebäudes unkommentiert zu lassen. Die GHB sieht sich demgemäß als das Kind, welches als einziges die unbequeme Wahrheit auszusprechen vermag. Entbunden aus Abhängigkeitsverhältnissen verfügt sie allein über einen unbestechlichen Blick auf die Scharade, die sich abspiele. Auch im Titel der Einreichung an den Architekten ist dieses Betrugs- und Täuschungsdeutungsmuster bereits angelegt. Die Überschrift »Vom Juwel der Museumsinsel zum Kuckucksei der Denkmalpflege« (Ludwig 1998) beschreibt nicht nur einen Abstieg, sondern bezichtigt die Denkmalpflege zudem der Täuschung. Diese sei nicht etwa Empfängerin des Kuckuckseis, sondern wird beschuldigt, es der Öffentlichkeit unterzujubeln. Im Text selbst wird mit der Rede von einer »intellektuell verordnete[n] Vergangenheitsbewältigung (Ludwig 1998:6), die »lediglich eine hohle Geste der political correctness (a.a.O. 7) sei, schließlich die Bedrohung durch Fremdbestimmung sowie durch äußere und innere Feinde dramatisiert.

In der Zeit der Agonie ist das Wesen des Ortes durch Vergessen oder Missachten der »richtigen « Regel bedroht. In den Wissensverhältnissen, die der heroische Kollektivierungsdiskurs der originalgetreuen Wiederherstellung stabilisiert, wird die Gegenwart als Zeit, in der die Gebote missachtet werden, charakterisiert. Mittels einer typischen Erweckungsrhetorik (Appell an die heroische Vergangenheit, Gegenwart als Zeit der Agonie) wird so ein »kontrapräsentischer Mythos« (Assmann 1992) erzeugt, der zur Intervention aufruft. In »Dornröschenschlaf« gefallen, sind die entzeitlichten Ideale durch Vergessen und Verfall bedroht. Neben dem eher passiven Vergessen der heroischen Vergangenheit wird eine aktive Bedrohung durch egoistische Architekten, potenziell betrügerische Denkmalpfleger und politisch »verordnete Vergangenheitsbewältigung« konstruiert. Diese Zeit des Niedergangs ist bevölkert von Täuschern und Falschspielern, die das Einzigartige missachten und das Profane karnevalesk erhöhen. Das Bedrohungsszenario kann (und muss) abgewendet werden. Rettung liegt allein in der »Wiedererweckung«, die durch die erneute Ausführung des Neuen Museums möglich erscheint und zu- 
dem den Status einer moralischen Pflicht erhält. Der Ausweg aus dieser Gegenwart führt einzig über die Vergangenheit.

\subsubsection{Entzeitlichung durch Wiederholung}

Zeitkonstitutionell handelt es sich hier also um eine Zweiteilung der Geschichte. Doch dürfen diese zwei fundamental verschiedenen Zeiten nicht einfach als chronologisch aufeinander folgend missverstanden werden. Im Sinne zyklischer Zeitlichkeit "verläuft« Zeit hier nicht, sondern schwingt ewig im Kreis (Arendt 2002:29). Dies führt dazu, dass Wiederholungen, in diesem Modus der Stabilisierung von Zeit, ein hoher Stellenwert beigemessen wird. Der Weg zurück zu alter Pracht steht weiterhin offen. Obgleich das »alte richtige, aber ruinöse« Museum in einem Meer der Bedeutungslosigkeit treibt und sich bei Wind und Wetter in ein »Dornröschenschloss« verwandelt hat, bleibt die Vergangenheit potenziell verfügbar. Wurde eingangs schon angedeutet, dass die Vergangenheit, »von der wir noch heute zehren «, keineswegs abgeschlossen ist, so wird nun auch der Modus erkennbar, mit dem die Verbindung zum Ursprung gesichert werden kann: »Es gab aber sichergestellte Relikte, Fotos und vor allem die Originalbaupläne! So stand trotz des traurigen Anblicks einer Wiedererweckung nichts wirklich entgegen« (Großmann 2009). Der Begriff »Wiedererweckung«, der - wie zuvor die sprachliche Figur der »Auferstehung« - seine Herkunft aus religiösem Sprachgebrauch offenbart, verleiht der Größe der Aufgabe ihre angemessene Würde.

Auch im Mittelpunkt der Frage nach der Wiederholung bauzeitlicher Gebäudeteile steht erneut das Treppenhaus. Unverständlich bleibt der GHB, warum das Treppenhaus nicht wiederhergestellt wird. Auch im Bericht von 2008 wird darauf hingewiesen, dass »Originalpläne von F. A. Stüler und die Vorzeichnungen für die großen Wandgemälde« noch vorhanden und auch der »früher vorhandene gliedernde Farbputz und die ornamentalen Wandgliederungen darüber [...] gut dokumentiert « seien (GHB 2008:14). Gleiches gilt für die Korenhalle im Treppenhaus, die gleichnishaft zum »Höchsten der Kunst hinaufführte«. Doch auch sie »wird nicht rekonstruiert (obwohl ein Gipsabguss existiert)« (a.a.O. 16). Wurde vonseiten der Denkmalpflege die Rekonstruktion, insbesondere die Wiederherstellung der Kaulbachfresken, mit dem Argument zurückgewiesen, dass die jeweilige künstlerische Leistung nicht wiederholbar sei (Wagner 1994), so sieht dies die GHB gänzlich anders. Da die »Belegstücke« ebenso wie die Schablonen der Kaulbachfresken und Originalpläne vorhanden seien, bleibt die »Nachfertigung ohne jenen Qualitätsverlust« möglich. ${ }^{30}$ In diesem Kontext findet sich eine Authentizitätsbehauptung,

30 Die Wiederholbarkeit des Treppenhauses wird an weiteren Stellen betont (etwa Sammler 2005:5). 
denn mit dem Verzicht auf die mögliche Wiederholung komme es zu einem »Verlust an geschichtlicher Echtheit « (GHB 2008:3). Dieser Vorwurf wird abermals in einer Stellungnahme anlässlich der Wiedereröffnung des Museums am 14. Oktober 2009 formuliert.

»Tatsächlich hat sich die Archäologie, die Altertumswissenschaft, die Gegenwart als Abenteuerspielplatz ausgesucht. Sie hat sich eine wohldemolierte Ersatz-Antike als edle Trümmerkulisse für die wirklich musealen antiken Bruchstücke eingerichtet. Was uns heute als sauthentisch<, echt, angepriesen wird, ist in Wahrheit entworfene >Echtheit<, also inszeniert, unecht« (Wendland 2009, Herv. JK).

Mit der Bezichtigung, dass sich die Archäologie die Gegenwart als »Abenteuerspielplatz « ausgesucht habe, wird die Infantilisierung der diskursiven Gegenformation erneuert. Was als authentisch bezeichnet wird, sei lediglich »entworfene >Echtheit«", »inszeniert « und »unecht«, wodurch auch das Deutungsmuster der Täuschung bekräftigt wird. Bemerkenswert ist, dass dabei immer wieder auf die Charta von Venedig (1964) Bezug genommen wird. Damit bezieht sich die GHB auf dasselbe Dokument, welches auch für die Begründung des »Denkmalpflegerischen Plädoyers « entscheidend war. Die Gestaltung der Treppenhalle widerspreche nämlich »diametral dem Prinzip des $\$ 12$ der Charta von Venedig (>Elemente, die fehlende Teile ersetzen, müssen sich harmonisch einfügen, aber vom Original unterscheidbar sein`)«(GHB 2008:16). Abgesehen davon, dass hier nicht sorgfältig zitiert wurde, ${ }^{31}$ setzten sich die Autoren an dieser Stelle mit der Unterschlagung des Halbsatzes »damit die Restaurierung den Wert des Denkmals als Kunstwerk- und Geschichtsdokument nicht verfälscht« $(1964, \$ 12)$ dem ihrerseits oft artikulierten Vorwurf der Fälschung aus. Die Dokumentation von Geschichte ist aus Perspektive der GHB nicht entscheidend. Unter abermaligem Bezug auf die Charta heißt es im Bericht der Gesellschaft:

»Die Baupläne sind im Original erhalten und aufgrund der Symmetrie des Cebäudes durch die vorhandenen Gebäudeteile belegt; ein Wiederaufbau auf der Grundlage der historischen Pläne wäre daher möglich und mit den Prinzipien der Charta von Venedig vereinbar gewesen (>Sie gründet sich auf die Respektierung des alten Originalbestands und auf authentische Urkunden. Sie findet dort ihre Crenze, wo die Hypothese beginnt`)«(CHB 2008:19, Herv. JK).

31 Im § 12 der Charta von Venedig heißt es: »Die Elemente, welche fehlende Teile ersetzen sollen, müssen sich dem Ganzen harmonisch einfügen und vom Originalbestand unterscheidbar sein, damit die Restaurierung den Wert des Denkmals als Kunst-und Geschichtsdokument nicht verfälscht.«[Die hervorgehobenen Stellen markieren fehlende oder anderslautend wiedergegebene Teile des Paragrafen, JK]. 
Authentisch sind nunmehr die »Urkunden«, mit welchen ein Wiederaufbau möglich erscheint. Wichtiger als der Dokumentencharakter der Materialität erscheint die genaue Anleitung zur erneuten Ausführung. »Vorhandene Gebäudeteile« können als »authentische Urkunden« herangezogen werden. Sie dienen als exakter Kodex, mit dem das Original wiederholt werden kann. So wie es wiederholt werden kann, kann es durch eine exakte Einhaltung der kodifizierten Regeln aus der, lediglich im chronologischen Sinn vergangenen, im normativen Sinn allerdings weiterhin gültigen Vergangenheit wiedergeholt werden. Die Auslegung der Charta von Venedig (1964) geschieht hier also im Modus ritueller Kohärenz (Kap. 4). Das Authentische bewegt sich auf der Ebene der Praxis (rituell) und nicht auf der der Materialität (textuell).

Eng verbunden mit der genauen Wiederholung der »Originalpläne« im Sinne einer rituellen Kohärenzsicherung, durch die einzig »Echtheit « gewährleistet werden kann, ist das durch diese diskursive Formation stets angemahnte Interpretationsverbot: Das »kulturelle Erbe ist zu wertvoll, um es dem Tagesgeschmack zu überlassen« (Ahme 2007:2.). Auch der amerikanische Kunsthistoriker Klahr weist die »Möglichkeit der Neuinterpretation« entschieden zurück und stellt die rhetorische Frage: "Who possesses the right to reinterpret a World Cultural Heritage Site?« (Klahr 2006:10). Das Welterbe darf unter keinen Umständen dem Tagesgeschmack, also einer bloß temporären Mode, angepasst werden. Es ist der Zeit des Alltags enthoben. Jedoch wird diese Entzeitlichung nur durch Wiederholung gewährleistet. Nur die Wiederholung und die exakte Ausführung der ursprünglichen Formen sichern das kulturelle Erbe. Eine moderne Interpretation wird als Bedrohung und als unrechtmäßig (»who possess the right«) wahrgenommen.

Da Vergangenheit und Gegenwart nicht durch den Fluss der Zeit getrennt sind, bleiben sie stets durch die Brücke der Wiederholung verbunden. Damit wird eine permanente Gegenwart hergestellt, die die Begriffe von Alt und Neu inadäquat erscheinen lässt. »Alt « und »Neu« bezeichnen - wie bereits gesehen - weniger chronologische als vielmehr normative Kategorien. Der Ursprung, an den man zurückkehren möchte, ist dabei eine Komposition in der Gegenwart, welche sich eklektisch eines Repertoires verschiedener Zeitpunkte bedient. Anhand der Pläne Alfred Messels für die Gestaltung des Bereiches zwischen Kupfergraben und Westseite des Neuen Museums können die Rekonstruktivität und Selektivität der Vergangenheitskonstruktion deutlich gemacht werden. Denn es wird behauptet, dass aufgrund der »architektonischen Abgeschlossenheit der Museumsinsel« für die »endgültige Gestaltung der Außenanlagen« einzig die Pläne des Architekten Alfred Messel von $1907 \mathrm{zu}$ verwenden seien. Diese wurden bis 1930 von Ludwig Hoffmann weiter umgesetzt, woraus der Autor folgt: »Es gibt keinen Grund, nicht an die 1930 unterbrochenen Arbeiten anzuknüpfen (GHB 2008:4). War an anderer Stelle davon die Rede, dass das Fest 1939 zu Ende gegangen ist, so wird nun abwechselnd 1930 oder 1907 zum zeitlosen Referenzpunkt. So kann schließlich eine Geschlossenheit 
des Ensembles antizipiert werden, die für eine >Wiederholung`von Plänen plädiert, die noch nie in der Geschichte der Museumsinsel umgesetzt wurden - wie etwa im Falle des Pergamonmuseums. Die unverwirklichten Pläne entsprechen damit einer vergangenen Zukunft, die durch die Hoffnung, die an sie geknüpft wird, auch für die Gegenwart handlungsleitend bleibt. Aus der Abgeschlossenheit der Museumsinsel ergibt sich jedoch keinesfalls ein Interventionsverbot, wohl aber - und das ist entscheidend - ein Interpretationsverbot.

Ernst Bloch beschließt sein monumentales Werk »Das Prinzip Hoffnung «, indem er jede Hoffnung unter den Horizont der Gegenwart stellt und sie an den Erfahrungsraum der Heimat bindet. Im hoffnungsvollen Blick zurück erscheint dann ein Idealzustand, welcher vertraut und dennoch nie gewesen ist. "Heimat« sei, was »allen in die Kindheit scheint und worin noch niemand war « (1968:1628, Orig. 1959). In Anlehnung an diesen Gedanken lässt sich für den heroischen Kollektivierungsdiskurs der originalgetreuen Wiederherstellung formulieren: Der Einbezug der Zukunft in die Vergangenheit entspricht der utopischen Hoffnung auf Rückkehr an einen Ort, an dem noch niemand gewesen ist.

\subsubsection{Zwischenfazit: Hoffnung auf eine bessere Vergangenheit}

Wie jeder gründende Mythos sich immer wieder den Erfordernissen der Gegenwart anpasst, so bestehen sein Sinn und seine Funktion gerade darin, diese permanente Adaption zu leugnen, um ewig gültige Gewissheit stiften zu können. Auch die Konstruktion einer heroischen Vergangenheit, die in ihrer Funktion auf Gegenwart und Zukunft gerichtet ist, trägt Spuren einer fundierenden Erzählung. Die ethnologische Forschung bietet einen reichen Schatz an mythischen Erzählungen, anhand derer dieser Zusammenhang veranschaulicht werden kann. Der Kulturwissenschaftler Tzvetan Todorov stößt in seiner historisch angelegten Studie über die »Entdeckung Amerikas« (1982) auf unterschiedliche Zeitkonstitutionen der Inka und der europäischen Eroberer (auch untereinander). Im neuzeitlichen Denken Cortés' ist es möglich, radikal Neues zu denken - eine Option, die dem zyklischen Denken der Inka (und auch Columbus') nicht zur Verfügung steht, weshalb die gesamte kosmologische Ordnung der Inkagesellschaft mit der Ankunft der Europäer ins Wanken gerät. Um die Gegenwart zu erklären und eine mögliche Zukunft zu antizipieren, ist es nötig, die Alten zu befragen, ob Ähnliches bereits vorgekommen sei. Die überraschende Erkenntnis, die Todorov anhand seiner Quellen eindrucksvoll darlegen kann, besteht nun darin, dass eine gewisse Zeit nach der Ankunft der Europäer die Alten tatsächlich beginnen sich zu erinnern. Alles hat bereits einmal stattgefunden. Die Ankunft der Europäer, der Krieg gegen Cortés, Pferde, Waffen, Krankheiten - all dies sei vor langer Zeit bereits einmal geschehen. Die neuen Lebensbedingungen können also in die kosmologische Welterklärung integriert werden, indem sie in der Vergangenheit >wiedergefunden` werden. 
Die Zeitkonstruktion des heroischen Kollektivierungsdiskurses der originalgetreuen Wiederherstellung entspricht also eindeutig einer kalten Institution, in die historischer Wandel durch die Forderung nach zyklischer Wiederholung integriert wird. Die Zweiteilung der Zeit ist dabei keineswegs chronologisch zu verstehen. Klaus E. Müller führte in diesem Zusammenhang weiter aus, dass in dieser Zeitkonstruktion alles, was sich auf vermeintliche »Ursetzungen« in der mythischen Schöpfungszeit zu gründen vermag, höchste Autorität und einen unanfechtbaren Gültigkeitsanspruch genießt (Müller, Kap. 4.2.3). Welche früheren Zeitpunkte dabei allerdings in die »Ursetzungen« mythischer Schöpfungszeit (Müller 1983:106) integriert werden und welche fremd bleiben, ist ein Komposit chronologisch höchst verschiedener Zeitpunkte (Kap. 5.2.1), die einzig in ihrer normativen Verbindlichkeit geeint sind. Eben diese Verbindlichkeit der Vergangenheit kann anhand eines 16-seitigen Diskursdokumentes von Rainer Jacob verdeutlicht werden. Der Autor plädiert dafür, die Pläne Alfred Messels für das Pergamonmuseum umzusetzen, da nur diese das Museum für die Zukunft wappnen würden. Folgendes wird dabei süffisant erwogen: „Vielleicht sollte man eine Petition aufsetzen und Herrn Ungers ersuchen: erstens, seine Entwürfe zurückzuziehen; zweitens: den Messel Hoffmannschen Entwurf letzter Hand statt dessen einzureichen. Weil es keinen besseren gibt« (Jacob 2007: 9). Auch das neu zu errichtende Eingangsgebäude der Museumsinsel solle in Gestalt des Hauses der Steuerdirektion der alten Packhofanlagen wieder(neu)entstehen, da es auch Antworten auf alle Anforderungen an den modernen Museumsbetrieb in der Zukunft bereithalte: »Dieses Eingangsgebäude sollte nicht nur die Umrisse, sondern exakt die äußeren Formen des ehemaligen Direktorenhauses haben. Die nur von der Bodestraße her sichtbare Verbindung kann aus Glas sein, sollte aber durch dorische Kolonnaden kaschiert werden« (a.a.O. 10).

Neben der Verbindlichkeit der Vergangenheit wird so auch das auf die Zukunft gerichtete Erinnern, der Befürworter einer originalgetreuen Wiederherstellung, erkennbar. Denn durch den »unanfechtbaren Gültigkeitsanspruch« des Ursprünglichen (Müller 1983:108) kann auch Zukunft bewältigt werden. Vor diesem Hintergrund ist es bezeichnend, dass das zitierte Dokument, dessen Inhalt sich ausführlich der Geschichte des Ortes widmet, den Titel »Zur Zukunft der Museumsinsel« (Jacob 2007, Herv. JK) trägt. Diese Hoffnung auf die Vergangenheit wird umso deutlicher, wenn kontrastierend dazu nochmals vergegenwärtigt wird, dass der Landeskonservator, Jörg Haspel, bereits 1994 einen Rückgriff auf die historische Planung von Messel für die Gestaltung des Bereichs zwischen Neuem Museum und Kupfergraben oder gar die Rekonstruktion des schinkelschen Packhofs kategorisch ausgeschlossen hat (1994:140f.). Was für die Denkmalpflege keinen gangbaren Weg darstellt, wird von der GHB als probates Mittel der Zukunftsbewältigung ins Feld geführt. Die »überlieferte Bausubstanz« der historischen Mitte »war kein Ballast«, sondern »die Geschichtlichkeit dieses Ortes bot eine unverwechselbare Qualität für die künftige Neugestaltung des Berliner Zentrums« (Hoya 2009). Die »unverwech- 
selbare Qualität« kann als Alleinstellungsmerkmal gelesen werden, das eine Nähe zu Fragen der Identität erkennen lässt. Wichtiger aber ist der Hinweis darauf, dass die »überlieferte Bausubstanz der historischen Mitte« »kein[en] Ballast« darstellt und für die »künftige Neugestaltung« Bedeutung behält. Obwohl das Vergangene den klaren Bezugspunkt bildet, stellt dies für die Mitglieder der GHB keineswegs nur retrospektive Nostalgie dar, sondern hat dadurch, dass damit die Zukunft bewältigt werden kann, auch einen klar prospektiven Wert.

So wie die Gewissheit der Inka, dass sich die gegenwärtige Bedrohung bereits einmal zugetragen hat, die beruhigende und hoffnungsvolle Einsicht bereithält, dass sich auch alles wieder zum Guten gewendet haben muss (sprich: die Europäer auch wieder gegangen sein müssen und demnach auch in Zukunft wieder gehen werden), ist auch hier die Wiederholung der Vergangenheit keineswegs nur rückwärtsgewandt. Die Vorstellung des ewig Guten strahlt auch auf die Zukunft aus. Sie wird damit zur Hoffnung auf eine bessere Vergangenheit. Prägnant wird dies in der bereits zitierten Einreichung von Ludwig (1998) auf den Punkt gebracht. Denn im Unterschied zu dem lediglich »Irritation und Empörung « stiftenden Restaurierungskonzept Chipperfields habe "nur die Rekonstruktion auch in Zukunft Bestand« (Ludwig 1998:7). Alles, was der Rückkehr zum Ursprung nicht folgt, sei »Tagesgeschmack«, Mode und demnach vergänglich. Ewig bleibt allein die heroische Vergangenheit, in Gegenwart und Zukunft.

\subsection{6. »Historische Insel«: Die vollkommene Harmonie der Räume}

Die wichtigsten zeitkonstitutionellen Merkmale des heroischen Kollektivierungsdiskurses bestehen somit in der Zweiteilung der Zeit. Dabei wird die heroische Vergangenheit (5.2.1.) in scharfer Abgrenzung zu einer Gegenwart konstruiert, die als Zeit der Agonie und der anhaltenden Zerstörung charakterisiert ist (5.2.2.). Im Sinne eines »kontrapräsentischen Mythos« (Assmann 1992) ergibt sich aus dieser Spannung das Gebot zur Intervention (5.2.3.). Der Ausweg aus der gegenwärtigen Zeit der Latenz führt über den Umweg der Vergangenheit schließlich auch in die Zukunft (5.2.5.). Die Existenz von Plänen und Urkunden erlaubt die erneute praktische Ausführung und Wiederholung der fundierenden Vergangenheit nach Maßgaben zeitlos gültiger Werte (5.2.4.).

Da im Folgenden die raumkonstitutionellen Deutungsmuster analysiert werden sollen und eine vollständige Trennung zwischen räumlichen und zeitlichen Aspekten nicht möglich erscheint, ist es hilfreich, die Codes der Verräumlichung zunächst in enger Anbindung an die beschriebene Zeitlichkeit zu rekonstruieren. So wie zu Beginn der Analyse der zeitlichen Konstitutionsweisen kann auch für die Darstellung der räumlichen Konstitutionsformen zunächst der Aufruf der Initiative »Rettet die Museumsinsel!« (Ahme 2007) herangezogen werden. Mit dem Hinweis darauf, dass anhand der Museumsinsel »die Geschichte und das Herkom- 
men der Stadt « erlebbar seien, wird die identifikatorische Bedeutung dieses Erbes unterstrichen, weshalb es sich verbieten müsse, es dem »Tagesgeschmack« anzupassen. Außerdem findet sich darin eine enge Kopplung zwischen dem Neuen Museum und der Ablehnung des neu zu errichtenden Eingangsgebäudes. Diese Verknüpfung kommt bereits in der Kopfzeile des Dokuments - welches sich gegen den Neubau an der Westfassade des Neuen Museums richtet - zum Ausdruck, denn hier ist das Neue Museum in historisierender Rekonstruktion abgebildet. Der Kampf gegen den Neubau und die Kritik an der Wiederherstellung des Museums werden also in enger Relation zueinander gestellt. Wird die Phänomenstruktur des Streitgegenstandes empirisch nachgezeichnet, zeigt sich zudem, dass die räumlichen Bezüge teilweise weit über die Museumsinsel hinausreichen. Es handele sich

»um nichts mehr und nichts weniger als den letzten wichtigen Baustein zu einer Auffassung des kleinen Bereichs von der Museumsinsel bis zum Brandenburger Tor als >Historische Insek, um die Geschichte und das Herkommen der Stadt sichtbar und erlebbar zu machen.«(Ahme 2007:8.).

Beschreibt der Begriff »Insel« einmal den Raum, der sich zwischen Lustgarten, Kupfergraben, Spree und Bodemuseum aufspannt, so reicht die »historische Insel«, die als Ursprung der Stadt hypostasiert wird, in diesem Zitat bis zum Brandenburger Tor. Im Sinne der empirischen Bestimmung des Untersuchungsgegenstandes gerät so neben dem Neuen Museum auch sein Umfeld in den Blick. Der räumliche Bezugsrahmen der Untersuchung wird also punktuell geweitet, indem er den Relationierungen der Akteure folgt.

\section{Einheit »natürlicher « Relationen}

Einen zentralen Referenzpunkt in diesem Modus der Verräumlichung stellen die als natürlich und ursprünglich behaupteten räumlichen Relationen der Gebäude zueinander dar. So heißt es etwa in dem Text »Rettet die Museumsinsel!«:

»Langfristig wäre eine - falls für nötig erachtet - >zentrale< Erschließung wieder über das Alte Museum anzustreben, da dies die >natürliche< Eingangssituation einmal war: Vom Schloß kommend ging man über die >Agoraく (den Lustgarten) hin zur `Stoa poikile`(dem Alten Museum). Diese Verknüpfung der Kultur mit den Anklängen an die demokratischen Ursprünge des Abendlandes (entsprungen der Freiheits- und Criechenland-Begeisterung der 1820/30er Jahre ...) ist eine zentrale geistige Komponente, die derzeit nicht erlebbar ist« (Ahme 2007:4.).

Teil der »zentralen geistigen Komponente« werden mit den »Ursprüngen des Abendlandes« verbunden. Dies deutet wieder darauf hin, dass die Trägerschicht der Identitätskonstruktion ein Komposit ist, welches die Antike ebenso wie die Griechenlandbegeisterung des 19. Jahrhunderts integriert. Das Wesentliche des Ortes sei lediglich »derzeit nicht erlebbar«, prinzipiell aber über alle Zeit hinweg 
vorhanden. Mit der Vorstellung eines entzeitlichten Ideals ("geistige Komponente«) kann die räumliche Kohärenz des Ensembles auch über Zeitspannen, in denen die räumliche Relation zwischen den Gebäuden materiell nicht erfahrbar ist, erhalten werden. Die Errichtung eines neuen Eingangsgebäudes untergräbt hingegen die »kulturelle Bedeutung« des Alten Museums. Die Störung der ursprünglichen Relationen stellt eine Gefahr für den Wesenskern der Gesamtanlage dar.

»Bei der Herrichtung des Alten Museums, die für 2009 geplant ist, müssen diese neuen (alten) Voraussetzungen berücksichtigt werden. Dagegen würde die Errichtung eines szentralen Eingangsgebäudes an anderer Stelle die Wiederherstellung der kulturellen Bedeutung des Alten Museums konterkarieren.« (GHB 2008:8).

Die neuen sind also auch die alten Voraussetzungen! Werden diese nicht beachtet und das Eingangsgebäude »an anderer Stelle« errichtet, wird dies erneut mit der Gefahr der Umkehrung und durch das Verb »konterkarieren« gekennzeichnet. Das Konterkarieren der Relationen stellt das räumliche Pendant zur diskursiven Konstruktion einer Zeit der Agonie dar. Denn das »originäre Eingangsgebäude« sei immer das Alte Museum gewesen; der Neubau am Kupfergraben hingegen sei eine "Zerstörung« und »Verfälschung« der denkmalgeschützten Bausubstanz (ebd.). Die genaue Orientierung an den ursprünglichen Relationen gewährt auch hier die Wiedergewinnung der »historische[n] Eingangssituation, die durch den stadträumlichen Bezug zum gegenüberliegenden Schloss entstand.« Nach der Wiederherstellung des Schlosses werde diese wieder bestehen (Hoya 2008:3). ${ }^{32}$ Im Aufruf »Rettet die Museumsinsel!« wird sogar argumentiert, dass, sobald das Schloss wieder da sei und auch die »störende Straße« unter die Erde verlegt werde (sic!), »ganz automatisch« die »ursprüngliche Anordnung« wiedergewonnen werden würde (Ahme 2007:2.).

Die Beziehungen der Gebäude zueinander sind als immaterielle und potenziell ewige "geistige Komponente« angelegt. Konstanz und Fortbestand der ursprünglichen Idee können so unabhängig von ihrem materiellen Erleben aufrechterhalten werden. Dass diese geistige Komponente »derzeit nicht erlebbar « ist, dient erneut der Charakterisierung der Gegenwart als Zeit der Latenz. Auch wenn gerade nicht verfügbar und durch die Zwischenzeit potenziell bedroht, bleibt der Wesenskern des Ensembles auf der Ebene räumlicher Relationen erhalten. Das "natürliche« Wesen des Ensembles wird damit in den Zwischenraum der Gebäude verlagert. ${ }^{33}$

32 Derselbe Wortlaut findet sich auch im Bericht der CHB (2008:8).

33 Wolf Jobst Siedler, der einer der Unterzeichner des Volksbegehrens »Kein Neubau auf der Museumsinsel!« war, hat bereits 1991 in seinem Aufsatz »Das Schloß lag nicht in Berlin - 


\section{"Abgeschlossenes Ensemble" und "Notbehelf "}

Zentral in der Argumentation der Gegner der Neubebauung und der Ergänzung des Ensembles der Museumsinsel ist der Verweis darauf, dass es sich bei dem baulichen Komplex um ein »abgeschlossenes Ensemble« handelt. Aus dem Interpretationsverbot folgt aber keineswegs ein Interventionsverbot. »Abgeschlossenes Ensemble« bedeutet nicht, dass der gegenwärtige Zustand unverändert bleiben soll. Vielmehr wird damit ein Zustand konstruiert, den es wieder herzustellen gilt. Dieser umschließt, wie bereits gezeigt, auch Planungen, die nie zur Ausführung gekommen sind. Die GHB hat in vielen ihrer Stellungnahmen darauf hingewiesen, dass auch die Antragsteller des UNESCO-Welterbeantrags davon ausgehen, dass der bauliche Komplex der Museumsinsel abgeschlossen sei.

»Im Nominierungsdokument heißt es auf S. 46 (engl. Fassung): ১Seitdem (1930) sind auf der Museumsinsel keine Baumaßnahmen mehr erfolgt, die dem Komplex einen neuen Cedanken hinzugefügt hätten. Er ist als abgeschlossen zu betrachten, ebenso wie die Geschichtsepoche, der er angehört.« (GHB 2008:2).

Hier wird wie im Aufruf »Initiative Rettet die Museumsinsel!« (Ahme 2007) aus dem Welterbeantrag zitiert, um der eigenen Forderung Nachdruck zu verleihen. Der Masterplan Museumsinsel stehe somit im Widerspruch mit den Vorgaben der UNESCO, da dem Ensemble dadurch ein weiteres Gebäude hinzugefügt werde. In direktem Anschluss an obige Passage heißt es weiter:

»Dagegen erhebt der Masterplan den Anspruch, nach den bisherigen fünf Kapiteln der Baugeschichte der >rote Faden durch dieses sechste Kapitel der Baugeschichte der Museumsinsel zu sein (S. 4), in direktem Widerspruch nicht nur zu der konstatierten Abgeschlossenheit, sondern auch zum Grundgedanken des Welterbes« (GHB 2008:2).

Wie das Adjektiv >alt $<$ ist auch >abgeschlossen $<$ hier nicht streng chronologisch, sondern normativ gemeint. Damit hat es in der Verwendung der GHB eher die Bedeutung von >vollendet<. Das Hinzufügen eines sechsten Kapitels wird deshalb als illegitim erachtet. Anders als etwa durch die Staatlichen Museen (Waetzoldt 1994) oder den Wettbewerbsbeitrag von Axel Schultes (1994:60f.) muss das Ensemble nicht erst fortgeschrieben werden; es muss nicht erst vollendet werden. Paradox erscheint hierbei, wie bereits weiter oben angedeutet, dass gerade das »abgeschlossene Ensemble« es erforderlich mache, in den aktuellen baulichen Zustand einzugreifen. Da die geistige Idealvorstellung vollendet, jedoch durch die unbefriedigende Verfallssituation bedroht ist, muss interveniert werden. Dies darf nur nach den Maßgaben ewig gültiger Gebote geschehen. Dass die Geschichtsepoche, der der Komplex angehört,

Das Schloß war Berlin « diese Form der Argumentation in den Diskurs eingebracht und damit wissenspolitisch verfügbar gemacht (Siedler 1991). 
abgeschlossen sei, bedeutet keineswegs, dass die in ihr gründenden Maßgaben außer Kraft gesetzt wären. Die räumliche Identifikation mit dem »abgeschlossenen Ensemble« führt dazu, dass eine konkrete Vorstellung davon, wie das Ensemble räumlich gestaltet werden soll, bekannt ist. Alle Elemente, die sich darin nicht einpassen, bekommen - übereinstimmend mit der Konstitution einer Zwischenzeit - Attribute des Vorläufigen und des Unfertigen zugeschrieben. In Analogie zur Trivialisierung der Zwischenzeit, die lediglich durch Nicht-Ereignisse (Berliner Wetter, Dornröschenschlaf) gekennzeichnet ist, werden nun die architektonischen Veränderungen des Interregnums als »Notbehelf« und bloße Übergangslösungen befremdet.

In dem bereits zitierten Text von Rainer Jacob »Zur Zukunft der Museumsinsel« (2007), der auf der Homepage Annette Ahmes zugänglich ist, lässt sich dies gut verdeutlichen. Alle baulichen Eingriffe, die von den ursprünglichen Plänen Alfred Messels für das Pergamon und die Gestaltung des Kupfergrabens abweichen, werden als Übergangslösungen diffamiert. So könne jedem, der den »Kolonnadenentwurf Messels« kenne, der »Glaskasten« [gemeint ist die moderne Ergänzung Oswald Ungers, JK] nur wie ein "nachkrieglicher Notbehelf« erscheinen (Jacob 2007:8). Gleiches gelte für den geplanten modernen Eingangsbau des Pergamons, welcher lediglich den »DDRzeitlichen Vorgängerbau paraphrasiert« (ebd.), der in einem »Scheußlichbraun« (a.a.O. 6) ausgeführt war. Mit der Bezugnahme auf die DDR und den "nachkrieglichen Notbehelf« werden die baulichen Veränderungen abermals mit der nicht identifikationsfähigen Zwischenzeit kontextualisiert. Genauso wie die Notbehelfe und unbefriedigenden Baukörper der Zwischenzeit werden auch »moderne Neubauten« als »empfindliche Störung « wahrgenommen, würden diese doch dem Komplex gänzlich unzulässig ein »sechstes Kapitel« und »einen neuen Gedanken hinzufügen« (GHB 2008:2). Alle diese Kontraste, die sich weigern, an den ursprünglichen Plänen Maß zu nehmen, werden als »Fremdkörper« beschrieben (Jacob 2007:8), denn die Verbindung zwischen älterer und zeitgenössischer Architektur sei immer ein »mißlichく Ding« (a.a.O. 9).

Mit dieser Rhetorik der Befremdung wird die Zwischenzeit räumlich übersetzt. Diese findet sich ebenso häufig in den Darstellungen des Neuen Museums. Aus der Warte der GHB werde damit ein potenziell bedrohlicher Schwebezustand, in dem sich das Gebäude befindet, verlängert, denn: »Insgesamt entsteht ein Eindruck von seltsamer Unfertigkeit. Die Idee, die dem ganzen Museum zugrunde lag, wurde negiert, obwohl sie Denkmalbestandteil ist (Großmann 2009, Herv. JK). »Seltsame Unfertigkeit« bedeutet vor allem, dass die Zwischenzeit keinen Abschluss findet und auf Dauer gestellt wird. Unfähig, Neues zu stiften, bleibt diese Zeit profaner Nicht-Ereignisse eine Zeit »seltsamer Unfertigkeit«. Alles, was nicht im Zeichen der »zugrunde« liegenden Pläne steht, erhält den Nimbus einer Übergangslösung oder der Negation der ursprünglichen Vollkommenheit. 
Derlei Bezichtigungen von Bauelementen, die als Störung eines ursprünglichen Zustandes konstruiert werden, widersetzen sich der Identifikation und sind in den Reinheitsfantasien der GHB häufig nachweisbar. Dies bedeutet jedoch keineswegs, dass sie nicht auch von Vertretern der Denkmalpflege zur Befremdung unerwünschter Zustände ins Feld geführt werden. Denn exakt dasselbe Muster der Befremdung wendet auch Jörg Haspel an, wenn er dafür plädiert, dass die »unsägliche Glasfront vor der offenen Treppenhalle« des Alten Museums verschwinden müsse. Diese würde »die grundlegende Entwurfsidee Schinkels konterkarier[n]« und sei »ein unhaltbares Provisorium und anhaltendes denkmalpflegerisches Ärgernis« (Haspel 2010:79ff.). Auch hier wird durch den Begriff »Provisorium« ein Zwischenzustand konstruiert und räumlich übersetzt. Dieser dient ebenso wie die Begriffe »Notbehelf « und »Fremdkörper« dazu, einen Zustand zu kennzeichnen, der sich einer Identifikation wiedersetzt. Mit dem Vorwurf, dass damit ein Ursprungszustand (»grundlegende Entwurfsidee«) »konterkariert« werde, wird sogar das gleiche Vokabular zur Befremdung dieser Zeitschicht als eine Zeit der Verkehrung verwendet. ${ }^{34}$

\section{Einheit von Ausstellung und Architektur}

Neben der Konstruktion einer ursprünglichen Anordnung stellt der Topos der Einheit im Inneren eine Identitätsressource dar. Das besondere Wesen des Gebäudes bestehe in der ursprünglich von Stüler geplanten und von Lepsius inspirierten Einheit von Ausstellung und Architektur, die durch didaktische Wandmalereien hergestellt wurde. Diese gelte es, laut der GHB, wiederherzustellen. Museums- und ausstellungsgeschichtlich verbarg sich dahinter tatsächlich ein Novum. Aufgrund der Statik des abgebildeten Wissensstandes, der sich durch weiteren Wissensgewinn überlebte, wurde die Darstellungen bereits im 19. Jahrhundert teilweise übermalt (Kap. 5.1.1). Die didaktische Einheit zwischen Ausstellung und Architektur wird von der GHB keinesfalls als historische Momentaufnahme ad acta gelegt, sondern bleibt weiterhin ein identifikatorischer Bezugspunkt. Räumliche Neuinterpretationen der Innengestaltung werden abermals abgelehnt.

»Die Einheit von Raumgestaltung und Ausstellungsstücken war das Besondere.

Der Besucher, gleich welchen gesellschaftlichen Standes, durfte nun einen Palast betreten, in dem ihm die Kunstschöpfungen vergangener Zeiten gezeigt wurden. Außer Originalen bediente man sich auch guter Kopien, damit ein ganzheitlicher Eindruck entstehen konnte.«(Großmann 2009).

34 Interessant vor diesem Hintergrund ist auch, dass Haspel im selben Dokument davon spricht, dass das Neue Museum »im Sinne einer bauarchäologischen Denkmalpflege restauriert und vervollständigt« wurde (2010:82, Herv. JK). 
Um den "ganzheitlichen Eindruck« als Besonderheit des Museums zu unterstreichen, wird abermals Stüler selbst zitiert, denn für ihn »erschien [es] als angemessen, die Räume in größtmöglicher Harmonie mit den aufzustellenden Gegenständen zu halten« (Stüler, zitiert nach Großmann 2009). Stüler wurde, laut GHB, damit dem Bildungsgedanken Humboldts »in vollendeter Weise gerecht« (ebd.). Mit dem »Bildungsgedanken Humboldts« wird ein weiterer der Heroen einer klassischen Epoche als Autorität und Orientierungspunkt für alle weiteren räumlichgestalterischen Maßnahmen ins Feld geführt. Die »vollendete Weise« legt zudem nahe, dass es keine bessere als eben diese Gestaltung der Räume geben kann. Die Besonderheit der einheitlichen Verknüpfung zwischen Ausstellung und Architektur macht das Museum zum »Palast«. Die »Kunstschöpfungen«, die im Gebäude gezeigt wurden und mit diesem gleichgesetzt werden, machen auch das Museum zur »Schöpfung«. Sein genialer Architekt wird abermals zum Schöpfer erhoben. Im Nordkuppelsaal, der seinen ruinösen Charakter auch nach der Wiederherstellung des Neuen Museums erhalten hat und in dem nun die Büste der Nofretete ausgestellt wird, sieht die GHB die Einheit und damit das Besondere des Museums grob verletzt:

»Ein weiterer Verstoß gegen den Weltkulturerbestatus ist die architektonische Umdeutung zwischen Raum und Kunstgegenständen. Das Prinzip der Einheit von Raumgestaltung und Ausstellungsgut ist verletzt. So wird das berühmteste $\mathrm{Mu}$ seumsgut, die Büste der Nofretete, im Nordkuppelsaal stehen, wo über ihr Herkules einen Hirsch am Ceweih zu Boden drückt und Perseus den Medusenkopf schwenkt.«(Großmann 2009).

Eine ägyptische Büste im ehemaligen »Griechischen Kuppelsaal« (van Wezel 2003:200f.) mit den Resten mythologischer Darstellungen (Perseus, Andromeda) wird als Regelverstoß und als gravierende Störung der Einheit, die schließlich das Besondere war und dies auch bleiben soll, wahrgenommen. Die Gestaltung des Nordkuppelsaals wird hier als disparat und unharmonisch beschrieben und erneut durch belustigende Wendungen befremdet. Die "architektonische Umdeutung" des Museums durch Chipperfield gewähre also keine »organische Verwandtschaft mit den [...] Kunstobjekten« (GHB 2008:18). Die Verletzung des Prinzips der »Einheit von Raumgestaltung und Ausstellungsgut « bringt erneut den normativ verbindlichen Charakter der »ursprünglichen Anordnung« zum Ausdruck. Neben dem Befremdungsmuster der Belustigung und dem Gebot der Nullabweichung werden allmählich die Topoi der Gefährdung durch Verunreinigung und Mischung deutlich. Denn ex negativo ergibt sich aus der starken Betonung der Einheit das Verbot der Vielheit.

Wie wir noch sehen werden, wird der Anspruch auf Harmonie und ein organisches Ganzes von allen diskursiven Formationen erhoben. Die Harmonie rekurriert an dieser Stelle allerdings vor allem auf die inhaltlich-didaktische Verbindung zwi- 
schen Ausstellungsobjekten und Wandmalereien, wie sie für den erbauungszeitlichen Zustand charakteristisch waren, und den Aspekt stilistischer Homogenität. Wie dies aussehen solle, wird oft durch den Vergleich zu den Restaurierungen der Alten Nationalgalerie und des Bodemuseums dargestellt (Ahme 2007b). Wie bereits gesehen, geht es keinesfalls um eine Rückkehr zu einem baugeschichtlich gesicherten Zustand, denn die baulichen Veränderungen im Kontext der Wiederherstellung der beiden Gebäude waren teilweise gravierend. ${ }^{35}$ Vielmehr geht es um eine Ästhetik der Einheit und Geschlossenheit, die ungeachtet, ob sie tatsächlich für das 19. Jahrhundert nachgewiesen werden kann oder nicht, eingefordert wird. Nicht ein bauforscherisch gesicherter Zustand, sondern die stilistisch geschlossene Vergangenheitskomposition in der Gegenwart ist mit dem Prädikat >ursprünglich gemeint. Die ästhetische Gleichmäßigkeit verbietet das Nebeneinander verschiedener Stile, genauso wie jede Abweichung von der als ursprünglich bezeichneten Innenraumgestaltung abgelehnt wird.

\subsection{7. "Raum-Monster « und »Beton-Skelett«: Die Verwundung des Baukörpers}

Die folgenden Deutungsmuster der Verunreinigung, der Monstrosität sowie der Gewalt, mit denen Fremdheit konstruiert wird, sind in der Argumentation und den Diskursdokumenten der originalgetreuen Wiederherstellung allgegenwärtig. Als negative Charakterisierung dienen sie auch einer vertiefenden Beschreibung dessen, was an der Museumsinsel und am Neuen Museum raumkonstitutionell als Wesensmerkmal in Anspruch genommen wird. Wieder werden die Konstitutionen von Eigen und Fremd wechselseitig vollzogen.

\section{Vom "magischen Blickpunkt" zum »Kohlenkeller "}

Die Geschichte der Wiederherstellung des Neuen Museums wird durch die GHB im Wesentlichen als eine Geschichte des anhaltenden Niedergangs beschrieben. In räumlicher Hinsicht werden dafür zahlreiche sprachliche Bilder der Trivialisierung herangezogen. Wieder kann dies anhand der Treppenhalle und der Diskussion um die Korenhalle des Erechtheion veranschaulicht werden. Diese Kopie eines Sanktuariums, welches Göttern und Heroen gewidmet war, stellte auf dem Höhepunkt der Griechenlandbegeisterung ein viel zitiertes Motiv dar. Auch die Treppenhalle des Neuen Museums erhielt ein Erechtheion, dessen kriegsbeschädigte

35 Eindrücklich verdeutlicht dies ein Raum im Erdgeschoss der Alten Nationalgalerie, in dem die ursprünglichen Deckenhöhen sowie zahlreiche Beschädigungen des Gebäudes noch erkennbar sind. Erst durch diese Vergleichsmöglichkeit lässt sich der ansonsten stilistisch geschlossene Zustand des restlichen Gebäudes als Ergebnis massiver baulicher Veränderungen erkennen (Kap. 4.2). 
Reste erst im Zuge der Wiederherstellung des Hauses vollständig abgetragen werden (Kap. 5.1.1). Nach langen Diskussionen wird schließlich auf die Rekonstruktion des Erechtheions verzichtet. Mit der Begründung, dass das Erechtheion lediglich ein Teil der Ausstellung und nicht Teil der Architektur sei, wird der Verzicht der Rekonstruktion begründet. Die GHB empört sich darüber:

»Der vertrauensselige Irrtum gegenüber den Bürgern wurde offenbar, als der berühmt-berüchtigte 1. Entwurf von Chipperfield die Runde machte und die fabel hafte Treppenhalle Stülers als schier unendlichen, unverputzten Kohlenkeller mit einer hellen, hinein gestellten Betontreppe zeigte. [...] Der magische Blickpunkt des Treppenhauses, die Korenhalle, wird einfach weggelassen.« (Großmann 2009, Herv. JK).

Der Niedergang der »fabelhaften Treppenhalle Stülers« vom »magische[n] Blickpunkt« zum »unverputzten Kohlenkeller« durch den »berühmt-berüchtigten« Entwurf Chipperfields bildet eine der zahlreichen räumlichen Übersetzungen der zeitlichen Zweiteilung. Diese Strategie der Trivialisierung findet sich ebenso in der Differenz zwischen dem »leichten und gefälligen Bogenbindern« des 19. Jahrhunderts und dem »Terrazzo im Stil sozialen Wohnungsbaus der Sechziger Jahre«, als welcher der im Treppenhaus verwendete Beton abgetan wird (Ludwig 1998:4). In die Liste der sprachlichen Bilder der Profanarchitektur (Kohlenkeller, sozialer Wohnungsbau), mit denen der Entwurf Chipperfields geschmäht wird, reiht sich auch ein, dass der vollständig neu entstandene Nordwestflügel als »Lagerhalle« (GHB 2008:17) und als »Industriegebäude« (a.a.O. 21) bezeichnet wird. Mit Begriffen aus dem semantischen Feld der Industrieproduktion wird die Arbeit des Architekten trivialisiert. Dies wird abermals durch kontrastierende Visualisierung hervorgehoben.

Auch anlässlich des 20-jährigen Bestehens der GHB wird die diskursive Profanierung mittels Metaphern der Industrieproduktion vertieft. »Statt die Aussage des Architekten Stüler wieder zur Geltung zu bringen, wird die Ruine konserviert und fehlende Bauteile durch moderne Sicht-betonfertigteile ersetzt« (Hoya 2009). Der Begriff »Sicht-betonfertigteile« suggeriert, dass das Material nichts Besonderes oder gar billige Stangenware sei. Es ist keineswegs mit der exzeptionellen Bedeutung des stülerschen Entwurfs vergleichbar. Obgleich die Bauteile durchaus eine hohe baukünstlerische Qualität besitzen und aufwendige Einzelanfertigungen sind, dient die Bezeichnung "Sichtbetonfertigteile« der Diskreditierung der modernen Ergänzungen als Massenware, die gegen die Einmaligkeit des Entwurfs Stülers abgegrenzt wird.

Die Charakterisierung der Betonbauteile wird von der GHB oft mit der Bezichtigung der »Gesichtslosigkeit « (Schlawe 2009) in Verbindung gebracht. Die Beliebigkeit der Architektur, die über keine eigenen, einzigartigen Wesensmerkmale verfüge, bleibt ohne erkennbare Identität. So ließe sich die Metapher der Ge- 
Abbildung 16: Der Griechische Saal (links) wurde im Krieg vollständig zerstört. Die moderne Interpretation durch Werkbetonteile (rechts) wird durch die kontrastierende Visualisierung befremdet.
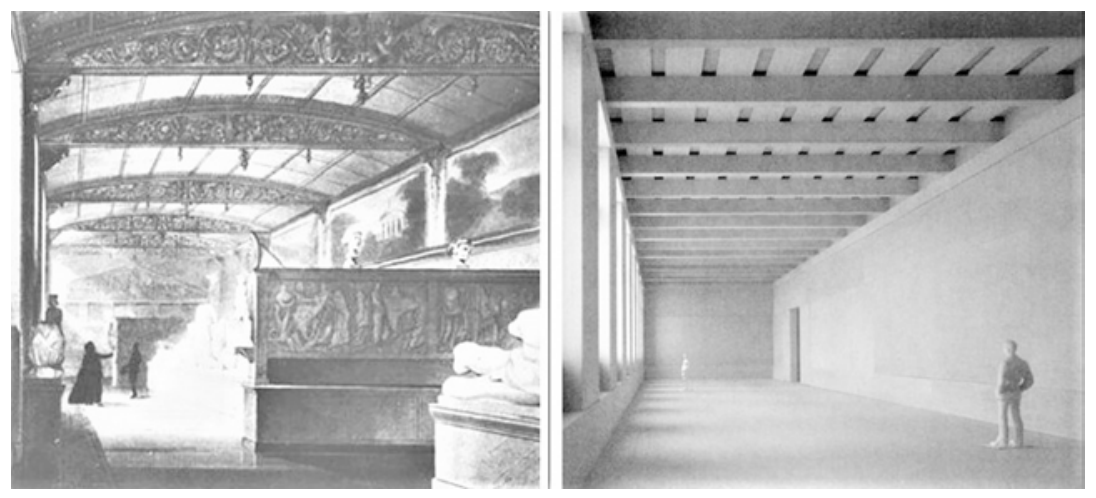

sichtslosigkeit als Abwesenheit eigener Wesens- und Wiedererkennungsmerkmale interpretieren. Die Rede von der gesichtslosen modernen Architektur und ihrer (vermeintlichen) Fertigteilproduktion deutet darauf hin, dass ihr keinerlei identitätsstiftende Kraft zugestanden wird. Ohne typische Charakteristika und ohne Gesicht bleibt sie anonym und nicht identifizierbar. Positive Alleinstellungsmerkmale sind aus dieser Perspektive nicht erkennbar. Mit den Bildern der Massenware, der Industriearchitektur, des sozialen Wohnungsbaus oder des Kohlenkellers wird ein Raum vollkommener Belanglosigkeit konstruiert, der als die räumliche Übersetzung der Nicht-Ereignisse der Zeit der Agonie verstanden werden kann und sich der Identifikation widersetzt.

\section{Ein verwundeter Baukörper}

Die Treppenhalle ist nunmehr auf die "nackten Ziegelmauern« entblößt und umschließt einen »erschütternden Leerraum« (Hoya 2009). Der Anblick ist nun nicht mehr magisch, sondern erschütternd. Die »nackten Ziegelmauern« erinnern an den Scharadevorwurf der GHB, wonach sich Architekten und Denkmalpfleger hier, im Sinne des Märchens von »des Kaisers neue Kleider«, eine Täuschung der Öffentlichkeit ausgedacht haben. In einem Flyer der GHB werden neben der sprachlichen und visuellen Kontrastierung der Vorwurf der »Irreführung der Öffentlichkeit« sowie das in diesem Unterkapitel zu analysierende Deutungsmuster der Gewalt zum Ausdruck gebracht. 
Abbildung 17: Flugblatt der Gesellschaft Historisches Berlin e.V. mit kontrastierender Visualisierung, Täuschungsvorwurf(Irreführung) und Anthropomorphismus (Beton-Skelett).

\section{Irreführung der Öffentlichkeit beim Wiederaufbau des Neuen Museums}

\section{Konservierte Ruine statt Wiederaufbau Sichtbeton statt Marmor} Beton-Skelett statt Griechischer Korenhalle

Wir fordern, dass die bereitgestellten 300 Mio. Euro für die denkmalgerechte Rekonstruktion des Weltkulturerbes verwendet werden!

Wir fordern den Dialog zwischen Öffentlichkeit, Denkmalpflege und Bauherrn!

\section{So oder So?}
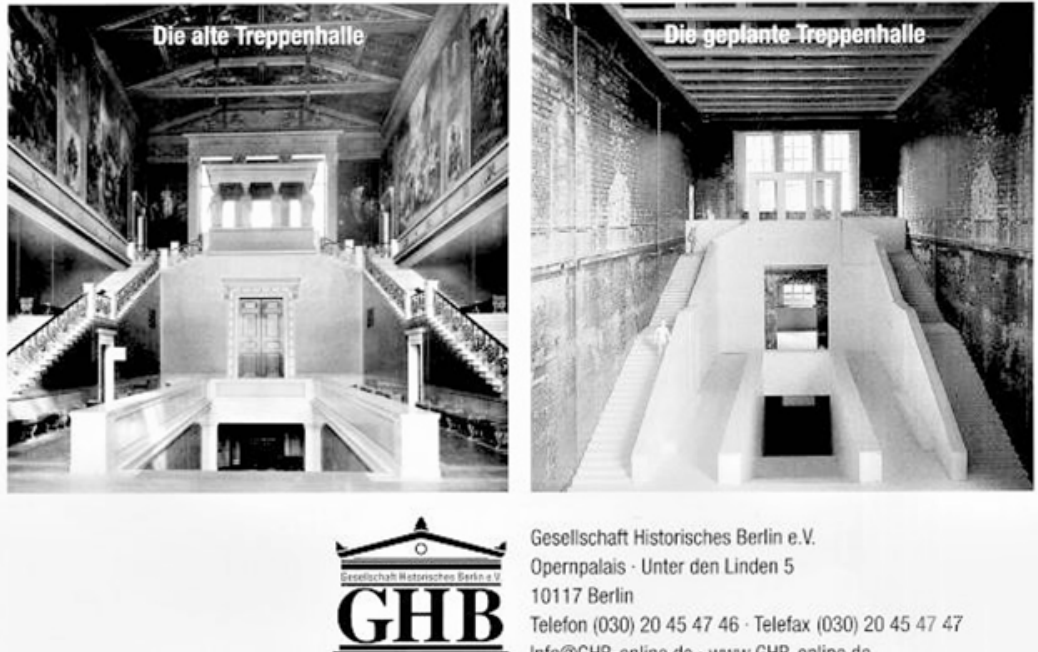

Gesellschaft Historisches Berlin e.V Opernpalais - Unter den Linden 5 10117 Berlin

Telefon (030) 20454746 - Telefax (030) 20454747 Info@GHB-online.de - www.GHB-online.de 
Was mit den ko-konstitutiven Metaphern des »magischen Blickpunktes« und des profanen »unverputzten Kohlenkeller[s]« eingeleitet und durch Attribute des Sterbens und des Todes weiter kontrastiert wird, lenkt den Blick auf eine der zentralsten sprachlichen Techniken der Befremdung. Dabei handelt es sich um den häufigen Rückgriff auf ein Repertoire an Begriffen aus dem semantischen Feld der Gewalt. Das Gegensatzpaar zwischen magisch und trivial wird in den Kontrast zwischen Leben und Tod übersetzt. Das Beton-Skelett, als welches die auf die bloße Struktur reduzierte und ihres Dekors entkleidete vormalige Treppenhalle beschrieben wird, kann als Ausdruck der im Verfall und im Absterben begriffenen Ruine interpretiert werden. Dazu passt auch, dass das Treppenhaus an anderer Stelle sowie der modern gestaltete Nordwestflügel als eine »unterkühlte glatte Ödnis« (Ludwig 1998:5) beschrieben werden. So wie die unterkühlte Ödnis Assoziationen zum Ödland, Absterben und Verfall weckt, so ist auch das Motiv des Todes in einer der medienwirksamen Aktionen der GHB zentral. Am 17. November 2007 rief die Gesellschaft zu einer Protestaktion auf, bei der in der Bodestraße entlang der Südseite des Neuen Museums die Worte »Welterbe ade« mit roten Grablichtern ausgelegt wurden. Die Aktion, die sich als inszenierte Grablege des Neuen Museums interpretieren lässt, verfehlte die erhoffte Aufmerksamkeit nicht und erzeugte ein mediales Echo. Damit diese Gewalt- und Todessemantik überhaupt plausibel wird, muss zunächst das Gebäude vermenschlicht werden. Das Museum in seinem ruinösen Zustand wird mittels zahlreicher Anthropomorphismen diskursiv zum Baukörper, der der Pflege und der Fürsorge bedarf.

»Der schwer kriegsverletzte Patient wurde absichtlich nicht geheilt: Rekonvaleszenz, Rekonstruktion war verboten - von der Denkmalpflege Berlins und den verbündeten Institutionen und Fachleuten. [...]. So wurden die Wunden des Patienten groß herausgestellt und aufwendig konserviert. Fehlende Körperteile wurden durch falsche Prothesen >modern< ersetzt. So steht er nun da in Sack und Asche, ein ausgemergelterchronisch Kranker, jetzt ein `klassischer Dauer-Pflegefall! Vermutlich wegen vieler Proteste der GHB wurde in letzter Minute dieser Cebäude-Leichnam außen farblich noch etwas aufgehübscht, so dass wir eine dezent geschminkte Mumie eines Museumsgebäudes bewundern dürfen. (Wendland 2009, Herv. JK).

Der »kriegsverletzte Patient « wurde absichtlich nicht »geheilt«. Die Liste der aufgerufenen Anthropomorphismen ist beeindruckend lang: »Wunden des Patienten«, »fehlende Körperteile«, »falsche Prothesen«, »ausgemergelter chronisch Kranker«, »Dauer-Pflegefall«, »Gebäude-Leichnam«, »geschminkte Mumie«. Die Vielzahl der Anthropomorphismen stellt im Kontext der Diskursivierung von Gebäuden ein wichtiges Vokabular der Identifikation dar. Herzstück, Prothesen ebenso wie das, was das Haus über den Lauf der Zeit »erlitten« habe, sind in Debatten um die Rekonstruktion kriegszerstörter Gebäude allgegenwärtig. 
Die Vermenschlichung des Baukörpers geht in einer Vielzahl von Dokumenten explizit mit der Betonung seiner Leidensgeschichte einher. So werde versucht, »durch eine moderne Kontrastarchitektur das historische Ensemble der Museumsinsel zu sprengen « (Hoya 2009). ${ }^{36}$ Außerdem wird die Symmetrie der Fassade zum Kupfergraben »bedenkenlos geopfert« (Ludwig 1998:4f.). Auch im Treppenhaus werde »die Einheit von Baustruktur und Ornamenten/Bauschmuck/Fresken der ursprünglichen Version« durch Chipperfield »verletzt« (GHB 2008:16, Herv. im Orig.). Das Ensemble der Museumsinsel und das Neue Museum werden gesprengt, geopfert, verletzt. Einen Höhepunkt im Hinblick auf die Dramatik der verwendeten Begriffe aus den semantischen Feldern der Gewalt ist mit einem Flugblatt der GHB anlässlich des Tages des offenen Denkmals 2008 erreicht. Diesem ist zu entnehmen: "Das einstige Neue Museum: Nun eine geschminkte Mumie, Museumsruine mit falschen Prothesen, als heimliches Kriegsdenkmal für erfolgreiche Bomberflotten, [...] eine Karikatur seiner selbst.« (Flugblatt der GHB, zitiert nach Wolters 2010:250).

Die Gleichsetzung Chipperfields mit den Piloten der Royal Air Force und damit die Assoziation zwischen sergänzender Wiederherstellung und den Zerstörungen des Bombenkriegs führten den Vorwurf der anhaltenden Zerstörung auf drastische Weise fort und konstruieren damit eine Exosphäre, in der der britische Architekt als Zerstörer auftaucht, der das Werk der Bomberflotten vollendet. Das »heimliche Kriegsdenkmal« stellt abermals den Bezug zum klandestinen Wirken einer hinter dem Rücken der Öffentlichkeit agierenden Denkmalschützerkaste her, die ebenfalls Teil der Exosphäre wird. Diskursiv fand diese unbesonnene Assoziation der Luftangriffe mit den Wiederherstellungsarbeiten des britischen Architekten neben dem Flugblatt der GHB auch medialen Widerhall. So titelte etwa >The Independent «: »The RAF took out a Berlin museum. They've asked a Brit to put it back« (Niesewand 1997). Wie noch zu zeigen ist, wird die britische Herkunft des Architekten vonseiten der Denkmalpflege gänzlich anders gedeutet. Denn was hier als Fortsetzung der Zerstörung dramatisiert wird, bildet andererseits den Ausgangspunkt zur Verständigung und Versöhnung. Obwohl Versöhnung für die GHB nicht in Sicht ist, wird die Möglichkeit der Heilung zumindest in Aussicht gestellt. Jedoch gewähre laut GHB nur die »Wieder-Findung« der stülerschen Bau-Idee eine »Heilung der Kriegs- und Nachkriegsschäden« (Ahme 2007:7.). Schließlich vervollstänsenen visuellen Gesamteindruck«(CHB 2008:11, Herv. JK). Im Gegensatz zu dieser gewaltbetonten Deutung wird das Gebäude im Tagesspiegel (Zajonz 23.10.2007) als »Zeichen der Toleranz« gedeutet und mit einer für Berlin reklamierten Identitätsressource in Verbindung gebracht. 
digt der Begriff der Heilung das semantische Feld der als körperlich empfundenen Gewalt.

\section{"Raum-Monster " und "Sachlichkeitswahn"}

Dem neu zu errichtenden Eingangsgebäude werden "falsche >Kolonnaden « und »unproportionale Maßverhältnisse« attestiert. Nach der unterlassenen Heilung des Neuen Museums sei demnach bereits das »nächste Ungemach [...] in Vorbereitung«. Denn auch der Entwurf für die James Simon Galerie von 2007 sei ein »proportionsgestörter Neubau« (Großmann 2009). Mit dem proportionsgestörten Neubau gerät eine weitere Strategie der räumlichen Befremdung in den Blick. Dabei handelt es sich um den Topos des Monströsen. Bereits im Kontext der Aktion »Welterbe ade« sprach die Vorsitzende der GHB von »monströsen Betoneinbauten « und kalkulierte damit zurecht eine mediale Resonanz, die dieses drastische Bild evozierte. Am Tag der Aktion wurde diese Formulierung medial wiederholt (Deutscher Depeschendienst 17.11.2007, Tagesspiegel 2007, Welt online 2007). Bereits vorher wurde Annette Ahme mit diesem geschickt lancierten sprachlichen Bild zitiert (Deutscher Depeschendienst 08.11.2007, Berliner Morgenpost 11.11.2007), wodurch es zu einer wirkmächtigen wissenspolitischen Intervention wurde.

Außerdem würden im Treppenhaus statt der leichten und gefälligen Bogenbinder des 19. Jahrhunderts nun »monströse Balken von nie gesehener Grobschlächtigkeit« das Auge irritieren (Ludwig 1998:4). Neben dem Nordkuppelsaal, der die Nofretete beherbergt, und dem Treppenhaus, in welchem einst das Erechtheion und die Kaulbachfresken $\mathrm{zu}$ sehen waren, stellt auch der Ägyptische Hof erneut einen der Brennpunkte der Debatte dar. Die Gegener der ergänzenden Wiederherstellung kritisieren: »Statt der konstitutiven Treppenhalle kommt ein roher, bedrückender Raum mit einer groben Beton-Treppe; statt des exorbitanten ägyptischen Hofes [...] kommt ein puristisches Raum-Monster, statt des griechischen Hofes ein ebensolches." (Ahme 2007:7.). Indem die Rauminversion Chipperfields im Ägyptischen Hof als bedrückender Raum und ebenso wie der Griechische Hof als Raum-Monster und als "größtes Vergehen« beschrieben wird, wird die normative Dimension dieser Deutung erkennbar: »Das größte Vergehen ist die Vernichtung des Ägyptischen Hofes. Hier hatte Chipperfield den Einfall, den Fußboden auszuschneiden und eine Etage höher zu heben. Damit ist das ganze Werk von Lepsius vernichtet und zu einem Neubau mutiert.« (Großmann 2009, Herv. JK).

Was an anderer Stelle Gegenstand nachgerade lyrisch-schwärmerischer Beschreibungen und als Beleg für Harmonie und Kontinuität der heutigen Ausstellungsräume gedeutet wird (Frampton 2009), erhält hier den Status des Monströsen. Der "proportionsgestörte Neubau«, die »Raum-Monster« vernichten das Werk Lepsius', welches so schließlich zum »Neubau mutiert«. Eng mit dem Vorwurf des Monströsen ist die Diskreditierung der Architekten und der Denkmalpflege 
als »entrückter Zirkel« (Ludwig 1998:6) verbunden. Nicht nur werden damit die Konzepte der Denkmalpflege in den Bereich einer Verrücktheit gestellt. Auch die Konstruktion einer der Alltagswelt »entrückten« Elite, eines Zirkels, der in Konkurrenz und potenzieller Feindschaft zum »kunstliebenden Publikum «steht, wird damit hergestellt (ebd.). Das Neue Museum dürfe daher nicht zur »Verfügungsmasse eines kleinen Zirkels von Museumsdirektoren, Denkmalpflegern und Architekten werden« (a.a.O. 7). Erneut wird eine Gefahr durch die Täuschung und den Betrug heraufbeschworen. Doch worauf nun hingewiesen werden soll, ist die Befremdungstechnik, mit der die diskursive Gegenposition in den Bereich potenzieller geistiger Unzurechnungsfähigkeit gestellt wird. Denn das Konzept sei ein "Angriff auf den gesunden Menschenverstand« (a.a.O. 5). In einer Pressemitteilung anlässlich der Wiedereröffnung des Museums spricht die GHB von einem »absurden Geschehen «, in dem es nicht gelungen sei, der »Vernunft nennenswert Raum« zu schaffen (Wendland/Hoya 2008).

$\mathrm{Zu}$ dieser Diskreditierung des Konzepts der >ergänzenden Wiederherstellung، als »Wahnsinn« (Ahme, zitiert in Berliner Morgenpost 11.11.2007) passt auch die Rede vom »Sachlichkeitswahn«. Denn im Entwurf der Treppenhalle würden sich »Ruinensehnsucht mit modernistischem Sachlichkeitswahn und Albert-SpeerÄsthetik« (Großmann 2009) mischen. Ebenso das diskreditierende Vokabular aus dem Bereich psychiatrischer Leiden und schwerer Geisteskrankheiten ist in den Debatten um Rekonstruktion, ebenso wie die Begriffe aus dem semantischen Feld der Gewalt und der Verwundung, weit verbreitet. ${ }^{37}$ Die monströsen Räume sind entrückt und Ausdruck von Unvernunft und Wahnsinn.

\section{"Fetisch", "Kult" und "Barbarismus"}

Weitere Formulierungen, mit denen Befremdung hergestellt wird, sind die Begriffe Fetisch und Kult sowie der, vom heroischen Kollektivierungsdiskurs oft ins Feld geführte, Vorwurf der Kulturlosigkeit und des Barbarismus. Die Begriffe verfügen darüber hinaus über eine lange Tradition der diskursiven Diskreditierung. Marx wählte den Begriff des Warenfetisches, um darauf hinzuweisen, dass sich der Wert der Waren keineswegs in ihrer tatsächlichen Qualität erschöpft, sondern darin ein gesellschaftlich konstruiertes Mehr zum Ausdruck kommt. In der Anwendung des Begriffs Fetisch, welcher in jener Zeit für sogenannte sprimitive Völker r reserviert war, auf die bürgerliche Gesellschaft lag natürlich eine Provokation. So spricht auch die GHB von einer »fetischhaften Überhöhung« der »Nachkriegs-Verwahrlosung« (Ahme 2007:7.). Die Zurschaustellung der »Wunden des Patienten« wird aus dieser

37 Eines der zahlreichen Beispiele dafür bietet auch die Problematisierung der sowohl modernen als auch historisierenden Bauteile der Berliner Schlossrekonstruktion als »bipolare Störung« (Rautenberg 2018:35). 
Perspektive nur als ungemäße Überhöhung der Zeit des Niedergangs (Verwahrlosung) gedeutet; die Ruine wird somit als Fetischobjekt denunziert. Die Begriffe suggerieren, dass den so überhöhten Objekten ein Wert zuerkannt wird, der ihnen nicht gebührt. Dass dies sogar mit einem Lustgewinn einherzugehen scheint, bleibt gänzlich unverständlich. ${ }^{38}$

So wie der Begriff Fetisch kann auch der Begriff Kult auf eine lange Tradition der gezielten Diskreditierung zurückgreifen. Wenn der Neugestaltung des Neuen Museums etwa ein »übertriebener Beleuchtungs- und Vitrinenkult« attestiert wird (Großmann 2009), so wird damit ein ganz ähnliches Kalkül verfolgt. Ana$\log$ zu Marx' Verwendung des Begriffs Fetisch ließe sich Alois Riegls vermutlich ebenfalls ironisch gebrochene Verwendung des Begriffs Kultus nennen. Der Bezeichnung moderner »Denkmalkultus« (Riegl 1988, Orig. 1903) kann ein ähnlicher Impetus zugeschrieben werden. Auch der »modere Kultus«, so ließe sich der Titel von Riegls für die Denkmalpflege kanonisch gewordenem Text interpretieren, bleibt an irrationale und in letzter Konsequenz nicht vollständig wissenschaftlich erfassbare Aspekte geknüpft. Dies erscheint umso bemerkenswerter, als sich Riegl um die Rationalisierung der Denkmalpflege bemühte. Mit der Verwendung des Begriffs Kultus erhält sich Riegl m.E. allerdings eine Restkategorie, die sich aus dem Wissen ergibt, dass trotz der Bemühungen um Rationalität und Wissenschaftlichkeit stets ein unauflösbarer Rest einer sich der objektiven Erfassung entziehenden Irrationalität erhalten bleibt.

In der Verwendung der Bezeichnungen Fetisch und Kult als diskursive Kampfbegriffe fehlt jedoch diese ironische Doppelbödigkeit. Bezeichnungen wie >fetischhafte Überhöhung der Runie`zur Diskreditierung der ergänzenden Wiederherstellung oder auch der Begriff »Attrappenkult« (von Buttlar et al. 2010) zur Ablehnung der Rekonstruktion des Berliner Stadtschlosses sind der Versuch, die diskursive Gegenposition der Unwissenheit, der Täuschung oder sogar der moralischen Unterlegenheit zu bezichtigen. Die wechselseitigen Bezichtigungen, auf vermeintlich illegitime Weise mit dem baulichen Erbe zu verfahren (sprich: falsch zu erben), vervollständigen sich schließlich durch einen dritten Begriff. Dabei handelt es sich um den Vorwurf, die Wiederherstellung des Museums durch Chipperfield sei ein Akt des »Barbarismus« (Jacob 2007:10). Neben den lauten Stimmen der Kritik aus den Reihen der GHB wurde der Vorwurf der »Barbarei« auch durch den CDUPolitiker Uwe Lehmann-Brauns (Rautenberg 2007) gegen Chipperfield erhoben. Dieser verwehrt sich dagegen, stellt lapidar fest: "Ich bin kein Barbar«, um schließlich die Bezichtigung der Unkultiviertheit zurückzugeben, indem er seine Kritiker der »Kleingeistigkeit« bezichtigt (ebd.). Wie unter Verweis auf Jurij Lotman gezeigt 
wurde (Kap. 4), wird im Moment der Grenzziehung stets eine innere Organisation und äußere Desorganisation erzeugt. Lotman führt aus:

»Die Antike konstruierte sich die >Barbaren< [...]. Dabei ist völlig unwichtig, dass diese >Barbaren<erstens über eine wesentlich ältere Kultur verfügen konnten und zweitens natürlich auch kein einheitliches Ganzes darstellten. [...] Nichtsdestoweniger konnte die antike Zivilisation sich als ein kulturelles Ganzes fühlen, indem sie einfach diese vermeintlich einheitliche `barbarische Welt konstruierte, deren grundlegendes Element das Fehlen einer mit der antiken Kultur gemeinsamen Sprache war. Die äußeren Strukturen, die jenseits der semiotischen Grenze liegen, werden zu Nicht-Strukturen erklärt.«(Lotman 1990:293f.).

Der gemeinsame Zweck der Verwendung von Begriffen wie >Kult<, >Fetisch $<$, >Barbarismus ${ }^{39}$ besteht in der wechselseitigen Denunziation, außerhalb der legitimen Kultur zu stehen. Damit wird nicht nur ein Recht der Deutungshoheit über Wert und Wesen der eigenen Kultur reklamiert, sondern gleichermaßen geklärt, wer ihr nicht zugehörig ist und potenziell eine Bedrohung für sie darstellt. Die Grenzkonstruktion schafft Desorganisation jenseits der Grenze des Eigenen. Ein frappierendes Beispiel für die fließende Variabilität des Grenzverlaufs und ein Beleg dafür, dass die Denunziation der Kulturlosigkeit ein diskursiver Kampfbegriff ist, wird erkennbar, wenn man sich vergegenwärtigt, dass das Konzept der ergänzenden Wiederherstellung andernorts als eine besonders subtile und hochkulturelle Art der musealen Gestaltung gedeutet wird. Was einerseits den Nimbus der barbarischen Unkultur erhält, wird andererseits auf den Sockel der Hochkultur gestellt. Mit der Grenzziehung, die den barbarischen Raum des Chaos und der Desorganisation vom zivilisierten Raum der Hochkultur trennt, werden beide Räume überhaupt erst hergestellt. Von wem die Grenze wo und mit welchen Deutungen gezogen wird, bleibt kontingent. Anhand der unterschiedlichen Deutungen der offenen Balkendecke, mit der Chipperfield die Treppenhalle überdacht hat, kann dies veranschaulicht werden. Die GHB kritisiert: »Die Decke verstärkt das Depressive, denn sie lastet schwer mit einem scheinbaren >Balkenwerk in düsterer Farbe. Bei einer offiziellen Führung fiel der Begriff `Ravennatische Balkendecke $\prec$. Was soll hier Ravenna?« (Großmann 2009).

Was hier mit dem Begriff »Ravennatische Balkendecke«, vor allem aber mit der rhetorischen Frage »Was soll hier Ravenna? « und der damit verbundenen Konstruktion einer Exosphäre befremdet wird, gilt dem Fachdiskurs stets als Beleg dafür, dass Chipperfield die "großartigste Verwirklichung dieser Bauidee« [gemeint ist Stülers offener Dachstuhl] übernahm und neu interpretierte (von Buttlar 2010:15;

39 Vor dem Hintergrund der Analyse des Barbarismus-Topos scheint auch der Vorwurf der Rohheit (rohe, unverputzte Ziegelmauern) in eine gewisse Nähe dazu zu treten. 
Berghorn 2016:149). Zudem wird mit der Behauptung, dass sich Schinkel in Ravenna hat inspirieren lassen und dies wiederum Stüler bewusst war, eine Kontinuitätslinie von Schinkel bis Chipperfield hergestellt. Wieder also wird die Parole ARTEM NON ODIT NISI IGNARUS von beiden Erbe-Formationen vereinnahmt und dient der wechselseitigen Konstitution einer zivilisierten Endosphäre und einer barbarischen Exosphäre. Die »Ravennatische Balkendecke« wird von der GHB als Fremdkörper gedeutet. Sie liegt außerhalb der eigenräumlichen Sphäre und wird deshalb zum Eindringling und Störenfried. In der Deutung der Denkmalpflege wird ein anderer Grenzverlauf gezogen. Endo- und Exosphäre werden dabei in anderer Weise relationiert. Denn die Interpretation einer großartigen Bauidee ermöglicht den Einschluss und die Integration des Fremden. In der integrativen Vereinnahmung verliert Ravenna seine Fremdartigkeit. Dies führt schließlich dazu, dass Ravenna durchaus an der Spree liegen kann.

\subsubsection{Purity endangered: \\ Die Wissensverhältnisse der soriginalgetreuen Wiederherstellung،}

Das Bild, mit welchem der heroische Kollektivierungsdiskurs der originalgetreuen Wiederherstellung den aktuellen Zustand des Neuen Museums und das Konzept der ergänzenden Wiederherstellung illustriert, ist in düsteren Farben gemalt. Die zur Gewissheit verfestigten Deutungen haben dabei anschlussfähige und somit stabile Wissensverhältnisse geschaffen (Kap. 3.3). Denn neben der Petition »Kein Neubau auf der Museumsinsel« (ca. 14.000 Unterschriften) und der Initiative »Rettet die Museumsinsel!«(ca. 20.000 Unterschriften) ist es vor allem der Einfluss, den diese artikulationsfähige diskursive Formation auf das Gesamtgespräch entfalten konnte, der als Indiz für den Erfolg der wissenspolitischen Interventionen in den Diskurs gewertet werden kann.

Die narrative Struktur erzählt sich dabei in etwa folgendermaßen: Abgestiegen vom magischen Ort zum Kohlenkeller, deutet nichts darauf hin, dass der anhaltenden Zerstörung des Gebäudes und des historischen Ensembles Einhalt geboten werde. Im Gegenteil werde durch das Festhalten an Notbehelfen und durch den zerstörerischen Umbau die natürliche Relation empfindlich gestört und der Agonie noch Vorschub geleistet. Die aktuelle räumlich-architektonische Verfassung des Gebäudes ist in einem barbarischen Akt zum Raum-Monster mutiert. Gesichtslos und wahnhaft verzerrt, sind die eigentlichen Identifikations- und Alleinstellungsmerkmale nicht mehr erkennbar. Die Ruine wird zum Fetischobjekt eines potenziell unzurechnungsfähigen und betrügerischen, entrückten Zirkels, bestehend aus Denkmalpflegern und Architekten, die, unfähig, dem Alten zu dienen, lediglich egoistisch und pubertär sich selbst verwirklichen wollen.

Vor dem Hintergrund dieses Schreckensszenarios erstrahlt die heroische Vergangenheit in umso hellerem Licht. Einzig der Palast, die Perle, der Tempel der Kul- 
tur, die unvergleichliche Kunstschöpfung, deren Besonderheit in dem ganzheitlichen Eindruck liegt, den Architektur und Ausstellung eingingen, zeugen von größter Harmonie. Dieses Prinzip der Einheit ist jedoch verletzt, wird geopfert, gesprengt. Ihm wird Gewalt angetan, durch Sachlichkeitswahn, Ruinenfetischismus und Albert-SpeerÄsthetik. Durch die Verunreinigung der Stileinheit wird dem Gebäude sein Recht vorenthalten und sein Status als Kulturerbe bedroht. Mit der Bedrohung durch moderne Kontrastarchitektur und der unzulässigen Vermischung fremder Stillelemente wird eine räumliche Exosphäre konstruiert, die die Reinheit der Form und damit die räumliche Identität des Gebäudes bedroht. Die Rettung der Museumsinsel muss aus dieser Perspektive als ganz und gar gescheitert konstatiert werden. Die Hoffnung auf die bessere Vergangenheit hat sich einstweilen nicht erfüllt.

Die englische Anthropologin Mary Douglas verweist - in ihrem zum Klassiker der Disziplin avancierten Buch »Purity and Danger « - darauf, dass die fundamentalen Klassifikationssysteme und die Gliederung der sozialen Welt in reine und unreine Dinge und Handlungen sich nicht hinreichend durch Aspekte der Hygiene oder Angst vor Krankheit erklären lassen (Douglas 2001, Orig. 1966). Was wesentlicher zu sein scheint, ist die Tatsache, dass Reinheitsvorschriften jedem Gegenstand und jeder Handlung einen Sinn zuschreiben und ihnen damit, im Kategoriensystem der sozialen Ordnung, ein fester Platz zugewiesen wird. Die fundamentalen Unterscheidungen verlaufen dabei entlang der Grenzen zwischen rein/unrein, innen/außen, eigen/fremd. Jedoch sind diese Codes immer nur relational und in einem spezifischen Bedeutungszusammenhang wirksam. Es gibt also nichts absolut Reines oder originär Eigenes, sondern immer nur das Unreine in einem spezifischen Kontext oder das Fremde in einer konkreten Konstellation. So ist Erde auf dem Acker unproblematisch. Doch dieselbe Erde auf dem Wohnzimmerteppich wird zum Problem und erhält schließlich eine kategoriale Umdeutung, indem sie $\mathrm{zu}$ `Schmutz« wird.

Dass die Ablehnung moderner Architektur auch im Falle der GHB nicht absolut, sondern relational ist, zeigt sich, wenn die Vorsitzende der GHB feststellt: Man habe nichts gegen moderne Architektur; diese könne durchaus ihren »Charme« haben, allerdings nur, wenn sie sich "am richtigen Ort« befindet (Ahme 2007:8.). Der Vorwurf gegen eine sich ungebührlich in den Vordergrund drängenden modernen Architektur stellt jedoch im Rahmen der Museumsinsel keine bloße Frage des Geschmacks dar (keine Frage des Tagesgeschmacks). Die Verunreinigung an diesem Ort bedroht nicht nur den Welterbestatus der gesamten Museumsinsel, sondern die "Geschichte und das Herkommen der Stadt « (ebd.) und damit das historische Erscheinungsbild, welches es wiederherzustellen und dadurch (paradoxerweise) zu bewahren gilt. Die Emotionalität der Debatte verweist auf die Klassifikationen und damit das normative Zentrum dieser Form der Selbstthematisierung. Damit wird das eigene Selbstverständnis infrage gestellt, also keinesfalls nur das, was gefällt, sondern das, was man ist (oder glaubt zu sein). 
Die Gebote geben die Codes der Verräumlichung hinsichtlich Form und Raumbezüge genauso wie im Hinblick auf Materialität und Dekor exakt vor. Dabei rekurriert diese diskursive Formation stets auf die Vorstellung von Reinheit und stilistischer Homogenität. Wie anhand der Begriffe aus dem semantischen Feld der Monstrosität wird die Stil-Mischung problematisiert. Das »Konzept mit seiner Mischung aus originalen Fassadenteilen, früher und später neuverputzten Flächen, geschlämmtem Rohziegelmauerwerk und optisch abgesetzten Einschusslöchern« macht aus dem Neuen Museum »ein archäologisches Objekt ohne Wert« (GHB 2008:23). Überall wo den Maßgaben der ewig gültigen und gebotenen Regeln nicht Folge geleistet wird, droht also eine kategoriale Umdeutung und damit eine Gefahr für das Eigene. Alois Hahn hat die wechselseitige Konstruktion von Fremdheit und Bedrohung auf die Formel gebracht: »Das Fremde ist bedrohlich und das Bedrohliche wird der Kategorie des Fremden zugeschlagen« (Hahn 1994:156).

Tatsächlich besteht der stärkste Eindruck bei der Betrachtung des Neuen Museums nicht in der Erinnerung an Krieg und Zerstörung, sondern in der Vielschichtigkeit von räumlichen Gestaltungen über die unterschiedlichen Jahrzehnte hinweg und damit von Vielzeitlichkeit. ${ }^{40}$ Das Neue Museum erschöpft sich nicht in der Zuschreibung an eine historische Epoche. Versuche, es als spätklassizistisches Gebäude, kriegszerstörte Ruine oder modernen Neubau zu beschreiben, sind gleichermaßen zulässig und plausibel, so wie sie gleichermaßen unzureichend sind, da sie immer nur Teilaspekte des Gebäudes betonen. Es sind gerade die Gleichzeitigkeit der Geschichten (im Plural) und die Unbestimmtheit dessen, was das Gebäude eigentlich ist, die es aus Perspektive der GHB fremd und seltsam unfertig erscheinen lassen. Schlimmer noch: Die unterschiedlichen Zeitschichten sind nicht nur gleichzeitig zu sehen, sondern stehen gleichberechtigt nebeneinander. Durch die synchrone Verräumlichung historischer Ereignisse wird die vergoldete Giebelinschrift mit ihrer humanistischen Dedikation neben den Einschusslöchern, Kriegszerstörungen und Nachkriegsschäden platziert. Ebenso werden alldem moderne Materialien im Inneren zur Seite gestellt werden. Nicht die unbequeme Erinnerung an einen unliebsamen Teil der Vergangenheit - namentlich den Zweiten Weltkrieg - , sondern die Uneindeutigkeit und die Vermischung vieler Vergangenheiten erscheinen in diesem Code der Verräumlichung problematisch. Das Gebäude entspricht aus Perspektive der GHB einer raumzeitlichen Verunreinigung. Mit der Darstellung von Vielräumlichkeit und Vielzeitlichkeit zieht die Gefahr herauf, dass das Eigene uneindeutig wird. Es ist kategorial nicht mehr zweifelsfrei vom Fremden unterscheidbar und wird dadurch von einer Vielzahl fremder Geschichten gestört. 
Analog zur Erde, die am falschen Ort zu `Schmutz`wird, führt die Verräumlichung der falschen Geschichten zu einer kategorialen Umdeutung. Das »Juwel preußischer Bildungslust« wird so zum »archäologischen Objekt ohne Wert«.

\subsection{Dokumentierte Vergangenheiten und harmonische Fragmente: Der Kollektivierungsdiskurs der sergänzenden Wiederherstellung،}

Um es vorwegzunehmen: Das Neue Museum und die Museumsinsel sind weiterhin Teil des Welterbes. Die UNESCO attestiert dem Ensemble nicht nur ein hohes Maß an Authentizität und Integrität, sondern betont zudem dessen »architectural continuity« sowie die »architectural coherence« (UNESCO 2012). Die Restaurierungsarbeiten am Neuen Museum werden sogar als ein "gelungenes Beispiel von Restauration und Rekonstruktion historischer Bauten « explizit gelobt (UNESCO 2014). Entgegen dem katastrophischen Szenario, welches die Kritikerinnen der ergänzenden Wiederherstellung ausgemalt haben, kann die Geschichte des Neuen Museums auch ganz anders erzählt werden. Eine Gegenüberstellung zweier Debattenbeiträge veranschaulicht dies. Suggeriert der Titel „Vom Juwel der Museumsinsel zum Kuckucksei der Denkmalpflege« (Ludwig 1998, Herv. JK) noch eine Geschichte der anhaltenden Entwertung, so wird mit dem Titel »Eine Ruine wird zum Juwel« (Wedel 2009, Herv. JK) der Plot der Erzählung umgedreht. Der von Carola Wedel anlässlich der Wiedereröffnung des Neuen Museums herausgegebene Sammelband beschreibt damit nicht mehr einen anhaltenden Niedergang, sondern einen Prozess der Veredelung. Diese Umkehrung der Erzählrichtung wird zusätzlich durch typische visuelle Aussagen gestützt, die nunmehr die Wiederherstellung als Überwindung der Ruinenzeit thematisieren.

So wie die Verlaufsrichtung des Plots der Erzählung umgedreht wird, so erhält auch das Deutungsmuster der Gewalt eine andere Form. Die Ambivalenz des ausgeführten Konzeptes der ergänzenden Wiederherstellung brachte der langjährige Landeskonservator Berlins im Titel eines häufig zitierten Aufsatzes mit dem doppelten Imperativ »Heile die Wunde - Zeige die Wunde« (Haspel 2007; 2009:82) zum Ausdruck. Die anthropomorphe Semantik (Wunde, Heilung) deutet auch hier auf eine Identifikation mit dem Bauwerk hin. Der Anspruch, »die Wunde« sowohl zu zeigen als auch zu `heilen<, zeugt allerdings davon, dass der Zerstörung des Gebäudes prinzipiell ein Recht auf Darstellung zugestanden wird. David Chipperfield fasst diesen doppelten Anspruch folgendermaßen zusammen: „Wir wollen auf der Grundlage des ursprünglichen Entwurfs einen neuen Raum schaffen, indem wir jene beeindruckenden, von den Bomben freigelegten Ziegelmauern so erhalten, wie sie sind« (Chipperfield 2004:106).

Die euphemistische Bezeichnung, dass die Ziegelmauern durch Bomben »freigelegt« worden seien, bildet den Gegenpol zu den von den Vertreterinnen der origi- 
nalgetreuen Wiederherstellung verwendeten Begriffen aus den semantischen Feldern der Gewalt und des Todes. ${ }^{41}$ Da durch dieses Ereignis - in der Lesart Chipperfields - nicht nur Bestehendes zerstört, sondern selbst eine neue geschichtliche Bedeutung erzeugt wurde, wird deutlich, dass die Zeit des Niedergangs hier keineswegs eine Zeit bedeutungsloser Nicht-Ereignisse (vgl. »Berliner Wetter «, Schulz 2005:142) ist. Der konnotative Unterschied zwischen >Zerstörung〈 und >Freilegen reklamiert ein ernsthaftes Bemühen um das Gebäude. War Chipperfield einerseits noch der Zerstörer des Museums, so wird ihm nun ein »sensibler Umgang« mit dem Treppenhaus und »Respekt für historische Schichtungen« attestiert (Frampton 2009:100).

$\mathrm{Zu}$ einer gänzlich anderen Deutung der architektonischen Intervention des britischen Architekten gelangt auch der Landeskonservator Jörg Haspel. Sprach die GHB noch von einem »heimlichen Kriegsdenkmal für erfolgreiche Bomberflotten« (Flugblatt der GHB, zitiert nach Wolters 2010:250), so sah Haspel in der Wahl eines englischen Architekturbüros und im Besuch der englischen Königin einen Beitrag zur »Verständigung und Versöhnung« (Haspel 2010:82), nicht ohne dabei zu betonen, dass dies dem "grenzüberschreitenden Charakter« einer »Welterbestätte« gemäß sei (ebd.). Die eigenräumliche Sphäre wird also nicht gegen, sondern mit Chipperfield konstruiert. ${ }^{42}$ Die unterschiedlichen Sujets, in welche der britische Architekt eingebunden wird (Lotman, Kap. 4.2.3), lassen diesen einerseits zum Zerstörer des Erbes werden; andererseits wird seine britische Herkunft als Zeichen der Versöhnung relevant gemacht. Dieses Beispiel deutet bereits darauf hin, dass die Relation zwischen Endosphäre und Exosphäre hier anders geknüpft wird. Im ausschließenden Code der Verräumlichung des heroischen Kollektivierungsdiskurses der originalgetreuen Wiederherstellung werden die Eingriffe des britischen Architekten zur exosphärischen Bedrohung des Erbes. Im integrativen Code der Verräumlichung der ergänzenden Wiederherstellung hingegen wird die Neugestaltung Teil der endosphärischen und versöhnenden Vollendung des Erbes. Mit der Darstellung der durch die Vertreter der ergänzenden Wiederherstellung geschaffenen Wissensverhältnisse wird schließlich ein raumzeitlich vollkommen anders gelagerter Kollektivierungsdiskurs erkennbar.

41 Eine ähnlich euphemistische Formulierung für die Beschädigung, die das Cebäude im Lauf der Jahrzehnte erfahren hat, verwendet ]örg Haspel, wenn er die Offenlegung konstruktionstechnischer Besonderheiten als »vom Zahn der Zeit [...] freipräpariert«bezeichnet (1994:144). Auch Neil MacGregor nutzt die Wiedereröffnung des Neuen Museums, um an die Ideale des Weltbürgertums und der Toleranz zu appellieren und diese dabei für das künftige Humboldt-Forum in der Rekonstruktion des Berliner Stadtschlosses nutzbar zu machen (Welt am Sonntag 18.10.2009). 
Abbildung 18: Bildfolge und narrative Struktur dieses Diskurses verhalten sich umgekehrt zu den Visualisierungen der Gesellschaft Historisches Berlin. Anstatt einer Geschichte des Niedergangs wird die Veredelung der Ruine visualisiert.
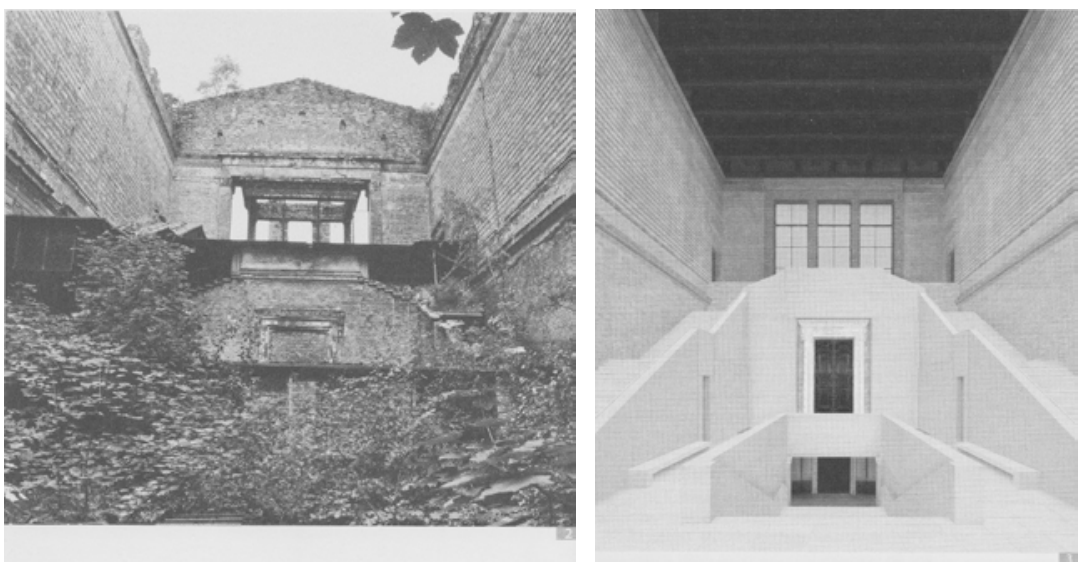

\subsubsection{Dokumentierte Zeitverläufe: Die Apotheose des Giovanni Battista Piranesi?}

Wurde aus dem Umfeld der GHB stets argumentiert, dass der Umstand, dass das Gebäude so lange als Ruine bestanden habe, nicht die Unterlassung der Rekonstruktion rechtfertige (Ludwig 1998:5), so bietet der Architekt der ergänzenden Wiederherstellung, David Chipperfield, eine andere Deutung der Geschichte des Hauses an. Anhand eines Aufsatzes, in dem das Konzept der Wiederherstellung theoretisiert wird, kann dies veranschaulicht werden.

»Die lange Zeit der Vernachlässigung hat es mit sich gebracht, dass nun ein Cebäude wiederhergestellt werden muss, das in erster Linie als Ruine im Gedächtnis haftet. Es ist ein Gebäude, das die Eigenschaften einer Ruine über die Jahre dermaßen verkörpert hat, dass es unmöglich ist, dies unbeachtet zu lassen. (Chipperfield 2004:83, Herv. JK).

Die Zeit der Vernachlässigung ist zum Wesensmerkmal geworden. Diese stellt einen legitimen Teil der Geschichte des Gebäudes dar, der »unmöglich unbeachtet« gelassen werden darf. Als »verkörperter « Teil seiner Geschichte ist sie ihm eigen geworden und nicht mehr fremd. Dass der Ruinenzeit sogar ein besonderer Wert zugesprochen wird, ist durch den Hinweis darauf, dass das Gebäude »in erster Linie als Ruine im Gedächtnis haftet«, gekennzeichnet. Was zuvor lediglich als Stö- 
rung des »Richtigen« diskreditiert wurde, erhält nun die Würde eines legitimen Teils des Baukörpers.

Malte die GHB noch ein düsteres Bild des neuen Neuen Museums, so wird die kriegszerstörte Ruine, welche 40 Jahre der Witterung ausgesetzt war, durch die Vertreter der ergänzenden Wiederherstellung gänzlich anders beschrieben. Eine besondere Rolle in den Beschreibungen der Ruine spielen dabei die stimmungsvollen Ruinenstiche des italienischen Künstlers Piranesi (Chipperfield 2008:8). David Chipperfield bemüht diesen Vergleich etwa in einem Gespräch mit Wolfgang Wolters und preist dabei die »rohe< Beschaffenheit des Baus « und dessen »Ausdruckskraft « an, welche durch eine traditionelle Restaurierung zerstört worden wären (Chipperfield/Wolters 2009:229). Demnach galt es, die »räumliche Situation, die an Piranesis Werke erinnerte«, und genau »diese spezifische Qualität« zu würdigen (ebd., kursiv im Original). Auch Julian Harrap deutet den ruinösen Modernen Saal als "Piranesi'sche Ruine« (Harrap 2009a:63). Die Museumsruine sei zudem »eine inspirierende Ansicht, erfüllt von Geschichte, Kultur und der Tragödie der Zerstörung« (Harrap 2009b:121). So wollte auch der Chefrestaurator die »außerordentlichen Schäden«, die der »natürliche Verfall« mit sich brachte, nicht »ausmerzen« (a.a.O. 131). Die Zerstörung des Gebäudes stellt eine »spezifische Qualität« dar, die ihrerseits keinesfalls zerstört werden darf. Die Begriffe »außerordentlich « und »ausmerzen« entstammen dabei erneut den semantischen Feldern der Besonderung und der Gewalt. Mit dem Beenden des »Verfallsprozesses« werde demnach auch »das Leben des Bauwerks als Ruine beendet« (a.a.O. 121). Der Ruine wird also eine besondere Qualität zuerkannt; sie ist Teil der Lebensgeschichte des Bauwerks und keinesfalls bloße Nachkriegsverwahrlosung.

Dass das zerstörte Museum »erfüllt von Tragödie« sei, erinnert an die »Stimmungswirkung«, die Alois Riegl zufolge im Modus des Alterswertes dem Aspekt des Verfalls zugesprochen wird (1988:60). ${ }^{43}$ Dies unterscheide die Ruine vom bloßen Steinhaufen (ebd.). Auch für Georg Simmel besteht der Reiz der architektonischen Ruine gerade darin, dass in ihr die Spannung zwischen Zweck und Zufall, Natur und Geist, Vergangenheit und Gegenwart zu einer Einheit des äußeren Bildes und der inneren Wirkung führt (Simmel 1911:145). Dabei verwendet auch Simmel die Unterscheidung zwischen Ruine und Steinhaufen (a.a.O. 140). Von diesem ist zu sprechen, wenn der Kampf zwischen Geistesentäußerung und Naturgewalt zugunsten der letzten entschieden sei. Wo allerdings die Grenze zwischen Ruine und Steinhaufen in Bezug auf das kriegszerstörte Neue Museum gezogen wird und ob

43 Riegl ist sich der Modernität dieser Auffassung durchaus bewusst. Denn erst die beschleunigte Umwälzung architektonischer Stile bringt die Vergangenheit als besonderes Cut hervor (Speitkamp 1996). So betont Riegl, dass der Claube an einen »objektive[n] Kunstkanon« im 19. Jahrhundert durch die Anschauung herausgefordert wird, dass in jeder Kunstweise ein »Stück ewigen Kanons«stecke (1988:54). 
man sich diesseits oder jenseits dieser Grenze bewege, wurde durch die diskursiven Formationen stets unterschiedlich beantwortet. Es ist also wichtig, darauf hinzuweisen, dass die Distinktion zwischen Ruine und Steinhaufen nicht (wie dies tendenziell von Riegl und Simmel getan wurde) als absolute Kategorien eines (wie auch immer) natürlich-diachronen Verfallsstatus verstanden werden darf. Vielmehr erhalten sie als relationale Kategorien in Abhängigkeit ihrer sozial-synchronen Deutung einen je verschiedenen Sinn. Sprachen die Vertreter der ergänzenden Wiederherstellung von einer stimmungsvollen Ruine, die an Stiche Piranesis erinnere (Chipperfield 2004:105), kann die GHB im Neuen Museum nurmehr einen »kulturellen Scherbenhaufen grotesken Ausmaßes« erkennen (Wendland 2009). Vom Standpunkt wissenssoziologischer Hermeneutik (Kap. 3.4) betrachtet, zeigt sich also erneut, dass ein und derselbe Verfallszustand des Neuen Museums gleichzeitig als >stimmungsvolle Ruine $<$ und als >grotesker Scherbenhaufen $<$ wahrgenommen werden kann. ${ }^{44}$

Mit dem Piranesi-Vergleich wird zunächst ein Muster der Identifikation erkennbar, welches die Zeitschicht der Ruine tendenziell verklärend herausstellt. Analog zur Verklärung der Architekten und Maler des 19. Jahrhunderts und der Konstruktion einer heroischen Vergangenheit, wie sie von der GHB betrieben wurde (Kap. 5.2.1), ließe sich also zunächst fragen, ob lediglich die Trägerschicht der identitätsstiftenden Vergangenheit ausgetauscht wurde. Wird das durch die Unbill der Jahrzehnte gezeichnete Gebäude zum zeitlich verbindlichen Referenzpunkt des Kollektivierungsdiskurses der ergänzenden Wiederherstellung oder gar Piranesi als neuer Heros überhöht? Es wird jedoch schnell ersichtlich, dass die Konstruktion historischer Bedeutsamkeit anders als der heroische Kollektivierungsdiskurs gelagert ist. Zwar bleibt der Piranesi-Vergleich in der Struktur der Zeitkonstitution der GHB vergleichbar, dennoch bleibt die positive Einschätzung nicht exklusiv auf die Ruine beschränkt. Der zeitkonstitutionelle Unterschied besteht nicht bloß in der Akzentuierung einer anderen, als identitätsstiftend bewerteten Epoche in der Gebäudegeschichte. Auch wenn behauptet wird, dass das Gebäude »in erster Linie als Ruine im Gedächtnis« hafte (Chipperfield 2004:83), so wird keineswegs nur die Trägerschicht der Identitätsverortung ausgetauscht. An

44 Aleida Assmann hat darauf aufmerksam gemacht, dass die Ruinen-Romantik, die in England Ende des 18. Jahrhunderts entstand, zwischen gotischen und griechischen Ruinen unterschied. Galten gotische Ruinen als Zeichen des Triumphs der Zeit über das Menschenwerk, so galten griechische Ruinen als Zeichen des Triumphs der Barbarei über den Ceschmack (2010:315, Orig. 1999). Im Sinne dieser kulturellen Lesart sähe die GHB das Neue Museum wohl eher als griechische Ruine, da die Gegenwart eindeutig als Zeit der Barbarei gekennzeichnet ist. Für die Denkmalpflege hingegen entspräche das Neue Museum, in dieser Terminologie, wohl eher einer gotischen Ruine, deren Anblick zwar melancholisch stimmt, aber dennoch nicht erschüttert. 
die Stelle der heroischen Vergangenheit treten nicht einfach das Pathos der Ruine und die Anmut piranesischer Stiche.

Dass die Zwischenzeit keineswegs nur eine Zeit bloßer Nicht-Ereignisse war, wird auch deutlich, wenn Chipperfield davon spricht, dass das Gebäude nicht nur Bomben- und Feuerschäden, sondern auch über sechzig Jahre den »Naturgewalten « ausgesetzt war, welche eine »Ruine von großer Wirkung « schufen (Chipperfield 2004:83). Die leichte Akzentverschiebung von »150 Jahre Berliner-Wetter « $\mathrm{zu}$ der Rede von den "Naturgewalten« deutet auf eine unterschiedliche Bewertung der Zwischenzeit hin. Diese Aufwertung der Zeit zwischen Kriegszerstörung und Wiederherstellung lässt sich auch im Denkmalpflegerischen Gutachten nachweisen. Dort ist sogar von Witterungsangriff die Rede, der in einem Atemzug mit den Kriegszerstörungen genannt wird. Denn so ist »der heutige Zustand des Neuen Museums Ergebnis der Zerstörung im Zweiten Weltkrieg, der anschließenden Bemühungen um eine Notsicherung, des stetigen Witterungsangriffs« (Badstübner et al. 1994:20). Neben der sprachlichen Aufwertung im Vergleich zu »Berliner Wetter « weckt dieser Begriff zusätzlich Assoziationen zu den Luftangriffen der Royal Air Force und damit zu einem unbestritten bedeutsamen Abschnitt in der Geschichte des Gebäudes. Die Betonung der Zwischenzeit deutet also eine Inwertsetzung verschiedener Zeitschichten an. In diesem Modus der Konstitution von Geschichtlichkeit wird nicht mehr ein einzelner Zustand, sondern der Lauf der Zeit selbst zum Referenzpunkt.

»Doch weil diese Umstände nicht allein der deutschen, sondern der allgemeinen Zeitgeschichte angehören (anders als ein zufälliges Brandunglück oder ähnliches), weil sich diese Umstände zudem von einem Ereignis zu einer geschichtlichen Tatsache zu wandeln beginnen und weil der physische Beleg dieser geschichtlichen Tatsache selten so anschaulich ist, wie im Neuen Museum, sollte man die Narben und Zerstörungen, die noch heute das Gebäude prägen, nicht ausradieren. Dieser Zustand (befördert durch die schwierigen politischen Zustände im Nachkriegsdeutschland, durch Teilung und Wiedervereinigung) ist Teil unseres Erbes. Es waren die Zeitverläufe, die aus dem Neuen Museum ein bauliches Dokument deutscher Ceschichte gemacht haben.«(Chipperfield 2004:94, Herv. JK).

Erneut wird auch hier mit dem Anthropomorphismus »Narben« eine Leib-/Körpersemantik bemüht, die auf eine Identifikation mit dem Gebäude hinweist. Dies schließt nun aber auch die Ruinenzeit mit ein, die keine Zeit der Agonie mehr ist. Zeitkonstitutionell interessant ist vor allem aber der letzte Satz. Der Verlauf der Zeit (»Zeitverläufe«) führt dazu, dass sich ein »Ereignis« zu einer »geschichtlichen Tatsache« wandelt. Auch der Verfall wird zu einem »Teil unseres Erbes«. Sprach die GHB lediglich von "Nachkriegsverwahrlosung « und anhaltender Zerstörung, so werden die verschiedenen "Zustände im Nachkriegsdeutschland « zu historischen Ereignissen, die durch das Gebäude dokumentiert werden. Das Gebäude 
wird zum Dokument einer nunmehr nicht nur deutschen, sondern allgemeinen Zeitgeschichte.

Die Empörung darüber, "Narben« oder die »Nacktheit« des Gebäudes bloßzustellen, verkehrt sich in ihr Gegenteil. Nur die Spuren der Zeit verleihen dem Gebäude "Würde« und Integrität (Chipperfield 2004). Die unterschiedlichen Epochen stehen (gleichwertig) nebeneinander, »ohne dass ein bestimmter Zeitpunkt wichtiger wäre« (a.a.O. 87, 89). Das Gebäude ist dieser Lesart zufolge nicht nur ein Mahnmal der Kriegszerstörung und der Nachkriegsverwahrlosung, sondern vielmehr ein Abbild verschiedener Geschichten. Dabei wird vor allem der Zeugnischarakter des Gebäudes (»bauliches Dokument«) hervorgehoben. Das Gebäude selbst wird zum Zeugen seiner eigenen Geschichte und, wie die Kunstwerke, die es beherbergt, zum Dokument. ${ }^{45}$ Die Apotheose Piranesis und damit die Verklärung der Ruine bleiben also einstweilen ohne Folgen. Da alle chronologisch früheren Zeitpunkte als legitimer Teil der Geschichte eingebunden werden, kann Vergangenheit in diesem Modus lediglich dokumentiert, jedoch nicht wiederholt werden.

\subsection{2. "Die tote Großmutter«: Auferstehung ausgeschlossen}

Nicht ein Zeitpunkt oder Zustand, sondern der Lauf der Zeit und damit ein Prozess stehen im Zentrum dieser Konstruktion von Zeitlichkeit. Dies führt dazu, dass die einzelnen Zeitabschnitte in der Geschichte des Gebäudes klar konturiert sind. Die Gegenwart ist sowohl von der Entstehungszeit des Hauses als auch von der Zeit seiner Zerstörung eindeutig getrennt. Da Zeit hier im ständigen Fluss ist und nicht ewig im Kreis schwingt (Arendt, Kap. 4), seien heutige Generationen, laut Chipperfield, mittlerweile von den »Umständen der ehemaligen Zerstörung weit entfernt (2004:94). Identifizierte sich die GHB noch stark mit dem Gebäude des 19. Jahrhunderts, so wird durch Chipperfield die Alterität der Vergangenheit hervorgehoben (»weit entfernt«). Mit der Annahme einer unüberbrückbaren Trennung zwischen Gegenwart und Vergangenheit wird auch dem von der GHB geforderten Aufbaukonzept eine klare Absage erteilt.

Wie bereits anhand des Umgangs mit den Kaulbachfresken im Treppenhaus gesehen, schließt die »unwiederholbare[n] künstlerisch-handwerkliche[n] Qualität" (Badstübner et al. 1994:26) die Rekonstruktion aus. Zudem erfordert die anachronistische Botschaft des Zyklus eine historische Perspektivierung (Wagner 1994). Genau dadurch wird die unüberbrückbare Fremdheit (Alterität) der Vergangenheit betont. Besonders deutlich betonen dies die Autoren des Denkmalpflegerischen

45 Hier deutet sich bereits die Kontextualisierung zwischen Gebäude und Exponaten an, auf die später noch stärker eingegangen werden muss, da auch dadurch Einheit und Harmonie behauptet werden. 
Gutachtens, wenn sie empfehlen, in der Treppenhalle das Schicksal der Zerstörung sichtbar zu lassen.

»Die Halle sollte eigenständig bleiben und das Schicksal der Zerstörung, des Verlustes, der Notsicherung und der Wiederbelebung spiegeln. [...] Erst so würde die Vergangenheit faßbar, die hier im untergegangenen Herzstück des Baudenkmals immer spürbar bleiben wird: die Unmöglichkeit, ein zerstörtes bauliches Kunstwerk zu heilen.«(Badstübner et al. 1994:26, Herv. JK).

Die »Wiederbelebung« erhält hier also lediglich als gescheiterter Versuch eine historische Relevanz. Neben der Zerstörung und dem Verlust sind auch die Arbeiten der Notsicherung Teil der Geschichte des Gebäudes und sollen deshalb sichtbar gelassen und dokumentiert werden. War die Vergangenheit für die GHB Quelle ewig gültiger Gebote und eines entzeitlichten Ideals, das auch in der Gegenwart relevant bleibt, so wird nun eine scharfe Grenzziehung zwischen Gegenwart und Vergangenheit vollzogen. Der Anthropomorphismus »Herzstück« kennzeichnet zwar auch hier den Wert, der dem ehemaligen Museum zugesprochen wird, dies schließt jedoch nicht die Inwertsetzung andere Zeitschichten aus. Einer der Mitverfasser des Denkmalpflegerischen Gutachtens bringt, was im Gutachten als die »Unmöglichkeit, ein zerstörtes bauliches Kunstwerk zu heilen«, bezeichnet wurde, in einem Interview folgendermaßen auf den Punkt: »das ist wie die tote Großmutter, was solls, die ist weg" (NM-2, 108-109).

Über den Fluss der Zeit, der Vergangenheit und Gegenwart trennt, führt keine Brücke mehr. ${ }^{46}$ An die Stelle der Wiederholung tritt das Gebot der Dokumentation. Der Weg der »Wiederbelebung« und der »Wiedererweckung« des Museums in seiner bauzeitlichen Form ist nicht mehr gangbar. Die Kaulbachfresken sind »unwiederholbar« verloren, das »Herzstück des Baudenkmals« für immer untergegangen. Die Großmutter ist tot. Eine Wiedererweckung ist nicht vorgesehen, eine Auferstehung damit gänzlich ausgeschlossen.

\subsection{3. "... Rekonstruktion zerstört«: Die Einmaligkeit der Vergangenheit}

Die unterschiedlichen Vorstellungen, was als anmutige Ruine oder als wertloser Steinhaufen wahrgenommen wird und wie die Geschichte des Hauses beerbt werden soll, werden gleichermaßen durch ein umfangreiches Authentifizierungsvokabular gestützt. So wie die GHB für sich in Anspruch genommen hat, das >richtige Museum` wiederherzustellen und sich dabei Begriffen aus dem semantischen Feld des Betrugs, der bewussten Täuschung (»komplottartige Strukturen«) oder der

46 Auch der Architekt Rik Nys spricht anlässlich der Wiedereröffnung des Neuen Museums, unter Verweis auf John Ruskin, davon, dass die Wiederherstellung ehemaliger Bauwerke so unmöglich sei, »wie die Toten zu erwecken« (Ruskin 1900, zitiert nach Nys 2009:151). 
Scharade (»des Kaisers neue Kleider«) bedient hat, untermauern auch die Vertreter der ergänzenden Wiederherstellung ihre Ansprüche durch ein Authentifizierungsvokabular. Auch die Bezichtigung der diskursiven Gegenposition der Täuschung und Zerstörung ist damit wechselseitig.

Der kategorische Ausschluss der Rekonstruktion wurde von Georg Mörsch in der Zuspitzung »Rekonstruktion zerstört « (Mörsch 2004) formuliert. Dieses Credo scheinen auch die Architekten und Restauratoren des neuen Neuen Museums verinnerlicht zu haben. So wiesen sowohl Harrap als auch Chipperfield darauf hin, dass die Ruine nicht zerstört werden dürfe (»ausmerzen«, »das Leben der Ruine beenden«). Auch Wolfgang Wolters nimmt explizit auf die Extremposition Mörschs Bezug, indem er sie einem Aufsatz voranstellt, der die Wiederherstellung des Neuen Museums Revue passieren lässt (Wolters 2010). Die Ablehnung der Rekonstruktion geht mit der Forderung einher, die klare Trennung zwischen Vergangenem und Gegenwart auch ästhetisch kenntlich zu machen. Gegen eine etwaige stilistische Geschlossenheit zu restaurierender Oberflächen wird ein Fälschungsvorwurf vorgebracht, welcher mit Begriffen »Disneyworld « (Nys 2009:152) oder »Attrappenkult« (von Buttlar et al. 2010) und damit mit Metaphern aus der Welt des Theaters unterlegt wird. ${ }^{47}$ Die Vorspiegelung falscher Tatsachen, die damit zum Ausdruck gebracht werden soll, ist oft mit dem Anspruch und dem Ideal der Wahrhaftigkeit und der Aufrichtigkeit gekoppelt; ${ }^{48}$ so etwa, wenn Julian Harrap davon spricht, dass er den »Betrachter niemals täuschen« wolle (Harrap 2009b:124). Auch die Vertreter der ergänzenden Wiederherstellung bedienen sich des Deutungsmusters des Betrugs und der Täuschung. Mit dem Vorwurf der Fälschung und der Unaufrichtigkeit wird deutlich, dass auch dieser Modus der Geschichtskonstitution normativen Gehalt hat.

Authentizität und Integrität stellen auch hier Schlüsselbegriffe dar (Chipperfield/Wolters 2009). Visuelle Integrität und historische Authentizität (Haspel 2010) werden allerdings durch eine Inversion dessen, was die GHB unter Bezugnahme auf dieselben Dokumente (UNESCO-Richtlinien, Charta von Venedig) gefordert hat, konstruiert. So sollen »die Verluste und Diskontinuität in der Chronik des Bauwerks [...] ebenfalls erfahrbar bleiben.« Ferner solle »das historische Fassadendekor und die Oberflächentextur auf dem Altbau erhalten und gesichert [werden],

47 Chipperfield spricht von der Rekonstruktion als einer »Disney-Kopie«. Wären alte und neue Gebäudeteile nicht unterscheidbar, so würde Stülers Werk unter einem »pseudoalten Mantel«verschwinden (Rautenberg 2007).

48 Astrid Swenson hat in einer Darstellung der historischen Semantik der Begriffe »Heritage«, »Patrimoine« und »Kulturerbe« darauf aufmerksam gemacht, dass das Retuschieren von Altersspuren bereits seit jeher mit der Bezichtigung der Täuschung, der Lüge oder gar der moralischen Unterlegenheit einherging. Begriffe wie >Vandalismus ‘ oder >Rückständigkeit ( vgl. Barbarismus) nehmen in der Begriffsgeschichte die Rolle von notwendigen Antonymen ein (2007). 
soweit sie überliefert, also historisch authentisch sind« (a.a.O. 162). Das historisch Authentische schließt also gerade auch die Schäden und die Spuren der Zeit mit ein und rekurriert nicht mehr auf einen klar bestimmbaren, früheren Zustand, der anhand »authentischer Urkunden« (GHB 2008:19) wiederholt werden kann. Ungeachtet dessen, dass die Charta von Venedig explizit betont, dass Stileinheit kein Erhaltungsziel darstelle (\$11), bezog sich auch die GHB auf dieses Dokument, um ihren Standpunkt zu untermauern. Dabei wurde vor allem der \$12 herangezogen. Betonte die GHB dabei, dass sich neue Teile der ergänzenden Wiederherstellung »harmonisch einfügen« $(1964$, \$12) müssen, so heben die Vertreter der ergänzenden Wiederherstellung stets den letzten Passus dieses Artikels hervor - welcher im Bericht der GHB (2008) zu den Verstößen gegen das Welterbe schlicht weggelassen wurde. Dieser besagt, dass das »Geschichtsdokument nicht verfälscht« werden dürfe. Die Dokumentation der Geschichte (aller Geschichten) erhält eine dem sharmonischen Einfügen ebenbürtige Rolle. Das Dokument dient nicht mehr nur der erneuten Ausführung des Kunstwerkes. Die authentischen Urkunden sind nicht mehr Mittel zum Zweck, sondern das Museum als Dokument seiner Geschichte wird zum Selbstzweck und muss geschützt werden.

Entgegen dem Gebot, das Alte zu respektieren, indem man es wiederholt, gelte es nun, das Alte $\mathrm{zu}$ »respektieren und nicht [zu] imitieren und dadurch in seiner Einmaligkeit [zu] entwerten « (Haspel 1994:140f.). Werden moderne Eingriffe von der GHB lediglich als Ausdruck von Geltungssucht und Respektlosigkeit der Architekten gegenüber dem Alten bezeichnet, so werden sie nun zum Ausdruck des Respekts. Denn die Einmaligkeit des historischen Bauwerks werde gerade durch dessen Imitation entwertet. Neben der Bezichtigung des Betrugs wird die Rekonstruktion von Baudenkmalen oft in den Bereich einer zwar nachvollziehbaren, aber einer dennoch intellektuell unterlegenen Sentimentalität gerückt. Auch hierfür lässt sich ein Beispiel in dem bereits zitierten Aufsatz Chipperfields finden:

»Und so glauben wir, dass der mit einer szenographischen Wiederherstellung einhergehende Verlust von noch bestehendem Material des Originals möglicherweise zwar seinen emotionalen Reiz haben könnte, intellektuell halten wir diese Wiederherstellung allerdings für inakzeptabel.« (Chipperfield 2004:94, 96).

Mit der Gegenüberstellung zwischen einer intellektuell begründeten Vorgehensweise und einer lediglich emotional reizvollen Rekonstruktion wird diese als bloße Sentimentalität abgetan. Chipperfield erweist sich dabei als generell misstrauisch gegenüber Bildern einer »besseren Vergangenheit « (2004:89). Die Tatsache, dass es keine »interessenlose Begegnung mit der Historie« gibt, habe dazu geführt, die baulichen, das heißt die authentischen und damit unschuldigen Überreste wertzuschätzen« (ebd.). Im selben Aufsatz spricht Chipperfield von einem »emotionalen Drang«, dem man nicht nachkommen dürfe, da dieser mit der »Philosophie unseres Projekts« (a.a.O. 106) unvereinbar sei. Vor dem Hintergrund einer rationalen 
Dokumentation von Geschichte erscheint die Rekonstruktion als intellektuell unlauter. Durch die Kontrastierung von »Philosophie« und »emotionale[m] Drang« erhält Letzterer lediglich den Rang einer bloßen Gefühlsduselei.

Das Authentische wird (vor allem) in der Materialität verortet. Das akribische Sichern von noch so kleinsten Spuren vergangener Einwirkungen und Schadensformen erfordert eine nüchterne, emotionslose Dokumentation der »unschuldigen Überreste.«Von der hohen Warte der Theorie betrachtet zeigen sich darin der Modus >Histoire und seine Nähe zur textuellen Form der Kohärenzsicherung. Der dokumentarische Charakter und die geradezu forensische Spurensicherung entspricht der von Jan Assmann beschriebenen Rechenschaftszeit (Kap. 4). Hier wird ein Bericht über den historischen Verlauf angefertigt. Dass aber auch dieser Rechenschaftsbericht keine absichtslose Begegnung mit der Vergangenheit ist und ebenso Aspekte der >Memoire < in sich trägt, betont Chipperfield selbst und beweist damit ein hohes Maß an Reflexivität über die Tragweite und Bedeutung des eigenen Eingriffs. ${ }^{49}$ Denn nachdem Chipperfield die Vor- und Nachteile der Positionen Rekonstruktion und kontrastierende "Alt-Neu-Strategie« referiert, denunziert er beide Positionen als »Ideologie der Standortlosigkeit « (Chipperfield 2004:90), da »beide Positionen versuchen die Notwendigkeit der historischen Interpretation $\mathrm{zu}$ vermeiden « (ebd.). Dass Geschichte in diesem Modus der Zeitkonstitution stets aufs Neue perspektiviert werden muss, erfordert die Arbeit der gegenwartsbezogenen Interpretation. Eine alleinige Dokumentation reicht nicht aus, wäre doch auch diese nicht standortlos. Da aber die Zeit verläuft, kann auch die Gegenwart durch selbstbewusste Interpretation in die Geschichte eingreifen und selbst historisch werden. Dies erfordert eine offene Struktur der Zeit.

\subsubsection{Eine offene Struktur der Zeit}

Im Obergeschoss des Pergamonmuseums befindet sich ein Teil des Palastes von Mschatta. Die reichen Ornamente und Reliefs im Kalkstein der Fassade konnten durch die Künstler teilweise nicht vollendet werden. Nicht nur die Spuren der Zeit, die seit der Errichtung des Palastes im 8. Jahrhundert vergangen ist, lassen sich in

49 Insbesondere die Einrichtung eines Fragmentariums, im Obergeschoss des Südflügels, zeugt von der Reflexivität gegenüber der eigenen Konstruktionsleistung, die sich somit von der Ideologie der Standortlosigkeit abgrenzt. Durch die Ausstellung geborgener, aber nicht wiederverwendeter Teile des ehemaligen Dekors wird die Zerstörungsgeschichte thematisiert und das eigene Vorgehen der Wiederherstellungsarbeiten transparent gemacht. Gerade die Architekten sind in ihren Beschreibungen der Wiederherstellung zurückhaltender als der zum Teil begeisterte Fachdiskurs der Kulturwissenschaften, der teilweise schwärmerische Sprachduktus der Denkmalpflege oder gar die pathetische Sprache der Stiftung Preußischer Kulturbesitz. 
den unterschiedlich stark bearbeiteten Steinen erkennen, sondern ebenso die verschiedenen Arbeitsschritte, die zur Ausschmückung der Fassade erforderlich waren. Gerade die Unfertigkeit gewährt so einen Einblick in den Bearbeitungsprozess und verleiht dem Kunstwerk die vierte Dimension der Zeit.

Die Kritiker des Konzepts der ergänzenden Wiederherstellung sprachen stets davon, dass die Museumsinsel ein »abgeschlossenes Ensemble« (Kap. 5.2.6) sei (und meinten dies eher normativ als chronologisch). Die Entwürfe Chipperfields hingegen seien durch eine »seltsame Unfertigkeit« geprägt. Der Vorwurf der Unfertigkeit, den die GHB immer wieder gegen das neue Neue Museum vorgebracht hat, ist keinesfalls aus der Luft gegriffen. Der bewussten Darstellung und (teilweise aufwendigen) Inszenierung der zwischenzeitlichen Spuren wird jedoch ein Wert beigemessen. Dieser besteht - wie in meiner Interpretation der Mschatta-Fassade - darin, dass das unfertige Relikt und die unversiegelte Oberfläche mehr über die Vergangenheit zu erzählen wissen, als es geschlossene Stileinheit vermag. Das Argument, dass das unvollendete Gebäude durch das Offenhalten seiner zerstörten Oberflächen ebenfalls die Tiefendimension der Zeit erhält, ist an eine offene Struktur der Zeitverläufe (nicht mehr an die eines Zeitpunktes) gebunden. Erst indem die Phasen seiner Erbauung, seiner Zerstörung sowie des sukzessiven Verfalls zugänglich bleiben, erhält es den historischen Informationsreichtum eines »Dokumentes" oder eines »Sachzeugnisses« (Badstübner et al. 1994:19).

Anhand der aufwendigen Wiederherstellung der Kolonnaden, die das Neue Museum umgeben, kann dies veranschaulicht werden. Bei der Wiedererrichtung des kriegsbeschädigten Säulengangs wurden die Einschusslöcher der Schrapnelle sichtbar gelassen. Ebenso wurden Spolien wiedereingesetzt sowie schließlich Fehlstellen durch neue Säulen rekonstruiert. Auch die Ornamente in den kassettierten Decken der Kolonnaden wurden partiell restauriert, teilweise lediglich in beschädigter Form gesichert, so wie an manchen Stellen das Ziegelwerk sichtbar gelassen wurde. Die teilweise unvollständig restaurierten Bereiche erlauben es auch hier, die einzelnen Arbeitsschritte der Steinmetze nachzuvollziehen. Dadurch, dass die Oberflächen nicht einheitlich geschlossen werden, kann somit der Konstruktionsprozess veranschaulicht werden. Die Offenheit und Verschiedenheit zeugen so von den doppelten Zeitverläufen der Herstellungs- und Zerstörungsgeschichte der Kolonnaden.

Der Dokumentencharakter, der den Schadensformen zugesprochen wird, erfordert gerade eine Offenheit und Sichtbarkeit der Spuren der Zeit (Chipperfield/Wolters 2009:234). Das Bewahren unterschiedlicher Zeiteindrücke führt dazu, dass eine Schließung der Oberfläche ausgeschlossen wird, würde diese doch die Zerstörung, die als Teil der Gebäudeidentität behauptet wird, ihrerseits zerstören. Diese Offenheit im architektonisch-ästhetischen Sinn ist eng mit einer Offenheit in zeitlicher Hinsicht verbunden. Da Zeit unaufhörlich vergeht, kann auch die Gegenwart historische Bedeutsamkeit erlangen. Dieser Aspekt 
kann anhand der Äußerungen eines langjährig am Prozess der Wiederherstellung beteiligten Denkmalpflegers zum Umgang mit dem Treppenhaus und dem Kaulbachzyklus veranschaulicht werden.

»Wenn künftige Generationen der Meinung sind, sie müssten das Neue Museum wiederaufbauen, haben wir nichts an dem Haus zerstört. Ganz im Gegenteil, die können das; was sie machen wollten, könnte man genauso wiederherstellen. Wer weiß, wie man das in ein paar Jahren sieht.«(NM-1, 822-830).

Abbildung 19: Die offene Struktur der Zeit wurde auch bei der Wiedererrichtung der Kolonnaden aufwendig inszeniert. Schadensformen und Arbeitsschritte bleiben erkennbar. Beim Aufstellen der Säulen wurde darauf geachtet, die Anordnung der Einschusslöcher anhand möglicher Schusssalven korrekt wiederzugeben; Abbildung 20: Offenes Mauerwerk in der Treppenhalle des Neuen Museums. Die erneute Schließung des Mauerwerks und die Wiederherstellung der Kaulbachfresken durch folgende Generationen werden zumindest theoretisch in Aussicht gestellt.
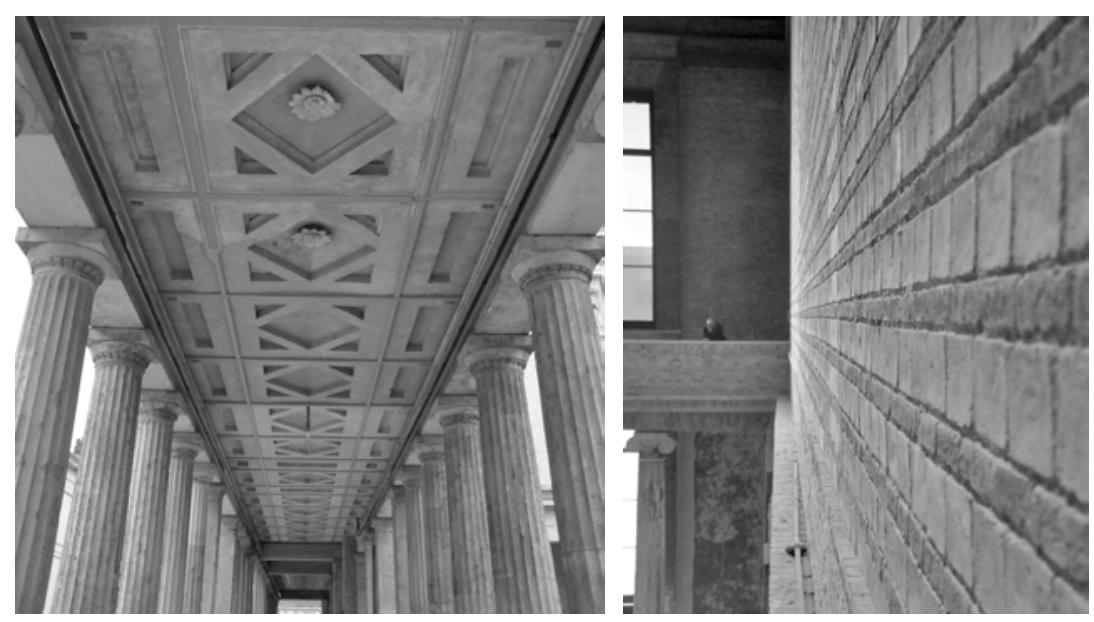

Der Hinweis, dass die originalgetreue Rekonstruktion des erbauungszeitlichen $\mathrm{Zu}$ standes auch für nachfolgende Generationen möglich bleibt, zeugt von einer im Hinblick auf die Zukunft offenen Struktur der Zeit. Bereits im Moment der Umsetzung eines baulichen Eingriffs wird dessen Revision zumindest potenziell in Erwägung gezogen. Die offene Frage, »wer weiß, wie man das in ein paar Jahren sieht «, deutet zudem auf eine unterschiedliche Perspektivierung des Erbes in Gegenwart und Zukunft und unterscheidet sich damit fundamental von dem zeitlosen Kanon im Umgang mit dem Gebäude, wie ihn die GHB definierte. Die Möglichkeit der Revision der in der Gegenwart getroffenen Entscheidung formulierte 
der Stiftungspräsident Lehmann in polemischer Zuspitzung sinngemäß: »Wenn das der nächsten Generation nicht gefällt, dann reißt man es eben wieder ab« (zitiert nach Jacob 2007:11). Erwartungsgemäß empörten sich die Vertreter der originalgetreuen Wiederherstellung darüber und sahen abermals gewissenlose und verschwenderische moderne Architekten am Werk, gegen die eine gewissenhafte und preußisch-sparsame Bauweise der alten Architekten (Schinkel und Stüler) in Stellung gebracht wurde (ebd.). Durch diese Kontrastierung wird umso deutlicher, dass im zeitkonstitutionellen Modus der ergänzenden Wiederherstellung Vergangenheit, Gegenwart und Zukunft klar voneinander abgegrenzt sind; eine eindeutig lineare Konstruktion von Geschichtlichkeit also, in der der Lauf der Zeit die Grenze zwischen den Generationen immer wieder neu zieht. Die Spuren der Vergangenheit müssen zwar dokumentiert werden, jedoch nimmt deren Verbindlichkeit $a b$, da prinzipiell alles historisch werden kann.

\subsubsection{Zwischenfazit: Ewig bleibt die Veränderung}

Wie jede Vergegenwärtigung und Interpretation stellt auch die moderne Gestaltung des Neuen Museum ein Novum dar, das sich auf Geschichte beruft. Die Akteure der ergänzenden Wiederherstellung legitimieren die moderne Gestaltung des Gebäudes, indem sie die Modernität des Gebäudes historisieren. Die Verbindung zwischen Vergangenheit und Gegenwart erfordert nun aber die vermittelnde Arbeit der Übersetzung nach Maßgaben der Tradition. Chipperfield bemerkt demgemäß: »Stülers Modernität übersetzten wir in unsere heutige Modernität, indem wir zum Beispiel Kunstwerkstein benutzen.«(Chipperfield, zitiert nach Wedel 2009:58). Dabei führt die Schaffung von Kontinuität über das Baumaterial; jedoch nicht, indem es eine Wiederholung der Form ist. Die Gemeinsamkeit besteht nunmehr in seiner Qualität als moderner Werkstoff.

Eng damit verbunden ist der Topos des Geistes, woraus sich das Deutungsmuster der >Wiederauferstehung im Geiste< ergibt. Unter der Überschrift »Den Geist des Hauses wiederentstehen lassen« (Wedel 2009:57f.) wird davon ausgegangen, dass auch wenn das Museum in der Form des 19. Jahrhunderts nicht wiederbelebt werden kann und Auferstehung ausgeschlossen bleibt, so doch der Geist des Hauses wiederentstehen könne. So spricht auch Julian Harrap davon, dass die Räume der südlichen Gebäudehälfte mittels »neuer Architrave« dem »Geiste nach wiederherzustellen« waren (Harrap 2009a:63). Eine indirektere Formulierung des Geisttopos findet sich in der, bereits eingangs zitierten, Laudatio von Buttlar (2010:95). Dieser hatte im neuen das alte Neue Museum in doppeltem Sinne "aufgehoben" gesehen. Vor dem Hintergrund des oft bemühten Deutungsmusters der »Wiederauferstehung im Geiste e erscheint auch diese indirekte Verbindung zu Hegel nicht mehr zufällig. Das wiederhergestellte Gebäude stellt, dieser Lesart zufolge, somit 
nur die (vorläufig) letzte Synthese in einer langen Reihe von Entäußerungen des Geistes des Gebäudes dar. ${ }^{50}$

Idealtypisch wird das Deutungsmuster einer Kontinuierung von Zeit im Geiste von Jörg Haspel formuliert. Denn das konservatorische und architektonische Vorgehen Chipperfields setze nämlich nicht auf Kontrast oder Konfrontation, sondern auf Kontinuität; diese sei allerdings »eine neue Kontinuität, nämlich eine geistige Kontinuität, die über die am Bau sichtbar belassenen Zeichen der historischen Diskontinuität hinweg Vergangenheit mit Gegenwart und Zukunft verbindet « (Haspel 2007:210, Herv. JK). Die nunmehr "geistige Kontinuität« verbinde zudem Schinkel, Stüler und Chipperfield, da diese trotz der Verschiedenheit ihrer Arbeiten in einer »inneren Haltung« geeint seien (ebd.). Die Trennung zwischen den unterschiedlichen Zeitschichten und der Ausschluss der Wiederholung führen also keineswegs zum Verzicht auf Vorstellungen von Beständigkeit. Denn »das Alte und das Neue sollten einander verstärken - nicht um des Kontrastes willen, sondern um Kontinuitäten aufzuspüren« (Chipperfield 2008:9). Mit der Verlagerung auf den Geist des Hauses als Sitz der Identität wird das Wesen des Gebäudes zu einer Idee, die prinzipiell zu jeder Zeit neu interpretiert werden kann. Galt das Erbe der GHB noch als zu wertvoll, um es dem »Tagesgeschmack anzupassen« (Ahme 2007), so bildet das Credo "Interpretation wagen «, wie es von den Akteuren der ergänzenden Wiederherstellung ausgegeben wird (Chipperfield/Wolters 2009:230ff.), den exakten Gegenpunkt dazu. Wurde die Erweckung der Toten zuvor noch kategorisch ausgeschlossen, so spricht die Stiftung Preußischer Kulturbesitz in der Jahrespressekonferenz des Präsidenten 2009 im Hinblick auf die bevorstehende Eröffnung des Neuen Museums von einer »wahren Wiedergeburt der gesamten Museumsinsel« (2009:14). Die Wiederholbarkeit verlagert sich nunmehr allerdings von der Form in die Idee.

Dass diese Argumentation auch auf gänzlich anders gestaltete Räume angewandt werden kann, wird abermals anhand der Neuinterpretation der stülerschen Raumstruktur im Ägyptischen Hof deutlich. Denn auch hier sei der »Eingriff inspiriert von dem Säulensystem des originalen Tempels« und befindet sich »innerhalb der umschließenden Mauern des Innenhofs« (Chipperfield 2004:106, Herv. JK). Der Eingriff in spiritus, also im Geiste, des Säulensystems des originalen Tempels folgt »übergeordneten Prinzipien des Stülerschen Entwurfs« und gewähre »sowohl ihre Kontinuität als auch ihre moderne Identität « (Chipperfield, zitiert nach Ludwig 1998:4). Wieder kann in direkter Bezugnahme zu dieser Argumentation der heroische Kollektivierungsdiskurs der originalgetreuen Wiederherstellung als Kontrastfolie herangezogen werden. Denn das Ausweichen auf die Ebene »übergeordneter

50 Auch medial sind oft Begriffe aus dem semantischen Feld des Geistes und damit der indirekten Bezugnahme auf die hegelsche Terminologie nachweisbar; etwa in der Frankfurter Rundschau vom 05.03.2009: »Chipperfields Wiederbelebung ist eine Großtat aus dem Geist der Synthese.« (Thomas 2009, Herv. JK). 
Prinzipien « wird als »Vergeistigung « scharf kritisiert. ${ }^{51}$ Das Besondere der stülerschen Architektur liege nicht in den Proportionen und Volumina, sondern in der Feinstruktur von Architektur und Dekor, so die Gegner der modernen Interpretation des Neuen Museums (Ludwig 1998:5).

Die klare lineare Zeitlichkeit dieses Kollektivierungsdiskurses erkennt in »übergeordneten Prinzipien« die Quelle der Kontinuität. Da diese nunmehr eine geistige und keine materielle ist, kann auch über »historische[n] Diskontinuität hinweg Vergangenheit mit Gegenwart und Zukunft« verbunden werden (Haspel 2007:210). Auf nachgerade idealtypische Weise entspricht diese Zeitkonstruktion der sheißen Option` im Umgang mit historischer Veränderung, von der Lévi-Strauss sprach. Das »Eindringen der Geschichte« wird auch hier zum Motor der eigenen Entwicklung (1981:270, Kap. 4.1). Da die Vergangenheiten jeweils abgeschlossen sind, können sie lediglich dokumentiert werden. Die Dokumentation und die geradezu detektivische Spurensicherung stellen - im wörtlichen Sinn - eine »rechenschaftszeitliche« Verarbeitung der Vergangenheit dar (J. Assmann, Kap. 4.1.1). Auch dem Denkmalpflegerischen Gutachten zufolge stellt das Gebäude ein historisches »Dokument « und »Sachzeugnis[ses]« dar (Badstübner et al. 1994:19), wodurch es seine eigene Geschichte bezeugt. Allerdings weit davon entfernt, absichtsloses »Speichergedächtnis« und nüchterner Bericht über die Vergangenheit zu sein, gelingt es auch in dieser linearen Thematisierung der Zeit, eine Wiederholungsstruktur auszubilden. Die fundierende Dimension des Funktionsgedächtnisses (A. Assmann, Kap. 4.1.2) dieser Erzählung verlagert die Ewigkeitskonstruktion nunmehr auf die Ebene historischer Gesetzmäßigkeiten. Nach Maßgaben übergeordneter Prinzipien und durch anhaltende Neu-Interpretation im Modus textueller Kohärenz kann so ebenfalls ein Gleichbleiben über historische Brüche hinweg stabilisiert werden (Kap. 4.1.3). Dies erzwingt allerdings eine stets neue Perspektivierung von Generation zu Generation.

Somit wird die historiografische Dokumentation identitätspolitisch vereinnahmt. Auch sie ist nicht lediglich protokollierendes Speichergedächtnis, sondern kann selbst neue Mythen begründen. Dies geschieht etwa, indem der historische Wandel selbst zur Identitätsressource erklärt wird. So verknüpft einer der am Wiederaufbau beteiligten Restauratoren die Geschichte des Neuen Museums mit dem Wesen Berlins. Im Rückgriff auf Karl Schefflers berühmten Essay »Berlin Ein Stadtschicksal« (Scheffler 1989, Orig. 1910) wird das Wesen der Stadt darin erkannt, nie sein zu können, sondern immerzu werden zu müssen (NM-3, 22-98). Dieses Deutungsmuster der sewigen Veränderungく wird auch von Jörg Haspel eng mit den mannigfaltigen Spuren der wechselhaften Geschichte des Neuen Museums verknüpft, wenn dieser darin ein »emblematisches Monument für das

51 Immaterielle Aspekte spielen auch in der Argumentation der CHB eine Rolle (vgl. »geistige Komponente«, Kap. 5.2.6). Jedoch wird daraus grundsätzlich anderes abgeleitet. 
Stadtschicksal Berlins im 19. und 20. Jahrhundert « erkennt (Haspel 2007:210, Herv. JK). ${ }^{52}$ Auch Jonathan Keates reproduziert dieses Deutungsmuster, wenn er in dem 2009 von David Chipperfield Architects (DCA) anlässlich der Eröffnung des Neuen Museums publizierten Essayband davon spricht, dass sich Berlin immer wieder auf seinem "sandig-unbeständigen Fundament « neu behaupten müsse (Keates 2009:51). Die diskursive Verknüpfung zwischen der sich stets wandelnden Stadt und dem wiederhergestellten Museum erlaubt eine Deutung des Erbes, mit der sowohl kontinuierliche Veränderung als auch eine Vorstellung von Beständigkeit konstruiert werden können. Der anhaltende Wandel wird zur Identitätsressource erhoben. Derselbe Autor geht allerdings noch einen Schritt weiter, indem er dieses (angebliche) Wesensmerkmal des Hauses im wörtlichen Sinne verewigt. Denn das Credo, welches dem Museum »innewohne« und nach dem sowohl Stüler als auch Chipperfield gehandelt hätten, würde lauten: »In meinem Ende ist mein Anbeginn« (Keates 2009:52, Herv. JK). Mit dieser Behauptung werden einerseits die Architekten von gestern und heute zueinander in Bezug gesetzt. Andererseits gelingt mit der Verknüpfung von Anfang und Ende die Konstruktion eines Bildes von Ewigkeit (Arendt, Kap. 4). Zeit kann somit nicht nur über Brüche und historische Zäsuren hinweg stabilisiert werden, sogar Vorstellungen von Ewigkeit lassen sich in diesen Deutungen nachweisen. Ewig bleibt nunmehr nur die Veränderung.

\subsubsection{Doppelte Modernisierung}

Die »zentrale Zielsetzung« bei der Wiederherstellung des Neuen Museums bestand darin, "die erhaltenen Fragmente des Originalbaus weitestgehend $\mathrm{zu}$ bewahren und auszustellen « (Chipperfield 2004:98). Eine weitere Aufgabe bestand jedoch auch darin, »ein modernes Museum aus den Ruinen eines Museums des 19. Jahrhunderts zu entwickeln« (a.a.O. 97). Das strukturelle Dilemma zwischen der Wahrung des Kulturdenkmals und einer zeitgemäßen Vermarktung wird auch in den Grußworten, die dem Masterplan Museumsinsel vorangestellt sind, betont (Lehmann 2000; Mausbach 2000). Die aktuellen und zukünftigen Anforderungen an den Museumsbetrieb mussten also bei der Wiederherstellung gleichermaßen berücksichtigt werden. Dies erzwang eine technische Modernisierung im handfesten materiellen Sinne (etwa durch den Einbau von Lüftungsanlagen und Fahrstühlen). Daneben durchlief das Neue Museum in der Zeit seiner Wiederherstellung allerdings auch eine diskursive Modernisierung. Die intensive Beschäftigung mit dem Gebäude und die akribische Sicherung der Spuren der Zeit führten einerseits dazu, dass der moderne Charakter der Konstruktion des 19. Jahrhunderts freigelegt wurde. Außerdem hatte dies auch zur Folge, dass nun in einer Reihe von Publikationen

52 Der Begriff»Stadtschicksal « wird zwar ohne expliziten Verweis auf Schefflers Essay verwendet, allerdings scheint die Wortwahl in diesem Zusammenhang nicht zufällig. 
der moderne Charakter des Gebäudes auch diskursiv in Wert gesetzt und als Wesensmerkmal konstruiert wurde. Das Neue Museum wird damit sowohl physisch als auch diskursiv zu einem ganz und gar modernen Bauwerk. In einem der im Jahr der Fertigstellung des neuen Neuen Museums veröffentlichten Sammelbände wird die diskursive Modernisierung etwa folgendermaßen vollzogen: »Viel wichtiger als die Auseinandersetzung um die Ausschmückung der Treppenhalle ist der Umstand, dass die technische Innovation des als >modernes` Bauwerk lange Zeit vollständig unterschätzen Gebäudes vorbildlich herausgestellt worden ist.« (Schulz 2009:54).

Wichtiger als die Ausschmückungen erscheint nun die technische Innovation des bereits vor 160 Jahren »modernen« Bauwerks. Die Liste der Begriffe, mit denen die Modernität des alten Neuen Museums diskursiv hervorgehoben wird, ist lang. So wird das alte Neue Museum etwa als »Hightech vom Feinsten « (Cobbers 2009:19ff.), »bemerkenswert innovativ« (Harrap 2009b:125) oder als »Leistungsschau der technischen Möglichkeiten« (Haspel 1994:139) beschrieben. Der Architekturhistoriker Kenneth Frampton spricht in dem von David Chipperfield Architects 2009 veröffentlichten Essayband davon, dass die Eisenbauelemente des alten Neuen Museums "Teil jenes Erbes« sind, mit dem sich Chipperfield und Harrap auseinandersetzen mussten (Frampton 2009:100). Dabei ziehe sich der »technische Fortschritt « wie ein »roter Faden« durch die Geschichte des Bauwerks, welcher »den ursprünglichen Bauprozess sowie die zeitgenössischen Restaurierungsarbeiten« geprägt habe (a.a.O. 99). Indem der technische Fortschritt zum gemeinsamen Nenner der unterschiedlichen Zeiten wird, kann der Eingriff in der Gegenwart mit der Vergangenheit verbunden und dadurch legitimiert werden. Dadurch, dass die Modernität des alten Neuen Museums zur Identitätsressource wird, bewegt sich auch das neue Neue Museum als "Schauspiel technischer und wissenschaftlicher Errungenschaften« (a.a.O. 106) in den Bahnen der Tradition.

Einen wichtigen Ausgangspunkt der diskursiven Modernisierung des Neuen Museums stellen, wie bereits eingangs erwähnt, die Arbeiten von Werner Lorenz dar. Vor allem auf seinen Aufsatz "Das Neue Museum - Inkunabel preußischer Konstruktionskunst im Zeichen der Industrialisierung (1994; 2009; 2014) wird oft Bezug genommen, womit dieser im Diskurs zu einer wirkmächtigen (wissenspolitischen) Intervention wird. Anhand von drei Aspekten stellt Lorenz die Modernität des Stülerbaus heraus. Technisch innovativ waren (1.) die Organisation des Konstruktionsprozesses und der Einsatz einer von Borsig installierten 5-PSDampfmaschine, die nicht nur für das Einrammen der Eichenstämme und damit zur Gründung eingesetzt wurde, sondern ebenso zum Mischen des Mörtels und als Antrieb für den Lastenaufzug (1994:99). Ebenso spiegele (2.) der umfangreiche Einsatz moderner Materialien (Eisenkonstruktionen, Bogensehnenträger) die Modernität der Epoche der Industrialisierung wider (a.a.O. 108). Damit sei ein neuartiges »High-Tech«-Gesamtkonzept umgesetzt worden (ebd.), welches etwa auch 
in dem »hochmodernen Industriedach« des Ägyptischen Hofs zum Ausdruck gekommen sei (a.a.O. 101). Ebenso werden die Tontöpfe, die »zur Minderung von Gewicht und Schub« (a.a.O. 103) eingesetzt wurden, als technische Innovation relevant gemacht. Die "zukunftsweisende Neuartigkeit« der Konstruktion zeige sich zudem (3.) in seiner »baukünstlerischen Adaption« (a.a.O. 99). Gemeint sind letztendlich eine konzeptionelle Offenheit und architektonische Modernität, die dem Neuen Museum, der breit geteilten Interpretation Lorenz' zufolge, von Beginn an zu eigen war. Es handelt sich hierbei also um die Traditionalisierung einer konzeptionellen Offenheit für technische Innovation und die Verwendung moderner Materialien. Diese wird über den Verweis auf Karl Boettichers »tektonischen Klassizismus« hergeleitet.

»Boettichers streng tektonischer Klassizismus, dessen Paradigmen unmittelbar auf Winckelmann und Schinkel zurückgingen, bejahte vorbehaltlos die Hinwendung zur Eisenarchitektur. Er eröffnete Stüler die Möglichkeit, klassizistische Grundvorstellungen widerspruchsfrei mit den neuen Konstruktionsweisen und Produktionsbedingungen der $\gg$ Eisenzeit $<$ zu verbinden« (a.a.O. 112).

Mit der Verbindung zu den Urvätern und dem Appell an eine Tradition der Integration des Neuen werden der Wert und die Bedeutung des Gebäudes als eine der frühesten Eisenkonstruktionen nochmals unterstrichen. Daraus folgert Lorenz schließlich:

»Der verbliebene Torso des Stülerschen Meisterwerks fordert heute eine dieser überragenden Bedeutung angemessene architektonische Antwort. Sie sollte von Parametern wie Respekt und Achtung, Sorgfalt und Behutsamkeit ebenso bestimmt sein wie vom Stülerschen Mut, auf schwierigste Randbedingungen mit der Entwicklung zukunftsweisender Lösungen zu reagieren« (ebd., kursiv JK).

Die »widerspruchsfreie« Synthese zwischen »klassizistischen Grundvorstellungen« und »neuen Konstruktionsweisen« ermögliche auch heute einen beherzten Eingriff. Denn neben der Forderung nach eher passiven Umgangsweisen wie »Respekt und Achtung« werden - unter Verweis auf den »Stülerschen Mut - ebenso »zukunftsweisende Lösungen« eingefordert. Auch medial wurden der Topos der technischen Modernität und der daraus abgeleitete Imperativ des Fortschreibens aufgegriffen; etwa von Nikolaus Bernau, der den Entwurf Chipperfields als die »Fortsetzung des Technikdenkmals Neues Museum ins nächste Jahrtausend« (1994:115) bezeichnet. Da es bei der Instandsetzung des Neuen Museums sowie der gesamten Museumsinsel auch darum ging, eine der wichtigsten Sehenswürdigkeiten der Stadt einer zeitgemäßen Vermarktung zuzuführen, erscheint diese Geschichtsdeutung des kontinuierlichen Fortschreibens hochgradig funktional. Mit dem Appell an die mutige Vorgehensweise Stülers (»stülerscher Mut«) und dem Verweis auf ein Konzept, welches Modernes »widerspruchsfrei« mit der Tradition zu verbin- 
den vermag, können die doppelten Anforderungen integriert werden. Diese Form der Geschichtsdeutung bietet somit eine Lösung für das strukturelle Dilemma zwischen Konservieren und Weiterentwickeln, auf welches Dehios Imperativ (konservieren, nicht restaurieren!) keine angemessene Antwort mehr bot. ${ }^{53}$ Denn indem die Modernität des Gebäudes in der Vergangenheit >wiedergefunden ‘ wird, können die Bedingungen, die die Gegenwart und die strukturellen Aspekte einer zeitgemäßen Vermarktung stellen, mit der Tradition in Einklang gebracht werden.

\subsubsection{Das Nebeneinander der Räume: Die Konstruktion räumlicher Kohärenz}

Chipperfield selbst erinnert daran, dass die Aufgabe, die sich am Neuen Museum stellte, sowohl darin bestand, »der Ruine ihre Identität zu lassen« als auch »dem wiederhergestellten Neuen Museum gleichzeitig Integrität zu geben« (2004:86). Neben dem strukturellen Dilemma zwischen Denkmalschutz und modernem $\mathrm{Mu}$ seumsbetrieb ergibt sich daraus auch ein räumliches Dilemma zwischen Disparatheit und Einheit. Die Zerstörungsgeschichte soll weiterhin Teil des Gebäudes bleiben, jedoch nicht dessen ausschließlicher Charakter sein (a.a.O. 96). So wie die Trennung der Zeitschichten nicht zum Verzicht auf Vorstellungen von Beständigkeit führt, so hat auch das ambige Wesen des Museums nicht zur Folge, dass auf die Konstruktion räumlicher Einheit verzichtet wird. Der Begriff der Harmonie bleibt dabei nicht der einzige Topos aus dem semantischen Feld der Akustik. Aufgabe dieses Unterkapitels ist es deshalb, aufzuzeigen, wie die Spannung zwischen Ambiguität und Integrität diskursiv aufgelöst wurde.

\section{Kohärenz der Raumstruktur}

Für die GHB war die Wiederholung des Stülerbaus ein Gebot der Achtung des Werkes des Architekten. Sie stellte den einzig gebotenen Umgang mit der Ruine dar, die aus dieser Perspektive eher ein Steinhaufen war. Ebendies entspräche für die Vertreter der ergänzenden Wiederherstellung gerade einer Geringschätzung des Werk Stülers. Wie im Masterplan Museumsinsel festgestellt wird: »Kein Wiederholungsversuch könnte der Qualität und der Bedeutung von Stülers Kunstwerk gerecht werden« (Haspel 2000:41). Zwar ist die erneute Ausführung des stülerschen »Kunstwerk[s]« unmöglich. Dennoch kann die »Kernform« der Treppenanlage wiederhergestellt werden (ebd.).

Da das Kunstwerk unwiderruflich verloren ist und es der Respekt vor der künstlerischen Leistung (Stülers, Kaulbachs) verbietet, dieses zu wiederholen, verlagert

53 Dies gelingt deshalb nicht mehr, da, wie Chipperfield an anderer Stelle nochmals betont, sowohl die »Kontinuität als auch moderne Identität des Neuen Museums « gesichert werden müssen (Chipperfield 2004:100). 
sich die Kohärenzbehauptung von der Form in die räumliche Struktur. Bereits im denkmalpflegerischen Gutachten wurde großer Wert darauf gelegt, dass auch die neu zu errichtenden Gebäudeteile in ihrer räumlichen Grundstruktur, also in Proportion und Grundriss, wiederhergestellt werden (Badstübner et al. 1994:23). Dass dies auch gelungen sei, wird etwa in dem vom Büro David Chipperfield Architects (DCA) herausgegebenen Sammelband durch Jonathan Keates betont. Demnach schlagen Chipperfield und Harrap einen Bogen zwischen moderner Gestaltung und den "zeitlosen Linien und Volumina« des Stülerbaus (Keates 2009:54). Nicht mehr die Kunstform, sondern die Kernform der Grundstruktur, des Bauvolumens und der »zeitlosen Linien« sichert also die Kohärenz und die Integrität des Bauwerks. »Die Wiedergewinnung der Treppenanlage « in ihrer Kernform stifte auch über das Haus hinaus reichende Bezüge; etwa zur Rotunde des Alten Museum. Vor allem aber sei sie »in ihrer axialen Beziehung zur Freitreppe der Alten Nationalgalerie [...] denkmalpflegerisch ohne Alternative.« (Haspel 2000:41). Mit der Nennung der räumlichen Bezüge zu den anderen Gebäuden wird die Einheit des Gesamtkunstwerks heraufbeschworen. Die formale Verschiedenheit der modernen Treppe des Neuen Museums und der in ihrer bauzeitlichen Form wiederhergestellten Freitreppe der Alten Nationalgalerie harmoniert, dieser Lesart nach, mit den umliegenden Bauwerken. Mit der wiederhergestellten räumlichen Struktur befindet sich die von Chipperfield entworfene Treppenhalle auch ohne das erbauungszeitliche Dekor in guter Nachbarschaft zu den anderen Museumsgebäuden.

\section{Ein modernes Palimpsest}

Ein im Zusammenhang mit der Diskursivierung von Baudenkmalen oft verwendetes Motiv ist das sprachliche Bild des Palimpsests. Ursprünglich bezeichnet der Begriff mehrfach überschriebene Schriftstücke (meist Kalbslederhäute), in denen die Spuren des ehemals Vorhandenen noch in Resten zu erkennen sind. Auch im Diskurs des Neuen Museums wird diese Metapher häufig verwendet. ${ }^{54}$ Anders als bei tatsächlichen Palimpsesten, in denen der Schimmer der alten Spuren ein unerwünschter Nebeneffekt ist, sollen die vielfältigen Einschreibungen der Zeitverläufe jedoch bewusst sichtbar gelassen werden. Die Vielzeitlichkeit des Hauses soll ganz bewusst in eine architektonisch-ästhetische Vielräumlichkeit übersetzt werden.

»Nach den Bomben- und Feuerschäden war das Cebäude dann über sechzig Jahre den Naturgewalten ausgesetzt, so dass wir heute sowohl einer Ruine von großer Wirkung gegenüberstehen als auch einem Cebäude, das sich durch eine komplexe Bedeutung und Ambiguität auszeichnet.« (Chipperfield 2004:83, Herv. JK).

Gerade die unterschiedlichen Ereignisse in der einzigartigen Geschichte des Gebäudes machen sein besonderes Wesen aus. Dies schließt sogar die Beschädigun- 
gen durch Schrapnellgeschosse ein, die laut Chipperfield »ein wesentlicher Teil der Geschichte des Baus« darstellen (a.a.O. 100). Was das Gebäude nunmehr auszeichnet, ist seine »komplexe Bedeutung und Ambiguität«. Neben dem Verweis auf eine tieferliegende räumliche Grundstruktur, die die Persistenz der ursprünglichen Raumschöpfung gewährt, wird gerade die komplexe Vielgestaltigkeit des Gebäudes als Identitätsressource relevant gemacht. Da die »Einfluss nehmenden Zeitläufe zu lang und zu komplex [waren], um sie leugnen zu können« (Chipperfield 2004:94), werden mehre Zeitschichten beerbt. ${ }^{55}$ Der damit verbundene Wert des >Sowohlals-auch wird in eine Ästhetik des Disparaten übersetzt.

Der Blick, der sich aus dem Mittelalterlichen Saal in den Modernen Saal und den Griechischen Hof ergibt, kann dies veranschaulichen. Im kriegszerstörten Modernen Saal mussten die Terrazzoböden vollständig neu ausgeführt werden. Die ionischen Kapitelle sowie die bauzeitlichen Säulen konnten wiederaufgestellt werden. Die neu aufgemauerten Joche im Mauerverbund von Neu- und Altziegeln stützen nun eine Decke aus modernen Betonelementen, die im Kontrast zu dem zwar ebenfalls neuen, aber weniger modern anmutenden Fußboden steht. Die feingliedrigen Decken des Saals wurden wieder freigelegt. Die Einbauten im $\mathrm{Zu}$ ge der Amarna-Sammlung sowie die ebenfalls im Kontext dieser Umbauten abgebrochene Apsis zum Griechischen Hof wurden in ihrem Volumen und mittels moderner Betonbauteile wieder ausgeführt. Bei der Wiederherstellung der Decken wurden nach historischen Verfahren neu produzierte Tontöpfe verwendet, die zu Stülers Zeit ein technisches Novum darstellten und die Errichtung des ersten dreigeschossigen Museums der Welt ermöglichten. Neben den unterschiedlichen Werkstoffen sind es schließlich die zahlreichen Schadensformen und unversiegelten Oberflächen, die das Bild des Palimpsestes vervollständigen. Der SchievelbeinFries im Griechischen Hof, auf welchem der Untergang Pompejis dargestellt wird, wurde in Teilen restauriert; beschädigte Flächen blieben sichtbar. Der Hof erhielt erneut ein modernes Glasdach, so wie das ursprüngliche Bodenniveau des 19. Jahrhunderts an dieser Stelle wiederhergestellt wurde.

Das zeitliche Nacheinander der Geschichten wird also in ein räumliches Nebeneinander verschiedener Stile, Materialien, Architekturen, Schadensformen übersetzt. Anders als bei mehrfach überschriebenen Palimpsesten ist die Ambiguität hier aber hochgradig konstruiert. Sie rekurriert auf eine Vielzahl von Zeitschichten, welche wiederum unterschiedlich stark betont werden. So wie das salte richtige Museum<, von welchem die GHB sprach, ein Komposit chronologisch früherer

55 Für diese positive Betonung der Vielschichtigkeit der historischen Spuren sowie der Disparatheit der Museumsinsel insgesamt sprach Hans Witschurke, anlässlich der Eröffnung der James Simon Calerie, von dem Ensemble als »Metamuseum «, an dem »die gesellschaftliche Entwicklung der letzten zweihundert Jahre ebenso abgelesen werden kann wie die Evolution des Cebäudetyps.«(2019:29). 
Zeitpunkte war, so ist auch die bewusste Inszenierung von Ambiguität keineswegs ein absichtsloses "Einfrieren« der Ruine (Harrap 2009b). Gerade die Abbildung der disparaten Spuren der Zeit führte vonseiten der GHB zum Vorwurf der Monstrosität und der Verunreinigung.

Dem vielgestaltigen Erscheinungsbild wird nun allerdings ein historischer Dokumentenwert zugestanden. Die gegenwärtig sichtbaren historischen Spuren und die mehrfachen Überschreibungen werden als wesenhaft für das Neue Museum beschrieben. Kenneth Frampton deutet dies in einem anlässlich der Neueröffnung 2009 publizierten Essay mit dem Titel »Das Museum als Palimpsest « folgendermaßen: „Das Neue Museum ist - und war in gewisser Weise schon immer - eine Art Palimpsest, in dem Vergangenheit und Gegenwart einander ständig spiegeln [...] und dabei eine endlose Reihe von Haken schlagen« (2009:100). Der spannungsreiche (Haken schlagende) Kontrast zwischen Vergangenheit und Gegenwart wird in eine Tradition gestellt und als »endlose Reihe« entzeitlicht. So wie der historische Wandel bleibt auch die Ambiguität widerspenstiger Spuren der Zeit im palimpsestartigen Wesen des Neuen Museums erhalten.

\section{Die Einheit der Fragmente}

1845 erhielt Hermann Schievelbein den Auftrag, im Griechischen Hof des Neuen Museums einen Stuckfries auszuführen. Der Fries zeigt die Bewohner Pompejis beim Versuch, ihre Kunstschätze zu retten, die durch den Ausbruch des Vesuvs bedroht sind. Die personifizierte Naturgewalt an der Nordseite des Hofes bildet das Zentrum des Frieses, welcher zu beiden Seiten die Schar der Flüchtenden abbildet. Diese werden schließlich an der Westseite des Hofes von zwei Personen empfangen, die die Kunstschätze zur sicheren Verwahrung entgegennehmen. Diese Figuren tragen die Gesichtszüge Friedrich August Stülers und Ignatz Maria Olfers (van Wezel 2003:191, Lorenz 2014:32f.); zweifelsfrei keine Koinzidenz, sollte damit doch die Kontinuität zwischen der antiken Kunst und dem preußischen Staat als Hort eben dieser Kunstschätze zum Ausdruck gebracht werden. In der Darstellung Preußens als legitimer Nachfolger der untergegangenen antiken Welt wird ebenso wie in den Kaulbachfresken das Sendungsbewusstsein und die historizistische Selbstüberhöhung des Staates (Kap. 5.1.1) und seiner Künstlerpersönlichkeiten erkennbar. ${ }^{56}$ Dabei wird die heidnische Antike mit der christlichen Gegenwart verknüpft und eine geschichtlicher Fortschritt proklamiert.

Eng mit dieser Selbstthematisierung verbunden war dabei die didaktische Einheit zwischen den Exponaten und der Innengestaltung des Museums. Dadurch konnten die unterschiedlichen Epochen in ein vereinheitlichendes Entwicklungs-

56 Eine vergleichbare Identifizierung des preußischen Staates mit der antiken Welt fand sich auch im Ägyptischen Hof. Hier befand sich eine in ägyptischen Hieroglyphen abgefasste Widmung für den preußischen König (van Wezel 2003:145). 
Abbildung 21: Der Blick vom Mittelalterlichen Saal in den Modernen Saal (links) und den Griechischen Hof (rechts) zeigt die Vielzahl der Schadensformen und Zeitschichten, auf die die Wiederherstellung rekurriert.

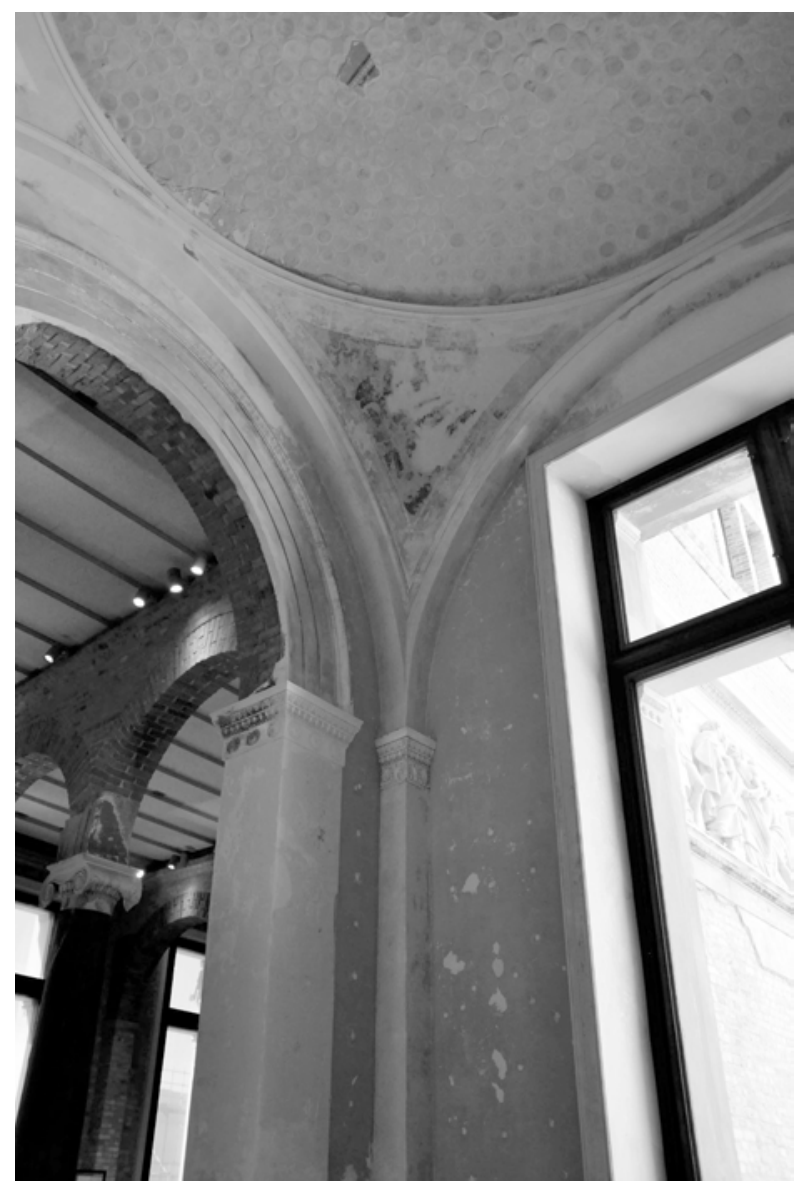

und Fortschrittsnarrativ eingebettet werden. Zwar erkannte auch die diskursive Formation der ergänzenden Wiederherstellung die didaktische Einheit zwischen Exponaten und Innengestaltung der ursprünglichen Museumsfassung als wesentlich an (Haspel 1994:139), jedoch wird dieses Wesensmerkmal einem verlorenen und (chronologisch) abgeschlossenen Teil der Gebäudegeschichte zugeschrieben. An die Stelle der stilistischen Homogenität, im Sinne eines als ursprünglich gedachten Zustandes, tritt das ambige Wesen des Gebäudes. Jedoch werden auch in 
diesem Modus der Verräumlichung die komplexe Ambiguität des Gebäudes und seine Exponate zu einer Einheit verknüpft. Dies geschieht hauptsächlich dadurch, dass die historische Signifikanz der Exponate mit der ebenfalls geschichtlichen Bedeutung des Neuen Museums zusammengebracht wird. Als gemeinsamer Nenner wird gerade die offen zutage tretende Brüchigkeit der Exponate und der Architektur relevant gemacht.

Ein erneuter Blick in den Griechischen Hof verdeutlicht dies. So werden hier sowohl (ca. 4.500 Jahre alte) ägyptische und (ca. 2.800 Jahre alte) babylonische Reliefs gezeigt. Zudem ist im Hof ein (ca. 2.100 Jahre alter) griechischer Torso einer Zeusstatue ausgestellt. Über den Exponaten fliehen, wie vor 160 Jahren, die Bewohner Pompejis. Der Unterschied besteht nun aber darin, dass der Fries Schievelbeins selbst als historisches Dokument Bedeutung erhält. Dies geschieht mittels einer Ausstellungstafel (Texttafel Nr. 013), die eine sprachliche Verbindung zwischen Exponat und Hof herstellt. In dem Text wird darauf hingewiesen, dass auch die von "Granatsplittern durchschlagenen Putzreste« wie die hier ausgestellten Exponate gleichermaßen von historischer Relevanz zeugen (ebd.). Diese Lesart, dass die Objekte und das Gebäude des Neuen Museums in ihrer historischen Bedeutung geeint sind, wird oft in den Fachdiskursen der Denkmalpflege, aber auch der kulturwissenschaftlichen Literatur bemüht. ${ }^{57}$ Das Argument lautet dabei wie folgt: »Die >Weltordnung im Griechischen Hof fügt ägyptische und assyrische Tempelreliefs, eine Zeusstatue und den Schievelbein-Fries zu einer thematischen Einheit zusammen« (Wedel 2009:79). Diese Einheit der Fragmente macht den brüchigen Charakter der Exponate und die Beschädigungen des Gebäudes als verbindende Klammer relevant und spricht beidem historische Bedeutung zu. Idealtypisch formuliert Carola Wedel dieses Argument folgendermaßen: »Die Bruchstückhaftigkeit des Gebäudes entspricht der Bruchstückhaftigkeit der in ihm gezeigten Fundstücke.«Anhand der Büste der Nofretete und des Nordkuppelsaals führt sie weiter aus:

»Nicht einmal der Kalksteinkopf der Nofretete ist in einem perfekten Erhaltungszustand - um wie viel weniger ist es der Nordkuppelraum, in dem sie alle Blicke auf sich zieht. Dabei leistet es gerade der entsprechend beschädigte und sorgsam bewahrte Umraum, ihre Zerbrechlichkeit überzeugend als Erbe ihrer eigenen Ceschichtlichkeit zu vermitteln.«(Wedel 2009:54f.).

Gebäude und Ausstellungsgegenstände sind in ihrer »Bruchstückhaftigkeit« und in ihrem nicht »perfekten Erhaltungszustand« geeint und treten als »Erben ihrer

57 So verknüpft etwa auch Kerstin Brandt den ästhetisierenden Umgang mit den Kriegszerstörungen im Griechischen Hof mit dem hier zeitweise gezeigten >Berliner Skulpturenfund . Die »devastations of World War II« würde so zur »common history« für beide (2011:306). 
eigenen Geschichtlichkeit« auf. Diese Technik der Vereinheitlichung kann nur gelingen, wenn sowohl den Exponaten als auch dem Gebäude ein historischer Wert beigemessen wird. Der Unterschied zwischen der 4.500 Jahre alten Nofretete und dem 160 Jahre alten Museumsbau ist, aus dieser Perspektive, lediglich quantitativer Natur; ein qualitativer Unterschied besteht nicht. So wie die Werkstoffe Stülers (Eisenkonstruktion) und die Chipperfields (Werkbetonteile) in ihrer Qualität als moderne Werkstoffe geeint sind, so werden auch die Objekte in ihrer historischen Qualität miteinander gleichgesetzt. Zudem liegt erneut gerade in der »Unvollständigkeit« ein informatorischer und geschichtlicher Mehrwert. Nofretete sei schließlich »eine reife Frau«, deren »Reiz gerade im Nicht-Perfekten, der Zeichnung durch die Jahre besteht« (Kuhn 2009:91).

Kritisierte die GHB noch die Disparatheit der Wandbilder des Saals, welche Szenen aus der griechischen Mythologie zeigten, mit dem nun am Ort gezeigten Exponat, so kann auch die Argumentation, in der Gebäude und Ausstellungsstücke in ihrer Brüchigkeit miteinander assoziiert sind, nur belächelt werden. Die GHB kommentiert sarkastisch, dass sich nun die unterschiedlichen Zerstörungen im Wettstreit miteinander befänden. Die beschädigte Nofretete stehe nun in einem »herrlich zermürbten Kuppelraum« (Wendland 2009). Für die GHB wurde das Neue Museum gerade durch diesen Umgang zum »archäologischen Objekt ohne Wert«. Tatsächlich wurde dem Gebäude im Zuge der Wiederherstellung eine archäologische Zuwendung zuteil. Dies dient ebenfalls der vereinheitlichenden Verräumlichung. Einer der Denkmalpfleger expliziert dies anhand einer Nische im Apollosaal, indem er darauf hinweist, dass diese erst im Zuge der Wiederherstellungsarbeiten entdeckt und, einer ägyptischen Grabkammer gleich, wiedergeöffnet wurde (NM-1, 764-767). Indem vor der wiedergefundenen Nische ein 3.300 Jahre altes ägyptisches Fresko platziert wurde, wird aus der thematischen auch eine räumliche Einheit. Museumsarchitektur und die Exponate sind also in ihrer historischen Bedeutung geeint.

Zudem wird die Schaffung von Einheit durch gezielte Spacings vollzogen. Dabei kommt den mit hohem Aufwand organisierten und wiederverwerteten erbauungszeitlichen Ziegel, die in zahlreichen Abbruchhäusern in Brandenburg gesammelt wurden, eine besondere Rolle $\mathrm{zu}^{58}$ Mit der Anordnung der fragmentarischen, 4.500 Jahre alten Reste ägyptischer Fresken vor unverputztem Mauerwerk bauzeitlicher Ziegel wird beides zwar nicht quantitativ, wohl aber qualitativ im Hinblick auf die historische Signifikanz verbunden. Das Museumsgebäude und die in ihm gezeigten Exponate werden so zu archäologischen Objekten von höchstem Wert. ${ }^{59}$

58 Von den rund 1,35 Millionen Altziegel, die zum Wiederaufbau der zerstörten Gebäudeteile verwendet wurden, entstammen 500.000 davon allein einer Kaserne aus dem 19. Jahrhundert in Schlesien (Frampton 2009:100).

59 Der Raum, in dem die Büste der Nofretete zu sehen ist, wird zudem durch Praktiken des ritualisierten Kunstgenusses auch situativ konstruiert. Neben dem Fotografieverbot gilt das 
Dass dabei erneut die Offenheit des Materials bedeutsam ist, kann anhand der Stempel, mit denen die Handstreichziegel versehen wurden, dargestellt werden. Obwohl nirgendwo im Diskurs direkt darauf Bezug genommen wird, lässt sich in freierer Interpretation eine ästhetische Kontextualisierung der Stempelabdrücke und der vor den unverputzten Ziegelwänden angeordneten antiken Reliefs erkennen. Für die Herkunft der Ziegel lassen sich nicht nur unterschiedliche Regionen und Parameter (etwa Rathenower Rot oder Birkenwerder Gelb) feststellen. Zudem entstammen die weit über eine Million Altziegel mindestens 49 im Hinblick auf die Produktionszahlen höchst verschiedenen Ziegeleien aus dem Berliner Umland (Leonhardt 2009:28). Mit hoher Wahrscheinlichkeit sind damit zumindest einige der Produktionsorte der aus dem 19. Jahrhundert stammenden Ziegel mit denen, die ursprünglich am Neuen Museum verwendet wurden, identisch.

Was einerseits als Störung wahrgenommen und als »herrlich zermürbter Kuppelraum« verschmäht wird, stellt andererseits ein authentisches Zeugnis der Geschichte dar und bietet einen Anknüpfungspunkt für die Identifikation mit dem Gebäude. Die disparaten Einzelteile können so zu einer kohärenten Einheit gebündelt werden, denn das »Gebäude selbst [ist] zu einem Sachzeugnis der Geschichte geworden, dessen Bewahrung ebenso öffentlicher Auftrag ist wie die Pflege der gesammelten Kunstwerke« (Badstübner et al. 1994:19). Vor allem der letzte Teil des Satzes vollzieht die Gleichung zwischen historischem Gebäude und den historischen Kunstwerken, die darin gezeigt werden. Auch die historischen Exponate sind in ihrem offen-fragmentarischen Charakter dem Gebäude ähnlich und bedürfen der Pflege. Mit der so geschaffenen Einheit der Fragmente hat sich letztlich die Befürchtung des ehemaligen Direktors des ägyptischen Museums, Dietrich Wildung, bewahrheitet, dass die Geschichte des Gebäudes die der Exponate wenn nicht überragt, so doch überschattet.

\section{Eine Partitur der Räume}

Ungeachtet des Wertes des >Sowohl-als-auch und der Sicherung des informatorischen Mehrwerts des Palimpsests macht der Anspruch, dem Gebäude Integrität zu geben, Techniken der Homogenisierung erforderlich. Neben der diskursiven Vereinheitlichung unter der Klammer der Historizität und der Brüchigkeit umfasste die Schaffung der Einheit im Neuen Museum auch handwerklich-restauratorische Techniken der Vereinheitlichung. Wurde die moderne Architektur einerseits als sich ungebührlich laut hervortuende Kontrastarchitektur beschrieben, so spricht Chipperfield in Bezug auf dieselben modernen Bauelemente von einer »ruhigen

Gebot der Stille, auf dessen Einhaltung die Museumsangestellten achten. Bernhard Giesen hat dies für Museen generell beschrieben, indem er darauf hingewiesen hat, dass abgesehen von Fachkommentaren Redeverbot herrscht und andere Einstellungen als Neugier oder ästhetischer Genuss mit Zurechtweisungen geahndet werden (Giesen 1999:236). 
Abbildung 22: Die Nische wurde im Zuge der Wiederherstellung wiederentdeckt. Durch die räumliche Kontextualisierung mit einem 3.300 Jahre alten Fresko, wird deren historische und archäologische Bedeutung betont; Abbildung 23: Relief vor freiliegendem Mauerwerk. Die Stempel der Ziegeleien bezeugen den gleichermaßen historischen Charakter der wiederverwendeten Ziegel und fungieren so als thematische Klammer.
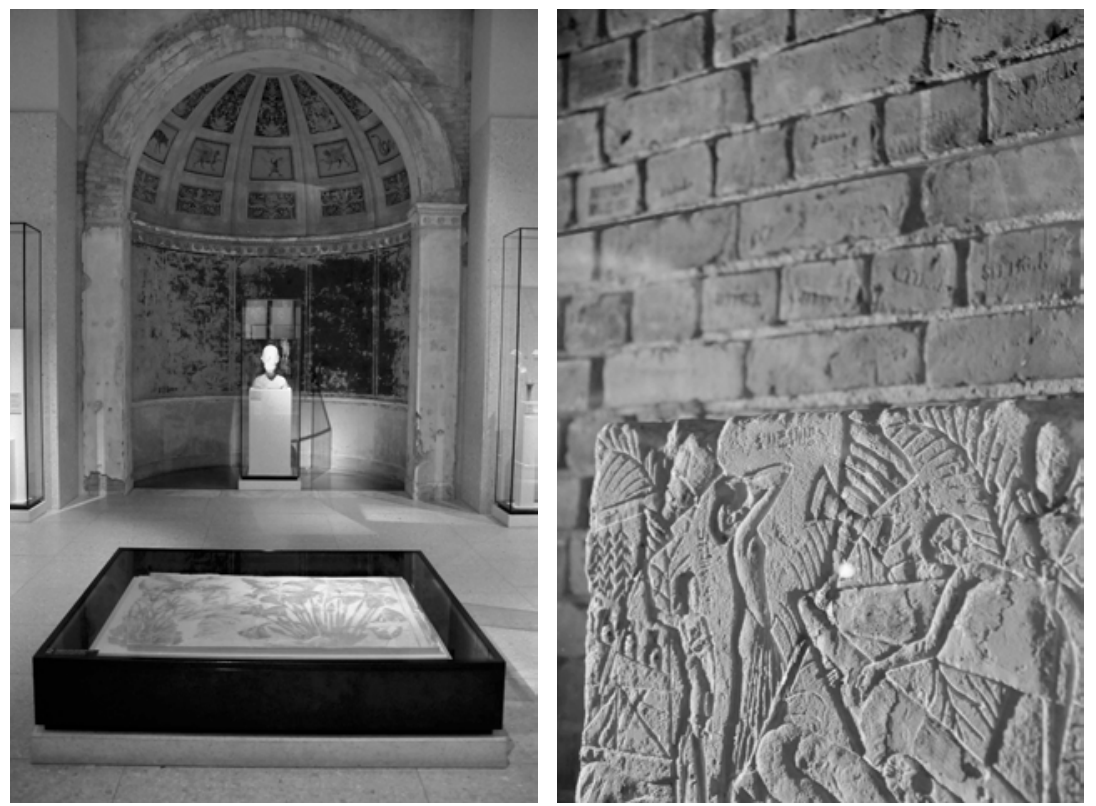

und passiven Architektur«, die dem »Gebäude Ordnung und Ganzheit« zurückgibt (2004:96f., Herv. JK). Die modernen Interventionen werden als »Rahmen ${ }^{60}$ und »neutraler Körper « verstanden. ${ }^{61}$ Da den disparaten Teilen des Gebäudes Ordnung und Ganzheit gegeben und eine »bauliche Kontinuität« erzielt werden soll, »ohne die Geschichte des Gebäudes zu verleugnen oder sie zu monumentalisieren« (a.a.O. 107), bedarf es einer Homogenisierung, die nun jedoch subtiler vollzogen wird.

Die bauzeitlichen Backsteine, die der GHB lediglich als in "Brandenburg zusammengesammelte alte Ziegel« galten (GHB 2008:15), werden nun für die Schaffung einer integren Ganzheit und eines ordnenden Rahmens relevant gemacht, da sie »kontinuierliche Übergänge« zwischen den alten und modernen Gebäudeteilen

60 Diese Rahmenmetapher lässt sich auch bei Harrap nachweisen (2009a:64).

61 Dazu auch Chipperfield (2009:56-59). 
gewähren würden (Chipperfield 2004:98). Mit der voraussetzungsvollen Beschaffung der Ziegel sollte verhindert werden, dass Maschinenziegel die materielle Harmonie stören. Deshalb musste auch die Ziegelfläche im Treppenhaus, die während der Wiederaufbaumaßnahmen in der DDR entstanden war, wieder zurückgebaut werden. Julian Harrap spricht davon, dass das Gebäude durch »hässliche >Ersatzteile entstellt" gewesen sei (Harrap 2009a:60). Dieser Form des Wiederaufbaus wird also kaum »kultureller Wert (ebd.) zugesprochen, wobei dies ebenfalls durch eine Terminologie der Zwischenzeit (»Ersatzteile«, »Notbehelf (Kap. 5.2.7), und die Gewaltsemantik (»aggressiv rote Klinkermauerteile« (a.a.O. 62)) gekennzeichnet wird. Die subtile Homogenisierung der Restauratoren stellt ebenfalls eine aktive Konstruktionsleistung dar. Das Arrangement aus bauzeitlichen Materialien, erhaltenen Schadensformen und modernen Bauteilen entspricht allerdings keiner Homogenisierung im Sinne der GHB. Die Art der Inszenierung erinnert eher an eine Collage, da bereits Vorhandenes neu zueinander in Bezug gesetzt wird und damit neue Bedeutung erhält. Wie bei einer Collage ist auch dieses Zusammenstellen nicht absichtslos, sondern eine voraussetzungsvolle Verknüpfungsleistung, bei der erprobungsweise ein einheitliches Bild erzeugt wurde (Harrap 2009a). Rekonstruktivität der Geschichte ist hier also wörtlich zu nehmen. Wie bei einer Collage, bei der Unterschiedliches miteinander verbunden wird, so geschieht dies doch stets mit dem Anspruch, ein Ganzes herzustellen.

Ein Blick in den Ägyptischen Hof verdeutlicht dies. Hier sind Fragmente der Veduten ägyptischer Tempelstätten zu sehen. Neben der Rauminversion aus modernen Betonelementen sind außerdem die, mit bauzeitlichen Ziegeln wieder aufgemauerten, Wände des Hofes erkennbar. An der nördlichen Wand wurde erneut ein zuvor entferntes Freskofragment angebracht. Vor den neuen unverputzten Wänden des Hofes wurden schließlich ca. 3.500 Jahre alte Reliefs drapiert, die zum Teil aus den Tempelstätten stammen, die ursprünglich in den Veduten des 19. Jahrhunderts dargestellt wurden. Die praktische Ausführung dieser Raumcollage wird diskursiv zu einer Einheit verbunden. Auf einer Schautafel werden die räumlichen Bezüge erklärt: »Neben diesen um 1850 geschaffenen Tempelansichten [...] stehen an den wiederaufgebauten Wänden des im Krieg zerstörten Hofes originale altägyptische Tempelreliefs.« (Texttafel Nr. 112 im Ägyptischen Hof). Die räumliche Anordnung bedarf also der sprachlichen Explikation, um von den Besuchenden des Hauses als Einheit wahrgenommen werden zu können. Die moderne Rauminversion Chipperfields - die der GHB noch als "Raum-Monster « und Mutation des stülerschen Werkes galt (Kap. 5.2.7) - wird in dieser Verknüpfungsleistung mit den Überresten der 170 Jahre alten Tempelansichten und den 3.500 Jahre alten altägyptischen Tempelreliefs zu einem harmonischen Ganzen synthetisiert.

Neben dieser eher collagenhaften Anordnung, die nichtsdestotrotz zu einem einheitlichen Raum verknüpft werden kann, verfolgten die Gestalter des Neuen Museums vor allem ein Prinzip, mit dem trotz vordergründiger Verschiedenheit 
Abbildung 24: Die Verknüpfung zwischen Ausstellung und Gebäude wird auch durch die Schaffung ästhetischer Einheit hergestellt. Durch gezielte Beleuchtung der Exponate und der Ziegelwand werden deren einheitliche Materialität und Farbgebung akzentuiert; Abbildung 25: Die Veduten im Ägyptischen Hof (rechts) wurden restauriert und Fehlstellen flächig geschlossen. Die Ziegelwand (mittig) wurde mit bauzeitlichen Ziegeln neu gemauert. Der Freskorest, der darauf zu sehen ist, wurde erneut angebracht. Die Betonelemente (links) nehmen in einer Raum-Inversion das Volumen des ehemaligen Hypostyls auf. Vor den Wänden sind Relieffragmente arrangiert, die teilweise den altägyptischen Tempeln entstammen, die aufden Veduten abgebildet sind.
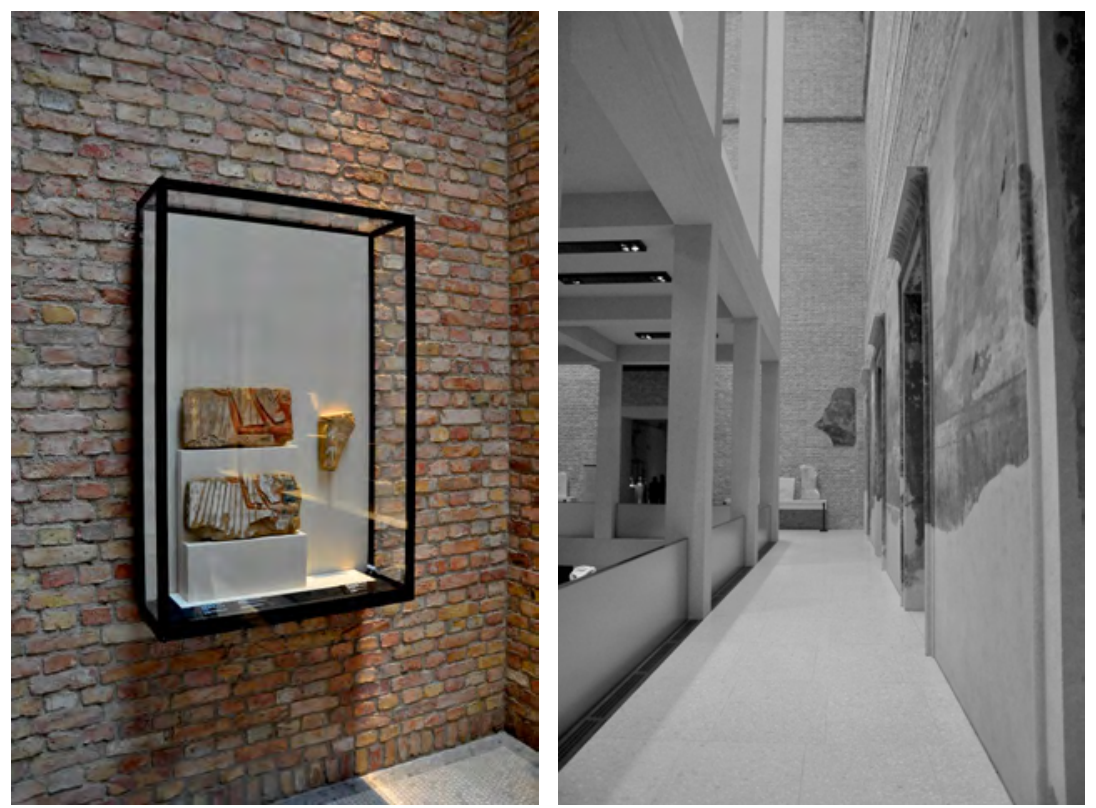

eine hintergründige Vermeidung allzu starker Kontraste angestrebt wird. Für die sprachliche Konstruktion von Homogenität werden oft Metaphern aus dem Feld der Akustik herangezogen. So betonte Julian Harrap noch anlässlich des Richtfestes 2007: "Jeder Raum muss klingen. Jeder für sich. Das ist mein Ziel. Doch der Klang stimmt noch nicht überall.« Bei der Schlüsselübergabe 2009 hingegen betonte der Restaurator schließlich: »Jetzt ist es so, wie ich es mir vorgestellt habe: Jetzt sind die Instrumente gestimmt, verschiedene Instrumente, so verschieden wie die Räume. Aber alle zusammen ergeben ein Konzert." (Harrap, zitiert nach Wedel 2009:62). Die Schaffung eines harmonischen Ganzen (Konzert) setzt gerade die Verschiedenheit der Räume (Instrumente) voraus. Dasselbe sprachliche Bild 
verwendet Harrap, wenn er sich als »Restaurator einer Geige« bezeichnet, der nach "Abschluss der Restaurierung die Saiten stimmen muss, um die Geige zum Klingen zu bringen « (Harrap 2009a:64). ${ }^{62}$

Die Dokumentation verschiedener, klar voneinander unterscheidbarer Zeiten wird in einen räumlich-ästhetischen Ausdruck übersetzt. So wie eine zeitliche Stabilisierung nur noch über die Arbeit der Interpretation zu gewährleisten ist, so werden die disparaten Teile und Einzelräume durch die collagenhafte Anordnung und eine subtile Homogenisierung vereinheitlicht. All dies legt nahe, dass keineswegs eine absichtslose Dokumentation Ziel der Restaurierung war, sondern vielmehr die Schaffung eines facettenreichen Ganzen. Der räumliche Konstitutionsmodus verfährt zwar diskret, schafft aber dennoch gänzlich neue Räume. Insbesondere die Architekten der ergänzenden Wiederherstellung sind sich dieser Doppelstrategie durchaus bewusst und reflektieren dies in einer Vielzahl von Aufsätzen. Gleichzeitig erweist sich der Diskurs als äußerst kreativ, die weiterhin erhaltene Verschiedenheit der Räume als ein einheitliches Ganzes zu deuten, wodurch selbst vollkommen neue Räume als harmonisch beschrieben werden können. So deutet Jonathan Keates in einem Essay, der durch seinen beinahe lyrischen Sprachduktus hervorsticht, den Ägyptischen Hof folgendermaßen: »Er stellt einen Moment der Stasis inmitten der Rhythmen und Pulsschläge des Gebäudes dar. Er ist wie eine jener alles entscheidenden Pausen in einer Partitur, in denen der Raum zwischen den Klangeinheiten ebenso deutlich hörbar wird wie die Noten selbst« (Keates 2009:58).

Sogar Räume, die sich in hohem Maße von den anderen unterscheiden, können damit als Teil einer harmonischen Einheit gedeutet werden. Sogar der Kontrast wird damit in die Partitur der Räume integriert.

\subsubsection{Concordia Discors:}

\section{Die Wissensverhältnisse der sergänzenden Wiederherstellung،}

Der Architekt Axel Schultes vertrat als Einziger der am Wettbewerb von 1994 Beteiligten die Position der prinzipiellen Korrekturbedürftigkeit der baulichen Strukturen auf der Museumsinsel. Sein Vorschlag zu einer grundlegenden Neuordnung sah für das Neue Museum ein dem Pergamonmuseum vergleichbares Raumvolumen vor. Schultes forderte eine »Lösung heraus aus dem Flickwerk chaotischer Parzellierung«. Dabei dürfe es keine musealen, keine baugeschichtlichen und keine denkmalpflegerischen Tabus geben: »[D]er Stüler-Bau [war] von Anfang an alles andere als hilfreich für die Entwicklung des nördlichen Inselareals; - heute ist er, ich mag nicht drumherumreden, Rest, Korridor, Passage zwischen den anderen, den prägenden Museumsbauten«(Schultes 1994:60f.). Die Vergangenheit wird hier

62 Auch Wolters und Chipperfield sprechen von den Räumen als Musikinstrumenten, die so die Assoziation eines harmonischen Canzen ergeben (Chipperfield/Wolters 2009:237f.). 
in erster Linie als Problem relevant gemacht. Sie ist Last und Entwicklungshemmnis; sie hat demzufolge keine verbindliche Kraft für Gegenwart und Zukunft und ist deshalb auch nicht durch Tabus vor Eingriffen geschützt.

Die beiden diskursiven Formationen der originalgetreuen und der ergänzenden Wiederherstellung hingegen hielten - trotz aller Unterschiede - am Wert und der Verbindlichkeit der Vergangenheit fest. Aus der Bezugnahme auf eine gleichermaßen fundierende Vergangenheit wurden jedoch unterschiedliche Schlussfolgerungen abgeleitet. Hatte die GHB die Stilvielfalt des Museums noch als raumzeitliche Verunreinigung und als Raum-Monster abgelehnt und dagegen eine Stilreinheit der Vergangenheit konstruiert, so musste andererseits die doppelte Anforderung zwischen einer Vielzahl von historischen Spuren, einer wiederzugewinnenden Integrität sowie einer geforderten »modernen Identität « (Chipperfield, zitiert nach Ludwig 1998:4) vermittelt werden. Dabei kommen materiell-gestalterische ebenso wie diskursive Konstruktionsleistungen zum Tragen. Übergeordnete Prinzipien erlauben eine Interpretation im Geiste und eine Übersetzung der ursprünglichen Idee und der räumlichen Strukturen des Museums. Technische Innovation sowie die Modernität der Werkstoffe werden historisiert, wodurch nicht die Materialität des Gebäudes wiederholt wird, sondern gegenwärtig innovative und moderne Werkstoffe zum Einsatz kommen. Ebenso wird nun die Einheit zwischen Museumsgebäude und Exponaten durch eine diskursiv erzeugte Klammer, gleichermaßen beschädigter und historischer Objekte, hergestellt. Schließlich können auch in dieser Wirklichkeitsdeutung stabile Wissensverhältnisse etabliert werden, die Beständigkeit und Einheit gewähren. Diese erfahren bei einem breiten Publikum Resonanz und erscheinen vor allem in Fachdiskursen der Kulturwissenschaften oder der Denkmalpflege besonders anschlussfähig.

Was einerseits als »Flickwerk chaotischer Parzellierug« problematisiert wird, kann andererseits als Identitätsressource entzeitlicht werden, indem es die Würde einer Tradition erhält. Dieses Deutungsmuster kann mit dem Begriff der >Concordia Discors` zusammengefasst werden. Was darunter verstanden wird, ist (wörtlich) im Masterplan Museumsinsel unter der Überschrift »Einheit des Verschiedenen« ausformuliert.

»Die anschauliche Signatur dieses weltweit einzigartigen Museumsensembles ist >concordia discors`, die Einheit des Verschiedenen. Schon Stülers erstes Museumsforum aus dem Dreiklang von Altem Museum, Neuem Museum und Nationalgalerie bildete eine solche >concordia discors $«$. Diese Disparatheit verstärkt sich noch durch das 1904 [...] eröffnete heutige Bodemuseum«(Schuster 2000:16).

Es wird nicht nur die Verschiedenheit als ein Wesensmerkmal der Insel behauptet, sondern dieses Merkmal zudem in eine Traditionslinie gestellt. Die "concordia discors « und die »Disparatheit « habe es schon immer gegeben, schon von Anbeginn des stülerschen »Dreiklangs«. So wie erst drei unterschiedliche Töne einen 
Akkord ergeben, bildet erst die Verschiedenheit der Museumsgebäude einen harmonischen Dreiklang. Wieder ist es eine Deutung aus dem semantischen Feld der Akustik, mit der Kohärenz über zeitliche Brüche gesichert und die vereinheitlichende Deutung verschiedener Architekturen vollzogen wird. Dass dieser Dreiklang am Ort noch immer nachhallt, ist keineswegs ein Makel, sondern entspricht der für die Museumsinsel charakteristischen »Signatur«, mit welcher diese ihre Einzigartigkeit bezeugt. Concordia Discors, die Einheit des Verschiedenen, wird somit zur allgemeinen Entwicklungslogik der Museumsinsel erhoben. Die Disparatheit des Neuen Museums und die moderne Architektur der James Simon Galerie können damit auf eine stolze Tradition verweisen und sind historisch legitimiert, indem sie sich harmonisch-disharmonisch einfügen. Die Disparatheit, die Schultes problematisiert, wird affirmiert und als Wesensmerkmal der Museumsinsel und ihrer Gebäude ausgegeben.

Ein weiterer Begriff, mit dem die Einheit des Verschiedenen behauptet wird, ist der der Collage. Auch hierbei verharrt das Ensemble nicht in einem Zustand, sondern ist einem Wandel unterworfen, über welchen hinweg es sich sein disparates Wesen erhält. So habe sich die Museumsinsel im Laufe ihrer 100-jährigen Geschichte selbst zu einer "singulären Architekturcollage aus Tempeln, Schloss, Pantheon und Aula« entwickelt (a.a.O. 17). Die Architekturcollage erlaubt dann den kontinuierlichen Brückenschlag zwischen Stüler und den Eingriffen in der Gegenwart:

„So hat sich Stülers erster Masterplan für die Museumsinsel letztlich im Bild einer vielfältig untergliederten und verbundenen Museumsstadt erfüllt. Die Berliner Museumsinsel entwickelte sich als architektonische Collage zu einer Akropolis deutscher Kunstsehnsucht."(Schuster 2000:17).

Die Traditionsverankerung der Collage sowie die enge Anbindung der Gegenwart an die Vergangenheit werden sogar mit der Bezeichnung »erster Masterplan« (!) für die Pläne Stülers betrieben. Der Masterplan der Museumsinsel aus dem Jahr 2000 (Lepik) ist somit nur die Fortsetzung und Übersetzung des ursprünglichen Plans. Der sprachliche Duktus, mit dem die Arbeit Chipperfields dabei bedacht wird, bedient sich derselben magisch-religiösen Metaphorik, die die GHB ausschließlich dem Stülerbau des 19. Jahrhunderts zuerkennt. So spricht der ehemalige Präsident der Stiftung Preußischer Kulturbesitz, Klaus-Dieter Lehmann, davon, dass es Chipperfield gelungen sei, die »Stülersche Vision eines arkadischen Museumsensembles in zeitgemäßer Form fortzuentwickeln und den Zauber einer Tempelstadt der Künste zur Vollendung zu bringen« (Lehmann, zitiert nach Berlin Magazin 2007). War Chipperfield in den Augen der GHB noch der Zerstörer der Museumsinsel und des Neuen Museums, so wird er nun zum Vollender des "arkadischen Museumsensembles«, dessen Architekturcollage zudem über die Geschichte des Ortes legitimiert ist. War die Museumsinsel für die GHB bereits ein »abgeschlos- 
senes (sprich: vollendetes) Ensemble«, so gelangen die »Vision« und der »Zauber« einer »Tempelstadt der Künste« hier erst jetzt zur »Vollendung«. Das »Flickwerk chaotischer Parzellierung « (Schultes 1994) kann also auch als eine arkadische Harmonie und vollendete Einheit gedeutet werden. Die Phänomenstruktur des Neuen Museums changiert so zwischen einem »heimlichen Kriegsdenkmal für erfolgreiche Bomberflotten « (GHB, Kap. 5.2.7) und einem preußischen Arkadien. Waren das Neue Museum und die James Simon Galerie für die GHB ausschließlich Fremdkörper, die Irritation und Unruhe stiften, und damit Störenfriede, die die Hausordnung der vollkommenen Harmonie ganz und gar missachten, so werden sie nun, obwohl formal hochgradig verschieden, als anschlussfähig zu den umliegenden Bauwerken betrachtet. Sie sind nicht nur in guter Nachbarschaft, sie sind in diesem Sinne auch gute Nachbarn, die sich der Hausordnung der Concordia Discors unterwerfen und dadurch keineswegs unangenehm auffallen.

\subsection{Fundierung durch zyklische und lineare Wiederholungsstrukturen}

»Nur als Flickenteppich unterschiedlicher Vergangenheiten lässt sich das Orientierungsbedürfnis unserer Zeit ganz befriedigen« (Sabrow 2011). Wenn diese zeitdiagnostische Einschätzung des Historikers Martin Sabrow zutreffend ist, stellt das Deutungsmuster der Concordia Discors vielleicht eine der Gegenwart angemessene Form der Identitätsbildung dar. Denn damit werden keineswegs nur die verschütteten Diskursschichten der Museumsinsel freigelegt oder absichtslos dokumentiert. Vielmehr werden Wandelbarkeit und Heterogenität durch die Anbindung an die Vergangenheit für die Gegenwart und Zukunft nutzbar gemacht. Allerdings zeigt der Diskurs des Neuen Museums auch, dass deshalb keineswegs heroische Vergangenheitsbezüge obsolet werden. Gleichermaßen lassen sich wirkmächtige Strategien zyklischer Zeitkonstruktion und auf zeitlose Konstanz rekurrierende Authentifizierungsstrategien finden. Die Anbindung an die Vergangenheit gelingt sowohl durch eine Wiederholung, die ewig im Kreis schwingt, als auch durch anhaltende Interpretationsleistungen, die das Erbe kontinuierlich neu perspektivieren, wodurch gleichermaßen stabile Wissensverhältnisse erzeugt werden können.

Auch in räumlicher Hinsicht begründen die beiden Kollektivierungsdiskurse anschlussfähige Wirklichkeitsdeutungen. Jedoch verändern sich dabei der Grad der Reflexivität und die Sichtbarkeit, mit der Veränderung thematisiert wird. Die Codes der Verräumlichung unterscheiden sich einerseits in einen exklusiven, auf Reinheit rekurrierenden Code, der eine statische Grenze konstruiert, die keine Übersetzung der spiegelbildlich konstruierten Räume erlaubt. Andererseits konnte ein integrativer Code rekonstruiert werden, der die Grenzziehung zwischen Endound Exosphäre, zwischen dem Eigenen und dem Fremden immer wieder neu ver- 
handelt. Disparates kann zur Einheit synthetisiert werden, da es ungeachtet seiner ästhetischen Andersartigkeit in seiner Qualität als historisch oder als modern geeint ist. Somit wird durch diesen integrativen Code der Verräumlichung nicht das Fremde, sondern Fremdheit ausgeschlossen.

Die Wissensverhältnisse des Diskurses der originalgetreuen Wiederherstellung, wie sie von der GHB vertreten wurde, konnten als heroischer Kollektivierungsdiskurs rekonstruiert werden. Diese Bezeichnung folgte einer Selbstbeschreibung, in der die Architekten, Museumsgründer und Wissenschaftler des 19. Jahrhunderts $\mathrm{zu}$ »Heroen« erklärt wurden, »von deren Leistungen wir noch heute zehren« (Kap. 5.2.1). Die verklärende Anrufung einer weiterhin verbindlichen Vergangenheit bleibt in dieser Form der Identitätsbildung zentral. Für die Wissensverhältnisse des Diskurses der ergänzenden Wiederherstellung, wie sie von den Denkmalpflegern, Architekten und Museumsdirektoren stabilisiert wurden, ergab sich hingegen keine vergleichbare Bezeichnung aus dem empirischen Material. Zwar nehmen Begriffe wie Dokumentation, Kontinuität und Interpretation eine zentrale Bedeutung ein, dennoch soll dieser Kollektivierungsdiskurs mit einem anderen Begriff bezeichnet werden. Obwohl der Lauf der Zeit nur noch dokumentiert werden kann, bedeutet dies nicht, dass in dieser linearen Zeitkonstruktion keine Wiederholungsstruktur ausgebildet werden kann. Im Modus textueller Kohärenz kann durch Interpretation Kontinuität erzeugt werden. Auch das Speichergedächtnis der dokumentierenden Geschichtsschreibung stiftet somit Orientierung. Da die historische Zeitstruktur in eine allgemeine Entwicklungsgeschichte eingeordnet wird, bildet sie erneut einen fundierenden Mythos. Für diese Form von Mythen, die sich auf Geschichte berufen, prägte Karl Popper den Begriff Historizismus (Kap. 5.1.1).

Die Grundannahme dessen, was Popper als Historizismus beschrieben und kritisiert hat, besteht darin, dass historische Entwicklungen als gesetzmäßig und deshalb als prognostizierbar gelten. Der Begriff des Historizismus bezeichnet also jene geschichts-metaphysische Vorstellung der hegelschen und marxschen Geschichtsphilosophie und deren Vereinnahmung in den teleologischen Fortschrittsnarrativen des Sozialismus (Popper 1965). Der anhand der ergänzenden Wiederherstellung des Neuen Museums analysierte raumzeitliche Modus der Identitätskonstruktion soll deshalb als historizistischer Kollektivierungsdiskurs bezeichnet werden. Die Kompatibilität dieser Bezeichnung für den Diskurs zeigt sich in den zahlreichen begrifflichen Parallelen, aber auch direkten Bezugnahmen auf Hegel. Adrian von Buttlar spricht etwa davon, dass »das alte Museum Stülers im doppelten Sinne des Wortes raufgehoben « sei und "seine tradierte historische Substanz und seine künstlerische Idee« sowohl »bewahrt und dennoch in eine neue Identität überführt« werden (von Buttlar 2010:95). Aber auch die Interpretation im »Geist (Kap. 5.3.8) nach »übergeordneten Prinzipien « (Chipperfield, zitiert nach Ludwig 1998:4), die eine "geistige Kontinuität« gewähre (Haspel 2007:210), bedient sich eines typi- 
schen historizistischen Wortschatzes. Dieser wird auch bemüht, wenn die ergänzende Wiederherstellung des Neuen Museums als "Großtat der Synthese« (Thomas 2009) gewertet wird. In dieser Form der Identitätskonstruktion wird nicht eine heroisierte Vergangenheit zum entzeitlichten Referenzpunkt, sondern die immer gleichen Gesetzmäßigkeiten des historischen Fortschritts. Die Disparatheit der Entwicklung wird nun durch die Behauptung allgemeiner Gesetze wieder zu einem historischen und ästhetischen Ganzen synthetisiert. Durch diese historizistische Selbstthematisierung werden also ehemals unvereinbare Vergangenheiten und Architekturen kommensurabel.

Als am 13. Juli 2019 die James Simon Galerie nach zehnjähriger Bauzeit und erheblichen Problemen bei der Fundierung des Gebäudes auf dem unsicheren Baugrund der Museumsinsel eröffnet wurde, artikulierten sich in den überwiegend positiven Pressestimmen abermals die Deutungsmuster des historizistischen Kollektivierungsdiskurses. Denn der elegante Bau des Architekten David Chipperfield, der auf der Fläche des ehemaligen Direktorenhauses der Packhofanlagen an der Westseite des Neuen Museums als zentrales Eingangsgebäude der Museumsinsel entstand, übersetze das »historische Motiv« in »moderne Formen« (Staatliche Museen Berlin 2019). Die prägenden Bautypologien der Museumsinsel (Freitreppe, Hof, Kolonnaden) würden auch hier neu interpretiert und von Chipperfield fortgeführt (Schulz 13.12.2018). So kämen schließlich »die Kolonnaden von den Griechen über die Preußen in unsere Zeit« (Chipperfield, zitiert nach dpa 2019). Die schlanken Stützen aus Werkbeton, der bereits im Neuen Museum verwendet wurde, stimmen somit in die vertraute Harmonie des Disharmonischen ein (Kap. 5.3.8). Die zeitgenössische Interpretation stehe durchaus im Einklang mit der Geschichte des Ortes. Sogar das anhand des Diskurses des Neuen Museums rekonstruierte Bild der Ewigkeit, wonach allein die Veränderung ewig bleibt (Kap. 5.3.5), wird vom Präsidenten der Stiftung Preußischer Kulturbesitz bemüht, indem er folgert: »Die Museumsinsel [...] wird sich verändern. Und nur was sich verändert, bleibt« (Parzinger 2019).

Mit der Eröffnung der James Simon Galerie erklingt allerdings noch ein neuer Topos in den Stimmen des historizistischen Diskurses. In der Berichterstattung sowie unter den Akteuren der Umgestaltung ist nun zunehmend von einer »Vollendung der Museumsinsel « die Rede (Tornau 2019). Chipperfield würde mit seinem »Eingangstempel« einen »Schlussstein« setzen und so die Museumsinsel vollenden (Schwartz 2019). Auch dies geschehe in »Schinkels Geist« (ebd.). Da das Entwicklungsnarrativ des historizistischen Kollektivierungsdiskurses in die Zukunft weist, schimmert unter der Oberfläche der ewigen Veränderung stets die Möglichkeit der Vollendung durch. So wurde bereits im Auslobungstext des Wettbewerbs von 1994 $\mathrm{zu}$ einer »Vervollständigung und Fortschreibung« der »Gesamtensembles« aufgerufen (Saya 1994:129). Das »Zu-Ende-Bauen und ein $\mathrm{Zu}$-Ende-Gliedern dieser monumentalen Akropolis« galten als erklärtes Ziel (Stegers 1994:120). Mit der Eröff- 
nung der James Simon Galerie scheint dieses tatsächlich erreicht zu sein. Denn auch die Akteure des Wiederaufbaus und die Architekten bemühen das Bild der Vollendung, wenn sie die James Simon Galerie als Eingang beschreiben, »der das Ensemble zwischen Kupfergraben und der Fassade des Neuen Museums vervollständige.« (David Chipperfield Architects 2019, Herv. JK). Diese Vollendungs-Rhetorik deutet eine schlussendliche Annäherung des heroischen und historizistischen Kollektivierungsdiskurses an. Die Angleichung des sprachlichen Duktus in den Beschreibungen der Gebäude der Museumsinsel verweist auf eine Schließung der raumzeitlichen Struktur des historizistischen Kollektivierungsdiskurs. Indem allmählich auch dieser Diskurs die Stifterfigur James Simon und den Architekten David Chipperfield heroisiert, scheinen eine Ausdehnung und Adaption des Mythos stattzufinden. Ob die neuen Heroen wirklich in das Pantheon derer, die die Museumsinsel einst prägten, aufgenommen werden, bleibt allerdings abzuwarten.

$* * *$

In diesem Kapitel konnte empirisch gezeigt werden, dass sowohl die zyklische Zeitlichkeit des heroischen Kollektivierungsdiskurses als auch die lineare Zeitgestalt des historizistischen Kollektivierungsdiskurses hochrelevant bleiben. Ihre Kohärenzsicherung durch Wiederholung oder Interpretation bildet sich auch in der räumlichen Deutung des Neuen Museums ab. Dabei gehen beide Diskurse, die in der Debatte um die Umgestaltung des Neuen Museums idealtypisch rekonstruiert wurden, von einem weiterhin verbindlichen Erbe aus. Der einzige Architekt im Wettbewerb von 1994, der die Geschichte des Ortes problematisierte und zur Umkehr und Korrektur aufrief, war Axel Schultes (Kap. 5.3.8). Dessen Pläne zu einer umfangreichen Revision der Relation der Baukörper der Museumsinsel blieben jedoch nicht anschlussfähig und konnten somit kein stabiles Wissensverhältnis etablieren. Im heroischen Kollektivierungsdiskurs der GHB hingegen wurden solcherlei Eingriffe, die auf eine Distanzierung von der Vergangenheit zielten, stets als Zeichen der Respektlosigkeit moderner Architektur gedeutet. Als beispielhaft für die angebliche Unfähigkeit moderner Architekten, der Würde alter Gebäude Rechnung zu tragen, wurde im Text der »Initiative Rettet die Museumsinsel!« auch das Militärhistorische Museum der Bundeswehr in Dresden genannt. Dort habe man ohne Not ein denkmalgeschütztes Gebäude zerstört, indem der Architekt Daniel Libeskind einen »Glas-Stahl-Pfeil« in den »völlig intakte[n] klassizistische[n] Altbau" getrieben hat (Ahme 2007:8.). Auch wenn die beiden Debatten um die Wiederherstellung des Neuen Museums in Berlin und die Neukonzeption des Militärhistorischen Museums in Dresden sich nicht überlagern, so berühren sie sich doch an diesem Punkt.

Die Störung der Harmonie des Gebäudes war tatsächlich ein erklärtes Ziel des Architekten und der Museumsgestalter und geschah im Einvernehmen der verant- 
wortlichen Institution. So wie Schultes dazu aufrief, das Erbe der Museumsinsel zu verwerfen, so stellt dies im Falle des schwierigen Erbes der Bundeswehr geradezu eine Notwendigkeit dar, um die moralische Integrität der Institution zu gewährleisten. Das Militärhistorische Museum und der Kollektivierungsdiskurs der Bundeswehr bilden somit den für die idealtypische Rekonstruktion raumzeitlicher Formen der Identitätsbildung vielversprechenden Fall eines negativen Vergangenheitsbezuges. Nicht mehr die Beschwörung des Erbes, die sich im Neuen Museum lediglich in den raumzeitlichen Formationsregeln des heroischen und des historizistischen Kollektivierungsdiskurses unterschied, sondern die Verschwörung gegen das Erbe (Derrida, Kap. 2), der Bruch mit der Vergangenheit und die größtmögliche Distanzierung davon sind nun geboten.

Nichtsdestotrotz bleibt das Erbe auch in der Ablehnung präsent und wird zum normativen Referenzpunkt, wodurch ebenfalls stabile Wissensverhältnisse erzeugt werden können. Die Art der Kontinuierung und die Wiederholungsstruktur dieses dritten Typus sind allerdings nicht mehr in den klassischen Kategorien zyklischer oder linearer Zeitgestalten beschreibbar. Vor dem Hintergrund dynamischer Veränderung in der Gegenwart und der Notwendigkeit, sich von der Vergangenheit zu distanzieren, erscheint ein gänzlich anders gelagerter raumzeitlicher Modus der Identitätskonstruktion. Ungeachtet des negativen Vergangenheitsbezuges kann auch hier ein Kollektivierungsdiskurs rekonstruiert werden, der sein Selbstbild nunmehr im episodischen Bruch mit der Vergangenheit erkennt. 


\section{Schwierige Erbschaft: Der Diskurs des Militärhistorischen Museums Dresden}

AUSPICIIS ALBERTI REGIS - auch der monumentale Eingang des Arsenalhauptgebäudes in der Dresdner Albertstadt wurde einst mit einer Widmung versehen. Laut dieser war das Gebäude der Macht und dem Schutz des sächsischen Regenten König Albert unterstellt. Anders allerdings als die Inschrift im Mittelrisalit des Neuen Museum in Berlin wurde die Dedikation in Dresden im Lauf der Zeit entfernt. Der Austausch der Insignien der Macht wiederholte sich in der wechselhaften Geschichte des Gebäudes gleich mehrmals. Auch nach 1933, 1945 und erneut 1990 mussten die jeweiligen staatlichen Hoheitssymbole entsorgt werden. Die Vergangenheit des Arsenalhauptgebäudes ist somit von episodischen Brüchen geprägt, die dazu führten, dass die Zukunft des Hauses auf bald schon bekannte Weise unbekannt blieb.

Umso bemerkenswerter ist, dass das Gebäude - ungeachtet historischer Zäsuren - im Hinblick auf seine Funktion als zentraler Ort der militärischen Selbstdarstellung eine erstaunliche Konstanz aufweist. Sechs verschiedene deutsche Staaten wählten das Arsenalhauptgebäude in der Dresdner Albertstadt als eine zentrale Stätte ihrer Selbstthematisierung und verräumlichten dabei auf jeweils sehr unterschiedliche Weise ihr Selbstbild. Als am 14. Oktober 2011 das Militärhistorische Museum der Bundeswehr in Dresden (MHM) nach einem tiefgreifenden Umbau wiedereröffnet wurde, vollzog sich in der Geschichte des Hauses - dieses Mal in einem sehr wörtlichen Sinn - abermals ein historischer Einschnitt. Mit einem spektakulären Keil aus Stahl und Beton wurde die spätklassizistische Fassade des Gebäudes asymmetrisch >durchschnitten . Begleitet wurde die architektonische Umgestaltung des Museums von dessen thematischer Neukonzeption. Beides wurde in der Öffentlichkeit teilweise kontrovers diskutiert. Anhand dieser Debatte und der damit eng verknüpften Selbstthematisierung der Bundeswehr kann neben dem heroischen und dem historizistischen ein dritter Kollektivierungsdiskurs rekonstruiert werden, der gerade die bewusste Störung vergangener Identitätspostulate selbst zur Identitätsressource erhebt. Am augenscheinlichsten in der Diskursivierung des MHM ist eine auf Abgrenzung von der Vergangenheit zielende Betonung von Diskontinuität, die sich in zeitkonstitutioneller Hinsicht von den Formen der 
Kohärenzsicherung, wie sie am Neuen Museum dargelegt wurden, erheblich unterscheidet. Nicht Wiederholung oder Vergegenwärtigung, sondern der gezielte Bruch mit der Vergangenheit erhält einen Wert. Eine der maßgeblichen Forderungen an die Architektur und das damit eng verknüpfte Ausstellungskonzept bestand deshalb darin, dass diese ein "gewandeltes Leitbild« (Rauchensteiner 2011:11) des deutschen Militärs zum Ausdruck bringen müssten. Anders als im Neuen Museum, wo das Erbe des Gebäudes zwar verschieden beschworen (Kap. 2), prinzipiell jedoch als Wert anerkannt wurde, müssen weite Teile des militärgeschichtlichen Erbes der Bundeswehr ausgeschlagen werden. Ungeachtet dessen kann über die diskontinuierlichen Brüche hinweg ein kohärentes und kontinuierliches Selbstbild stabilisiert werden.

Indem die Ewigkeitspostulate einer heroischen Selbstimagination anhaltend problematisiert werden, tritt an die Stelle unverbrüchlicher Wesensmerkmale und zeitloser militärischer Tugenden der skeptische Blick auf die eigene Vergangenheit und eine ungewisse Zukunft. Insbesondere das Misstrauen gegenüber alten Erfahrungsräumen und die Aussicht auf einen ungewissen Erwartungshorizont führen dazu, dass »Zukunft auf bekannte Weise unbekannt bleibt « (Koselleck, Kap. 1). Zum zentralen Merkmal dieses Kollektivierungsdiskurses wird der reflexive Umgang mit der eigenen Vergangenheit im Modus der Selbstkritik. Auch in der Verschwörung gegen das Erbe (Derrida, Kap. 2) wird dieses präsent gehalten. Denn diese Struktur des Erbens kommt in anhaltender Negation immer wieder auf sich selbst zurück und kann dadurch eine inkrementelle Vorstellung von Dauerhaftigkeit erzeugen (Kap. 6.4.4). Der dramatisch inszenierte Bruch erzeugt einen Fluchtpunkt der Selbstthematisierung, der normative Orientierung stiftet und dadurch die Distinktion von anderen Armeen ermöglicht. Reflexivität und anhaltende Neuperspektivierung erlauben eine "gleichermaßen im Fluss« befindliche »sekundäre Traditionalisierung« (Knoblauch, Kap. 1). Dadurch wird der Wert des Kritisierens und Hinterfragens der eigenen Institution $\mathrm{zu}$ einem entzeitlichten Wesensmerkmal. Allgemeiner formuliert bedeutet dies, dass die Bundeswehr ihre Identität durch die zentrale Thematisierung ihrer iterativen Nicht-Identität gewinnt (Kap. 6.5).

\subsection{Selbstvergewisserung in schwierigem Gelände}

Der Wert der Abgrenzung von der Vergangenheit wird aus den Besonderheiten der deutschen Militärgeschichte sofort ersichtlich. So verfügt die Bundeswehr über ein umfangreiches Repertoire an >nicht identitätsfähigen Vergangenheiten. Diese stehen nicht nur einer affirmativen Identitätskonstruktion im Weg, sondern müssen durch Ablehnung aktiv auf Distanz gehalten werden. In zahlreichen Publikationen werden die spektakuläre Architektur Daniel Libeskinds und die museale Neukonzeption des MHM als räumlicher Ausdruck dieser Befremdung gedeutet. Der Ge- 
samtkomplex sei demnach eine »kritisch codierte Architektur«, die die heroischen Inszenierungen der Vergangenheit hinterfrage, und daher kein Haus der "Sinnstiftung", sondern der "Denkstiftung" (Pieken 2010b:7). Was für die Zeitkonstitution die kritische Abkehr und damit die >Diskontinuität ist, stellt in Bezug auf die Raumkonstitution der häufig eingeforderte Anspruch der >Multiperspektivität‘ (Rogg 2011:9) dar. So wie die Betonung der Diskontinuität die Vergangenheit nicht beschließt, sondern stets neu perspektiviert, so bleibt auch der Anspruch der Multiperspektivität auf die Bundeswehr bezogen. Denn Geschichte multiperspektivisch zu erzählen setzt eine Standpunkt- und Interessenlosigkeit voraus, die im Falle des MHM gerade nicht gegeben ist. Wie die Expertenkommission der Neukonzeption der Ausstellung deutlich betonte, bedürfe das Militär generell - und damit auch die Bundeswehr im Speziellen - »einer aus den Leistungen der Vergangenheit gespeisten Selbstvergewisserung und Identitätsstiftung.« (Konzeptgruppe 2003:31).

Bleibt die Funktion der »Identitätsstiftung« also auch im neu gestalteten Leitmuseum der Bundeswehr erhalten, so unterscheidet sich einzig der Modus, in dem die Vergangenheitsbezüge verräumlicht werden. Die Expertenkommission hob ebenfalls hervor, dass sowohl die Neukonzeption des Museums als auch die architektonische Gestaltung des Gebäudes sich an den »veränderten Aufgabenstellungen der Streitkräfte« orientieren müssen (a.a.O. 28). Im Sinne der Rekonstruktivität der Vergangenheit (Kap. 2) stehen die Traditionsbildung und ihr architektonischer Ausdruck auch hier im Dienst der sozialen und politischen Herausforderung der Gegenwart. In architektonischer, stadträumlicher sowie nationalstaatlicher Hinsicht zielt dieser Kollektivierungsdiskurs auf eine Integration möglichst vieler und immer wieder neuer Perspektiven. Dabei werden nicht mehr Einheit und Harmonie angestrebt, sondern das bewusste Stören räumlicher Relationen sowie die kreative (Re-)Kombination verschiedener räumlicher Bezugsgrößen. Dieser multiperspektivische Code der Verräumlichung erhält seinen Sinn einerseits aus der spezifisch deutschen Militärgeschichte, in der die Möglichkeit einer national begrenzten Selbstthematisierung historisch diskreditiert ist. Andererseits erscheint eine ausschließlich nationale Rahmung des Selbstbildes auch aufgrund gegenwärtiger Anforderungen, etwa der Einbindung in das westliche Verteidigungsbündnis, inopportun.

Die umfangreichen Deutungen der Architektur und der Ausstellung werden durch eine Vielzahl von Publikationen vermittelt. Dadurch werden sie der Analyse zugänglich, so wie damit die diskursive Vermittlungsbedürftigkeit der Architektur und Ausstellungskonzeption unterstrichen wird. Aufgrund dessen unterscheidet sich die Vorgehensweise der Interpretation des Textkorpus in diesem Kapitel von der Analyse der Debatte des Neuen Museums. Dies wird durch den unterschiedlichen Status der Empirie erforderlich, denn die diskursiven Formationen der Kritiker und Befürworter der Neukonzeption des MHM sind medial sowohl qualitativ als auch quantitativ sehr verschieden abgebildet. Der Fokus der folgenden 
Analyse liegt auf den offiziellen Dokumenten, Veröffentlichungen sowie Stellungnahmen des Museums (Museumskataloge, Ausstellungsführer, Positionspapiere, museologische Leitlinien, Flyer, Ausstellungstexte, Interviews mit Vertretern des Museums), in denen Architektur und Ausstellungskonzept umfangreich gedeutet werden. Zudem bilden offizielle Dokumente der Bundeswehr, in denen diese ihr Selbstverständnis kodifiziert (Traditionserlässe, Konzeption der Inneren Führung), einen weiteren Kreis des Diskurses. Der mediale Gegendiskurs ist vor allem durch Artikel in Zeitschriften und Debattenbeiträgen zugänglich, die an den Rändern des politischen Spektrums verortet werden können. Die durch starke Ablehnung gekennzeichneten Diskursdokumente dienen dabei in erster Linie als Kontrastfolie (Oevermann 2001:11), die es erlaubt, die Facetten der Selbstthematisierung des MHM deutlicher zu konturieren.

Die Spannungslinien des Diskurses, zwischen den Extremen eines heroischen Selbstbildes und einer Selbstthematisierung, die versucht, militärisches Pathos zu meiden, treten dadurch deutlich ins Profil. Dies gilt ebenso für die unterschiedliche Bedeutung, die der Selbstkritik und dem Hinterfragen der Vergangenheit zugeschrieben wird. Was einerseits als zentrales Wesensmerkmal höchste Relevanz erhält, wird an anderer Stelle als »einzigartiger Nationalmasochismus« (Frisch 2011:4) diffamiert. Die Beschreibung des Gegendiskurses dient, anders als im Diskurs des Neuen Museums, vor allem dazu, die Besonderheiten der Selbstbeschreibung der Bundeswehr hervorzuheben. Ohne diese Referenzgröße, die mit ihrer Forderung nach Stileinheit und zeitloser Konstanz weitgehend denselben Formationsregeln des heroischen Kollektivierungsdiskurses folgt, könnte nicht plausibel gemacht werden, worin die Charakteristika einer für die Bundeswehr spezifischen Selbstimagination liegen. Als Kontrastfolien und Referenzpunkte stellen diese gegenläufigen Deutungen eine unverzichtbare Hilfe für die Rekonstruktion eines dritten raumzeitlichen Kollektivierungsdiskurses dar.

Obwohl der Begriff Identität in den Publikationen des MHM eher selten verwendet wird, erscheint die Frage nach einem weiteren Kollektivierungsdiskurs dennoch richtig adressiert. Denn grundsätzlich muss davon ausgegangen werden, dass das MHM - welches eine Dienststelle der Bundeswehr ist und als deren Leitmuseum dient - eine zentrale Rolle bei der Vermittlung eines Selbstbildes der Armee einnimmt. Es erscheint vor diesem Hintergrund plausibel, dass das Museum als Lehr- und Ausbildungsstätte ein Identitätsangebot formulieren muss. Dass das MHM weiterhin eine zentrale Einrichtung der Selbstdarstellung und der Legitimierung staatlicher Gewalt bleibt, wird zu Beginn dieses Kapitels anhand der institutionellen Konstellation verdeutlicht.

Anlässlich der Sonderausstellung mit dem Titel »60 Jahre Bundeswehr« wies der Direktor des Museums und Oberst der Bundeswehr, Mattias Rogg, auf die generelle Verbindung zwischen Museen und Identitätsstiftung hin, wenn er schreibt: »History museums deal with questions of identity in a way that few other cultu- 
ral institutions do. The Bundeswehr Museum of Military History is no exception." (Rogg 2015). Obwohl dieser allgemeine Konnex auch im MHM erhalten bleibt, so ist der Modus, in dem der Kollektivierungsdiskurs der Bundeswehr sein Selbstbild stabilisiert, in vielerlei Hinsicht besonders. Persistenz und Wandel sind ebenso wie die Spannung zwischen der Distanzierung von der Vergangenheit und der anhaltenden Anforderung nach Sinnstiftung anhand der wechselvollen Ortsgeschichte des Arsenalhauptgebäudes besonders deutlich erlebbar. Das Gebäude dient, wie den vorangegangenen deutschen Staaten, auch der Bundeswehr als Leitmuseum und als zentraler Ort militärischer Repräsentationen. Daraus ergibt sich schließlich das zentrale Dilemma, in welchem sich die Bundeswehr und mit ihr das MHM befinden. Einerseits besteht die Notwendigkeit, sich von der Vergangenheit abzugrenzen und weiten Teilen des historischen Erbes kritisch zu begegnen. Andererseits erfordert die Funktion des MHM, sich über die Alleinstellungsmerkmale der Institution zu verständigen und einen legitimen Traditionsbestand zu beerben. Aus dieser Gemengelage ergeben sich die zentralen Fragen: Inwiefern kann der Kollektivierungsdiskurs der Bundeswehr im schwierigen Gelände deutscher Militärgeschichte über Geschichte legitimiert werden? Wie kann trotz der historischen Brüche und anhaltender Veränderungen ein kohärentes Identitätsnarrativ artikuliert und die hergestellten Vergangenheitsbezüge in der Architektur des Leitmuseums und in seiner diskursiven Deutung verräumlicht werden?

\subsubsection{Das doppelte Dresden}

AUSPICIIS ALBERTI REGIS - die Widmung des sächsischen Königs Albert, das Hoheitssymbol des sächsischen Wappens und das Königliche Initial »A« finden sich bis heute an zahlreichen Gebäuden der Dresdner Albertstadt. ${ }^{1}$ Deren Entstehung stand ganz im Zeichen des Krieges. Nach dem Deutsch-Französischen Krieg 1871 wird hier bis 1876 ein Komplex, bestehend aus Kasernen, Lazaretten, Magazinen, Munitionsfabriken, Militärgericht, Militärgefängnis, Heeresbäckerei, Soldatenheim, Artilleriedepots, Werkstätten und einer Garnisonskirche, errichtet (Lisewski 1997:11; Gräfe 2012:22ff.).

Die Geschichte Dresdens ist bereits seit der frühen Neuzeit eng mit der hier ansässigen Garnison verbunden. Nach dem Dreißigjährigen Krieg entstanden stehende Heere, die nicht mehr aus Lehnsleuten, sondern aus Soldaten bestanden, die einem Herrscher unterstellt waren. Die territorialstaatliche Figuration der heraufziehenden Moderne führte dazu, dass in Dresden dauerhaft eine Garnison behei-

So findet sich die Widmung AUSPICIIS ALBERTI RECIS im Mittelrisalit der ehemaligen Pionierkaserne, die heute vom Mitteldeutschen Rundfunk (MDR) genutzt wird. Das königliche Wappen prangt noch immer im Tympanon des ehemaligen Militärgefängnisses in der Königsbrücker Straße und dem einstigen Militärgerichtsgebäude in der Fabricestraße. 
matet wurde, deren Aufgabe im Schutz des Herrscherhauses lag. Fest eingebunden in den Kalender staatlicher, kirchlicher und städtischer Repräsentation war sie auch mit zivilen Aufgaben betraut, wie etwa dem Öffnen und Schließen der Stadttore (Bauer 2012:4ff.). Das Militär war in der Stadt stets sichtbar und stellte zudem einen beträchtlichen Wirtschaftsfaktor dar (a.a.O. 6). Mit der Errichtung des Militärkomplexes im Norden Dresdens am Ende des 19. Jahrhunderts erreicht die Bedeutung des Militärs einen vorläufigen Höhepunkt (Bauer 2012:6). Mit den Kasernen werden die Soldaten vor die Tore der Stadt verlegt. Der Bau der »größten zusammenhängenden Kasernenanlage des damaligen Deutschen Reiches« (Gräfe 2012:22) wurde durch das Anwachsen der Truppenstärke der Dresdner Garnison erforderlich $^{2}$ und ist unmittelbar mit dem Sieg über Frankreich von 1870/71 verbunden, denn die Fertigstellung konnte unter anderem durch französische Reparationszahlungen finanziert werden (von Loh 2012:97). Als spiritus rector dieser Militärstadt gilt der sächsische Kriegsminister General Alfred Graf von Fabrice (Gräfe 2012:24), dessen Mausoleum auch heute noch an der Haupterschließungsachse der Albertstadt zu sehen ist. Ebenso sind die anderen, zumeist aus Elbsandstein errichteten und schiefergedeckten Gebäude im Stil der Neo-Renaissance überwiegend zur Stadt hin ausgerichtet (Gräfe 2012:25). Auch durch diesen stadträumlichen Bezug wird die »Soldatenstadt« (Kunz 2003:5) zum Kontrapunkt und zum Komplement der Dresdner Altstadt.

Das Zentrum der im Volksmund auch »Kasernopolis« (Rogg 2011a:7) genannten Albertstadt bildet bis heute das Arsenalhauptgebäude, welches 1876 fertiggestellt wurde (Kunz 2003:7). Die exponierte Stellung der Dreiflügelanlage, deren Architekt in der Literatur zur Baugeschichte des Museums nur lose der »Semper-Schule« zugeschrieben wird (Pieken 2010a:25), ${ }^{3}$ wird durch einen künstlichen Sockel, auf welchem das Gebäude thront, deutlich unterstrichen. Die wehrhafte Rustika des Arsenalhauptgebäudes stellt einen Bezug zur Festungsarchitektur her und verstärkt damit den militärischen Charakter des Gebäudes. Genau zentriert erhebt sich auf der gebänderten Rustika ein Palladio-Motiv. Diese, Triumphbögen entlehnte, Anordnung wird im Mittelrisalit durch vier Kolossalsäulenpaare auf schlichten Postamenten gebildet und erstreckt sich über zwei Stockwerke. Der monumentalisierte Haupteingang wird schließlich durch verkröpfte Gesimse, einen Aufbau mit ehrenkranzgeschmückten Bogenfeldern und ein Konsolgesims bekrönt. Das Entree wird so zum weithin sichtbaren Bezugspunkt einer wehrhaft-militärischen und gleichermaßen triumphal-feierlichen Architektur.

\footnotetext{
2 Bestand diese noch 1855 aus 3.000 Soldaten wuchs sie bis 1873 auf 10.000 und bis zum Beginn des Ersten Weltkrieges auf 15.000 Soldaten an (Gräfe 2012:23).

3 Inwiefern Fabrice in den Entwurf des Arsenalhauptgebäudes involviert war, bleibt ungewiss (Scheerer 2000:5). Auch wenn sein Einfluss wahrscheinlich ist, werden für die architektonische Ausführung der Gebäude in der Literatur neben Hermann Nicolai (von Loh 2012:93) auch die Architekten Niess und Rumpel genannt (Gräfe 2012:24).
} 
Abbildung 26: Das Arsenalhauptgebäude im Jahr 1897. Die Gesamtanlage ist durch die Symmetrie der wehrhaften Architektur geprägt. Im Zentrum des monumentalen Eingangs ist die Widmung AUSPICIIS ALBERTI REGIS angebracht.

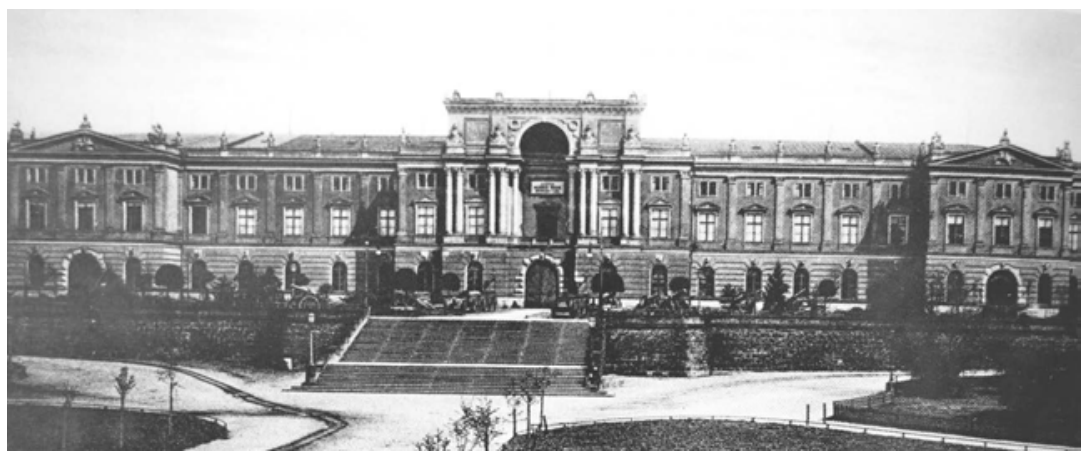

Auch die antikisierenden Kapitelle der Kolossalsäulen mit Akanthusblattwerk und behelmten Figuren unterstreichen den triumphalen Ausdruck. Die Kapitelle werden durch die Pilaster der Seitenflügel in gleichmäßigem Rhythmus fortgesetzt. Die Seitenrisalite werden durch flachgieblige Tympana abgeschlossen, die, etwas niedriger als der schmuckvolle Haupteingang, eine flankierende Funktion erfüllen. Die Gleichmäßigkeit der Seitenabschlüsse, die sich gegenüber dem Palladio-Motiv zurückhalten, trägt wesentlich zu der für die gesamte Anlage maßgeblichen Symmetrie bei. In den Feldern der Tympana ist jeweils ein in Stuck ausgeführtes Paar aus Ross und Reiter erkennbar. Die sich aufrichtenden Rosse sowie die Blickrichtung der Reiter fokussieren den Eingang. Die behelmten Reiter tragen Ehrenkränze und stellen damit den Bezug zu den Kränzen in den Bogenfeldern des Haupteingangs her. Die bestimmenden Motive von Wehrhaftigkeit und Triumph werden damit erneut aufgenommen. Die in älteren Aufnahmen abgebildeten Akrotere sind bereits in Darstellungen aus der Zeit der DDR nicht mehr vorhanden. Gleiches gilt für die Rüstungen und Trophäen der Attika, die ursprünglich das Gebäude nach oben abschlossen.

Die symmetrische Anlage der Albertvorstadt und der künstlich aufgeschüttete Sockel, mit dem das Arsenalgebäude exponiert wird, unterstreichen die Hierarchie der Baukörper. Die Erhöhung des Arsenals erinnert unweigerlich an die Tempelarchitekturen der Nationalmuseen des späten 19. Jahrhunderts, wie sie etwa auch für die Berliner Nationalgalerie charakteristisch sind. Teil dieser heroisierenden Inszenierung des Militärs war die Sammlung im Inneren des ursprünglichen Arsenals. Den Grundbestand bildeten neben der »Thierbachschen Gewehrsammlung« (Lisewski 2012:32ff.) Beutewaffen und Trophäen des ehemaligen Dresdner 
Zeughauses, welche von der ruhmreichen Niederwerfung der Feinde zeugten. Der Doppelcharakter Dresdens als Stadt der Kunst und des Militärs wird dabei besonders deutlich. Einige Jahre nach Fertigstellung des Arsenalhauptgebäudes wurden die reichen Bestände des alten Dresdner Zeughauses von 1884 bis 1889 vom »Tempel des Waffenruhmes« zum »Tempel der Musen« umgebaut (Lisewski 1997:13). Das nunmehr Kunstschätze beherbergende alte Zeughaus erhielt fortan den $\mathrm{Na}$ men Albertinum. Ebenso wie für die im Entstehen begriffene Militärstadt stand auch hier der sächsische Fürst als Financier und Namensgeber Pate. Der im Norden Dresdens gelegene Stadtteil verweist damit auf eine Facette der Stadtgeschichte, die in den bestimmenden Topoi der Stadtnarrative vom »Elbflorenz« Canalettos und August des Starken kaum je thematisiert wurde. "Das alte Dresden«, wie es etwa durch Fritz Löfflers gleichnamiges Buch (1981, Orig. 1955) fest im öffentlichen Bewusstsein der Stadt verankert ist, scheint das andere Dresden zu überragen. ${ }^{4}$ Dresden war jedoch immer auch eine Stadt des Militärs und ist es bis heute (Heuser 2006:4). Dass dieses doppelte Dresden lange eine der größten Garnisonsstädte Deutschlands war (Kunz 2003:10), scheint jedoch kein breit geteilter Wissensbestand zu sein. Albertinum und Albertstadt, der Tempel der Musen und der Tempel der Waffen, Stadt und Militär standen stets in enger Verbindung.

Bereits kurze Zeit nach Fertigstellung des Arsenalgebäudes führten die militärstrategischen Entwicklungen und die Notwendigkeit der permanenten Kampfbereitschaft moderner Heere dazu, dass die getrennte Aufbewahrung von Truppen und Waffen ihren Sinn und damit auch Arsenale alter Prägung ihre Daseinsberechtigung verloren (Kunz 2003:7). Aufgrund veränderter militärtechnischer Anforderungen war das Arsenalgebäude zum Anachronismus geworden. Indem das Gebäude am 2. Mai 1897 der Öffentlichkeit zugänglich gemacht wurde, wird es schließlich fortan als Museum genutzt. Nicht mehr als Verwahrungsort für Beutewaffen und Kriegsgerät, sondern als Schaustätte militärtechnischer Leistungen wird das Areal zunehmend zur Selbstinszenierung der noch jungen deutschen $\mathrm{Na}$ tion, vor allem aber des sächsischen Heeres genutzt. Ungeachtet der mannigfaltigen Brüche in der deutschen Geschichte weisen die militärgeschichtliche Prägung und museale Nutzung der Anlage dennoch eine erstaunliche Beständigkeit vom Sächsischen Königreich, dem Deutschen Kaiserreich, der Weimarer Republik über die Zeit des Nationalsozialismus und die Deutsche Demokratische Republik bis in die Gegenwart auf. ${ }^{5}$ Obwohl die Dresdner Albertvorstadt heute bis auf die

4 So findet sich in Fritz Löfflers auflagenstarkem Buch, welches die Erinnerung an die zumeist kriegszerstörten oder -beschädigten Bauten durch zahlreiche Abbildungen in der Dresdner Stadtgemeinschaft wachhielt, kein einziges Gebäude der Dresdner Albertstadt.

5 Im Kaiserreich und in der Weimarer Republik lag der inhaltliche Fokus auf der sächsischen Armee. Die Bezeichnungen der Sammlungen in jener Zeit als »Königliche Arsenal-Sammlung«, »Königlich Sächsisches Armeemuseum « und schließlich »Sächsisches Armeemuseum« (Pieken 2011:17) zeugen davon. 
Graf-Stauffenberg-Kaserne und das MHM weitgehend zivil genutzt wird (Pieken 2012b:90; von Loh 2012:93), hat das militärgeschichtliche Erbe aller historischen Episoden im Stadtraum, in den Straßennamen sowie in der Architektur der fast in Gänze erhaltenen >Soldatenstadt< Spuren hinterlassen. ${ }^{6}$

Der verlorene Erste Weltkrieg und die Revolution von 1918/19 brachten das Ende der Monarchie. Die königliche Militärstadt war damit durch den Lauf der Geschichte erneut aus der Zeit gefallen. Die Widmung AUSPICIIS ALBERTI REGIS verlor spätestens mit dem Abdanken des Königs ihren Sinn. Dass das Gebäude ebenso wie der Staat nun nicht mehr der Macht und dem Schutz des Fürsten unterstanden, soll der damalige König von Sachsen, Friedrich August III., zudem mit den Worten »dann Macht euren Dreck alleene« quittiert haben (Beyer 2012:67). Als Folge des Versailler Vertrages wurden die Maschinen der Artilleriewerkstätten und Munitionsfabriken verschrottet. In den leerstehenden Räumlichkeiten des Arsenaldepots siedelte sich nun zivile Industrie an (Gräfe 2012:30). Diese ist bis heute vor allem im Norden des Arsenalareals anzutreffen. Die Zukunft des Armeemuseums blieb zunächst ungewiss. Öffentlich wurden sowohl dessen Schließung und die Vernichtung seiner Bestände ebenso wie die Aufwertung im Sinne nationalistischer Revision gefordert (Kunz 2003:9). Ungeachtet dessen, dass in dieser Zeit weite Teile der Kasernen anderen Nutzungen zugeführt wurden, beherbergte das Arsenalgebäude auch in der Weimarer Republik das Sächsische Armeemuseum. Mit dem Umzug der Infanterieschule der Reichswehr von München nach Dresden, welcher durch den gescheiterten Hitlerputsch erforderlich wurde, wurde Dresden 1928 zu einer der größten Garnisonen der Weimarer Republik (Beyer 2012:68). Die große militärische Bedeutung der Stadt lässt sich auch anhand der Tatsache verdeutlichen, dass jeder 23. Soldat der Reichswehr in Dresden stationiert war (Wehner 2012:56). War der Putsch von 1923 noch gescheitert, so ergriffen bekanntlich 1933 die Nationalsozialisten die Macht, wodurch die Zukunft des Arsenalhauptgebäudes auf nunmehr bereits bekannte Weise erneut unbekannt wurde.

Das statistische Verhältnis änderte sich bis 1939 dahingehend, dass nur noch etwa jeder 200. deutsche Soldat in Dresden stationiert war (a.a.O. 57). Nichtsdestotrotz blieb Dresden auch in dieser Zeit von großer militärischer Bedeutung. Dies zeigt sich darin, dass in Dresden-Klotzsche die erste Luftkriegsschule Deutschlands errichte wurde. Dresden war zudem Standort der ersten Panzereinheit der Wehrmacht; eines »Stammbataillons« der SS-Pioniere sowie eines Außenlagers des

$6 \quad$ Neben den denkmalgeschützten Bauwerken der Albertstadt sind es vor allem die weitläufigen Anlagen der Graf-Stauffenberg-Kaserne sowie das Arsenalgelände, die den militärischen Charakter des Stadtteils bis heute prägen. Auch zeugen zuweilen noch Reste der Außenwerbung von Geschäften, die militärbezogene Dienstleistungen anboten, von der einstigen wirtschaftlichen Bedeutung der Garnison für die Bevölkerung. So ist etwa an der Fassade eines Hauses in der Rudolf-Leonhard-Straße noch sichtbar, dass hier einst die »Anfertigung von Uniformkragen«beworben wurde. 
Konzentrationslagers Flossenbürg (Wehner 2012:60). Der Historiker Jens Wehner kommt deshalb zu dem Schluss, dass die Dresdner Garnison einen »wesentlichen Beitrag für den Eroberungs- und Vernichtungskrieg der deutschen Wehrmacht« leistete und somit »im Koordinatensystem des Dritten Reiches einen bedeutenden Platz« einnahm (Wehner 2012:63). Mit der Machtergreifung der Nationalsozialisten 1933 wurde auch das Museum in den Dienst der allgemeinen Kriegsvorbereitung gestellt (Kunz 2003:9). Mit dem Überfall der Wehrmacht auf Polen wuchsen die Bestände des nunmehr »Heeresmuseum Dresden«, später »Armeemuseum Dresden« genannten Arsenalgebäudes. Am »Tag der Wehrmacht«, am 23. Mai 1941, wurden Beutewaffen von aktuellen Kriegsschauplätzen ausgestellt (a.a.O. 10). Erneut bot der Ort eine treffliche Bühne für die Inszenierung von militärischer Stärke und der ruhmreichen Niederwerfung der Feinde. Verweise auf die Zeit des Nationalsozialismus finden sich in der Albertstadt heute vor allem anhand von Straßennamen und Platzbezeichnungen, die an die Gruppe um den Hitlerattentäter Stauffenberg erinnern. Die ehemalige Nordallee, die die Haupterschließungsachse der Albertstadt darstellt, wurde 1991 in Stauffenbergallee umbenannt. Der Schnittpunkt von Stauffenbergallee, (Friedrich) Olbrichtplatz und Hans-Oster-Straße befindet sich vor dem Arsenalhauptgebäude und damit im Zentrum der Albertstadt. Diese stadträumliche Zentralität verweist bereits auf die Traditionsbildung der Bundeswehr, die mit den Mitgliedern der Gruppe des 20. Juli 1944 ein nicht unumstrittenes Erbe beschwört und ins Zentrum ihrer Selbstthematisierung stellt. ${ }^{7}$

Albertstadt und Armeemuseum überstanden die Bombenangriffe auf Dresden in der Nacht vom 13. auf den 14. Februar 1945 fast unversehrt (Rogg 2012:102). Nach 1945 begann abermals eine neue Episode in der Geschichte des Ortes. Der ehemalige Hort der Beutewaffen wurde selbst zur Beute und von der Roten Armee nach Moskau und Leningrad abtransportiert. Mit der Direktive des Alliierten Kontrollrates, alle »Museen und Ausstellungen militärischen Charakters« aufzulösen, wird auch das Armeemuseum 1947 geschlossen (Kunz 2003:10). Nach einer Interimszeit von zehn Jahren beginnt die Nationale Volksarmee (NVA) erneut damit, ein militärhistorisches Museum zu planen. Das dafür anvisierte Marmorpalais in Potsdam ist als Ort des »ersten sozialistischen deutschen Armeemuseums « allerdings nur bedingt geeignet, weshalb man schließlich 1967 wieder auf das vormalige Arsenalhauptgebäude in Dresden zurückkommt (a.a.O. 11f.). Baulich erhielt das Gebäude eine moderne Ergänzung in Gestalt eines flachen Vorbaus, der dem Haupteingang vorgelagert war. Außerdem wurde das Staatswappen der DDR als weithin sichtbares Zeichen staatlicher Macht im Zentrum des triumphalen Eingangs, ungefähr auf der Höhe der einstigen königlichen Widmung, angebracht. 
Abbildung 27: Das Armeemuseum der NVA im Jahr 1972. Eingangsbereich mit vorgelagertem Flachbau und dem Staatswappen der DDR.

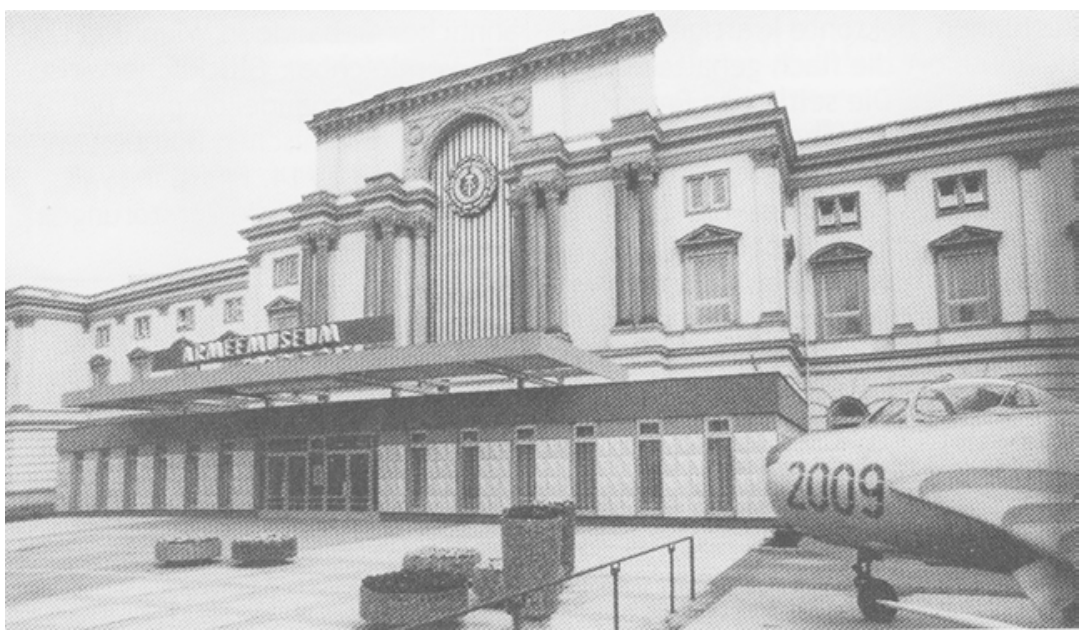

Im Zentrum der Ausstellung stand die Konstruktion von »revolutionären Traditionen« (Rogg 2012:102). Von den als >frühbürgerliche Revolution ‘ bezeichneten Bauernkriegen des 16. Jahrhunderts über die Befreiungskriege gegen Napoleon bis zur Befreiung vom Hitlerfaschismus durch die Rote Armee war hier alles in einen teleologisch gerichteten Geschichtsverlauf eingefasst. So wie die BRD in der Nachkriegszeit die Allianz mit den Westmächten in ihr Selbstbild integriert, so wurde in der DDR die Waffenbrüderschaft mit der Sowjetunion beschworen und mit der Betonung der preußisch-russischen Allianz gegen Frankreich während der Befreiungskämpfe über die Geschichte legitimiert. Im Innenhof des MHM befindet sich heute ein Gemälde von Bruno Dolinski, welches Geschichte als Abfolge revolutionärer Umwälzungen thematisiert. Obwohl dieses nicht Teil des Armeemuseums der NVA war, verdeutlicht es dennoch diesen Aspekt und das Geschichtsbild des SED-Staates.

Zudem konnte durch die Grenzziehung zwischen Faschismus und Kommunismus eine legitime deutsche Tradition des Antifaschismus betont werden. Der internationale Kampf gegen den Faschismus erlaubte, die deutschen Kommunisten in die Nationen einzureihen, die sich gegen den Faschismus erhoben hatten. Der Umweg über den Internationalismus bot die Möglichkeit, den diskreditierten Teil der deutschen Geschichte als Barbarei des Nazismus von der freiheitlich- 
antifaschistischen Tradition abzuspalten. ${ }^{8}$ Der antifaschistische Internationalismus erlaubte so, eine Traditionslinie zu konstruieren, mit der sich auch die Streitkräfte der DDR von ihrer Vergangenheit abgrenzen konnten. Ohnehin hatte die internationale »kommunistische Humanität geschichtsnotwendig das letzte Wort « (Knigge 2009:125, Herv. im Orig.). Diese Form der Selbstthematisierung im Einklang mit der marxschen Geschichtsphilosophie kann vor dem Hintergrund der bisher gewonnenen Erkenntnisse also als historizistischer Kollektivierungsdiskurs (Kap. 5.4) bezeichnet werden.

Tatsächlich war das vorläufige Ende der Geschichte bereits 1990 auch im NVAArmeemuseum erreicht - freilich ganz anders, als das marxistisch-leninistische Geschichtsbild es vorhergesehen hatte. ${ }^{9}$ Durch die historischen Ereignisse war das Museum erneut aus der Zeit gefallen und die Zukunft erneut auf bekannte Weise unbekannt.

Mit der Wiedervereinigung geht die zuvor drastisch reduzierte Truppenstärke der NVA in der Bundeswehr auf (Kunz 2003:14) Mit den Soldaten und Beständen der DDR-Armee musste die Bundeswehr ein weiteres Erbe deutscher Militärgeschichte integrieren. Neben den dominanten Hoheitssymbolen der DDR, welche unmittelbar nach der Wiedervereinigung von der Fassade des Museums entfernt wurden, verschwindet auch der flache Eingangsbau der 1970er Jahre. Dieser wird allerdings erst im Zuge der umfangreichen Neugestaltung des Gebäudes ab 2001 vollständig demontiert (a.a.O. 15f.). Als ein bauliches Zeugnis aus der Zeit der DDR haben sich im Norden des Arsenalgeländes die denkmalgeschützten Gebäude der VEB Turbinenfabrik erhalten, in welchen heutzutage sowohl militärisch als auch zivil genutzte Werkstätten untergebracht sind.

Mit dem Entschluss des Bundesministers der Verteidigung vom 14. Juni 1994 über die »Konzeption für das Museumswesen in der Bundeswehr« wurde bekräftigt, dass dem Militärhistorischen Museum Dresden die Funktion eines Leitmuseums im Museums- und Sammlungsverbund der Bundeswehr zukommt. Das ehemalige Arsenalhauptgebäude dient somit der Bundeswehr und damit bereits dem sechsten deutschen Staat als zentraler Ort der Selbstthematisierung. Trotz dieser Konstanz der Repräsentation staatlicher Streitkräfte sowie der anhaltenden militärischen Prägung des Stadtteils sind erneut andere Formen der Selbstdarstellung erforderlich. Ungeachtet des für eine Vielzahl der militärischen Bauten der Albertvorstadt ausgesprochenen Denkmalschutzes wurde mit Beginn der Planung für die

8 Diese Form der Traditionsbildung wird im Gedenken an den Aufstand der Cefangenen von Buchenwald besonders anschaulich (Knigge 2009). Die diskursive Konstruktion einer antifaschistischen Internationalen, die die Deutschen zu Cleichen unter Gleichen werden ließ, findet sich auch in dem vom Militärverlag der DDR herausgegebenen Buch »Stärker als die Wölfe« (Kühn/Weber 1984: insb. 82ff.).

9 Für eine detailliertere Analyse der Raum- und Zeitbegriffe auf der Ebene der politischen Selbstlegitimation des SED-Staates siehe Kibel (2019). 
Abbildung 28: Das Wandbild von Bruno Dolinski entstand Mitte der 1970er Jahre und zeigt Motive der Befreiungskriege. Die Graffiti im unteren Drittel zeugen von der erneuten Revision dieses Geschichtsbildes.

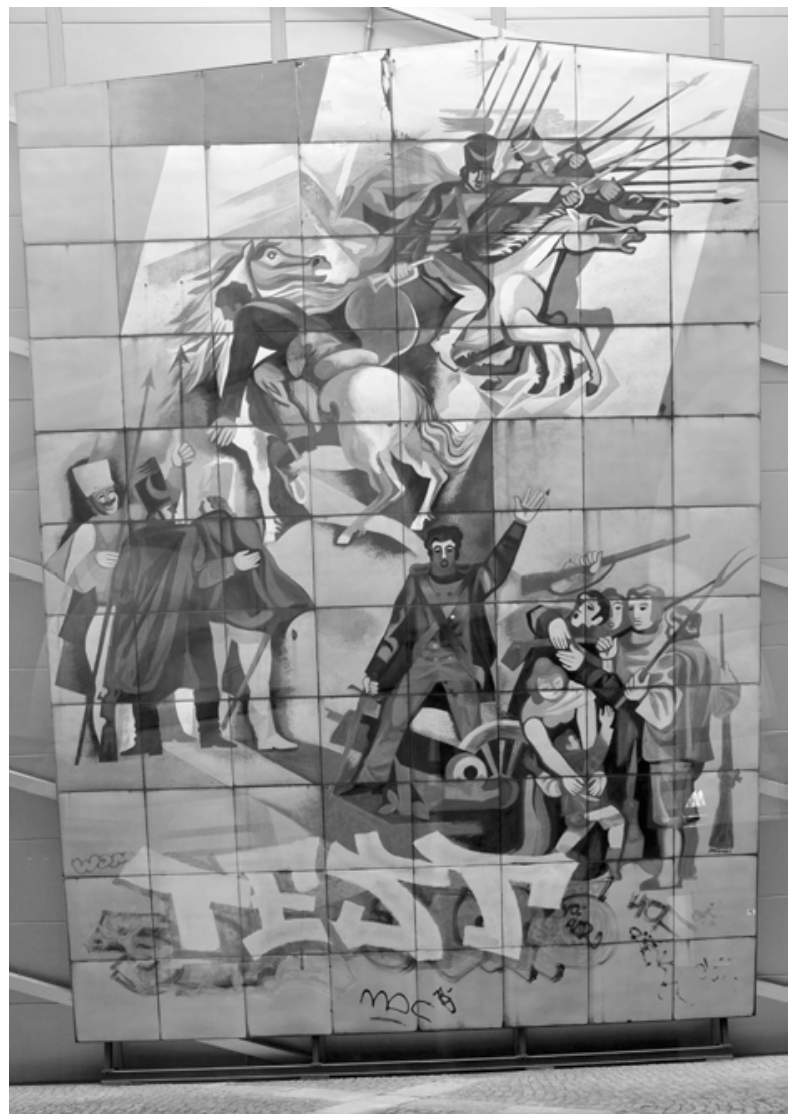

Neukonzeption der Ausstellung auch eine weitreichende architektonische Neugestaltung des Arsenalgebäudes angestrebt. Wie tiefgreifend die bauliche Veränderung ausfallen würde, war zum Zeitpunkt des Wettbewerbs noch nicht zu erahnen. Entsprechend seiner Geschichte im 20. Jahrhundert sahen das Gebäude und die Ausstellung, die es beherbergte, erneut einer ungewissen Zukunft entgegen.

Anstelle der Militaria-Sammlungen des ehemaligen Arsenals und »Schatzgewölbes« sollte nun ein »sehenswertes Museum« entstehen, welches den »museumspädagogischen Anforderungen des zu Ende gehenden 20. und des beginnen- 
den 21. Jahrhunderts" gewachsen sein musste (Rauchensteiner 2011:11). Entgegen den denkmalpflegerischen Bemühungen um das Neue Museum in Berlin stand dabei die gezielte Abgrenzung von einer problematischen Vergangenheit im Vordergrund, die auch architektonisch zum Ausdruck gebracht werden sollte. Zwar wird das Arsenalhauptgebäude in der Denkmalbegründung des Landesdenkmalamtes als das "aufwendigste und architekturhistorisch interessanteste Bauwerk der Albertvorstadt« beschrieben, dessen öffentliches Erhaltungsinteresse aus seiner »baukünstlerischen, militärgeschichtlichen und städtebaulichen Bedeutung« resultiere (Müller 2012). Dennoch führte dies nicht dazu, dass die Bausubstanz unantastbar wurde. Wurde das Neue Museum von den Kollektivierungsdiskursen übereinstimmend als wertvoll thematisiert und von allen Beteiligten ein respektvoller Umgang mit der historischen Substanz eingefordert, so wurden die ersten Entwürfe für die Umgestaltung des Arsenalgebäudes mit dem Hinweis zurückgewiesen, dass »die meisten Architekten vor dem historischen Gebäudekomplex $z u$ viel Respekt« gehabt hätten (Rauchensteiner 2011:14, Herv. JK).

Der Entwurf des Architekten Daniel Libeskind, der den Wettbewerb für sich entscheiden konnte und im Jahr 2002 den Auftrag zur Umgestaltung erhielt, durchdringt mit einem massiven Keil aus Stahl und Beton das Gebäude im Innern wie im Außenbereich vertikal. Die windschiefe Dreiecksform steht in deutlichem Kontrast zur Symmetrie der Fassade. Im vorderen Teil des Gebäudes überragt der Keil den triumphalen Mittelrisaliten steil und fällt im hinteren Gebäudeteil, den er ebenfalls durchdringt, flach ab. Durch die Stahllamellen des modernen Baukörpers hindurch sind die asymmetrischen Querverstrebungen im Inneren des Keils je nach Beleuchtung entweder kaum oder aber deutlich zu erkennen. Der massive Charakter des Keils wird je nach Tageslichteinfall verstärkt oder abgemildert. Die Asymmetrie des Keils wird durch die Wegeführung im Äußeren aufgenommen. Neben dem unmittelbaren Gebäudeumfeld werden durch die Spitze des Keils, die auf einen der Dresdner Kriegstrümmerberge verweist, neue stadträumliche Bezüge hergestellt. Durch die Neu-Anordnung der Architektur (Spacing) und die Syntheseleistung der Diskursivierung (Löw, Kap. 4) entsteht eine neue Relationierung von Altstadt und Albertstadt. Indem auf die Zerstörung Dresdens verwiesen wird, werden die Geschichte der Stadt und das verheerende Zusammenspiel der beiden Teile des doppelten Dresdens auf neue Weise verräumlicht.

Nachdem der Umbau des Arsenalhauptgebäudes und die konzeptionelle Neuausrichtung der Sammlung abgeschlossen waren, konnte das vollständig umgestaltete Arsenalhauptgebäude schließlich am 14. Oktober 2011 zum wiederholten Mal in seiner Geschichte feierlich eröffnet werden. An dem Keil, der nun die Fassade des alten Gebäudes senkrecht durchteilte, schieden sich ebenso die Geister der nun aufkommenden Debatte. 


\subsubsection{Die institutionelle Konstellation}

Nach der Darstellung der wechselhaften Ortsgeschichte ist es zunächst wichtig darauf hinzuweisen, dass ungeachtet der tiefgreifenden Umgestaltung des Museums dessen Funktion konstant blieb. Denn so wie das ehemalige Arsenalhauptgebäude weiterhin im Zentrum des sanierten Arsenalkomplexes steht, stellt das neue MHM erneut ein Abbild staatlicher Selbstvergewisserung dar. Mit der Nennung der »Konzeption für das Museumswesen der Bundeswehr« (1994) ist bereits auf die besondere institutionelle Konstellation hingewiesen, die im Folgenden skizziert werden soll. Da dem MHM als Leitmuseum der Bundeswehr erneut »eine Schlüsselstellung« zukommt (Rogg 2011a:13), wird es oft als pars pro toto für das Selbstbild der Institution und als deren musealer Ausdruck bezeichnet. Neben der Darstellung der involvierten Akteure wird im folgenden Unterkapitel die Entwicklung der Neukonzeption nachgezeichnet, um die später zu analysierenden Diskursdokumente benennen und zuordnen zu können.

\section{Akteure des Diskurses aus Wissenschaft und Politik}

Am Anfang stand also der am 14. Juni 1994 erlassene Beschluss des Bundesministers der Verteidigung zur »Konzeption für das Museumswesen in der Bundeswehr« (1994), mit welchem dem MHM die Funktion eines Leitmuseums im Museums- und Sammlungsverbund der Bundeswehr zukommt (Kunz 2003:15). Obwohl die Entscheidungsträger - Bauherrin ist die Bundesrepublik, vertreten durch das Bundministerium der Verteidigung (BMVg) - zu diesem Zeitpunkt noch keinen umfangreichen Neubau erwogen, ging es darum, »notwendige grundlegende Veränderungen am ehemaligen Armeemuseum der DDR« durchzuführen. Das gesteckte Ziel bestand von Beginn an und allen historischen Widrigkeiten zum Trotz darin, den Ort, das Gebäude und das Museum so zu gestalten, dass »sich die Bundeswehr und darüber hinaus der Gesamtstaat mit diesem Museum identifizieren konnten.« (Rauchensteiner 2011:11). Dieser Aspekt muss deutlich unterstrichen werden, da die Größe der Aufgabe damit prägnant artikuliert wird. »Bundeswehr« und »Gesamtstaat« müssen sich mit diesem Museum identifizieren können. Die Funktion des Gebäudes als Identifikationsort mit einem staatlichen Selbstbild bleibt in der Gegenwart erhalten. Die eigentümliche Rede vom »Gesamtstaat«, der sich mit diesem Haus identifizieren müsse, macht deutlich, dass das identitätsstiftende Potenzial, welches dem Haus abverlangt wird, nicht allein auf die Integration der Bundeswehr beschränkt bleibt, sondern zudem gesamtgesellschaftliche Strahlkraft entfalten sollte.

Durch die enge Verbindung von Staat und Museum kann die Umgestaltung des MHM durchaus als eine Repräsentation staatlicher Macht verstanden werden. Durch den methodischen Zugang der wissenssoziologischen Hermeneutik (Kap. 3) 
wird allerdings gewährleistet, dass auch anderslautende Rezeptionen dieses staatlichen Ausdrucks analysiert werden können. Da diese Oberflächenhermeneutik jedoch nicht ohne die Kenntnis der strukturellen Dimension ihres Gegenstandes auskommt, muss im Folgenden die institutionelle Konstellation der Akteure dargestellt werden. Bereits mit der Wiedervereinigung 1990 wurde das Museum dem Militärgeschichtlichen Forschungsamt (MGFA) unterstellt. ${ }^{10}$ Mit der Entscheidung von 1994 wurde aber schnell klar, dass die problematische Geschichte des Ortes einem Museum, mit dem sich der »Gesamtstaat« identifizieren könne, im Weg stand. 1998 schließlich wird der Erweiterte Wissenschaftliche Beirat (EWB) vom Bundesminister der Verteidigung berufen. Dieser sollte das Museum »beraten und notfalls korrigierend begleiten«. Dies war die »Geburtsstunde des Erweiterten Wissenschaftlichen Beirates «(EWB), welcher aus dem Wissenschaftlichen Beirat (WB) des MGFA hervorging. Im Unterschied zum WB, der primär auf Forschung ausgerichtet war, bestand die Aufgabe des EWB explizit darin, sich der neuzugestaltenden Ausstellung zu widmen (Rauchensteiner 2011:11). Die komplexe Aufgabe der Umgestaltung des Museums in identitätspolitisch schwierigem Gelände und die Ausarbeitung einer Konzeption für das neue Leitmuseum bedurften einer Vielzahl wissenschaftlicher und personeller Ressourcen, die direkt von staatlicher Seite (dem Bundesminister der Verteidigung) berufen und einer wissenschaftlichen Institution der Bundeswehr (dem MGFA) unmittelbar zugeordnet waren. Der EWB wird auch nötig, so lässt sich daraus folgern, da die Überführung der deutschen Militärgeschichte in ein kohärentes Narrativ der Selbstdarstellung mit den bisherigen Konzepten und militärgeschichtlichen Darstellungsformen nicht zu bewerkstelligen war.

Die Bedeutung des EWB, der aus »renommierten Historikern, Museumswissenschaftlern und einem aktiven sowie einem pensionierten General der Bundeswehr« bestand (Kraus 2011:43), wird vom ehemaligen stellvertretenden Leiter des Museums als maßgeblich für die »Selbstvergewisserung und Selbstbestimmung der Projektgruppe Neukonzeption« bezeichnet (a.a.O. 47). Dennoch, so zeigt die Darstellung der institutionellen Zusammenhänge, ist der EWB stets dem MGFA, damit dem Referatsleiter Innere Führung und über diesen schließlich dem BMVg rechenschaftspflichtig. Denn das MGFA untersteht dem Referatsleiter Innere Führung, dessen Position direkt im Führungsstab der Streitkräfte des BMVg angesiedelt ist. Dieser nimmt über seinen »Referenten für das Museumswesen der Bundeswehr « direkten Einfluss auf die inhaltlichen und administrativen Linien bei der Verwirklichung der neuen Ausstellung.«(a.a.O. 41f). Die Weisungsbefugnis deshalb wurde das Amt 2012 in Zentrum für Militärgeschichte und Sozialwissenschaften der Bundeswehr (ZMSBw) umbenannt. 
des MGFA und damit des Bundesministeriums hat also auch über die Phase der Neukonzeption hinaus Bestand: "Das MHM ist als militärische Dienststelle truppendienstlich und fachlich dem Militärgeschichtlichen Forschungsamt (MGFA) in Potsdam unterstellt.« (Ebd.). Hier werden zwei Aspekte ersichtlich: Der Einfluss der Inneren Führung ist groß und unmittelbar. Neben der direkten Einflussnahme wird außerdem deutlich, dass das MHM als Dienststelle der Bundeswehr fortlaufend dem Einfluss der staatlichen Institutionen ausgesetzt bleibt.

Dass durch den Beirat dennoch richtungsweisende Impulse für die Konzeption des Museums gegeben wurden, zeigt das Grundsatzpapier des Historikers Gregor Schöllgen (der ebenfalls Teil des EWB war). Dieses wurde 1999 vom BMVg in Auftrag gegeben. Darin wird dafür plädiert, Militärgeschichte als integrativen Bestandteil der Geschichtswissenschaft zu verstehen (Schöllgen, zitiert nach Rauchenstein 2011:11). Daraus resultierte der Anspruch, Militärgeschichte im Zusammenhang von geschichtlichen Gesamtentwicklungen einer Epoche darzustellen (a.a.O. 12). Eine Weitung des inhaltlichen Fokus war also fachlich gewünscht, womit nicht mehr nur exklusiv Militärgeschichte, sondern ebenso zivile Aspekte des Krieges thematisiert werden sollten. Diese thematische Weitung ist eine der maßgeblichen Richtungsentscheidungen des EWB und definierte eine der Leitlinien der späteren Ausstellung. Außerdem bedeutet dies eine Revision einer noch 1992 vom MGFA formulierten Forderung. Danach sollte die Darstellung der deutschen Militärgeschichte vom Heiligen Römischen Reich Deutscher Nation bis in die Gegenwart unter besonderer Berücksichtigung der sächsischen Militärgeschichte im Mittelpunkt der Ausstellung stehen (a.a.O. 13). Auch ein umfangreicher architektonischer Eingriff und ein weitreichender Neubau waren anfänglich keineswegs geplant. Die Arbeiten des EWB hatten also eine deutliche konzeptionelle Neubestimmung zur Folge. Diese führte sowohl zur inhaltlichen Erweiterung der Ausstellung als auch zu einer umfassenden architektonischen Veränderung des bestehenden Museums. Die dadurch herbeigeführte Hauptverschiebung in der Entwicklung des Museumskonzeptes bestand also vom Rückgriff auf die »Strukturen der ursprünglichen Albertstadt« (Kunz 2003:14) zu deren umfangreichen Revision.

Im Dezember 2001 werden die Ergebnisse des EWB dem Beirat des Ministers für das Militärgeschichtliche Forschungsamt (MGFA) präsentiert. Das Konzept, welches mit wenigen Änderungen angenommen wurde, bildete die Grundlage des Wettbewerbs, mit dem das Team aus Architekten und Ausstellungsgestaltern ermittelt werden sollte (Kraus 2011:41). Im Jahr 2002 wurde schließlich der Architekt Daniel Libeskind mit der Sanierung des Altbaus und der Gestaltung eines Neubaus beauftragt. Außerdem erhielten die Innenarchitekten HG Merz und Barbara Holzer den Auftrag für die Gestaltung der Ausstellung.

Das Geflecht der institutionellen Zusammenhänge ist nicht leicht zu durchschauen. Es ist aber wichtig darauf hinzuweisen, dass das MHM in der Konzeption seiner Neugestaltung sowie in seiner gegenwärtigen Tätigkeit als Dienststelle 
der Bundeswehr (Kraus 2011:43) direkt mit der höchsten Ebene staatlicher Institutionen verbunden ist. Darüber hinaus bleibt das MHM als Ort der Ausbildung von Führungskräften der Armee und in deren Legitimierung auf eine staatliche Funktion bezogen. Anhand der Darstellung der institutionellen Konstellation kann verdeutlicht werden, dass das musealisierte Selbstbild des MHM in hohem Maße von den Entscheidungen staatlicher Akteure abhängt. Dass der anhaltende Einfluss auch über die Phase der konzeptionellen Verständigung hinaus besteht, wird nicht nur im »direkten Einfluss « des MGFA und des Referatsleiters Innere Führung deutlich (Kraus 2011:41f.), sondern ebenso in der Koordination der Bauaufgaben, die der Wehrbereichsverwaltung Ost (WBV Ost) und damit einer weiteren staatlichen Behörde oblag (a.a.O. 43).

\section{Zuordnung der Diskursdokumente}

Nachdem die institutionelle Konstellation verdeutlicht wurde, können nun die Diskursdokumente zugeordnet werden. Jeder der bisher genannten Akteure nimmt durch Erlässe (BMVg 1982, 1994, 2008, 2018a, 2018b), Konzepte (Konzeptgruppe 2003; Merz/Holzer 2003; Pieken 2010a, 2010b, 2012a) sowie eine Vielzahl von Publikationen, in denen Architektur und Ausstellung des Museums gedeutet werden (Libeskind 2003, 2010, 2011; Pieken 2010b, 2012a; Libeskind/Pieken 2013; Pieken/Rogg 2011a, 2011b), am Diskurs des MHM teil. Diese Diskursdokumente sind ein wichtiger Transmissionsriemen zwischen dem Selbstverständnis der Institution und der Öffentlichkeit. Dadurch, dass die Bundeswehr der öffentlichen Akzeptanz bedarf, muss ihr Leitmuseum auch die Aufgabe der Legitimation des Militärs erfüllen (Konzeptgruppe 2003). Neben den beiden Ausstellungsführern, die Museumsdirektor Matthias Rogg und der Projektleiter der Neukonzeption Gorch Pieken im Jahr 2011 editierten, stellen auch die bereits ab dem Jahr 2000 regelmäßig vom MHM herausgegebenen Hefte mit dem Titel »Sammeln, Bewahren, Erforschen, Ausstellen« einen wichtigen Teil der Diskursivierung dar. Dies gilt insbesondere für die Ausgaben Nr. 1 und Nr. 5, in denen sowohl die Ausstellungen von 1990 bis 2000 sowie die Geschichte des Arsenals als Museum ausführlich dargestellt werden (Scheerer 2000, 2003). Außerdem boten die Museumshefte sowohl der Expertenkommission der Neukonzeption, dem Architekten des Neubaus, Daniel Libeskind, als auch den Innenarchitekten HG Merz und Barbara Holzer die Möglichkeit der umfangreichen Darstellung ihrer Entwürfe. Gerade die vermittlungsbedürftige und in weiten Teilen auf Versprachlichung angewiesene Architektur Libeskinds (Kap. 3) ist Gegenstand zahlreicher weiterer Veröffentlichungen. Zudem werden die Entwürfe Libeskinds auf dessen Homepage erklärt. Auch die so veröffentlichte Deutung der Architektur ist damit der Analyse zugänglich.

Vor allem der Einfluss des Referatsleiters Innere Führung macht deutlich, dass das MHM ein unmittelbarer Ausdruck dieses zentralen Selbstbestimmungsnarra- 
tivs der Bundeswehr ist. Dass das Konzept der Inneren Führung das Selbstverständnis der Bundeswehr definiert, wird bereits im Titel der zentralen Dienstvorschrift »Innere Führung - Selbstverständnis und Führungskultur« (2008) deutlich. Als zentraler Zweck dieser Regelung wird explizit die »Festlegung der Konzeption der Inneren Führung als grundlegendes Prinzip des Dienstes in der Bundeswehr« hervorgehoben. Des Weiteren kodifiziere dieses Konzept das "Selbstverständnis der Soldatinnen und Soldaten« (2008, Titelseite). Als »zentrale Dienstvorschrift» hat die Konzeption der Inneren Führung zudem verbindlichen Charakter. Gleiches gilt für die unmittelbar aus der Feder des Bundesministeriums der Verteidigung stammenden Traditionserlässe von 1965, 1982 und deren Neufassung, die die Bundesverteidigungsministerin am 28. März 2018 anlässlich der Umbenennung einer Kaserne unterzeichnete. Allein die Existenz dieser Dokumente und die Reformulierung des Traditionserlasses von 1982, zur welcher sich die Ministerin Ursula von der Leyen nach dem Eklat um Nazidevotionalien in Kasernen der Bundeswehr veranlasst sah, verdeutlichen die Virulenz und die Schwierigkeiten der Traditionspflege der Bundeswehr.

Überdies steht das "grundlegende Prinzip des Dienstes in der Bundeswehr" (ebd.) immer wieder im Zentrum der Kritik. Vor allem die ablehnende Haltung gegenüber dem MHM, wie sie im medialen Gegendiskurs unüberhörbar ist, nimmt immer wieder Bezug auf das Konzept der Inneren Führung. Die diskursive Verbindung zwischen der Neukonzeption und der Inneren Führung bleibt auch hier, diesmal negativ gewendet, erhalten; beispielsweise wenn dieses Selbstverständnis als »Innerer Wahnsinn« diffamiert wird (Springer, Sezession im Netz 2012). $\mathrm{Zu}$ den umfangreichen Beschlüssen, Erlässen, Konzeptpapieren und Ausstellungsführern kommt so ein weiteres Korpus an Zeitschriftenbeiträgen und Zeitungsartikeln. Zwar übernimmt der medial abgebildete Diskurs weitgehend die Deutungen der Museumsmacher; harsche Kritik hingegen und gänzlich andere Deutungen von Architektur und Ausstellung kommen vonseiten politisch teilweise weit rechts stehender Zeitschriften (Meyer, Junge Freiheit 2012; Frisch, Nationalzeitung 2011). Wie bereits ausgeführt wird dieser Gegendiskurs vor allem dazu dienen, die offiziellen Selbstdarstellungen und Deutungen von Architektur und Ausstellung besser zu konturieren.

Mit der Darstellung der institutionellen Konstellation lässt sich einerseits ein Beleg dafür finden, dass die militärische Nutzung ungebrochen und die selbstvergewissernde Schaffung von Identitätsangeboten erhalten bleibt. Andererseits zeigt die Fülle der Publikationen auch, dass dieses Angebot vermittlungsbedürftig und die Architektur, die dies ausdrücken soll, deutungsbedürftig ist. Im Folgenden soll das Selbstbild der Bundeswehr, wie es in den Traditionserlässen und der Konzeption der Inneren Führung kodifiziert ist, genauer dargestellt werden. Diese Dokumente sind keineswegs randständig für den Diskurs und die verschiedenen Deutungen des MHM. Obwohl nur selten innerhalb des Diskurses explizit darauf 
Bezug genommen wird, gilt dies auch für die Traditionserlässe, da, wie die institutionelle Konstellation gezeigt hat, diese Dokumente die Rahmenbedingungen und die Freiheitsgrade definieren, innerhalb derer sich das »musealisierte Selbstverständnis der Bundeswehr« (Rauchnsteiner 2011:11) bewegt.

\subsection{Die Kodifizierung des Selbstbildes}

Wie die Darstellung der Ortsgeschichte gezeigt hat, bestehen neben Kontinuitäten auch zahlreiche Brüche in der deutschen Militärgeschichte. Zwischen diesen muss die Traditionsbildung der Bundeswehr stets manövrieren. Die teilweise widersprüchlichen raumzeitlichen Anforderungen sowie die Skepsis gegenüber einem durch die Geschichte diskreditierten Kollektivismus bilden dabei zentrale Spanungslinien. Dieses schwierige Gelände, in welchem sich der Kollektivierungsdiskurs der Bundeswehr bewähren muss, soll im Folgenden genauer analysiert werden. ${ }^{11}$ Damit reagiert dieser nicht nur auf historische Schwierigkeiten, sondern auch auf die Erfordernisse der Gegenwart.

Anhand der bereits erwähnten Traditionserlässe und der zentralen Dienstvorschrift der Inneren Führung kann dies erläutert werden. Die Traditionsbildung der Bundeswehr reagiert dabei auf mindestens drei Herausforderungen: Zeitkonstitutionell muss zwischen Kontinuität und Diskontinuität vermittelt werden; raumkonstitutionell erscheint eine alleinige nationalräumliche Fixierung inopportun; schließlich muss zwischen einem kollektivistischen Corpsgeist und dem Schutz individueller Freiheit vermittelt werden. Im Kern geht es darum, mündige Soldatinnen und Soldaten auszubilden, die einer willfährigen Instrumentalisierung des Militärs durch undemokratische Politik entgegenwirken.

\subsubsection{Das zeitkonstitutionelle Dilemma}

Wie bereits weiter oben erwähnt, steht die Notwendigkeit, problematische Geschichtsbestände aktiv auf Abstand zu halten, einer uneingeschränkt affirmativen Identitätsbehauptung im Weg. Dass das Leitmuseum der Bundeswehr jedoch ein Identitätsangebot formulieren muss, mit dem sich auch der »Gesamtstaat identifizieren« kann, wurde anhand der institutionellen Konstellation deutlich. Hierin besteht ein zentrales zeitkonstitutionelles Dilemma. Auf eine Formel gebracht bedeutet dies: Eine alleinige Abgrenzung von Vergangenem verhindert Identität, eine bruch-

11 Bereits 1989 analysierte Donald Abenheim in seiner grundlegenden Studie die »Suche nach dem gültigen Erbe des deutschen Soldaten« (so der Untertitel der Studie in der deutschen Übersetzung) und stellte fest, dass die Traditionsfrage weitgehend ungelöst war (Abenheim 1989) und es vermutlich auch in Zukunft so sein wird (Biehl/Leonhard 2018). 
lose Nähe zu Vergangenem hingegen gefährdet die moralische Integrität. Diese Inkompatibilität von Beständigkeit und Diskontinuität kann anhand der Traditionserlässe des Bundesministeriums der Verteidigung von 1982 und 2018 verdeutlicht werden; etwa wenn die »tiefen Einbrüche« in der Geschichte der deutschen Streitkräfte betont werden: "Die Geschichte deutscher Streitkräfte hat sich nicht ohne tiefe Einbrüche entwickelt. In den Nationalsozialismus waren Streitkräfte teils schuldhaft verstrickt, teils wurden sie schuldlos missbraucht.« (BMVg 1982:1).

Daraus folgt schließlich: „Ein Unrechtsregime, wie das Dritte Reich, kann Tradition nicht begründen.«(Ebd.). Dies erfordert auch eine Distanzierung von Symbolen »ehemaliger deutscher Streitkräfte«. Denn auch »Fahnen und Standarten früherer deutscher Truppenteile werden in der Bundeswehr nicht mitgeführt. [...] Kennzeichen, insbesondere das Hakenkreuz, dürfen nicht gezeigt werden. (BMVg 1982:3, P.22). Dieser Passus findet sowohl in der zentralen Dienstvorschrift der IInneren Führungく (BMVg 2008:4, P.201) als auch nahezu unverändert in der Neuformulierung des Traditionserlasses vom Frühjahr 2018, zu der sich die Ministerin insbesondere nach den Skandalen um Nazidevotionalien in deutschen Kasernen veranlasst sah. ${ }^{12}$ Damit reagierte das Ministerium auch auf die »entwürdigenden Aufnahmerituale am Ausbildungszentrum der Bundeswehr [...] in Pfullendorf« (Wissenschaftliche Dienste des Bundestages 2017:4) und die im Kontext der Nachforschungen entdeckten Wehrmachtsdevotionalien in Kasernen der Bundeswehr (ebd.). Auch im Dokument »Die Tradition der Bundeswehr « von 2018 heißt es: "Der verbrecherische NS-Staat kann Tradition nicht begründen.« (BMVg 2018b:6, P.3.4.1.). Wehrmacht und SS sind nun aber nicht mehr die einzigen problematischen Geschichtsbestände. Mit der Wiedervereinigung und der Eingliederung der NVA in die BW wird auch der Ausschluss dieses Teils der Geschichte deutscher Streitkräfte mit einer fast identischen Formulierung vollzogen. Denn die NVA und ihre Verbände »begründet keine Tradition der Bundeswehr. In ihrem eigenen Selbstverständnis war sie Hauptwaffenträger einer sozialistischen Diktatur.« (BMVg 2018b:6, P.3.4.2.).

Aus derlei, auf Abgrenzung von der Vergangenheit rekurrierenden Zeitkonstitutionen, erwächst schließlich das Problem, die eigene Institution nicht mehr uneingeschränkt über Geschichte legitimieren zu können, denn Tradition kann dadurch nicht begründet werden. Gründende Erzählungen lassen sich hieraus nicht mehr formulieren. In assoziativerer Weise interpretiert heißt dies auch, dass Geschichte als Letztbegründung der Selbstvergewisserung, wenngleich nicht vollständig ausscheidet, so doch kein festes Fundament, sondern lediglich einen unsiche-

12 Diese Vorfälle wurden als wichtiger Impuls für die Reformulierung des Traditionserlasses angegeben. Obwohl auch die NVA bereits Anfang der 1990er Jahre als nicht traditionswürdig eingestuft wurde, wurde erst bei dieser Celegenheit - fast 30 ]ahre nach dem Ende der DDR - der Umgang mit der NVA im Traditionsbestand der Bundeswehr offiziell geregelt. 
ren Grund darstellt. Dies ist der Preis für die im Fall der Bundeswehr dringend benötigte Abkehr von alten Geschichtsbeständen und die damit verbundene Hoffnung auf Selbsterneuerung.

Bei aller Notwendigkeit, sich von den vielfältig problematischen Vergangenheiten zu distanzieren, können die Bundeswehr und das MHM aber dennoch nicht auf einen legitimen Traditionsbestand verzichten. Allein die Existenz der Traditionserlässe kann als Indiz dafür gelten, dass ebenso persistente Wesensmerkmale angegeben werden sollen. So weisen die Traditionserlässe auch darauf hin, dass neben der Notwendigkeit der Abgrenzung die Notwendigkeit zur Sicherung von Identität bestehe. Dies gewähren Traditionen, denn: »Tradition verbindet die Generationen, sichert Identität und schlägt eine Brücke zwischen Vergangenheit und Zukunft.« (BMVg 1982:1, P.1). ${ }^{13}$ Was hier gleich zu Beginn des Traditionserlasses postuliert wird, ist ein linearer Brückenschlag, der Kontinuität herstellen und Identität sichern soll. Der Hinweis auf die Verbindung der Generationen zeugt von der kohäsionsstiftenden Funktion, die Traditionen zugesprochen wird. Damit wird die doppelte Konnektivität des Erinnerns thematisiert, die Jan Assmann in »Zeitdimension« (hier: Kontinuität) und »Sozialdimension« (hier: Verbindung der Generationen) unterschied (Kap. 2). Wichtig im grundlegenden Verständnis von den Traditionen der Bundeswehr ist, dass »Tradition« selbst der Status eines menschlichen Grundbedürfnisses zugesprochen wird. So sei »Tradition [...] eine wesentliche Grundlage menschlicher Kultur.«(BMVg 1982:1, P.1). Zwar kann sich die Traditionsbildung der Bundeswehr nicht unumwunden an den Beständen deutscher Militärgeschichte bedienen; ungeachtet dessen bilde aber das Phänomen Tradition eine »Grundlage menschlicher Kultur und sei eine anthropologische Grunddisposition der Kultur. ${ }^{14}$

Neben den gegenläufigen Bedürfnissen der Abgrenzung von der Vergangenheit und der (natürlichen) Suche nach selbstvergewissernden Traditionen kann anhand der Traditionserlässe noch eine weitere zeitkonstitutionelle Herausforderung veranschaulicht werden: die Integration von Wandel. Bereits dem Traditionserlass von 1982 ist zu entnehmen, dass »militärische Leistungen der Vergangenheit « zwar für die Ausbildung der Streitkräfte bedeutsam sein können; diese müssen sich aber vor dem Hintergrund einer sich unaufhörlich wandelnden Gegenwart fortlaufend neu bewähren und gegebenenfalls verworfen werden. Es sei demnach »stets zu prüfen,

13 Auch dieser Passus bleibt in der aktualisierten Version des Traditionserlasses an gleichermaßen exponierter Stelle sinngemäß erhalten. Nunmehr heißt es dort: »Die Tradition der Bundeswehr ist der Kern ihrer Erinnerungskultur. [...] Als geistige Brücke zwischen Vergangenheit und Zukunft verbindet Tradition die Generationen und gibt Orientierung für das Führen und Handeln.«(BMVg 2018b:2, P.1.1.).

14 Diese anthropologische Letztbegründung tritt im MHM an besonders zentraler Stelle in Erscheinung. Auf die zentrale Argumentationsfigur der Anthropologie wird deshalb noch ausführlich eingegangen (Kap. 6.4.1). 
inwieweit Überliefertes angesichts ständig sich wandelnder technischer und taktischer, politischer und gesellschaftlicher Gegebenheiten an Wert behält.« (BMVg 1982:3, P.19, Herv. JK). Diese zeitkonstitutionelle Herausforderung erzwingt, wie anhand der zentralen Dienstvorschrift der Inneren Führung gezeigt wurde, eine »andauernde Notwendigkeit zur Weiterentwicklung« (BMVg 2008:4, P.108, Herv. im Orig.) und damit eine anhaltende Anpassungsleistung.

Ein unverbrüchlicher Kanon oder eine maßgebliche heroische Vergangenheit ist mit diesem dynamischen Traditionsverständnis nicht mehr artikulierbar. Die selbstvergewissernde Kraft der Vergangenheit wird deutlich relativiert, denn »Geschichte liefert keine Anweisungen für künftiges Verhalten, wohl aber Maßstäbe und Orientierungen für Haltungen.« (BMVg 1982:3, P.19). Demgemäß erscheint die »Offenheit gegenüber gesellschaftlichen Entwicklungen« funktional. Bemerkenswert ist dabei, dass diese Form der Anpassungsfähigkeit im Lauf der Zeit selbst wiederum als Teil der bereits gepflegten Tradition der Bundeswehr ausgegeben wird (BMVg 1982:3, P.20). Die Offenheit gegenüber gesellschaftlichen Entwicklungen und die andauernde Weiterentwicklung der Tradition werden im Traditionserlass von 2018 als eine der Bundeswehr eigentümliche Tradition aufgelistet.

Nicht nur das schwierige Erbe der Vergangenheit, sondern auch die dynamischen Entwicklungen in der Gegenwart erfordern somit eine »lebendige Tradition«, die sich allen Versuchen entziehen, sie »dauerhaft festlegen $\mathrm{zu}$ wollen.« (BMVg 2018b:3, P.1.5). Die Dynamisierung gesellschaftlichen Wandels verlangt jedoch umso mehr nach Selbstvergewisserung. Dies wird deutlich, wenn die Bundesverteidigungsministerin das »Verständnis von unserer Vergangenheit « aus den sich schnell verändernden Herausforderungen ableitet.

»Cerade weil sich die Herausforderungen heute so schnell verändern, brauchen wir ein gemeinsames Verständnis von unserer Vergangenheit. Wir müssen wissen, woher wir kommen, um mit Cewissheit in die Zukunft zu gehen. Wir müssen uns immer wieder selbst vergewissern, auf welchem Grund wir stehen.« (von der Leyen 2018:2).

Nicht nur das problematische Erbe erfordert eine Vergewisserung über »unsere« Vergangenheit, sondern auch die Tatsache, dass sich die Gegenwart schnell verändert. Die anhaltende Selbstvergewisserung über den »Grund, auf welchem wir stehen «, macht ein dynamischeres Verständnis von Tradition erforderlich. Militärische Traditionspflege bleibt zwar ein Instrument der Selbstvergewisserung, jedoch wird mit der Dynamisierung der Herausforderungen, die sich immer wieder neu und immer wieder anders stellen, auch die Vorstellung von Tradition selbst dynamisiert. Die Selbstvergewisserung über den Grund, in dem Tradition wurzeln soll, ist also unaufhörlich zu prüfen.

Die tiefe Skepsis gegenüber dem Grund, »auf welchem wir stehen«, fasst die zwei zeitkonstitutionellen Schwierigkeiten deutlich zusammen. Einerseits kann 
Identität allein auf dem Boden der Vergangenheit nicht begründet werden. Diese muss in weiten Teilen befremdet werden. Dennoch bleibt der Brückenschlag zwischen Vergangenheit und Gegenwart notwendig, um eine Verbindung der Generationen und damit gesellschaftliche Kohäsion zu gewährleisten. Dies ist das zeitkonstitutionelle Dilemma. Ein Geschichtsverständnis, das allein auf Beständigkeit rekurriert, wird vor diesem Hintergrund schließlich zum Problem. Andererseits erfordert die Dynamisierung gesellschaftlichen Wandels eine Form der Traditionsbildung, die nicht mehr statisch, sondern anpassungsfähig ist. Zwar ist jede Struktur der Selbstthematisierung dynamisch und anpassungsfähig, unabhängig davon, ob sie diese Adaptionsleistung reflektiert (Kap. 4.1). Der zentrale Unterschied in Bezug auf die Traditionsbildung der Bundeswehr besteht aber darin, dass das Bewusstsein für sozialen Wandel und die dadurch erforderlichen Anpassungsleistungen nun selbst ins Zentrum dieses Kollektivierungsdiskurses gestellt werden.

\subsubsection{Das raumkonstitutionelle Dilemma}

Neben den zeitkonstitutionellen Schwierigkeiten fordert die Einbindung des deutschen Militärs in internationale Bündnisse die Identitätsbildung der Bundeswehr auch in räumlicher Hinsicht heraus. Auch der nationalstaatliche Rahmen ist über die Geschichte weitgehend diskreditiert. Jedoch erscheint nationale Geschlossenheit vor dem Hintergrund der Verankerung der Bundeswehr in der NATO inopportun. Die Einbindung der späteren Bundeswehr in das westliche Verteidigungsbündnis wird bereits in der sogenannten »Himmeroder Denkschrift« von Oktober 1950 festgehalten. Die personellen Kontinuitäten zwischen Wehrmacht und Bundeswehr zeigen sich darin, dass unter den 15 Mitgliedern des »militärischen Expertenausschusses«, welcher mit dem Verfassen der Denkschrift betraut wurde, zahlreiche Wehrmachtsgenerale und -admirale waren, die sich gegenüber Militärreformen meist nur wenig aufgeschlossen zeigten (Wissenschaftliche Dienste 2017:5). Diesem Unwillen zur Reform stand der Begründer des Konzeptes der Inneren Führung, Wolf Graf von Baudissin, gegenüber. Ihm ist es zu verdanken, dass in die Denkschrift von Himmerod bereits erste Überlegungen des späteren Reformkonzepts der Inneren Führung aufgenommen wurden. Neben einer tiefgreifenden Reform der militärischen Kultur und der Abkehr von der Wehrmacht, die im Jahr 1950 noch keineswegs gewiss war, wurde mit der »Himmeroder Denkschrift« zunächst die strategische und geopolitische Einbindung der aufzubauenden deutschen Streitkräfte festgehalten. Dass dabei der multinationale Anspruch zentral war, wird im offiziellen Titel der Schrift deutlich, lautete dieser doch: »Denkschrift über die Aufstellung eines deutschen Kontingents im Rahmen einer übernationalen Streitmacht zur Verteidigung Westeuropas.« (Himmeroder Denkschrift 1950, nach Rautenberg/Wiggershaus 1985). 
Erschienen in der Traditionsbildung der Nationalen Volksarmee (NVA) die Waffenbrüderschaft mit Russland und die Konstruktion einer internationalen antifaschistischen Tradition raumkonstitutionell geboten, so galt dies auch für die Bundesrepublik und ihre Einbettung in das westliche Militärbündnis. Entsprechend wurde die Waffenbrüderschaft mit den Amerikanern Teil der bundesrepublikanischen Traditionsbildung. Im Staatsakt, den Bundeskanzler Kohl und US-Präsident Reagan am 5. Mai 1985 gemeinsam anlässlich des 40. Jahrestages des Endes des Zweiten Weltkrieges auf dem Soldatenfriedhof in Bitburg, auf welchem auch SSAngehörige beigesetzt waren, begingen, sah Jürgen Habermas den Versuch einer »Entsorgung der Geschichte« (Habermas 1985). Neben der Abkehr von einer »destabilisierenden Vergangenheit« (a.a.O. 2) und der »Rückkehr zu deutschen Kontinuitäten« sah der Philosoph in der »Bezeugung aktueller Waffenbrüderschaft« eine »retroaktive Verlängerung der Waffenbrüderschaft« (a.a.O. 5) zwischen Deutschen und Amerikanern rückwirkend in den Krieg hinein. Diese Art des Erinnerns erschien im Kalten Krieg auch deshalb funktional, da sie es dem westdeutschen Militär ermöglichte, sich - umgekehrt zu den ostdeutschen Streitkräften - als schon immer gewesene Antikommunisten zu gebärden. In der Polemik des Historikerstreites (Augstein 1987), der in den folgenden Jahren vordergründig um die Unvergleichbarkeit der Shoah kreiste, tatsächlich aber die Frage nach deren Bedeutung für ein deutsches Selbstbild thematisierte, kritisierte Habermas diese geschichtspolitische Normalisierung unter den raumkonstitutionellen Erfordernissen der Westbindung scharf. Obwohl auch Habermas die »vorbehaltlose Öffnung der Bundesrepublik gegenüber der politischen Kultur des Westens« forderte (1987:75), warnte er vor »apologetischen Tendenzen« (a.a.O. 65) und geschichtsrevisionistischer Normalisierung, die ab der ersten Legislaturperiode des promovierten Historikers Helmut Kohl zu beobachten seien. Dem setzte Habermas die Forderung nach einer "postkonventionellen Identität « entgegen, in der an die Stelle von nationalem Stolz universalistische Werteorientierung trete (Habermas 1987:75).

Die nicht mehr exklusiv nationalstaatliche Traditionsbildung erschien durchaus funktional, so wie sie angesichts des gegenwärtigen Engagements der Bundeswehr in internationalen Auslandseinsätzen geboten ist. ${ }^{15}$ Neben der Einbettung in ein »multinationales Umfeld «(BMVg 2008:17, P.634) wird zudem kulturelle Sensibilität eingefordert, die unter anderem auch der Auftragserfüllung und dem Selbstschutz dient.

»Der richtige Umgang mit Menschen, die einen anderen kulturellen Hintergrund haben, die interkulturelle Kompetenz, erhöht die Handlungs- und Verhaltenssicher-

Aktuell beteiligt sich die Bundeswehr bei 12 Einsätzen in 15 Staaten mit rund 1.200 Soldatinnen und Soldaten. Die Unterrichtung der Öffentlichkeit findet auch über die Homepage der Bundeswehr statt. https://www.bundeswehr.de/portal/a/bwde/start/einsaetze/ueberblick/lag e/ (Stand 13.05.2019). 
heit der Soldatinnen und Soldaten und sichert die Akzeptanz von Minderheiten in der Bundeswehr. Im Auslandseinsatz ist interkulturelle Kompetenz zudem eine wesentliche Voraussetzung für die Auftragserfüllung und den Eigenschutz.« (BMVg 2008:14, P.620, Herv. im Orig.). ${ }^{16}$

So wie das Konzept der Inneren Führung in zeitkonstitutioneller Hinsicht auf "ständige Entwicklung und Veränderung« reagiert und Ausdruck einer »andauernden Notwendigkeit zur Weiterentwicklung« ist (BMVg 2008:4, P.108.), erscheint auch eine räumliche Dynamisierung des Traditionsverständnisses durch die gegenwärtigen Anforderungen in einem »multinationalen Umfeld« opportun. Neben der Beschleunigung von sozialem Wandel besteht zusätzlich die Anforderung, heterogene Erfahrungsräume im Inneren $\mathrm{zu}$ integrieren (Kap. 1). Die Selbstdarstellung der Bundeswehr lässt ein Bewusstsein für die Vielfältigkeit von Weltdeutungen, wie sie für funktional differenzierte Gesellschaften typisch ist, erkennen. Denn auch der Umgang mit »Vielfalt«, »Interessenskonflikten«, widerstreitenden Meinungen sowie »unterschiedlichen Kulturen und Herkünfte[n] « in "pluralistischen Gesellschaften" (a.a.O. 7, P.312) sei Wesensmerkmal dieses Selbstverständnisses. Die Konzeption der Inneren Führung widmet sich auch dieser Frage der Sozialintegration unter Bedingungen der deutschen Gegenwartsgesellschaft:

"312. In der Bundesrepublik Deutschland besteht eine freiheitliche und pluralistische Cesellschaft, die von vielfältigen Überzeugungen, Lebensentwürfen, religiösen und weltanschaulichen Bekenntnissen, Meinungen und Interessen gekennzeichnet ist. Diese unterliegen einer ständigen Entwicklung und Veränderung und stehen teilweise im Wettbewerb miteinander.

313. Die Menschen in der Bundeswehr sind Teil der Cesellschaft mit ihrer Vielfalt, aber auch mit ihren Interessengegensätzen und Konflikten. Damit steht auch die Bundeswehr selbst im Widerstreit der Meinungen und im Spannungsfeld unterschiedlicher Cenerationen, Kulturen und Herkünfte. Der Inneren Führung entspricht es, dass die Angehörigen der Bundeswehr einander als Mitglieder einer freiheitlichen und pluralistischen Gesellschaft anerkennen und sich mit den gesellschaftlichen Entwicklungen auseinandersetzen.«(BMVg 2008:7, Herv. im Orig.).

Neben der Notwendigkeit zur Integration von zeitlichen Brüchen besteht die Herausforderung, sozialräumliche Heterogenität $\mathrm{zu}$ integrieren. Dies ist eine allgemeine Anforderung, der sich funktional differenzierte und kulturell vielfältige Gesellschaften gegenübersehen. Interessant ist dabei, dass, neben dem erneuten Hinweis auf die »ständige Entwicklung und Veränderung«, der konflikthafte Charakter 
kulturell und weltanschaulicher Diversität explizit thematisiert wird. Ungeachtet der herausgestellten Schwierigkeiten bestehen ein möglicher Umgang mit gesellschaftlicher Vielfalt und der Versuch, diese zu vereinheitlichen, in der Traditionalisierung der Heterogenität. Vielfalt sei demnach eine deutsche Eigentümlichkeit, die in der deutschen Geschichte schon immer bestanden habe.

»Die deutsche Geschichte hat eine Fülle landsmannschaftlicher, regionaler und lokaler Besonderheiten hervorgebracht. Die Vielfalt ist eine deutsche Eigentümlichkeit. Bei der Traditionspflege hat es sich als sinnvoll erwiesen, an solchen Besonderheiten anzuknüpfen.«(BMVg 1982:4, P.24).

Nicht nur liest sich dies wie eine Rechtfertigung für die Übernahme von Traditionen, deren Ursprung vor 1945 liegt. Vielfalt wird selbst als Alleinstellungsmerkmal relevant gemacht und zur »deutschen Eigentümlichkeit« erklärt. Auch wenn dadurch Vielfalt noch nicht zu »integrierter Einheit« wird (Beck Kap. 1), so wird doch die Heterogenität historisch legitimiert, denn die »Fülle der Besonderheiten« entstammt der deutschen Geschichte. Sie wird durch diese »hervorgebracht«.

Durch die »Offenheit gegenüber gesellschaftlichen Entwicklungen« und die "andauernde[n] Weiterentwicklung«, wie sie in den Traditionserlässen (BMVg 1982, 2018a) und der zentralen Dienstvorschrift der Inneren Führung (BMVg 2008) betont werden, wird kulturelle Vielfalt in die Tradition der Bundeswehr eingeschlossen, indem sie in der Vergangenheit >wiedergefunden $<$ wird. Dies erscheint deshalb funktional, da eine allzu große nationalräumliche Geschlossenheit sowohl die Integration nach Außen (in ein »multinationales Umfeld«) als auch nach Innen (in eine "pluralistische Gesellschaft") verhindert. Bemerkenswert ist, dass die Bundeswehr nicht bloß ein Bewusstsein für die raumzeitlichen Herausforderungen der Identitätsbildung in der deutschen Gegenwartsgesellschaft entwickelt, sondern neben Anpassungsfähigkeit auch Vielfalt und widerstreitende Meinungen ins Zentrum des Bildes rückt, welches sie von sich zeichnet.

\subsubsection{Individuelle Tradition und ziviles Militär}

Die Thematisierung der "pluralistischen Gesellschaften« bildet das sozialräumliche Pendant zur zeitlichen Herausforderung der anhaltenden Veränderung. Dabei wird auf den Verlust einheitlicher Weltdeutungen und verbindlicher historische Ereignisse in der deutschen Gegenwartsgesellschaft reagiert. So wie in der zentralen Dienstvorschrift der Inneren Führung explizit auf eine "pluralistische Gesellschaft» verwiesen wird, so werden diese sozialen Bedingungen auch in den Traditionserlässen (BMVg 1982, 2018a) betont:

»In der pluralistischen Gesellschaft haben historische Ereignisse und Gestalten nicht für alle Staatsbürger gleiche Bedeutung, geschichtliche Lehren und Erfah- 
rungen nicht für alle den gleichen Grad an Verbindlichkeit. Tradition ist auch eine persönliche Entscheidung.«(BMVg 1982:1, P.3).

Wichtiger erscheint nun, dass durch die Heterogenität der "pluralistischen Gesellschaften« die Möglichkeit der Sozialintegration abnimmt. Denn »historische Ereignisse « und Personen bieten keinen "gleichen Grad an Verbindlichkeit«. Wie zuvor die Determinationskraft der Geschichte für die Gegenwart und die Zukunft abgenommen hat, so ist nun auch die Kohäsionskraft gleichermaßen bedeutender »Ereignisse«, »Gestalten« und »Erfahrungen« im Schwinden begriffen. Da ein gleicher »Grad an Verbindlichkeit« fehlt, kann Vergangenheit allein auch keine gesellschaftliche Verbindung mehr stiften. Die Sozialintegration ist geschwächt, da ein gemeinsamer und verbindlicher Geschichtsbestand unwahrscheinlicher geworden ist. Im Ausweichen auf die Ebene "persönlicher Entscheidung« gibt sich also eine Individualisierung der Verbindung mit der Vergangenheit zu erkennen. Diese wird damit zunehmend unverbindlich.

Bereits die Bezeichnung »innere Führung« deutet auf die Subjektzentriertheit dieser Identitätsbildung hin. Im Rückzug auf die Ebene von Individualität und Innerlichkeit artikuliert sich neben der eingangs zitierten Vorstellung einer Tradition als "persönliche Entscheidung« in "pluralistischen Gesellschaften« eine tiefe Skepsis gegenüber jeder Form des Kollektivismus, wie er durch den Nationalsozialismus und den realexistierenden Sozialismus diskreditiert ist. Die Betonung der Innerlichkeit moralisch integrer Subjekte wird aus der deutschen Geschichte ersichtlich. Die Abkehr von der bedingungslosen Unterordnung des Individuums kann als Kern der Inneren Führung angesehen werden, dem sich auch einer der Ausstellungsführer widmet (Rogg/Pieken 2011a:35, 41, 170ff.). Darin heißt es, die Gehorsamspflicht endet einerseits (quasi nach oben hin) an den Grenzen des »übergeordneten Völkerrechts « und andererseits (quasi nach innen hin) im »Gewissen jedes einzelnen Soldaten« (Rogg/Pieken 2011a:171). Dadurch wird der Kontrastpunkt zu einem den Willen des Einzelnen negierenden Corpsgeist gesetzt, der in dem grotesken Hitlerzitat »Du bist nichts, dein Volk ist alles « zum Ausdruck kommt. Dieses Zitat auf einem Porzellanteller, welcher ein Exponat der Ausstellung ist, wird im Museumskatalog unter Bezugnahme auf die Entstehungsgeschichte der Inneren Führung thematisiert (a.a.O. 2011a:146). Das Reformkonzept der Inneren Führung widmet sich ausführlich dem Konfliktpotenzial, welches sich zwischen Gehorsamspflicht und moralischem Handeln ergeben kann, und das durch den Nationalsozialismus besonders virulent geworden ist. Denn zu den Grundsätzen der Inneren Führung gehören auch die »Grenzen für >Befehl und Gehorsam« (BMVg 2008:7f., 3.6). In einer bemerkenswerten Stelle des Dokumentes sind unter dem Titel $\gg$ Rechte und Pflichten der Soldatinnen und Soldaten« die Grenzen der Gehorsamspflicht definiert. 
»Um Missbrauch der Gehorsamspflicht auszuschließen, sind Inhalt und Grenzen des Gehorsams gesetzlich festgelegt: [...]

- Es ist nicht Ungehorsam, wenn ein Befehl nicht befolgt wird, der die Menschenwürde verletzt [...]

- Ein Befehl darf nicht befolgt werden, wenn dadurch eine Straftat begangen würde [...]

- Die Cewissensfreiheit (Art. 4 Abs. 1 CG) garantiert, dass der Staat grundsätzlich niemanden zu Handlungen zwingen darf, die gegen eigene ethische Maßstäbe von Gut und Böse verstoßen.« (BMVg 2008:28f., 7.2, Herv. im Orig.).

Innere Führung fordert somit eine innere Haltung. Sie kodifiziert die rechtlich verbriefte Möglichkeit der Befehlsverweigerung. Vor allem der letztgenannte Aspekt der Gewissensfreiheit etabliert »eigene ethische Maßstäbe« als höchste Instanz, vor der sich soldatisches Handeln im Zweifelsfall verantworten muss. Dieses Selbstbestimmungsnarrativ, welches dem Gewissen und der ethischen Urteilskraft des Einzelnen einen zentralen Stellenwert einräumt, lässt sich im Kern auf die Bertolt Brecht zugeschriebene Formel bringen: »Wo Unrecht zu Recht wird, wird Widerstand zur Pflicht. "Diese Maxime stellt die größtmögliche Distanz zur SS-Losung »Meine Ehre heißt Treue« dar. Der Idee der Gehorsamspflicht als oberste Tugend und die damit verbundene Verleugnung des Individuums werden also die Möglichkeit der Befehlsverweigerung und die moralische Integrität der "Staatsbürger in Uniform« entgegengestellt (BMVg 2008:8, P.316). Damit gelingt die Distanzierung von der Vergangenheit. Eben dies ist der Zweck dieses Kollektivierungsdiskurses.

Dem durch die deutsche Geschichte mindestens suspekt gewordenen Begriff der »Führung« wird also die Innerlichkeit moralisch integrer Subjekte zur Seite gestellt werden. Die Abgrenzung von antidemokratischen Tendenzen artikuliert sich bereits früh in einem der Kernsätze der »Himmeroder Denkschrift«: »Das Ganze wie der Einzelne haben aus innerer Überzeugung die demokratische Staatsund Lebensform zu bejahen.« (zitiert nach Bald 2005b:179). ${ }^{17}$ Die Betonung einer innerlich gefestigten demokratischen Haltung schloss im Kalten Krieg natürlich auch die Abgrenzung von der Welt des realexistierenden Sozialismus jenseits des Eisernen Vorhangs ein. ${ }^{18}$ Mit der Inneren Führung steht ein Reformkonzept im

17 In den Anfangsjahren der Bundeswehr konnte bei der Überprüfung der demokratischen Gesinnung der Offiziersanwärter Adornos Studie zum autoritären Charakter (1995, Orig. 1950) einen gewissen Einfluss entfalten. Die Doppelrolle, die der Philosoph als eine Art etablierter Außenseiter einnahm und die zur Bedingung seines Einflusses wurde, hat Clemens Albrecht pointiert dargestellt (Albrecht 2004).

18 In einem Vertiefungsraum der Ausstellung des MHM, der der Inneren Führung gewidmet ist, zeigen die Ausstellungsmacher einen Schulungsfilm aus dem Jahr 1958. Die Betonung der demokratischen Haltung wird dabei vor allem als Immunisierung und Resilienz gegenüber kommunistischer Propaganda thematisiert. 
Zentrum der Selbstthematisierung der Bundeswehr, welches die "Zivilisierung des soldatischen Leitbildes « (Bald 2005b:179) und die Festigung demokratischer Werte zum Ziel hat. Im Ideal des »Staatsbürgers in Uniform« ist dieser Anspruch formelhaft kodifiziert. Vor diesem Hintergrund erscheinen auch die Zentralität ziviler Aspekte und die explizite Thematisierung der zahlreichen Verbindungen zwischen dem Militär und der Zivilgesellschaft in der Ausstellung des MHM keinesfalls zufällig. Vielmehr müssen diese als Ausdruck des durch die neuen politischen und gesellschaftlichen Gegebenheiten notwendig gewordenen Zivilisierungsversuchs des Militärischen verstanden werden.

\subsubsection{Ein dynamischer Kollektivierungsdiskurs}

Auf einer Ausstellungstafel mit dem Titel »Staatsbürger in Uniform und Innere Führung « in einem der Vertiefungsräume im MHM ist zu lesen, dass »[d]er Kalte Krieg einen neuen soldatischen Typus [forderte], der mehr war als ein reiner Kämpfer.« (Texttafel, Vertiefungsraum Innere Führung). Das gewandelte Soldatenbild war also nicht nur Resultat einer moralischen Läuterung, sondern wurde auch erforderlich, da der martialische Kämpfer der Eroberungskriege der 1930er und 4oer Jahre durch die neue politische Konstellation des Kalten Krieges inopportun geworden war. Die Forderung nach der moralischen Integrität demokratisch gesinnter »Staatsbürger in Uniform « ist also nicht (nur) Resultat eines historischen Reifungsprozesses, sondern erhält wie jede Traditionsbildung - im Sinne der Rekonstruktivität des Erinnerns (Kap. 2) - ihren Wert durch die Anforderungen der jeweiligen Gegenwart, auf die sie reagiert. Gleiches gilt für die Forderung nach einer »lebendigen Tradition« (BMVg 2018b:3, P.1.5) und die Akzentuierung »interkultureller Kompetenz« (BMVg 2008:14, P.620), mit denen auch auf raumzeitliche Herausforderungen, die sich der Bundeswehr gegenwärtig stellen, reagiert wird. Neben der Rekonstruktivität wird damit abermals die Prospektivität des Erinnerns deutlich. Dennoch ist es in hohem Maße bemerkenswert, dass der Kollektivierungsdiskurs einer staatlichen Institution Wandlungsfähigkeit und die Integration verschiedener Erfahrungsräume ins Zentrum seiner Selbstthematisierung rückt. Die Attribute, die dabei betont werden, reflektieren (im doppelten Sinn des Wortes) die gesellschaftlichen Kontingenz- und Unschärfeerfahrungen einer "pluralistischen Gesellschaft « am Beginn des 21. Jahrhunderts. So entsteht ein Diskurs, der zwischen Abgrenzung von und Verbindung mit der Vergangenheit, zwischen Normalstaatlichkeit und nationalen Alleinstellungsmerkmalen sowie zwischen Individualismus und Sozialintegration manövriert und dennoch ein kontinuierliches und kohärentes Selbstbild formen kann. Dass dieser integrative und dynamische Kollektivierungsdiskurs auch tatsächlich mit dem Museum verknüpft wird, zeigt sich neben der institutionellen Konstellation (Kap. 6.1.2) vor allem in der diskursiven Deutung der Architektur. So kommt es, dass die zentralen Eigentümlichkei- 
ten der Bundeswehr, die in den Dokumenten der Inneren Führung und der Traditionserlässe redundant eingefordert werden, auch in der Diskursivierung des Leitmuseums der Bundeswehr und seiner spektakulären Architektur eine zentrale Rolle spielen. Die Struktur des Erbens (Kap. 2) und die Codes der Verräumlichung (Kap. 4), wie sie im Diskurs des MHM rekonstruiert werden können, verweisen in das Zentrum des reflexiven Kollektivierungsdiskurses der Bundeswehr.

\subsection{Die normative Verbindlichkeit eines negativen Geschichtsbildes}

Gemäß dem zeitkonstitutionellen Dilemma bedarf die Bundeswehr zunächst einer scharfen Abgrenzung von ihrem vielfältigen Repertoire problematischer Geschichtsbestände. Dabei sind es vor allem die Menschheitsverbrechen der Shoah, die eine Distanzierung erforderlich machen. Die Zurschaustellung des historischen Bruchs weist der Diskontinuität einen entscheidenden Wert zu. Dieser »negative Gründungsmythos« (Assmann 2016:67ff.) (im Sinne eines >so sind wir nicht mehrs) soll im Folgenden analysiert werden. Anhand der Diskursivierung der Ausstellung und der Architektur des MHM wird deutlich, dass auch dieses "negative Geschichtsbild «19 normative Orientierung stiftet und eine Vorstellung ewig gültiger Bezugspunkte fixiert. Nachdem bisher die Analyse der Diskursdokumente von allgemeinerer Reichweite im Vordergrund stand, treten nun die im Kontext des Diskurses des MHM entstandenen Dokumente deutlicher hervor. Neben Zeitungsartikeln und den Konzeptionen der Akteure der Umgestaltung werden nun auch die Ausstellungsführer und Museumskataloge genauer analysiert.

\subsubsection{Geschichte und Raum als Problem}

Noch bevor klar wurde, wie sich das MHM in Zukunft präsentieren wird, stand eines bereits fest: Das Museum müsse ein »gewandeltes Selbstbild« (Rauchensteiner 2011:11) zum Ausdruck bringen. Zurückhaltende Entwürfe wurden explizit mit Verweis auf ihre respektvolle Haltung gegenüber dem alten Arsenalgebäude zurückgewiesen (a.a.O. 14). Man vergegenwärtige sich hierbei den Unterschied zum Neuen Museum, in dem alle diskursiven Formationen für sich in Anspruch nahmen, Kontinuitäten des Ortes entweder aufzunehmen oder wiederherzustellen. Unabhängig des Modus der Identifikation war in Berlin die Geschichte des Ortes ausnahmslos positiv konnotiert. Obwohl unterschiedliche Auffassungen über den

19 Diese Formulierung wählte etwa auch der Leiter des Zentrums für Militärgeschichte und Sozialwissenschaften der Bundeswehr (ZMSdBW, ehemals MCFA), Dr. Jörg Hillmann, in einer Ansprache zu einer Konferenz zu Cewaltgedächtnissen am 14. März 2019 in Potsdam. 
Raum bestanden, galt die jeweils als wesenhaft behauptete Idee des Neuen Museums als unbedingt schützenswert. Die umfangreichen und jeweils sehr verschiedenen Strategien der Kohärenzsicherung, wie sie dort analysiert wurden, stellen in der Dresdner Albertstadt jedoch kein probates Mittel dar. Die Distanzierung von der Vergangenheit und der Wunsch nach einem "gewandelten Leitbild « führen zu einer umfangreichen Befremdung des bisherigen Ortes. Die enge Kopplung zwischen Raum und Geschichte vollzieht auch der Projektleiter der Neukonzeption, der darauf hinwies, dass auch die neue Architektur »Ausdruck unserer problematischen Geschichte « sein solle. (Pieken 2011:17). Die konkrete Ortsgeschichte und die architektonisch-räumliche Gliederung des Arsenalgebäudes werden dabei mit der allgemeinen deutschen Militärgeschichte kontextualisiert. Der Raum des alten Arsenalgebäudes wird zum Platzhalter einer Vergangenheit, die auf vielerlei Ebenen problematisiert wird.

Architektur, Raum und Geschichte können in Dresden nicht als Identitätsressource relevant gemacht werden. Im Gegenteil: Da sie die Integrität der Bundeswehr gefährden, müssen sie unbedingt auf Abstand gehalten werden. Die Abgrenzung zu früheren Epochen, die radikale ästhetische Umgestaltung sowie die Neuordnung räumlicher Relationen werden vor diesem Hintergrund funktional. In einem der beiden Ausstellungsführer des MHM wird die Notwendigkeit, mit der Vergangenheit auf Distanz zu gehen, folgendermaßen beschrieben:

»Das Leitmuseum der Bundeswehr konnte sich nicht mit einer gewissen Beliebigkeit mit der deutschen Militärgeschichte beschäftigen. Vielmehr war vorauszusetzen, dass man in- und außerhalb Deutschlands neugierig und vielleicht auch argwöhnisch auf die Darstellung der militärischen Vergangenheit des Landes und das musealisierte Selbstverständnis der Bundeswehr blicken würde. Und was da an ersten Ergebnissen gezeigt wurde, war sicherlich nicht geeignet, als moderne Museumskonzeption und darüber hinaus als Ausdruck eines gewandelten Leitbilds gesehen zu werden.«(Rauchensteiner 2011:11).

Deutsche Militärgeschichte darf keinesfalls, wie anhand der Traditionserlässe gezeigt wurde, unumwunden affirmiert werden; sie kann Tradition nicht begründen. Deshalb muss sich das »Selbstverständnis der Bundeswehr« vor allem problembewusst präsentieren. Das »Leitmuseum« und das »musealisierte Selbstverständnis der Bundeswehr« dürfen sich keinesfalls mit »Beliebigkeit« an den vielfach problematischen Geschichtsbeständen deutscher Militärgeschichte bedienen. Vielmehr sehen sich die Museumsmacher den kritischen Augen einer skeptischen Öffentlichkeit ausgesetzt. Der sargwöhnische Blick v von außerhalb wird bereits in der Frühphase der Planung mitreflektiert. Dies wird zwar auch für die »militärische[n] Leistungsschauen « und "patriotische[n] Heilsgeschichten« (Pieken 2010b:6) der Vergangenheit gegolten haben; bemerkenswert ist jedoch, dass das Ausland nun als Rechtfertigungsinstanz Bedeutung erhält, um deren wohlwollende Anerkennung 
geworben wird. Der Code der Verräumlichung rekurriert nicht auf Abgrenzung von anderen Armeen, sondern zielt auf die Distanzierung von der eigenen Vergangenheit; oder, wie in der Zeitschrift für Architektur Bau-Netz zum Zeitpunkt der Eröffnung zu lesen war, habe der Neubau dem Altbau den Krieg erklärt (Heilmeyer 2011). Diese Distanzierung wird auch mittels visueller Äußerungen vollzogen, die, wie im Diskurs des Neuen Museums, zu typischen und typisierbaren Aussagen werden. So findet sich auf den ersten beiden Doppelseiten einer Broschüre mit dem Titel »40,1 ${ }^{\circ}$ (2013), in der die Architektur des Hauses und dessen Bedeutung für die Leitidee des Museums beschreiben werden, eine kontrastierende Bildfolge.

Abbildung 29: Die Asymmetrie des Keils wird in der Wegeführung des Vorfeldes aufgenommen (oben). In der Abbildung von 1897 (unten) unterstreicht die militärische Formation der Geschütze und Kanonenkugeln die Symmetrie der Gesamtanlage.

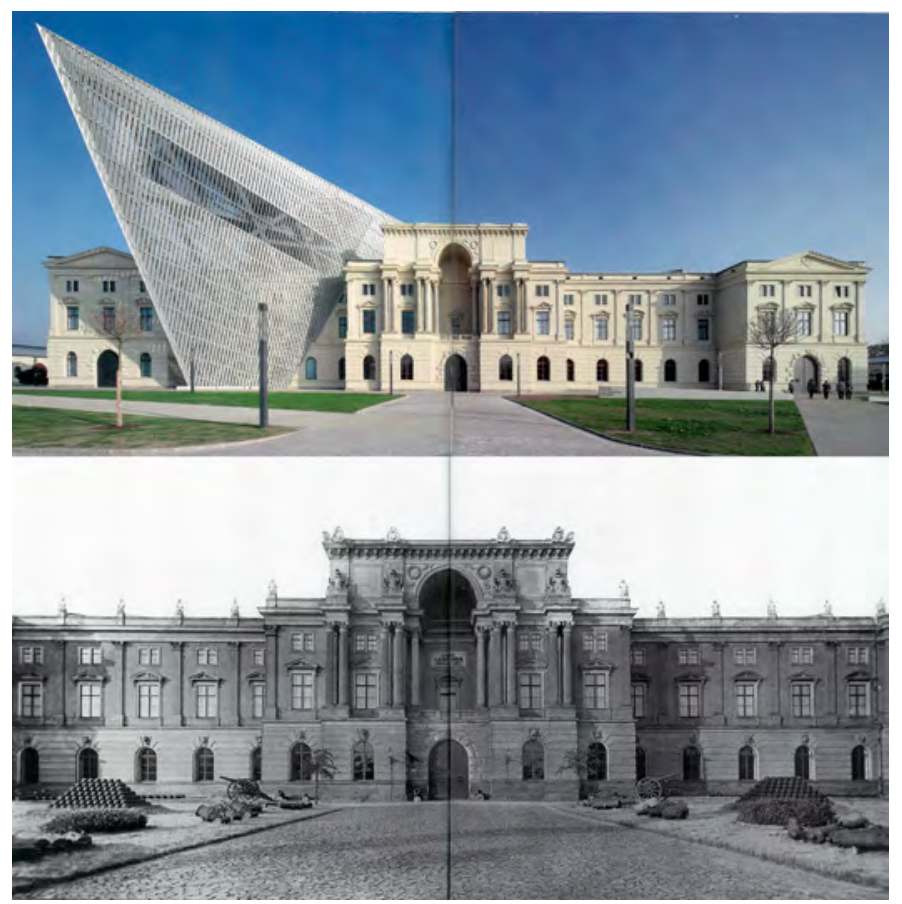

Dass diese kontrastierende Visualisierung ganz im Sinne der Problematisierung der Ortsgeschichte steht, zeigt der nachfolgende Auszug, in dem der Projektleiter der Neukonzeption, Gorch Pieken, einen Artikel aus dem Magazin »Der Spiegel« zitiert, um zu demonstrieren, als was sich das MHM verstanden wissen 
möchte: »Until now, most military museums ... have served as high altars of war. ... The new military museum in Dresden aims to defy this tradition.« (Popp, zitiert nach Pieken 2013:8, Ausl. im Orig.).

Die religiöse Metapher »Hochaltar des Krieges« erinnert an die »patriotischen Heilsgeschichten«, von welchen man sich abgrenzen möchte. Solcherlei Ausdrücke dienten der Abgrenzung von der Apologetik der militärgeschichtlichen Inszenierungen der Vergangenheit. Ziel des Museums sei es, die Traditionen der Verherrlichung des Militärs auf dem »Hochaltar des Krieges« zu verwerfen. Auf der Darstellung unten wirkt die Fassade tatsächlich wie ein Triptychon, zu dessen Füßen in militärischer Form Kriegsgerät in Stellung gebracht wurde. Die Inszenierung des Eingriffs oben vor strahlend blauem Himmel widersetzt sich hingegen dieser Tradition (»defy this tradition«). Die plakative Botschaft scheint darin zu bestehen, dass die in der Sonne glänzenden Edelstahllammellen mit dem Altbau auch gleichzeitig die Tradition militärisch-martialischer Repräsentation durchschneiden.

Übereinstimmend mit den Museumsmachern lehnt auch ein Autor der Süddeutschen Zeitung (Müller 2011) die apologetische Inszenierung von Militaria ab. Im Unterschied zu den Kuratoren der Ausstellung sieht er den Anspruch allerdings in der Ausstellung nicht eingelöst. Bemerkenswert ist dabei, dass er sich für die Formulierung dieses Vorwurfs desselben religiösen Vokabulars bedient, von welchem sich das MHM seinerseits klar distanzierte. Die Schuhe der Ermordeten von Majdanek würden durch die Inszenierung in der Ausstellung zu »Reliquien« und $\mathrm{zu}$ Überbleibseln vergangener »Martyrien«, womit deren Gewaltcharakter in der »Andacht« der Ausstellung erhalten bleibe. Der Vorwurf besteht also darin, dass das MHM die selbstgegebene Maxime der kritischen Darstellung >ohne Pathos nicht einlöse. Somit verbliebe auch das MHM im Modus der »Normal-Musealität« (ebd.). ${ }^{20}$

Dessen ungeachtet heißt es an anderer Stelle in dem für die Deutung der Architektur instruktiven Text: »The wedge-shaped, asymmetric extension [...] cuts through the massive existing building and its classical vocabulary.« (Pieken 2013:10). Der asymmetrische Keil zerschneide das massive, klassische Gebäude und mit ihm die an diesem Ort zusammenlaufenden Traditionslinien. Die Asymmetrie des Keils wird auch in der Wegeführung im Vorfeld des Museums aufgenommen.

Die Visualisierung setzt nicht nur die sprachlichen Topoi ins Bild, sondern gibt ebenso Auskunft über den modus operandi dieses Kollektivierungsdiskurses. So wie die Bilder kontrastierend angeordnet sind, so werden Vergangenheit und Gegenwart auch sprachlich durch Gegenüberstellung hergestellt. Die Abgrenzung von der

20 Entgegen dieser Einschätzung wertet der mediale Diskurs die Neugestaltung als tiefgreifend (Altmann 2012). So bemerkt etwa Nikolaus Bernau, dass sich das Museum »geradezu neu erfunden« habe (Bernau 2011). 
Vergangenheit wird durch die Abwertung des ehemaligen Museumsraumes betrieben. Die Asymmetrie der Neugestaltung erhält als Chiffre einer militärkritischen Inszenierung Bedeutung, wobei die Symmetrie des Altbaus mit einer apologetischen Inszenierung gleichgesetzt und schließlich abgelehnt wird. Dabei wird das alte Arsenalhauptgebäude sowohl architektonisch, nationalräumlich, ästhetisch als auch sozialräumlich mit der Vergangenheit identifiziert. Geschichte und Raum werden somit miteinander verbunden und umfangreich problematisiert.

\section{Architektur als Problem}

Eine erste Problematisierung der Vergangenheit wird über die Architektur vollzogen. Die Räume des alten Arsenals werden mit den neuen Räumen, die eine moderne Ausstellung gewährleisten sollen, deutlich kontrastiert. So stehe das alte Arsenal für die »Militärphilosophie des 19. Jahrhunderts«. Seine Funktion bestand darin, »die Militaria-Sammlung des Königreichs, nicht zuletzt Beutewaffen zu verwahren und schließlich auch zu zeigen." (Rauchensteiner 2011:11). Demnach ging es bei der Planung des Neubaus explizit nicht darum, ein »Museumsparkhaus zu errichten, bei dem es nur auf die Zahl der Quadratmeter ankommt «. Vielmehr war entscheidend, dass »die Architektur symbolischer Ausdruck unserer problematischen Geschichte wird. (Pieken 2011:17). Das »Museumsparkhaus«, das es zu vermeiden gilt, bildet das Äquivalent zur bloßen Verwahrung von Beutewaffen, wie sie für die Militärphilosophie des 19. Jahrhunderts charakteristisch sei. Das »Arsenal und Schatzgewölbe« (Rauchensteiner 2011:11), welches im Geiste des 19. Jahrhunderts durch Niederwerfung der Feinde und die Ausstellung ihrer Waffen einem heroischen Kollektivierungsdiskurs entspricht, kann keinesfalls als Blaupause für ein Haus dienen, mit dem sich die Bundeswehr und der "Gesamtstaat identifizieren« sollen. Mit den Begriffen »Museumsparkhaus«, »Verwahren«, »Beutewaffen und Schatzgewölbe« wird dem Raum gleichzeitig eine Passivität zugesprochen, die mit der Aktivität, die den Räumen der Neugestaltung zugestanden wird, kontrastiert. Werden die alten Räume meist als geschlossen, starr, langweilig, repetitiv und dunkel beschrieben, so heißt es über die neuen Räume, sie seien transparent, spannend, hell. Die Architektur des Altbaus macht einen Wandel erforderlich. Zielsetzung war schließlich, inhaltlich und baulich neue Wege zu beschreiten (Pieken 2010b:7).

»Der von Libeskind entworfene keilförmige, asymmetrische Neubau durchdringt den massiven, militärisch streng gegliederten Altbau. Die neue Architektur stellt einen Einschnitt in das Cebäude dar, wodurch nicht nur seine äußere Gestalt, sondern auch das innere Raumgefüge grundlegend verändert wird: >Der neue Baukörper kontrastiert innen und außen in Form und Charakter deutlich mit dem vorhandenen.< Der Neubau ergänzt die horizontalen, durch ein Säulenraster geglieder- 
ten Flügel des Arsenals mit vertikalen, geschossübergreifenden Sälen und schafft damit Platz für große und sperrige Großexponate.«(Pieken 2010b:7).

Die Beschreibung des Altbaus als »massiv« und »militärisch streng gegliedert « unterstreicht abermals die problematisierte Schwerfälligkeit des Gebäudes. Dass die Strenge der Anlage, die künstlich exponierte Lage des Gebäudes und gerade auch die Massivität des Altbaus Darstellungsformen des 19. Jahrhunderts waren, disqualifiziert sie, ein »gewandeltes Leitbild« auszudrücken. Auch das »Säulenraster« steht für eine als eng und einschränkend empfundene, vorgegebene Strukturierung räumlicher Bezüge. Dies führt zu einer Begrenzung der musealen Möglichkeiten. Mit der starren Vorgabe räumlicher Gliederung und durch die »militärische Strenge« wird dem bestehenden Raum ein repressiver Charakter zugeschrieben. Er erzwingt mit seinem Raster eine bestimmte Ausstellungsform und schränkt Möglichkeiten und damit Freiheiten ein. Eine bruchlose Inanspruchnahme des Raumes ist nicht möglich. Das horizontale Säulenraster wird durch vertikale Säle ergänzt, aufgebrochen oder gar befreit.

Entgegen der Einschränkung und strengen Begrenzung von Möglichkeiten werden die baulichen Veränderungen als Räume beschrieben, die Optionen öffnen. Denn wie die Innenarchitekten der Neukonzeption hervorheben, habe der Libeskind-Bau deren Arbeit positiv befördert (Merz/Holzer 2011:34; Bäumel 2015). So wie der Altbau mit Schwerfälligkeit, Passivität, Strenge und der Verhinderung von Optionen in Verbindung gebracht wird, so werden dem Neubau Transparenz, Aktivität, Subversion und Gestaltungsoptionen zugesprochen. Dass der asymmetrische Neubau den Altbau nicht nur durchdringt, sondern den durch horizontale Säulenraster gegliederten Flügel des Arsenals vor allem »ergänzt« (Libeskind 2003:48), macht deutlich, dass mit der baulichen Veränderung - neben ihrem symbolischen Wert - auch ein Zugewinn an Möglichkeiten thematisiert wird. Obwohl der Keil an anderer Stelle mit typischen Begriffen der Gewaltsemantik (Kap. 5.2.7) beschrieben wird (sprengen, durchschneiden, aufbrechen; etwa bei Engel (2012)) steht hier das positiv konnotierte »Ergänzen« im Vordergrund. Durch den Hinweis auf die modernen Anforderungen und die Unzulänglichkeiten des Altbaus wird der räumliche Kontrast schließlich in einen zeitlichen rückübersetzt. Der Unterschied und die zeitliche Distanz zwischen der »Militärphilosophie des 19. Jahrhunderts« und den Ansprüchen von »museumspädagogischen Anforderungen [...] des 21. Jahrhunderts« könnten kaum größer sein.

\section{Nationale Geschlossenheit als Problem}

In Verbindung mit der räumlichen Enge und der Geschlossenheit der Bestände wird auch die nationale Geschlossenheit der ehemaligen Ausstellungen thematisiert. Hierin besteht ein zweiter Aspekt der Befremdung der Vergangenheit durch die Problematisierung des Raumes. Vor allem der nationalaffirmative Charakter 
der ehemaligen Ausstellungen wird hervorgehoben. Denn die »geschlossenen Bestände« machten das Militär zu einem »Fixpunkt nationaler Identität« (Rogg 2011a:8). Dies sei überhaupt der Anlass dafür gewesen, dass das sächsische Kriegsministerium schließlich die Tore des alten Arsenals für das Publikum öffnete (ebd.). Die Vermittlung eines gleichermaßen geschlossenen Weltbildes und einer vorbehaltlosen Affirmation der eigenen Nation im Lichte ihrer "glorreichen Kriege« wird als Konstante der bisherigen Ausstellungen thematisiert (Rogg 2011a.9f). Auch in der Weimarer Republik habe das Museum als Bühne und "geschichtspolitische[r] Kampfplatz nationalstaatlicher Vergangenheitsbewältigung und Identitätssuche« gedient (ebd.). Die veränderte Rolle einer dezidiert international wahrgenommenen Ausstellung, die dieser national geschlossenen Vergangenheit entgegengesetzt wird, ist bereits anhand der Wahrnehmung der Ausstellung im Ausland angesprochen geworden. Vor dem Hintergrund der vielseitigen Einbindung der Bundeswehr in internationale Verteidigungsbündnisse wird eine nationalräumlich geschlossene Selbstthematisierung zum Problem. Dass Internationalität nun sogar explizit als Teil des Traditionsbestandes relevant gemacht wird, belegt ein Blick in den Traditionserlass, wonach die »kameradschaftliche $\mathrm{Zu}$ sammenarbeit mit den verbündeten Streitkräften auf der Grundlage gemeinsamer Werte« eine der Bundeswehr eigene Tradition bilde (BMVg 1982:3, P.20). Nationale Geschlossenheit wird durch die Erfordernisse der Gegenwart inopportun und muss auch im Leitmuseum der Bundeswehr problematisiert werden. Tatsächlich zeichnet sich die Neugestaltung des MHM durch eine weitgehende Abwesenheit nationalstaatlicher Hoheitssymbole aus. Embleme der Bundeswehr sind weder im Innern noch im Außenbereich auffindbar. Lediglich ein peripher aufgestellter Fahnenmast auf der Höhe des östlichen Flügels - und damit keinesfalls an exponierter Stelle - gibt Auskunft darüber, dass es sich bei dem Gebäude um eine Dienststelle der Bundeswehr handelt. ${ }^{21}$ Der Vergleich zum Armeemuseum der NVA, in dem das Staatswappen der DDR das Zentrum des triumphalen Eingangs bildete (s. Abb. 27), verdeutlicht diese auffällige Unauffälligkeit der gegenwärtigen Positionierung staatlicher Symbole.

Durch die Deutung der Architektur wird zudem eine Kontextualisierung von baulicher und nationaler Schließung vollzogen. Dieser sprachliche Konnex bleibt auch in der Verknüpfung von architektonischer und internationaler Öffnung erhalten. So wie der Keil das alte Arsenalgebäude aufbreche und neue räumliche Bezüge zu seinem Umfeld ermögliche, so stehe der Altbau für eine starre "nationale Prägung« (Pieken 2010b:6), wird als »Fixpunkt nationaler Identität« (Rogg 2011a:8)

21 Dies gilt auch für die verschiedenen Ausstellungsführer, in denen sich jeweils genau einmal das Logo der Bundeswehr findet; abgedruckt stets kleinformatig und auf der letzten Seite (2011a:193; 2011b:144). Auch auf den Flyern des Hauses stellt das Symbol der Bundeswehr keine offensive Repräsentation staatlicher Macht dar. 
identifiziert und verkörpert eine abgrenzende und wehrhafte Haltung nach außen. Die Rede vom »Kampfplatz nationaler Vergangenheitsbewältigung (ebd.) bringt ein tiefes Misstrauen gegenüber nationaler Geschlossenheit zum Ausdruck. Wehrhaftigkeit und Abgrenzung sind nicht mehr Teil des legitimen Werterepertoires und werden nunmehr als Problem verhandelt. Wieder wird das Phänomen der nationalen Schließung in der Architektur denunziert und damit erneut über den Raum problematisiert. Zur Passivität des Raumes und seiner Charakterisierung als streng und einschränkend kommt also das Problem der nationalen Geschlossenheit hinzu. Daran anschließend werden auch die apologetische Inszenierung der Armee und die damit verbundene Kritiklosigkeit in der Zurschaustellung von Militaria abgelehnt.

\section{Heroisierende Ästhetik als Problem}

Einem der beiden Ausstellungskataloge kann folgende Charakterisierung der vergangenen Ausstellungen entnommen werden: »Ein heroisiertes Militärbild in sschimmernder Wehr avancierte so zum zentralen Bezugspunkt monarchischer und öffentlicher Selbstvergewisserung.« (Rogg 2011a:8). So wie die Architektur für eine militaristische Geisteshaltung steht, gilt dies auch für den wehrhaften, geschlossenen Charakter der Inszenierung im Inneren. In der Tat dienten die wehrhaften und Ehrfurcht gebietenden Bauwerke der Albertstadt und die martialische Inszenierung staatlicher Macht am Ende des 19. Jahrhunderts und vor dem Erlass der Sozialistengesetze nicht nur als Schutzgebärde gegenüber äußeren, sondern vor allem auch als Drohgebärde gegenüber inneren Feinden (von Loh 2012:94).

Das oben beschriebene »heroisierte Militärbild« ist jedoch nicht nur eine absichtslose Beschreibung der Vergangenheit, sondern definiert als Abgrenzungsversuch ex negativo als was sich das MHM heute versteht - nämlich als ein »Museum ohne Pathos «(Pieken 2010b:7; 2012a:164). Diese wiederholt verwendete Formulierung geht Hand in Hand mit einer umfangreichen Befremdung jedweder heroischen Inszenierung von Militaria. An die Stelle der apologetischen Waffenschau trete so das »Museum ohne Pathos«. Dass diese Lesart auch vom medialen Diskurs, sowohl in ablehnenden als auch zustimmenden Artikeln, mitgetragen wird, zeigt sich etwa, indem die Berliner Tageszeitung feststellt, dass es sich bei MHM um kein »Mekka für Militaria-Fans« handele und diese »heilsam enttäuscht werden« (Bartsch, taz 2011), oder darin, dass das MHM als ein »Militärmuseum im Reflexions-Taumel beschrieben wird (Güntner, NZZ 2011). Die Differenz zwischen Früher und Heute wird also auch dadurch kenntlich gemacht, indem der Heroik von einst die Losung entgegengestellt wird: »Denkstiftungs-, kein Sinnstiftungsmuseum «(Pieken, nach Güntner 2011). Dabei dient die negative Vergangenheit - unabhängig von ihrem tatsächlichen apologetischen Gehalt - der Konstruktion einer anderen Gegenwart, 
deren zentraler Topos in der kritischen Reflexion des belastenden Erbes besteht. Die nachfolgende Beschreibung des Projektleiters der Neukonzeption fassen die Problematisierungen der in den Räumen des Museums denunzierten Geschichte prägnant zusammen.

»Die Geschichte der militärhistorischen Museen beginnt bei den Zeughäusern und Trophäensammlungen, aus denen Ruhmeshallen und Armeemuseen mit starker nationaler Prägung wurden: Orte militärischer Leistungsschauen mit Bildern vom braven Sterben in glorreichen Kriegen, Hallen für technische Sammlungen und patriotische Heilsgeschichten. Kritische Reflexionen auf die selbstgewählte Perspektive hatten dort keinen Platz.«(Pieken 2010b:6).

Die Begriffe »Ruhmeshalle«, »Heilsgeschichte« und "glorreicher Krieg« sowie die weiter oben formulierte »Verherrlichung von Waffen« problematisieren die Verklärung des Militärs und denunzieren diese auch in der Ästhetik des alten Gebäudes. Neben der Kritik an der nationalen Schließung ("patriotische Heilsgeschichte«, »starker nationaler Prägung «) wird hier vor allem durch ein quasi-religiöses Vokabular Befremdung erzeugt. Die bereits zu Beginn dieses Kapitels wiedergegebene Rede vom »Hochaltar des Krieges« reiht sich in die Problematisierung des Apologetischen ein. Die Sakralisierung des Krieges und damit die Unterordnung unter dessen Gebote erzwangen »braves Sterben«. Damit wird die Verbindung zur zuvor als »streng« beschriebenen Architektur wieder aufgenommen. Die Vergangenheit und mit ihr das alte Arsenalgebäude verströmen, dieser Lesart zufolge, den Geist des Militarismus. Dieser sei heroisch und apologetisch. Vor allem aber fordert er Unterwürfigkeit und die kritiklose Hinnahme der Befehle (»braves Sterben«). Die problematischen Aspekte der Vergangenheit und ihre räumlich-ästhetische Übersetzung münden schließlich in den zentralen Vorwurf der Kritiklosigkeit. Denn in den Häusern der Vergangenheit hatten »kritische Reflexionen auf die selbstgewählte Perspektive keinen Platz.« Die Distanzierung von einer als unkritisch beschriebenen Vergangenheit dient dazu, den überragenden Wert der Kritik hervorzuheben, den dieser für die gegenwärtige Ausstellung und das Selbstverständnis der Bundeswehr einnimmt.

\section{Sozialräumliche Verengung als Problem}

Mit der Erwähnung der »militärische[n] Leistungsschauen« und der »technischen Sammlungen « gerät schließlich eine vierte Ebene der Problematisierung des $\mathrm{Mu}$ seumsraumes in den Blick. Auch das Problem der Reduktion des Krieges auf rein technische Aspekte wird in ein räumliches Problem übersetzt. Die mangelnde Reflexion über zivile Aspekte der Gewalt und die Fokussierung auf Militärtechnik entsprechen einer sozialräumlichen Eingrenzung. Neben den nationalen Scheuklappen seien die früheren Ausstellungen dadurch zusätzlich in ihrem Blick verengt. So sollten in früheren Militärmuseen »Technik und Glanz der Waffen für sich 
sprechen« (Pieken 2010b:6). Dass Technik und Waffen für sich sprechen, bedeutet auch, dass sie nicht kommentierungsbedürftig gewesen sind. Somit wird abermals der Konnex zwischen einer technikoptimistischen Faszination, die unhinterfragt bleibt, und dem Problem der Kritiklosigkeit geknüpft. In Abgrenzung dazu verstehe sich das MHM allerdings nicht "primär als Technikmuseum«, sondern als ein Haus, das auch zivile Fragen von Krieg und Gewalt thematisieren möchte (a.a.O. 7). Obwohl das »verengte Interesse« von primär an Militärtechnik Interessierten zwar nicht grundsätzlich abgelehnt wird, soll dennoch eine Reduktion der Ausstellung auf technikgeschichtliche Aspekte vermieden werden (MHM-2, 476-485).

Hierbei zeichnet sich eine der zentralen Bruchlinien des Diskurses ab. Diese verläuft entlang der Frage, wie weit die sozialräumliche Rahmung einer militärgeschichtlichen Ausstellung gefasst werden sollte. Der ausschließlichen und unreflektierten Zuwendung an die Militärtechnik wird die Forderung der Denkstiftung gegenübergestellt. Dass das MHM kein Technikmuseum, sondern »kritisch codierte Architektur« und damit »weniger ein Haus der Sinnstiftung als der Denkstiftung« sei (Pieken 2010b:7), stellt eine Maxime der Museumsmacher dar, die auch im medialen Diskurs oft wiederholt wurde (Güntner 2011). Mit dem Vorwurf der technikgeschichtlichen Verengung und der Kritiklosigkeit wird ein Unbehagen gegenüber einer bloß instrumentellen Vernunft artikuliert, deren Gefahrenpotenzial durch Kritik und Denken in Schach gehalten werden soll. >Denkstiftung statt Sinnstiftung bedeutet genau dies und stellt die aufklärerische Selbstermächtigung mündiger Subjekte ins Zentrum dieses Identitätsdiskurses. Das Leitbild mündiger »Staatsbürger in Uniform«, die sich nicht als »Staat im Staate« (Himmeroder Denkschrift 1950, nach Rautenberg/Wiggershaus 1985:185), sondern als Teil der Zivilgesellschaft verstehen, führt dazu, dass die Relevanz ziviler Aspekte in der Ausstellung durchaus den (umkämpften) Kern des Selbstbildes der Bundeswehr berührt.

Die Geschichte des Arsenalhauptgebäudes wird also in erster Linie als Problem und nicht als Identitätsressource thematisiert. Die Befremdung der Geschichte verläuft dabei über umfangreiche abwertende Charakterisierungen des Raumes. Dieser wird auf architektonischer, nationalstaatlicher, ästhetischer sowie lebensweltlicher (sozialräumlicher) Ebene als Problem konstruiert. Die narrative Struktur, der Plot dieser Diskursivierung (Kap. 3.5), erzählt sich bis hierher in etwa folgendermaßen:

Der beschriebene Raum und mit ihm die Vergangenheit sind geschlossen, dunkel, langweilig und von schwerfälliger Passivität; ein bloßer Verwahrungsort (Museumsparkhaus), der in erster Linie eine Last darstellt. Er ist Sinnbild militärischer Strenge im Innern und nach außen. Trotz aller Passivität verströmt der Raum den repressiven Geist des 19. Jahrhunderts. Dieses problematische Erbe ist militaristisch, martialisch, apologetisch, undurchsichtig und national verengt. Der Raum des Arsenals, seine rasterhafte Symmetrie sowie die räumliche Strukturierung werden zur Chiffre für vorgegebene Perspektiven, Gehorsam, Kritiklosigkeit und man- 
gelnde Selbstreflexion. Der zusätzlich im Modus technischer Leistungsschauen verengte Blick blendet zivile Aspekte und Fragen des Leidens am Krieg aus. Diese Aspekte stellen in erster Linie eine Herausforderung dar und stehen einem Museum, mit dem sich der Gesamtstaat identifizieren kann, im Weg. Auch die sozialräumliche Verengung und die technische Reduktion auf Aspekte bloßer instrumenteller Vernunft verhindern Kritik und Selbstreflexion. Die Maxime lautet deshalb: keine Sinnstiftung in schimmernder Wehr, sondern Denkstiftung durch kritische Reflexion.

\subsubsection{Störung, Zerstörung und Verstörung als Wert}

Dadurch, dass die Vergangenheit des Arsenals über den Raum problematisiert wurde, muss sie auf Abstand gebracht werden. Wie dies durch die diskursive Deutung des MHM vollzogen wird, ist Gegenstand des folgenden Unterkapitels. Obwohl sich die Diskursivierungen von Raum und Zeit empirisch durchdringen, ist es sinnvoll diese analytisch getrennt $\mathrm{zu}$ interpretieren.

\section{Zeitliche Strukturierung}

Die umfangreiche Diskontinuitätssemantik, die in der Selbstdarstellung des MHM nachweisbar ist, dient in erster Linie dazu, eine Demarkationslinie zwischen Damals und Heute zu ziehen. Dabei wird Zeit in ein Davor und ein Danach eingeteilt. Anders aber als bei der Konstruktion einer »heroischen Vergangenheit «, wie sie für die Vertreterinnen der GHB im Kontext des Neuen Museums konstitutiv war (Kap. 5.2), ist hier die Rückkehr oder gar die Wiederholung der Vergangenheit gerade nicht geboten. Wie bereits anhand der Traditionserlässe deutlich wurde, (BMVg 1982, 2018) scheidet Vergangenheit als Identitätsressource aus: »Ein Unrechtsregime, wie das Dritte Reich, kann Tradition nicht begründen.« (BMVg 1982:1, P.6). Eine zeitkonstitutionell wichtige Ergänzung findet sich in der zentralen Dienstvorschrift der Inneren Führung, denn dem ansonsten unveränderten Passus wird folgender Imperativ hinzugefügt: »Eine Wiederholung gilt es für alle Zukunft auszuschließen.«(BMVg 2008:4, P.201).

Instruktiv dafür, wie seine Wiederholung für alle Zukunft auszuschließen sei und wie die Architektur in diesem Sinne zu verstehen ist, ist erneut einer der Ausstellungsführer.

»Mit der Formensprache der Architektur wird so die Leitidee des Militärhistorischen Museums für alle sichtbar übersetzt: die traditionellen und überlieferten Sichtweisen einer gewaltverdichteten Geschichte zu erkennen, durch neue Perspektiven zu hinterfragen und wo nötig zu brechen.«(Rogg 2011a:15).

Neben der Verknüpfung von Leitidee und Architektur werden die Techniken der Distanzierung von der Vergangenheit benannt. Der Bruch mit der Geschichte, das Eröffnen >neuer Perspektiven sowie ein Misstrauen gegenüber den >traditionellen 
Sichtweisen räumen dem Aspekt der Diskontinuität und der Störung einen hohen Stellenwert ein. Das eindringlichste Symbol für den Versuch, mit der Geschichte und dem problematischen Erbe zu brechen, stellt der massive Eingriff in Form des keilförmigen Neubaus dar. Wie der Keil zu dechiffrieren ist, wird in den Publikationen des Museums weiter ausgeführt: »Der Keil wird zum Gewaltinstrument, der das Arsenal zerschneidet, zum Stachel, zum Zeichen für Krieg und Schmerz, zum Kontrapunkt des Arsenals, der Krieg nicht anerkennt, sondern in Frage stellt.« (Pieken 2010b:7; identisch 2011:17).

Die Distanzierung von der Vergangenheit wird mit denselben sprachlichen Mitteln hergestellt, die auch im Diskurs des Neuen Museums erkennbar wurden. Die Verwendung plakativer Begriffe aus dem semantischen Feld der Gewalt (Gewaltinstrument, zerschneidet, Stachel, Zeichen für Krieg und Schmerz) dient auch hier der Befremdung. Da die militärische Vergangenheit, die im Raum virulent bleibt, als Bezugspunkt einer positiven Selbstimagination ausscheidet, erscheint die Gewalt gegen die eigene Vergangenheit aber gerade erwünscht, funktional und als moralisch geboten. Da Geschichte hier in erster Linie als Problemgeschichte (und nicht als Identitätsressource) beschrieben wird, erscheint die Gewalt gegen die bauliche Substanz - im Unterschied zum Neuen Museum - legitim. In den Worten Derridas handelt es sich hier also um einen triumphierenden Diskurs (Kap. 2), da die Struktur des Erbens über das Erbe triumphiert und die Abgrenzung davon weithin sichtbar in der Architektur verräumlicht.

Der oben zitierte Absatz wird ebenso im englischsprachigen Architekturführer, der für die Deutung der Architektur instruktiv ist, sinngemäß übernommen. Hier heißt es: »The wedge becomes a weapon severing the arsenal. It is a thorn, a symbol of war and pain, and a counterpoint to the arsenal." (Pieken 2013:12). Nun wird der Keil (»wedge«) sogar als Waffe (»weapon«) bezeichnet und unterstreicht damit die Funktionalität der Begriffe aus dem semantischen Feld der Gewalt. Dieser Nutzen besteht darin, den Lauf der Geschichte in ein Davor und ein Danach einzuteilen. Die zeitliche Struktur besteht auch hier zunächst in einer zeitlichen Zweiteilung. Früher und Heute werden - wie im heroischen Kollektivierungsdiskurs der Gesellschaft Historisches Berlin (Kap. 5.2) - durch größtmögliche Kontrastierung voneinander unterschieden. Allerdings haben sich die Vorzeichen, mit denen die beiden Hemisphären der Zeit versehen werden, umgekehrt. Im Sinne einer umgekehrten Erweckungsrhetorik ist es nicht mehr die Rückkehr zur Vergangenheit, mit der die Zeit der Agonie in der Gegenwart überwunden werden muss. Vielmehr wird die Waffe (»weapon«) der kritischen Reflexion nun auf die Vergangenheit gerichtet, damit diese auf Abstand bleibt.

Gerade die Deutung des Eingriffs als »Kontrapunkt« (»counterpoint«) dient diesem Zweck. Auch die Grundidee des Entwurfs Libeskinds reiht sich so in die Zweiteilung der Zeit ein. Bereits der ursprüngliche Titel des Konzepts »Beyond the Ar- 
senal« artikuliert diesen Anspruch. ${ }^{22}$ Auf der Homepage des Architekten heißt es dazu:

»The winning design boldly interrupts the original building's classical symmetry. [...] The new façade's openness and transparency is intended to contrast with the opacity and rigidity of the existing building. The latter represents the severity of the authoritarian past, while the former reflects the transparency of the military in a democratic society.« (Libeskind 2011).

Dem als mutig beschriebenen Eingriff wird nicht nur eine räumliche Veränderung zugesprochen; er stehe außerdem für eine Zeitenwende. Die autoritäre Vergangenheit, deren Undurchschaubarkeit und Rigidität (opacity, rigidity) weichen einer offenen und demokratischen Gegenwart (transparency, democratic society). Diese gebe sich in der kontrastierenden, aber transparenten Fassade zu erkennen. Die Zeitenwende enthält so auch eine normative Wendung. »Beyond the Arsenal« lässt sich sowohl als räumliches "hinter« als auch als zeitliches "nach« interpretieren. In den Deutungen der Entwürfe durch den Architekten und die anderen Akteure der Neukonzeption wird stets wiederholt, dass Bestehendes hinter sich gelassen und hinterfragt werden soll. Aber auch zeitlich wird damit eine Neuorientierung nach der Zeit des Nationalsozialismus und der Zerstörung der Altstadt Dresdens eingefordert. Der Gegensatz zwischen »authoritarian past« und »democratic society « kann zudem als eine Distanzierung von der DDR gedeutet werden. Denn auch dieser Geschichtsbestand muss aktiv auf Abstand gehalten werden und ist mit der allgemeineren Betonung einer »autoritären Vergangenheit« eingeschlossen. Die kontrastierende Gegenüberstellung und die dramatische Inszenierung eines endgültigen zeitlichen Bruchs befolgen somit den eingangs zitierten Imperativ, wonach eine Wiederholung für alle Zukunft auszuschließen ist.

Das Gebot der Rekonstruktion einer "heroischen Vergangenheit« verkehrt sich hier in die Pflicht zur Dekonstruktion derselben. Bruch, Diskontinuität und Neuorientierung sind dabei nicht nur Schlüsselbegriffe in der Diskursivierung des MHM, sondern ebenso die grundlegenden Motive des "Stunde-Null-Mythos" (Hein-Kircher 2013:37). Dieser gehört zu den fundierenden Erzählungen der Bundesrepublik. Der »mythomotorische« Mehrwert (Assmann 1992) scheint hier wie dort in der Verheißung der Selbsterneuerung zu bestehen, derer die Bundeswehr vor dem Hintergrund der Geschichte so dringend bedarf. Eine weitere Parallele zum Stunde-Null-Mythos bildet der Aspekt der Neuorientierung, welcher sich in der Sprache des Mythos als Neuanfang übersetzen lässt. Der Keil greift nicht nur in die symmetrische Architektur ein, die als Chiffre für "authoritarian past«, Kritiklosigkeit, Undurchsichtigkeit und schwerfällige Passivität Bedeutung erhält. Die Störung der alten architektonischen Anordnung führe zudem zu einer 
stadträumlichen Neuorientierung des Gebäudes. Libeskind selbst knüpft diese Verbindung in einer umfangreichen Darstellung seines Konzeptes in einem der vom MHM herausgegebenen Hefte (Scheerer 2003). Der Erweiterungsbau schaffe eine "grundlegende Neuausrichtung«, er »erhebt« sich über das Alte und ermöglicht eine Öffnung zur Stadt (Libeskind 2003:48). Dass sich der Neubau über den Altbau »erhebt«, unterstreicht nochmals die Maxime, das Alte nicht unhinterfragt anzuerkennen.

\section{Räumliche Strukturierung}

Ein weiteres Ziel der baulichen Intervention und des Aufbrechens der Symmetrie bestehe außerdem darin, den Gästen neue Wege aufzuzeigen: »Der Neubau bricht mit der Symmetrie des Gebäudes und [ergibt] eine prinzipielle Neuausrichtung, die die Bewegung des Besuchers umlenkt und auf neue Wege führt." (Libeskind 2003:48). Dass diese »neuen Wege« auch eine Neuausrichtung stadträumlicher Bezüge umfassen, wird zudem durch eine Skizze expliziert, die dem Text zur Seite gestellt ist. Der Keil verweist demnach mit seiner Spitze auf das Ostragehege, insbesondere auf das darauf befindliche Sportgelände, welches den Bombern der Alliierten als Triangulationspunkt diente (Libeskind 2010, 2011). Diese setzten von dort, in gleichmäßigem Winkelmaß, Leuchtmarkierungen für die Bombardierung der Dresdner Altstadt. Das trichterförmige Areal, welches dadurch aufgespannt wurde, wird durch die Form des Keils aufgenommen. Ebenso erinnern die Umrisse des modernen Baukörpers aus der Vogelperspektive an die Flugformation eines Bombergeschwaders.

Paul Jones konnte anhand der 1.776 Fuß des Freedom Towers in New York und der Zahlensymbolik im Jüdischen Museum in Berlin darauf hinweisen, dass diese Referenzen, mit denen Libeskind seine Architektur deutet (und verkauft), nicht intuitiv am Objekt nachvollziehbar sind (Kap. 3). Auch die Interpretationen der Winkelbezüge, die sowohl die räumlichen als auch die historischen Beziehungen in Dresden neu relationieren, sind auf die Versprachlichung in den Publikationen des Museums angewiesen. Die diskursive Konstruktion der stadträumlichen Bezüge findet neben dem Entwurfskonzept des Architekten (Libeskind 2003) auch über eine Broschüre mit dem kryptischen Titel »40,1 ${ }^{\circ}$ (Pieken/Libeskind 2013) Eingang in die Bedeutungskonstruktion der Architektur. Der Titel dieser Publikation nennt schließlich das Winkelmaß des durch die Markierungspunkte der alliierten Bomber aufgespannten Zerstörungsbereiches der Dresdner Altstadt. Zudem laufen die Fluchtlinien in der Spitze des Keils im selben Winkel zusammen. Auch die Spitze des Keils verweist in einem Winkel von 40,1 ${ }^{\circ}$ auf das Ostragehege. Gerade die Vermittlungsbedürftigkeit des architektonischen Konzeptes eröffnet dem Architekten und den Museumsbetreibern Freiheitsgrade in der Auslegung der Entwürfe 
und ermöglicht so Interpretationen im Sinne eines erwünschten musealisierten Selbstbildes.

Sowohl die Sportanlagen des Ostrageheges als auch der in der Nähe des Alberthafens nach 1945 entstandene Trümmerberg sind aus der begehbaren Spitze des Keils jedoch kaum erkennbar. Die Schaffung neuer stadträumlicher Bezüge bleibt an die diskursive Konstruktion gebunden, zumal selbst mit dem Wissen um dieses behauptete Verweissystem sowohl das Ostragehege als auch der dortige Kriegstrümmerberg nur mühsam und bei starker optischer Vergrößerung erfassbar sind. Keineswegs jedenfalls ist der relevant gemachte räumliche Bezug zum Triangulationspunkt der Bombardierung Dresdens intuitiv erlebbar. ${ }^{23}$ Unabhängig davon, ob der Winkel von 40,1 ${ }^{\circ}$ oder die stadträumlichen Relationen erfahrbar sind, werden sie in den erklärenden Publikationen des MHM zu wichtigen Werkzeugen der Raumkonstruktion. Dank der diskursiven Konstruktion räumlicher Bezüge wird das Arsenalgebäude nicht mehr ausschließlich mit der glanzvollen Silhouette des >Elbflorenz« assoziiert. Die moderne Ergänzung des Gebäudes wird so zum Fingerzeig Richtung Ostragehege und weist damit nicht nur an einen anderen Ort, sondern auch in eine andere Vergangenheit. Dieser Fingerzeig der Architektur ruft nun nicht mehr die heroische Vergangenheit des Alten Dresden auf, sondern die Zerstörungen der Bombardierung Dresdens am 13. und 14. Februar 1945. Indem das Gebäude eine grundlegende Transformation seines Raumgefüges erfährt (Libeskind 2003:48), werden die stadträumlichen Relationen zwischen Albertstadt und Dresdner Altstadt schließlich vor dem Hintergrund eines auf Abkehr rekurrierenden >negativen Geschichtsbildes` neu zueinander in Bezug gesetzt.

Die prinzipielle Neuausrichtung betrifft allerdings nicht nur stadträumliche Relationen, sondern umfasst ebenfalls eine "grundlegende Transformation « und »einen Einschnitt im Inneren des Hauses. Dass die Architektur eine »grundlegende Transformation« des Gebäudes und »seines Raumgefüges« und überdies »Ausstellungsräume einer neuen Qualität« ermögliche (Libeskind 2003:48), macht nochmals deutlich, dass dies als Zugewinn an Möglichkeiten verstanden wird. Dem Aspekt der Störung wird auch im Inneren eine positive Rolle zugeschrieben; dieses Mal allerdings als Instrument einer bewussten Irritation der Besuchenden. Die Aktivität und die aktivierende Rolle, die dem neuen Gebäudeteil zugesprochen werden, erhalten abermals durch die Gegenüberstellung mit der bereits problematisierten Passivität des alten Gebäudes ihren semantischen Sinn. Die Umkehrung ehemaliger Ausstellungen, deren Ziel neben der Demonstration von Stärke gerade

23 Gleiches gilt für die umgekehrte Blickrichtung vom Kriegstrümmerberg Richtung MHM. Trotz des massiven Eingriffs hebt sich auch der Keil der Neugestaltung kaum zwischen den Dächern der umgebenden Gebäude ab. Auf den Trümmerberg wiederum wird im Stadtraum zumeist nicht verwiesen. Auch in Stadtplänen ist dieser meist nicht eingezeichnet (etwa Falk 2006). 
Abbildung 30: Die stadträumlichen Bezüge der Architektur werden durch Abbildungen vermittelt. Die obere Line verbindet das Museum mit dem Ostragehege, indem sie von der ursprünglichen Achse in einem Winkel von 40,1 ${ }^{\circ}$ abweicht; Abbildung 31: Die vertikale Vitrine gestattet die etagenübergreifende Inszenierung verschiedener Geschosse aus unterschiedlichen Kriegen und Epochen.
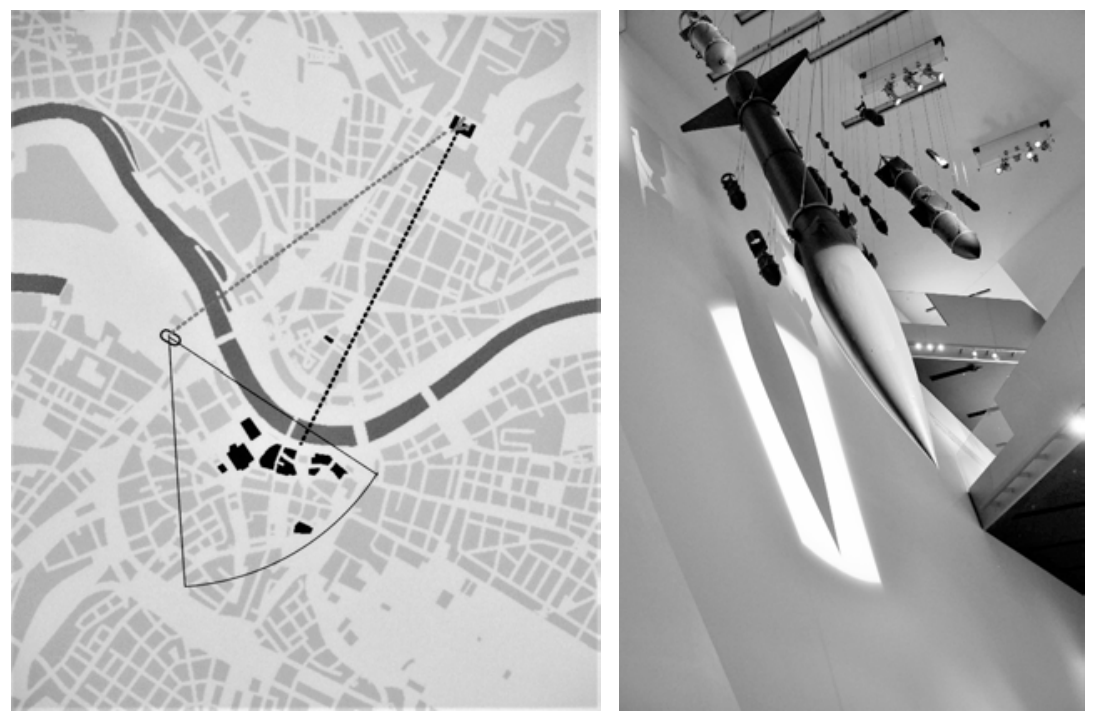

in der Selbstvergewisserung lag, besteht darin, das Leiden am Krieg, die Bedrohung durch Gewalt, vor allem aber die damit verbunden Selbst-Verunsicherungen zu thematisieren. Die neue Ausstellung will demnach bewusst verstören und die Rezipierenden auf emotionaler Ebene ansprechen (Merz/Holzer 2003:56). Sie will nicht mehr für den Krieg (positiv) euphorisieren, sondern für das Leiden am Krieg sensibilisieren und in diesem Sinne (negativ) emotionalisieren.

Besondere Bedeutung wird den fallenden Wänden im Inneren, die so eine dramatische Inszenierung der Exponate in »vertikalen Vitrinen « erlauben (Merz/Holzer 2003), und den künstlerischen Installationen in der Ausstellung zugeschrieben. Im Eingangsbereich erwartet die Gäste ein »Bombenhagel«, der auf die Betonkonstruktion eines Einpersonenbunkers niedergeht. Durch die Innenarchitektur der modernen Ergänzung des Museums wird die Botschaft, dass im Angesicht enthemmter Gewalt auch der massivste Schutzraum unzulänglich bleibt, eindringlich ins Bild gesetzt. Ebenfalls im Erdgeschoss findet sich eine Installation, in der ein Lichtblitz den Moment der Detonation der Atombombe von Hiroshima imitiert. Durch den Schattenwurf der Rezipierenden, der sich so auf einer der fallenden 
Wände kurzzeitig abbildet, werden die Rezipierenden Teil der Installation. Nach einiger Zeit verschwinden die Silhouetten der Betrachtenden wieder, wodurch in der Tat eine verunsichernde Dissoziationserfahrung erlebt wird und eine intendierte »überraschende Wahrnehmung des eigenen Körpers, der sich von seinem Schatten löst « (Pieken 2010b:9). Nicht nur die bedrohliche Inszenierung, sondern auch die Dissoziation von Schatten und eigenem Körper stiften tatsächlich ein verstörendes Gefühl der (Selbst-)Verunsicherung. Auch in ihrem ephemeren Charakter kontrastiert diese Darstellungsform stark mit Beständigkeit und ewigen Ruhm verheißenden Waffenschauen der Vergangenheit.

Die weitere Analyse zeigt also, dass die Distanzierung von der Vergangenheit, die im Raum denunziert wird, durch den Aspekt erwünschter Störung betrieben wird. Die narrative Struktur (Kap. 3.5) kann somit folgendermaßen weitererzählt werden:

Mit dem asymmetrischen Keil wird die rhythmisch und gleichmäßig gegliederte Fassade des Gebäudes, die zuvor zur Chiffre einer rigiden und autoritären Vergangenheit gemacht wurde, aufgebrochen. Die Architektur bricht Bestehendes auf und erzeugt Störung. Erst durch die Neuordnung des räumlichen Verweissystems werden alte Relationen aufgekündigt. Durch die räumliche Neuorientierung wird die Zer-Störung Dresdens mit der Ortsgeschichte des Arsenalgebäudes in Verbindung gebracht. Schließlich wird der Architektur im Inneren ein emotionalisierendes Potenzial der Ver-Störung zugesprochen. Irritation und Verunsicherung erscheinen gerade als Abkehr von "glanzvollen Waffenschauen" und heroischen Bildern in »schimmernder Wehr notwendig. In allen drei Dimensionen wird dem Keil im Innern wie im Äußeren ein aktives Handlungspotenzial zugesprochen. Er »bricht auf«, er »hinterfragt«, führt Besucher auf »neue Wege«, »eröffnet neue Perspektiven« und stellt neue Relationen her. So wird der keilförmige Neubau zur Waffe (weapon), mit der die Vergangenheit gezwungen wird, Abstand zu halten.

Das Deutungsangebot der Museumsmacher und der Architekten entspricht damit dem, was die Architektursoziologin Heike Delitz als produktiven Stör-Akt bezeichnet hat. Die Architektur Sarah Hadids, Frank O. Gehrys und Daniel Libeskinds sei demnach der »Antiheld im Verlangen nach der >europäischen Stadt««; durch die "Ablösung von der Geschichte« werde sie zum Stör-Akt (2010b). Produktiv sei diese Architektur, da sie durch »Nicht-Ordnung neue Bewegungen« evoziere; das Soziale soll so in Bewegung kommen und sich dynamisieren (Delitz 2010a). Tatsächlich findet diese These im Falle des MHM nachgerade idealtypische Bestätigung, denn die produktive Unruhe wird für die umfangreiche Neuordnung nutzbar gemacht. Aus glanzvoller Selbstvergewisserung wird emotionalisierende Verunsicherung, aus apologetischer Geschlossenheit eine bauliche Offenheit, die mit dem Anspruch der Dekonstruktion und demokratischer Transparenz, Integrität und Kritik verbunden wird. Die Architektur soll demnach Irritation im Inneren wie in der Außenbeziehung stiften. Sie soll betroffen machen, Blick- und Wahrnehmungsmuster 
irritieren und erneuern. Indem sie auf das Leiden am Krieg aufmerksam macht, wird sie so tatsächlich zu einem dennoch gefeierten Antihelden.

\subsection{3. »Identitäres Trümmerfeld«: Rekonstruktion statt Dekonstruktion}

Angesichts der verheerenden deutschen Militärgeschichte, der Shoah, zahlreicher Kolonial- und Kriegsverbrechen und des millionenfachen Sterbens in zwei Weltkriegen mag das Gebot der Distanzierung nicht besonders überraschen. Die scharfe Abgrenzung von der Vergangenheit wurde allerdings weder in der Gründungsphase der Bundeswehr noch in der Gegenwart einhellig gefordert oder mitgetragen. Bereits die Verfasser der »Himmeroder Denkschrift« setzten eher auf Kontinuität denn auf den Bruch mit der Vergangenheit. Hitlernahe Generäle, wie etwa Hermann Foertsch, vertraten die Meinung, dass zeitlose soldatische Tugenden auch weiterhin Gültigkeit besäßen und durchaus auch als Fundament der »Neuen Wehrmacht « [sic!] (Bald 2005b:179) taugten. ${ }^{24}$ Der Historiker Detlef Bald betont, dass die erste Fassung der »Denkschrift von Himmerod« noch keinen Satz zur Reform des Militärs vorsah und der »militärische Traditionalismus so programmatisch gefeiert« wurde (ebd.). Somit kann die Denkschrift anfänglich eher als Dokument der Restauration und nicht des demokratischen Neuanfangs gewertet werden. Erst die ultimative Drohung des Begründers der Inneren Führung, Graf von Baudessin, die Denkschrift in ihrer ersten Fassung nicht zu unterschreiben, führte schließlich da$\mathrm{zu}$, dass »durch bescheidene Ergänzungen des Textes eine normative Wertewendung« vollzogen wurde (Bald 2005b:179). Dieser »Gründungskompromiss« (ebd.) und die Auseinandersetzung zwischen »Reformern und Traditionalisten « (Prüfert 2005) bilden bis heute die zentrale Spannungslinie der Kollektivierungsdiskurse im Kontext der Bundeswehr. ${ }^{25}$

An diesem Punkt treten deutlich die unterschiedlichen zeitkonstitutionellen Logiken verschiedener Kollektivierungsdiskurse hervor. Auch im Ausstellungsführer des MHM wird auf diese Spannungslinie aufmerksam gemacht. Dort heißt es: »Viele trugen in den Aufbaujahren die scharfe Abgrenzung zur Wehrmacht nicht mit. Sie sahen sich als Kämpfer, die einem besonderen Stand mit eigenen Regeln angehörten und zeitlosen soldatischen Tugenden folgten.«(Pieken/Rogg 2011a:171, Herv. JK).

24 Des Weiteren waren Adolf Heusinger und Hans Speidel Mitautoren der Denkschrift von Himmerod. Als Mitglieder des Ceneralstabes der Wehrmacht waren beide an der Planung und Durchführung der Vernichtungskriege beteiligt (Bald 2018).

25 Das Reformkonzept der Inneren Führung wurde und wird anhaltend diffamiert. Die Polemik gegen die zentrale Dienstvorschrift erklingt zuweilen sogar aus den höchsten Führungsebenen der Institution; etwa als Franz Josef Strauß - in seiner Funktion als Bundesverteidigungsminister (!) - vom inneren Cefüge der Bundeswehr abwertend als einem »inneren Cewürge« sprach (Bald 2018, s.a. Abenheim 1989:113ff., insb. 119). 
Die bruchlose Konstanz »zeitlose[r] soldatischer Tugenden«, die im Modus der Wiederholung eines ewig gültigen Kanons verfährt, steht einer diskontinuierlichen "scharfe[n] Abgrenzung zur Wehrmacht« entgegen. Dass die Innere Führung bei einem Teil der Truppe nicht verfängt und beharrlich als »weiche Welle« (ebd.) verhöhnt wird, zeigt sich auch anhand der Funde von Nazidevotionalien in den Kasernen der Bundeswehr, die wiederum eine Reformulierung des Traditionserlasses und damit eine erneute Bekräftigung der »scharfen Abgrenzung « zur Folge hatten (Kap. 6.2). Diese Debatten verweisen auf die beiden Fronten des Gründungskompromisses, die bis heute bestehen und durch zyklisch sich wiederholende Skandale in den vergangenen Jahrzehnten immer wieder aufflackerten. Auch die "grundlegende Neuorientierung (Libeskind 2003:48) des MHM wurde keinesfalls unumwunden als Wert anerkannt. Im Schatten des keilartigen Störkörpers, der die Fassade und das Innere des Arsenalhauptgebäudes in der Dresdner Albertstadt durchschneidet und den Bruch in der Geschichte der Institution verdeutlicht, verschaffen sich die Gegenstimmen eines anderen Kollektivierungsdiskurses Gehör. Unter Zuhilfenahme der Kontrastfolie dieses Gegendiskurses wird eine gänzlich andere Deutung der Architektur erkennbar.

Der Versuch, konkurrierende Wissensverhältnisse zu etablieren, wurde im Vorfeld der Dresdner Kommunalwahlen am 13. Juni 2004 unternommen, indem sich das sogenannte Nationale Bündnis Dresden (NBD) klar gegen die Neukonzeption des MHM positionierte. ${ }^{26}$ Auf einem der Flyer dieses Parteienzusammenschlusses heißt es dazu:

»... das unverwechselbare Stadtgesicht von Elbflorenz soll den verrückten Ideen von Pop-Avantgardisten ... zum Opfer fallen, ... deren Sympathie den kalten, geschichtslosen und gesichtslosen Kapitalistenmetropolen in den USA gilt. « (zitiert nach Legner-Zuriel 2004, Ausl. im Orig.).

Die Identität der Stadt ist bedroht! Das Alleinstellungsmerkmal ist durch einen Anthropomorphismus gekennzeichnet. Das »unverwechselbare Stadtgesicht « wird mit den gesichtslosen (sprich: nicht identifizierbaren) Kapitalistenmetropolen kontrastiert. Das eigenräumliche »Elbflorenz« ist durch die Exosphäre USA bedroht. Diese ist nicht nur »kalt« und »gesichtslos«, sondern vor allem »geschichtslos«. In letzterem Attribut klingt eine Mahnung vor Geschichtsvergessenheit an. Das Stadtgesicht, welches durch die »verrückten Ideen« der »Pop-Avantgardisten« bedroht

26 Dieser Zusammenschluss auf städtischer Ebene bestand aus NPD, DVU, der Deutschen Partei und den Republikanern (Legner-Zuriel 2004). Inwiefern dies bei den Wählerinnen auf Resonanz stieß, kann hier nicht überprüft werden. Die Entscheidung, die Neukonzeption des MHM zum Wahlkampfthema zu machen, legt allerdings nahe, dass mit einem gewissen Unmut über die Umgestaltung des Arsenalgebäudes in der Bevölkerung durchaus zu rechnen war. 
ist, verknüpft die Gefahr wieder mit dem semantischen Feld der Gewalt. In diesem Kontext und im Dunstkreis rechtsnationaler Kreise war überdies sogar von einer »zweiten Bombardierung « Dresdens die Rede (zitiert nach Teidelbaum 2011:1). Vor dem Hintergrund dieser drastischen Formulierung erhält die fremdweltliche Sphäre der USA ein zusätzliches Bedrohungspotenzial, da die Architektur Libeskinds mit der Zerstörung Dresdens durch britische und US-amerikanische Bomber kontextualisiert wird.

In einem Artikel in der Zeitschrift »Sezession im Netz« malt einer der Redakteure dieses düstere Bild der Bedrohung weiter aus. Vor allem aber wird nun die Unmöglichkeit der Identifikation mit der neuen Museumsarchitektur bereits mit dem sprechenden Titel »Militärgeschichte ohne Identität« hervorgehoben.

»Zu behaupten, man wolle nun in dieses vollkommen anorganische und nicht einmal halbherzig gelebte Stückwerk befohlener Identität noch >einen Keil treiben<, grenzt eigentlich an politisch-historische Nekrophilie. Es ist eine peinlich verspätete Szene, den New Yorker Stararchitekten auf dem identitären Trümmerfeld Bundeswehr stolz seine >Dekonstruktion verkünden zu lassen, die sich zudem längst zur intellektuellen Retorte entwickelt hat.«(Springer 2012).

Der Bruch mit der Vergangenheit wird nicht als notwendige Dekonstruktion einer problematischen Geschichte empfunden, sondern als Zertrümmerung (»Trümmerfeld Bundeswehr«) eines weiterhin identitätsstiftenden Gesamtbestandes deutscher Militärgeschichte. Dass das Verwerfen der Tradition von der Tageszeitung »taz« als »heilsam enttäuschend« (zitiert nach Springer 2012) betitelt wurde, empört den Autor zusätzlich. Was einerseits Heilung verspricht, wird andererseits als Zerstörung des Eigenen wahrgenommen. Mit den Begriffen >Heilung und >Zerstörung<werden abermals die Extrempunkte des semantischen Feldes der Gewalt genannt (Kap. 5.2.7). Neben der Pathologisierung als »politisch-historische Nekrophilie« und der Rede von den »verrückten Ideen « ist ebenso das diskreditierende Vokabular aus dem semantischen Feld des Wahnsinns auffindbar. Unter dem Titel »Alles schräg« formuliert ein Autor der rechtsnationalen Zeitung »Junge Freiheit« seine Kritik, die explizit an der Ästhetik der Diskontinuität Anstoß nimmt. Das Logo des MHM dient dabei als Beispiel für eine auch im Allgemeinen »schräge« Ausstellung.

»Das schief durchschnittene Signet des neuen Militärhistorischen Museums ist Programm: Hier soll Bestehendes gebrochen und Schräges zur Norm werden. Eine krude Botschaft, die in den stürzenden Wänden des Architekten Daniel Libeskind eine konsequente Fortsetzung erfährt.«(Schulze-Wegener 2011).

Was einerseits als notwendige und innovative Form des Vergangenheitsbezuges seinen Wert erhält, wird als »krude Botschaft« befremdet. Unüberhörbar wird das Unerwünschte pathologisiert und in den Bereich der Unvernunft und Anomalie ge- 
stellt, etwa durch die Bezichtigung, dass hier "Schräges zur Norm« erhoben werde. Die stets wiederkehrende Pathologisierung des Traditionsverständnisses der Inneren Führung findet sich auch in Kommentaren zu dem Artikel in der Zeitschrift Sezession im Netz; etwa wenn dort vom Konzept der Inneren Führung als »Innere[m] Wahnsinn« geredet wird.

»In Koblenz hat das Zentrum Innere Führung (Innerer Wahnsinn) solch Schwachsinn schon vor Jahren verbreitet. Die rote Zelle im MGFA (Militärgeschichtliches Forschungsamt) Potsdam produziert schon über Jahrzehnte die passenden Bücher.« (Kommentar zu Springer 2012, Junge Freiheit am 11. Januar 2012).

Abbildung 32: Schräg durchschnittenes Signet des Militärhistorischen Museums der Bundeswehr in Sichtbeton rechts des Haupteingangs.

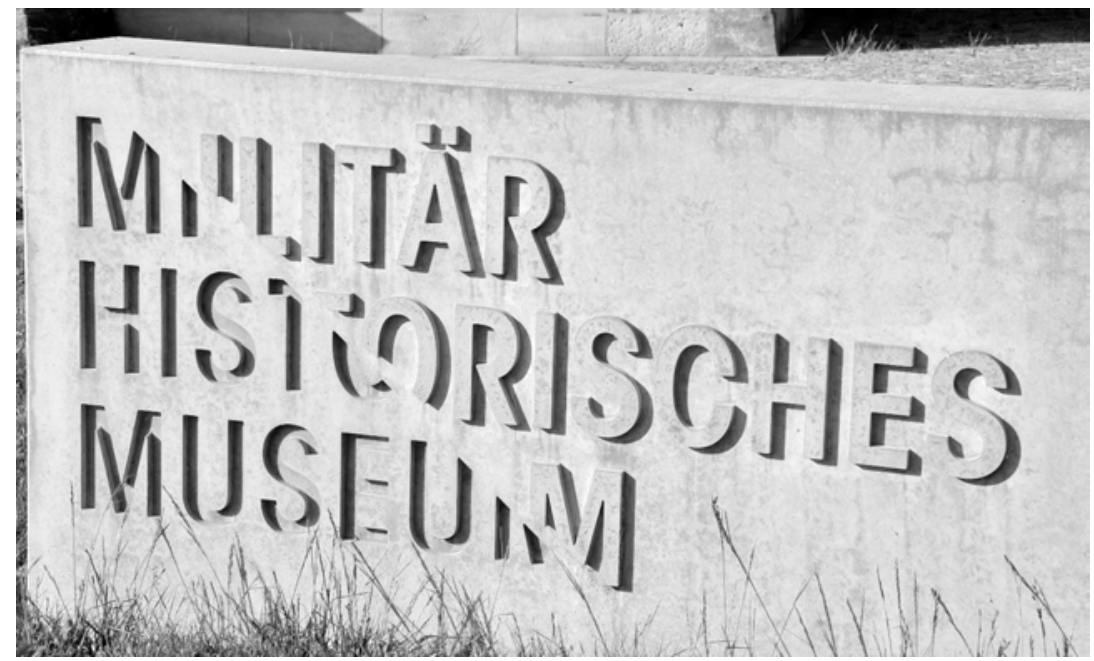

Indem die diskursive Gegenformation in den Bereich geistiger Unzurechnungsfähigkeit gerückt wird, findet sich erneut der Topos des `Wahnsinns` (Kap. 5.2.7), mit dem die neue Ausstellung des MHM diskreditiert wird. Die Rede von einer »roten Zelle« legt Assoziationen zu einer Unterwanderung der Bundeswehr nahe. Verrat und eine fremdgesteuerte Umerziehung (»befohlene Identität«), von der in diesem Zusammenhang ebenfalls die Rede ist, bilden das Pendant zu den »entrückten Zirkeln«, von denen im Neuen Museum die Rede war. Von dem Fremden, das hier konstruiert wird, geht erneut eine besondere Gefahr aus, da es sich im Inneren der eigentlich als eigen reklamierten Institution befindet. Genauso wie der heroische Kollektivierungsdiskurs der originalgetreuen Wiederherstellung das Neue Museum durch die Eliten der Denkmalpfleger und selbstgefälligen Stararchitekten in 
Gefahr sah, wird das deutsche Militär, der Wahrnehmung dieses Diskurses zufolge, ebenfalls aus dem Inneren heraus verraten. Der Feind im Inneren, das Fremde im Eigenen verleiht der konstruierten Bedrohungssituation Dramatik und erklärt die heftigen Reaktionen und die besondere rhetorische Schärfe.

Gewalt gegen das Bestehende oder ein Bruch mit der Vergangenheit erscheinen hier gerade nicht als legitim. So wurde auch in der »Nationalzeitung« (Frisch 2011) die Neukonzeption als »Zerstörerischer Eingriff» bezeichnet. Die Distanzierung von der Vergangenheit wird hier nur als Zerstörung eines legitimen und überdies schützenswerten Traditionsbestandes gedeutet. Neben der antipathetischen Darstellung der deutschen Militärgeschichte ohne »Stolz« und »Helden«, was nun als Missstand wahrgenommen wird, trage diese nicht dazu bei, »die Deutschen mit ihrer Vergangenheit zu versöhnen « (Frisch 2011:4). Anstatt einer Distanzierung von der Vergangenheit wird eine Versöhnung mit dieser gefordert. Mit der Bezeichnung »Nationalmasochismus« (ebd.) rückt der Autor die Neukonzeption zudem in den Bereich einer ebenfalls pathologischen Auto-Aggressionsstörung. Die Gewalt des Eingriffs ist nicht gegen eine fremde (oder zu befremdende) Vergangenheit gerichtet, sondern zielt auf einen Teil der Geschichte, dem man sich nach wie vor verbunden und verpflichtet fühlt. Störung und Problematisierung des bestehenden Raumes werden deshalb als Aggression gegen das Eigene empfunden (»Masochismus«). Dass dies sogar plakativ herausgestellt wird - also sogar noch mit einem Lustgewinn einhergeht - kann aus dieser Perspektive nur als "masochistisch« oder als »Demokratiefetischismus« (Springer 2012) pathologisiert und abgelehnt werden.

Das »identitäre Trümmerfeld« Bundeswehr bedarf also der Rekonstruktion. Die Dekonstruktion im Modus kritischer Reflexion erhält lediglich als »Innerer Wahnsinn« einer bedrohlichen »roten Zelle« Bedeutung und stellt eine einzigartige Fehlleistung dar. Die zeitliche Struktur dieses Kollektivierungsdiskurses besteht in der Charakterisierung der Gegenwart als eine Zeit des Niedergangs, gegen welche eine heroische Vergangenheit konstruiert wird, die verbindlich bleibt. Dies geschieht mit der bereits im Kontext des Neuen Museums analysierten zeitkonstitutionellen Zweiteilung, im Sinne eines »kontrapräsentischen Mythos«. Die typischen Topoi der Erweckungsrhetorik (Assmann 1992) sind auch hier auffindbar. Demnach ist die Gegenwart zuvorderst eine Zeit der Bedrohung für die weiterhin gültige und wesensstiftende Vergangenheit. Letztere kann und muss auch hier wiedergewonnen werden. Auch im heroischen Kollektivierungsdiskurs, wie er durch die Gegner des MHM wahrnehmbar ist, werden die üblichen erweckungsrhetorischen Muster artikuliert. In einem weiteren Kommentar zu dem oben erwähnten Artikel in der Zeitschrift Sezession im Netz heißt es bedeutungsschwer: "Ich bin überzeugt, daß es nach der Revolution und nach der Wiederherstellung der Freiheit in Deutschland wieder in den historischen Zustand versetzt werden wird. Nur eine Frage der Zeit.« (Kommentar zu Springer 2012, quer am 14. Januar 2012). 
So wie in Bezug auf das Neue Museum von einer »Zeit der Agonie« gesprochen wurde, so wird auch in Dresden die Gegenwart unüberhörbar als eine Zeit der Unfreiheit beschrieben. Mit der Forderung nach »Revolution« wird die Gegenwart kontrapräsentisch als Zeit der Unterdrückung und der Ungerechtigkeit charakterisiert. Die Ablehnung der Architektur und der neuen Ausstellung erhält damit den Charakter der Auflehnung gegen die Obrigkeit, womit sich die Sprechenden dieses Diskurses in die schmeichelhafte Rolle des Widerstandskämpfers und des (rechten) Revolutionärs imaginieren. In ihrer zeitlichen Struktur und ihrer räumlichen Forderung nach Rekonstruktion handelt es sich beim Gegendiskurs des MHM - wie bei der Forderung nach originalgetreuer Wiederherstellung des Neuen Museums - um einen heroischen Kollektivierungsdiskurs. Wie in Berlin wird auch in der rechtsnationalen Kritik am MHM ein kontrapräsentischer Mythos stabilisiert (Kap. 5.2.2). Im Sinne einer »nationalen Erweckungsbewegung (Assmann 1992:55) steht die Gegenwart in »krasse[m] Gegensatz zur Gegenwart«. Die Vergangenheit wird so »zum Inbegriff des wahren, wieder herbeizuführenden Zustands« (ebd.). Denn der »historische Zustand« bleibt Fixpunkt der `wiederherzustellenden Freiheit«. Er bleibt Referenzpunkt der Identifikation.

Mittels der Kontrastierung der Deutungen treten somit beide Kollektivierungsdiskurse des MHM deutlich ins Profil. Die einerseits dringend erforderliche $\mathrm{Ab}$ kehr von der Vergangenheit und die Vermeidung ihrer Wiederholung (»Eine Wiederholung gilt es für alle Zukunft auszuschließen.«(BMVg 2008:4, P.201)) werden durch die besonders lauten Stimmen dieses Gegendiskurses als Bedrohung und als Gefahr für das Eigene relevant gemacht. Diese Gefahr kann nur durch die »Wiederherstellung der Freiheit« und »den historischen Zustand « gebannt werden. Es lässt sich also in beiden Deutungen eine Zweiteilung der Zeit nachweisen. Wie im nächsten Unterkapitel deutlich wird, stabilisiert auch die Inszenierung von Diskontinuität eine normative Vergangenheit - unter umgekehrtem Vorzeichen. Auch in der Selbstthematisierung des MHM vergeht Vergangenheit nicht, sondern behält ewige Gültigkeit, jedoch ohne die zeitlos gültigen Tugenden (einer heroischen Vergangenheit) in Anspruch zu nehmen.

\subsubsection{Normative Vergangenheit ohne Pathos?}

Als was sich das MHM versteht, wird zumeist negativ beschrieben, indem gesagt wird, was es nicht (mehr) ist. Seiner Selbstbeschreibung zufolge ist es zuvorderst ein »Museum ohne Pathos« (Pieken 2010b, 2012a). Die Betonung historischer Brüche und die Distanzierung von der Militärgeschichte dürfen aber nicht als eine Marginalisierung oder ein Vergessen der Vergangenheit verstanden werden. Denn auch durch die anhaltende Negation und die kontrastierende Gegenüberstellung mit der Gegenwart wird die Vergangenheit stets diskursiv erneuert. Die Zeit des Nationalsozialismus bleibt gerade dadurch, dass sie aktiv befremdet wird, gegen- 
wärtig. In diesem Sinne bleibt sie eine normative Vergangenheit (Kap. 4.1); dieses Mal jedoch mit umgekehrtem Vorzeichen. In Dresden wird nicht an eine heroische Vergangenheit appelliert oder eine Rückkehr zu dieser eingefordert. Vielmehr gilt es, die Geister der Vergangenheit dauerhaft in Schach zu halten: »Eine Wiederholung gilt es für alle Zukunft auszuschließen.« (BMVg 2008:4). Dadurch wird die Vergangenheit allerdings anhaltend vergegenwärtigt. Der Bruch zieht also keinen Schlussstrich unter die Geschichte. Vielmehr bleiben das Alte und das Neue im Sinne einer wechselseitigen Illumination aufeinander bezogen. Gerade durch den spannungsreichen Kontrast erhält beides seinen semantischen Sinn. Die Anwesenheit des Alten und der effektvolle moderne Eingriff ergeben erst in ihrer Verbindung ein Sinnbild für die Abkehr von der deutschen Militärgeschichte. Durch die Abgrenzung wird die Anwesenheit der Vergangenheit gleichsam auf Dauer gestellt. Sie bleibt ein normativer Bezugspunkt für die Selbstthematisierung der Bundeswehr, des MHM und - im Sinne seines eigenen Anspruchs - des »Gesamtstaates«. Auch die ins Negative gewendete Vergangenheit bleibt der zentrale Referenzpunkt der handlungsleitenden Normen und Maximen der Gegenwart. Die Ablehnung des Erbes bedeutet gerade nicht, dass es an Relevanz verliert. Auch die Verschwörung gegen das Erbe (Derrida, Kap. 2) hält dieses präsent, formt es nach Maßgaben der Gegenwart um und stellt es in seiner Negation ins Zentrum dieses Kollektivierungsdiskurses.

Der Historiker Ernst Nolte, einer der Hauptprotagonisten des Historikerstreites, sprach von einer »Vergangenheit, die nicht vergehen will« (Nolte 1987:39ff., Orig. 1986) und prägte dafür den Begriff der »negativen Lebendigkeit« des Dritten Reiches (Nolte 1987:14, Orig. 1980). Inspiriert von dieser für die deutsche Erinnerungskultur zentralen Auseinandersetzung hat Aleida Assmann die begriffliche Unterscheidung zwischen »Schlussstrich « und »Trennungsstrich« vorgeschlagen (Assmann 2016:49ff.). Im Unterschied zum Schlussstrich, mit dem verschiedene Teile der Vergangenheit abschließend historisiert und den Geschichtsbüchern übergeben werden, besteht der Sinn des Trennungsstrichs gerade darin, die immer noch gegenwärtige und immer wieder vergegenwärtigte Vergangenheit auf Distanz zu halten. Im Zentrum des deutschen Historikerstreites der 1980er Jahre standen genau diese zwei unterschiedlichen Modi im Umgang mit der Vergangenheit (Augstein 1987); einerseits die abschließende Historisierung, andererseits das, was sich als >trennende Verbindung bezeichnen ließe. Denn gerade weil die Zeit des Nationalsozialismus im entzeitlichten Zentrum der Selbstimagination steht und in diesem Sinne nicht vergeht, muss sie immer wieder aufs Neue befremdet werden. Durch die anhaltende Distanzierung wiederum wird sie fortlaufend erneuert und kann deshalb nicht vergehen.

Würde dem Nationalsozialismus eine ähnliche historische Bedeutung beigemessen wie etwa dem Dreißigjährigen Krieg, erschiene jede gezielte und energisch betriebene Abgrenzung davon sinn- und funktionslos. Als eine normative Vergangenheit bleibt die Zeit des Nationalsozialismus gerade in der 
Abgrenzung davon relevant und steht im Zentrum des Kollektivierungsdiskurses der Bundeswehr. Aber auch in der Abgrenzung wird nicht auf eine Vorstellung von Zeitlosigkeit (sprich: ewiger Gültigkeit) verzichtet. Die Distanzierung konstruiert so eine Vergangenheit, die nicht vergeht. Diese trägt schließlich ebenfalls Merkmale einer Identitätsressource. Sie ist ewig gültig und dient der Abgrenzung von anderen Armeen. In einem der Ausstellungskataloge wird gerade der Bruch mit der Vergangenheit zum Alleinstellungsmerkmal. Denn die Bundeswehr habe »keine ungebrochene Tradition, wie andere Armeen« (Pieken/Rogg 2011a:188). Das besondere Verhältnis der Bundeswehr zu ihrer Geschichte erhält den Status einer Eigentümlichkeit. Die Alterität vom Nationalsozialismus wird so zum Kern der Identität. Die Distanzierung von der eigenen Geschichte dient damit auch der Distinktion von anderen Armeen.

Wurde dem sächsischen Kriegsminister und spiritus rector der Albertstadt, General Alfred Graf von Fabrice, aufgrund seiner Verdienste im Feld und um die Planung der Militärstadt noch ein Mausoleum im Zentrum derselben errichtet, so scheinen die Zeiten der Heroisierung > großer Männer « tatsächlich einer vergangenen Vergangenheit anzugehören. Um die Abkehr von derlei heroischen Inszenierungen deutlich zu machen, wird zuweilen das Adjektiv "postheroisch« gewählt (Münkler 2007; von den Hoff et al. 2013; Bröckling 2015, 2018, Leonhard 2016). Auch wenn dieser Begriff in der Selbstdiskursivierung des MHM nicht zu finden ist, ist doch mit der Rede vom »Museum ohne Pathos« genau dies gemeint. Wird der Begriff des Postheroischen zur Analyse des Kollektivierungsdiskurses der Bundeswehr herangezogen, so ergeben sich mindestens zwei weitere Erkenntnisse. Erstens: Klassische heroische Formen der Selbstinszenierung sind keineswegs obsolet geworden. Die großen Zapfenstreiche, mit Fackeln, Marschmusik und Stiefeln, die auf den mit Granitplatten ausgelegten Hof des Bendlerblock donnern, gehören nach wie vor zum identitätspolitischen Repertoire der Bundeswehr und folgen einer rituellen Form der Kohärenzsicherung. Auch die Interventionen in den Diskurs durch zumeist rechtsnationale Kreise haben deutlich gemacht, dass gerade der Verzicht auf einen heroischen Vergangenheitsbezug für viele zum Problem wird. Die Sehnsucht nach einer heroischen Vergangenheit kommt deutlich zum Ausdruck, wenn Stimmen des Gegendiskurses davon sprechen, dass es in beiden Weltkriegen »zahlreiche Heldentaten gab, die man nicht schamvoll verstecken oder umdeuten muss." (Frisch 2011:4). Empirisch scheint also wenig dafür zu sprechen, dass klassische Heldenbilder nicht mehr >nachgefragt $<$ würden.

Erscheint die Rede von einem postheroischen Zeitalter also einerseits empirisch fragwürdig, so wirkt der Begriff zudem suggestiv. Zweitens suggeriert er also eine Fortschrittlichkeit, die eine grundsätzliche Verschiedenheit von der Vergangenheit in Aussicht stellt. So wie die Betonung des Bruchs die Vorstellung von zeitloser Gültigkeit nicht aufhebt, sondern lediglich anders herstellt, so führt auch der Anspruch eines »Museums ohne Pathos« keineswegs zum Verzicht auf pathe- 
tische Darstellungsformen. Auch wenn klassische Pathosformeln (Warburg) abgelehnt werden, da sie als Signum einer unheilvollen Vergangenheit disqualifiziert sind, kann die dramatisch inszenierte Architektur Libeskinds durchaus als Ausdruck einer abstrakteren und entpersonalisierten Pathosformel gedeutet werden. Vor allem in der Beschreibung des Keils mit Begriffen aus dem semantischen Feld der Gewalt (weapon, Stachel, durchschneiden, aufbrechen) bleibt auch der für Heroisierungen typische Konnex zwischen Gewalt und Heroik erhalten (Falkenhayner et al. 2018). Die Attribute der heroisch aufgeladenen Gewalt bestehen nun allerdings nicht mehr in der heldenhaften Niederwerfung äußerer Feinde, sondern in der kritischen und verantwortungsvollen Auseinandersetzung mit der eigenen Geschichte.

»Wir suchen keine Götter in Weiß. Wir suchen Helden in Grün.« Mit diesem Slogan warb die Bundeswehr für die Ausbildung als Arzt und Offizier im Stabsdienst. Wenige Monate später wurde der Begriff »Helden« durch »Retter« ersetzt. Zudem wurde das Bild der Kampagne, welches einen dunkelhäutigen Oberstabsarzt im Feld über einen Verwundeten gebeugt zeigt, durch eine weniger martialisch anmutende Darstellung ersetzt. Wie Daniel Koch (2018) in einer Analyse dieser Kampagne darlegt, zeigt sich darin sowohl das ambivalente Verhältnis der Bundeswehr zu klassischen Heroismen als auch die tendenzielle Zivilisierung des Heldentums (Koch 2018:59). Auch dieses Beispiel zeigt, dass die Diagnose eines postheroischen Zeitalters keineswegs das Ende heroischer Anrufungen bedeutet (Bröckling 2015:106), wohl aber, wie sich idealtypisch im Leitmuseum der Bundeswehr in Dresden zeigt, die anhaltende Problematisierung vergangener Heroismen.

Trotz der abstrakteren Inszenierung des Exzeptionellen verzichtet aber auch der Kollektivierungsdiskurs der Bundeswehr nicht gänzlich auf eine personenbezogene Traditionsbildung. Der Glaube an Personen, die Außergewöhnliches geleistet haben, wird nun allerdings anders formuliert als noch in den Waffenschauen in "schimmernder Wehr", von denen man sich distanzieren möchte. Bereits die Gründung der Bundeswehr am 12. November 1955 wurde bewusst auf den 200. Geburtstag des preußischen Heeresreformers Gerhard von Scharnhorst gelegt (Pieken/Rogg/Schröder 2015:10). Im Ausstellungsführer zur Sonderausstellung »60 Jahre Bundeswehr« werden so die »Reformer« von 1806 mit den »Reformern« im Amt Blank (die Vorgängerinstitution des BMVg) identifiziert (a.a.O. 16). Die Bundeswehr stellt sich so in die Tradition der preußischen Heeresreformer und verleiht dem >Reformkonzept< der Inneren Führung sowie dem Ideal des »Staatsbürgers in Uniform « historische Kontinuität. ${ }^{27}$ Der erste Demokratisierungsversuch des

27 Darauf, dass Scharnhorst als »Erfinder des Volksheeres « auch für die historische Legitimation der NVA vereinnahmt wurde und ebenso bedeutend für die Traditionalisierung der deutschsowjetischen Freundschaft in der DDR war, hat Gabi Dolff-Bonekämper im Kontext der De- 
deutschen Militärs, wie er von Scharnhorst angeregt wurde, stellt somit gemeinsam mit den Demokratisierungsversuchen von 1848 und 1919 einen legitimen Traditionsbestand dar (Bald 2005b:179). Ungeachtet dessen, dass die Demokratisierung des Militärs und die Verhinderung eines `Staates im Staate auch in der Geschichte der Bundeswehr immer wieder infrage gestellt wurden, ${ }^{28}$ sind die Helden, mit denen man sich heutzutage identifiziert, gerade die kritischen Geister und Reformer von einst, die dem Neuen zugewandt mit alten Konventionen brachen. ${ }^{29}$

Sprach Habermas in Bezug auf die Traditionalisierung des Bündnisses mit den USA von einer »retroaktiven Verlängerung der Waffenbrüderschaft« (Kap. 6.2.2), so ließe sich die Integration des preußischen Generals Scharnhorst als eine retroaktive Verlängerung der kritischen Reformbestrebungen bezeichnen. Das ambivalente Anforderungsprofil zwischen Tradition und Traditionsbruch, dem damit Rechnung getragen wird, betrifft in besonderem Maße die Gruppe des 20. Juli 1944. Hieß es im ersten Traditionserlass der Bundeswehr von 1965 noch: »Zur besten Tradition deutschen Soldatentums gehört gewissenhafte Pflichterfüllung« (BMVg 1965:2, P.12), so konnte anhand der zentralen Dienstvorschrift der Inneren Führung (Kap. 6.2) gezeigt werden, dass dem Widerstand aus Gewissensgründen nichts Ehrenrühriges mehr anhaftet. Auch wenn Reformer und Widerstandskämpfer in der Terminologie der Bundeswehr vielleicht nicht den Nimbus von Heroen erhalten, so werden das Auflehnen gegen Missstände sowie die Kritik an bestehenden Strukturen doch zum Gebot. Obwohl der Antisemitismus und die mangelnde demokratische Gesinnung der Gruppe des 20. Juli betont werden müssen (Geisel 2015, Orig. 1994), werden mit deren Bezeichnung als »Widerstandskämpfer« die klassischen heroischen Topoi des Kampfes, der Auflehnung und der Opferbereitschaft aufgerufen. Gerade weil damit der »zählebige Gründungsmythos« vom »anderen Deutschland « bedient wird, sieht Eike Geisel darin ein »moralisches Bindeglied « (2015:27), mit welchem im Sinne des zeitkonstitutionellen Dilemmas (Kap. 6.2.1) trotz der Abkehr von der Barbarei des Nationalsozialismus auch Kontinuität gewährleistet wird. Inwiefern es sich bei den Widerstandskämpfern nicht vielleicht

batte um die Neugestaltung der Neuen Wache in Berlin hingewiesen (Dolff-Bonekämper 1993:37f.)

Eine besonders nachdrückliche Forderung der Revision der Demokratisierung der Armee stellte das ab 1969 vom Kommandostab des Korps in Unna verfasste sogenannte »UnnaPapier « dar. Darin wurde, unter dem Eindruck der Entspannungspolitik, die Integration des Militärs in die Gesellschaft und dessen parlamentarische Kontrolle scharf kritisiert sowie für die erneute Einführung einer eigenen Wehrjustiz plädiert (Bald 2005a:89ff.).

Neben den Reformern um Scharnhorst und der Widerstandsgruppe des 20. Juli 1944 finden mittlerweile in der Traditionsbildung der Bundeswehr auch die »Bürgersoldaten« der Revolution von 1848/49 größeres Interesse (Pieken/Rogg 2011a:189). Auch diese reihen sich mit der Betonung des zivilen »Bürgers« und dem Pathos der Veränderung (Revolution) in das Anforderungsprofil der Tradition der Bundeswehr ein. 
doch um kritische Helden handelt kann an dieser Stelle nicht weiter vertieft werden. Wichtiger erscheint in diesem Zusammenhang, dass an die Stelle der kritischen Helden das Ideal einer heldenhaften Kritik tritt und als zentrale Identitätsressource der Bundeswehr angegeben wird. Ob historisch korrekt oder nicht, wird damit das Auflehnen gegen bestehende Strukturen in die Tradition der Bundeswehr integriert.

Das Zentrum der Albertstadt bildet heute in der Tat nicht mehr das Mausoleum des Grafen von Fabrice. Vielmehr kann das räumliche und symbolische Zentrum nunmehr im Kreuzungspunkt von Olbrichtplatz, Stauffenbergallee und Hans-Oster-Straße ${ }^{30}$ gesehen werden. Unter dem Eindruck der raumzeitlichen Herausforderungen der deutschen Gegenwartsgesellschaft schafft sich die Bundeswehr so die Helden, die zu ihr passen.

\subsection{Eine doppelte Struktur von Raum und Zeit}

Dem Historiker Dan Diner zufolge bestehe nach Auschwitz eine negative »deutschjüdische« Symbiose. Diese ergibt sich daraus, dass die Menschheitsverbrechen der Shoah im Sinne einer "gegensätzlichen Gemeinsamkeit « zum Ausgangspunkt des Selbstverständnisses auf beiden Seiten werden (Diner 1987:185). Die dramatische Inszenierung der historischen Diskontinuität, die keinesfalls mit abschließender Historisierung gleichzusetzen ist, kann so auch als Ausdruck des damit verbundenen negativ fundierenden Vergangenheitsbezuges verstanden werden. Der deutsche Gründungsmythos - im Sinne eines >so sind wird nicht (mehr)< - bedient sich der Shoah als einem negativen Referenzpunkt. Die kontrastierende Darstellung des Gegendiskurses hat jedoch gezeigt, dass gerade das Fehlen positiver Bezugnahmen auf die Vergangenheit - im Sinne eines >so sind wir (immer noch)<problematisiert wurde. Obwohl die Stimmen aus rechtskonservativen Kreisen diese Kritik besonders laut und mit beißendem Spott vortrugen, wird damit doch ein identitätspolitisches Problem benannt, welches für die Bundeswehr durchaus relevant ist. Wie bereits die Analyse der Traditionserlässe verdeutlichte, bedarf die Bundeswehr neben der Dissoziation auch positiver Formen der Assoziationen mit der Vergangenheit. Diese ambivalente Anforderung sah etwa Eike Geisel im ehrenden Gedenken an die Widerstandskämpfer der Gruppe des 20. Juli 1944, die so die Funktion eines moralischen Bindegliedes übernahmen, erfüllt. Auf dieses zeitkonstitutionelle Dilemma (Kap. 6.2.1) reagiert auch das Leitmuseum der Bundeswehr des gegen Hitler: General Friedrich Olbricht, Oberst Claus Schenk Graf von Stauffenberg sowie Generalmajor Hans Oster. 
in Dresden. Denn eine allzu große Nähe zur Vergangenheit gefährdet die moralische Integrität. Eine alleinige Abgrenzung von der Vergangenheit kann Identität jedoch nicht stiften.

Wie die Expertenkommission, die die Rahmenkonzeption der neuen Ausstellung des MHM entwickelte, feststellte, bedarf das Militär auch weiterhin »einer aus den Leistungen der Vergangenheit gespeisten Selbstvergewisserung und damit Identitätsstiftung. «Zudem halten die Experten, die maßgeblich für die Umgestaltung des Hauses verantwortlich sind, fest, dass der »in traditionsstiftender Absicht « in die Vergangenheit gerichtete Blick seinen Bezug stets in der jeweils »aktuellen politisch-sozialen Interessenlage« findet (Konzeptgruppe 2003:31). Im Folgenden möchte ich deshalb argumentieren, dass die Ausstellungsgestaltung des MHM auf diese »aktuellen politisch-sozialen Interessenlagen« mit einer doppelten Strukturierung von Raum und Zeit reagiert. Der Kollektivierungsdiskurs muss dabei mehrstimmig verfahren, da er neben dem Bruch mit der Vergangenheit auch auf die Konstruktion zeitloser Konstanz und entwicklungsgeschichtlicher Kontinuität angewiesen ist. Der Anspruch einer multiperspektivischen Darstellungsweise reflektiert zudem den Verlust eindeutiger Sichtweisen aufgrund disparater Erfahrungsräume (Kap. 1). Denn wie in den Traditionserlässen festgehalten wurde, haben in >pluralistischen Gesellschaften « "historische Ereignisse und Gestalten nicht für alle Staatsbürger gleiche Bedeutung, geschichtliche Lehren und Erfahrungen nicht für alle den gleichen Grad an Verbindlichkeit« (BMVg 1982:1, P.3). Neben dem zeitkonstitutionellen Dilemma manövriert die Traditionsbildung der Bundeswehr mittels eines multiperspektivischen Codes der Verräumlichung ebenso zwischen widersprüchlichen Anforderungen des raumkonstitutionellen Dilemmas (Kap. 6.2.2), wonach nationalräumliche Abgrenzung allein inopportun ist, auf die Bestimmung nationaler Alleinstellungsmerkmale aber dennoch nicht verzichtet werden kann.

In der Debatte um die Neugestaltung des MHM stand insbesondere die ungewöhnliche Inszenierung der Ausstellung und ihre doppelte raumzeitliche Strukturierung immer wieder im Fokus der Kritik. Die Entscheidung, im Folgenden die verschiedenen Deutungen der Ausstellungsbereiche im Inneren des Museums zu analysieren, ist somit durch die empirische Rahmung des Untersuchungsgegenstandes begründet (Kap. 3; 4), da der Diskurs - anders als im Neuen Museum oft die Ausstellung zum Gegenstand machte. Bereits im Eingangsbereich des Leitmuseums der Bundeswehr werden die Gäste des MHM deshalb mit zwei Ausstellungsbereichen konfrontiert, die »räumlich und methodisch klar voneinander unterschieden sind «(Pieken 2010b:8). Dabei handelt es sich um die Bereiche Themenparcours und Chronologie. Diese beiden Bereiche bieten den Besuchenden einerseits einen »klassischen chronologischen Rundgang « und eine »nach Daten sortierte Zeitreise in den Flügeln des historischen Arsenalgebäudes«; zum anderen einen »thematischen Querschnitt, den Themenparcours im Neubau«, dessen Erzählrichtung nicht durch die Chronologie vorgegeben wird (Pieken 2010a:26, 2010b:8). Die 
unterschiedlichen räumlichen Anordnungen werden explizit mit den jeweils darin umgesetzten zeitlichen Strukturierungen in Verbindung gebracht. Die unterschiedlichen Formen der Verräumlichung entsprechen also unterschiedlichen Formen der Verzeitlichung. Der räumliche und methodische Unterschied zwischen den Ausstellungsbereichen wird auf die Formel gebracht: »two approaches to presenting history, each separated from the other by both space and method « (Pieken 2013:10).

Dass die Architektur Daniel Libeskinds auch für die Gestaltung im Inneren die zentralen Gestaltungsmöglichkeiten eröffnete, bestätigt die Innenarchitektin und Ausstellungsgestalterin Barbara Holzer (Breiner 2011). Der Architekt selbst führt den zeitstrukturellen Unterschied der Ausstellungsbereiche in einem Interview weiter aus, indem er die zeitliche Struktur des einschneidenden Keils (intersection) und die damit verbundene Funktion erklärt.

»The intersection of the arsenal creates a completely new spatial form that contrasts the chronological, horizontal historiography of the old building with a vertical structure and lighting. This raises completely new questions that are outside a linear timeline.« (Libeskind 2013:18f., Herv. JK).

Aufgabe des im Keil untergebrachten Ausstellungsteils ist es demzufolge, neue Fragen jenseits eines linearen Zeitstrahls zu stellen. Da die in diesem Teil der Aussellung behandelten Themen »outside a linear timeline« liegen, sind sie dem chronologischen Lauf der Zeit enthoben und verweisen auf allgemeine kulturgeschichtliche Zusammenhänge zwischen Militär und Zivilleben. Die unterschiedlichen raumzeitlichen Strukturierungen der Bereiche bestehen also in einem universal-ahistorischen gerahmten Themenparcours im Neubau, der mit seiner vertikalen Struktur (vertical structure) die chronologisch-horizontale Struktur des Altbaus schneidet. Der Ausstellungsteil Chronologie hingegen ist eher national-entwicklungsgeschichtlich gegliedert und thematisiert in horizontaler Abfolge die Entstehung des deutschen Militärs. So wie der Keil quer zum Altbau liegt, so liegen auch die hier thematisierten Aspekte quer zu allen zeitlichen und räumlichen Rahmungen des Krieges. Indem die vertikalen Durchbrüche des Themenparcours neue Perspektiven zwischen den Ausstellungsteilen eröffnen, ist die Rede von den »thematischen Querschnitten« durchaus wörtlich zu verstehen. Erneut wird das aktivierende Potenzial der Architektur des Neubaus gegen den eher zurückhaltenden Charakter des Altbaus kontrastiert.

»Anders als in der Chronologie, wo die Ausstellungsgestaltung eine weitgehend neutrale Folie für die Objektpräsentation bildet, mischt sich hier der raumbildende Ausbau selber ein. Die Raumgestaltung entwickelt Plotstrukturen und eindringliche Assoziationskontexte. Mittels Collagen aus audiovisuellen Medien werden Klang- und Bildräume geschaffen. In sechs geschossübergreifenden prisme- 
nartigen Ausstellungsschächten, die Daniel Libeskind `vertikale Vitrinen nennt, werden Exponate im Raum installiert.«(Pieken 2010b:9).

Die Raumgestaltung des Neubaus entwickelt »Plotstrukturen«, »eindringliche Assoziationskontexte« sowie »prismenartige Ausstellungsschächte«. Der Themenparcours erlaube eine assoziative Darstellung und die collagenartige Verknüpfung disparater Themenfelder. Die schillernden Farben und das breite Spektrum des Prismas kontrastieren deutlich mit der »neutralen Folie« nüchterner »Objektpräsentation« im klassischen Rundgang der Chronologie. Anhand einer Gegenüberstellung der Begriffe, mit denen die Ausstellungsbereiche beschrieben werden, wird deren kontrastierende raumzeitliche Strukturierung deutlich.

Der alte Gebäudeteil und die darin untergebrachte Chronologie ermöglichen die Thematisierung einer linear voranschreitenden nationalgeschichtlichen Historiografie. Die horizontale Erzählrichtung und die neutrale Anordnung der Vitrinen ermöglichen Zeitreisen, da historische Ereignisse und Epochen klar voneinander getrennt sind. Die Struktur dieses Ausstellungsteils ist dokumentarisch. Sie soll auf instruktive Weise Fakten vermitteln. Die passive Rezeption wird durch den klassischen Rundgang auch mit dem historischen Gebäudeteil in Verbindung gebracht. Der neue Gebäudeteil und der darin beherbergte Themenparcours hingegen ermöglichen die Thematisierung potenziell ahistorischer Fragen menschlicher Gewalt. Indem sie outside a linear timeline liegen, sind sie dem Lauf der Chronologie enthoben. Die vertikalen Vitrinen ermöglichen räumliche und thematische Querschnitte und liegen quer zum Zeitverlauf. Die Rezeption dieses Ausstellungsteils ist assoziativ. Sie soll bewusst Verbindungen über Themenbereiche und Epochen hinweg ermöglichen. Die Architektur des Neubaus entwickelt Plotstrukturen und eindringliche Assoziationskontexte.

Obwohl die Ausstellungsbereiche klar voneinander unterschieden werden, sind sie dennoch keineswegs voneinander getrennt, denn indem sie sich durchdringen, perspektivieren sie sich stets aufs Neue. Eben dieses Zusammenspiel der Ausstellungsbereiche, vor allem aber die doppelte Strukturierung von Raum und Zeit werden vom Museumsdirektor besonders betont. Erst durch die gleichzeitige Thematisierung von Kontinuität und Diskontinuität, also im Zusammenspiel der Ausstellungsteile, erhält der historische Wandel den Charakter einer Gewissheit.

»Libeskind greift auf den einfachen, aber unbestrittenen geschichtswissenschaftlichen Ansatz zurück, dass der Lauf der Geschichte von einem ständigen Wechsel von Kontinuität und Diskontinuität bestimmt wird. [...] Diese äußerliche scheinbare Kontinuität mit ihren zahlreichen inneren Wechseln und Brüchen, die von der Formensprache über den Umgang mit der Architektur bis zur Sammlungsphilosophie reicht, bildet das historische Fundament des MHM.«(Rogg 2011a:16). 
Ewig bleibt allein die Veränderung! So lautet auch hier die implizite Feststellung mit Verweis auf den »unbestrittenen« Aspekt des »ständigen Wechsels«. Diese Grundidee des Museums wird mit den architektonischen Veränderungen und der wechselhaften Geschichte (Kap. 6.1.1) des Gebäudes in Verbindung gebracht. Zudem klingt hier ein Misstrauen gegenüber historischen Kontinuitäten an. Kontinuität ist hier »äußerlich[e]« und »scheinbar[e]«, wobei im Inneren Wechsel und Brüche bestimmend sind, die das eigentliche »historische Fundament des MHM« bilden. Mit den wertenden Begriffen »scheinbare Kontinuität« im Unterschied zum »unbestrittenen« Axiom »ständigen Wechsel« wird also ein authentifizierendes Vokabular bemüht. Demnach wird das »historische Fundament des MHM« nicht etwa von zeitloser Konstanz, sondern gerade von den "zahlreichen inneren Wechseln und Brüchen« gebildet. Der Wandel wird so zur Gewissheit, die Veränderung zum Fundament.

Das Zusammenspiel zwischen Kontinuität und Diskontinuität wird mit dem »Materialwechsel vom hellen Sandstein des Altbaus zu den silbrig glänzenden Aluminiumlamellen des Keils« in Verbindung gebracht. Dabei weiche die »klassische Architekturgliederung des alten Arsenalgebäudes [...] je nach Lichtverhältnissen einer transparenten oder einer nicht zu durchschauenden Flächigkeit« (a.a.O. 17). Somit werden das ständige Wechselspiel der Lichtverhältnisse und das sich so stetig wandelnde Erscheinungsbild der Architektur sogar innerhalb der Zeitspanne eines Tages behauptet. Der massige Keil erscheint bald leicht durchschimmernd, bald drückend schwer. Nicht mehr die Inszenierung bruchloser Ewigkeit in Stein, sondern die im Wechsel der Lichtverhältnisse sich stets neu perspektivierenden Materialien werden so hervorgehoben. Gerade das Wechselspiel von Kontinuität und Diskontinuität wird durch die (unterschiedlichen) Architektur(en) verräumlicht und sprachlich ins Bild gesetzt. Die effektvolle Kontrastierung der beiden unterschiedlichen Ausstellungsbereiche und die Anordnung der verschiedenen architektonischen Formensprachen werden zu einer Chiffre für Kontinuität und Diskontinuität und schließlich zu der Gewissheit "ständigen Wechsel« synthetisiert. Eben diese doppelte Struktur von Raum und Zeit erlaubt der Bundeswehr, zwischen Konstanz (»dem Bleibenden im Menschen«) und Wandel (»ständigen Wechsel von Kontinuität und Diskontinuität«) einen Kollektivierungsdiskurs zu etablieren, der sich durch die anhaltende und multiple Perspektivierung seines militärgeschichtlichen Erbes stabilisiert. Dass die »zahlreichen inneren Wechsel und Brüche« zum »historischen Fundament des MHM« werden, bedeutet auch, dass Geschichte immer wieder neu betrachtet werden muss und Zukunft auf bekannte Weise unbekannt bleibt (Koselleck, Kap. 1). 
Abbildung 33: Wechselseitige Perspektivierung der Architekturen im Eingangsbereich. Der vertikale Betonschacht erinnert an andere Entwürfe Daniel Libeskinds, insbesondere an die ebenfalls vertikalen Räume der Leere (Voids) im Jüdischen Museum Berlin; Abbildung 34: Plan der Ausstellung. Die Einfärbungen veranschaulichen die wechselseitige Durchdringung der Bereiche Themenparcours im Neubau und Chronologie im Altbau.
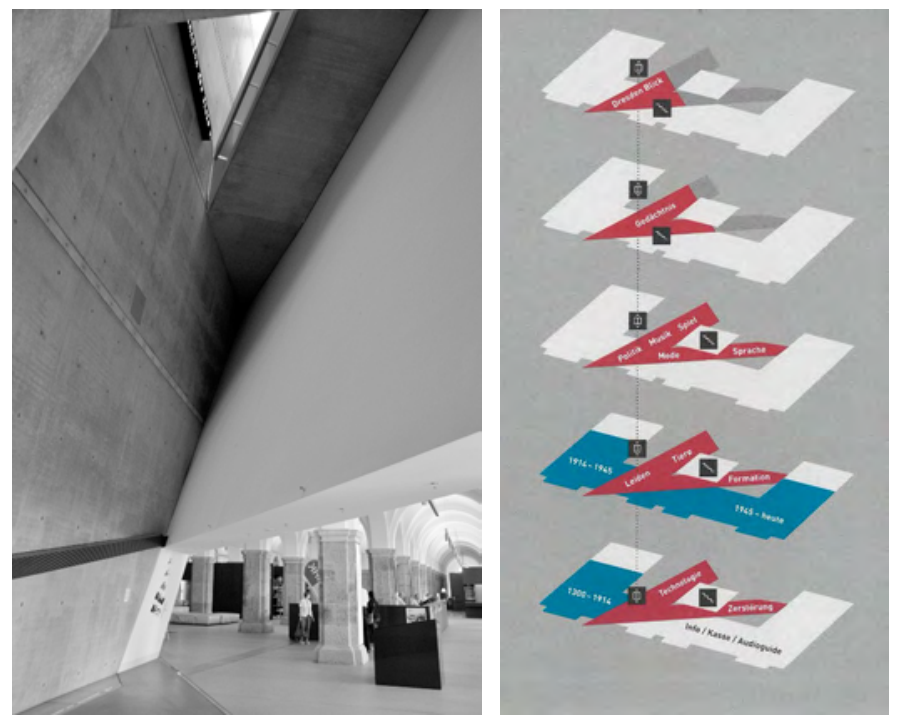

\subsubsection{Krieg als conditio humana?}

Im Ausstellungsteil Themenparcours findet sich eine erste Antwort auf die Frage, wie das Erbe des deutschen Militärs ausgeschlagen und dennoch Konstanz hergestellt werden kann. Denn ein Topos, der in allen vom MHM herausgegebenen Publikationen $\mathrm{zu}$ finden ist, besteht in dem, was im Folgenden anthropologische Ewigkeit genannt werden soll. Anstatt einer nationalen Geschichte des Militärs sei man vielmehr daran interessiert, eine »Kulturgeschichte der Gewalt« darzustellen (Konzeptgruppe 2003:28f.). Dieser Anspruch wird vor allem im Neubau eingelöst. Auch in der Außenwahrnehmung des MHM wird dieser Ausstellungsbereich besonders umfangreich thematisiert. Die thematischen Querschnitte und der weitgefasste Anspruch einer »Kulturgeschichte der Gewalt« stellten die Museumsmacher zunächst vor Probleme. Dass das Ausweichen auf die Ebene (vermeintlicher) menschheitsgeschichtlicher Konstanten bei der Entwicklung der Konzeption als vielversprechender Ausweg erschien, veranschaulicht nachstehendes Zitat: 
»Schließlich fraßen sich alle Beteiligten, also nicht nur Beiräte, sondern die Vertreter aller an der Neukonzeption beteiligten wissenschaftlichen Einrichtungen und ministeriellen Dienststellen, am Begriff Anthropologie fest: Das MHM sollte die Frage der strukturellen und individuellen Gewalt in den Mittelpunkt stellen. Frei nach Kant: Was ist der Mensch?«(Rauchensteiner 2011:12).

Dass mit dem Wort "Anthropologie«, an dem sich nunmehr alle Beteiligten >festfraßen<, ein Zugang zum Thema gefunden wurde, scheint auch mit einer gewissen Erleichterung einhergegangen zu sein, die im Zitat unüberhörbar anklingt. Mit der Idee, das MHM zuvorderst als Geschichtsmuseum und nicht in erster Linie als Militärmuseum zu konzeptualisieren, wurde der thematische Fokus der Ausstellung geweitet. Auch von der ursprünglichen Forderung nach »besonderer Berücksichtigung der sächsischen Militärgeschichte« (Rauchensteiner 2011:13) ist im weiten Feld menschheitsgeschichtlicher Kulturphänomene und einer allgemeinen Gewaltheuristik nichts mehr zu erkennen. Nicht etwa die Frage »Was ist das deutsche Militär?«, sondern die Frage »Was ist der Mensch?« weitet den räumlichen und zeitlichen Fokus der Ausstellung und entledigt sie vorerst nationalräumlicher Beschränkungen zugunsten eines anthropologischen Erkenntnisinteresses:

»[Das] Leitmotiv der Ausstellung, das alle Ausstellungsbereiche durchdringt: die anthropologische Disposition des Menschen. Die anthropologischen Crundfragen suchen nach Konstanz und nach dem Bleibenden im Menschen: der Mensch mit seinen Hoffnungen und Leidenschaften, seinen Erinnerungen und Ängsten und mit seiner Aggressionsbereitschaft.«(Pieken 2011:19f., Herv. JK).

Die schwierige Suche nach Konstanz in der deutschen Vergangenheit bedarf der raumzeitlichen Entgrenzung. Da etwa die Suche nach dem >Bleibenden im deutschen Militär< gerade nicht geboten ist, verlagert sich die explizit so benannte >Suche nach Konstanz« auf das »Bleibende im Menschen«. Im Zentrum der neuen Ausstellung stehe demnach »der Mensch, die anthropologische Seite von Gewalt« (Pieken 2011:19). »Anthropologische Seite von Gewalt« bedeutet auch, dass die wechselhafte Geschichte des deutschen Militärs zu einem Oberflächenphänomen einer seit Anbeginn der Zeit und bis in alle Ewigkeit in der Tiefe menschlicher Grunddisposition verankerten Gewaltaffinität wird. In einem der Ausstellungsführer wird diese Naturalisierung der Gewalt und damit in letzter Konsequenz die Zwangsläufigkeit des Krieges konstruiert, indem die rhetorische Frage gestellt wird, ob »Aggressivität evolutionsbiologisch möglicherweise in jedem Menschen angelegt« und damit eventuell so »selbstverständlich und unvermeidbar wie das Bedürfnis zu schlafen, $\mathrm{zu}$ essen oder zu trinken« ist (Pieken 2011:22). Die Einfassung gänzlich verschiedener historischer Formen von Gewalt vor dem Hintergrund menschheitsgeschichtlicher Konstanten und ihre Trivialisierung (wie essen, schlafen, trinken) werden sprachlich ins Bild gesetzt: »So verstanden, ist Krieg nur eine Erscheinungsform 
der Gewalt. Das Militär ist lediglich die berühmte Spitze des Eisberges, dessen Schwerpunkt weit unterhalb der Wasserlinie im Bereich der Anthropologie und Kulturgeschichte des Menschen liegt.«(Pieken 2011:19).

Die formulierte Ewigkeitsbehauptung wird nötig, da der Glaube an einen Grundbestand »zeitloser soldatischer Tugenden« (Pieken/Rogg 2011a:171) - und damit im Bereich der Kultur - nicht mehr in Anspruch genommen werden kann. Da Zeitlosigkeit (vorerst) nicht mehr auf der Ebene gesellschaftlicher (oder gar spezifisch deutscher) Tugenden zu finden ist, kann sie nur noch auf der allgemeinsten Ebene (vermeintlich) menschlicher Grunddispositionen und damit im Bereich der Natur verankert werden. Letztverbindlichkeit und ein ewiger Wesenskern scheinen nur noch in kulturgeschichtlicher Konstanz menschlicher Gewalt plausibel. Auch dieser Topos der kulturgeschichtlichen Fokusweitung wird durch die mediale Resonanz weitgehend unhinterfragt reproduziert (Jaeger, Badische Zeitung 2011 oder Altmann 2012). Mit der anthropologischen Ewigkeit, die das Militär zu einem bloßen Oberflächenphänomen (»Spitze des Eisbergs«) menschlicher Grunddispositionen macht, geht die diskursive Konstruktion eines negativen Menschenbildes einher, welches für die Legitimation des Museums und des deutschen Militärs von großer Bedeutung ist:

»Will man das Kriegspotential unserer Welt ein wenig mehr verstehen, um es hinterfragen und vielleicht sogar überwinden zu können, muss man sich den Ursachen und dem Wesen jenes Cewalt->Anteils « zuwenden, der in uns selbst und allen Menschen in allen bekannten Cesellschaftsordnungen zu allen Zeiten angelegt war und ist.«(Pieken 2010b:8).

Wesenhaft für den Menschen sei also ein »Gewalt->Anteik«, in dem die Ursache für Gewalt und schließlich Krieg stecke. Es wird eine natürliche Anlage zur Gewalt attestiert, die nicht nur immer (»Zu allen Zeiten«), sondern auch überall (»in allen bekannten Gesellschaftsordnungen «) in »allen Menschen « »angelegt war und ist «. Anhand der in die Nähe einer Naturgesetzmäßigkeit gerückte Gewaltbereitschaft des Menschen wird ein durchgängig negatives, an Thomas Hobbes erinnerndes Menschenbild (homo homini lupus), gezeichnet. Unabhängig davon, welche natürliche Grundhaltung man dem Menschen unterstellt - egal ob Hobbes oder Rousseau -, von Interesse ist hier lediglich, dass damit eine doppelte Setzung vollzogen wird. Erstens: Alle Menschen verfügen trotz ihrer Individualität über eine anthropologische Ausstattung, die sie eint. Zweitens: Das Militär ist nur die natürliche Konsequenz dieser Grunddisposition und legitimiert sich gleichsam natürlich. Dass mit der Behauptung einer anthropologisch konstanten Gewaltaffinität des Menschen en passant eine natürliche Legitimation der eigenen Institution geliefert wird, ist Gegenstand der Kritik an der Ausstellung in einem Artikel, der in der politisch eher links zu verortenden Zeitschrift »FairQuer« erschienen ist. Laut dem Autor könne das »Interesse der Bundeswehr, mit ihrem eigenen Museum Politik zu machen«, 
nicht verwundern. Vielmehr werde deutlich, worin das eigentliche Interesse des Hauses bestehe, nämlich: »In der Legitimation des deutschen Militärs, in diskursivem Gewand und mit Spuren kritischer Selbstreflexion« (Ungewitter 2012:29f.).

Eine erste Antwort auf die Frage, welche positiven Formen der Selbstthematisierung im Sinne eines sso sind wir vor dem Hintergrund der deutschen Militärgeschichte noch artikuliert werden können, besteht also in der Verankerung der eigenen Institution in der Tiefe menschlicher Grunddispositionen. Das positive Identitätsangebot lautet dabei schlicht: Wir sind immer und überall Menschen und als solche ist und bleibt uns stets ein »Gewalt->Anteik« zu eigen. Die Unkonkretheit der anthropologischen Ewigkeit eines unabänderlichen Menschseins bleibt jedoch identifikatorisch äußerst limitiert. Festgehalten werden muss aber auch, dass mit dieser Naturalisierung schließlich die Notwendigkeit des kritischen Hinterfragens zu einer dauerhaften Aufgabe wird. Da der Mensch prinzipiell ein gewalttätiges Wesen sei, bedürfe es der Selbstreflexion, dieses zu zähmen. Die Suche nach Konstanz und dem Bleibenden im Menschen führt also einstweilen auf die allgemeine Ebene menschheitsgeschichtlicher Universalismen und einer anthropologischen Ewigkeitsbehauptung. Damit wird die Brennweite des Fokus des Kollektivierungsdiskurses vergrößert. Allerdings wird das Bild, das dabei entsteht, diffus. Anthropologie allein bietet lediglich die allerweiteste Klammer und vermag ein spezifisches Selbstbild noch nicht zu stiften.

Abbildung 35: Postkarte des Militärhistorischen Museums. Figurengruppe in Schutzkleidung im diachronen Vergleich. Mit diesem Spacing wird Gewalt als anthropologische Konstante thematisiert.

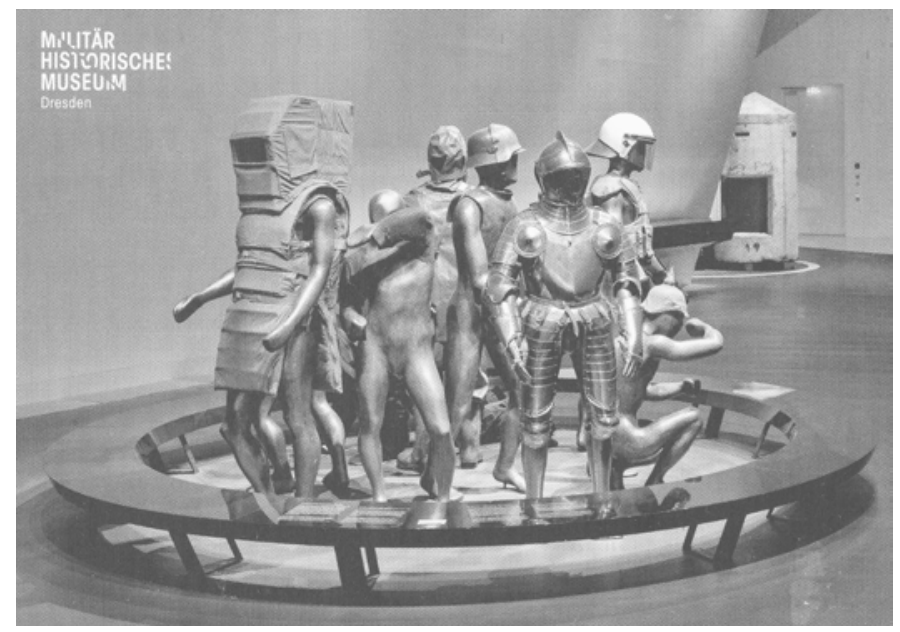




\subsection{2. „Multiperspektivität«: Jenseits nationalhistorischer Grenzen}

Im Vorwort eines der Ausstellungsführer und somit an exponierter Stelle macht der Museumsdirektor Matthias Rogg deutlich, wie das MHM Militärgeschichte erzählen möchte, nämlich »multiperspektivisch, kritisch, modern und auf der Höhe der Forschung.« (Rogg 2011b:9). Insbesondere der »multiperspektivische Ansatz« sei demnach zentral für die gesamte Ausstellung (Pieken 2010b:7). Die Wechselwirkung der Ausstellungsbereiche impliziert einerseits die mannigfachen Verbindungen zwischen der Chronologie deutscher Militärgeschichte und den kulturgeschichtlichen Aspekten des Zivillebens im Themenparcours. Die unterschiedlichen Perspektiven, die sich aus den alltagskulturellen Bereichen Spiel, Musik und Kleidung auf die deutsche Militärgeschichte ergeben, führen dazu, dass »jedes Exponat in Wechselwirkung mit den es umgebenden Objekten, den Elementen der Ausstellungsgestaltung und mit der Architektur«steht. (Pieken 2011:24). Einerseits werden mit der sozialräumlichen Durchmischung und der Betonung ziviler Aspekte die Maxime des "Staatsbürgers in Uniform« sowie die Zivilisierung und Demokratisierung des Militärs bedient (Kap. 6.2.3). Die zentrale Thematisierung der Verflechtungen zwischen dem Zivilen und dem Militärischen kann damit auch als musealer Ausdruck der Inneren Führung gewertet werden. Andererseits werden mit dem Anspruch des multiperspektivischen Ansatzes auch verschiedene nationale Perspektiven für den Kollektivierungsdiskurs der Bundeswehr in Anspruch genommen.

Gerade vor dem Hintergrund der deutschen Militärgeschichte erscheint das Versprechen einer multiperspektivischen Erzählweise verheißungsvoll, erlaubt sie doch, die diskreditierte, exklusiv nationalstaatliche Rahmung $\mathrm{zu}$ umgehen, die als räumlicher Referenzrahmen für den Kollektivierungsdiskurs der Bundeswehr nicht mehr uneingeschränkt zur Verfügung steht. So wie der Themenparcours »outside a linear timeline« (Libeskind 2013:19) und damit jenseits der entwicklungsgeschichtlichen Chronologie liegt (Konzeptgruppe/Expertenkommission 2003:34), erlaubt der multiperspektivische Code der Verräumlichung der Neukonzeption und ihrer diskursiven Deutung die Thematisierung deutscher Militärgeschichte jenseits nationaler Grenzen. Wie bereits erläutert, zeigt sich dies auch anhand der weitgehenden Abwesenheit nationaler Hoheitssymbole (Kap. 6.3.1). Im Sinne eines geschichtlichen Museums sauf der Höhe der Forschung tritt die dominante Rahmung der Ausstellungskonzeption im Themenparcours tatsächlich aus dem Containerraum »nationalhistorische[r] Denkweise« (Osterhammel 2001:9).

Damit verfolgt das Museum - ohne dass dies im Diskurs explizit so genannt wird - einen Ansatz des Historikers Jürgen Osterhammel. Dieser plädiert für eine "Geschichtswissenschaft jenseits des Nationalstaats « und nennt dies »Beziehungsgeschichte« (2001). Der relationale geschichtswissenschaftliche Ansatz erkennt in den »Beziehungen« den Stoff, aus dem Geschichte gemacht ist, und unternimmt 
so den Versuch, "nationalhistorische Selbstbezogenheit « zu überwinden (Osterhammel 2001:7), um Geschichte »jenseits des Nationalstaates« zu perspektivieren. Beziehungsgeschichte umfasse demnach »Relationales aller Art (ebd.). Die Herstellung von multiplen und immer wieder neuen Sichtbezügen auf den Ebenen der Architektur, des Stadtraumes und zwischen den Ausstellungsteilen entspricht exakt diesem national entgrenzten Geschichtsverständnis. ${ }^{31}$ Der Ausstellungsraum »Dresden Blick« in der Spitze des Keils bietet ein anschauliches Beispiel dafür, wie im Kollektivierungsdiskurs der Bundeswehr tatsächlich »Relationales aller Art « miteinander verknüpft wird und räumliche Bezüge über nationale Grenzen hinweg durch die Spacings der Exponate und die Architektur sowie deren diskursive Syntheseleistung (Löw, Kap. 4.2) hergestellt werden. Zudem kann damit auch gezeigt werden, warum gerade dieser multiperspektivische Code der Verräumlichung vor dem Hintergrund deutscher Militärgeschichte und den gegenwärtigen raumzeitlichen Herausforderungen funktional erscheint.

Folgt man den Rezeptionsinstruktionen der Ausstellung, so führt der Weg der Besuchenden mit dem Fahrstuhl in das vierte Stockwerk in die Spitze der Keilform des Neubaus. Dort beginnt der Rundgang durch die Ausstellung mit dem Ausstellungsraum »Dresden Blick«. Der Raum verfügt über keinerlei rechten Winkel, jede Fläche ist schief, wodurch ein Gefühl der Orientierungslosigkeit erzeugt werden soll (Rogg 2012:105f.). In dem Raum, der sich am höchsten Punkt der Ausstellung befindet und durch eine Glaswand hindurch den Blick in die Spitze des Keils und von dort weiter Richtung Dresdner Altstadt gewährt, befinden sind drei Exponate. ${ }^{32}$ Dabei handelt es sich um Gehwegplatten aus Wieluń und Dresden, die durch Bombenangriffe zerstört wurden sowie eine ebenfalls durch Luftangriffe zerstörte Statue aus Sandstein, die das Portal eines Waisenhauses in Rotterdam schmückte. ${ }^{33}$ Das Arrangement der Zeugnisse des Krieges aus drei europäischen Städten

31 Obgleich der Hinweis auf Osterhammels »Ceschichtswissenschaft jenseits des Nationalstaates (2001) nirgendwo im Diskurs expliziert wird, ist davon auszugehen, dass die renommierten Historiker des Erweiterten Wissenschaftlichen Beirats sowie der Expertenkommission diesen einschlägigen theoretischen Ansatz kannten.

32 Die Tatsache, dass der spektakulärste Raum der Ausstellungsarchitektur, der in zahlreichen Publikationen mit komplexen Deutungen bedacht wird, ursprünglich ein Café hätte aufnehmen sollen, zeigt, dass die diskursive Bedeutungszuschreibung hier ex post geschehen ist. www.das-neue-dresden.de/bundeswehrmuseum-dresden.html

33 Ein weiteres Fragment dieses Portals des Waisenhauses, welches am 14. Mai 1940 durch die deutsche Luftwaffe zerstört wurde, befand sich im Sommer 2019 als Leihgabe des Stichting Museums Rotterdam in der Außenstelle des MHM in Berlin-Gatow. Obwohl so eine weitere räumliche Relation zu dem geschichtsträchtigen Militärflughafen geknüpft werden kann, wird diese Verbindung diskursiv nicht hergestellt. Die Außenstellen des MHM in Gatow sowie auf der Festung Königstein folgen noch einer weitgehend klassisch-chronologischen Ausstellungskonzeption. Zum Zeitpunkt dieser Untersuchung werden aber auch diese im Sinne der Umgestaltung des Mutterhauses neu konzipiert. 
erinnert durch die Präsentation auf einfachen Holzkonstruktionen an die Lagerung historischer Funde in archäologischen Depots. Spannender scheint jedoch die Anordnung der drei Exponate zueinander zu sein. Durch diese Art der Relationierung wirken die Exponate wie steinerne Fragmente eines Ganzen. Die ebenfalls windschiefen Flächen der hölzernen Konstruktionen, auf denen die Exponate ruhen, unterstreichen diesen Eindruck noch, indem sie die verschobene Geometrie des Ausstellungsraumes aufnehmen. So wie die asymmetrisch zueinander angeordneten Ausstellungsgegenstände stellen auch die Bruchlinien auf den Gehwegplatten eine Verbindung zu den sich ebenfalls asymmetrisch kreuzenden Linien in der Spitze des Keils her. Fast scheint es, als würden Architektur und Ausstellungsarrangement die Linien der zerbrochenen Gehwegplatten aufnehmen.

Die Kontextualisierung der Exponate aus drei europäischen Städten knüpft Relationen zwischen dem polnischen Wielun, welches am 1. September 1939 - noch bevor der Krieg erklärt war - von deutschen Sturzkampfbombern zerstört wurde, die teilweise auch in Dresden-Klotzsche stationiert waren (Wehner 2012:62), dem holländischen Rotterdam, welches am 14. Mai 1940 - noch während der Kapitulationsverhandlungen mit den Niederlanden - von der deutschen Luftwaffe zerstört wurde, und dem deutschen Dresden. Durch die beziehungsgeschichtliche Verräumlichung wirken die Exponate wie die Bruchstücke eines Ganzen. Vor allem aufgrund der Sichtachsen, die sich aus dem Ausstellungsbereich hinaus in den Stadtraum und auf die wiederaufgebaute Dresdner Altstadt ergeben, werden weitere über den nationalräumlichen Rahmen hinausreichende Relationen geknüpft. Mit dem Blick auf die einst zerstörte und nun wiederaufgebaute Stadt wird die Dramaturgie dieser Erzählung, durch die implizite Thematisierung britischer und US-amerikanischer Bomber, die schließlich am 13. Februar 1945 Dresden bombardierten, weiter gespannt.

Beim Blick aus der Spitze des Keils wird die Silhouette der Dresdner Altstadt allerdings durch die fallenden Linien der Stahllamellen, mit welchen der moderne Erweiterungsbau verkleidet ist, durchschnitten. Der Ausblick auf die Frauenkirche, den Hausmannturm des Residenzschlosses und die Semperoper wird durch die gitterartige Stahlstruktur getrübt. Indem die fallenden Linien der Verkleidung des Keils den Blick stören, wecken sie zudem Assoziationen zu den stürzenden Fluglinien der einst über Dresden abgeworfenen Bomben. Lässt man sich auf diese assoziative Deutung ein, so erinnern auch die Lamellen, die sich in unterschiedlichen Neigungswinkeln schrittweise öffnen, an das Öffnen von Bombenschächten, aus denen sich die zerstörerische Fracht der Bomber einst über Dresden und den anderen europäischen Städten entlud.

Durch die Anordnung der Exponate, die Verräumlichung in der Architektur sowie durch die stadträumlichen Relationen werden Bezüge zwischen verschiedenen europäischen Städten und mehreren Nationalstaaten hergestellt. Dem Anspruch der multiperspektivischen Geschichtsbetrachtung wird mittels vielseitiger Verwei- 
Abbildung 36: Kriegstrümmer aus Wieluń, Rotterdam und Dresden. Die Anordnung auf windschiefen Holzpodesten kontextualisiert die Exponate untereinander und stellt Bezüge zum Ausstellungsraum, zu den asymmetrischen Linien im Keil und zum Dresdener Stadtraum her.

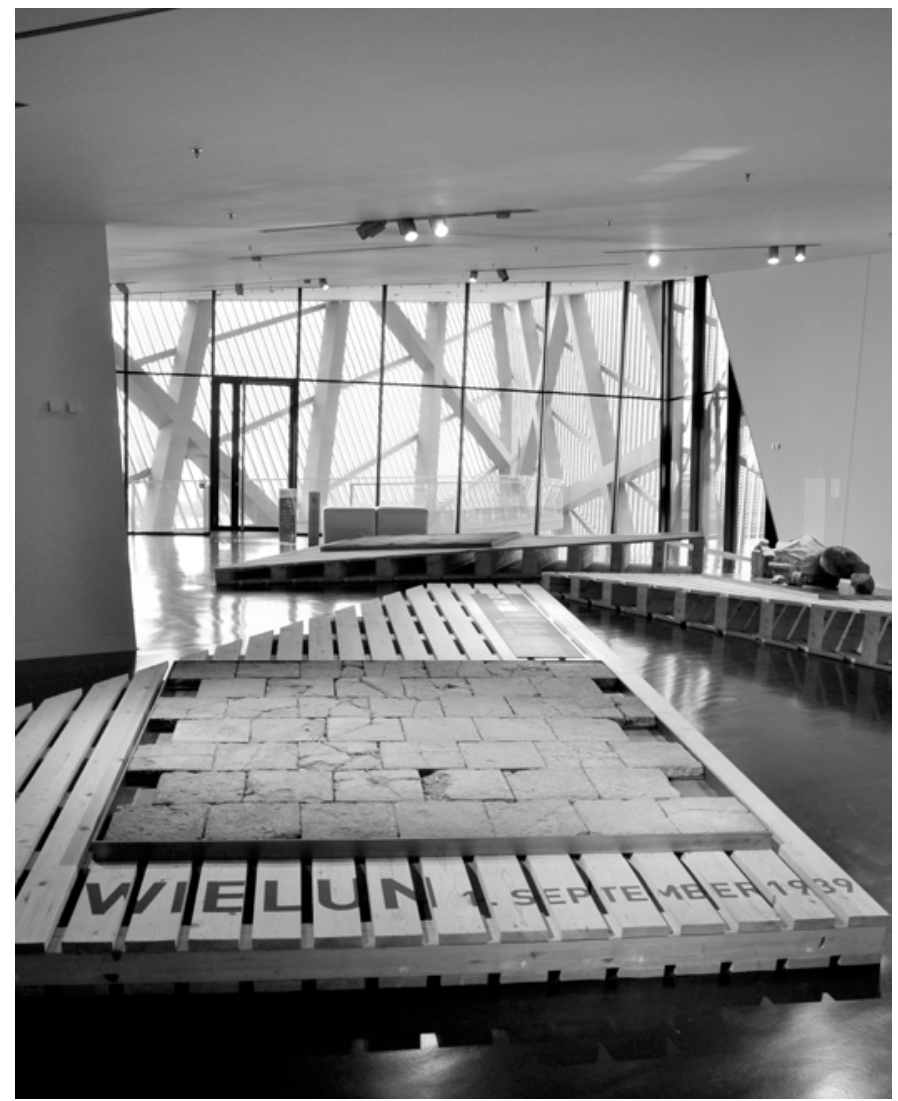

se und des Verzichts auf eine exklusiv nationale Eingrenzung der Geschichtserzählung Rechnung getragen. Neben den unterschiedlichen nationalen Perspektiven werden verschiedene lebensweltliche Perspektiven integriert. Um auch dies im Ausstellungsraum »Dresden Blick « einzulösen, sind an den Kriegstrümmern Texttafeln angebracht. Diesen sind jeweils zwei persönliche Erzählungen zu entnehmen. So werden die steinernen Zeugnisse der Zerstörung mit jeweils zwei Lebensläufen kontextualisiert, die "zwei unterschiedliche Perspektiven auf ein und dasselbe historische Ereignis« gewähren (Pieken 2011:20). Den von Brandbomben durchschlagenen Gehwegplatten aus der Dresdner Johannstadt ist die Erzählung 
Abbildung 37: Blick auf Dresden (rechts) und die Garnisonskirche der Albertstadt (links) durch die Lamellen, welche sich in unterschiedlichen Winkeln öffnen und so den Ausblick einschränken.

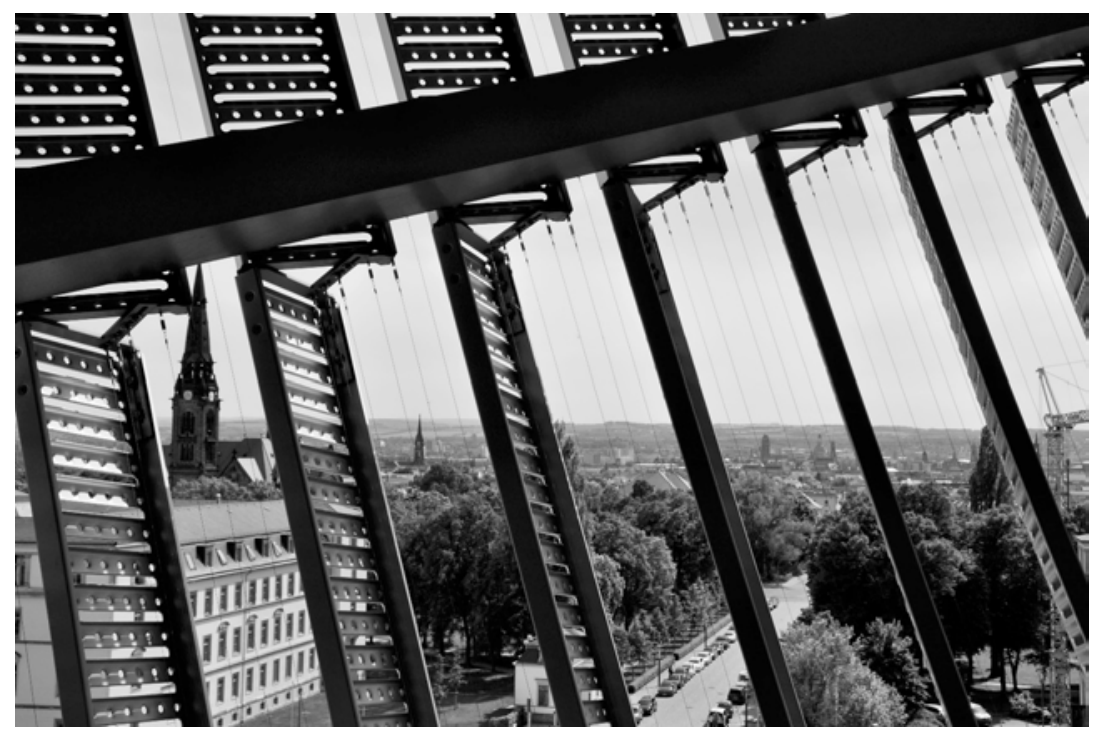

eines Jungen zur Seite gestellt, der bei dem Angriff seine gesamte Familie verlor. Dasselbe Exponat wird zudem mit den Schilderungen eines Mädchens jüdischen Glaubens kontextualisiert, das durch die Bombardierung der Stadt vor der Deportation gerettet wurde. Das Bombardement Dresdens vom 13. Februar 1945 wird dadurch unterschiedlich perspektiviert. Es wird zum Tag der Zerstörung und des Sterbens, aber auch zum Tag der Befreiung und der Rettung. Das Museum wird damit nicht nur dem multiperspektivischen Ansatz gerecht, sondern reflektiert auch die verschiedenen Bedeutungen einzelner »historischer Ereignisse« (BMVg 1982:1, P.3) und die verschiedenen Erfahrungsräume, die daraus hervorgehen.

Wie eine langjährige Mitarbeiterin des MHM betont, wurde im Ausstellungsbereich »Dresden Blick« besonders darauf geachtet, nicht den »Opfermythos Dresden« zu reproduzieren (MHM-2, 210-213). Durch die Thematisierung der bereits unmittelbar nach der Bombardierung einsetzenden und lang nachwirkenden propagandistischen Vereinnahmung durch die Nationalsozialisten sowie durch die Kontextualisierung mit dem allgemeinen Kriegsverlauf, an dessen Anfang Wielun und an dessen Ende Dresden steht, gelingt dies auch. Dennoch bietet die multiperspektivische Verknüpfung der einzelnen Fragmente prinzipiell die Möglichkeit einer symmetrischen Verhandlung des Bombenkriegs und der Thematisierung des 
deutschen Militärs als einem Gleichen unter Gleichen. Dies geschieht, wenn ein US-amerikanischer Funker zitiert wird, dessen Worte an dem Exponat aus Dresden angebracht sind. Beim Anblick des zerstörten Dresdens hält der Funker fest: »Ich muss gestehen, dass ich mich schämte, wir waren auf dem Niveau der $>$ Krauts angelangt.« (Texttafel im Ausstellungsteil »Dresden Blick«). Unter der allgemeineren thematischen Klammer des Bombenkrieges findet somit eine partielle Angleichung von Opfern und Tätern statt.

Auch in den Denkmaldebatten der Berliner Republik - bei der Gestaltung der Neuen Wache in Berlin (Roters 1993) zu einem zentralen Gedenkort oder der Kontroverse um die Errichtung des »Denkmals für die ermordeten Juden Europas« (Jeismann 1999) - lässt sich diese erinnerungspolitische Strategie der Angleichung nachweisen. So wurden durch die Inschrift in der Neuen Wache in Berlin, »Den Opfern von Krieg und Gewaltherrschaft«, die Grenzen zwischen dem im Feld gefallenen deutschen Landser und den in Auschwitz ermordeten Kindern aufgehoben (Mittig 2005:76). Indem mit dieser allgemeinen Formulierung alle zu Opfern erklärt wurden, wird die wichtige Unterscheidung zwischen victima (dem Opfer von etwas) und scrificium (dem Opfer für etwas) verwischt. Die Frage nach den Tätern blieb so auf bequeme Art unbeantwortet (Koselleck 1993). Die Vereinnahmung der Opfer für die nationale Identitätsstiftung und deren Positionierung auf der Bühne des »Gedächtnistheaters« sind oft thematisiert und kritisiert worden (Bodeman 1996; Czollek 2018). Den Hinweis darauf, dass die jüdischen Opfer so für einen fundierenden Kollektivierungsdiskurs der deutschen Mehrheitsgesellschaft vereinnahmt werden, hat die Denkmalpflegerin und Kunsthistorikerin Gabi DolffBonekämper im Zusammenhang der Debatte um das Denkmal für die ermordeten Juden Europas auf die treffende Formulierung eines "geliehenen Schmerzes« gebracht (Dolff-Bonekämper 1999).

Man muss die Polemik dieser Kritik nicht teilen, um dennoch festzustellen, dass durch den inklusiven Anspruch multiple Perspektiven in die Gestaltung der Ausstellung einzuschließen sowie durch die anthropologisch entgrenzte Gewaltthematisierung auch hier der thematische Fokus geweitet und nationale Unterschiede tendenziell nivelliert werden. Wie das wiedervereinigte Deutschland in Bezug auf das Holocaust-Mahnmal »Subjekt des Erinnerns« bleibt (Young 1999:223), so bleibt auch die Bundeswehr das Subjekt des Erinnerns in ihrem Leitmuseum. Allerdings machen die zentrale Thematisierung der Multiperspektivität sowie die Abwesenheit nationalstaatlicher Hoheitssymbole (Teidelbaum 2011:2) dann nur umso deutlicher, dass die Verräumlichung der deutschen Militärgeschichte jenseits nationalhistorischer Grenzen einen für die Bundeswehr probaten Weg der Selbstthematisierung darstellt. Gerade aufgrund der besonderen Umstände der deutschen Militärgeschichte und der raumzeitlichen Herausforderungen in der Gegenwart reagiert dieser räumliche Synthesemodus so auf strukturelle Anforderungen. Wie der Projektleiter der Neukonzeption im Ausstellungsführer betont, sei 
die Bundeswehr »[e]ingebunden in multinationale Strukturen und den Werten der Charta der Vereinten Nationen verpflichtet«. Zudem befindet sich das deutsche Militär "nach mehreren Strukturreformen in einem Prozess beständiger Transformation, um sich laufend der Realität der Einsatzziele und -bedingungen anzupassen." (Pieken 2011:36, Herv. JK). Vor diesem Hintergrund erscheint die multinationale Erzählweise, die sich zudem im »Prozess beständiger Transformation« (ebd.) befindet, nicht nur als normativ geboten, sondern eben auch den Anforderungen der Gegenwart adäquat. Eben diesen beständigen Adjustierungsprozessen durch sich laufend ändernde Konstellationen von Freund und Feind wird auch architektonisch und diskursiv Ausdruck verliehen. Der multiperspektivische Code der Verräumlichung nach Maßgaben einer relationalen Beziehungsgeschichte erscheint für den Kollektivierungsdiskurs der Bundeswehr auch deshalb opportun, da im Feld wechselnder »multinationale[r] Strukturen « und anhaltend sich verändernder »Einsatzziele« etwa das Bild klassisch-martialischer Erbfeindschaften seinen Sinn verloren hat.

Die Selbstthematisierung des deutschen Militärs verschafft sich einerseits mit der thematischen Weitung einer allgemeinen Gewaltthematisierung ein anthropologisches Fundament. Zudem führt der Kollektivierungsdiskurs des deutschen Militärs über den Umweg jenseits nationalhistorischer Denkweisen. Dennoch steht die multiperspektivische Verknüpfungsleistung, mit der unterschiedliche National-, Sozial- und Erfahrungsräume in Relation zueinander gesetzt werden, im Dienst institutioneller »Selbstvergewisserung und Identitätsstiftung«, mit einem Bezug zu den »aktuellen politisch-sozialen Interessenlagen« (Konzeptgruppe 2003:31). Die vielseitigen und dynamischen räumlichen Verknüpfungsleistungen der Multiperspektive setzen dabei eine Standortlosigkeit voraus, die im Kontext des MHM als Dienststelle der Bundeswehr gerade nicht gegeben ist. Festzuhalten ist deshalb, dass der Kollektivierungsdiskurs der Bundeswehr auch weiterhin aus den Besonderheiten der deutschen Vergangenheit und Gegenwart seinen Sinn erhält. Die nationalräumlich entgrenzte Darstellungsform bleibt im Hinblick auf ihren Darstellungszweck an die Erfordernisse einer nationalstaatlich deutschen Repräsentation des Militärs gebunden. Mit der nationalen Akteurzentrierung im Leitmuseum der Bundeswehr bleibt auch die multiperspektivische Ausstellungsgestaltung an die Institution der Bundeswehr gebunden und über den Referatsleiter Innere Führung dem BMVg unterstellt (Kap. 6.1.2). Eben dies kritisierte auch die Informationsstelle Militarisierung, die vermutete, dass im Fahrwasser der Dekonstruktion glanzvoller Waffenschauen »in schimmernder Wehr«, wie sie das MHM betreibt, erneut "neomilitaristische Werte« verfestigt würden, wodurch schließlich das »Blendwerk angeblicher Ideologiefreiheit« zerfalle (Mickan 2011:3).

Trotz des Überwindungsversuchs »nationalhistorische[r] Selbstbezogenheit « (Osterhammel 2001:7) bleibt der collagenhafte und relationale Konstitutionsmodus also in seiner Funktion auf das deutsche Militär und die Herausforderungen der 
deutschen Gegenwartsgesellschaft bezogen. Da der nationale Container für den Kollektivierungsdiskurs der Bundeswehr als zu eng erscheint, ist er auf einen multiperspektivischen Code der Verräumlichung angewiesen. Unabhängig davon, ob man die wissenschaftliche Leistung der zahlreichen Historiker und die Reflexivität der Ausstellung unter Ideologieverdacht stellt, wie dies in obigem Zitat durch die Informationsstelle Militarisierung e.V. getan wird, oder nicht, so ist von besonderer Bedeutung, dass dieser spezifische, wenngleich abstraktere Code der Verräumlichung es dem Kollektivierungsdiskurs der Bundeswehr ermöglicht, auf die typischen raumzeitlichen Herausforderungen und die Bedingungen der Moderne (Sebald/Weyand, Kap. 1) zu reagieren, indem er sich laufend den sich ändernden Realitäten anpasst.

\subsubsection{Der Architekt als Raum-Trickster}

Dass die Anordnung der Exponate sowie deren multiperspektivische Synthetisierung trotz großer Zustimmung keinesfalls unumwunden bejaht werden und sich auch Teile der Bundeswehr nicht damit zu identifizieren vermögen, verdeutlicht der kontrastierende Blick auf den Gegendiskurs. Indem ein gänzlich anderer Code der Verräumlichung erkennbar wird, werden erneut die unterschiedlichen Wissensverhältnisse (Kap. 3), welche in den kontrastierenden Deutungen des Museums stabilisiert werden, weiter konturiert. Anhand eines Artikels aus der Nationalzeitung, der kurz nach der Neueröffnung des Museums erschien, kann dies stellvertretend für weitere Stimmen aus dem rechtskonservativen Milieu veranschaulicht werden. Der Autor problematisiert darin gerade die multiperspektivische Verknüpfung zwischen Militaria und alltagskulturellen Exponaten, vor allem aber die nationalräumliche Entgrenzung in der Ausstellung des MHM. Voller Unverständnis moniert der Autor:

»Auch Exponate, die mit der deutschen Militärgeschichte nichts zu tun haben, werden ausgestellt, so die Beinprothesen eines Jungen aus Kambodscha, der auf eine Mine getreten ist, oder eine Schallplatte von Elvis Presley aus seiner Zeit als in Deutschland stationierter Gl.« (Frisch 2011).

Die Beinprothesen aus Kambodscha und die Schallplatte Elvis Presleys haben dieser Deutung zufolge - »mit der deutschen Militärgeschichte nichts zu tun«. Deutsche Militärgeschichte endet hier also an der deutschen Staatsgrenze - ein klar nationalräumlich definiertes Geschichtsbild, welches den Gegenpol zu einem multiperspektivischen Geschichtsverständnis jenseits des Nationalstaates bildet.

Anhand der Charakterisierung des Architekten können die verschiedenen Codes der Verräumlichung weiter profiliert werden. Wie durch die unterschiedliche Bewertung der Rolle des Architekten David Chipperfield bereits am Neuen Museums gezeigt werden konnte (Kap. 5.3), wird auch der Architekt des MHM, 
Daniel Libeskind, in den Erzählungen der diskursiven Formationen zum Handlungsträger höchst verschiedener Sujets (Lotman, Kap. 4.2). Wie unterschiedlich durch die Thematisierungen des Architekten Räume zueinander in Bezug gesetzt werden, kann anhand von zwei Zitaten gezeigt werden. So charakterisiert eine in der Pressearbeit des Museums tätige Person die Rolle Libeskinds folgendermaßen:

»Es ist immerhin Libeskind, der sich hier erst das zweite Mal verewig hat, und zwar verewigt hat in einem Kontext, der ungewöhnlich ist. Also dass Libeskind das ]üdische Museum in Berlin gestaltet hat, könnte man sagen: Ja, war zu erwarten. Dass er als New Yorker den Ground Zero mitgestaltet hat, könnte man sagen: Ja, war zu erwarten. Aber dass Libeskind ein Militärmuseum in Deutschland gestaltet, das wirkt auf den ersten Blick erst mal überraschend. Aber vielleicht ist es gerade diese Überraschung, dieser Kontrast, diese Spannung, die wiederum auch wieder Faszination ausübt, die dann auch wieder Menschen in dieses Haus bringt, die nicht primär wegen der Ceschichte, sondern eher wegen Libeskind kommen. Und die dann überrascht sind, wie man Ceschichte auch darstellen kann, in einem Militärmuseum. Nämlich reflektiert, kritisch, multiperspektivisch.«(MHM-1, 222236).

Gerade die unkonventionelle Kombination, dass "Libeskind ein Militärmuseum in Deutschland gestaltet«, verheißt »Überraschung «, »Kontrast « und »Spannung «, die schließlich »Faszination« ausüben. Der Architekt aus der Ferne erzeugt eine erwünschte »Überraschung «, die sich aus der als ungewöhnlich beschriebenen räumlichen Verbindung ergibt. Sein Werk entfaltet »Faszination«, gerade weil es kontrastreich ist. Libeskind wird zum Publikumsmagnet, der dem Museum sowie der Institution über die Landesgrenzen zu Reputation verhilft. Indem die Arbeit des Architekten außerdem mit den zentralen Begriffen der Selbstthematisierung (»reflektiert, kritisch, multiperspektivisch «) verbunden wird, befindet er sich im Einklang mit diesem Kollektivierungsdiskurs. Der Architekt aus der Fremde verliert so seine Fremdheit.

Eine gänzlich andere Thematisierung allerdings findet sich im Gegendiskurs, der den Architekten nun zum Handlungsträger eines vollkommen anderen Sujets macht.

»Libeskind wurde 1946 in Lodz als Sohn polnischer Juden geboren, die 1957 nach Israel emigrierten, drei Jahre später jedoch in die USA übersiedelten. Dort nahm die gesamte Familie die US-Staatsbürgerschaft an. 1989 zog der Star-Architekt nach Berlin um. Nachdem er 2003 die Architekturausschreibung zum Neubau des World Trade Center gewann, verlegte er seinen Hauptsitz schließlich nach New York. In Deutschland wurde Libeskind vor allem durch den zickzackförmigen Bau des ]üdischen Museums in Berlin bekannt. Vorgefundene Strukturen sind dem de- 
konstruktivistischen Architekten stets Anlass zu Widerspruch und Provokation.« (Frisch 2011:4, Herv. JK).

In der Polemik gegen den jüdischen Architekten artikuliert sich ein kaum verhohlener Antisemitismus, indem typische antijüdische Klischees aufgerufen werden. Die Beschreibung des Architekten und die ausführliche Darlegung seines Lebenslaufs sprechen eine undeutliche Sprache. Der Architekt lässt sich räumlich nicht eindeutig zuordnen: Lodz, polnischer Jude, Israel, USA, Berlin, zurück nach New York, erneute Rückkehr nach Berlin. Neben der räumlichen Uneindeutigkeit wird die zeitliche Unstetigkeit thematisiert: 1946, 1957, drei Jahre später, 1989, 2003 bezeichnen die Momente der Ortswechsel. Der Architekt wird als räumlich nicht zuordenbar und zeitlich unstet charakterisiert. Er emigriert, siedelt über, zieht um. Libeskind wird so zu einer Art Trickster-Figur, zu einem Wandler zwischen den Welten also, der sich über Grenzen hinwegsetzt. Fast scheint es, als würden die unsteten Bewegungen des Architekten mit dem »zickzackförmigen Bau« des Jüdischen Museums identifiziert werden. Wie dieses schlägt auch der Architekt Haken und entzieht sich so einer eindeutigen räumlichen Zuordnung. Dabei dekonstruiert er Strukturen und stellt deshalb eine Gefahr für die räumliche Ordnung dar. Denn, wie der Autor der Nationalzeitung schließlich folgert: »Vorgefundene Strukturen sind dem dekonstruktivistischen Architekten stets Anlass zu Widerspruch und Provokation.« (Frisch 2011:4).

Unter dem Feigenblatt dieser Charakterisierung sind die üblichen antisemitischen Klischees vom wurzellosen Kosmopoliten und Störenfried nur notdürftig bemäntelt. Indem die Unstetigkeit und die Vielzahl räumlicher Bezugspunkte problematisiert werden, bleiben die vielfachen Grenzüberschreitungen des Architekten eine Quelle der Uneindeutigkeit, weshalb dem weltweit tätigen Architekten misstraut wird. Der Architekt aus der Ferne, der morgen vielleicht schon wieder woanders dekonstruiert und provoziert, verliert hier also nicht seine Fremdheit. Er bleibt fremd und dadurch eine Gefahr für vorgefundene Strukturen.

Schließlich wird die Ausstellung des MHM als eine einzigartige Fehlleistung beschrieben. Kein Militärmuseum der Welt, weder in Paris, London oder Peking, käme demnach auf die Idee, »die Geschichte der eigenen Armee so einseitig negativ darzustellen« (Frisch 2011:4). Der Autor folgert daraus: »Der auf die Spitze getriebene Nationalmasochismus ist tatsächlich nur in Deutschland vorstellbar« (ebd.). Die Tatsache, dass ein solches Museum in anderen Ländern (angeblich) nicht möglich sei, scheint durchaus ein medial geteilter Wissensbestand zu sein (Jaeger, Tagesspiegel 2011; Schmid 2011; Fuhre 2011). Dabei wird die Architektur Libeskinds zumeist zum Signum eines positiven Alleinstellungsmerkmals. Der Autor der Nationalzeitung allerdings kann darin nur den Ausdruck eines "gestörten und ganz dem Zeitgeist unterworfenen Traditionsverständnis[ses] der Bundeswehr« erken- 
nen (Frisch 2011:4), womit die Umgestaltung des MHM zum negativen Alleinstellungsmerkmal wird.

\subsubsection{Identität durch Kritik: "Andere Armeen haben das so nicht"}

Anlässlich der Ausstellung »60 Jahre Bundeswehr« wird im dazugehörigen Ausstellungsführer des MHM die Wandlungsfähigkeit der Institution und ihr Adaptionsvermögen an sich verändernde gesellschaftliche Bedingungen gewürdigt. Im Rückblick auf die vergangenen 60 Jahre heißt es dort: »This shows that the Bundeswehr has always been changing - it has been flexible enough to adapt not only to new security parameters but also to changes in society.« (Rogg 2015:3). Was zuvor als Anpassung an den vermeintlich "gestörten Zeitgeist « diffamiert wurde, steht also im Zentrum des dynamischen Kollektivierungsdiskurses der Bundeswehr. Jahrestage, wie der des 60-jährigen Bestehens der Bundeswehr, sind jedoch keineswegs nur Momente der Rückschau, sondern dienen ebenso der Modifikation der Vergangenheit, um diese in Einklang mit den Anforderungen der Gegenwart zu bringen (Kap. 2). Wie die Kommission der Neugestaltung des MHM betonte, bedürfen Institutionen wie das Militär »in besonderer Weise einer aus den Leistungen der Vergangenheit gespeisten Selbstvergewisserung und damit der Identitätsstiftung.« Der in "traditionsstiftender Absicht « in die Vergangenheit gerichtete Blick führt dann zu einer stetigen »Umdeutung der überlieferten Zeichensysteme« (Konzeptgruppe 2003:31). So wie die Bundeswehr sich die Helden konstruiert, die zu ihr und ihren gegenwärtigen Aufgaben passen (Kap. 6.3.4), so passt sich auch ihre Tradition »dem Erkenntnishorizont der jeweiligen Epoche« und den »aktuellen politischsozialen Interessenlagen « an (ebd.). Die Behauptung, dass die Bundeswehr auch früher bereits flexibel (flexible enough) gewesen sei und sich in stetigem Wandel (always been changing) befinde, formt die Vergangenheit so um, dass die Anpassungsfähigkeit an militärische Herausforderungen (new security parameters) und soziale Veränderungen (social changes) in Übereinstimmung mit der Gegenwart gebracht werden.

Unter dem Eindruck der gewonnenen Erkenntnisse kann nun dargestellt werden, dass der Kollektivierungsdiskurs der Bundeswehr neben der Konstruktion einer anthropologischen Ewigkeit (Kap. 6.4.1) zusätzlich eine Wiederholungsstruktur aufbaut, die selbst Prozesscharakter annimmt. Gerade das Immer-wieder-andersSein, was vom Gegendiskurs als ein dem Zeitgeist unterworfenes Traditionsverständnis geschmäht wird, wird in traditionsstiftender Absicht in der Vergangenheit wiedergefunden. Trotz der episodischen Neuausrichtung und der fortlaufenden Adaption an sich verändernde Verhältnisse können auch in diesem hochdynamischen Kollektivierungsdiskurs Wiederholungsstrukturen etabliert werden. Damit dies gelingt, benötigt das Selbstbild der Bundeswehr, welches in schillernden Farben immer wieder anders erscheint, einen stabilisierenden Rahmen. Eben die- 
ser Rahmen wird durch den Wert der Kritik gebildet: Weil der stete Wandel den Charakter einer Gewissheit erhält (Kap. 6.4), wird die kritische Prüfung der eigenen Geschichte auf Dauer gestellt. Die Identität der Bundeswehr wird dabei durch anhaltende Selbstbefremdung (sprich: Nicht-Identität) stabilisiert.

Eine in der Presseabteilung des MHM tätige Person verdeutlicht die Quintessenz dieses Kollektivierungsdiskurses und die Relevanz der Selbst-Befremdung von der eigenen Institution auf besonders plastische Weise. Zudem wird ein enger Bezug zwischen dem Museum und dem Konzept der Inneren Führung hergestellt, indem das Gebäude als »museale[r] Ausdruck« der zentralen Dienstvorschrift bezeichnet wird.

»Diese Unternehmensphilosophie hat den Namen Innere Führung, da kommt ganz viel rein, unter dieser Bezeichnung wird ganz viel subsumiert, unter anderem auch diese Selbstkritik, die das Sich-kritisch- selbst-Hinterfragen, das Hinterfragen des eigenen Handelns kritisch, vielleicht auch das Hinterfragen der Vorgesetzten, vielleicht auch das Hinterfragen dessen, was die Bundeswehr insgesamt tut. Das ist Teil der Unternehmenskultur der Bundeswehr. Andere Armeen haben das so nicht, da ist die Unternehmenskultur eine andere, aber die Bundeswehr hat diese Unternehmenskultur der Inneren Führung, von daher ist das für mich persönlich eigentlich nur ein musealer Ausdruck dieser Unternehmensphilosophie, der kritischen Auseinandersetzung mit seinem eigenen Denken und Handeln.«(MHM-1, 148-160).

»Selbstkritik « und das »Hinterfragen des eigenen Handelns« bezeugen - unabhängig davon, ob sie eingelöst werden oder nicht - , dass der Wert der Kritik im Zentrum dieser Form der Selbstbeschreibung steht. Das anhaltende Hinterfragen, hier sogar auf einen fundamentalen Zweifel am Handeln der eigenen Institution erweitert, wird zum zentralen Wesensmerkmal erhoben. In Anlehnung an die marktförmige Formulierung und die Rede von der »Unternehmenskultur « wird die »kritische Auseinandersetzung « so zum Markenkern der Bundeswehr. Mit dem Hinweis »andere Armeen haben das so nicht « wird schließlich deutlich, dass die Betonung dieses Merkmals auch der Distinktion von anderen Armeen dient. Was zuvor noch als »einzigartiger Nationalmasochismus« (Frisch 2011) geschmäht wurde, erhält nun den Stellenwert eines positiven Alleinstellungsmerkmals. Indem das anhaltende Hinterfragen des eigenen Handels und die »kritische Auseinandersetzung mit der Vergangenheit « (BMVg 2018a:13; 2018b:2) ebenso als »unverwechselbare Merkmale der Bundeswehr« (BMVg 1982:3, P.20) in Anspruch genommen werden, gelingt mit der anhaltenden Selbst-Distanzierung auch die Grenzziehung $\mathrm{zu}$ »anderen Armeen«. Mit der Abgrenzung von der eigenen Vergangenheit wird schließlich auch eine Abgrenzung von anderen Armeen vollzogen. Die Distanzierung vom eigenen Erbe dient so der identitätsstiftenden Distinktion. 
Doch wird mit dem Wert der Kritik nicht nur Distinktion erzeugt. Wie bereits eingangs durch die Traditionalisierung der Wandlungsfähigkeit verdeutlicht wurde, erhält dieser zentrale Wert schließlich die Würde einer der Bundeswehr eigentümlichen Tradition. So heißt es in direktem Anschluss an die oben zitierte Sequenz:

»Und dass das nicht nur einfach so hingesagt ist, sieht man daran, wir haben in der Bundeswehr ein Forschungsamt, das militärgeschichtliche Forschungsamt, das seit 50 Jahren Ceschichtsforschung betreibt, und wenn sie in die Ceschichte des Militärhistorischen Forschungsamts hineinschauen, dann ist diese Geschichte auch geprägt durch Diskurse, durch Konflikte um historische Themen. Was auch zeigt, dass in unserem Mutterhaus im Militärgeschichtlichen Forschungsamt Ceschichte ja nach geschichtswissenschaftlichen Kriterien wissenschaftlich bearbeitet ist und das heißt immer auch kritisch [...] Also und das auch nicht erst seit einem 3/4 Jahr, sondern im Militärgeschichtlichen Forschungsamt in unserem Mutterhaus auch schon seit Jahrzehnten.«(MHM-1, 160-173).

Die »kritische Auseinandersetzung " mit dem »eigenen Denken und Handeln« sowie die »konflikthafte" und kritische Selbst-Beforschung nach "geschichtswissenschaftlichen Kriterien« werden als eigentümliche und tradierte Umgangsformen behauptet (»seit 50 Jahren«, »schon seit Jahrzehnten«). Die Würdigung der Selbstkritik strahlt dabei einerseits in Richtung Vergangenheit aus, indem etwa der Reformgeist der Heeresreformer und Widerstandskämpfer in der Geschichte des deutschen Militärs >wiedergefunden

Hatte die Bundesverteidigungsministerin Ursula von der Leyen bei der Implementierung des neuen Traditionserlasses im Frühjahr 2018 noch die Mahnung ausgesprochen, dass es gelte, sich immer wieder »selbst $[\mathrm{zu}]$ vergewissern«, auf welchem »Grund wir stehen « und auf welche »Fundamente [...] wir die Gestaltung unserer Zukunft bauen" (von der Leyen 2018:2), galt dies auch als Signum sowohl einer Vergangenheit als auch einer Zukunft, die an Determinationskraft für das eigene Selbstverständnis verloren haben. Die anhaltende Prüfung der Geschichtsbestände allerdings verlagert die Kohärenzsicherung nun von der (verbindlichen) Vergangenheit auf den (verbindlichen) Akt des kritischen Selbstprüfens. Die Konstruktion einer Tradition des Traditionsskeptizismus, die Tradition des Hinterfragens und nötigenfalls des Brechens von bestehenden Strukturen ermöglicht so ein Gleichbleiben im Moment der Veränderung und Kontinuität im Wandel. Denn durch die Betonung der Kritik und der anhaltenden Skepsis gegenüber der eigenen Vergangenheit und der Gegenwart gelingt es auch, diesem Kollektivierungsdiskurs eine Wiederholungsstruktur auszubilden, mit der ein Gleichbleiben über die episodischen Brüche der Zeit behauptet wird.

Der Kreislauf ewiger Wiederholung schließt sich nunmehr an der Stelle einer immer gleichen Kritikwürdigkeit der Verhältnisse in der Vergangenheit, Gegen- 
wart und Zukunft. Schließlich kann dadurch auch das Künftige bewältigt werden. Denn wie jede Traditionsbildung verfügt auch die Tradition des Traditionsbruchs über eine prospektive Dimension und strahlt damit auch in Richtung Zukunft aus. Auch diese Vergangenheitskonstruktion hält somit die Hoffnung auf eine bessere Vergangenheit bereit. Denn so wie sich aus dem ständigen Wechsel der Zeiten die Maxime der anhaltenden Neu-Perspektivierung ergibt, so hält dieser Kollektivierungsdiskurs die beruhigende Gewissheit bereit, dass es auch morgen noch etwas $\mathrm{zu}$ kritisieren gibt.

\subsection{Inkrementelle Identität: Die Wissensverhältnisse des Kollektivierungsdiskurses der Bundeswehr}

Sowohl der Blick in eine andere Vergangenheit als auch der Blick in eine andere Zukunft werden durch die Gewissheit vereinheitlicht, dass es hier wie dort etwas $\mathrm{zu}$ kritisieren gab und geben wird. Um über vergangene und zukünftige episodische Brüche hinweg eine Wiederholungsstruktur etablieren zu können, bedient sich die Bundeswehr eines komplexen Kollektivierungsdiskurses, dessen narrative Struktur (Kap. 3.5) schließlich folgendermaßen zu Ende erzählt werden kann:

Auch in Zeiten anhaltenden Wandels können mindestens drei Gewissheiten diskursiv aufrechterhalten werden. Erstens bleibt die Rückkehr zur Vergangenheit ein unumstößliches Verbot. Eine »Wiederholung gilt es für alle Zukunft« auszuschließen (Kap. 6.3.2, Herv. JK). Der negative Referenzpunkt des Nationalsozialismus ist zwar ein Erbe, das ausgeschlagen wird, nichtsdestotrotz bleibt es durch die anhaltende Negation hoch relevant (Kap. 6.3.4). Auch der triumphierende Diskurs, der sich gegen das Erbe verschwört (Derrida Kap. 2), hält das Erbe fortlaufend präsent. Die Ablehnung des Erbes bedeutet zwar dessen Umformung, aber gerade nicht, dass es an Relevanz verliert. Die Alterität der Vergangenheit entspricht einem umgekehrten kontrapräsentischen Mythos (Assmann 1992). Anders als in diesem wird nun nicht die Abkehr von einer als problematisch beschriebenen $\mathrm{Ge}$ genwart gefordert, sondern der größtmögliche Kontrast zur Vergangenheit gesucht. Alle Beschreibungen der Vergangenheit in diesem Kollektivierungsdiskurs sind so auch immer negative Definitionen und normativ gehaltvolle Beschreibungen einer erwünschten Gegenwart. In Anlehnung an kontra-präsentische Mythen, die die Rückkehr zur Vergangenheit fordern, ließe sich im Fall der Bundeswehr von einem kontra-präteritistischen Mythos sprechen. Denn auch dieser fungiert fundierend und stabilisiert die Gewissheit, dass sich die Gegenwart - trotz stetigen Wandels (Kap. 6.4.1) - endgültig von der Vergangenheit abgewendet hat.

Als eine zweite Gewissheit wird zudem ein negatives Menschenbild verfestigt. Dies geschieht durch die raumzeitliche Weitung des thematischen Rahmens, in- 
nerhalb welchem sich der Kollektivierungsdiskurs verortet. Indem die Gewaltaffinität des Menschen in seiner anthropologischen Grunddisposition verankert wird, wird der sehr allgemeine Gewaltbegriff zum Merkmal aller Zeiten und aller bekannten Gesellschaften (Kap. 6.4.2). Durch die multiperspektivische Darstellung vor einem universell und thematisch geweiteten Horizont (Kap. 6.4.3), werden verschiedene nationale und historische Gewalterfahrungen nivelliert. Jedoch verbleibt die verallgemeinernde Klammer der Anthropologie im Allgemeinen und vermag eine spezifische Identität nicht zu stiften. In Verbindung mit den uneindeutig gewordenen und multiperspektivischen Wirklichkeitsdeutungen in pluralistischen Gesellschaften kann schließlich die immerwährende Notwendigkeit der kritischen Selbstprüfung als eine indirektere dritte Gewissheit verfestigt werden. Gerade im Zusammenspiel der unterstellten anthropologisch konstanten Gewaltaffinität und der anhaltenden Veränderung der Wertmaßstäbe in sich dynamisch wandelnden Gesellschaften erhält so der Wert der Kritik zentrale Bedeutung. Der Kollektivierungsdiskurs der Bundeswehr gewinnt seine Kohärenz und Kontinuität schließlich dadurch, dass trotz der Verschiedenheit von Vergangenheit, Gegenwart und Zukunft diese stets in ihrer Kritikwürdigkeit geeint bleiben:

Weil der Mensch immer gewalttätig ist und weil die Welt sich immer wandelt, muss (und kann) immer kritisiert werden. In einer Paraphrase eines Bertolt Brecht zugeschriebenen Zitates (Kap. 6.2.3) lässt sich die narrative Struktur dieses Kollektivierungsdiskurses auf folgende Formel bringen: Wo Ungewissheit zur Gewissheit wird, wird die kritische Selbstprüfung zur dauerhaften Pflicht.

Ungewissheit und unzureichend klar definierte Zielvorgaben, so hat der Organisationssoziologe Charles Lindblom überzeugend dargelegt, führen auch in komplexen Planungskontexten öffentlicher Verwaltungen, in denen weder hinreichendes Wissen über die zu bearbeitende Aufgabe noch langfristige Planungshorizonte definiert werden können, dazu, dass inkrementelle Strategien der Problembearbeitung funktional erscheinen (Lindblom 1959). An die Stelle eindeutiger und endgültiger Festlegungen tritt dann die schrittweise Anpassung der Bearbeitungsstrategie von Problemen, die nur noch näherungsweise bestimmt werden können. Gerade bei Abwesenheit klarer Ziele erscheint die Strategie dieses »Muddling through « also des "Sich-Durchwurstelns" - durchaus angebracht. Denn diese "succession of incremental changes « führt zur Vermeidung von schwerwiegenden und dauerhaften Fehlentscheidungen (Lindblom 1959:86). Sich nicht endgültig festlegen zu müssen, ist also gerade kein Makel, sondern wird den strukturellen Anforderungen vollumfänglich gerecht.

Der Soziologe Uwe Schimank wiederum überträgt den Begriff des Inkrementalismus auf den Kontext von Bewältigungsstrategien lebensweltlicher Ungewissheiten in biografischen Erzählungen. Dabei analysiert er eine Form der Identitätskonstruktion, die er als »biographischen Inkrementalismus« bezeichnet (2002). Das zentrale Merkmal inkrementeller Biografisierung besteht auch hier in 
ihrem »nicht-teleologischen Charakter« (Schimank 2002:244). An die Stelle einer abschließenden Selbstbeschreibung tritt dann eine inkrementelle Strategie der Problemverschiebung. Die eigene Biografie wird dabei anhaltend umgearbeitet, indem die Betreffenden »in Form bestimmter Negation auf sich selbst als problembehaftet reagieren « (ebd., Herv. JK). Dieser "Prozess iterativer Problemverschiebung « (ebd.) gestattet dann, »lebensgeschichtliche Einheit« schließlich durch eine »Prozessform, die, anders als teleologische Prozesse, auch Ziellosigkeit, Widersprüche, Brüche zu vereinheitlichen vermag und nicht als bloße Ereignissukzession stehen lässt«, herzustellen (Schimank 2002:247). So ermöglicht dieser Modus der Biografisierung auch in Zeiten stetigen Wandels ein Minimum an Konstanz. Dies bringt Schimank auf die prägnante Formel: »Ich weiß niemals, was ich will - doch ich weiß wenigstens immer wieder, was ich nicht will.« (2002:245, Herv. JK).

Durch die empirische Analyse des Kollektivierungsdiskurses der Bundeswehr konnte nachgewiesen werden, dass negative Formen der Selbstbeschreibung auch hier von zentraler Bedeutung sind. Dies betrifft einerseits die Distanzierung von dem in vielfacher Hinsicht problematischen Erbe deutscher Militärgeschichte. Die Abgrenzung, insbesondere von der Zeit des Nationalsozialismus, fungiert zwar als orientierungsstiftende, normative Vergangenheit und bleibt damit verbindlich (Kap. 6.3); darüber hinaus konnte allerdings gezeigt werden, dass die Forderung nach dem kritischen Hinterfragen der eigenen Institution und damit die Option der Selbstnegation auch in der Gegenwart erhalten bleiben. Auf die mannigfaltigen Kontingenzerfahrungen und den "Prozess beständiger Transformationen « (Pieken 2011:36; Kap. 6.4.2), in dem sich die Bundeswehr in der Gegenwart befindet, genauso wie auf die Zukunft, die damit auf bekannte Weise unbekannt bleibt, reagiert dieser Kollektivierungsdiskurs mit der Möglichkeit anhaltender Kurskorrekturen. Indem die Bundeswehr in anhaltenden Negationen auf sich selbst als kritikwürdig und kritikbedürftig zurückkommt, kann über episodische Brüche in der Vergangenheit und mangelnde fraglose Weltbezüge in der Gegenwart hinweg ein kohärentes Selbstbild gezeichnet werden. Das Fehlen eindeutiger Zielorientierungen und abschließender oder dauerhaft verbindlicher Orientierungspunkte führt letztlich zu Selbstbeschreibungen, die sich im Sinne negativer Dialektik vollziehen (Adorno 1990, Orig. 1966). Es gilt: Nie kann abschließend gesagt werden, wie die Bundeswehr ist. Immer jedoch kann (und muss) gesagt werden, wie sie nicht (mehr) sein darf.

Da gerade kein eindeutiger Kanon (Kap. 2) an gleichermaßen verbindlichen historischen Ereignissen (Kap. 6.2.3) bestimmt werden kann, werden schließlich Werte etabliert, die selbst Prozessform annehmen. Um ein Gleichbleiben in einer Welt des Wandels und Einheit im Moment der Vielfalt herzustellen, beziehen sich die Werte, die nunmehr als Wesensmerkmale betont werden, nicht auf zeitlose soldatische Tugenden wie Treue, Ehre, Pflichterfüllung (Kap. 6.3.3), sondern auf eine Art des Umgangs mit sich selbst, wie Wandlungsfähigkeit, Reflexivität, vor 
allem aber die dauerhafte Bereitschaft zur Selbstkritik. Was sich daraus gewinnbringend für die Theoretisierung der am MHM gewonnenen Erkenntnisse ableiten lässt, ist die Einsicht, dass der inkrementelle Kollektivierungsdiskurs der Bundeswehr seine prozessuale Einheit durch die fortdauernde Selbst-Negation gewinnt. Oder abstrakter formuliert: Die Bundeswehr gewinnt ihre Identität durch einen (dauerhaften) Prozess iterativer Nicht-Identität.

Die empirische Analyse hat außerdem gezeigt, dass es gerade die Topoi des fortwährenden Hinterfragens und der anhaltenden Selbst-Befremdung der eigenen Institution im Modus wissenschaftlicher Kritik sind, die die prozessuale Einheit dieser Form der Identitätsbildung garantieren und zudem der Abgrenzung von anderen dienen (Kap. 6.4.4). Mit der Distanzierung von der eigenen Vergangenheit gelingt so auch die Distinktion von den Armeen anderer Länder. Dadurch, dass die »kritische Auseinandersetzung mit der Vergangenheit « nunmehr eine »Tradition der Bundeswehr ist «, wie in den Dokumenten "Die Tradition der Bundeswehr« (2018a:2) und »Die Konzeption der Bundeswehr« (2018b:13) an zentraler Stelle kodifiziert, wird die Kritik schließlich in den Rang einer Tradition erhoben und damit selbst zum Identifikationsmerkmal der Institution. Hatte Nietzsche in seiner zweiten unzeitgemäßen Betrachtung noch vor einem »Zersplittern und Zerfasern aller Fundamente (Nietzsche 2009:87) durch ein »Uebermaass an Historie«, die nicht mehr wisse, sich der »Vergangenheit wie einer kräftigen Nahrung zu bedienen« (a.a.O. 107), gewarnt (Kap. 1.1), so zeigt sich anhand des Kollektivierungsdiskurses der Bundeswehr, dass im Modus kritischer Historiografie und wissenschaftlicher Reflexivität durchaus Orientierung gestiftet und Identität fundiert werden kann. Indem historische Bildung und »kritische Auseinandersetzung « mit Fragen der Orientierung verbunden werden, nähern sich Histoire und Memoire erneut aneinander an. Im neuen Traditionserlass heißt es etwa: »Historische Bildung ist Voraussetzung für eine werteorientierte Traditionspflege. Sie vermittelt Orientierungswissen, Identität sowie die Fähigkeit zur kritischen Auseinandersetzung mit der eigenen Geschichte.«(BMVg 2018b:7).

Dabei wird den »Schulen und Bildungseinrichtungen der Bundeswehr« (ebd.) explizit eine Vermittlerrolle für das Traditionsverständnis und die Traditionspflege zugesprochen. Diese Vermittlungsinstanzen nehmen so eine doppelte Rolle ein, die mit den beiden dialektisch aufeinander bezogenen erinnerungspolitischen Strategien des Speicher- und Funktionsgedächtnisses (Kap. 4.1.2), also der Kritik und der Fundierung, zusammenfallen. So wie der Imperativ zur »kritischen Auseinandersetzung « zum normativ verbindlichen Ausgangspunkt einer ernsthaften historiografischen Begegnung mit der eigenen Vergangenheit wird, so trägt die Arbeit des ehemaligen Militärgeschichtlichen Forschungsamts (MGFA) und des heutigen Zentrums für Militärgeschichte und Sozialwissenschaften der Bundeswehr (ZMSBw) ebenso zur sinnstiftenden Fundierung und identitätsbildenden Distinktion bei, indem »Geschichtswissen und Geschichtsbewusstsein» 
zur »unverzichtbaren Voraussetzung « des eigenen Traditionsverständnisses werden (BMVg 2018a:14). Durch die institutionelle Konstellation (Kap. 6.1.2) und die Nähe zur Macht erscheinen sowohl der zentrale Repräsentationsort des MHM als auch die institutionalisierte Selbstbeforschung im Modus wissenschaftlicher Reflexivität als produktive Akteure der Identitätskonstruktion und somit als »Gedächtnisentrepreneur[e]« (François/Puschner 2010:16). Indem die (geschichts-)wissenschaftliche Selbstthematisierung zum positiven Alleinstellungsmerkmal erhoben wird, werden die Forschungsinstitutionen der Bundeswehr zum wichtigen Werkzeug einer Form reflexiver Identitätsbildung.

Die inkrementelle Wiederholungsstruktur, die so stabilisiert werden kann und mit der die disparaten historischen Episoden verbunden werden, findet in dem Credo »Denkstiftung statt Sinnstiftung ihren plakativen Ausdruck (Pieken 2010b:7). Allerdings bleibt in der Denkstiftung auch die Sinnstiftung in ihrer (anhaltenden) Negation aufgehoben. Das Credo »Denkstiftung statt Sinnstiftung«, das als Alleinstellungmerkmal dient, führt so erneut zu Sinnstiftung. Indem die Kritik als entzeitlichte Norm stabilisiert wird, gerät sie somit selbst in den Bereich des fundierenden Mythos. Entgegen der Fragmentierung und Zerfaserung der Fundamente (Nietzsche) werden so im Modus (ernsthafter) wissenschaftlicher Kritik wandlungsfähigere, gleichsam im Fluss befindliche (und immer wieder neue) Fundamente begründet. Die kritische Selbstbeforschung nach (geschichts-)wissenschaftlichen Kriterien erlaubt so nicht nur die kritische Historiografie (Speichergedächtnis), sondern gewährt, insbesondere durch die Distinktion von anderen, gleichermaßen die Integration der eigenen Institution (Funktionsgedächtnis). Indem sich die Bundeswehr selbst immer wieder als problembehaftet zum Gegenstand macht, gelingt es, auf die dynamischen und unvorhersehbaren Richtungswechsel gesellschaftlicher Entwicklung mit anhaltenden Kurskorrekturen zu reagieren, um schließlich zwischen der Skylla der Retrotopie und der Charybdis der Anomie (Kap. 1) so zu navigieren, dass dennoch ein konstantes Selbstbild erreicht werden kann.

Indem dieser Kollektivierungsdiskurs auf die raumzeitlichen Herausforderungen mit einer dynamischen Traditionsbildung reagiert und diese in den diskursiven Deutungen des Leitmuseums der Bundeswehr in Dresden zum Ausdruck bringt, gelingt es schließlich, Kohärenz im Nebeneinander verschiedener Erfahrungsräume und Orientierung unter dem ungewissen Erwartungshorizont der deutschen Gegenwartsgesellschaft zu stiften. Schließlich wird deutlich, dass diese Form reflexiver Identitätsbildung im Modus wissenschaftlicher Selbstbeforschung keinesfalls (nur) eine Reaktion auf die Geschichte darstellt, sondern (auch) ein Resultat gegenwärtiger Herausforderungen, die sie identitätspolitisch verabeitet. Wie alle Prozesse der Traditionsbildung finden auch diese »kompositorischen Prinzipien« ihren »Bezug in der aktuellen politisch-sozialen Interessenlage« (Konzeptgruppe 2003:31). Damit ist allerdings auch gesagt, dass möglicherweise 
eine Kongruenz zwischen den empirischen Funden der Selbstthematisierung der Bundeswehr, ihrem multiperspektivischen Code der Verräumlichung sowie der inkrementellen Stabilisierung von Zeit und anderen Kollektivierungsdiskursen besteht. Im Folgenden sollen deshalb die Ergebnisse der empirischen Analyse abschließend theoretisiert werden, um schließlich die allgemeinere Reichweite der im Speziellen gefundenen Ergebnisse zu eruieren. 



\section{Unter dem Erwartungshorizont der Gegenwart: Konstanz - Kontinuität - Kritik}

Als am 13. Juli 2019 die James Simon Galerie auf der Berliner Museumsinsel feierlich eröffnet wurde, kehrte die Vergangenheit wieder; allerdings nicht in Form einer Rekonstruktion des schinkelschen Packhofes, sondern als eine Vergegenwärtigung der Geschichte dieses Ortes. Einer der Gründungspfähle des bis 1938 an dieser Stelle befindlichen Direktorenhauses der Packhofanlagen, der bei den Arbeiten am Fundament des neuen Eingangsgebäudes aus dem weichen Untergrund der Museumsinsel gezogen wurde (Kap.5.1.2), fand als Exponat zurück an seinen ursprünglichen Ort, an dem zwischenzeitlich der Neubau der James Simon Galerie errichtet worden war. Der Wandel der Museumsinsel und die historische Entwicklung des Ortes wurden so selbst zum Gegenstand der Musealisierung.

Jede Vorstellung des Sozialen, so argumentiert Gunter Weidenhaus, ist auf Referenzpunkte angewiesen, die als zeitlos imaginiert werden. Um ein Gleichbleiben im Wandel zu ermöglichen, müssen diese `Fixpunkte` allerdings immer wieder neu bestimmt werden. Weidenhaus verdeutlicht dies anhand einer Metapher: In eine dynamische Wirklichkeit würden stets Pflöcke eingeschlagen, deren Merkmal es ist, als ewig imaginiert $\mathrm{zu}$ werden. Obwohl sich zwar von außen "permanent das Herausziehen, Wegwerfen und Neueinschlagen dieser Pflöcke beobachten « lässt, gelingt es der sich verändernden sozialen Welt dennoch, die Vorstellung von Dauerhaftigkeit abzuringen (Weidenhaus 2016:5). Lässt man sich auf das Bild der Holzpflöcke ein, welches den anhaltenden Prozess der Fundierung sozialer Wissensverhältnisse illustriert, dann zeigt sich, dass der Grad der Reflexivität, womit Neupositionierung und Neufundierung (sprich: das Einschlagen und Ziehen der Pfähle) thematisiert werden, stark variiert. Die Perspektive von außen entspricht dem Bewusstsein, welches für die historische Veränderung besteht. Obwohl der Abstraktionsgrad - also der Grad der Äußerlichkeit - in den Kollektivierungsdiskursen sehr verschieden ist, konnte empirisch gezeigt werden, dass es allen Formen der Identitätsbildung gelingt, eine Vorstellung von Dauerhaftigkeit aufzubauen und diese in der diskursiven Deutung der gebauten Welt zu verräumlichen. In allen idealtypisch rekonstruierten Diskursen gelingt es, die Vergangenheit so zu deuten, dass Wiederholungsstrukturen aufgebaut werden können. In kreativen vergangenheits- 
bezogenen Deutungen des Erbes gelang es allen drei Typen, sich temporär und partiell aneinanderzubinden und so gleichermaßen fundierende Erzählungen zu artikulieren. Zudem konnte gezeigt werden, dass die Wissensverhältnisse, die dabei stabilisiert wurden, sich auf sehr unterschiedliche Art ihrer Gründungspfähle bedienen.

Im Folgenden sollen deshalb die Ergebnisse zusammengefasst und anhand ihres Abstraktionsniveaus, mit dem die eigene Historizität reflektiert wird, differenziert werden. Wie gezeigt werden konnte, verändert sich dabei auch die Ebene, auf der jeweils Wiederholungsstrukturen etabliert werden. Die Fundierung der Kollektivierungsdiskurse gründet somit in sehr unterschiedlichen Schichten. Außerdem soll dies auch der Rückbindung an den weiteren Kreis anderer Kollektivierungsdiskurse dienen und mögliche Schnittpunkte mit diesen aufzuzeigen. Da Strukturhomologien zwischen den analysierten Diskursen und möglichen anderen Diskursen vermutet werden, dies allerdings einer gesonderten empirischen Prüfung bedarf, sind diese Überlegungen auch als Ausblick auf weitere Forschung zu verstehen.

\subsection{Der Heroische Kollektivierungsdiskurs}

Der heroische Kollektivierungsdiskurs erweist sich als weitgehend blind für das Ziehen und Neueinschlagen der Pflöcke. Wandel kann im Sinne mythologischer Zeit nicht reflexiv in den Blick genommen werden. Obwohl auch hier Vergangenheit stets rekonstruiert wird, vereint sie zahlreiche chronologisch frühere Zeitpunkte, die zu einer heroischen Vergangenheit idealisiert werden und sich spiegelbildlich $\mathrm{zu}$ einer stigmatisierten Gegenwart verhalten, die als Zeit der Agonie charakterisiert wird (Kap.5.2.2). Zeit zerfällt also in zwei Hemisphären, wobei Vergangenheit und Gegenwart weniger zeitliche als vielmehr normative Begriffe darstellen. Vergangenheit wird zu einem ewig gültigen Ideal und zeitlosen Referenzpunkt verklärt, wodurch diese Form der Identitätsbildung bruchlose Konstanz imaginiert.

Das zentrale Merkmal dieses Diskurses - wie er idealtypisch in den Forderungen der GHB nach einer originalgetreuen Rekonstruktion des Neuen Museums dargestellt wurde - besteht in der anhaltenden Verbindlichkeit der Vergangenheit. Eine klare Trennung zwischen Vergangenheit, Gegenwart und Zukunft besteht im strengen Sinne nicht. Der Lauf der Zeit schwingt ewig im Kreis (Arendt 2002:29), zerfällt allerdings in zwei Hälften. Diese Zweiteilung der Zeit besteht in einem idealisierten Ursprung und einer sich spiegelbildlich dazu verhaltenden Zeit des Niedergangs. Der heroische Kollektivierungsdiskurs nimmt somit im Hinblick auf seine zeitliche Struktur den typischen Charakter mythischer Zeitlichkeit an. Dabei konnte ebenfalls gezeigt werden, dass durch die Ausdehnung der mythischen Zeit eine Vielzahl chronologisch früherer Zeitpunkte integriert und zu einem normativ verbindlichen Ursprung zusammengefasst wird. Auch hier gilt, dass alles, was sich 
Abbildung 38: Gründungspfahl des ehemaligen Direktorenhauses der Packhofanlagen in der auf diesem Gelände entstandenen James Simon Galerie.

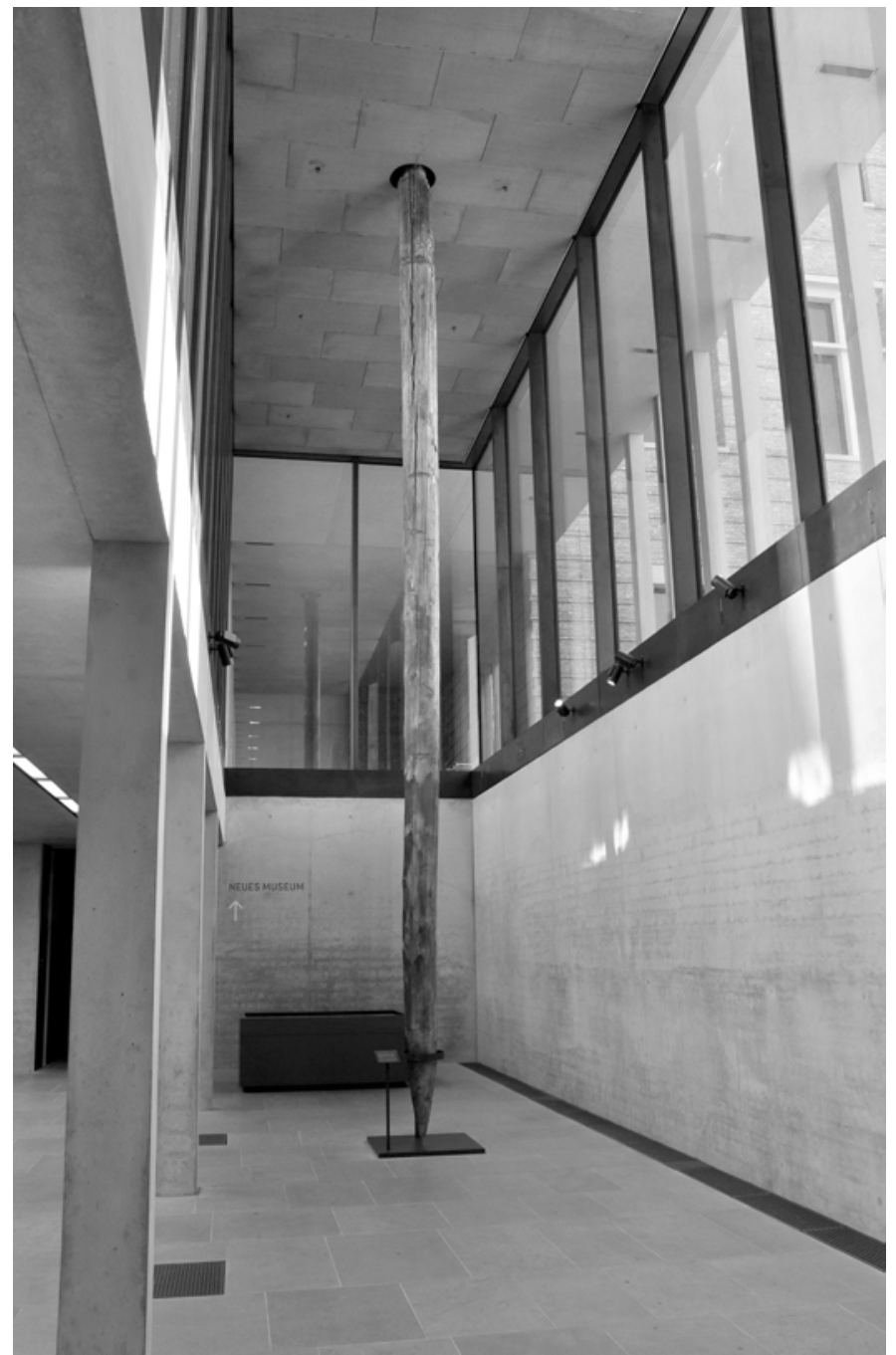

auf diesen >Ursprung zu gründen vermag, »höchste Autorität, ja einen schlechthin unanfechtbaren Gültigkeitsanspruch« besitzt (Müller 1983:108). Die Heroisierung des Ursprünglichen wird $\mathrm{zu}$ einer normativen Vergangenheit, die nicht vergeht und immer wiederholt werden muss, da sie verbindlich bleibt. 
Dass das Ensemble der Museumsinsel in diesem heroischen Kollektivierungsdiskurs als "abgeschlossenen « bezeichnet wurde, bildete stets eine normative und gerade keine chronologische Zuschreibung. Denn rabgeschlossen $<$ war stets als vollendet zu verstehen. Wie anhand der Pläne Alfred Messels für die Bebauung an der Westseite des Neuen Museums gezeigt werden konnte, kann der >Ursprungく sogar Bauwerke in die Vergangenheit integrieren, die noch nie gebaut wurden (Kap. 5.2.4). Dass so auch Zukunft Teil der Vergangenheit werden kann, entspricht einer Rückkehr an einen Ort, an dem man noch nicht gewesen ist (Kap.5.2.5). Damit verfügt der retrospektive Appell an eine heroische Vergangenheit über eine funktional prospektive Versprechung. Denn was ewig gut ist, erlaubt die Strukturierung nicht nur der Gegenwart, sondern ebenso der Zukunft.

Im Sinne kontrapräsentischer Mythen (Assmann 1992) und der dafür üblichen Erweckungsrhetorik wird Gegenwart als Zeit der Latenz charakterisiert. Da die zu einem weiterhin verbindlichen Kanon hypostasierten Gebote der Vergangenheit in der Gegenwart außer Kraft gesetzt seien, gerät die eigene Identität in Gefahr. Die Rückkehr zu einem Ursprung, der als zeitloses Maß aller Dinge verklärt wird, fordert die zyklische Wiederholung. Der Weg in eine bessere Zukunft nimmt in der Überwindung der als mangelhaft charakterisierten Gegenwart seinen Anfang und führt über den Umweg der Vergangenheit. Die Rekonstruktivität der Vergangenheit, die zentrales Merkmal jedes Vergangenheitsbezuges ist (Kap. 2.3), darf hierbei aber nicht sichtbar werden. Dass mehrere und immer wieder andere chronologisch frühere Zeitpunkte in die Konstruktion eines verbindlichen Ursprungs integriert werden können, erlaubt dennoch, auch diesen Modus sich den wechselnden Bedingungen der Gegenwart anzupassen. Dies geschieht allerdings nicht, indem das Erbe, sondern der Mythos an die gegenwärtigen Herausforderungen angepasst wird. In dem angeführten Bild der Gründungspfähle sind das Einschlagen und Ziehen der Pflöcke, auf denen sich die fundierende Erzählung dieses Kollektivierungsdiskurses gründet, nicht beobachtbar. Im heroischen Kollektivierungsdiskurs gibt es somit keine >Außenperspektive «. Die Konstruktion eines zeitlos gültigen Ideals erlaubt es in diesem Modus nicht, die anhaltende Neujustierung und anhaltende Rekonstruktion der Vergangenheit zu reflektieren. Die anhaltende Adaption des Mythos bleibt unsichtbar.

Das Abstraktionsniveau - also die Ebene, auf der Fundierung gelingt - besteht somit in der zeitlosen Konstanz ewig gültiger Gebote, die (obwohl sie immer wieder angepasst werden) gerade nicht hinterfragt oder interpretiert werden dürfen. Das ewig verbindliche Erbe wird anhaltend beschworen und galt als zu wertvoll, um es dem Zeitgeist anzupassen. Seine Veränderung durch Interpretation stellte geradezu einen Akt des Rechtsbruchs dar, was etwa mit der rhetorischen Frage "who possesses the right to interprete a world heritage site gekennzeichnet wurde (Klahr, Kap. 5.2.4, Herv. JK). Im Sinne der kalten Institution des Mythos wird »das Eindringen der Geschichte« (Lévi-Strauss 1981:270, Kap. 4.1) abgewehrt. 
Ebenfalls im Einklang damit wird ein Gleichbleiben im (Kreis-)Lauf der Zeit im heroischen Kollektivierungsdiskurs durch die erneuerungszeitliche rituelle Kohärenz gewährleistet (Assmann 1997:87ff., Kap. 4.1.1). Die Hälften, in die Zeit zerfällt, bleiben also durch die Möglichkeit der Rückkehr miteinander verbunden. Wiederholung wird zum Gebot. Die spiegelbildlich zur idealen Vergangenheit als mangelhaft konstruierte Gegenwart muss überwunden werden. Die Dokumente, Originalentwürfe und Urkunden, allgemein das Wissen darum, wie es war (sprich: wie es richtig ist), erlauben im Falle der GHB nicht nur eine Wiederholung, sondern haben schlichtweg verpflichtenden Charakter. Authentizität wird so auf der Ebene der Ausführung der praktischen Arbeit gewährleistet. Das sabgeschlossene Erbe beschreibt ein zeitloses Ideal, welches prinzipiell verfügbar bleibt. Da die mangelhafte Zeit der Agonie überwunden werden muss, begründet dieses Ideal zwar ein Interpretationsverbot, gleichzeitig aber auch ein Interventionsgebot.

In räumlicher Hinsicht rekurriert dieser Kollektivierungsdiskurs auf das Ideal der Reinheit und stilistischen Einheit. Die spiegelbildliche Konstruktion der Zeithälften bildete sich in der räumlichen Deutung der Architektur ab. Alles, was sich auf Ursprünglichkeit berufen kann und ungeachtet chronologischer Bestimmungen dem idealisierten Ursprung zugesprochen wird, wird positiv bewertet. Was hingegen als abweichend denunziert wird, egal, ob es eventuell tatsächlich der Vergangenheit angehört hat, wie etwa die bunte Farbgestaltung der erbauungszeitlichen Fassade, wird als Bedrohung des Eigenen wahrgenommen (Kap. 5.2.8). Mit zahlreichen Anthropomorphismen werden die endosphärischen Räume beschrieben (Herz, Leichnam, Seele), während in scharfer Abgrenzung dazu die modernen Interpretationen als exosphärische Räume gedeutet und mit Begriffen aus dem semantischen Feld der Gewalt beschrieben werden (sprengen, vernichten, demütigen). Durch die sich komplementär zueinander verhaltenden Begriffsfelder der Vermenschlichung und der Verletzung wird eine scharfe Grenzziehung zwischen den Räumen der Identifikation und den Räumen der Befremdung vollzogen, mit der beide ihren spezifischen Sinn erhalten (Kap. 5.2.7).

Alle Räume, die als Ausdruck der Zwischenzeit gewertet und der Zeit der Agonie zugerechnet werden, erfahren eine Trivialisierung, die durch Vergleiche mit Profanbauten (sozialer Wohnungsbau, Kohlekeller, Lagerhalle, Kap. 5.2.7) betrieben wurde und sich gleichermaßen spiegelbildlich zu Begriffen aus dem semantischen Feld des Heiligen verhält, mit denen das Erbe des 19. Jahrhunderts verklärt wurde (Tempel, magischer Blick, Schöpfung, Kap. 5.2.1). Das zentrale Sujet dieser Wirklichkeitsdeutung wies den modernen Architekten und Denkmalpflegern die Rolle derer zu, die sich über diese klare Abgrenzung hinwegsetzen und die räumliche Ordnung durchkreuzen und somit eine raumzeitliche Verunreinigung erzeugen (Douglas, Kap. 5.2.8). Wie die Missachtung der scharfen Grenzziehung aus Perspektive des heroischen Kollektivierungsdiskurses bewertet und diskreditiert wurde, ließ sich anhand der Deutungsmuster der Täuschung, der Monstrosi- 
tät und des Wahnsinns rekonstruieren. Demnach versuchten die Architekten und Denkmalpfleger bewusst die UNESCO zu täuschen und brachten damit das Erbe in Gefahr; sie schufen »Raum-Monster«. Das Erbe »mutierte«. Durch »Sachlichkeitswahn« und die »fetischhafte Überhöhung der Ruine« wurde die Gegenwart anhand der räumlichen Deutung als eine Zeit der Verkehrung denunziert und die diskursive Gegenformation pathologisiert (Kap. 5.2.7).

Der zentrale Wert, auf den der exklusive Code der Verräumlichung dieses Kollektivierungsdiskurses rekurriert, besteht in der ästhetischen Homogenisierung. Die stilistische Reinheit und die homogene Schließung der Schäden/Spuren der Zeit galten als einzig akzeptabel. Jeder anderslautende Umgang mit dem Erbe war Ausdruck von Täuschung, Gewalt, Gefahr, Verunreinigung und wurde als Zeichen des Wahnsinns, der Monstrosität und der schmachvollen Trivialisierung gedeutet. Gleiches galt auch für die räumlichen Relationen der Gebäude der Museumsinsel zueinander. Indem auch hier ein »abgeschlossenes Ensemble« behauptet wurde, dessen Relationen nicht gestört werden dürften, bot dies zudem die Möglichkeit, auch bei Abwesenheit einzelner Gebäude oder Gebäudeteile eine Vorstellung zeitloser Präsenz in der räumlichen Struktur des Ortes und seinen sursprünglichen Relationen gleichsam überwintern zu lassen. Auch deshalb scheint Fundierung einzig durch Wiederholung gewährleistet und zudem möglich.

\subsection{Der Historizistische Kollektivierungsdiskurs}

Der historizistische Kollektivierungsdiskurs bezieht sich nicht auf eine zeitlos verbindliche Vergangenheit, sondern auf entwicklungsgeschichtliche Kontinuität. Nunmehr wird auf der Ebene kontinuierlicher Entwicklungsgesetze eine Vorstellung von Dauerhaftigkeit erzeugt. Das Ziehen und Neueinschlagen der Gründungspfähle (wie anhand des Pfahls in der James Simon Galerie veranschaulicht) wird nun explizit thematisiert. Der Grad der Reflexivität und der Äußerlichkeit erlaubt es, Zeit entlang des chronologischen Dreischrittes in Vergangenheit, Gegenwart und Zukunft zu trennen, womit der Glaube an einen zeitlos gültigen Referenzpunkt verloren geht. Im anhaltenden Prozess der Neuausrichtung werden aber zeitlos gültige Muster und historische Regeln (Popper 1965) behauptet, die trotz Veränderung ein Gleichbleiben im Strom der Zeit erlauben. Die Bahnen, in denen die Zeit dabei verläuft, erzeugen Fortschritt, der schließlich auch $\mathrm{zu}$ Vollendung führen kann, wodurch diese Form der Identitätsbildung Kohärenz durch voranschreitende Kontinuität gewinnt.

Die zeitliche Struktur dieses Kollektivierungsdiskurses - wie er idealtypisch anhand der ergänzenden Wiederherstellung des Neuen Museums rekonstruiert wurde - besteht in einer linearen Verbindung zwischen Vergangenheit, Gegenwart und Zukunft. In einem strengen Sinn des Wortes lässt sich nur in diesem Modus 
von Kontinuität sprechen, da Kontinuität im Unterschied zu Konstanz immer Veränderung impliziert. Dies führt dazu, dass der Strom der Zeit verschiedene Vergangenheiten immer weiter von der Gegenwart entfernt, die schließlich selbst zur Vergangenheit und somit historisch werden kann. In diesem Diskurs sind es nicht mehr die Heroen einer glanzvollen Vorzeit, sondern die »Zeitverläufe«, die das Museum zu einem authentischen Zeugnis der Geschichte gemacht haben (Chipperfield, Kap. 5.3.1). Anders als die zyklische Zeit des Mythos, die zwar gleichermaßen historischer Veränderung ausgesetzt ist, dieses »Eindringen der Geschichte« aber abwendet, so wird nun ein Bewusstsein historischen Wandels zum »Motor der eigenen Entwicklung« (Lévi-Strauss 1981:270, Kap.4.1). Vollendung war in diesem Diskurs nicht durch Rückkehr, sondern nur durch die Weiterentwicklung und das Weiterbauen des Neuen Museums sowie des gesamten Erbes der Museumsinsel erreichbar (Badstübner et al. 1994; Hamm 2009). Die zeitliche Struktur des historizistischen Kollektivierungsdiskurses der ergänzenden Wiederherstellung des Neuen Museums entspricht also nicht der des Mythos, sondern der der Geschichte.

Da die verschiedenen Zeitschichten klar voneinander getrennt sind und eine Wiederholung oder Rückkehr ausgeschlossen ist, müssen diese dokumentiert werden. Die nachgerade forensisch-dokumentarische Sicherung historischer Spuren, wie durch die Vertreter der ergänzenden Wiederherstellung betrieben, wurde stets auch als ehrlicher und aufrichtiger Umgang mit der Vergangenheit thematisiert. Dadurch, dass über die verschiedenen Vergangenheiten des Gebäudes Rechenschaft abgelegt werden musste, erhielt auch dieser Umgang mit dem Erbe verpflichtenden Charakter (Mörsch, Kap. 5.3.3). Im Sinne der heißen Option erscheint ein Gleichbleiben im Wechsel durch rechenschaftszeitliche textuelle Kohärenz (Assmann, Kap. 4.1) gewährleistet. Zeit schwingt nicht mehr ewig im Kreis, sondern sie verläuft. Allerdings geschieht dies, dieser Deutung zufolge, nicht planlos. Historische Veränderung muss dokumentiert werden. Die Interpretationen entlang eines zeitlos gültigen Repertoires an Gesetzmäßigkeiten erlaubt ein Gleichbleiben im Wandel. Da diese zeitliche Struktur Geschichtsbildern entspricht, die unterschiedliche historische Epochen in ein überzeitliches Narrativ einordnen und die Spezifik einzelner Vergangenheiten als Stufen einer allgemeineren Entwicklungsgeschichte deuten, wurde dieser Kollektivierungsdiskurs als historizistisch bezeichnet (Popper, Kap. 5.4).

Mit dem Abstraktionsniveau dieses Diskurses verlagert sich die Tiefenschicht, in der er seine Fundierung erreicht. Dies geschieht nun nicht mehr auf der Ebene zeitloser Konstanz, sondern voranschreitender Kontinuität. Nicht durch die Wiederholung des immer Gleichen, sondern durch die Interpretation des Verschiedenen nach vermeintlich überzeitlichen Gesetzmäßigkeiten kann die Gegenwart immer wieder in eine dauerhaftere "geistige Kontinuität« (Haspel, Kap. 5.3.5) eingereiht werden. Dabei werden Begriffe wie Fortschritt und Entwicklung sowie Ver- 
gegenwärtigung und Interpretation zentral. Übersetzt in die Metapher der Pflöcke bedeutet dies, dass zwar das Ziehen der fundierenden Bezugspunkte beobachtet werden kann und sogar zum Gegenstand der historiografischen Selbstthematisierung wird; beim Neueinschlagen der Referenzpunkte, anhand derer eine fundierende Erzählung aufgespannt wird, werden allerdings zeitlos gültige Muster behauptet. Die Neuausrichtungen in der Gegenwart, so die Behauptung, lassen sich stets in Einklang mit entzeitlichten Prinzipien und bereits bekannten Traditionen bringen. Wiederholung findet dann auf der Ebene ideeller Prinzipien statt, die durch Interpretation im `Geiste immer wieder neu entfaltet werden können. Anhand dieses Diskurses konnte gezeigt werden, dass auch in linearen Zeitstrukturen fundierende Erzählungen formuliert werden können. Auch die Selbstthematisierung im Modus historiografischer Dokumentation erlaubt es, Vergangenheit so zu deuten, dass eine gleichsam abstraktere Wiederholungsstruktur ausgebildet werden kann. Hatte Nietzsche noch befürchtet, dass ein Übermaß an Historie und Kritik die Fundamente der Sinnstiftung untergrabe (Nietzsche 2009:87), gelingt es auch im historizistischen Kollektivierungsdiskurs, ein Bild von Ewigkeit (Kap. 4) zu zeichnen. Ewig bleibt nunmehr jedoch nur die Veränderung.

Die Räume sind nun nicht mehr in ihrer Ästhetik einheitlich, sondern in ihrer Eigenschaft als gleichermaßen moderne, historische oder ruinöse Relikte unterschiedlicher Vergangenheiten, die alle gleichberechtigt nebeneinanderstehen (Kap. 5.3.6; 5.3.7). Wie im heroischen Kollektivierungsdiskurs wurden dieselben Begriffe zur räumlichen Deutung des Erbes in Anspruch genommen. Die verschiedenen bauzeitlichen Räume, die Schäden des Krieges und der Nachkriegszeit ebenso wie die modernen Ergänzungen konnten allerdings mithilfe eines integrativeren Codes der Verräumlichung als Ausdruck der Harmonie gedeutet werden. Mit zahlreichen Begriffen aus dem semantischen Feld der Akustik wurde nun gerade die Verschiedenheit der Räume als »Partitur« oder als Orchester bezeichnet, dessen Einheit gerade durch die unterschiedlichen »Instrumente« (Räume) und deren harmonisches Zusammenspiel entsteht (Kap. 5.3.7). Anders als der heroische Kollektivierungsdiskurs, der auf Reinheit rekurriert, gelingt es in diesem Kollektivierungsdiskurs, auch disparate Gebäudeteile zu einer Einheit zu synthetisieren. Für diese subtile Homogenisierung erwies sich das Deutungsmuster der Concordia Discors - der Harmonie des Unharmonischen (Kap. 5.3.8) - als zentral. Der integrative Code der Verräumlichung erlaubte es den Vertretern der ergänzenden Wiederherstellung des Neuen Museums, die modernen Eingriffe und die disparaten Gebäudeteile mit dem (angeblichen) Geist der Tradition zu versöhnen, um so den Anforderungen nach Kontinuität und Erneuerung Rechnung zu tragen. Indem die Gleichzeitigkeit unterschiedlicher Ästhetiken als Wesensmerkmal der Museumsinsel thematisiert wurde, stand nun auch die disparate Ästhetik des neuen Neuen Museums im Einklang mit der Vergangenheit und den benachbarten Gebäuden; ebenso wie die Entwicklung selbst als Identitätsressource des Ensembles thema- 
tisiert wurde. War die Museumsinsel für den heroischen Kollektivierungsdiskurs schon immer ein rabgeschlossenes Ensemble< (also ein zeitloses Ideal), so erschien sie im historizistischen Kollektivierungsdiskurs schon immer im Werden und in anhaltender Entwicklung (Scheffler, Kap. 5.3.5).

Auch die räumlichen Relationen der Gebäude zueinander konnten dabei auf eine Weise thematisiert werden, die es erlaubte, neu geschaffene (Zwischen-)Räume als Teil eines harmonischen Ganzen zu vereinheitlichen. Die subtile Homogenisierung erfolgte einerseits über die verwendeten Materialen (etwa die Werkbetonsteine der James Simon Galerie, das Material der Fensterstürze des Nordwestflügels des Neuen Museums sowie dessen moderne Ergänzungen im Inneren) und damit über die architektonische Verräumlichung; andererseits auch und vor allem durch die diskursive Verräumlichung. So wie die Gebäudegeschichte fortgeschrieben werden konnte, so konnten auch disparate Ästhetiken und gänzlich neue Gebäude integriert werden, indem darauf hingewiesen wurde, dass sich die für die Museumsinsel charakteristischen Typologien wiederholen würden. Die neuen baulichen Interventionen verloren ihren fremden Charakter dadurch, dass die neu geschaffenen Höfe und Kolonnaden sowie die Freitreppe der James Simon Galerie als aktuelle Interpretation traditioneller und für die gesamte Museumsinsel prägender Bautypologien gedeutet wurden.

Der heroische Kollektivierungsdiskurs bediente sich eines exklusiven Codes der Verräumlichung, in dem eine scharfe Abgrenzung zwischen eigen- und fremdräumlichen Sphären vollzogen wurde. Dabei konstruierte dieser Diskurs eine Art Gegenwelt, in der die moderne Architektur als mutiert, monströs, infantil, unreif, aufdringlich, als Ausdruck von Verrücktheit und Akt der Zerstörung diskreditiert wurde. Der historizistische Kollektivierungsdiskurs hingegen bedient sich eines inklusiven Codes der Verräumlichung. Dieser erlaubt es, die gleichermaßen als disparat und verschieden thematisierten Räume dennoch so zu deuten, dass sie ihre Fremdheit verlieren. Im Rückgriff auf eine binäre Unterscheidung, die Claude Lévi-Strauss vorgeschlagen hat, weisen die beiden Codes der Verräumlichung Parallelen $\mathrm{zu}$ anthropoemischen und anthropophagen Strategien im Umgang mit Andersartigem und Abweichung auf (Lévi-Strauss 1989:382ff., Orig. 1955). Während eine emische Thematisierung des Fremden auf die Vernichtung des Anderen zielt, besteht das Ziel phagischer Umgangsweisen in der Vernichtung der Andersartigkeit (Bauman 2016:120ff.). Was einerseits durch Exklusion ausgeschlossen wird, kann andererseits durch Inklusion eingeschlossen, verarbeitet, verdaut werden und verliert so schließlich den Status des Fremden. Überträgt man das Begriffspaar auf die räumliche Sinnbildung der Identitätskonstruktionen, so wird deutlich, dass der heroische Kollektivierungsdiskurs Räume auf phagische Weise relationiert. Durch scharfe Kontrastierung bleibt das Fremde klar getrennt und zudem bedrohlich. Der historizistische Diskurs hingegen bedient sich eines emischen Umgangs, indem nicht das Fremde ausgeschlossen, sondern Fremdheit integriert wird. 


\section{Erster Schnittpunkt: Rekonstruktion und Retrotopie}

Sowohl strukturell als auch in Bezug auf die verwendeten Begriffe weisen die Debatte des Neuen Museums und die darin konfligierenden Kollektivierungsdiskurse frappierende Ähnlichkeiten zu anderen Rekonstruktionsdebatten auf. Die wechselseitige Bezichtigung der diskursiven Formationen, das Erbe zu gefährden, die Öffentlichkeit zu täuschen oder die Geschichte zu verfälschen, lässt sich teilweise mit identischen Begriffen in anderen Debatten um historisierende Rekonstruktionen in Deutschland finden. Vom Streit um den Wiederaufbau des Goethehauses in Frankfurt (Dirks 1947) bis zur Rekonstruktion des Berliner Schlosses (Kuhnert/Ngo 2011) sind nicht nur ähnliche Topoi, sondern auch gleichermaßen normative Semantiken nachweisbar. Sowohl die >Wieder-Holung \& der Vergangenheit als auch die Forderung nach Dokumentation und Erhalt historischer Spuren haben jeweils verpflichtenden Charakter. Die Vielzahl der Anthropomorphismen, die bemüht werden, wenn etwa von der Wiedergewinnung des Herzens, der Seele oder des unverwechselbaren Angesichts der Gebäude oder ganze Stadtkerne die Rede ist, kann ebenso wie die Annullierung von Zwischenzeiten und die Verunglimpfung ihrer baulichen Spuren als monströs, als ein allgemeines Charakteristikum heroischer Kollektivierungsdiskurse im Kontext von Rekonstruktionsdebatten gewertet werden. ${ }^{1}$ Gleichermaßen kann auch die Diskreditierung von historisierenden Rekonstruktionen als Attrappe (von Buttlar et al. 2010) oder >Disneylandisierung und somit als Ausdruck einer mangelnden Aufrichtigkeit im Umgang mit der Vergangenheit als verallgemeinerbare Strategie des historizistischen Kollektivierungsdiskurses bezeichnet werden. Vor dem Hintergrund der empirischen Analyse steht damit im Zentrum der Debatten um die Rekonstruktion der Dresdner Frauenkirche oder der Frankfurter Altstadt der Konflikt zwischen heroischen und historizistischen Kollektivierungsdiskursen.

Obwohl die Debatte des Neuen Museums zeigt, dass voreilige Zuordnungen der Kollektivierungsdiskurse zu politischen Lagern vereinfachend wären, weist die raumzeitliche Strukturierung des heroischen Diskurses Parallelen zu einer rechtskonservativen Kulturkritik auf, die sich oft im Modus vermeintlich neutraler Architekturkritik artikuliert. Zwar kann nicht davon ausgegangen werden, dass jede heroische Form der Identitätsbildung politisch rechts stehende Inhalte reproduziert, dennoch scheint umgekehrt vieles darauf hinzudeuten, dass die meisten rechtspopulistischen Identitätsdiskurse einer raumzeitlichen Konstruktionslogik folgen, die als heroischer Idealtypus rekonstruiert wurde. Der Appell an eine ebenfalls heroische Vergangenheit, wie er sich in den rechtskonservativen Gegenstimmen der Neugestaltung des Militärhistorischen Museums besonders laut hervortat, macht 
diesen Zusammenhang deutlich. Antisemitische Ressentiments gegen den jüdischen Architekten (Kap. 6.4.3) sowie die generelle Ablehnung eines offenen Traditionsverständnisses, wie es die Innere Führung der Bundeswehr darstellt, werden auch hier eng mit der Ablehnung der Architektur verknüpft. Besonders brisant erscheint, dass die ablehnenden Stimmen teilweise aus der Truppe selbst stammen und das offizielle Identitätsangebot der Bundeswehr somit aus den eigenen Reihen unter Beschuss gerät.

Wie zuletzt in der Debatte um sogenannte »rechte Räume« (Ngo 2019, Trüby 2019a, 2019b) und die identitätspolitische Aufladung der historisierenden Rekonstruktionen der Frankfurter Altstadt deutlich wurde, behält - trotz aller Polemik - die von Stephan Trüby vertretene These Gültigkeit, dass Rekonstruktionsarchitektur (keinesfalls nur, aber eben auch) als Schlüsselmedium der autoritären, völkischen und geschichtsrevisionistischen Rechten vereinnahmt wird (Trüby 2019b:161). Dem Architekturtheoretiker wurde dabei unterstellt, in Bausch und Bogen jedes Rekonstruktionsprojekt und seine Fürsprecher in den Bereich revisionistischer Geschichtsklitterung zu verweisen. Trüby erlaubte sich jedoch, auf zwei Dinge hinzuweisen: Zum einen weisen die Topoi der Architekturkritik rechter Provenienz, wie Trüby überzeugend darlegt, tatsächlich eine erstaunliche Kontinuität vom 19. Jahrhundert bis in die Gegenwart auf (Trüby 2019a). Zum anderen wird ebenso überzeugend deutlich, dass die Rekonstruktion von Altstädten (und vielleicht noch mehr die Debatten, die darum geführt werden) von rechten Demagogen gezielt zum Zwecke der Etablierung eines revisionistischen Geschichtsbildes instrumentalisiert wird. Daraus den oben unterstellten Fehlschluss abzuleiten, erscheint tatsächlich nach gängigen Regeln der Logik unzulässig. Dass dieser syllogistische Schluss allerdings nicht von Trüby selbst stammt, sondern Ergebnis einer bewusst verkürzenden Fehldarstellung ist, die durch die bewusst polarisierende rhetorische Frage »Ist Fachwerk faschistisch?« (Guratzsch 2018) zugespitzt wurde, zeigt in Übereinstimmung der gewonnenen Erkenntnisse das hohe identitätspolitische Konfliktpotenzial konkurrierender Deutungen der gebauten Welt. Selbst wenn Architektur keine inhärente politische Gesinnung hat, eröffnen sich durch ihre Diskursivierung Deutungsräume, die für geradezu gegenteilige Anliegen politisch vereinnahmt werden können. Da vieles dafür spricht, dass vor allem die diskursive Deutung und Semantisierung der Rekonstruktionen und nicht allein deren materielle Umsetzung für die jeweiligen erinnerungspolitischen Zwecke instrumentalisiert werden, erscheint das Plädoyer Trübys für eine Re-Ideologisierung der Debatte allerdings problematisch (Trüby 2019b), würde dadurch doch eher einer weiteren Polarisierung Vorschub geleistet.

Die Rückkehr in vermeintlich bessere Zeiten ist zudem ein zentrales Motiv in den retrotopischen (Bauman 2017) Verheißungen politischer Führer weltweit. Die Heroisierung einer weniger chronologisch, sondern normativ bestimmten Vergangenheit wird zum entzeitlichten Referenzpunkt und verspricht, abwechselnd >wie- 
der groß< (Trump) oder >wieder selbstbestimmt < (Brexit) zu werden. Dass die Rekonstruktion historischer Bauwerke oft ein Werkzeug der Retrotopie darstellt, zeigt sich etwa in der türkischen Hauptstadt Ankara. Nicht nur, dass dort osmanische Stadttore (wieder)errichtet werden, die es nie gab, gleichzeitig wird das moderne bauliche Erbe der Stadt zerstört. Vor dem Hintergrund einer (auch im architektonischen Maßstab) zur Über-Größe heroisierten Vergangenheit des Osmanischen Reiches werden die heterogenen Dokumente moderner Architekturen mit einem exklusiven Code der Verräumlichung zugunsten einer Stilreinheit annulliert (Dağıstanlı 2016). Auch hier müssen die zwischenzeitlichen Spuren (ungeachtet ihrer architektonischen Qualität) weichen, damit der Weg zugleich vorwärts und zurück zur imperialen Größe des »Neo-Osmanismus« frei wird (Appadurai 2017:21).

Räumliche und ethnische Reinheitsfantasien gehören zum bekannten Repertoire nationaler Erweckungsbewegungen. Im Sinne kontrapräsentischer Mythen (Assmann 1992) wird die Gegenwart ebenfalls als eine Zeit der Latenz und des Niedergangs, des Chaos und der Verkehrung einer vermeintlich natürlichen Ordnung pathologisiert. Die Naturalisierung von Identitätspostulaten zeigt sich prototypisch im Ethnonationalismus der sogenannten Identitären Bewegung (Brumlik 2017). Die zahlreichen Begriffe aus dem semantischen Feld geistiger Unzurechnungsfähigkeit und einer als ungerechtfertigt empfundenen Überhöhung, wie sie in den heroischen Kollektivierungsdiskursen nachgewiesen werden konnten (»innerer Wahnsinn«; »Nationalmasochismus«; »Demokratiefetischismus«; >fetischhafte Überhöhung der Ruine`), gehören ebenfalls zum unverzichtbaren Wortschatz reaktionärer Politiker und rechter Demagogen. Die Pathologisierungen der Anerkennung sexueller Vielfalt und geschlechtlicher Diversität als »Gendergaga« (Kalbitz, zitiert nach Müller 2019) bilden nur ein aktuelles Beispiel dieses Deutungsmusters. Übereinstimmend mit der Analyse der inhärenten Zeitkonstruktion des heroischen Diskurses zeigt sich ebenfalls die Unfähigkeit, historische Veränderung zu thematisieren. Auch hier werden verschiedene chronologische Zeitpunkte zu einer mythischen Ursprungszeit hypostasiert, die zeitlos gültig bleibt. Ein Beispiel dafür bildet die beeindruckend realitätsferne Behauptung zeitloser Konstanz eines angeblich »schlafende[n] Furor[s] teutonicus«. Die Apologeten der Identitären Bewegung stellen abermals der Zeit der Latenz (»schlafend«) »das ewig unzivilisierbare, urdeutsche Fieber, das uns aus germanischen Urwäldern wie aus gotischen Kathedralen entgegenstrahlt« als zeitlos gültiges Korrektiv zur Seite (zitiert nach Brumlik 2019). Ebenfalls im Einklang mit der zeitlichen Zweiteilung von Erweckungsmythen wird das Einlenken in der Gegenwart gefordert und artikuliert sich etwa in der Forderung einer »Erinnerungspolitischen Wende um $180^{\circ}$ " (Höcke, zitiert nach dpa 2017) oder der Marginalisierung des für die deutsche Erinnerungskultur zentralen Referenzpunkts des Nationalsozialismus als »Vogelschiss« (Gauland 2018). 
Die Erweckungsrhetorik des heroischen Kollektivierungsdiskurses stellt einen kontrapräsentischen Mythos par excellence dar. Diese Konstruktionslogik kollektiver Identität findet in der sogenannten »Konservativen Revolution « (Breuer 1995) ein historisches Vorbild. Die unter diesem Sammelbegriff zusammengefassten kulturpessimistischen Autoren (etwa Oswald Spengler und Ernst Jünger) erfreuen sich gerade unter Anhängern rechtspopulistischer Parteien einer großen Leserschaft. Der Soziologe Matthias Quent argumentiert in seiner Analyse des deutschen Rechtsextremismus, dass gerade kulturpessimistische Wirklichkeitsdeutungen stark mit der Hinwendung $\mathrm{zu}$ rechtspopulistischen Parteien korrelieren. Noch vor ökonomischen Indikatoren bildet eine pessimistische Weltsicht die einflussreichere Variable (Quent 2019:126, 166). Die damit verbundene Flucht in eine bessere Vergangenheit deckt sich vollständig mit den zentralen Merkmalen dessen, was in dieser Arbeit als heroischer Kollektivierungsdiskurs rekonstruiert wurde. Quent stellt fest, dass die "Paranoia vom drohenden Untergang, die sich vom NSU über Sarrazin, Sieferle und Pegida bis zu Höckes AfD zieht, der Markierung von Feinden und der Konstruktion eines heroischen Selbstbildes [dient].« (Quent 2019:183). Auch hier kann also Zukunft nur durch den revisionistischen Rückgriff auf eine heroisierte Vergangenheit angeeignet werden.

Insbesondere das Selbstbestimmungsnarrativ der Europäischen Union (Žižek 2017) sowie der westliche Liberalismus allgemein (Krastev/Holms 2019) tauchen dabei als zentrales Feindbild auf. Dieses Identitätsnarrativ weist wiederum starke raumzeitliche Parallelen mit dem historizistischen Kollektivierungsdiskurs auf, womit ein Indiz für einen weiteren Schnittpunkt der im Speziellen gefundenen raumzeitlichen Zusammenhänge mit dem Kreis allgemeinerer Identitätsdiskurse gefunden ist. Das Bonmot >In Vielfalt geeint< scheint eine andere Formulierung dessen zu sein, was im historizistischen Kollektivierungsdiskurs als Concordia Discors - als die Harmonie des Disharmonischen - bezeichnet wurde. Im Einklang damit werden auch hier kulturelle Vielfalt zur Identitätsressource und historischer Wandel zu Konstanten erhoben. Diese raumzeitliche Formationsregel scheint charakteristisch für Identitätsdiskurse zu sein, in denen Heterogenität und historischer Wandel reflexiv verarbeitet werden. Historische Veränderung wird kontinuiert, indem auf historische Gesetzmäßigkeiten verwiesen und Entwicklungslinearität unterstellt wird. Die zeitkonstitutionelle Logik folgt auch hier dem Credo: Ewig bleibt die Veränderung. Historische Entwicklung wird in die Zukunft extrapoliert und führt wie in jedem geschichtsmythischen Fortschrittsdiskurs zu einem historischen Ziel. Dabei erschien lange Zeit ein Ideal als gewiss, welches heute weit entfernt scheint und in der Vollendung der Europäischen Integration bestand (etwa Todorov 2003; Habermas 2011; Beck 2012).

Zumindest in der Art, wie Zeit und Raum thematisiert werden, weisen die im Speziellen gewonnenen Erkenntnisse und die analysierten diskursiven Strategien Ähnlichkeiten mit einer der zentralen Spannungslinien unterschiedlicher Imagi- 
nationen kollektiver Identität auf. Vieles deutet also darauf hin, dass die vorschnelle Diagnose, zyklische und lineare Zeit hätten in der flüchtigen Moderne (Bauman 2007) an Relevanz verloren, haltlos erscheint. Eher zeigt sich weltweit eine Rückkehr reaktionärer Bewegungen (della Porta 2017), die unvermeidlich die Mythen einer heroischen Vergangenheit mit sich führen und diese auch in räumliche Reinheitsfantasien übersetzen.

\subsection{Der Reflexive Kollektivierungsdiskurs}

Mit dem reflexiven Kollektivierungsdiskurs nimmt der Grad der >Äußerlichkeit<, durch die historische Veränderung in den Blick genommen werden kann, abermals zu. Weder der Glaube an ein zeitlos gültiges Ideal noch der Glaube an eine kontinuierliche Entwicklung können nunmehr begründet werden. Da Vergangenheit nunmehr einen negativen Referenzpunkt darstellt, müssen ihre Fundamente verworfen werden. Die Abkehr davon führt aber keineswegs zu Vollendung, da auch ein gesetzmäßiger Fortschritt (sprich: ein Muster des Einrammens und Ziehens der Pfähle) als unwahrscheinlich gilt. Da die Ungewissheit geschichtlicher und gesellschaftlicher Veränderung zur einzigen Gewissheit wird, müssen nunmehr die Pflöcke anhaltend kontrolliert und immer wieder verworfen werden. Wie die Bundesverteidigungsministerin in ihrer Rede anlässlich des Inkrafttretens des neuen Traditionserlasses 2018 mahnte, müsse die Bundeswehr sich »immer wieder selbst vergewissern, auf welchem Grund« sie steht (von der Leyen 2018:2). Unter dem wachsamen Auge der kritischen Dauerprüfung und fortgesetzten Selbst-Negation gelingt es - quasi mit Verweis auf die gezogenen Gründungspfähle -, eine fundierende Erzählung zu stabilisieren. Kohärenz wird in dieser Form der Identitätsbildung durch andauernde Reflexion und (Selbst-)Kritik gewonnen.

Durch die Abkehr von der Vergangenheit und die ungewisse Zukunftserwartung tritt im reflexiven Kollektivierungsdiskurs an die Stelle mythischer Konstanz und entwicklungsgeschichtlicher Chronologie nun diskontinuierliche Kontingenz. Die konnektive Struktur der Selbstthematisierung der Bundeswehr, wie anhand der zentralen Dokumente und der Diskursivierung ihres Leitmuseums dargestellt werden konnte, entspricht diesem Idealtyp. Es konnte gezeigt werden, dass auch das ausgeschlagene Erbe der deutschen Militärgeschichte als negativer Referenzpunkt hoch relevant bleibt. Nicht mehr die Wiederholung der Vergangenheit, sondern deren zyklische Abwehr sowie die anhaltende Selbstnegation in der Gegenwart werden nun zentral. Gerade weil die Vergangenheit auf Distanz gehalten werden muss, wird sie immer wieder thematisiert und bleibt dadurch der zentrale Bezugspunkt der Selbstthematisierung. Wie im heroischen Kollektivierungsdiskurs vergeht Vergangenheit auch hier nicht, sondern wird gerade, indem sie abgewehrt wird, immer wieder erneuert und so zu einer normativen Vergangenheit (Assmann 
2016). In der anhaltenden Negation der Vergangenheit und der andauernden Vergewisserung, dass sich die Gegenwart davon unterscheidet, artikuliert sich so ein negativer Mythos. Zwar wird Zeit ebenfalls in zwei Hälften geteilt, allerdings sind die Vorzeichen vertauscht, mit denen Ursprung und Gegenwart gekennzeichnet werden. Die Vergangenheit ist gerade nicht wiederholungswürdig. Dadurch, dass nunmehr die Vergangenheit und nicht mehr die Zukunft eine negative Einschätzung erfährt, lässt sich die zeitliche Struktur dieses Diskurses auch als eine invertierte kalte Institution beschreiben.

Wichtig ist allerdings darauf hinzuweisen, dass die Abkehr der Vergangenheit und die Hinwendung an eine bessere Gegenwart im Falle der Bundeswehr dennoch keinen Diskurs der Vollendung begründen. Auch die Gegenwart bedarf der anhaltenden Prüfung, da sich die Bundeswehr in einem »Prozess beständiger Transformation« befindet und »sich laufend der Realität der Einsatzziele und -bedingungen an[zu]passen « muss (Pieken 2011:36, Kap. 6.4.2). Die Überwindung der Vergangenheit ist nie gewiss und zudem erlaubt auch die sich dynamisch verändernde Gegenwart keine endgültige Festlegung. Deshalb werden eine anhaltende Selbstprüfung und die dauerhafte Option der Kursänderung erforderlich. Somit besteht die zeitliche Struktur dieses Kollektivierungsdiskurses nicht nur in einer zyklischen Abkehr (also in einem negativen Mythos), sondern auch in der Thematisierung episodischer Diskontinuität mit der Vergangenheit, in der Gegenwart und potenziell in der Zukunft. Durch anhaltende Selbstnegation kann eine inkrementelle Wiederholungsstruktur etabliert werden. Der Kreislauf schließt sich dann nämlich in der Kritikbedürftigkeit aller Verhältnisse, egal ob vergangen oder zukünftig. Zeitliche Stabilität gewinnt dieser Diskurs also durch eine inkrementelle Struktur anhaltender Selbstnegation (Schimank, Kap. 6.5). Im reflexiven Kollektivierungsdiskurs werden historischer Wandel und gegenwärtige Veränderung nicht nur sichtbar, sondern selbst zentral und als Identitätsressource ausgegeben. Es gilt: Da nie gesagt werden kann (und darf), wie wir sind, kann (und muss) immer gesagt werden, wie wir nicht mehr sind. Identität wird schließlich durch iterative Nicht-Identität gewonnen. Dabei werden Werte zentral, die selbst Prozesscharakter annehmen. Werte wie Kritik, Reflexivität und Wandlungsfähigkeit erhalten nun den Stellenwert von Identitätsressourcen. Auch der kritische Umgang mit der Vergangenheit und das Auflehnen gegen bestehende Strukturen werden in der Vergangenheit >wiedergefunden (Kap. 6.3.4). In dieser dynamischen Kontinuierung episodischer Zeit nehmen die Traditionen selbst Prozesscharakter an, wodurch eine Vorstellung von Dauerhaftigkeit formuliert werden kann sowie die Zukunftserwartung, dass auch morgen noch das Gebot der kritischen Selbstprüfung gelten wird.

In räumlicher Hinsicht wird die gezielte Störung bestehender räumlicher Relationen propagiert. Neben der gezielten Störung räumlicher Relationen der Architektur des Militärhistorischen Museums und seiner Ausrichtung im Stadtraum, der Entgrenzung des klassischerweise getrennten Bereichs des Zivillebens 
und technisch-militärischer Aspekte sowie der kreativen (Neu-)Verknüpfung unterschiedlicher sozialräumlicher Themenbereiche in der Ausstellung (Kap. 6.3.2) wird der Anspruch der Selbst-Befremdung durch eine multiperspektivische Darstellung verräumlicht. Damit wird dem Fremden abermals eine gänzlich andere Rolle zugesprochen. Sowohl die Vielfalt unterschiedlicher Perspektiven, die Irritation alter Sehgewohnheiten als auch die nationale Entgrenzung (Kap. 6.4.2) erfüllen nun den zentralen Wert der fortgesetzten Selbstprüfung und der dafür erforderlichen Selbst-Befremdung. In der Ausstellung des Militärhistorischen Museums Dresden erhält die Assoziation mit dem Fremden somit den Nimbus eines positiven Bezugspunktes für die eigene Identität. Das Fremde erhält als ein notwendiges Korrektiv Bedeutung, indem es die zentrale Funktion der Selbstprüfung ermöglicht. Das Fremde fordert nicht mehr das Eigene heraus, sondern fördert so die positive Bestimmung des Eigenen.

Im Bild einer Collage lässt sich dieser multiperspektivische Code der Verräumlichung vielleicht am besten beschreiben. In diesem Synthesemodus werden Raumcollagen arrangiert, die es erlauben, Disparatheit und Vielfalt immer wieder neu $\mathrm{zu}$ thematisieren. Im Unterschied zur subtilen Homogenisierung (Kap. 5.3.7) wird das multiperspektivische Raumerrangement (Kap. 6.4.2) aber bewusst nicht vereinheitlicht. Mit dem Bild der Raumcollage wird ein räumlicher Konstitutionsmodus beschrieben, in dem Disparatheit und Heterogenität gerade nicht integriert werden. Dennoch ist die Darstellung des Verschiedenen, wie bei einer Collage, nichts Zufälliges, sondern eine sehr voraussetzungsvolle Verknüpfungsleistung. Auch dieses kreative Arrangement verschiedener Raumelemente bleibt stets eine absichtsvolle Konstruktion. So wie die Verbindung zwischen zivilen und militärischen Aspekten dem Anspruch eines demokratischen Militärs und dem Leitbild des »Staatsbürgers in Uniform« entspricht, so wird Multiperspektivität explizit mit der Meinungsvielfalt "pluralistischer Gesellschaften« assoziiert. Auch der multiperspektivische Code der Verräumlichung bleibt also mit seinen collagenhaften Spacings in seiner Funktion auf die Bundeswehr bezogen (Kap. 6.4.2). Diese bleibt Subjekt des Erinnerns (Young 1999:223); ihr Kollektivierungsdiskurs bleibt an die geschichtlichen und politischen Anforderungen der deutschen Gegenwartsgesellschaft gebunden.

Was mit dem Kollektivierungsdiskurs der Bundeswehr gelingt, ist schließlich die Institutionalisierung der Dauerreflexion (Schelsky 1957). Helmut Schelsky hat bereits 1957 im Hinblick auf die evangelische Kirche in Deutschland die Frage aufgeworfen, ob die »ewige Wahrheit« der Kirche, die durch die »dauernde Steigerung des Bewusstseins« und die sich stark »verändernden Sozialstrukturen der modernen Welt« herausgefordert wird, es vermag, sich neu zu »gründen« (Schelsky 1957:155, 160). Die zentrale Verschiebung der Institutionalisierung der (evangelischen) Religiosität bringt Schelsky auf die Formel, dass sich das Wesen der Kirche vom >Betsaal zum Sprechsaak wandele (a.a.O. 169). Dem entspricht ein Wandel der 
Organisations- und Kommunikationsform, in der Tagungen, Diskussionen und Seminare einen festen Platz erhalten und somit Reflexion verstetigt wird. Allerdings bleiben - wie im Fall der Bundeswehr - die Grundlagen der Selbstvergewisserung stets instabil, weshalb auch hier ihre Dauerreflexion »chronisch und fundamental für das Leben einer Glaubensgemeinschaft moderner Menschen« wird (a.a.O. 170). Zwar fehlt in der Darstellung der Transformationsprozesse des (evangelischen) Gemeindelebens der späten 1950er Jahre das für die Bundeswehr zentrale Moment der Diskontinuität und der anhaltenden Selbstnegation; dennoch, so konnte anhand der Analyse des Identitätsdiskurses gezeigt werden, besteht damals wie heute die prinzipielle Möglichkeit, durch eine Art stereotyper Autokommunikation Institutionen und damit neue Selbstverständlichkeiten auszubilden. Der Dauerreflexion wird auch im Falle der Bundeswehr ein fester Platz zugewiesen. Dies geschieht etwa in Form der Schriftenreihe >Innere Führung oder in ihren Forschungseinrichtungen (Zentrum für Militärgeschichte und Sozialwissenschaften (ZMSBw)), im Besonderen aber - wie gezeigt werden konnte - in der Diskursivierung des Leitmuseums in Dresden. ${ }^{2}$ Zudem wurde deutlich, dass es innerhalb dieser Institutionen vor allem die prozessualen Werte und die Topoi der Kritik, der Reflexivität und der Multiperspektive sind, die ein routinisiertes Selbstgespräch ermöglichen und so neue Gewissheiten stiften.

Die Analyse hat außerdem deutlich gemacht, dass nicht nur Ungewissheit und historische Brüche integriert werden können, sondern mit der anhaltenden SelbstDistanzierung auch die Distinktion von anderen Armeen gelingt (Kap. 6.4.4). Mit dem Kollektivierungsdiskurs der Bundeswehr ist somit ein empirischer Beleg für einen Prozess reflexiver Identitätsbildung gefunden, in dem es (so jedenfalls die Behauptung) nur noch eine Außenperspektive gibt; eine Art der Identitätsbildung also, die einerseits hochdynamischen Prozessen ausgesetzt ist, andererseits (und das ist wichtiger) diese weder, wie in der kalten Institution, einfriert und annulliert noch, wie in der heißen Institution, zum Motor ihrer Entwicklung macht, sondern sie in ihr symbolisches Zentrum rückt und durch architektonische und diskursive Verräumlichung zum Ausdruck bringt. Trotz diskontinuierlicher Abkehr von der Vergangenheit und anhaltender Selbstkritik in der Gegenwart und Zukunft kann durch eine stereotype Autokommunikation, in der gerade »Reflexivität« einen zentralen Topos darstellt, Identität begründet werden. Indem sogar die Tradition des Kritisierens in der Vergangenheit swiedergefunden wältigt werden kann, artikuliert sich erneut Hoffnung auf eine bessere Vergantionsbildung (Biehl/Leonhard 2018:37, 45) steht vor dem Hintergrund der gewonnenen Erkenntnisse ganz im Einklang mit der Selbstreferenzialität dieser reflexiven Form der Identitätsbildung. 
genheit, da es gelingt, eine Art Metatradition der dauerhaften Kurskorrektur zu etablieren.

Übersetzt in das Bild der Pflöcke, wird in diesem Modus weder an deren Zeitlosigkeit geglaubt noch sind Muster oder allgemeine Prinzipien erkennbar, nach welchen sie eingeschlagen werden können. Die Außenperspektive, von der Weidenhaus sprach, wird durch die Sprecher dieses Diskurses selbst reklamiert. Die doppelte Struktur von Raum und Zeit, also die wechselseitige Durchdringung des Altbaus und des modernen Keils, ermöglichen es, dies auch museumsarchitektonisch umzusetzen (Kap. 6.4). Aus dem Ausstellungsteil Krieg und Spiel eröffnet sich ein Blick in das historische Treppenhaus, in dem Porträts ehemaliger Regenten und Militärs der sächsischen Armee zu sehen sind. Indem das Innere so zum Außen wird, verleiht der Blick - quasi in umgekehrter Richtung - dem Fenster den Charakter einer Vitrine und lässt die Geschichtsdarstellungen von einst zu Exponaten von heute werden. Vor dem Hintergrund der empirischen Betrachtung der Selbstthematisierung der Bundeswehr lässt sich darin ein Sinnbild dieser Form der Identitätskonstruktion erkennen. Denn hier werden nicht einfach verschiedene Vergangenheiten sichtbar gelassen und dokumentarisch abgebildet (wie im historizistischen Diskurs). Im Sinne einer reflexiven Geschichtswissenschaft, wie sie von Pierre Nora entwickelt wurde (1989; 2005), wird nicht einfach Vergangenheit dargestellt, sondern unterschiedliche vergangene Geschichtsdarstellungen in den Blick genommen. Im übertragenen Sinn gelingt so eine institutionelle exzentrische Positionalität (Plessner). Der damit verbundene Anspruch, sich immer wieder neu und gleichsam von außen in den Blick nehmen zu können, wird so zum Ausgangspunkt dieser reflexiven Identitätskonstruktion.

\section{Zweiter Schnittpunkt: Identität durch Kritik}

Wenn Reflexivität eine Lücke in die Erinnerungskultur reißt (Dimbath et al. 2020), so lässt sich anhand des Kollektivierungsdiskurses der Bundeswehr zeigen, dass diese Lücke paradoxerweise durch Reflexivität erneut geschlossen werden kann. Die dynamische Traditionsbildung der Bundeswehr verdeutlicht, dass es auch durch die reflexive Selbstthematisierung und die iterative Selbst-Negation gelingt, eine fundierende Wiederholungsstruktur $\mathrm{zu}$ stabilisieren. Die verschiedenen Weltdeutungen führen im Militärhistorischen Museum zu einem skeptischen Umgang mit der eigenen Geschichte. Der Skeptiker ist jedoch nicht derjenige, der keine Position hat, sondern der zu viele davon besitzt. Gerade im Zweifel, also dem Aushalten verschiedener (mindestens zwei) Weltsichten, lässt sich dann vielleicht ein der Moderne angemessener Umgang mit Pluralität und Wandel erkennen (Marquard 2007:51f.). Der Verzicht auf einen Absolutheitsanspruch in der Selbstthematisierung führt nämlich nicht zum Ausschluss von Letztverbindlichkeit. Wie gezeigt werden konnte, kann auch die Praxis des Zweifelns neue Institutionen 
Abbildung 39: Vitrine mit Spielgerät in militärischer Marschformation (vorn). Aus dem Neubau wird das historische Treppenhaus (hinten) neu perspektiviert, dessen Fenster wird zum Schaukasten. Die Porträts der Regenten und Militärs werden nun von außen betrachtet.

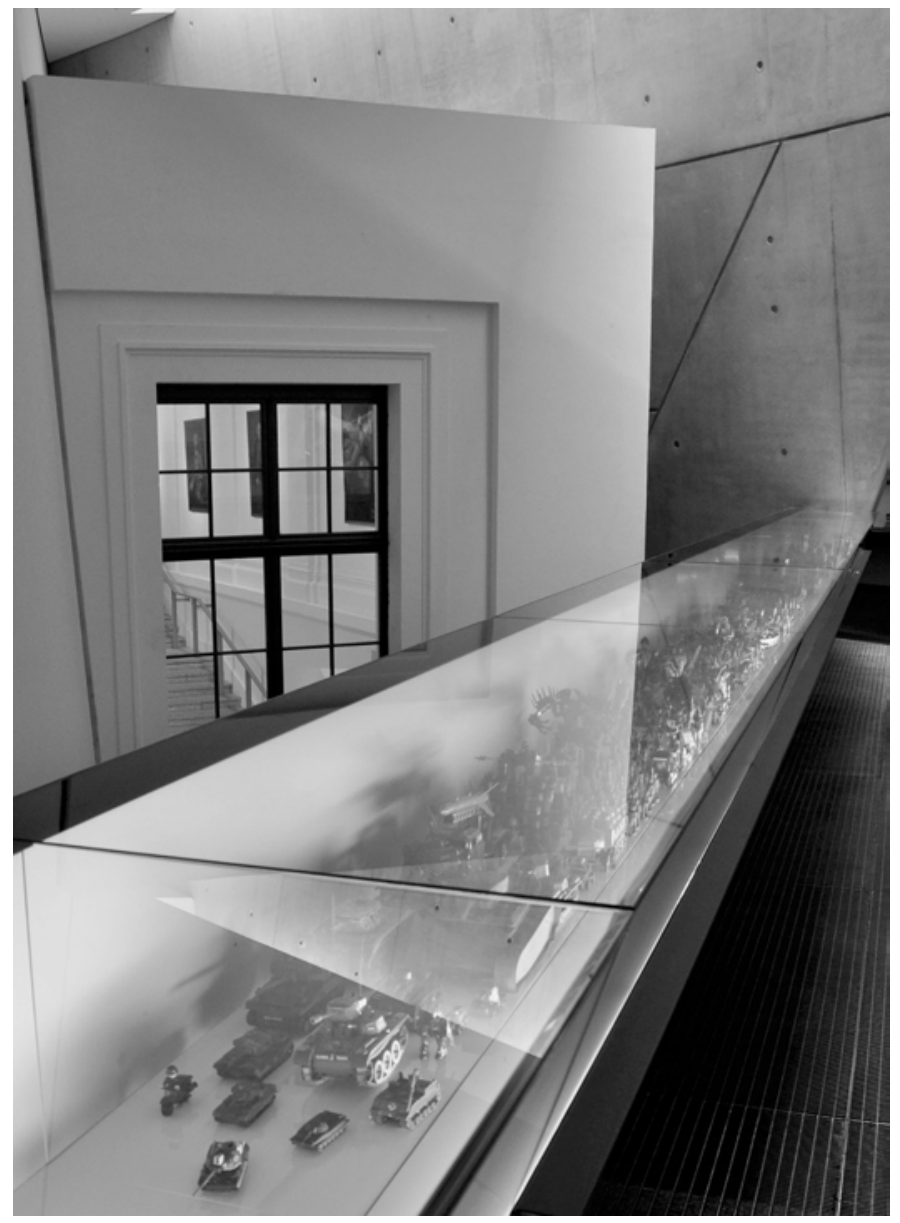

erzeugen. Dass der Wert der Kritik besondere Bedeutung erhält, ist in der paradoxalen Konstellation begründet, dass unter den dynamischen Bedingungen der Moderne Gewissheit auch durch fortgesetztes Zweifeln erreicht werden kann. Dass Kritik gleichzeitig immer Dissoziation wie Assoziation impliziert (Jaeggi/Wesche 2016:8, Orig. 2009), zeigt sich anhand des Kollektivierungsdiskurses der Bundeswehr auch darin, dass die Distanzierung von der Vergangenheit zur 
Distinktion von anderen herangezogen wird und der Anspruch der »kritischen Auseinandersetzung« selbst wiederum fundierend wirkt.

Als eine Art identitätspolitische Copingstrategie reagiert diese inkrementelle Form der Selbstproblematisierung auf gegenwärtige Herausforderungen und ist nicht allein Resultat historischer Erfahrungen. Sie trägt typische Merkmale "postheroischer Politik« (Schimank 2011), in der letztbegründete Gewissheiten nicht mehr verfügbar sind, wodurch eindeutige und endgültige Festlegungen dysfunktional erscheinen. Wie die architektursoziologische Analyse gezeigt hat, findet der postheroische Identitätsdiskurs im MHM auch architektonischen Ausdruck. Nicht mehr die Anrufung "zeitloser soldatischer Tugenden« (Pieken/Rogg 2011a:171) wie Ehre, Treue, Pflichterfüllung und die damit verbundene Monumentalästhetik einer »Rhetorik der Standhaftigkeit« (Springer 2009), sondern Werte wie Wandlungsfähigkeit, Reflexivität, Kritik sind nunmehr funktional und werden auf spezifische Weise verräumlicht. Dabei zeigt sich allerdings auch, dass der Anspruch, ein »Museum ohne Pathos« (Pieken 2010b:7; 2012a:164) zu sein, durch neue Formen der Heroik und durch postheroische Pathosformeln (Sabrow 2013) überlagert wird.

Ähnliche Muster dieser Form reflexiver Identitätsbildung können überall dort vermutet werden, wo Vergangenheit zwar als Problem thematisiert wird, aber dennoch eine kollektive Identität konstruiert werden muss. In besonderem Maße trifft dies auf die kritische Auseinandersetzung mit dem Erbe des deutschen Kolonialismus zu. So zeigt etwa das Beispiel der Gestaltung des Berliner Humboldt-Forums einerseits, dass die richtige Ausstellungsform eher erprobend gesucht wird. Andererseits, so scheint es, artikuliert sich ein Identitätsnarrativ, das Pluralität vereint und die Last kolonialer Vergangenheit ebenfalls im Modus wissenschaftlicher Kritik $\mathrm{zu}$ integrieren versucht. In institutionalisierter Selbstbeforschung und ritualisierter Abkehr von der Vergangenheit gelingt es eventuell auch hier, in iterativer Selbstproblematisierung und in anhaltenden Negationen auf sich selbst zurückzukommen (Schimank, Kap 6.5), um so zu einer anpassungsfähigeren Identität und einer Integration widerstreitender (multipler) Perspektiven zu gelangen.

Das Verhältnis zwischen den beiden gedächtnispolitischen Strategien (Kap. 4) des Mythos und der Kritik steht fraglos in beständiger Spannung. Die Grenzlinie zwischen beiden bleibt aber relational und wird stets zur wechselseitigen Diskreditierung konkurrierender Identitätspostulate anders gezogen. Sowohl ein ernsthaftes Bemühen um den reflexiven Umgang als auch eine Immunisierung gegenüber der Kritik durch die Vereinnahmung derselben scheinen Anteil an diesem kontrovers diskutierten Museumsprojekt zu haben. Der Vorwurf, sich an Letzterem zu beteiligen, traf den Künstler Philip Kojo Metz, als dieser im Herbst 2019 seine Skulptur »SORRYFORNOTHING « im Humboldt-Forum präsentierte, mit der er auf die Unsichtbarkeit deutscher Kolonialgeschichte in der Erinnerungskultur des Landes aufmerksam macht. Dass das Kunstwerk Teil der Ausstellung im Humboldt- 
Forum werden soll, brachte dem Künstler unter anderem die Kritik ein, dass er so "zur Legitimierung dieses (post)kolonialen Prestigeprojektes beitrage« (Mboro, zitiert nach Breher 2019:11). Ob es durch die Institutionalisierung kritisch-reflexiver Selbstgespräche tatsächlich gelingt, das bisher Ungesagte in der deutschen Erinnerungskultur durch eine Polyphonie der Stimmen zu artikulieren oder ob damit lediglich ein diskursiver Schwebezustand erzeugt wird, in dem durch das Postulat anhaltender Selbstreflexion neue Mythen konstruiert werden, bleibt eine stets abzuwägende Frage.

Die Unterscheidung zwischen zeitloser Konstanz zyklischer Zeit und fortschreitender Kontinuität linearer Zeit bleibt hoch relevant. Zusätzlich wird aber der Modus der inkrementellen Kritik erkennbar. Auch diesem gelingt, durch anhaltende Selbst-Negation und über episodische Brüche hinweg, erneut eine Annäherung von multiplen Erfahrungsräumen und ungewissen Erwartungshorizonten. Dabei zeigt sich auch, dass zwischen den Codes der Verräumlichung und den spezifischen Formen der Konstruktion sozialer Zeit ein starker raumzeitlicher Zusammenhang im Sinne Gunter Weidenhaus' (2015) besteht. Die Zweiteilung der Zeit, die charakteristisch für die mythologische Zeitgestalt ist, rekurriert auf das ästhetische Ideal der Homogenität. Indem die normativ gemeinten Zeitbegriffe (Vergangenheit und Gegenwart) spezifischen Architekturen zugewiesen und scharf gegeneinander abgegrenzt werden, erscheint der Zusammenhang zwischen kontrapräsentischen Identitätsmythen und einem exklusiven Code der Verräumlichung zwingend. Auch für den historizistischen und den reflexiven Kollektivierungsdiskurs gilt, dass mit spezifischen Konstruktionen von Zeit auch spezifische Raumkonstitutionen einhergehen.

Neben den raumzeitlichen Konstruktionsformen hat sich zudem gezeigt, dass der Grad der Reflexivität, mit dem die Konstruktion des eigenen Selbstbildes in den Blick genommen wird, ein aussagekräftiges Differenzkriterium darstellt, entlang welchem die Formen der Identitätsbildung unterschieden werden können. Die gewonnenen Erkenntnisse lassen sich somit folgendermaßen abbilden: 
Abbildung 40: Idealtypische Darstellung der Kollektivierungsdiskurse und ihrer Codes der Verräumlichung.

\begin{tabular}{|c|c|c|c|}
\hline & $\begin{array}{l}\text { Heroischer } \\
\text { Diskurs }\end{array}$ & $\begin{array}{l}\text { Historizistischer } \\
\text { Diskurs }\end{array}$ & $\begin{array}{l}\text { Reflexiver } \\
\text { Diskurs }\end{array}$ \\
\hline & schwach & Reflexivität & stark \\
\hline Zeit & $\begin{array}{l}\text { Mythos } \\
\text { Zweiteilung der Zeit }\end{array}$ & $\begin{array}{l}\text { Chronologie } \\
\text { Dreischritt der Zeit }\end{array}$ & $\begin{array}{l}\text { Kontingenz } \\
\text { Fragmentierung der Zeit }\end{array}$ \\
\hline Modus & $\begin{array}{l}\text { Zyklische Rückkehr } \\
\text { Rituelle Wiederholung } \\
\text { Konstanz }\end{array}$ & $\begin{array}{l}\text { Lineare Entwicklung } \\
\text { Textuelle Interpretation } \\
\text { Kontinuität }\end{array}$ & $\begin{array}{l}\text { Episodische Abkehr } \\
\text { Inkrementelle Negation } \\
\text { Kritik }\end{array}$ \\
\hline $\begin{array}{l}\text { Identi- } \\
\text { fikation }\end{array}$ & $\begin{array}{l}\text { Retrospektiv } \\
\text { Vergangenheit als posi- } \\
\text { tiver Referenzpunkt }\end{array}$ & $\begin{array}{l}\text { Prospektiv } \\
\text { Vergangenheiten als } \\
\text { Entwicklungsstufen }\end{array}$ & $\begin{array}{l}\text { Prozessual } \\
\text { Vergangenheit als nega- } \\
\text { tiver Referenzpunkt }\end{array}$ \\
\hline Raum & $\begin{array}{l}\text { Homogenität } \\
\text { Reinheit }\end{array}$ & $\begin{array}{l}\text { Heterogenität } \\
\text { (integriert) } \\
\text { Dokumentation }\end{array}$ & $\begin{array}{l}\text { Heterogenität } \\
\text { (desintegriert) } \\
\text { Bruch, Störung }\end{array}$ \\
\hline Code & $\begin{array}{l}\text { Spiegelbildlich } \\
\text { exklusiv } \\
\text { Scharfe Grenzziehung }\end{array}$ & $\begin{array}{l}\text { Vereinheitlichend } \\
\text { inklusiv } \\
\text { Flexibler Grenzverlauf }\end{array}$ & $\begin{array}{l}\text { Raumcollage } \\
\text { multiperspektivisch } \\
\text { Entgrenzung }\end{array}$ \\
\hline $\begin{array}{l}\text { Befrem- } \\
\text { dung }\end{array}$ & $\begin{array}{l}\text { Ausschluss des } \\
\text { Fremden }\end{array}$ & $\begin{array}{l}\text { Ausschluss von } \\
\text { Fremdheit }\end{array}$ & $\begin{array}{l}\text { Iterative } \\
\text { Selbst-Befremdung }\end{array}$ \\
\hline
\end{tabular}

Entgegen zeitdiagnostischer Einschätzungen, dass in der Gegenwart lineare und zyklische Konstruktionen von Zeit an Bedeutung verlieren (Bauman 2007a:180f.), zeigt sich, dass dies entschieden zurückgewiesen werden muss. Heroische Appelle an eine vermeintlich bessere Vergangenheit bleiben hoch aktuell. Insbesondere die Vereinnahmung des baukulturellen Erbes steht dabei im Zentrum gesellschaftspolitischer Konflikte weltweit. Außerdem müssen die aus den pessimistischen Gegenwartsdiagnosen gezogenen Schlüsse im Hinblick auf die Konstruktionsmöglichkeiten kollektiver Identität um eine weitere Form der Selbstthematisierung ergänzt werden. Denn die dynamischen Verhältnisse der Gegenwart bringen einen Modus der Identitätsbildung hervor, der durch anhaltende Kurskorrekturen Konstanz erzeugt und so einen Weg zwischen Skylla und Charybdis der Kompensation und Anomie findet (Kap. 1).

Zudem stellen Begriffe wie Reflexivität, Multiperspektivität, Diskontinuität und Pluralität nicht nur Schlüsselbegriffe der Diskursivierung des Leitmuseums der Bundeswehr dar, sondern scheinen zuweilen selbst soziologischen Gegenwartsdiagnosen $\mathrm{zu}$ entstammen. Mit dem Wissen darum, dass die Kuratoren und Ausstellungsgestalter des Leitmuseums der Bundeswehr oft eine geisteswissenschaftliche Ausbildung absolviert haben, erscheinen solcherlei Parallelen 
keineswegs zufällig. Insbesondere die Analyse des reflexiven Kollektivierungsdiskurses legt deshalb die Vermutung nahe, dass die Diagnosen einer risikobeladenen Moderne (Beck) oder der ambivalenten Freiheit der flüchtigen Moderne (Bauman) zu Reservoiren von Stichworten werden, derer sich reflexive Formen der Identitätsbildung bedienen. Indem zentrale Topoi daraus entlehnt werden, mit denen eine prozessuale Neufundierung gelingt, werden die Autoren der zeitdiagnostischen Literatur selbst als »Gedächtnisentrepreneurs« (François/Puschner 2010) vereinnahmt und zu Leiharbeitern am kulturellen Gedächtnis. Auch die kritische Selbstbeforschung wird so zur Gedächtnisarbeit, wobei sie in einem andauernden Prozess der Selbstproblematisierung eine anpassungsfähige Vorstellung von Identität ermöglicht.

Wie gezeigt wurde, können durch routinisierte Selbstbefragung und reflexive Selbstanalyse im Modus der Kritik Institutionen ausgebildet werden, die integrierend und legitimierend wirken. Ob die Traditionsbildung durch reflexive Thematisierung der eigenen Geschichte allerdings vor dem Hintergrund neuer Kampfeinsätze der Bundeswehr Bestand haben wird oder ob Strahlkraft und Funktionalität dieser Form der Identitätsbildung limitiert sind, bleibt einstweilen offen. In ihrer Analyse des Traditionserlasses von 2018 kommen Nina Leonhard und Heiko Biehl, die beide in der Bundeswehr forschen, jedenfalls zu dem Ergebnis, dass der Traditionskanon der deutschen Streitkräfte für die gegenwärtigen Einsätze keine Vorbilder kennt (Biehl/Leonhard 2018:47). Wie das öffentliche Gelöbnis der Soldatinnen und Soldaten im Herbst 2019 vor dem Reichstagsgebäude zeigt, kehren eventuell im Fahrwasser zunehmender Kampfeinsätze der Bundeswehr auch klassische Formen militärischer Selbstinszenierung zurück. Auch diese Entwicklung bleibt abzuwarten.

Indem alle Formen der Selbstthematisierung ein Bild von Vergangenheit entwerfen, welches normative Orientierung stiftet und in der Gegenwart handlungsleitend bleibt, können auf sehr unterschiedliche Art gründende Erzählungen artikuliert werden; ebenso wird damit auf die Bedingungen der Gegenwart reagiert und schließlich Zukunft bewältigt. In diesem Sinne artikulieren alle Selbstimaginationen, egal ob sie im Modus der Konstanz, der Kontinuität oder der Kritik operieren, eine Hoffnung auf eine bessere Vergangenheit. Unter dem ungewissen Erwartungshorizont der Gegenwart finden neben dem reflexiven Modus der Identitätsbildung jedoch alle hier dargestellten Kollektivierungsdiskurse ihre Fürsprecher. Wie die scharfe Kritik des Gegendiskurses des Militärhistorischen Museums gezeigt hat, treten insbesondere der heroische und der reflexive Kollektivierungsdiskurs in deutliche Konkurrenz zueinander. Obwohl Letzterer mit seiner inkrementellen Zeitstruktur und seinem multiperspektivischen Code der Verräumlichung ein Identitätsangebot formulieren kann, welches auf die Bedingungen der späten Moderne reagiert, so scheint gerade die Polarisierung dieser beiden Identitätsdiskurse eher Indikator einer Verschärfung gesellschaftlicher Konflikte 
zu sein. Im Sinne einer Re-Figuration von Räumen verweist das Konfliktpotenzial zwischen den Kollektivierungsdiskursen also auf eine zunehmende Polarisierung konkurrierender räumlicher Imagination von Gesellschaft (Knoblauch/Löw 2020). Eine Erkenntnis, die anhand der hier analysierten Debatten gewonnenen werden konnte, besteht auch darin, dass es insbesondere das Feld der Erinnerungspolitik ist, auf welchem gesellschaftliche Konflikte ausgetragen werden. Mit der idealtypischen Darstellung der Identitätsdiskurse können die Akteure innerhalb dieser Arena bestimmt werden. Ihre jeweilige raumzeitliche Verfasstheit gibt damit Aufschluss über den Modus, in welchem Vergangenheit beerbt und verräumlicht wird. Der Frontverlauf zwischen den Diskursen bildet die zentrale Spannungslinie konkurrierender Imaginationen kollektiver Identität und verschiedener Gesellschaftsentwürfe. So stellt die reflexive Form der Identitätsbildung zwar eine mögliche, wenngleich keine hinreichende Antwort auf die Frage nach der Sozialintegration unter den Bedingungen der späten Moderne dar. Das Bild, welches sich aus der prozesshaften Perspektive anhaltender Selbstbefragung ergibt, hält möglicherweise auch für die Identitätsforschung selbst die hoffnungsvolle Botschaft bereit, dass es auch morgen noch etwas zu kritisieren gibt. 


\section{Danksagung}

Dissertationen entstehen nicht im luftleeren Raum, sondern sind Resultate gemeinschaftlichen Nachdenkens und des Austauschs von Gedanken, Ideen, Argumenten. In den vergangenen drei Jahren bot mir das DFG-Graduiertenkolleg 2227 »Identität und Erbe« einen Rahmen, in dem dies in kollegialer und freundschaftlicher Atmosphäre möglich war. Mein besonderer Dank gilt deshalb den Vorsitzenden Gabi Dolff-Bonekämper und Hans-Rudolf Meier, die den Gedankenaustausch über Fachgrenzen ermöglichten und denen ich alles verdanke, was ich in dieser Zeit über die Denkmalpflege gelernt habe.

Bedanken möchte ich mich außerdem bei Aleida Assmann und Jürgen Straub, die bei gemeinsamen Workshops und Seminaren wichtige Gedanken dieser Arbeit angeregt haben. Ebenso danke ich den Kolleginnen und Kollegen des Graduiertenkollegs, die mich durch neue Perspektiven bereicherten, durch kritische Anmerkungen verbesserten und durch ungezählte Gespräche motivierten. Die Begriffe für die Beschreibung der historischen Museumsbauten, die normalerweise nicht zum Wortschatz eines Soziologen gehören, verdanke ich Konstantin Wächter. Besuche im Neuen Museum mit Elena Rădoi halfen mir die >Präsenz der Absenzen wahrzunehmen. Gülşah Stapel verdanke ich inspirierende Gespräche über das vielfältige Erbe Berlins. Neben Michael Lüthy wurden mir die Augen für die visuelle Dimension der Diskurse von Claudia Jürgens und Sarah Alberti geöffnet, die zudem vom ersten Satz an die Entstehung meiner Arbeit begleitet und befördert haben. Michaela Schmälzle und Wolfram Höhne danke ich für die unermüdliche Korrektur meiner Texte, vor allem für das Bezwingen zahlreicher Schachtelsätze. Außerdem danke ich Michael Wetzels, der durch hilfreiche Anmerkungen die Arbeit unterstützt hat. Bedanken möchte ich mich zudem bei Silke Steets, für die schnelle und wohlwollende Begutachtung der Dissertation. Zoya Masoud und Jurek Elżanowski danke ich für ihre freundschaftliche Unterstützung, für neue Einblicke bei großen und kleinen Exkursionen und tägliche Ausblicke bei gemeinsamen Mittagessen.

Schließlich gilt mein besonderer Dank Martina Löw und Gunter Weidenhaus, die mich während der gesamten Zeit hervorragend unterstützt und mich durch ihr Nachdenken über Raum und Zeit weit über den Kontext dieser Arbeit inspiriert haben. Ihnen allen danke ich herzlich für ihre Unterstützung und Freundschaft. 



\section{Abbildungsverzeichnis}

Abb. 1: Westliche Fassade des Neuen Museum und James Simon Galerie.

(c) Staatliche Museen zu Berlin/Foto: Jochen Kibel, 2019.

Abb. 2: Militärhistorisches Museum der Bundeswehr in Dresden.

(C) Militärhistorisches Museum der Bundeswehr/Foto: Jochen Kibel, 2019.

Abb. 3: Museumsinsel Berlin.

(c) Staatliche Museen zu Berlin/Foto: Jochen Kibel, 2018.

Abb. 4: Vitrinen im Ausstellungsteil Krieg und Gedächtnis.

(c) Militärhistorisches Museum der Bundeswehr/Foto: Jochen Kibel, 2018.

Abb. 5: Giovanni Battista Segantini (1858-1899) »Rückkehr zur Heimat«.

(c) Staatliche Museen zu Berlin, Nationalgalerie/Foto: Jörg P. Anders, 1995.

Abb. 6a: Kriegszerstörter Raum im Erdgeschoss der Alten Nationalgalerie.

(c) Staatliche Museen zu Berlin, Nationalgalerie/Foto: Jochen Kibel, 2019.

Abb. 6b: Bauliche Veränderungen in den gegenwärtigen Ausstellungsräumen.

(c) Staatliche Museen zu Berlin, Nationalgalerie/Foto: Jochen Kibel, 2019.

Abb. 7: Neues Museum, Direktorenhaus und Altes Museum um 1920.

(c) Staatliche Museen zu Berlin, Zentralarchiv/Quelle: Bloch/Hölz 1994:61.

Abb. 8: Packhofanlagen und Rückseite des Direktorenhauses.

(c) Staatliche Museen zu Berlin, Zentralarchiv/Quelle: Bloch/Hölz 1994:140.

Abb. 9: Südkuppelsaal des Neuen Museums und Übergang zum Alten Museum 1945.

(c) Staatliche Museen zu Berlin, Zentralarchiv/Quelle: Schulz 2009:39.

Abb. 10: Säulen des Ägyptischen Hofes im Jahr 1988.

(c) Staatliche Museen zu Berlin, Zentralarchiv/Quelle: Schulz 2009:49.

Abb. 11: Entwurf von Frank O. Gehry aus dem Jahr 1993.

(c) Gehry Partners, LLP.

Abb. 12: Siegerentwurf von Giorgio Grassi aus dem Jahr 1993.

(C) Giorgio Grassi/Quelle: Bundesamt für Bauwesen und Raumordnung.

Abb. 13: James Simon Galerie und Westseite des Neuen Museums.

(c) Staatliche Museen zu Berlin/Foto: Jochen Kibel, 2018.

Abb. 14: Gründungspfahl des ehemaligen Direktorenhauses.

(c) Bundesamt für Bauwesen und Raumordnung/Foto: Monika Fielitz, 2009. 
Abb. 15: Kontrastierende Bildfolge gegen die ergänzende Wiederherstellung. Bildfolge: (c) Gesellschaft Historisches Berlin e.V./Quelle: GHB 2008:16. Rechts: (c) Gesellschaft Historisches Berlin e.V. Links: @ Staatliche Museen zu Berlin, Zentralarchiv.

Abb. 16: Griechischer Saal um 1890 und Entwurf Chipperfields um 2000. Bildfolge: (c) Gesellschaft Historisches Berlin e.V./Quelle: GHB 2008:17. Rechts: (c) David Chipperfield Architects. Links: @ Staatliche Museen zu Berlin, Zentralarchiv.

Abb. 17: Flugblatt mit kontrastierender Visualisierung der Treppenhalle des Neuen Museums.

(c) Gesellschaft Historisches Berlin e.V./Quelle: Klahr 2006.

Abb. 18: Visualisierung der narrativen Struktur der Wiederherstellung.

Bildfolge: ( E. A. Seemann Verlag/Quelle: Hamm 2009:61.

Rechts: ( ) David Chipperfield Architects.

Links: ( ) Staatliche Museen zu Berlin, Zentralarchiv/Foto: Schreibe, 1985.

Abb. 19: Schadensformen der wiedererrichteten Kolonnaden der Museumsinsel.

(c) Staatliche Museen zu Berlin,/Foto: Jochen Kibel, 2017.

Abb. 20: Offenes Mauerwerk in der Treppenhalle des Neuen Museums.

(C) Staatliche Museen zu Berlin, Ägyptisches Museum und Papyrussammlung/ Foto: Jochen Kibel, 2017.

Abb. 21: Mittelalterlicher Saal, Moderner Saal und Griechischer Hof.

(c) Staatliche Museen zu Berlin, Ägyptisches Museum und Papyrussammlung/ Foto: Jochen Kibel, 2018.

Abb. 22: Wiederentdeckte Nische und 3.300 Jahre altes Fresko.

(C) Staatliche Museen zu Berlin, Ägyptisches Museum und Papyrussammlung/ Foto: Jochen Kibel, 2018.

Abb. 23: Relief vor freiliegendem Mauerwerk.

(C) Staatliche Museen zu Berlin, Ägyptisches Museum und Papyrussammlung/ Foto: Jochen Kibel, 2018.

Abb. 24: Einheit von Ausstellung und Architektur.

(C) Staatliche Museen zu Berlin, Ägyptisches Museum und Papyrussammlung/ Foto: Jochen Kibel, 2018.

Abb. 25: Der Ägyptische Hof im Neuen Museum.

(C) Staatliche Museen zu Berlin, Ägyptisches Museum und Papyrussammlung/ Foto: Jochen Kibel, 2018.

Abb. 26: Das Arsenalhauptgebäude in Dresden im Jahr 1897.

(c) Militärhistorisches Museum der Bundeswehr/Quelle: Scheerer 2003:6.

Abb. 27: Das Armeemuseum der NVA in Dresden um 1972.

(C) Militärhistorisches Museum der Bundeswehr/Quelle: Scheerer 2003:18.

Abb. 28: Wandbild von Bruno Dolinskis im Innenhof des MHM.

(C) Militärhistorisches Museum der Bundeswehr/Foto: Jochen Kibel, 2019. 
Abb. 29a: Militärhistorisches Museum nach der Umgestaltung im Jahr 2011.

(c) Sandstein Verlag, Militärhistorisches Museum der Bundeswehr/Quelle: Pieken 2013:2-3/Foto: Nick Hufton.

Abb. 29b: Arsenalhauptgebäude um 1897.

(c) Sandstein Verlag, Militärhistorisches Museum der Bundeswehr/Quelle: Pieken 2013:4-5.

Abb. 30: Visualisierung stadträumlicher Bezüge der Architektur des MHM.

(c) Thomas Kantschew/Quelle: das-neue-dresden.de/bundeswehrmuseum-dres den.html?id=510639, geprüft am 30.07.2020.

Abb. 31: Etagenübergreifende Inszenierung unterschiedlicher Geschosse.

(c) Militärhistorisches Museum der Bundeswehr/Foto: Jochen Kibel, 2017.

Abb. 32: Schräg durchschnittenes Logo des Militärhistorischen Museums.

(c) Militärhistorisches Museum der Bundeswehr/Foto: Jochen Kibel, 2017.

Abb. 33: Vertikaler Betonschacht im Eingangsbereich des MHM.

(C) Militärhistorisches Museum der Bundeswehr/Foto: Jochen Kibel, 2019.

Abb. 34: Plan der Ausstellungsbereiche Themenparcours und Chronologie.

(C) Militärhistorisches Museum der Bundeswehr/Quelle: Rogg/Pieken 2011a: Einband.

Abb. 35: Postkarte des Militärhistorischen Museums.

(c) Militärhistorisches Museum der Bundeswehr/Foto: David Brandt.

Abb. 36: Kriegstrümmer aus Wieluń, Rotterdam und Dresden.

(C) Militärhistorisches Museum der Bundeswehr/Foto: Jochen Kibel, 2018.

Abb. 37: Blick auf Dresden aus der Ausstellung des Militärhistorischen Museums.

(C) Militärhistorisches Museum der Bundeswehr/Foto: Jochen Kibel, 2018.

Abb. 38: Gründungspfahl des ehemaligen Direktorenhauses in der James Simon Galerie.

(c) Staatliche Museen zu Berlin/Foto: Jochen Kibel, 2019.

Abb. 39: Vitrine mit Spielgerät in militärischer Marschformation im Militärhistorischen Museum.

(C) Militärhistorisches Museum der Bundeswehr/Foto: Jochen Kibel, 2019.

Abb. 40: Tabelle der Kollektivierungsdiskurse und ihrer Codes der Verräumlichung. (c) Jochen Kibel, 2019. 



\section{Literaturverzeichnis}

Abenheim, Donald (1989): Bundeswehr und Tradition. Die Suche nach dem gültigen Erbe des deutschen Soldaten, München, Oldenbourg: De Gruyter.

Adorno, Theodor W. (1990): Negative Dialektik, Frankfurt a.M.: Suhrkamp.

Adorno, Theodor W. (1995): Studien zum autoritären Charakter, Frankfurt a.M.: Suhrkamp.

Adorno, Theodor W./Horkheimer, Max (2001): Dialektik der Aufklärung. Philosophische Fragmente, Frankfurt a.M.: Fischer Verlag.

Ahme, Annette (2007): Initiative Rettet die Museumsinsel!, www.ahme.de/volksbe gehren205.pdf, geprüft am 12.03.2019.

Ahme, Annette (2007a): Initiative Rettet die Museumsinsel! vor zerstörerischem Umbau (Neues Museum!) und entstellendem Neubau. Presseerklärung, www. ahme.de/volksbegehren202.pdf, geprüft am 12.03.2019.

Ahme, Annette (2007b): Kein Neubau auf der Museumsinsel!, www.ahme.de/volks begehrenoo1.pdf, geprüft am 12.03.2019.

Ahme, Annette (2007c): »Re: »Fahrlässig«? Presseerklärung, www.ahme.de/volksb egehren201.htm, geprüft am 13.03.2019.

Ahme, Annette (2018): Berliner Historische Mitte e. V. Chipperfield: „Form follows function is over«. Presseerklärung Nr. 360 vom 26.12.2018, Berlin.

Albrecht, Clemens (2004): »Expertive versus demonstrative Politikberatung. Adorno bei der Bundeswehr«, in: Stefan Fisch/Wilfried Rudloff (Hg.), Experten und Politik. Wissenschaftliche Politikberatung in geschichtlicher Perspektive, Berlin: Duncker \& Humblot, S. 297-308.

Altmann, Susanne (2012): »Kunst statt Militaria. Militärhistorisches Museum Dresden«, in: art - Das Kunstmagazin vom 05.01.2012.

Anderson, Benedict (2016): Imagined communities. Reflections on the Origin and Spread of Nationalism, London, New York: Verso.

Appadurai, Arjun (2017): »Demokratiemüdigkeit«, in: Heinrich Geiselberger (Hg.), Die große Regression. Eine internationale Debatte über die geistige Situation der Zeit, Berlin: Suhrkamp, S. 17-35.

Arendt, Hannah (2002): Vita activa oder vom tätigen Leben, München, Zürich: Piper. 
Assmann, Aleida (1999): »Das Gedächtnis der Orte«, in: Ulrich Borsdorf/Heinrich T. Grütter (Hg.), Orte der Erinnerung. Denkmal, Gedenkstätte, Museum, Frankfurt a.M.: Campus Verlag, S. 59-77.

Assmann, Aleida (2009): »Geschichte findet Stadt«, in: Moritz Csáky (Hg.), Kommunikation - Gedächtnis - Raum. Kulturwissenschaften nach dem »Spatial Turn«, Bielefeld: transcript, S. 13-27.

Assmann, Aleida (2010): Erinnerungsräume. Formen und Wandlungen des kulturellen Gedächtnisses, München: C.H. Beck.

Assmann, Aleida (2016): Das neue Unbehagen an der Erinnerungskultur. Eine Intervention, München: C.H. Beck.

Assmann, Aleida/Friese, Heidrun (Hg.) (1998): Identitäten. Erinnerung, Geschichte, Identität 3, Frankfurt a.M.: Suhrkamp.

Assmann, Jan (1983): »Das Doppelgesicht der Zeit im altägyptischen Denken«, in: Armin Mohler/Anton Peisl (Hg.), Die Zeit, München, Wien: Oldenbourg, S. 189223.

Assmann, Jan (1992): »Frühe Formen politischer Mythomotorik. Fundierende, kontrapräsentische und revolutionäre Mythen«, in: Dietrich Harth/Jan Assmann (Hg.), Revolution und Mythos. Sieben Thesen zur Genesis und Geltung zweier Grundbegriffe historischen Denkens, Frankfurt a.M.: Fischer Verlag, S. 39-61.

Assmann, Jan (1995): »Erinnern, um dazuzugehören. Kulturelles Gedächtnis, Zugehörigkeitsstruktur und normative Vergangenheit«, in: Kristin Platt/Mihan Dabag (Hg.), Generation und Gedächtnis. Erinnerungen und kollektive Identitäten, Opladen: Leske und Budrich, S. 51-75.

Assmann, Jan (1997): Das kulturelle Gedächtnis. Schrift, Erinnerung und politische Identität in frühen Hochkulturen, München: C.H. Beck.

Assmann, Jan (1999a): »Kollektives und kulturelles Gedächtnis. Zur Phänomenologie und Funktion von Gegen-Erinnerung«, in: Ulrich Borsdorf/Heinrich T. Grütter (Hg.), Orte der Erinnerung. Denkmal, Gedenkstätte, Museum, Frankfurt a.M.: Campus Verlag, S. 13-32.

Assmann, Jan (1999b): »Zeitkonstruktion und Gedächtnis als Basisfunktionen historischer Sinnbildung. Eine Reaktion auf Peter Burkes Thesen«, in: Jörn Rüsen (Hg.), Westliches Geschichtsdenken. Eine interkulturelle Debatte, Göttingen: Vandenhoeck \& Ruprecht, S. 81-98.

Assmann, Jan (2002): "Das kulturelle Gedächtnis. Wahrnehmen - Erinnern - Vergessen«, in: Christian Meier/Venanz Schubert (Hg.), Begegnung der Zeiten. Über Zeit, Kultur und Wissenschaft, St. Ottilien: EOS Verlag, S. 63-85.

Assmann, Jan (2005): »Einführung: Zeit und Geschichte«, in: Jan Assmann/Klaus E. Müller (Hg.), Der Ursprung der Geschichte. Archaische Kulturen, das Alte Ägypten und das Frühe Griechenland, Stuttgart: Klett-Cotta, S. 7-16.

Assmann, Jan (2006): »Zeit und Geschichte in frühen Kulturen«, in: Friedrich Stadler/Michael Stöltzner (Hg.), Time and history. Proceedings of the 28. Interna- 
tional Ludwig Wittgenstein Symposium, Kirchberg am Wechsel, Austria, 2005, Frankfurt a.M.: Ontos Verlag, S. 489-507.

Augstein, Rudolf (Hg.) (1987): »Historikerstreit«. Die Dokumentation der Kontroverse um die Einzigartigkeit der nationalsozialistischen Judenvernichtung, München, Zürich: Piper.

Badstübner, Ernst/Dorgeloh, Hartmut/Gebeßler, August et al. (Hg.) (1994): Das Neue Museum in Berlin. Ein denkmalpflegerisches Plädoyer zur ergänzenden Wiederherstellung (= Beiträge zur Denkmalpflege in Berlin, Band 1), Berlin: Kulturbuchverlag.

Bald, Detlef (2005a): Die Bundeswehr. Eine kritische Geschichte 1955-2005, München: C.H. Beck.

Bald, Detlef (2005b): "Die gespaltene Ausrichtung der Bundeswehr. Oder: warum sich die Bundeswehr mit der »Inneren Führung« seit 1950 schwer tut«, in: Sicherheit und Frieden - Security and Peace 23 (4), S. 177-179.

Bald, Detlef (2018): Die Generale proben den Putsch. Arbeitskreis Darmstädter Signal das kritische Forum für Staatsbürger in Uniform, https://www.darmsta edter-signal.de/meldungen/detlef-bald-die-generale-proben-den-putsch/, geprüft am 29.07.2020.

Bartsch, Michael (2011): »Mensch gegen Mensch. Das neu gestaltete Militärhistorische Museum zeigt seelische Abgründe und logistische Perfektion. Es ist nichts für Ballerfans, eher für Antwortsuchende.«, in: TAZ vom 16.10.2011, https://taz .de/!5109846/, geprüft am 29.07.2020.

Bauer, Gerhard (2012): »Der Anfang der Dresdner Garnison und der Beginn des stehenden Heeres in Sachsen (1662-1830)«, in: Dresdner Hefte. Beiträge zur Kulturgeschichte. Dresden als Garnisonstadt 53 (16), S. 4-12.

Bauman, Zygmunt (1997): Flaneure, Spieler und Touristen. Essays zu postmodernen Lebensformen, Hamburg: Hamburger Edition.

Bauman, Zygmunt (2007a): »Schneller Leben: Lernen und Vergessen in der Flüchtigen Modere«, in: Zygmunt Bauman (Hg.), Leben in der flüchtigen Moderne, Frankfurt a.M.: Suhrkamp, S. 145-208.

Bauman, Zygmunt (2007b): »Vom Regen in die Traufe: Die Kunst zwischen Markt und Verwaltung «, in: Zygmunt Bauman (Hg.), Leben in der flüchtigen Moderne, Frankfurt a.M.: Suhrkamp, S. 209-247.

Bauman, Zygmunt (2016): Flüchtige Moderne, Frankfurt a.M.: Suhrkamp.

Bauman, Zygmunt (2017): Retrotopia, Berlin: Suhrkamp.

Bauman, Zygmunt (Hg.) (2007): Leben in der flüchtigen Moderne, Frankfurt a.M.: Suhrkamp.

Bäumel, Mathias (2011): »Einzigartige Herausforderung. Was und wer hinter der neuen Dauerausstellung des Militärhistorischen Museums steckt«, in: Dresdner Neuesten Nachrichten vom 15.10.2011. 
Baur, Joachim (Hg.) (2010): Museumsanalyse. Methoden und Konturen eines neuen Forschungsfeldes, Bielefeld: transcript.

Bausinger, Hermann (1990): "Heimat in einer offenen Gesellschaft. Begriffsgeschichte als Problemgeschichte«, in: Will Cremer/Ansgar Klein (Hg.), Heimat. Analysen, Themen, Perspektiven, Bonn: Bundeszentrale für Politische Bildung, S. 76-90.

Beck, Ulrich (1986): Risikogesellschaft. Auf dem Weg in eine andere Moderne, Frankfurt a.M.: Suhrkamp.

Beck, Ulrich (1988): Gegengifte. Die organisierte Unverantwortlichkeit, Frankfurt a.M.: Suhrkamp.

Beck, Ulrich (1993): Die Erfindung des Politischen. Zu einer Theorie reflexiver Modernisierung, Frankfurt a.M.: Suhrkamp.

Beck, Ulrich (2004): Der kosmopolitische Blick oder. Krieg ist Frieden, Frankfurt a.M.: Suhrkamp.

Beck, Ulrich (2008): »Jenseits von Klasse und Nation. Individualisierung und Transnationalisierung sozialer Ungleichheiten«, in: Soziale Welt 59, S. 301-325.

Beck, Ulrich (2012): Das deutsche Europa. Neue Machtlandschaften im Zeichen der Krise, Berlin: Suhrkamp.

Beck, Ulrich (2015): Was ist Globalisierung? Irrtümer des Globalismus - Antworten auf Globalisierung, Frankfurt a.M.: Suhrkamp.

Berger, Peter L./Luckmann, Thomas (1980): Die gesellschaftliche Konstruktion der Wirklichkeit. Eine Theorie der Wissenssoziologie, Frankfurt a.M.: Fischer Verlag.

Berghorn, Frauke (2016): Kontrast oder Verschmelzung? Bauen mit Ruinen heute, Berlin: Logos Verlag.

Berlin Magazin (2007): Neue Chipperfield Entwürfe für Museumsinsel, www. berlin-magazin.info/berlin-fuehrer/berlinermuseen/museumsinselo/neueent wuerfe.html, geprüft am 29.07.2020.

Berliner Morgenpost (2007): »Lichteraktion gegen Museumspläne. 600 Grabkerzen gegen zig Tonnen Beton«, in: Berliner Morgenpost vom 11.11.2007, https:// www.morgenpost.de/printarchiv/berlin/article103336590/Lichtaktion-gegenMuseumsplaene.html, geprüft am 25.11.2019.

Bernau, Nikolaus (13.10.11): »Die Folgen des Krieges. Daniel Libeskinds Keilschlag ins Armeemuseum«, in: Berliner Zeitung vom 13.10.11.

Bernau, Nikolaus (1994): "Das Museum als Besuchermaschine«, in: Amber Sayah (Hg.), Museumsinsel Berlin. Wettbewerb zum Neuen Museum, Stuttgart, Berlin, Paris: avedition, S. 114-115.

Beyer, Manfred (2012): "Dresden als eine Keimzelle des militärischen Widerstandes?«, in: Dresdner Hefte. Beiträge zur Kulturgeschichte. Dresden als Garnisonstadt 53 (16), S. 66-74. 
Biehl, Heiko/Leonhard, Nina (2018): »Bis zum nächsten Mal? Eine funktionalistische Interpretation der Debatte um die Tradition der Bundeswehr«, in: Donald Abenheim/Uwe Hartmann (Hg.), Tradition in der Bundeswehr. Zum Erbe des deutschen Soldaten und zur Umsetzung des neuen Traditionserlasses, Berlin: Miles-Verlag, S. 36-55.

Binder, Beate (2009): Streitfall Stadtmitte. Der Berliner Schloßplatz, Köln, Weimar, Wien: Böhlau.

Binnewerg, Anke (2013): »Menschen und Steine. Die Anwendbarkeit von Maurice Halbwachs' Thesen zu Erinnerung und Raum für die Denkmalpflege«, in: HansRudolf Meier/Ingrid Scheurmann/Wolfgang Sonne (Hg.), Werte. Begründungen der Denkmalpflege in Geschichte und Gegenwart, Berlin: Jovis Verlag, S. 90-99.

Bloch, Ernst (1968): Das Prinzip Hoffnung. Wunschbilder des Erfüllten Augenblicks (= Das Prinzip Hoffnung, Band 3), Frankfurt a.M.: Suhrkamp.

Bloch, Peter/Hölz, Christoph (Hg.) (1994): Berlins Museen. Geschichte und Zukunft, München, Berlin: Deutscher Kunstverlag.

Bodemann, Y. Michal (1996): Gedächtnistheater. Die jüdische Gemeinschaft und ihre deutsche Erfindung, Hamburg: Rotbuch.

Boer, Pim d./Duchhardt, Heinz/Kreis, Georg et al. (Hg.) (2012): Europäische Erinnerungsorte. Gesamtausgabe, München: De Gruyter.

Bogner, Alexander (2012): Gesellschaftsdiagnosen. Ein Überblick, Weinheim, Basel: Beltz Juventa.

Borchmeyer, Dieter (2001): „Goethe«, in: Étienne François/Hagen Schulz (Hg.), Deutsche Erinnerungsorte, München: C.H. Beck, S. 187-206.

Borsdorf, Ulrich/Grütter, Heinrich T. (Hg.) (1999): Orte der Erinnerung. Denkmal, Gedenkstätte, Museum, Frankfurt a.M.: Campus Verlag.

Brandt, Kerstin (2011): »Working through Ruins. Berlin's Neues Museum«, in: The Germanic Review: Literature, Culture, Theory 86 (4), S. 294-307.

Breher, Nina (2019): »Kritische Leerstelle im Humbolt-Forum. Künstler thematisiert deutsche Kolonialgeschichte«, in: Tagesspiegel vom 26.10.2019, S. 11.

Breiner, Rolf (2011): »Nicht nur reflektieren, sondern auch inspirieren«, in: literaturundkunst vom 2011.

Breuer, Stefan (1995): Anatomie der konservativen Revolution, Darmstadt: Wissenschaftliche Buchgesellschaft.

Brightman, Edgar S. (Hg.) (1927): Proceedings of the Sixth International Congress of Philosophy, New York: Longmans, Green and Co.

Bröckling, Ulrich (2015): »Heldendämmerung? Der Drohnenkrieg und die Zukunft des militärischen Heroismus«, in: BEHEMOTH A Journal on Civilisation 8 (2), S. 97-107.

Bröckling, Ulrich (2018): »Bloß keine Leichensäcke!« Eine Hantologie postheroischer Kriegführung«, in: Leviathan 46 (3), S. 453-465. 
Brumlik, Micha (2017): Zur Aktualität der identitären Ideologie. Die Vordenker einer neuen rechten Internationalen, www.boell.de/de/2017/04/18/boellbrief -demokratiereform-2-zur-aktualitaet-der-identitaeren-ideologie, geprüft am 28.07.2020.

Brumlik, Micha (2019): Martin Heidegger. Vom wahren Sein zur Volksgemeinschaft. Zentrum Liberale Moderne, https://gegneranalyse.de/personen/martin -heidegger/\#identitaere, geprüft am 05.12.2019.

Bude, Heinz (2014): Gesellschaft der Angst, Hamburg: Hamburger Edition.

Bundesamt für Bauwesen und Raumordnung (2010): Neues Museum. Wiederaufbau, www.bbr.bund.de/BBR/DE/Bauprojekte/Berlin/Kultur/Museumsinsel /NeuesMuseum/neuesmuseum.html, geprüft am 25.11.2019.

Bundesamt für Bauwesen und Raumordnung (2020): Weiterführende Informationen zum Bau der James-Simon-Galerie. Bundesamt für Bauwesen und Raumordnung, https://www.bbr.bund.de/BBR/DE/Bauprojekte/Berlin/ Kultur/Museumsinsel/James-Simon-Galerie/DasProjektJSG/weiterfuehrendeinformationen.html, geprüft am 29.07.2020.

Bundesministerium der Verteidigung (1965): Bundeswehr und Tradition. Fü B 14 - Az 35-08-07, Bonn, https://augengeradeaus.net/wp-content/uploads/2017/11/ Traditionserlass_Bw_1965.pdf, geprüft am 28.07.2020.

Bundesministerium der Verteidigung (1982): Traditionserlass der Bundeswehr. Richtlinien zum Traditionsverständnis und zur Traditionspflege in der Bundeswehr, https://www.helmut-lent.de/wp-content/uploads/2018/o1/Traditions erlass-von-1982.pdf, geprüft am 29.07.2020.

Bundesministerium der Verteidigung (1994): Konzeption für das Museumswesen in der Bundeswehr, BMVg.

Bundesministerium der Verteidigung (2008): Zentrale Dienstvorschrift. Innere Führung. Selbstverständnis und Führungskultur. BMVg FüSK II 4, www.bm vg.de/resource/blob/14258/aoe22992bc053f873e402c8aaf2efa88/b-01-02-02download-data.pdf, geprüft am 29.07.2020.

Bundesministerium der Verteidigung (2018a): Konzeption der Bundeswehr. Erlassen von Dr. Ursula von der Leyen. Berlin, den 20. Juli 2018, Berlin, www.bmvg.de/resource/blob/26544/9ceddf6df2f48ca87aaoe3ce2826348d/2 0180731-konzeption-der-bundeswehr-data.pdf, geprüft am 29.07.2020.

Bundesministerium der Verteidigung (2018b): Die Tradition der Bundeswehr: Richtlinien zum Traditionsverständnis und zur Traditionspflege. Erlassen von Dr. Ursula von der Leyen. Hannover, den 28. März 2018, www.bmvg.de/resour ce/blob/23234/6a93123be919584d48e16c45a5d52c10/20180328-die-tradition-derbundeswehr-data.pdf, geprüft am 29.07.2020.

Burzan, Nicole (2017a): »Menschen im Museum. Theoretische Perspektiven auf empirische Erkundungen«, in: Sociologia Internationalis 55 (1), S. 1-26. 
Burzan, Nicole (2017b): »Zum Wandel von Raum- und Zeitstrukturierungen am Beispiel von Museen«, in: Zeitschrift für theoretische Soziologie 6 (4), S. 171187.

Buttlar, Adrian v. (2010): Neues Museum Berlin. Architekturführer, Berlin, München: Staatliche Museen zu Berlin; Deutscher Kunstverlag.

Buttlar, Adrian v./Dolff-Bonekämper, Gabi/Falser, Michael S. et al. (Hg.) (2010): Denkmalpflege statt Attrappenkult. Gegen die Rekonstruktion von Baudenkmälern - eine Anthologie, Basel: Birkhauser.

Charta von Venedig (1964): Internationale Charta über die Konservierung und Restaurierung von Denkmälern und Ensembles. Arbeitsblätter des Bayerischen Landesamtes für Denkmalpflege, http://trommer-restaurierung.de/wp-conte nt/uploads/2019/01/charta_von_venedig_1964.pdf, geprüft am 29.07.2020.

Chipperfield, David (1994): »Zweiter Preis«, in: Amber Sayah (Hg.), Museumsinsel Berlin. Wettbewerb zum Neuen Museum, Stuttgart, Berlin, Paris: avedition, S. 48-51.

Chipperfield, David (2004): »Das Neue Museum«, in: Klaus-Dieter Lehmann (Hg.), Jahrbuch Preussischer Kulturbesitz, Berlin: Gebrüder Mann Verlag, S. 83-107.

Chipperfield, David (2008): »Wiederaufbau des Neuen Museums Berlin. Restaurierung, Reparatur und Intervention«, in: Bund Deutscher Architekten BDA Berlin (Hg.), Berliner BDA Architekten Band II, Berlin: Jovis Verlag, S. 8-11.

Chipperfield, David (2009): „Das Neue Museum. Architektonisches Konzept«, in: Oliver G. Hamm (Hg.), Das Neue Museum Berlin. Konservieren, Restaurieren, Weiterbauen im Welterbe, Leipzig: Seemann, S. 56-59.

Chipperfield, David/Wolters, Wolfgang (2009): »David Chipperfield im Gespräch mit Wolfgang Wolters. Treppenhalle, Neues Museum, 17. September 2008«, in: Rik Nys/Martin Reichert (Hg.), Neues Museum Berlin, Köln: König, S. 229-240.

Cobbers, Arnt (2009): »August Stüler. Der Traum vom Gesamtkunstwerk«, in: Carola Wedel (Hg.), Das Neue Museum. Eine Ruine wird zum Juwel, Berlin: Jaron, S. 15-35.

Czollek, Max (2018): Desintegriert euch!, München: Carl Hanser Verlag.

Dağıstanlı, Hakan (2016): Architekturführer Ankara (= Architekturführer), Berlin: DOM publishers.

Das Neue Dresden (2011): Militärhistorisches Museum als Leitmuseum der Bundeswehr (Heer, Luftwaffe und Marine). Nachdenken über Krieg und Frieden, www.das-neue-dresden.de/bundeswehrmuseum-dresden.html, geprüft am 29.07.2020.

David Chipperfield Architects (2019): James-Simon-Galerie, https://davidchipperfi eld.com/files/pdfs/4321/1-text-credits-190701-en.pdf, geprüft am 28.07.2020.

Dehio, Georg (1988): »Denkmalschutz und Denkmalpflege im neunzehnten Jahrhundert. Festrede an der Kaiser-Wilhelms-Universität Straßburg den 2. Januar 1905«, in: Marion Wohlleben/Georg Mörsch (Hg.), Konservieren, nicht re- 
staurieren. Streitschriften zur Denkmalpflege um 1900, Braunschweig:Vieweg, S. 88-103.

Dehio, Georg (1988): »Was wird aus dem Heidelberger Schloß werden?«, in: Marion Wohlleben/Georg Mörsch (Hg.), Konservieren, nicht restaurieren. Streitschriften zur Denkmalpflege um 1900, Braunschweig: Vieweg, S. 34-42.

Delanty, Gerard/Jones, Paul R. (2002): »European Identity and Architecture«, in: European Journal of Social Theory 5 (4), S. 453-466.

Delitz, Heike (2010a): »Parasitäre Strategien der De-Konstruktion. Eine architektursoziologische Skizze«, in: dérive 38 (1), S. 28-32.

Delitz, Heike (2010b): »Rekonstruktion und Dekonstruktion. Zur soziologischen Analyse des aktuellen Städtebaus«, in: dérive 38 (1), S. 5-6.

Della Porta, Donatella (2017): »Progressive und regressive Politik im späten Neoliberalismus«, in: Heinrich Geiselberger (Hg.), Die große Regression. Eine internationale Debatte über die geistige Situation der Zeit, Berlin: Suhrkamp, S. 57-76.

den Hoff, Ralf von/Asch, Ronald G./Aurnhammer, Achim/Bröckling, Ulrich/Korte, Barbara/Leonhardt, Jörn/Studt, Birgit (2013): »Helden - Heroisierungen Heroismen. Transformationen und Konjunkturen von der Antike bis zur Moderne«. Konzeptionelle Ausgangspunkte des Sonderforschungsbereichs 948, in: helden.heroes.héros. 1 (1), S. 7-14.

Derrida, Jacques (2016): Marx' Gespenster. Der Staat der Schuld, die Trauerarbeit und die neue Internationale, Frankfurt a.M.: Suhrkamp.

Deutsche Presse-Agentur (2017): »Die Höcke-Rede von Dresden in WortlautAuszügen. Dokumentation« vom 18.01.2017, www.zeit.de/news/2017-01/18/par teien-die-hoecke-rede-von-dresden-in-wortlaut-auszuegen-18171207, geprüft am 19.11.2019.

Deutsche Presse-Agentur (2019): ßBerliner Museumsinsel: James-Simon-Galerie ist fertig«, in: Hamburger Abendblatt vom 01.07.2019.

Deutscher Bundestag (2008): Bericht des Petitionsausschusses (2. Ausschuss). Bitten und Beschwerden an den Deutschen Bundestag. Die Tätigkeit des Petitionsausschusses des Deutschen Bundestages im Jahr 2007, http://dipbt.bunde stag.de/dip21/btd/16/095/1609500.pdf, geprüft am 12.03.2019.

Deutscher Depeschendienst (2007): »Protest gegen Chipperfield-Pläne für Neues Museum geplant «, in: Berlin Online vom 08.11.2007.

Deutscher Depeschendienst (2007): »Protestaktion gegen Ausverkauf des Weltkulturerbes Museumsinsel. Lichterkette gegen Chipperfield-Pläne für Neues $\mathrm{Mu}$ seum angekündigt «, in: PR Inside online vom 17.11.2007.

Dimbath, Oliver (2013): »Soziologische Rahmenkonzeptionen. Eine Untersuchung der Rahmenmetapher im Kontext von Erinnern und Vergessen«, in: René Lehmann/Florian Öchsner/Gerd Sebald (Hg.), Formen und Funktionen sozialen Er- 
innerns. Sozial- und kulturwissenschaftliche Analysen, Wiesbaden: VS Verlag für Sozialwissenschaften, S. 25-48.

Dimbath, Oliver/Heinlein, Michael (2014): »Arbeit an der Implementierung des Gedächtniskonzepts in die soziologische Theorie. Eine Einführung«, in: Oliver Dimbath/Michael Heinlein (Hg.), Die Sozialität des Erinnerns. Beiträge zur Arbeit an einer Theorie des sozialen Gedächtnisses, Wiesbaden: Springer VS, S. 1-23.

Dimbath, Oliver/Rauer, Valentin/Leonhard, Nina (2020): «An Auschwitz scheitert jede Gewissheit...«. Wissenssoziologische Perspektiven auf die Möglichkeit einer skeptischen Erinnerungspolitik«, in: Oliver Dimbath/Michaela Pfadenhauer (Hg.), Gewissheit. Beiträge und Debatten zum 3. Sektionskongress der Wissenssoziologie, Weinheim: Beltz Juventa.

Diner, Dan (1987): »Negative Symbiose. Deutsche und Juden nach Auschwitz«, in: Dan Diner (Hg.), Ist der Nationalsozialismus Geschichte? Zu Historisierung und Historikerstreit, Frankfurt a.M.: Fischer Verlag, S. 185-197.

Dirks, Walter (1947): »Mut zum Abschied. Zur Wiederherstellung des Frankfurter Goethehauses«, in: Frankfurter Hefte 2 (8), S. 819-882.

Dolff-Bonekämper, Gabi (1993): "Schinkels Neue Wache Unter den Linden. Ein Denkmal in Deutschland«, in: Eberhard Roters (Hg.), Streit um die neue Wache. Zur Gestaltung einer zentralen Gedenkstätte, Berlin: Akademie der Künste, S. $35-44$.

Dolff-Bonekämper, Gabi (1999): »Der geliehene Schmerz. Das Holocaust-Denkmal und die politische Emotionalität«, in: Michael Jeismann (Hg.), Mahnmal Mitte. Eine Kontroverse, Köln: DuMont, S. 184-188.

Douglas, Mary (2001): Purity and danger. An analysis of the concepts of pollution and taboo, London, New York: Routledge.

Dube, Klaus-Dieter (1994): »Zielvorstellungen der Staatlichen Museen«, in: Amber Sayah (Hg.), Museumsinsel Berlin. Wettbewerb zum Neuen Museum, Stuttgart, Berlin, Paris: avedition, S. 24-27.

Egger, Stephan (2003): »Auf den Spuren der »verlorenen Zeit«. Maurice Halbwachs und die Wege des »kollektiven Gedächtnisses«, in: Maurice Halbwachs: Stätten der Verkündigung im Heiligen Land. Eine Studie zum kollektiven Gedächtnis, S. 219-268.

Eigmüller, Monika/Vobruba, Georg (Hg.) (2016): Grenzsoziologie. Die politische Strukturierung des Raumes, Wiesbaden: Springer VS.

Engel, Gonni (2012): "Altbau gesprengt. Libeskind-Umbau in Dresden«, in: Bauhandwerk vom 2012.

Enss, Carmen M./Vinken, Gerhard (Hg.) (2016): Produkt Altstadt. Historische Stadtzentren in Städtebau und Denkmalpflege (= Urban Studies), Bielefeld: transcript. 
Ezli, Özkan (2012): »Auf Empfang eingestellt...«. Autokommunikation als kulturelle Dynamik in Rainer Werner Fassbinders Angst essen Seele auf«, in: Susi K. Frank (Hg.), Explosion und Peripherie. Jurij Lotmans Semiotik der kulturellen Dynamik revisited, Bielefeld: transcript, S. 247-268.

Falk (2006): Dresden. Mit Durchfahrtsplan und Verkehrslinienplan (= Cityplan), Ostfildern.

Falkenhayner, Nicole/Korte, Barbara/Bensch, Matthias J./Hardt, Maria-Xenia (2018): »Heroik - Gewalt - Medialität. Working Paper der Verbundarbeitsgruppe 7 »Medialität«, in: helden.heroes.héros. 6 (1), S. 61-70.

Foucault, Michel (1990): Archäologie des Wissens, Frankfurt a.M.: Suhrkamp.

Foucault, Michel (1992): »Andere Räume«, in: Karlheinz Barck (Hg.), Aisthesis. Wahrnehmung heute oder Perspektiven einer anderen Ästhetik. Essais, Leipzig: Reclam, S. 34-46.

Foucault, Michel (2003): »Das Spiel des Michel Foucault«, in: Michael Bischoff/Daniel Defert (Hg.), Schriften in vier Bänden. Dits et écrits, Frankfurt a.M.: Suhrkamp, S. 391-439.

Foucault, Michel (2009): Überwachen und Strafen. Die Geburt des Gefängnisses, Frankfurt a.M.: Suhrkamp.

Foucault, Michel (Hg.) (1975): Der Fall Rivière. Materialien zum Verhältnis von Psychiatrie und Strafjustiz, Frankfurt a.M.: Suhrkamp.

Frampton, Kenneth (2009): »Das Museum als Palimpsest «, in: Rik Nys/Martin Reichert (Hg.), Neues Museum Berlin, Köln: König, S. 97-106.

François, Étienne/Puschner, Uwe (Hg.) (2010): Erinnerungstage. Wendepunkte der Geschichte von der Antike bis zur Gegenwart, München: C.H. Beck.

François, Étienne/Schulz, Hagen (Hg.) (2001): Deutsche Erinnerungsorte (= Deutsche Erinnerungsorte, Band 1), München: C.H. Beck.

Frank, Michael C. (2012): „Sphären, Grenzen und Kontaktzonen. Jurij Lotmans räumliche Kultursemiotik am Beispiel von Rudyard Kiplings Plain Tales from the Hills«, in: Susi K. Frank (Hg.), Explosion und Peripherie. Jurij Lotmans Semiotik der kulturellen Dynamik revisited, Bielefeld: transcript, S. 217-246.

Frank, Susi K. (Hg.) (2012): Explosion und Peripherie. Jurij Lotmans Semiotik der kulturellen Dynamik revisited (= Kultur- und Medientheorie), Bielefeld: transcript.

Frank, Susi K./Ruhe, Cornelia/Schmitz, Alexander (2012): »Vorwort«, in: Susi K. Frank (Hg.), Explosion und Peripherie. Jurij Lotmans Semiotik der kulturellen Dynamik revisited, Bielefeld: transcript, S. 7-24.

Frisch, Alexander (2011): »Zerstörerischer Eingriff. Das wiedereröffnete Militärhistorische Museum Dresden«, in: Nationalzeitung vom 21.10.2011.

Fuhrer, Armin (2011): »Wozu Menschen fähig sind«, in: Fokus vom 14.10.2011.

Gauland, Alexander (2018): Wortlaut der umstrittenen Passage der Rede von Alexander Gauland. Beim Kongress der Jungen Alternative am 2. Ju- 
ni, www.afdbundestag.de/wortlaut-der-umstrittenen-passage-der-rede-vonalexander-gauland/, geprüft am 28.07.2020.

Gehry, Frank O. (1994):»Vierter Preis«, in: Amber Sayah (Hg.), Museumsinsel Berlin. Wettbewerb zum Neuen Museum, Stuttgart, Berlin, Paris: avedition, S. 56-59. Geisel, Eike (2015): »Runder Tisch mit Eichmann. Über den kleinen Unterschied zwischen dem »anderen Deutschland« und der zivilisierten Welt«, in: Eike Geisel (Hg.), Die Wiedergutwerdung der Deutschen. Essays \& Polemiken, Berlin: Edition Tiamat, S. 21-31.

Geiselberger, Heinrich (Hg.) (2017): Die große Regression. Eine internationale Debatte über die geistige Situation der Zeit, Berlin: Suhrkamp.

Gesellschaft Historisches Berlin e.V. (2008): Bericht und Dokumentation über festgestellte und drohende Gefahren für die Welterbestätte Nr. 896 (Museumsinsel Berlin). Gesellschaft Historisches Berlin e.V., www.ghb-online.de/images/stor ies/bericht-dokumentation-roteliste.pdf, geprüft am 12.03.2019.

Gesellschaft Historisches Berlin e.V. (2009): Stellungnahme der GHB vom 11. August 2009. Gesellschaft Historisches Berlin e.V., www.ghb-online.de/museums insel/eingangsbereich/99-geplanter-neubau-stellungsnahme.html, geprüft am 12.03.2019.

Gesellschaft Historisches Berlin e.V. (2009): Vergleich Vorentwurf 2007 - Entwurf 2008. Gesellschaft Historisches Berlin e.V., www.ghb-online.de/museumsinse 1/eingangsbereich/115-vergleich-vor, geprüft am 12.03.2019.

Giddens, Anthony (1988): Die Konstitution der Gesellschaft. Grundzüge einer Theorie der Strukturierung, Frankfurt a.M., New York: Campus Verlag.

Giesen, Bernhard (1999): Kollektive Identität. Die Intellektuellen und die Nation 2, Frankfurt a.M.: Suhrkamp.

Giesen, Bernhard/Junge, Kay (1991): »Vom Patriotismus zum Nationalismus. Zur Evolution der »Deutschen Kulturnation", in: Bernhard Giesen (Hg.), Nationale und kulturelle Identität. Studien zur Entwicklung des kollektiven Bewusstseins in der Neuzeit, Frankfurt a.M.: Suhrkamp, S. 255-303.

Goethe, Johann W. v. (1920): Von Deutscher Baukunst, München: Münchner Lesebogen.

Goffman, Erving (1964): »The Neglected Situation«, in: American Anthropologist 66 (6), S. 133-136.

Gräfe, Roland (2012): »Die Entstehung und Entwicklung der Albertstadt (1873-1918). Ein geschichtlicher Abriß«, in: Dresdner Hefte. Beiträge zur Kulturgeschichte. Dresden als Garnisonstadt 53 (16), S. 22-30.

Grassi, Giorgio (1994): „Erster Preis«, in: Amber Sayah (Hg.), Museumsinsel Berlin. Wettbewerb zum Neuen Museum, Stuttgart, Berlin, Paris: avedition, S. 42-47. Große-Rhode, Barbara (2009):»Vom Wettbewerb über das Gutachterverfahren zum Masterplan Museumsinsel«, in: Oliver G. Hamm (Hg.), Das Neue Museum Ber- 
lin. Konservieren, Restaurieren, Weiterbauen im Welterbe, Leipzig: Seemann, S. 50-55.

Großmann, Mairanne (2009): Das Neue Museum. Die Perle preußischer Bildungslust, im Wiederaufbau demontiert. Gesellschaft Historisches Berlin e.V., www. ghb-online.de/museumsinsel/neues-museum.html, geprüft am 25.11.2019.

Güntner, Joachim (2011): »Dieses Haus der Gewalt hat nicht seinesgleichen«, in: Neue Zürcher Zeitung vom 15.10.2011.

Guratzsch, Dankwart (1994): "Schießscharten in Ziegelhülle«, in: Amber Sayah (Hg.), Museumsinsel Berlin. Wettbewerb zum Neuen Museum, Stuttgart, Berlin, Paris: avedition, S. 116-118.

Guratzsch, Dankwart (2018): »Ist Fachwerk faschistisch?«, in: Die Welt vom 23.04.2018, www.welt.de/kultur/plus175716225/Frankfurter-Altstadt-Was-hint er-der-Nazi-Verschwoerung-steckt.html, geprüft am 14.11.2019.

Habermas, Jürgen (1979): Strukturwandel der Öffentlichkeit. Untersuchungen zu einer Kategorie der bürgerlichen Gesellschaft, Darmstadt, Neuwied: Luchterhand.

Habermas, Jürgen (1985): »Die Entsorgung der Vergangenheit«, in: Die Zeit vom 17.05.1985, www.zeit.de/1985/21/die-entsorgung-der-vergangenheit, geprüft am 29.08.2019.

Habermas, Jürgen (1987): »Eine Art Schadensabwicklung. Die apologetischen Tendenzen in der deutschen Zeitgeschichtsschreibung«, in: Rudolf Augstein (Hg.), »Historikerstreit«. Die Dokumentation der Kontroverse um die Einzigartigkeit der nationalsozialistischen Judenvernichtung, München, Zürich: Piper, S. 6276.

Habermas, Jürgen (2011): Zur Verfassung Europas. Ein Essay, Berlin: Suhrkamp. Hahn, Alois (1994): »Die soziale Konstruktion des Fremden«, in: Walter M. Sprondel (Hg.), Die Objektivität der Ordnungen und ihre kommunikative Konstruktion. Für Thomas Luckmann, Frankfurt a.M.: Suhrkamp, S. 140-163.

Halbwachs, Maurice (1985): Das Gedächtnis und seine sozialen Bedingungen, Frankfurt a.M.: Suhrkamp.

Halbwachs, Maurice (2003): Stätten der Verkündigung im Heiligen Land. Eine Studie zum kollektiven Gedächtnis, Konstanz: UVK.

Hallet, Wolfgang/Neumann, Birgit (2009): »Raum und Bewegung in der Literatur. Zur Einführung«, in: Wolfgang Hallet/Birgit Neumann (Hg.), Raum und Bewegung in der Literatur. Die Literaturwissenschaften und der Spatial Turn, Bielefeld: transcript, S. 11-32.

Hamm, Oliver G. (Hg.) (2009): Das Neue Museum Berlin. Konservieren, Restaurieren, Weiterbauen im Welterbe, Leipzig: Seemann.

Harrap, Julian (2009a): »Das Neue Museum. Denkmalpflegerisches Restaurierungskonzept «, in: Oliver G. Hamm (Hg.), Das Neue Museum Berlin. Konservieren, Restaurieren, Weiterbauen im Welterbe, Leipzig: Seemann, S. 60-64. 
Harrap, Julian (2009b): »Die Runie einfrieren«, in: Rik Nys/Martin Reichert (Hg.), Neues Museum Berlin, Köln: König, S. 121-132.

Harvey, David (2003): The Condition of Postmodernity. An Enquiry into the Origins of Cultural Change, Cambridge, Mass: Blackwell.

Haspel, Jörg (1994): »Zur Zukunft des Neuen Museum. Erhaltung und Wiederaufbau als denkmalpflegerische Notwendigkeit «, in: Peter Bloch/Christoph Hölz (Hg.), Berlins Museen. Geschichte und Zukunft, München, Berlin: Deutscher Kunstverlag, S. 139-144.

Haspel, Jörg (2000): »Die Denkmale der Museumsinsel. Konservatorische Aspekte der Gesamtplanung und Einzelprojekte«, in: Andres Lepik (Hg.), Masterplan Museumsinsel Berlin. Ein europäisches Projekt, Berlin: G+H Verlag, S. 38-48.

Haspel, Jörg (2007): »Heile die Wunde - Zeige die Wunde. Rebuilding Neues Museum«, in: Jahrbuch Preußischer Kulturbesitz 2006, S. 189-210.

Haspel, Jörg (2009): »Vom Bau zum Wiederaufbau. Zur Vorgeschichte des Neuen Museum «, in: Oliver G. Hamm (Hg.), Das Neue Museum Berlin. Konservieren, Restaurieren, Weiterbauen im Welterbe, Leipzig: Seemann, S. 14-21.

Haspel, Jörg (Hg.) (2010): Welterbe weiterbauen - St. Petersburg und BerlinPotsdam. Veranstaltungen der Arbeitsgruppe Kultur des Petersburger Dialogs, der Staatlichen Eremitage St. Petersburg und der Staatlichen Museen zu Berlin - Stiftung Preußischer Kulturbesitz (= Hefte des Deutschen Nationalkomitees/ICOMOS, Band 49), Berlin: Bäßler.

Heilmeyer, Florian (2011): »Die Geste bleibt Gag. Militärmuseum in Dresden von Libeskind eröffnet «, in: BauNetz vom 13.10.2011.

Hein-Kircher, Heidi (2013): »Deutsche Mythen und ihre Wirkung«, in: Aus Politik und Zeitgeschichte 63 (13-14), S. 33-38.

Henze, Wulfgang/Sommer, Heiner (2007): Neues Museum - ein Denkmal im Ensemble der Museumsinsel Berlin auf der UNESCO-Welterbeliste. Fakten zur Sammlungs- und Ausstellungsgeschichte des Neuen Museums. Pressemappe vom 21.09.2007, Berlin, https://www.smb.museum/presse/pressemitteilungen /detail/richtfest-neues-museum-auf-der-museumsinsel-berlin/?tx_smb_pi1\% 5BpressReleaseYear\%5D=2007\&cHash=068ac09c38829eab3fba5853f 9 b9268d, geprüft am 28.07.2020.

Heuser, Franz-Josef (Hg.) (2006): Militärhistorisches Museum der Bundeswehr in Dresden. Dresden und das Militär (= Sammeln Bewahren Erforschen Ausstellen, Band 10), Dresden: Sächsisches Druck- und Verlagshaus AG.

Hitzler, Ronald/Reichertz, Jo/Schröer, Norbert (1999): „Das Arbeitsfeld einer hermeneutischen Wissenssoziologie«, in: Ronald Hitzler/Jo Reichertz/Norbert Schröer (Hg.), Hermeneutische Wissenssoziologie. Standpunkte zur Theorie der Interpretation, Konstanz: UVK, S. 9-16. 
Hoya Gerhard (2008): Das sogenannte Eingangsgebäude. Gesellschaft Historisches Berlin e.V., www.ghb-online.de/museumsinsel/eingangsbereich/40-eingangsb ereich.html, geprüft am 28.07.2020.

Hoya Gerhard (2009): Die Berliner Museumsinsel seit 1990. Gesellschaft Historisches Berlin e.V., Berlin, www.ghb-online.de/museumsinsel/59-museumsinsel .html, geprüft am 28.07.2020.

Hoya Gerhard (2015): Das Empfangsgebäude für die Museumsinsel in Berlin wird mit ca. 150 Millionen Euro doppelt so teuer als geplant. Gesellschaft Historisches Berlin e.V., www.ghb-online.de/museumsinsel/eingangsbereich/438-das -empfang, geprüft am 28.07.2020.

Jacob, Rainer (2007): Zur Zukunft der Museumsinsel, insbesondere des Pergamonmuseums, www.ahme.de/volksbegehren203.pdf, geprüft am 25.11.2019.

Jaeger, Falk (2011): »Keil der Wahrheit. In Dresden eröffnet das von Daniel Libeskind neu gestaltete Militärhistorische Museum«, in: Tagesspiegel vom 12.10.2011.

Jaeger, Falk (2011): »Kulturgeschichte der Kriegsgewalt. Das neu gestaltete Militärhistorische Museum Dresden«, in: Badische Zeitung vom 14.10.2011.

Jaeggi, Rahel/Wesche, Tilo (2016): »Einführung. Was ist Kritik?«, in: Rahel Jaeggi/Tilo Wesche (Hg.), Was ist Kritik?, Frankfurt a.M.: Suhrkamp, S. 7-20.

Jakubeit, Barbara (1994): »Vorwort der Präsidentit der Bundesbaudirektion«, in: Amber Sayah (Hg.), Museumsinsel Berlin. Wettbewerb zum Neuen Museum, Stuttgart, Berlin, Paris: avedition, S. 4-5.

Jeismann, Michael (Hg.) (1999): Mahnmal Mitte. Eine Kontroverse, Köln: DuMont. Jones, Paul (2006): »The Sociology of Architecture and the Politics of Building. The Discursive Construction of Ground Zero«, in: Sociology 40 (3), S. 549-565.

Jones, Paul (2009): »Putting Architecture in its Social Place. A Cultural Political Economy of Architecture«, in: Urban Studies 46 (12), S. 2519-2536.

Kant, Immanuel (2008): Zum ewigen Frieden. Ein philosophischer Entwurf, Stuttgart: Reclam.

Keates, Johnatan (2009): »Die Kunst des Fortbestehens«, in: Rik Nys/Martin Reichert (Hg.), Neues Museum Berlin, Köln: König, S. 49-59.

Kelle, Udo/Kluge, Susann (2010): Vom Einzelfall zum Typus. Fallvergleich und Fallkontrastierung in der qualitativen Sozialforschung, Wiesbaden: VS Verlag für Sozialwissenschaften.

Keller, Reiner (2001): »Wissenssoziologische Diskursanalyse als interpretative Analytik«, in: Reiner Keller/Andreas Hirseland/Werner Schneider et al. (Hg.), Die diskursive Konstruktion von Wirklichkeit. Zum Verständnis von Wissenssoziologie und Diskursforschung, Opladen: Leske und Budrich, S. 49-75.

Keller, Reiner (2007): »Diskurse und Dispositive analysieren. Die Wissenssoziologische Diskursanalyse als Beitrag zu einer wissensanalytischen Profilierung der Diskursforschung «, in: Forum: Qualitative Sozialforschung Social Research 8 (2), S. 1-32. 
Keller, Reiner (2011): Wissenssoziologische Diskursanalyse. Grundlegung eines Forschungsprogramms, Wiesbaden: VS Verlag für Sozialwissenschaften.

Keller, Reiner (2012): "Zur Praxis der Wissenssoziologischen Diskursanalyse«, in: Reiner Keller/Inga Truschkat (Hg.), Methodologie und Praxis der wissenssoziologischen Diskursanalyse. Band 1: Interdisziplinäre Perspektiven, Wiesbaden: VS Verlag für Sozialwissenschaften, S. 27-68.

Keller, Reiner (2016): „Die komplexe Diskursivität der Visualisierungen«, in: Saša Bosančić/Reiner Keller (Hg.), Perspektiven wissenssoziologischer Diskursforschung, Wiesbaden: VS Verlag für Sozialwissenschaften, S. 75-93.

Keller, Reiner (Hg.) (2005): Die diskursive Konstruktion von Wirklichkeit. Zum Verhältnis von Wissenssoziologie und Diskursforschung (= Erfahrung - Wissen Imagination, Bd. 10), Konstanz: UVK.

Keller, Reiner/Hirseland, Andreas/Schneider, Werner/Viehöver, Willy (2001): »Die diskursive Konstruktion von Wirklichkeit. Einleitende Bemerkung zum Verhältnis von Wissenssoziologie und Diskursforschung«, in: Reiner Keller/Andreas Hirseland/Werner Schneider et al. (Hg.), Die diskursive Konstruktion von Wirklichkeit. Zum Verständnis von Wissenssoziologie und Diskursforschung, Opladen: Leske und Budrich, S. 7-21.

Kibel, Jochen (2019): »Historische Mission und gebaute Zukunft. Raum-, Zeit- und Wissensbegriffe in der Stadtraumgestaltung der DDR«, in: Tino Mager/Bianka Trötschel-Daniels (Hg.), Rationelle Visionen. Raumproduktion in der DDR, Kromsdorf: Bauhaus-Universitätsverlag Weimar, S. 65-78.

Klahr, Douglas (2006): Verstöße gegen UNESCO Rechtlinien in Bezug auf das Weltkulturerbe Nr. 896, die Berliner Museumsinsel. Juni 2006 (= Schinkelkonferenz), Berlin Humboldt Universität.

Knigge, Volkhard (2009): »Buchenwald«, in: Martin Sabrow (Hg.), Erinnerungsorte der DDR, München: C.H. Beck, S. 118-127.

Knoblauch, Hubert (1999): »Das kommunikative Gedächtnis«, in: Claudia Honegger/Stefan Hradil/Franz Traxler (Hg.), Grenzenlose Gesellschaft? Verhandlungen des 29. Kongresses der Deutschen Gesellschaft für Soziologie, des 16. Kongresses der Österreichischen Gesellschaft für Soziologie, des 11. Kongresses der Schweizerischen Gesellschaft für Soziologie in Freiburg 1998, Wiesbaden: VS Verlag für Sozialwissenschaften, S. 733-748.

Knoblauch, Hubert (2000): »Topik und Soziologie«, in: Thomas Schirren/Gert Ueding (Hg.), Topik und Rhetorik. Ein interdisziplinäres Symposium, Berlin, Boston: De Gruyter, S. 651-668.

Knoblauch, Hubert (2001): »Diskurs, Kommunikation und Wissenssoziologie«, in: Reiner Keller/Andreas Hirseland/Werner Schneider et al. (Hg.), Die diskursive Konstruktion von Wirklichkeit. Zum Verständnis von Wissenssoziologie und Diskursforschung, Opladen: Leske und Budrich, S. 207-223. 
Knoblauch, Hubert (2016): »Diskurstheorie als Sozialtheorie? Das Verhältnis des diskursiven zum kommunikativen Konstruktivismus«, in: Saša Bosančić/Reiner Keller (Hg.), Perspektiven wissenssoziologischer Diskursforschung, Wiesbaden: VS Verlag für Sozialwissenschaften, S. 11-27.

Knoblauch, Hubert/Löw, Martina (2017): »On the Spatial Re-Figuration of the Social World«, in: Sociologica 11 (2), S. 1-27.

Knoblauch, Hubert/Löw, Martina (2020): »The Re-Figuration of Spaces and Refigured Modernity. Concept and Diagnosis«, in: Historical Social Research 45 (2), S. 263-292.

Koch, Daniel (2018): «Wir suchen keine Götter in Weiß. Wir suchen Helden in Grün«. Das Heldenkonzept der Bundeswehr«, in: helden.heroes.héros. 5 (1), S. 57-59.

Konzeptgruppe/Expertenkommission (2003): »Das Militärhistorische Museum Dresden 2006. (Konzeption)«, in: Thomas E. Scheerer (Hg.), Militärhistorisches Museum der Bundeswehr in Dresden. Arsenal und Museum. Vergangenheit Gegenwart Zukunft, Dresden: Sächsisches Druck- und Verlagshaus AG, S. 2847.

Korff, Gottfried/Roth, Martin (Hg.) (1990): Das historische Museum. Labor, Schaubühne, Identitätsfabrik, Frankfurt a.M., New York: Campus Verlag.

Koschorke, Albrecht (2012): »Zur Funktionsweise kultureller Peripherien«, in: Susi K. Frank (Hg.), Explosion und Peripherie. Jurij Lotmans Semiotik der kulturellen Dynamik revisited, Bielefeld: transcript, S. 27-39.

Koselleck, Reinhart (1993): »Stellen uns die Toten einen Termin?«, in: Eberhard Roters (Hg.), Streit um die neue Wache. Zur Gestaltung einer zentralen Gedenkstätte, Berlin: Akademie der Künste, S. 27-34.

Koselleck, Reinhart (2004): »Gibt es ein kollektives Gedächtnis?«, in: Divinatio 19 (19), S. 23-28.

Koselleck, Reinhart (Hg.) (1989): Vergangene Zukunft. Zur Semantik geschichtlicher Zeiten, Frankfurt a.M.: Suhrkamp.

Koselleck, Reinhart/Gadamer, Hans-Georg (Hg.) (2000): Zeitschichten. Studien zur Historik, Frankfurt a.M.: Suhrkamp.

Krastev, Ivan/Holmes, Stephen (2019): Das Licht, das erlosch. Eine Abrechnung, Berlin: Ullstein Verlag.

Kraus, Herbert (2011): "Die Organisation der Neukonzeption des Militärhistorischen Museums der Bundeswehr«, in: Gorch Pieken/Matthias Rogg (Hg.), Militärhistorisches Museum der Bundeswehr. Ausstellung und Architektur, Dresden: Sandstein Verlag, S. 40-47.

Kühn, Günter/Weber, Wolfgang (1984): Stärker als die Wölfe. Ein Bericht über die illegale militärische Organisation im ehemaligen Konzentrationslager Buchenwald und den bewaffneten Aufstand, Berlin: Militärverlag der Deutschen Demokratischen Republik. 
Kuhn, Nicola (2009): »Die Ausstellung. Einblicke in drei Sammlungen«, in: Carola Wedel (Hg.), Das Neue Museum. Eine Ruine wird zum Juwel, Berlin: Jaron, S. 83-125.

Kuhnert, Nikolaus/Ngo, Anh-Linh (2011): »Die Krise der Repräsentation. Editorial«, in: Arch+Zeitschrift für Architektur und Urbanismus (204), S. 6-7.

Kunz, Manfred (2003): »Ein Stück von Sachsens Glanz. Das Arsenal in der Dresdner Albertstadt «, in: Thomas E. Scheerer (Hg.), Militärhistorisches Museum der Bundeswehr in Dresden. Arsenal und Museum. Vergangenheit Gegenwart Zukunft, Dresden: Sächsisches Druck- und Verlagshaus AG, S. 5-16.

Läpple, Dieter (1992): »Essay über den Raum. Für ein gesellschaftswissenschaftliches Raumkonzept«, in: Hartmut Häußermann/Walter Siebel (Hg.), Stadt und Raum. Soziologische Analysen, Pfaffenweiler: Centaurus-Verlag, S. 157-207.

Lefebvre, Henri (2006): "Die Produktion des Raumes«, in: Jörg Dünne/Stephan Günzel (Hg.), Raumtheorie. Grundlagentexte aus Philosophie und Kulturwissenschaften, Frankfurt a.M.: Suhrkamp, S. 330-342.

Legner-Zuriel, Sharona (2004): »Kampagne gegen Libeskind-Baute. Rechte starten fragwürdige Kampagne für Kommunalwahl«, in: Zentralrat der Juden in Deutschland vom 19.03.2004.

Lehmann, Klaus-Dieter (2000): »Grußwort«, in: Andres Lepik (Hg.), Masterplan Museumsinsel Berlin. Ein europäisches Projekt, Berlin: G+H Verlag, S. 7-8.

Lehmann, Klaus-Dieter (Hg.) (2004): Jahrbuch Preussischer Kulturbesitz (= Jahrbuch Preussischer Kulturbesitz, Bd. 40), Berlin: Gebrüder Mann Verlag.

Leonhard, Nina (2014): "Gedächtnis, Wissen und soziale Integration«, in: Oliver Dimbath/Michael Heinlein (Hg.), Die Sozialität des Erinnerns. Beiträge zur Arbeit an einer Theorie des sozialen Gedächtnisses, Wiesbaden: Springer VS, S. 199-216.

Leonhard, Nina (2016): »Die postheroische Gesellschaft und ihr Militär«, in: Matthias Junge (Hg.), Metaphern soziologischer Zeitdiagnosen, Wiesbaden: Springer VS, S. 101-121.

Leonhardt, Rainer W. (2009): »Historische Mauerziegel für den Wiederaufbau des Neuen Museums Berlin«, in: Rainer Leonhardt (Hg.), Restaurator im Handwerk. Neues Museum - Themenschwerpunkt, Lemgo-Lieme, S. 26-31.

Lepik, Andres (Hg.) (2000): Masterplan Museumsinsel Berlin. Ein europäisches Projekt, Berlin: $\mathrm{G}+\mathrm{H}$ Verlag.

Lévi-Strauss, Claude (1981): Das wilde Denken, Frankfurt a.M.: Suhrkamp. Lévi-Strauss, Claude (1989): Traurige Tropen, Frankfurt a.M.: Suhrkamp.

Leyen, Ursula von der (2018): Rede der Bundesministerin der Verteidigung am 28. März 2018. Anlässlich der Umbenennung der »Emmich-Cambrai-Kaserne« in "Hauptfeldwebel-Lagenstein-Kaserne«, Hannover, https://www.bmvg.de/ resource/blob/23252/938d7cadf2565c4803b12did92c846b9/20180328-rede-derverteidigungsminsiterin-in-hannover-data.pdf, geprüft am 28.07.2020. 
Libeskind, Daniel (2003): »Die Architektur des Arsenal-Hauptgebäudes. (Konzeption)«, in: Thomas E. Scheerer (Hg.), Militärhistorisches Museum der Bundeswehr in Dresden. Arsenal und Museum. Vergangenheit Gegenwart Zukunft, Dresden: Sächsisches Druck- und Verlagshaus AG, S. 48-51.

Libeskind, Daniel (2010): »Dresden's Past Is Not Just a Footnote. Interview with Architect Daniel Libeskind«, in: Spiegel online vom 13.02.2010, https://www. spiegel.de/international/germany/interview-with-architect-daniel-libeskinddresden-s-past-is-not-just-a-footnote-a-677601.html, geprüft am 20.11.2019.

Libeskind, Daniel (2011): Military History Museum. Dresden, Germany. Studio Libeskind, https://libeskind.com/work/military-history-museum/, geprüft am 30.08.2019.

Libeskind, Daniel (2013): »Architect and Architecture. Daniel Libeskind in conversation with Gorch Pieken «, in: Gorch Pieken (Hg.), 40,1 ${ }^{\circ}$. Architecture, Dresden: Sandstein Verlag, S. 14-24.

Lindblom, Charles E. (1959): »The Science of »Muddling Through«, in: Public Administration Review 19 (2), S. 79-88.

Lisewski, Eugen A. (1997): Von der Arsenalsammlung zum Königlich Sächsischen Armeemuseum 1897 bis 1918. Die Anfangsjahre des Sächsischen Armeemuseums, Dresden: Verlag Sachsen.

Lisewski, Eugen A. (2012): »Vom Zeughaus zum Königlichen Sächsischen Armeemuseum«, in: Dresdner Hefte. Beiträge zur Kulturgeschichte. Dresden als Garnisonstadt 53 (16), S. 31-38.

Löffler, Fritz (1981): Das alte Dresden. Geschichte seiner Bauten, Leipzig: Seemann. Loh, Dietrich von (2012): "Die Albertsadt heute«, in: Dresdner Hefte. Beiträge zur Kulturgeschichte. Dresden als Garnisonstadt 53 (16), S. 93-100.

Lorenz, Ulrike/Ullrich, Wolfgang (2018): Was muss das Museum? Was kann das Museum? Ein Streitgespräch zwischen Ulrike Lorenz und Wolfgang Ullrich, Köln: König Walther.

Lorenz, Werner (1994): „Stülers Neues Museum. Inkunabel preußischer Konstruktionskunst im Zeichen der Industrialisierung«, in: Peter Bloch/Christoph Hölz (Hg.), Berlins Museen. Geschichte und Zukunft, München, Berlin: Deutscher Kunstverlag, S. 99-112.

Lorenz, Werner (2009): »Kernform und Kunstform. Preußische Konstruktionskunst im Zeichen der Industrialisierung«, in: Oliver G. Hamm (Hg.), Das Neue Museum Berlin. Konservieren, Restaurieren, Weiterbauen im Welterbe, Leipzig: Seemann, S. 38-43.

Lorenz, Werner (2014): Das Neue Museum Berlin (= Historische Wahrzeichen der Ingenieurbaukunst in Deutschland, Band 15), Berlin: Bundesingenieurkammer.

Lotman, Jurij M. (1972): Die Struktur literarischer Texte, München: Fink. 
Lotman, Jurij M. (1990): »Über die Semiosphäre«, in: Zeitschrift für Semiotik 12 (4), S. 287-305.

Lotman, Jurij M. (2010): Die Innenwelt des Denkens. Eine semiotische Theorie der Kultur, Berlin: Suhrkamp.

Löw, Martina (2008): »The Constitution of Space. The Structuration of Spaces Through the Simultaneity of Effect and Perception«, in: European Journal of Social Theory 11 (1), S. 25-49.

Löw, Martina (2012): Raumsoziologie, Frankfurt a.M.: Suhrkamp.

Löw, Martina (2013): »Vielfalt und Repräsentation. Über den Bedeutungsverlust der symbolischen Mitte«, in: Soziologie 42 (1), S. 29-41.

Löw, Martina (2018): Vom Raum aus die Stadt denken. Grundlagen einer raumtheoretischen Stadtsoziologie (= Materialitäten, Band 24), Bielefeld: transcript.

Löw, Martina/Weidenhaus, Gunter (2017): "Borders that relate. Conceptualizing boundaries in relational space«, in: Current Sociology 65 (4), S. 553-570.

Lübbe, Hermann (2003): Im Zug der Zeit. Verkürzter Aufenthalt in der Gegenwart, Berlin, Heidelberg: Springer VS.

Lübbe, Hermann (2005): »Der Fortschritt von gestern. Über Musealisierung als Modernisierung«, in: Jörn Rüsen/Heinrich T. Grütter/Ulrich Borsdorf (Hg.), Die Aneignung der Vergangenheit. Musealisierung und Geschichte, Bielefeld: transcript, S. 13-38.

Ludwig, Kristian (1998): Das Neue Museum. Vom Juwel der Museumsinsel zum Kuckucksei der Denkmalpfleger und Museologen. Eingaben an den Architekten David Chipperfield, www.web.archive.org/web/20101128120824/www.stadtbil d-berlin.de/Stadtbild/neues_museum.pdf, geprüft am 13.03.2019.

Ludwig, Kristian (2006): Das Neue Museum. Vom Juwel der Museumsinsel zum Kuckucksei der Denkmalpflege und Museologen. Bebilderte Version der Eingabe von 1998, www.web.archive.org/web/20101117161743/www.stadtbild-berli n.de/Stadtbild/neues_museum.htm, geprüft am 13.03.2019.

Maaz, Bernhard (2001): „Bau und Umbau der Alten Nationalgalerie. Voraussetzungen und Ergebnisse, Ziel und Wege«, in: Bernhard Maaz (Hg.), Die Alte Nationalgalerie. Geschichte, Bau und Umbau, Berlin: G+H Verlag, S. 47-223.

MacGregor (2009): »Ort des Wissens und der Schönheit «, in: Welt am Sonntag vom 18.10.2009, S. 72-73.

Mager, Tino (2016): Schillernde Unschärfe, Berlin, Boston: De Gruyter.

Mann, Tobias (2009): »Rohbau Bestand/Kolonnaden/Neubau«, in: Oliver G. Hamm (Hg.), Das Neue Museum Berlin. Konservieren, Restaurieren, Weiterbauen im Welterbe, Leipzig: Seemann, S. 138-141.

Marchart, Oliver (2013): Das unmögliche Objekt. Eine postfundamentalistische Theorie der Gesellschaft, Berlin: Suhrkamp.

Markschies, Christoph J./Wolf, Hubert/Schüler, Barbara (Hg.) (2010): Erinnerungsorte des Christentums, München: C.H. Beck. 
Marquard, Odo (2007): »Skepsis in der Moderne. Überlegungen im Blick auf Heinrich Heine«, in: Odo Marquard (Hg.), Skepsis in der Moderne. Philosophische Studien, Stuttgart: Reclam, S. 40-54.

Marquard, Odo (2013): »Über die Unvermeidlichkeit der Geisteswissenschaften«, in: Odo Marquard (Hg.), Apologie des Zufälligen. Philosophische Studien, Stuttgart: Reclam, S. 98-116.

Marquart, Christian (1994): „Er will Schinkel nicht zu nahe treten«, in: Amber Sayah (Hg.), Museumsinsel Berlin. Wettbewerb zum Neuen Museum, Stuttgart, Berlin, Paris: avedition, S. 121-122.

Marx, Karl/Engels, Friedrich (1973): »Manifest der Kommunistischen Partei«, in: Karl Marx/Friedrich Engels (Hg.), MEW. Band 18, Berlin/DDR: Karl Dietzt Verlag, S. 459-493.

Mausbach, Florian (2000): »Grußwort«, in: Andres Lepik (Hg.), Masterplan Museumsinsel Berlin. Ein europäisches Projekt, Berlin: G+H Verlag, S. 9-10.

Mead, George H. (1912): »The Mechanism of Social Consciousness«, in: Journal of Philosophy, Psychology and Scientific Methods 9, S. 401-406.

Mead, George H. (1927): »The Objective Reality of Perspectives«, in: Edgar S. Brightman (Hg.), Proceedings of the Sixth International Congress of Philosophy, New York: Longmans, Green and Co, S. 75-85.

Menke-Schwinghammer, Annemarie (1994): Weltgeschichte als »Nationalepos«. Wilhelm von Kaulbachs kulturhistorischer Zyklus im Treppenhaus des Neuen Museums in Berlin, Berlin: Deutscher Verlag für Kunstwissenschaft.

Merz, H. G./Holzer, Barbara (2003): »Die Ausstellung im Arsenal-Hauptgebäude. (Konzeption)«, in: Thomas E. Scheerer (Hg.), Militärhistorisches Museum der Bundeswehr in Dresden. Arsenal und Museum. Vergangenheit Gegenwart Zukunft, Dresden: Sächsisches Druck- und Verlagshaus AG, S. 52-60.

Merz, H. G./Holzer, Barbara (2011): "Man kann nicht gegen die Architektur von Libeskind arbeiten«, in: Bauwelt 43, S. 34-37.

Meuser, Pilipp (2002): »Die ungebaute Museumsinsel. Eine Architekturgeschichte anhand von Skizzen, Zeichnungen und Modellen«, in: Carola Wedel (Hg.), Die neue Museumsinsel. Der Mythos, der Plan, die Vision, Berlin: Nicolai, S. 178189.

Meyer, Andrea/Savoy, Bénédicte (Hg.) (2014): The Museum Is Open. Towards a Transnational History of Museums 1750-1940, Berlin: De Gruyter.

Meyer, Johannes (2012): "Keine Sympathie für das Militär. Das neugestaltete Bundeswehr-Museum weicht bei seiner Suche nach der Spur der Gewalt in der Geschichte zentralen Fragen aus«, in: Junge Freiheit vom 06.01.2012.

Mickan, Thomas (2011): »Wenn der Kontext das Problem ist. Das Militärhistorische Museum der Bundeswehr in Dresden «, in: Informationsstelle Militarisierung (IMI) e.V. vom Januar 2011, S. 3-4. 
Mittig, Hans-Ernst (2005): Gegen das Holocaustdenkmal der Berliner Republik, Berlin: Kramer.

Mörsch, Georg (2004): »Rekonstruktion zerstört «, in: Georg Mörsch (Hg.), Denkmalverständnis. Vorträge und Aufsätze 1990 - 2002, Zürich: Hochschulverlag der ETH, S. 63-74.

Mouffe, Chantal (2017): Über das Politische. Wider die kosmopolitische Illusion, Frankfurt a.M.: Suhrkamp.

Müller, Ann-Katrin (2019): »Die Akte Kalbitz. Der Machthaber der AfD und sein braunes Netzwerk«, in: Spiegel online vom 23.08.2019, https://www. spiegel.de/plus/andreas-kalbitz-der-machthaber-der-afd-und-sein-braunesnetzwerk-a-00000000-0002-0001-0000-000165579689, geprüft am 19.11.2019. Müller, Burkhard (2011): »Militärhistorisches Museum der Bundeswehr. Reliquien der Gewalt«, in: Süddeutsche Zeitung vom 17.11.2011, www.sueddeutsche.de/ kultur/militaerhistorisches-museum-der-bundeswehr-von-zinnsoldaten-undanderen-reliquien-der-gewalt-1.1165470, geprüft am 05.11.2019.

Müller, Klaus E. (1983): »Grundzüge des menschlichen Gruppenverhaltens«, in: Rudolf Schenkel/Christian Vogel/Hansjürgen Müller-Beck et al. (Hg.), Biologie von Sozialstrukturen bei Tier und Mensch. Vorträge, gehalten auf der Tagung der Joachim-Jungius-Gesellschaft der Wissenschaften, Hamburg am 14. und 15. November 1981, Göttingen: Vandenhoeck \& Ruprecht, S. 93-112.

Müller, Klaus E. (2005): »Der Ursprung der Geschichte«, in: Jan Assmann/Klaus E. Müller (Hg.), Der Ursprung der Geschichte. Archaische Kulturen, das Alte Ägypten und das Frühe Griechenland, Stuttgart: Klett-Cotta, S. 17-86.

Müller, Michael (2012): Arsenalhauptgebäude. Kulturdenkmale im Freistaat Sachsen: Denkmaldokument. Landesamt für Denkmalpflege Sachsen. Dresden.

Münkler, Herfried (2007): »Heroische und postheroische Gesellschaften«, in: Merkur 61 (700), S. 742-752.

Ngo, Anh-Linh (2019): »Die Geschichte gegen den Strich bürsten«, in: Arch+Zeitschrift für Architektur und Urbanismus (235), S. 1-3.

Niesewand, Nonie (1997): »Architecture: The RAF took out a Berlin museum. They've asked a Brit to put it back «, in: The Independent vom 13.11.1997.

Nietzsche, Friedrich (2009): Vom Nutzen und Nachtheil der Historie für das Leben, Stuttgart: Reclam.

Nietzsche, Friedrich (2015): Die Geburt der Tragödie. Oder Griechenthum und Pessimismus, Stuttgart: Reclam.

Nolte, Ernst (1987): „Vergangenheit, die nicht vergehen will. Eine Rede, die geschrieben, aber nicht gehlaten werden konnte«, in: Rudolf Augstein (Hg.), »Historikerstreit«. Die Dokumentation der Kontroverse um die Einzigartigkeit der nationalsozialistischen Judenvernichtung, München, Zürich: Piper, S. 39-47.

Nolte, Ernst (1987): »Zwischen Geschichtslegende und Revisionismus? Das Dritte Reich im Blickwinkel des Jahres 1980«, in: Rudolf Augstein (Hg.), »Historiker- 
streit«. Die Dokumentation der Kontroverse um die Einzigartigkeit der nationalsozialistischen Judenvernichtung, München, Zürich: Piper, S. 13-35.

Nora, Pierre (1989): »Between Memory and History. Les Lieux de Mémoire«, in: Representations 26, S. 7-24.

Nora, Pierre (1996): Realms of memory. Rethinking the French past, New York: Columbia University Press.

Nora, Pierre (2005):»Wie lässt sich heute eine Geschichte Frankreichs schreiben?«, in: Pierre Nora (Hg.), Erinnerungsorte Frankreichs, München: C.H. Beck, S. 1523.

Nora, Pierre (Hg.) (2005): Erinnerungsorte Frankreichs, München: C.H. Beck.

Nys, Rik (2009): »Der Verrat durch Fälschung«, in: Rik Nys/Martin Reichert (Hg.), Neues Museum Berlin, Köln: König, S. 145-156.

Nys, Rik/Reichert, Martin (Hg.) (2009): Neues Museum Berlin, Köln: König.

O'Doherty, Brian (1990): Inside the white cube. The ideology of the gallery space, Santa Monica: The Lapis Press.

Oevermann, Ulrich (2001): »Zur Analyse der Struktur von sozialen Deutungsmustern «, in: sozialersinn 2 (1), S. 3-33.

Osrecki, Fran (2011): Die Diagnosegesellschaft. Zeitdiagnostik zwischen Soziologie und medialer Popularität, Bielefeld: transcript.

Osterhammel, Jürgen (Hg.) (2001): Geschichtswissenschaft jenseits des Nationalstaats. Studien zu Beziehungsgeschichte und Zivilisationsvergleich (= Kritische Studien zur Geschichtswissenschaft, Band 147), Göttingen: Vandenhoeck \& Ruprecht.

Ottmann, Henning (2010): »Der Geist der Geisteswissenschaften«, in: SYNTHESIS PHILOSOPHICA 49 (1), S. 101-107.

Parzinger, Hermann (2019): »James-Simon-Galerie führt Berliner Museumsinsel ins 21. Jahrhundert. Gastbeitrag", in: Berliner Zeitung vom 10.07.2019.

Pieken, Gorch (2010a): «Militärgeschichte ausstellen« am Beispiel der Neukonzeption des Militärhistorischen Museums der Bundeswehr in Dresden", in: Arbeitskreis Militärgeschichte e.V. 15 (2), S. 23-27.

Pieken, Gorch (2010b): »Militärgeschichte ausstellen. Die Neukonzeption des Militärhistorischen Museums der Bundeswehr in Dresden«, in: Museumsblätter Mitteilungen des Museumsverbandes Brandenburg 16 (Juli), S. 6-9.

Pieken, Gorch (2011): »Inhalt und Raum. Neukonzeption und Neubau des Militärhistorischen Museums der Bundeswehr«, in: Gorch Pieken/Matthias Rogg (Hg.), Militärhistorisches Museum der Bundeswehr. Ausstellung und Architektur, Dresden: Sandstein Verlag, S. 16-40.

Pieken, Gorch (2012a): »Contents and Space: New Concept and New Building of the Militärhistorisches Museum of the Bundeswehr«, in: Wolfgang Muchitsch (Hg.), Does War Belong in Museums?, Bielefeld: transcript, S. 163-173. 
Pieken, Gorch (2012b): »Dresden als Garnisonstadt nach 1945«, in: Dresdner Hefte. Beiträge zur Kulturgeschichte. Dresden als Garnisonstadt 53 (16), S. 81-92.

Pieken, Gorch (Hg.) (2013): 40,1 ${ }^{\circ}$. Architecture, Dresden: Sandstein Verlag.

Pieken, Gorch/Rogg, Matthias (Hg.) (2011a): Das Militärhistorische Museum der Bundeswehr. Ausstellungsführer, Dresden: Sandstein Verlag.

Pieken, Gorch/Rogg, Matthias (Hg.) (2011b): Militärhistorisches Museum der Bundeswehr. Ausstellung und Architektur (= Militärhistorisches Museum der Bundeswehr in Dresden, Band 12), Dresden: Sandstein Verlag.

Pieken, Gorch/Rogg, Matthias/Schröder, Thomas (Hg.) (2015): 60 years of Bundeswehr. Exhibition Guide, Dresden: Sandstein Verlag.

Pieper, Katrin (2010): »Resonanzräume. Das Museum im Forschungsfeld Erinnerungskultur«, in: Joachim Baur (Hg.), Museumsanalyse. Methoden und Konturen eines neuen Forschungsfeldes, Bielefeld: transcript, S. 187-212.

Planungsgruppe Museumsinsel Berlin (Hg.) (2000): Wege zum Masterplan. Museumsinsel Berlin 1998 - 2000, Berlin: G+H Verlag.

Platon (2009): Timaios. Griechisch/deutsch (= Reclams Universal-Bibliothek), Stuttgart: Reclam.

Plessner, Helmuth (1985): »Über die Beziehung der Zeit zum Tode«, in: Günter Dux (Hg.), Helmuth Plessner. Gesammelte Schriften. Schriften zur Philosophie, S. 224-262.

Popper, Karl R. (1965): Das Elend des Historizismus, Tübingen, Stuttgart: Ernst Klett.

Pries, Ludger (2008): Die Transnationalisierung der sozialen Welt. Sozialräume jenseits von Nationalgesellschaften, Frankfurt a.M.: Suhrkamp.

Prüfert, Andreas D. (2005): „Editorial«, in: Sicherheit und Frieden - Security and Peace 23 (4), S. 2.

Quent, Matthias (2019): Deutschland rechts außen. Wie die Rechten nach der Macht greifen und wie wir sie stoppen können, München: Piper.

Rădoi, Elena (2017): »The gap is in the eye of the beholder. Treatment of lacunae in Neues Museum Berlin«, in: Caiete ARA 8, S. 85-90.

Rauch, Friederike v./Chipperfield, David/Lepik, Andres et al. (Hg.) (2009): Neues Museum, Ostfildern: Hatje Cantz.

Rauchensteiner, Manfried (2011): „Von Beiräten, Hofräten und anderen Menschen«, in: Gorch Pieken/Matthias Rogg (Hg.), Militärhistorisches Museum der Bundeswehr. Ausstellung und Architektur, Dresden: Sandstein Verlag, S. 10-15. Rautenberg, Hanno (2007): »Ich bin kein Barbar«, in: Die Zeit vom 22.03.2007.

Rautenberg, Hanno (2018): »Bipolare Störung«, in: Die Zeit vom 16.08.2018.

Rautenberg, Hans-Jürgen/Wiggershaus, Norbert (1985): Die »Himmeroder Denkschrift« vom Oktober 1950. Politische und militärische Überlegungen für einen Beitrag der Bundesrepublik Deutschland zur westeuropäischen Verteidigung, Karlsruhe: Braun. 
Reichert, Martin (2010): »Denkmalpflegerische Praxis am Beispiel des Neuen Museums in Berlin. Management, Planung und Baubetreuung für eine nachhaltige Konservierung«, in: ICOMOS - Hefte des Deutschen Nationalkomitees 49, S. 84-91.

Reichertz, Jo (1997): „Objektive Hermeneutik«, in: Ronald Hitzler/Anne Honer (Hg.), Sozialwissenschaftliche Hermeneutik. Eine Einführung, Opladen: Leske und Budrich, S. 31-55.

Reichertz, Jo (2005): »Order at all Points. Lassen sich Diskursanalyse und Hermeneutik gewinnbringend miteinander verbinden?«, in: Reiner Keller (Hg.), Die diskursive Konstruktion von Wirklichkeit. Zum Verhältnis von Wissenssoziologie und Diskursforschung, Konstanz: UVK, S. 149-178.

Riegl, Alois (1988): »Der moderne Denkmalkultus, sein Wesen und seine Entstehung «, in: Marion Wohlleben/Georg Mörsch (Hg.), Konservieren, nicht restaurieren. Streitschriften zur Denkmalpflege um 1900, Braunschweig: Vieweg, S. 43-87.

Riesman, David/Denney, Reuel/Glazer, Nathan (1982): Die einsame Masse. Eine Untersuchung der Wandlungen des amerikanischen Charakters, Hamburg: Rowohlt.

Rogg, Matthias (2011a): »Der historische Ort«, in: Gorch Pieken/Matthias Rogg (Hg.), Das Militärhistorische Museum der Bundeswehr. Ausstellungsführer, Dresden: Sandstein Verlag, S. 7-19.

Rogg, Matthias (2011b): »Ein Wort vorweg«, in: Gorch Pieken/Matthias Rogg (Hg.), Militärhistorisches Museum der Bundeswehr. Ausstellung und Architektur, Dresden: Sandstein Verlag, S. 9.

Rogg, Matthias (2012): »Das Militärhistorische Museum der Bundeswehr. Neuer Weg in der musealen Vermittlung von Militär und Geschichte«, in: Dresdner Hefte. Beiträge zur Kulturgeschichte. Dresden als Garnisonstadt 53 (16), S. 101107.

Rogg, Matthias (2015): »Welcome«, in: Gorch Pieken/Matthias Rogg/Thomas Schröder (Hg.), 60 years of Bundeswehr. Exhibition Guide, Dresden: Sandstein Verlag, S. 1-4.

Rosa, Hartmut (2005): Beschleunigung. Die Veränderung der Zeitstrukturen in der Moderne, Frankfurt a.M.: Suhrkamp.

Rosa, Hartmut (2007): "Heimat im Zeitalter der Globalisierung«, in: Siegfried Reusch (Hg.), Heimat, Stuttgart: Omega Verlag, S. 155-164.

Rosa, Hartmut (2009): »Kapitalismus als Dynamisierungsspirale - Soziologie als Gesellschaftskritik«, in: Klaus Dörre/Stephan Lessenich/Hartmut Rosa (Hg.), Soziologie - Kapitalismus - Kritik. Eine Debatte, Frankfurt a.M.: Suhrkamp, S. 87-125.

Rotbard, Sharon (2015): White City, Black City. Architecture and War in Tel Aviv and Jaffa, Cambridge: MIT Press. 
Roters, Eberhard (Hg.) (1993): Streit um die neue Wache. Zur Gestaltung einer zentralen Gedenkstätte, Berlin: Akademie der Künste.

Ruskin, John (1900): Die sieben Leuchter der Baukunst. Ausgewählte Werke, Dresden.

Sabrow, Martin (2009): „Die DDR erinnern«, in: Martin Sabrow (Hg.), Erinnerungsorte der DDR, München: C.H. Beck, S. 11-27.

Sabrow, Martin (2011): Mythos - Zankapfel - Erinnerungsort. Die Potsdamer Garnisonkirche in der deutschen Erinnerungskultur, https://garnisonkirchepotsdam.de/fileadmin/user_upload/Website/Dokument/vortraege_und_pred igten/Die-Garnisonkirche-Mythos-Zankapfel-Erinnerungsort-Vortrag-Prof.Sabrow-Juni-2011-.pdf, geprüft am 25.11.2019.

Sabrow, Martin (2013): »Die postheroische Gedächtnisgesellschaft. Bauformen des historischen Erzählens der Gegenwart«, in: Étienne François/Kornelia Kończal/Robert Traba et al. (Hg.), Geschichtspolitik in Europa seit 1989. Deutschland, Frankreich und Polen im internationalen Vergleich, Göttingen: Wallstein Verlag, S. 311-322.

Sammler, Christina (2005): Das Neue Museum von Freidrich August Stüler auf der Berliner Museumsinsel. Konzeption der Gesellschaft Historisches Berlin zum Wiederaufbau der Treppenhalle und der Nord-Westfassade, Berlin: typossatz.

Savoy, Bénédicte (2011): Nofretete. Eine deutsch-französische Affäre 1912-1931, Köln: Böhlau.

Savoy, Bénédicte (2018): Die Provenienz der Kultur. Von der Trauer des Verlusts zum universalen Menschheitserbe, Berlin: Matthes \& Seitz.

Savoy, Bénédicte/Skott, Sabine (2014): »A European Museum-Cocktail around 1900. The Pushkin State Museum of Fine Arts in Moscow«, in: Andrea Meyer/Bénédicte Savoy (Hg.), The Museum Is Open. Towards a Transnational History of Museums 1750-1940, Berlin: De Gruyter, S. 77-88.

Sayah, Amber (Hg.) (1994): Museumsinsel Berlin. Wettbewerb zum Neuen Museum, Stuttgart, Berlin, Paris: avedition.

Scheerer, Thomas E. (2000): »Das Militärhistorische Museum der Bundeswehr in Dresden. Geschichte, Auftrag, Realisierung, Perspektive«, in: Thomas E. Scheerer (Hg.), Militärhistorisches Museum der Bundeswehr in Dresden. Ausstellungen 1990-2000. Eröffnung der Ausstellung Deutsch Militärgeschichte 19902000, Dresden: Sächsisches Druck- und Verlagshaus AG, S. 5-8.

Scheerer, Thomas E. (Hg.) (2003): Militärhistorisches Museum der Bundeswehr in Dresden. Arsenal und Museum (= Sammeln Bewahren Erforschen Ausstellen, Band 5), Dresden: Sächsisches Druck- und Verlagshaus AG.

Scheffler, Karl (1989): Berlin. Ein Stadtschicksal (= Berliner Texte, Band 3), Berlin: Fannei \& Walz. 
Schelsky, Helmut (1957): »Ist die Dauerreflexion institutionalisierbar? Zum Thema einer modernen Religionssoziologie«, in: Zeitschrift für Evangelische Ethik 1 (1), S. 153-174.

Scheve, Christian von (2019): »Social collectives«, in: Jan Slaby/Christian von Scheve (Hg.), Affective Societies. Key Concepts, Milton: Routledge, S. 267-278.

Schimank, Uwe (2002): »Biografischer Inkrementalismus. Lebenslauf - Lebenserfahrung - Lebensgeschichte in der funktional differenzierten Gesellschaft«, in: Uwe Schimank (Hg.), Das zwiespältige Individuum. Zum Person-GesellschaftArrangement der Moderne, VS Verlag für Sozialwissenschaften, S. 235-247.

Schimank, Uwe (2011): »Nur noch Coping. Eine Skizze postheroischer Politik«, in: Zeitschrift für Politikwissenschaft 21 (3), S. 455-463.

Schimank, Uwe/Volkmann, Ute (2000): Soziologische Gegenwartsdiagnosen I. Eine Bestandsaufnahme, Wiesbaden: VS Verlag für Sozialwissenschaften.

Schlawe, Sigrid (2009): Ein Verein wird gegründet und mischt sich ein. Erfolgreiche Arbeit in eingetragener Rechtsform. Gesellschaft Historisches Berlin e.V., https://www.ghb-online.de/component/content/article.html?id=197:Zwan zig-jahre-gesellschaft-historisches-berlin, geprüft am 26.03.2019.

Schmid, Thomas (2011): »Ein Keil ohne Donner. Daniel Libeskind hat ein Meisterwerk geschaffen: Das Militärhistorische Museum der Bundeswehr in Dresden lässt ins Alte den Blitz der Moderne fahren«, in: Die Welt vom 08.10.2011, https://www.welt.de/print/die_welt/kultur/article13648344/Ein-Kei l-ohne-Donner.html, geprüft am 20.11.2019.

Schröer, Norbert (1997): »Wissenssoziologische Hermeneutik«, in: Ronald Hitzler/Anne Honer (Hg.), Sozialwissenschaftliche Hermeneutik. Eine Einführung, Opladen: Leske und Budrich, S. 109-129.

Schultes, Axel (1994): »Fünfter Preis«, in: Amber Sayah (Hg.), Museumsinsel Berlin. Wettbewerb zum Neuen Museum, Stuttgart, Berlin, Paris: avedition, S. 60-63. Schulz, Bernhard (2009): »David Chipperfield. Erhaltung, Restaurierung und Ergänzung«, in: Carola Wedel (Hg.), Das Neue Museum. Eine Ruine wird zum Juwel, Berlin: Jaron, S. 37-55.

Schulz, Bernhard (2018): »Frankfurts Altstadt ist wieder wie neu«, in: Tagesspiegel vom 28.09.2018, https:/www.tagesspiegel.de/gesellschaft/panorama/s anierung-beendet-frankfurts-altstadt-ist-wieder-wie-neu/23128242.html, geprüft am 28.07.2020.

Schulz, Bernhard (2018): »James-Simon-Galerie eröffnet. Das Entree für Berlins Museumsinsel ist fertig«, in: Tagesspiegel vom 13.12.2018.

Schulz, Matthias (2005): »Neue Heimat für die Königin«, in: Der Spiegel vom 01.08.2005, S. 140-142.

Schulze, Gerhard (1992): Die Erlebnis-Gesellschaft. Kultursoziologie der Gegenwart, Frankfurt a.M.: Campus Verlag. 
Schulze-Wegener, Guntram (2011): »Militärhistorisches Museum in Dresden. Alles schräg«, in: Junge Freiheit vom 14.10.2011, www.jf-archiv.de/archiv11/20114210 1405.htm, geprüft am 05.11.2019.

Schuster, Peter-Klaus (2000): »Berliner Museumspläne«, in: Andres Lepik (Hg.), Masterplan Museumsinsel Berlin. Ein europäisches Projekt, Berlin: G+H Verlag, S. 11-24.

Schuster, Peter-Klaus (2001): »Vorwort«, in: Bernhard Maaz (Hg.), Die Alte Nationalgalerie. Geschichte, Bau und Umbau, Berlin: G+H Verlag, S. 6-7.

Schwartz, Claudia (2019): "James-Simon-Galerie. David Chipperfield vollendet in Berlin mit einem Eingangstempel die Museumsinsel«, in: Neue Zürcher Zeitung vom 12.07.2019, https://www.nzz.ch/feuilleton/james-simon-galer ie-david-chipperfield-vollendet-in-berlin-mit-einem-eingangstempel-die-mu seumsinsel-ld.1495000, geprüft am 28.07.2020.

Sebald, Gerd/Weyand, Jan (2011): "Zur Formierung sozialer Gedächtnisse. On the Formation of Social Memory«, in: Zeitschrift für Soziologie 40 (3), S. 174-189.

Sennett, Richard (1998): Der flexible Mensch. Die Kultur des neuen Kapitalismus, Berlin: Berlin Verlag.

Siebeck, Cornelia (2017): Erinnerungsorte. Lieux de Mémoire. Zentrum für Zeithistorische Forschung Potsdam, www.docupedia.de/zg/Siebeck_erinnerungsorte _v1_de_2017, geprüft am 28.07.2020.

Siedler, Wolf J. (1991): »Das Schloß lag nicht in Berlin - Berlin war das Schloß«, in: Wolf J. Siedler (Hg.), Abschied von Preussen, Berlin: Siedler, S. 122-137.

Simmel, Georg (1908): "Die Kreuzung sozialer Kreise«, in: Georg Simmel (Hg.), Soziologie. Untersuchungen über die Formen der Vergesellschaftung, Berlin: Duncker \& Humblot, S. 305-344.

Simmel, Georg (1911): »Die Ruine«, in: Werner Klinkhardt (Hg.), Philosophische Kultur. Gesammelte Essais, Leipzig: Verlag Werner Klinkhardt, S. 137-146.

Soeffner, Hans-Georg (1999): »Verstehende Soziologie und sozialwissenschaftliche Hermeneutik. Die Rekonstruktion der gesellschaftlichen Konstruktion der Wirklichkeit«, in: Ronald Hitzler/Jo Reichertz/Norbert Schröer (Hg.), Hermeneutische Wissenssoziologie. Standpunkte zur Theorie der Interpretation, Konstanz: UVK, S. 39-49.

Soeffner, Hans-Georg (2004): Auslegung des Alltags - Der Alltag der Auslegung. Zur wissenssoziologischen Konzeption einer sozialwissenschaftlichen Hermeneutik, Stuttgart: UTB Sozialwissenschaften.

Speitkamp, Winfried (1996): Die Verwaltung der Geschichte. Denkmalpflege und Staat in Deutschland 1871-1933 (= Kritische Studien zur Geschichtswissenschaft, Band 114), Göttingen: Vandenhoeck \& Ruprecht.

Springer, Felix (2012): »Militärgeschichte ohne Identität. Das neue Militärhistorische Museum der Bundeswehr in Dresden«, in: Sezession im Netz vom 11.01.2012. 
Springer, Peter (2009): »Rhetorik der Standhaftigkeit. Monument und Sockel nach dem Ende des traditionellen Denkmals«, in: Peter Springer (Hg.), Denkmal und Gegendenkmal, Bremen: Aschenbeck Verlag, S. 245-296.

Sprondel, Walter M. (Hg.) (1994): Die Objektivität der Ordnungen und ihre kommunikative Konstruktion. Für Thomas Luckmann, Frankfurt a.M.: Suhrkamp. Staatliche Museen zu Berlin. Preußischer Kulturbesitz (2019): James-SimonGalerie. Bezüge zur historischen Museumsinsel, https://www.smb.museum /museen-und-einrichtungen/james-simon-galerie/ueber-uns/profil.html, geprüft am 03.12.2019.

Stadler, Friedrich/Stöltzner, Michael (Hg.) (2006): Time and history. Proceedings of the 28. International Ludwig Wittgenstein Symposium, Kirchberg am Wechsel, Austria, 2005, Frankfurt a.M.: Ontos Verlag.

Star, Susan L./Griesemer, James R. (1989): »Institutional Ecology, >Translations ‘ and Boundary Objects. Amateurs and Professionals in Berkeley's Museum of Vertebrate Zoology, 1907-39«, in: Social Studies of Science 19 (3), S. 387-420.

Steets, Silke (2015a): Der sinnhafte Aufbau der gebauten Welt. Eine Architektursoziologie, Berlin: Suhrkamp.

Steets, Silke (2015b): »Taking Berger and Luckmann to the Realm of Materiality. Architecture as a Social Construction«, in: Cultural Sociology 10 (1), S. 93-108.

Stegers, Rudolf (1994): »Die preußische Akropolis«, in: Amber Sayah (Hg.), Museumsinsel Berlin. Wettbewerb zum Neuen Museum, Stuttgart, Berlin, Paris: avedition, S. 119-121.

Stiftung Preußischer Kulturbesitz (2009): Jahrespressekonferenz des Präsidenten am 28. Januar 2009, Berlin, www.preussischer-kulturbesitz.de/fileadmin/ user_upload_SPK/documents/presse/pressemitteilungen/2009/090128_JPK_ Papier.pdf, geprüft am 28.07.2020.

Straub, Jürgen (1998): »Personale und kollektive Identität. Zur Analyse eines theoretischen Begriffs«, in: Aleida Assmann/Heidrun Friese (Hg.), Identitäten. Erinnerung, Geschichte, Identität 3, Frankfurt a.M.: Suhrkamp, S. 73-104.

Straub, Jürgen (2004): »Identität«, in: Friedrich Jäger/Burkhard Liebsch/Jörn Rüsen et al. (Hg.), Handbuch der Kulturwissenschaften. Grundlagen und Schlüsselbegriffe, Stuttgart: Metzler'sche Verlagsbuchhandlung und Carl Ernst Poeschel Verlag, S. 277-303.

Straub, Jürgen (2016): Religiöser Glaube und säkulare Lebensformen im Dialog. Personale Identität und Kontingenz in pluralistischen Gesellschaften (= Diskurse der Psychologie), Gießen: Psychosozial-Verlag.

Swenson, Astrid (2007): »Heritage«, »Patrimoine« und »Kulturerbe«. Eine vergleichende historische Semantik«, in: D. Hemme/M. Tauschek/R. Bendix (Hg.), Prädikat »Heritage«. Wertschöpfungen aus kulturellen Ressourcen, Münster: Lit Verlag. 
Tagesspiegel (2007): »Neues Museum. »Welterbe ade«, in: Tagesspiegel vom 17.11.2007, https://www.tagesspiegel.de/neues-museum-welterbe-ade/109875 8.html, geprüft am 28.07.2020.

Teidelbaum, Lucius (2011): »Ein Gang durch das Militärhistorische Museum in Dresden«, in: Informationsstelle Militarisierung (IMI) e.V. vom Januar 2011, S. 1-2.

Thomas, Christian (2009): »Raum für Raum. Das Neue Museum Berlin«, in: Frankfurter Rundschau vom 05.03.2009.

Todorov, Tzvetan (1982): Die Eroberung Amerikas. Das Problem des Anderen, Frankfurt a.M.: Suhrkamp.

Todorov, Tzvetan (2003): Die verhinderte Weltmacht. Reflexionen eines Europäers, München: Goldmann Wilhelm Verlag.

Tornau, Olivera (2019): Berlin: Museumsinsel vor Vollendung. Die Museumsinsel in Berlin ist mit der Eröffnung der James-Simon-Galerie vollendet. Arte, https://www.arte.tv/de/videos/091249-000-A/berlin-museumsinsel-vor-vol lendung/, geprüft am 28.07.2020.

Trüby, Stephan (2019a): »Eine »Neue« Rechte gibt es nicht. Zur Architekturhistoriographie und -theorie der Rechten in Deutschland einst und heute«, in: Arch+ Zeitschrift für Architektur und Urbanismus (235), S. 12-23.

Trüby, Stephan (2019b): »Altstadt-Opium fürs Volk. Der Streit um die Neue Frankfurter Altstadt zeigt wie im Brennglas, auf welche Auseinandersetzungen Wissenschaft und Journalismus in politisch polarisierten Zeiten zusteuern«. Eine Sammelreplik, in: Arch+ Zeitschrift für Architektur und Urbanismus (235), S. 159-167.

Tuchen, Birgit, Fuchs, Peter R. (2002): »Eine Insel auf 40.000 Pfählen. Pfahlgründungen gestern und heute«, in: Carola Wedel (Hg.), Die neue Museumsinsel. Der Mythos, der Plan, die Vision, Berlin: Nicolai, S. 48-52.

Tuchen, Birgit, Fuchs, Peter R. (2009): »Das Haus der Witwe Levy und die Planung auf der Museumsinsel«, in: Oliver G. Hamm (Hg.), Das Neue Museum Berlin. Konservieren, Restaurieren, Weiterbauen im Welterbe, Leipzig: Seemann, S. 44-47.

Uekötter, Frank (Hg.) (2014): Ökologische Erinnerungsorte, Göttingen: Vandenhoeck \& Ruprecht.

UNESCO (2012): Museumsinsel (Museum Island). Berlin Ref: 896. UNESCO, whc.unesco.org/en/list/896, geprüft am 28.07.2020.

UNESCO (2014): Welterbe Museumsinsel Berlin. Materieller Ausdruck der Aufklärung im Herzen Berlins. UNESCO, https://www.unesco.de/kultur-und-natur/ welterbe/welterbe-deutschland/museumsinsel-berlin, geprüft am 28.07.2020. Ungewitter, Carsten (2012): »Umgängliche deutsche Schutzmacht. Die WiederEröffnung des Militärhistorischen Museums der Bundeswehr«, in: FairQuer 33, S. 29-30. 
Vigarello, Georges (2005): »Die Tour de France«, in: Pierre Nora (Hg.), Erinnerungsorte Frankreichs, München: C.H. Beck, S. 452-480.

Vinken, Gerhard (2010): Zone Heimat. Altstadt im modernen Städtebau, Berlin: Deutscher Kunstverlag.

Vinken, Gerhard (2017): »Erbe ist kein Dokument. Berlin zwischen Ruin und Restauration«, in: Österreichische Zeitschrift für Kunst und Denkmalpflege LXXI, S. 156-161.

Vogtherr, Christoph M. (1997): »Das Königliche Museum zu Berlin. Planung und Konzeption des ersten Berliner Kunstmuseum«, in: Jahrbuch der Berliner Museen 39, S. 4-302.

Voigt, Frank (2014): »Die Aktualität von Halbwachs' Kritik an Bergson und Durkheim. $\mathrm{Zu}$ einigen Problemen in den Halbwach-Lektüren bei Aleida und Jan Assmann«, in: Zeitschrift für Religions- und Geistesgeschichte 66 (3-4), S. 243-269.

Vovell, Michel (2005): »Die Marseillaise. Krieg oder Frieden«, in: Pierre Nora (Hg.), Erinnerungsorte Frankreichs, München: C.H. Beck, S. 63-112.

Waetzoldt, Stephan (1994): "Zur Baugeschichte der Berliner Museumsinsel«, in: Amber Sayah (Hg.), Museumsinsel Berlin. Wettbewerb zum Neuen Museum, Stuttgart, Berlin, Paris: avedition, S. 8-17.

Wagner, Monika (1994): »Wohin mit der verlorenen Geschichte? Kaulbachs weltgeschichtlicher Bildzyklus im Neuen Museum«, in: Peter Bloch/Christoph Hölz (Hg.), Berlins Museen. Geschichte und Zukunft, München, Berlin: Deutscher Kunstverlag, S. 87-98.

Wedel, Carola (2009): »Von der schönsten Ruine Berlins zum Juwel der Museumsinsel«, in: Carola Wedel (Hg.), Das Neue Museum. Eine Ruine wird zum Juwel, Berlin: Jaron, S. 57-81.

Wedel, Carola (Hg.) (2002): Die neue Museumsinsel. Der Mythos, der Plan, die Vision, Berlin: Nicolai.

Wehner, Jens (2012): »Die Dresdner Garnison im »Dritten Reich« und ihre Bedeutung für die Kriegsführung«, in: Dresdner Hefte. Beiträge zur Kulturgeschichte. Dresden als Garnisonstadt 53 (16), S. 56-65.

Weidenhaus, Gunter (2015): Soziale Raumzeit, Frankfurt a.M.: Suhrkamp.

Weidenhaus, Gunter (2016): Ewigkeit. Vortrag gehalten am 06.07.2016. Unveröffentlichtes Manuskript (= Social Theory Colloquium), Friedrich Schiller Universität Jena.

Welt online (2007): »Museumsinsel: Protest gegen Chipperfield-Plan«, in: Welt online vom 19.11.2007.

Wendland, Bernd (2009): Nofretete in Trümmern. Welterbe beschädigt. Stellungnahme der Gesellschaft Historisches Berlin zur Wiedereröffnung des Neuen Museums auf der Museumsinsel zu Berlin am 16. und 17. Oktober 2009. Gesellschaft Historisches Berlin, www.ghb-online.de/oeffentlichkeitsarbeit/pressem 
itteilungen/106-nofretete-in-truemmern-welterbe-beschaedigt.html \%20, geprüft am 29.07.2020.

Wendland, Bernd/Hoya Gerhard (2008): Stiftung Preußischer Kulturbesitz baut auf der Welterbestätte Museumsinsel seit Jahren ohne Wissen der UNESCOZentrale in Paris. Pressekonferenz der GHB am 25. November 2008. Gesellschaft Historisches Berlin, www.ghb-online.de/unsere-themen/alt-berlin-und -seine-stadterweiterungen/13-static-content/allgemein.html?start=30, geprüft am 29.07.2020.

Westendorf, Wolfhart (1983):»Raum und Zeit als Entsprechungen der beiden Ewigkeiten «, in: Hellmut Brunner (Hg.), Fontes atque pontes. Eine Festgabe für Hellmut Brunner, Wiesbaden: Harrassowitz Verlag, S. 422-435.

Wezel, Elsa van (2003): Die Konzeptionen des Alten und Neuen Museums zu Berlin und das sich wandelnde historische Bewusstsein. Jahrbuch der Berliner Museen 2001, Berlin: Mann.

Wissenschaftliche Dienste des Deutschen Bundestag (2017): Die Konzeption der "Inneren Führung" der Bundeswehr. Entstehungsgeschichte - Inhalte Herausforderungen. WD2-3000-04/17, https://www.bundestag.de/resource/bl ob/513082/da6d3a256102e8fd1325doc580981561/WD-2-041-17-pdf-data.pdf, geprüft am 28.07.2020.

Witschurke, Hans (2019): »Die Wandlung zum Metamuseum «, in: Bauwelt vom 22.01.2019, https://www.bauwelt.de/dl/1391679/artikel.pdf, geprüft am 29.07.2020, S. 28-33.

Wohlleben, Marion/Mörsch, Georg (Hg.) (1988): Konservieren, nicht restaurieren. Streitschriften zur Denkmalpflege um 1900, Braunschweig: Vieweg.

Wolters, Wolters (2010): »Zur Instandsetzung von Stülers Neuem Museum auf der Berliner Museumsinsel«, in: Hans-Rudolf Meier/Ingrid Scheurmann (Hg.), DENKmalWERTE. Beiträge zur Theorie und Aktualität der Denkmalpflege. Georg Mörsch zum 70. Geburtstag, München: Deutscher Kunstverlag, S. 241-250. Wullen, Moritz (2002): Die Deutschen sind im Treppenhaus. Der Fries Otto Geyers in der Alten Nationalgalerie, Berlin, Köln: DuMont.

Yaneva, Albena (2008): »How Buildings s Surprise . The Renovation of the Alte Aula in Vienna«, in: Science \& Technology Studies 21 (1), S. 8-28.

Young, James E. (1999): »Gegen Sprachlosigkeit hilft kein Kreischen und Lachen. Wer an die Vernichtung erinnern will, muß die Leere gestalten«. Berlins Problem mit dem Holocaust-Denkmal - und meines, in: Michael Jeismann (Hg.), Mahnmal Mitte. Eine Kontroverse, Köln: DuMont, S. 218-227.

Zajonz, Michael (2007): "Der gute Geist von Berlin«, in: Tagesspiegel vom 23.10.2007, www.tagesspiegel.de/kultur/architektur-der-gute-geist-von-berli n/1075522.html, geprüft am 26.03.2019.

Zimmermann, Fritz (2013): „Ein Grundstein ohne Grund. Was es auf der Museumsinsel so alles zu sehen gibt«, in: Berliner Abendblatt vom 15.11.2013, http 
s://www.abendblatt-berlin.de/2013/11/15/ein-grundstein-ohne-grund/, geprüft am 25.11.2019.

Zimmermann, Michael F. (1994): "Einleitung«, in: Peter Bloch/Christoph Hölz (Hg.), Berlins Museen. Geschichte und Zukunft, München, Berlin: Deutscher Kunstverlag, S. 9-20.

Žižek, Slavoj (2017): "Die populistische Versuchung«, in: Heinrich Geiselberger (Hg.), Die große Regression. Eine internationale Debatte über die geistige Situation der Zeit, Berlin: Suhrkamp, S. 293-313. 


\section{Kulturwissenschaft}

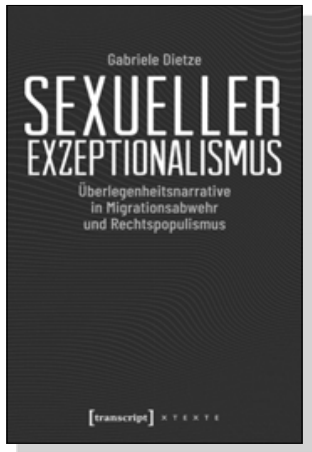

Gabriele Dietze

\section{Sexueller Exzeptionalismus}

Überlegenheitsnarrative in Migrationsabwehr und

Rechtspopulismus

2019, 222 S., kart., Dispersionsbindung, 32 SW-Abbildungen $19,99 €(D E), 978-3-8376-4708-2$

E-Book: 17,99 € (DE), ISBN 978-3-8394-4708-6

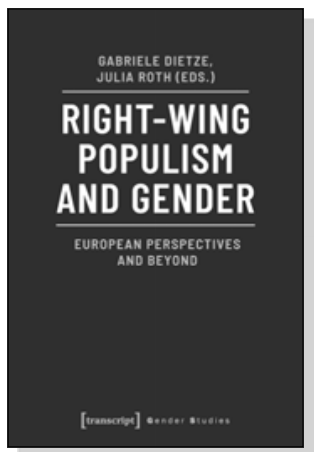

Gabriele Dietze, Julia Roth (eds.)

\section{Right-Wing Populism and Gender}

European Perspectives and Beyond

April 2020, 286 p., pb., ill.

35,00 € (DE), 978-3-8376-4980-2

E-Book: 34,99 € (DE), ISBN 978-3-8394-4980-6

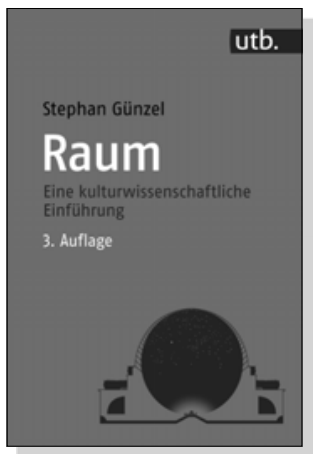

Stephan Günzel

\section{Raum}

Eine kulturwissenschaftliche Einführung

März 2020, 192 S., kart.

20,00€ (DE), 978-3-8376-5217-8

E-Book: 17,99 € (DE), ISBN 978-3-8394-5217-2 


\section{Kulturwissenschaft}

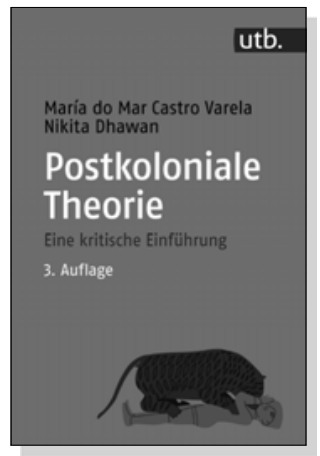

María do Mar Castro Varela, Nikita Dhawan

Postkoloniale Theorie

Eine kritische Einführung

Februar 2020, 384 S., kart.

25,00€ (DE), 978-3-8376-5218-5

E-Book: 22,99 € (DE), ISBN 978-3-8394-5218-9

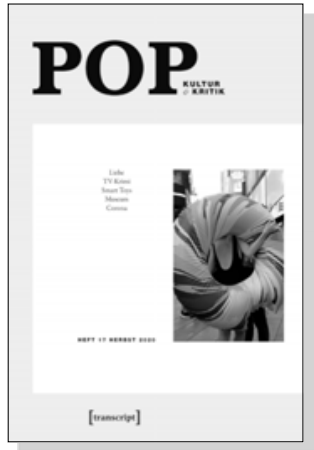

Thomas Hecken, Moritz Baßler, Elena Beregow,

Robin Curtis, Heinz Drügh, Mascha Jacobs,

Annekathrin Kohout, Nicolas Pethes, Miriam Zeh (Hg.)

POP

Kultur \& Kritik (Jg. 9, 2/2020)

Oktober 2020, 178 S., kart.

$16,80 €(D E), 978-3-8376-4937-6$

E-Book:

PDF: $16,80 €(D E)$, ISBN 978-3-8394-4937-0

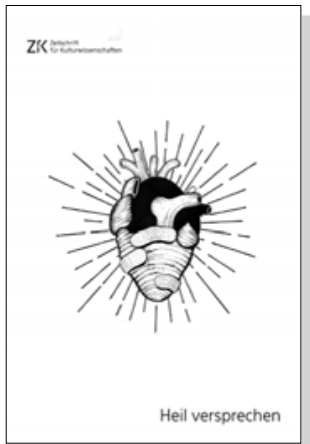

Karin Harrasser, Insa Härtel,

Karl-Josef Pazzini, Sonja Witte (Hg.)

Heil versprechen

Zeitschrift für Kulturwissenschaften, Heft 1/2020

Juli 2020, 184 S., kart.

$14,99 €(D E), 978-3-8376-4953-6$

E-Book:

PDF: $14,99 €$ (DE), ISBN 978-3-8394-4953-0 